Eduardo Aurélio Barros Aguiar

\title{
COMPORTAMENTO DE CHUMBADORES GRAUTEADOS DE LIGAÇÕES VIGA-PILAR PARCIALMENTE RESISTENTES A MOMENTO FLETOR
}

Tese apresentada à Escola de Engenharia de São Carlos, da Universidade de São Paulo, como parte dos requisitos para obtenção do título de Doutor em Engenharia de Estruturas.

Orientador: Prof. Tit. Mounir Khalil El Debs 
AUTORIZO A REPRODUÇÃO E DIVULGAÇ̃̃O TOTAL OU PARCIAL DESTE TRABALHO, POR QUALQUER MEIO CONVENCIONAL OU ELETRÔNICO, PARA FINS DE ESTUDO E PESQUISA, DESDE QUE CITADA A FONTE.

Ficha catalográfica preparada pela Seção de Tratamento da Informação do Serviço de Biblioteca - EESC/USP

A282C

Aguiar, Eduardo Aurélio Barros

Comportamento de chumbadores grauteados de ligações viga-pilar parcialmente resistentes a momento fletor / Eduardo Aurélio Barros Aguiar ; orientador Mounir Khalil El Debs. -- São Carlos, 2010.

Tese (Doutorado-Programa de Pós-Graduação e Área de Concentração em Engenharia de Estruturas) -- Escola de Engenharia de São Carlos da Universidade de São Paulo, 2010 .

1. Ligações viga-pilar. 2. Chumbador grauteado. 3. Ligação semi-rígida. 4. Concreto pré-moldado.

I. Título. 


\section{FOLHA DE JULGAMENTO}

\section{Candidato: Engenheiro EDUARDO AURELIO BARROS AGUIAR.}

Tese defendida e julgada em 05/05/2010 perante a Comissão Julgadora:

$\frac{\text { Antor. Titular MOUNIR KHALIL EL DEBS - (Orientador) }}{\text { Aprovadu }}$ (Escola de Engenharia de São Carlos/USP)

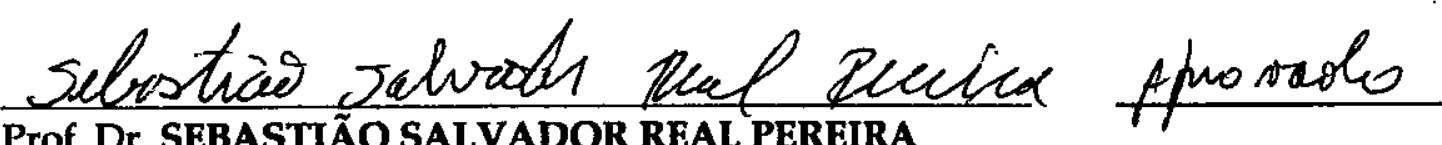
Prof. Dr. SEBASTIÃO SALVADOR REAL PEREIRA

(Universidade Federal de Minas Gerais/UFMG)

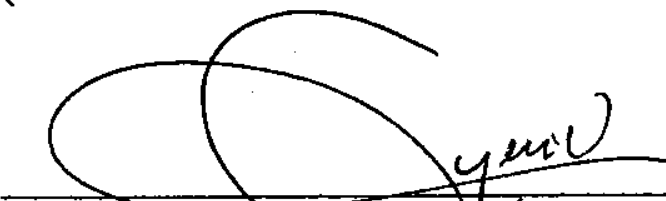

Prof. Dr. JASSO RODRIEUÉ DE FIQUEIREDO FILHO

(Universidade Federat de São Carlos/UFSCar)

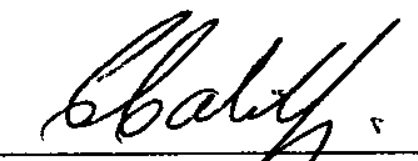

$$
7^{\mathrm{T}} \mathrm{r}
$$

Prof. Titular CARLITO CALIL JUNIOR

(Escola de Engenharia de São Carlos/USP)

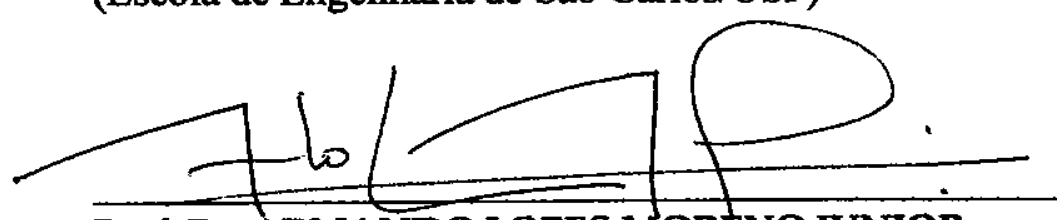

Prof. Dr. ARMANDO LOPES MOR

(Universidade Estadual de Campinas/UNICAMP)

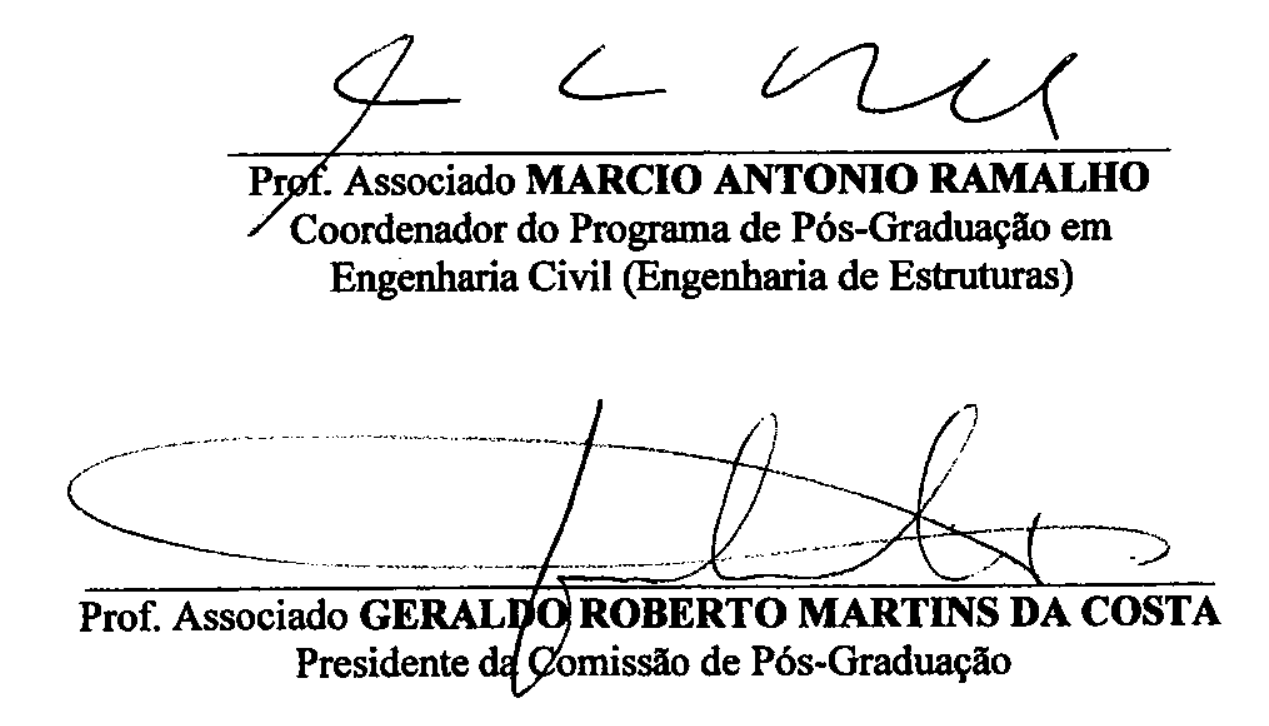




\section{AGRADECIMENTOS}

Agradeço primeiramente a Deus, pela proteção e pelas oportunidades oferecidas a cada dia.

Ao Professor Mounir Khalil El Debs, pelo cuidadoso trabalho de orientação, dedicação, valiosos ensinamentos e pela amizade demonstrada ao longo destes anos de convivência.

Ao Professor Paulo B. Lourenço por suas preciosas contribuições na análise numérica realizada neste trabalho e por sua receptividade acolhedora na Universidade do Minho, Portugal.

À Coordenação de Aperfeiçoamento de Pessoal de Nível Superior (CAPES) pelo apoio financeiro no âmbito do Programa de Doutorado no País com Estágio no Exterior (PDEE) durante a realização da pesquisa e estada em Guimarães/Portugal.

À Universidade Estadual do Maranhão (UEMA), através da concessão de afastamento das atividades de docência e de Bolsa de Doutorado durante a realização da pesquisa e permanência em São Carlos/SP.

A Fabíola de Oliveira Aguiar, esposa e companheira, pelo amor, carinho, e compreensão ao longo desses dezenove anos de casamento.

A Eduardo Aurélio de Oliveira Aguiar, filho e amigo, pelo incentivo e pela companhia sempre agradável.

Minha eterna gratidão aos meus pais, Ari Manoel Aguiar e Maria Vitória Barros Aguiar, pela amizade, apoio, dedicação, constantes incentivos e compreensão.

Aos meus sogros, Abílio Álvares de Oliveira e Lucínda Furtado de Oliveira, pelos sinceros incentivos, apoio e confiança em mim depositada.

Aos meus irmãos Lúcio e Gardenia, e a minha cunhada Fabiana pelos incentivos e pela amizade.

A minha tia Maria Amélia, sempre solícita e carinhosa, pelos incentivos.

Ao Prof. Luís Alberto de Castro Albuquerque, da Universidade Estadual do Maranhão, pelo incentivo constante e pela amizade. 
Ao Prof. Marcos Fernandes Marques, da Universiade Estadual do Maranhão, pelo incentivo, amizade e pelo convívio sempre agradável.

Aos Amigos Jorge Rayol, Vitor Brandão, Fabiano Ayres e Williame Braga, pelo incentivo, convívio e pela amizade sólida conquistada no tempo de graduação.

Aos amigos Toca, Rose, Karina, José (Ju), Seu José, D. Palma, D. Terezinha, Ronaldo, Dani e Felipe, pelas horas agradáveis de convívio em São Carlos.

A todos os colegas do Departamento de Engenharia de Estruturas, pela convivência ao longo do Doutorado.

Aos técnicos do Laboratório de Estruturas da Escola de Engenharia de São Carlos, pela disposição durante todo o programa experimental.

Aos funcionários do Departamento de Engenharia de Estruturas da Escola de Engenharia de São Carlos, especialmente, Rosi Aparecida Jordão Rodrigues e Maria Nadir Minatel pela dedicação e eficiência nos serviços prestados. 


\section{RESUMO}

AGUIAR, E. A. B. (2010). Comportamento de chumbadores grauteados de ligações viga-pilar parcialmente resistentes a momento fletor. Tese (Doutorado) - Escola de Engenharia de São Carlos, Universidade de São Paulo, São Carlos. 2010.

Neste trabalho estudou-se o comportamento dos chumbadores grauteados, usados em ligações viga-pilar parcialmente resistentes a momento fletor. O foco da pesquisa foi a análise teórica e experimental do mecanismo resistente do chumbador inclinado. O programa experimental englobou 15 modelos, sendo que as variáveis analisados foram: a) diâmetros dos chumbadores, de 16 mm, 20 mm e 25 mm; b) inclinações dos chumbadores, de $0^{\circ}$ (chumbador normal à interface), $45^{\circ}$ e $60^{\circ}$; c) resistência à compressão do concreto adjacente ao chumbador, sendo usado concreto das classes C35 e C50; d) aplicação de força de compressão normal à interface. Os resultados experimentais indicaram aumentos significativos tanto na capacidade última quanto na rigidez a cisalhamento do chumbador. Foram realizadas simulações numéricas, onde foi verificada a sensibilidade dos resultados aos parâmetros inerentes à interface concreto - almofada de apoio, sendo desenvolvidas expressões para estimar tais parâmetros. Com base na análise experimental e em análises numéricas, foram propostos modelos analíticos que conseguiram representar de forma satisfatória a influência da inclinação e demais parâmetros analisados no mecanismo resistente do chumbador.

Palavras-chave: ligação viga-pilar, chumbador grauteado, ligação semi-rígida, concreto pré-moldado 



\section{ABSTRACT}

AGUIAR, E. A. B. (2010). Behavior of grouted dowel of partial moment resistant beam-to-column connections. Tese (PhD Thesis) - Escola de Engenharia de São Carlos, Universidade de São Paulo, São Carlos. 2010.

This research deals with the behavior of grouted dowels, used in partial moment resistant beam-to-column connections. The focus of the research was the theoretical and experimental analysis of dowels resistant mechanism. The experimental program include 15 models, and its variables analyzed were: a) the dowel diameter of $16 \mathrm{~mm}$, $20 \mathrm{~mm}$ and $25 \mathrm{~mm}$; b) the dowel inclination of $0^{\circ}$ (dowels perpendicular to the interface), $45^{\circ}$ and $60^{\circ}$; c) compressive strength of concrete adjacent to the dowels of classes C35 and C50, d) application of compression load, normal to the interface. Experimental results indicated significant increases in ultimate capacity and the shear stiffness of the dowels. Numerical simulations were carried out which identified the sensitivity of results to the parameters of the interface concrete -bearing pad, and developed expressions to estimate such parameters are given. Based on experimental and numerical analysis analytical models have been proposed that could adequately represent the influence of inclination and other parameters in the mechanism resistant dowels.

Key-words: beam-column connection, grouted dowels, semi-rigid connection, precast concrete 



\section{LISTA DE FIGURAS}

Figura 1.1: Ligação viga-pilar estudada por MIOTTO (2002)

Figura 1.2: Ligação viga-pilar estudada por BALDISSERA (2006) 7

Figura 1.3: Estado de tensões não-uniforme no concreto 9

Figura 2.1: Deformabilidade ao momento fletor em uma ligação viga-pilar $\quad 14$

Figura 2.2: Curva momento-rotação para uma ligação 16

Figura 2.3: Reta Beam-Line com a curva momento-rotação da ligação 17

Figura 2.4: Diagrama Bi-Linear construído a partir do método “Beam-Line” 19

Figura 2.5: Classificação das ligações segundo o EUROCODE 3 (2002) 22

Figura 2.6: Classificação das ligações quanto à resistência 24

Figura 2.7: Modelo de molas para uma ligação viga-pilar-laje 29

Figura 2.8: Comprimento efetivo de uma barra inserida em um elemento de concreto.

Figura 2.9: Distribuição simplificada de tensões de aderência de barras tracionadas.

Figura 2.10: Relação entre tensão de aderência e deslizamento proposto pelo CEB.

Figura 2.11 - Deslocamento entre dois elementos de concreto adjacentes

Figura 2.12 - Esquema dos ensaios de tração realizados por

ENGSTROM (1992a).

Figura 2.13: Tensão de aderência e deslizamento proposto por

ENGSTROM (1992a)

Figura 2.14: Relação força x deslocamento - aproximação trilinear. 37

Figura 2.15: Tensões no concreto devido ao efeito de pino em análise linear $\quad 39$

Figura 2.16: Formação de rótula plástica e zona de ruptura

Figura 2.17: Formação de rótula plástica em chumbadores inseridos em dois elementos

Figura 2.18: Modelo analítico proposto por FERREIRA (1999). 46

Figura 2.19: Mecanismo de deformação ao cisalhamento por meio de molas $\quad 48$

Figura 2.20: Ligações ensaiadas por DOLAN et al (1987) 50

Figura 2.21: Ligações viga-pilar ensaiadas por KERONEN (1996). 52 
Figura 2.22: Ligações viga-pilar estudada por CHEFDEBIEN (1998)

Figura 2.23: Instrumentação dos modelos ensaiados por

CHEFDEBIEN (1998)

Figura 2.24: Curva momento fletor-rotação dos modelos de

CHEFDEBIEN (1998)

Figura 2.25 - Ligações viga-pilar utilizadas na Inglaterra 56

Figura 2.26 - Esquema dos modelos ensaiados por ELLIOTT et al. (1998). 57

Figura 2.27 - Esquema dos ensaios dos modelos 2.1 e 2.2 (dimensões em cm). 58

Figura 2.28 - Esquema de ensaio - ilustração (modelo 2.1) 59

Figura 2.29: Curva momento-rotação do modelo 2.1 para momento negativo $\quad 60$

Figura 2.30: Curva momento-rotação do modelo 2.1 para momento positivo $\quad 60$

Figura 2.31: Características geométricas do modelo I de

BALDISSERA (2006) 61

Figura 2.32: Esquema de ensaio do modelo I de BALDISSERA (2006) 62

Figura 2.33: Vista do ensaio do modelo I de BALDISSERA (2006) 62

Figura 2.34: Vista do ensaio realizado por KATAOKA (2007) 64

Figura 2.35: Detalhe da armadura de continuidade do modelo 1 de KATAOKA (2007)

Figura 2.36: Detalhe da armadura de continuidade do modelo 2 de

KATAOKA (2007) 65

Figura 3.1: Comportamento isolado do chumbador e montagem do modelo $\quad 69$

Figura 3.2: Perspectiva dos modelos utilizados no programa

$\begin{array}{ll}\text { experimental piloto } & 70\end{array}$

Figura 3.3: Dimensões e detalhes do modelo piloto com chumbador retilíneo $\quad 72$

Figura 3.4: Dimensões e detalhes do modelo piloto com chumbador

inclinado a $45^{\circ} \quad 73$

Figura 3.5: Dimensões e detalhes do modelo piloto com chumbador inclinado a $60^{\circ} \quad 74$

Figura 3.6: Dimensões e detalhes do modelo com chumbador retilíneo 76

Figura 3.7: Dimensões e detalhes do modelo com chumbador inclinado a $45^{\circ} \quad 77$

Figura 3.8: Dimensões e detalhes do modelo com chumbador inclinado a $60^{\circ} \quad 78$

$\begin{array}{ll}\text { Figura 3.9: Detalhe dos chumbadores inclinados } & 79\end{array}$

Figura 3.10: Armadura adotada no modelo piloto com chumbador retilíneo $\quad 80$

Figura 3.11: Armadura adotada no modelo piloto com chumbador 
inclinado a $45^{\circ}$

81

Figura 3.12: Armadura adotada no modelo piloto com chumbador inclinado a $60^{\circ}$

Figura 3.13: Armadura dos modelos que compõem o programa experimental final

Figura 3.14: Dimensões das almofadas utilizadas nos modelos do ensaio piloto

84

Figura 3.15: Detalhamento das formas utilizadas

Figura 3.16: Seqüência de execução das formas de madeira

Figura 3.17: Confecção dos chumbadores usados nos modelos

Figura 3.18: Seqüência de montagem das armaduras

Figura 3.19: Ensaio de caracterização da areia

Figura 3.20: Concretagem do modelo 03

Figura 3.21: Concreto usinado utilizado na confecção dos modelos $07,10,13$ e 15.

Figura 3.22: Confecção das almofadas de apoio 93

Figura 3.23: Seqüência de montagem dos modelos 94

Figura 3.24: Aperto das porcas na montagem dos blocos externos 94

Figura 3.25: vista dos modelos com força de compressão aplicada 95

Figura 3.26: Cura e rompimento dos corpos-de-prova 96

Figura 3.27: Ensaios para a determinação do módulo de elasticidade 98

Figura 3.28: Ensaio de caracterização do aço. $\quad 100$

Figura 3.29: Instrumentação do chumbador de eixo reto 104

Figura 3.30: Instrumentação do chumbador inclinado a 45² 105

Figura 3.31: Instrumentação do chumbador inclinado a 60 . 106

$\begin{array}{ll}\text { Figura 3.32: Etapas de instrumentação dos chumbadores } & 107\end{array}$

$\begin{array}{ll}\text { Figura 3.33: Instrumentação externa do modelo } & 108\end{array}$

Figura 3.34: Esquema de ensaio na máquina INSTRON $8506 \quad 110$

$\begin{array}{ll}\text { Figura 3.35: Esquema de ensaio no atuador A1891Y } & 111\end{array}$

Figura 3.36: Aspecto do cabo de protensão de 15,2 mm 112

Figura 3.37: Aspecto dos modelos com duas cordoalhas de 12,7mm 112

Figura 3.38: Ciclos de carregamento e descarregamento aplicados nos modelos. 114

Figura 4.1: Detalhe do apoio utilizado nos modelos 116

$\begin{array}{ll}\text { Figura 4.2: Resumo dos resultados experimentais do modelo } 02 & 117\end{array}$ 
Figura 4.3: Ensaio experimental do modelo $02 \quad 118$

Figura 4.4: Aspecto da ruptura da seção transversal do chumbador 118

$\begin{array}{ll}\text { Figura 4.5: Detalhe do chumbador após a ruptura } & 119\end{array}$

Figura 4.6: Deformação dos pontos de extensometria ao longo do chumbador 119

Figura 4.7: Ensaio experimental do modelo $03 \quad 120$

Figura 4.8: Aspecto da fissuração do modelo $03 \quad 121$

Figura 4.9: Resumo dos resultados experimentais do modelo $03 \quad 122$

Figura 4.10: Aspecto do ensaio experimental do modelo 08

Figura 4.11: Resumo dos resultados experimentais do modelo $08 \quad 124$

Figura 4.12: Deformada do chumbador do modelo $08 \quad 125$

Figura 4.13: Posição experimental e teórica da rótula plástica no modelo 08126

Figura 4.14: Resumo dos resultados experimentais do modelo 01

Figura 4.15: Aspecto da fissuração do modelo $01 \quad 127$

Figura 4.16: Resumo dos resultados experimentais do modelo $04 \quad 128$

Figura 4.17: Esquema do ensaio experimental do modelo $04 \quad 129$

Figura 4.18: Resumo dos resultados experimentais do modelo $05 \quad 130$

Figura 4.19: Aspecto da fissuração dos blocos externos do modelo $05 \quad 130$

Figura 4.20: Resumo dos resultados experimentais do modelo $06 \quad 131$

Figura 4.21: Vista do ensaio realizado no modelo $06 \quad 132$

Figura 4.22: Visualização do chumbador do modelo 06 após a ruptura. 132

Figura 4.23: Força de protensão aplicada no modelo $07 \quad 133$

Figura 4.24: Resumo dos resultados experimentais do modelo $07 \quad 134$

Figura 4.25: Aspecto da fissuração do bloco externo do modelo $07 \quad 134$

Figura 4.26: Visualização do chumbador do modelo 07 após a ruptura. 135

Figura 4.27: Posição experimental e teórica da rótula plástica no modelo $07 \quad 136$

Figura 4.28: Força de protensão aplicada no modelo $09 \quad 136$

Figura 4.29: Resumo dos resultados experimentais do modelo $09 \quad 137$

Figura 4.30: Aspecto da fissuração dos blocos externos do modelo 09.

Figura 4.31: Deformada do chumbador do modelo $09 \quad 138$

Figura 4.32: Força de protensão aplicada no modelo $10 \quad 139$

Figura 4.33: Aspecto da protensão realizada no modelo $10 \quad 139$

Figura 4.34: Resumo dos resultados experimentais do Modelo $10 \quad 140$

Figura 4.35: Deformada do chumbador do modelo $10 . \quad 140$

Figura 4.36: Força de protensão aplicada no modelo 11 
Figura 4.37: Resumo dos resultados experimentais do modelo $11 \quad 142$

Figura 4.38: Estado de fissuração do bloco externo do modelo 11

Figura 4.39: Deformada do chumbador do modelo 11.

Figura 4.40: Posição experimental e teórica da rótula plástica no modelo $11 \quad 144$

$\begin{array}{ll}\text { Figura 4.41: Força de protensão aplicada no modelo } 12 & 144\end{array}$

Figura 4.42: Resumo dos resultados experimentais do modelo 12145

Figura 4.43: Aspecto do ensaio do modelo $12 \quad 146$

Figura 4.44: Aspecto do ensaio experimental do modelo $13 \quad 146$

Figura 4.45: Resumo dos resultados experimentais do modelo $13 \quad 147$

$\begin{array}{ll}\text { Figura 4.46: Resumo dos resultados experimentais do modelo } 14 & 148\end{array}$

Figura 4.47: Aspecto do ensaio do modelo $14 \quad 149$

Figura 4.48: Resumo dos resultados experimentais do modelo 15

Figura 4.49: Aspecto da fissuração no modelo 15

Figura 5.1: Elemento finito plano CQ 16M 154

Figura 5.2: Tipologia e deslocamentos do elemento de interface CL 12I 155

Figura 5.3: Malha em Elementos Finitos adotada para os modelos 156

Figura 5.4: Disposição das armaduras nos modelos numéricos 156

Figura 5.5: Modelos constitutivos à tração no Total Strain Crack Model. 158

Figura 5.6: Modelos constitutivos à compressão no Total Strain Crack Model. 158

Figura 5.7: Resultado da simulação numérica do modelo 01.

Figura 5.8: Comparação entre resultado numérico e experimental para o modelo 01.

Figura 5.9: Resultado da simulação numérica do modelo 05.

Figura 5.10: Comparação entre resultado numérico e experimental para o modelo 05.

Figura 5.11: Deformação do chumbador na simulação numérica (modelo 01) 166

Figura 5.12: Comparação entre resultados numéricos para os modelos 01 e 05167

Figura 5.13: Chumbador considerado como viga sobre base elástica. 168

Figura 5.14: Tensões atuantes na seção plastificada do chumbador 169

Figura 5.15: Geometria e esforços na posição deformada para $\begin{array}{ll}\text { chumbadores retos } & 171\end{array}$

Figura 5.16: Influência do esforço normal na seção transversal do chumbador. 172

Figura 5.17: Geometria e esforços na posição deformada para chumbadores inclinados 
Figura 5.18: Comparação de resultados experimentais e analíticos chumbadores retos

Figura 5.19: Comparação de resultados experimentais e analíticos chumbadores a $45^{\circ}$

Figura 5.20: Comparação de resultados experimentais e analíticos chumbadores a $60^{\circ}$

Figura 5.21: Proposta de diagrama analítico para chumbadores de eixo reto

Figura 5.22: Proposta de diagrama analítico para chumbadores de eixo inclinado

Figura 6.1: Resultados experimentais para os modelos 01 e 05

Figura 6.2: Resultados experimentais e analíticos dos modelos 01 e 05

Figura 6.3: Resultados experimentais e numéricos dos modelos 01 e 05

Figura 6.4: Resultados experimentais para os modelos 08 e 11

Figura 6.5: Resultados experimentais e analíticos dos modelos 08 e 11

Figura 6.6: Resultado experimental e numérico do modelo 08

Figura 6.7: Resultados experimentais para os modelos 05 e 11

Figura 6.8: Resultados experimentais para os modelos 01 e 07

Figura 6.9: Resultados experimentais para os modelos 02 e 06

Figura 6.10: Resultados experimentais e analíticos dos modelos 02 e 06

Figura 6.11: Resultados experimentais e numéricos dos modelos 02 e 06

Figura 6.12: Resultados experimentais para os modelos 13 e 15

Figura 6.13: Resultados experimentais e analíticos dos modelos 13 e 15

Figura 6.14: Resultado experimental e numérico do modelo 15

Figura 6.15: Resultados experimentais para os modelos 02, 09 e 13

Figura 6.16: Resultados experimentais para os modelos 10 e 12

Figura 6.17: Resultados experimentais e analíticos dos modelos 10 e 12

Figura 6.18: Resultados experimentais e numéricos dos modelos 10 e 12

Figura 6.19: Resultados experimentais para os modelos 04, 10 e 14

Figura 6.20: Resultados experimentais para os modelos 04 e 14

Figura 6.21: Resultados experimentais e analíticos dos modelos 04 e 14

Figura 6.22: Resultado experimental e numérico do modelo 04

$$
\text { junto ao modelo } 14
$$

Figura 6.23: Resultados experimentais para os modelos 05 e 06 
Figura 6.25: Resultados experimentais para os modelos 11 e $12 \quad 201$

Figura 6.26: Resultados experimentais e analíticos dos modelos 11 e $12 \quad 201$

Figura 6.27: Resultados experimentais para os modelos 13 e 14

Figura 6.28: Resultados experimentais e analíticos dos modelos 13 e $14 \quad 202$

Figura 6.29: Resultados experimentais para os modelos 08, 09 e $10 \quad 203$

Figura 6.30: Resultados experimentais e analíticos dos modelos 09 e $10 \quad 204$

Figura 6.31: Resultados experimentais e numéricos dos modelos 09 e $10 \quad 204$ 



\section{LISTA DE TABELAS}

Tabela 2.1: Limite de classificação à rigidez estabelecido por normas

Tabela 2.2: Limite de classificação à rigidez estabelecido por outros pesquisadores

23

Tabela 2.3: Resumo dos momentos previstos e suportados pelas ligações 51

Tabela 2.4: Características dos modelos ensaiados por CHEFDEBIEN (1998) 54

Tabela 2.5: Resultados característicos das ligações de CHEFDEBIEN (1998) 55

Tabela 2.6 - Resumo do programa experimental - ligação $n^{\circ} 2$.

Tabela 2.7: Resumo dos resultados experimentais $\quad 59$

Tabela 2.8: Momentos máximos atuantes em cada modelo 63

Tabela 2.9: Resumo das rigidezes dos modelos I e E 63

Tabela 3.1: Programa experimental inicialmente proposto 68

$\begin{array}{ll}\text { Tabela 3.2: Resumo do programa experimental efetuado } & 71\end{array}$

Tabela 3.3: Traço do concreto usado na confecção dos modelos 89

Tabela 3.4: Traço utilizado na confecção das almofadas 92

Tabela 3.5: Evolução da resistência à compressão nas primeiras

idades (Modelo 02) 97

Tabela 3.6: Resistência à compressão do concreto na data dos $\begin{array}{ll}\text { ensaios dos modelos } & 97\end{array}$

Tabela 3.7: Resistência à tração do concreto na data dos ensaios dos modelos 98

Tabela 3.8: Módulo de elasticidade do concreto para os modelos 99

Tabela 3.9: Propriedades mecânicas dos aços 100

Tabela 3.10: Características mecânicas do graute empregado 101

Tabela 3.11: Características mecânicas da almofada de apoio 102

Tabela 3.12: Equipamentos e instrumentação usados 103

Tabela 3.13: Previsão de carga dos modelos 113

Tabela 4.1: Resumo dos principais resultados experimentais 151

Tabela 5.1: Valores de $G_{f 0}$ em função do tamanho do agregado. 159

Tabela 5.2: Coeficientes propostos para ajuste dos modelos 161

Tabela 5.3: Propriedades mecânicas do aço usadas na simulação numérica. 162

Tabela 5.4: Coeficientes propostos para diagrama de chumbadores 
de eixo inclinado

182

Tabela 6.1: Comparação entre resultados para os modelos 01 e 05

185

Tabela 6.2: Comparação entre resultados para os modelos 08 e 11

187

Tabela 6.3: Comparação entre resultados para os modelos 02 e 06

191

Tabela 6.4: Comparação entre resultados para os modelos 13 e 15

193

Tabela 6.5: Comparação entre resultados para os modelos 10 e 12

196

Tabela 6.6: Comparação entre resultados para os modelos 04 e 14

199

Tabela 6.7: Comparação entre resultados para os modelos 09 e 10

204 


\section{LISTA DE ABREVIATURAS ES SGLAS}

$\begin{array}{ll}\text { ACI } & \text { - American Concrete Institute } \\ \text { CEB } & \text { - Comitê Euro-International du Betón } \\ \text { COST } 1 & \text { - European Cooperation in the Field of Scientific and Thecnical Research } \\ \text { EUROCODE } & \text { - European Commitee for Standardization } \\ \text { FIB } & \text { - Federation Internationale du Beton } \\ \text { MC } & \text { - Model Code } \\ \text { MEF } & \text { - Método dos Elementos Finitos } \\ \text { NBR } & \text { - Norma Brasileira Registrada } \\ \text { PCA } & \text { - Portland Cement Association } \\ \text { PCI } & \text { - Precast/Prestressed Concrete Institute }\end{array}$





\section{SUMÁ RIO}

RESUMO

ABSTRACT

ii

LISTA DE FIGURAS iii

LISTA DE TABELAS Xi

LISTA DE ABREVIATURAS E SIGLAS xiii

1- INTRODUÇÃO

1.1- GENERALIDADES 1

1.2- OBJETIVOS

1.3- JUSTIFICATIVA 8

1.4- METODOLOGIA DA PESQUISA 10

1.5- APRESENTAÇÃO DO TRABALHO 11

2- REVISÃO BIBLIOGRÁFICA 13

2.1- GENERALIDADES 13

2.2- CLASSIFICAÇÃO DAS LIGAÇÕES 19

2.2.1- Classificação quanto à rigidez 20

2.2.2- Classificação quanto à resistência 23

2.3- COMPORTAMENTO DE LIGAÇÕES SEMI-RÍGIDAS 25

2.3.1- Determinação da relação momento-rotação 25

2.3.2- Método dos Componentes 26

2.3.3- Mecanismos básicos de deformação 30

2.3.3.1- Mecanismo de deformação por tração de uma barra inserida no concreto 31

2.3.3.2- Mecanismo de deformação por cisalhamento de uma barra inserida no concreto 38

2.4- PRINCIPAIS ESTUDOS RELACIONADOS 49 
3.1- GENERALIDADES

3.2- DESCRIÇÃO DOS MODELOS 68

3.2.1- Especificação do concreto $\quad 79$

$\begin{array}{ll}\text { 3.2.2- Armadura de projeto } & 79\end{array}$

3.2.3- Graute $\quad 84$

3.2.4- Almofada de apoio $\quad 84$

3.3- CONFECÇÃO DOS ELEMENTOS 85

3.3.1- Fôrma

3.3.2- Confecção dos chumbadores $\quad 87$

3.3.3- Armação dos modelos $\quad 88$

3.3.4- Moldagem dos modelos $\quad 89$

3.3.5- Graute 92

3.3.6- Almofada de apoio $\quad 92$

3.4- MONTAGEM DOS MODELOS 93

3.5- PROPRIEDADES MECÂNICAS DOS MATERIAIS 95

3.5.1- Concreto 95

3.5.2- Armadura 99

3.5.3- Graute 101

$\begin{array}{ll}\text { 3.5.4- Almofada de apoio } & 101\end{array}$

3.6- EQUIPAMENTOS E INSTRUMENTAÇÃO 102

3.6.1- Instrumentação interna 103

3.6.2- Instrumentação externa 107

3.7- PROCEDIMENTO DE ENSAIO 109

4- RESULTADOS EXPERIMENTAIS 115

4.1- GENERALIDADES 115

$\begin{array}{ll}\text { 4.2- MODELOS PILOTOS } & 117\end{array}$

4.2.1- Modelo 02

4.2.2- Modelo $03 \quad 120$

4.2.3- Modelo 08

4.3- MODELOS SEM FORÇA DE COMPRESSÃO - CLASSE C35 126 
4.3.1- Modelo $01 \quad 126$

4.3.2- Modelo $04 \quad 128$

$\begin{array}{ll}\text { 4.3.3- Modelo } 05 & 129\end{array}$

4.3.4- Modelo $06 \quad 130$

4.4- MODELOS COM FORÇA DE COMPRESSÃO - CLASSE C35 132

4.4.1- Modelo 07

4.4.2- Modelo $09 \quad 136$

4.4.3- Modelo $10 \quad 138$

4.4.4- Modelo $11 \quad 140$

4.4.5- Modelo $12 \quad 144$

4.5- MODELOS SEM FORÇA DE COMPRESSÃO - CLASSE C50 146

4.5.1- Modelo 13

4.5.2- Modelo $14 \quad 148$

4.5.3- Modelo $15 \quad 149$

4.6- RESUMO DOS RESULTADOS 151

5- MODELOS NUMÉRICO E ANALÍTICO 153

5.1- GENERALIDADES 153

5.2- MODELO NUMÉRICO 153

5.2.1- Elementos finitos utilizados 154

5.2.2- Modelos constitutivos 157

5.2.3- Resultados preliminares da simulação numérica 162

5.3- PROPOSTA DE MODELO ANALÍTICO 167

5.3.1- Fase inicial de equilíbrio 168

5.3.2- Consideração da força normal 171

5.3.2.1- Chumbadores de eixo reto 171

5.3.2.2- Chumbadores de eixo inclinado 174

5.3.3- Formulação geral da capacidade de carga 176

5.3.4- Proposta de diagrama analítico força por barra $\begin{array}{ll}\mathrm{x} \text { deslocamento } & 180\end{array}$

6- ANÁLISE DE RESULTADOS 183 
6.1- GENERALIDADES 183

6.2- CHUMBADORES DE EIXO RETO 183

6.2.1- Influência do diâmetro do chumbador 183

6.2.2- Influência da força de compressão aplicada 188

6.3- CHUMBADORES DE EIXO INCLINADO A 45ำ 189

6.3.1- Influência do diâmetro do chumbador 189

6.3.2- Influência da força de compressão aplicada 194

6.4- CHUMBADORES DE EIXO INCLINADO A 60 194

6.4.1- Influência do diâmetro do chumbador 195

6.4.2- Influência da força de compressão aplicada 197

6.4.3- Influência da resistência à compressão do concreto 197

6.5- INFLUÊNCIA DA INCLINAÇÃO DO CHUMBADOR 199

7- CONSIDERAÇÕES FINAIS E CONCLUSÕES 207

$\begin{array}{ll}\text { REFERÊNCIAS BIBLIOGRÁFICAS } & 213\end{array}$ 


\section{IN T R O D U Ç Ã O}

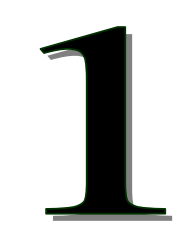

Capítulo

\subsection{GENERALIDADES}

A utilização de sistemas construtivos de concreto pré-moldado vem ao longo dos anos se consolidando como uma alternativa importante para a construção civil brasileira, que tem sido caracterizada por apresentar baixos índices de produtividade e grande desperdício de materiais.

A pré-moldagem é uma atividade em evolução tanto no mercado brasileiro quanto no mercado mundial, e ainda precisa vencer barreiras culturais e técnicas para sua viabilização plena. A necessidade de equipamentos para a montagem dos elementos de concreto pré-moldado é um exemplo de barreira técnica que limita a utilização desse sistema construtivo.

A necessidade de se estabelecer as ligações entre os vários elementos que compõem a estrutura pode ser encarada como a principal dificuldade a ser enfrentada no projeto do concreto pré-moldado.

Em estruturas de concreto pré-moldado, as ligações devem ser projetadas levando-se em consideração requisitos estruturais importantes como resistência aos esforços solicitantes, durabilidade, ductilidade (capacidade da ligação de apresentar deformações inelásticas acentuadas sem perda significativa de resistência, antes de atingir a ruptura) e resistência ao fogo. A construtibilidade da ligação também deve ser garantida, e deve ser compreendida como um requisito tão importante quanto os requisitos estruturais.

As ligações são regiões de comportamento complexo, onde ocorrem concentrações de tensões consideráveis, e portanto, necessitam de grande atenção ao serem concebidas. Segundo ORDONEZ et al. (1974), a influência das ligações no 
concreto pré-moldado é tão grande que alguns especialistas afirmam que a dificuldade de projetá-las e de executá-las é que têm impedido a substituição dos métodos construtivos convencionais pelo sistema pré-moldado.

De maneira geral, as ligações entre os elementos de concreto pré-moldado exercem influência tanto na etapa de produção quanto no comportamento da estrutura já montada, necessitando assim de atenção especial ao serem concebidas.

FERREIRA (1999) comenta que a garantia da segurança no cálculo estrutural é diretamente influenciada pelo grau de conhecimento que se possui sobre o comportamento de um sistema estrutural. Entretanto, nas estruturas de concreto pré-moldado, em alguns casos, o comportamento estrutural ainda não pode ser completamente definido devido à escassez de informações quanto à deformabilidade nas suas ligações.

No concreto pré-moldado, as ligações tendem a apresentar um comportamento variado, podendo ser classificadas como ligações rígidas, articuladas ou semi-rígidas.

As ligações articuladas, em geral mais simples, acarretam elementos estruturais mais solicitados à flexão, quando comparados com elementos similares de concreto moldado no local, bem como estruturas com pouca capacidade de redistribuição de esforços. Já as ligações rígidas possibilitam a transmissão de momentos fletores e tendem a produzir estruturas com comportamento próximo aos das estruturas de concreto moldadas no local. As ligações que apresentam um comportamento intermediário, tendendo a se aproximar ou das ligações articuladas ou das ligações rígidas, podem ser classificadas como ligações semi-rígidas. O termo "ligações semi-rígidas” foi aplicado inicialmente no estudo de estruturas metálicas, em meados da década de 30, sendo posteriormente incorporado ao estudo de estruturas de concreto pré-moldado.

Por outro lado as ligações rígidas são, via de regra, mais difíceis de serem executadas e em geral mais caras que as ligações articuladas, além de exigirem mais tempo de execução.

A determinação da resistência e da rigidez das ligações entre os elementos de concreto pré-moldado é uma tarefa difícil e muitas vezes imprecisa, pois existem parâmetros (geometria de chumbadores, grautes, armadura de continuidade, entre outros) que podem influenciar o seu comportamento estrutural e que são difíceis de serem quantificados devido à falta de resultados experimentais sobre o comportamento dessas ligações. 
Segundo CHEOK \& LEW (1991) as estruturas de concreto pré-moldado tendem a ser consideradas como menos dúcteis e estáveis que as estruturas monolíticas devido à falta de resultados experimentais sobre as ligações viga-pilar.

EL DEBS (2000) comenta que a resistência e a rigidez das ligações podem ser determinadas por formulações analíticas, para alguns casos, ou por meio de testes de laboratório, destacando que nesse último caso devem ser previstas as imperfeições de montagem, em campo, devido às condições serem diferentes das de laboratório.

O comportamento das ligações entre elementos de concreto pré-moldados começou a ser estudado de forma expressiva e abrangente no início da década de 60, através da realização de um programa de pesquisa experimental desenvolvido pela Portland Cement Association (PCA), que tinha como objetivo um aumento do banco de dados, além de compreender e sistematizar os projetos dessas ligações.

No ano de 1986 foi lançado o programa PCI Specially Funded Research and Development Program 1 and 4 (PCI-SFRAD) tendo como objetivo analisar as ligações entre elementos pré-moldados mais utilizadas nos Estados Unidos da América. Os resultados desse programa foram publicados por DOLAN et al. (1987).

Com o objetivo de ampliar o conhecimento sobre as ligações presentes na Engenharia Civil, possibilitando benefícios sobre o custo das estruturas e gerando novos conceitos na preparação das normas, foi iniciado em 1991 o programa COST C1 “Control of the Semi-rigid Behavior of Civil Engineering Structural Connections” com a participação de 23 países. O programa COST C1 teve sete anos de duração e foram publicados mais de 125 projetos sobre estruturas de concreto, aço, estruturas mistas, estruturas de madeira, materiais compostos por polímeros, projetos sísmicos e simulações numéricas.

No Brasil ainda existem poucos centros de pesquisa que desenvolvem estudos sobre o comportamento de ligações entre elementos pré-moldados, o que dificulta a proliferação e a divulgação do conhecimento técnico nessa área. Dentre esses poucos centros de pesquisa, pode-se destacar a Escola de Engenharia de São Carlos da Universidade de São Paulo (EESC-USP), que tem prestado grandes contribuições, principalmente no estudo de ligações semi-rígidas.

As pesquisas em ligações de elementos pré-moldados na EESC-USP tiveram início com BALLARIN (1993), que estabeleceu sistemas de classificação tipológica e uma avaliação crítica através de análises sistemáticas dos desempenhos das ligações. 
FERREIRA (1993) realizou estudo teórico sobre deformabilidade de alguns tipos de ligações pré-moldadas, onde foram desenvolvidos analiticamente modelos de cálculo para as ligações estudadas. Posteriormente, FERREIRA (1999) realizou estudo experimental também sobre deformabilidade, onde foram ensaiados dois tipos de ligações (viga-pilar) solicitadas a esforços de cisalhamento, flexão e torção. Com a continuidade dos estudos foi possível um aperfeiçoamento das expressões apresentadas por FERREIRA (1993), tendo em vista os resultados do estudo experimental realizado.

SOARES (1998) realizou estudo teórico e experimental sobre deformabilidade de ligações viga-pilar, submetidas à flexão, em pórticos pré-moldados de duas águas tipo galpão.

BARBOZA (2002) analisou o comportamento de juntas de argamassa solicitadas à compressão, visando à determinação de sua resistência e deformabilidade, de forma a obter recomendações que auxiliassem no projeto desses elementos.

MIOTTO (2002) estudou o comportamento de duas ligações viga-pilar em concreto pré-moldado com ênfase na deformabilidade ao momento fletor. A primeira ligação, dando continuidade ao trabalho de SOARES (1998), foi executada sobre consolo com chumbadores. A segunda ligação, muito utilizada em estruturas de edifícios de múltiplos pavimentos, foi executada utilizando almofada de apoio, chumbador e laje alveolar com capa de concreto moldado no local.

O trabalho de MIOTTO (2002) contou com um programa experimental composto por dois tipos de ligações, cada um com dois modelos físicos, totalizando assim quatro modelos ensaiados. Com base nos resultados experimentais obtidos, e em análises numéricas via Método dos Elementos Finitos, foram propostos modelos analíticos, baseado no Método dos Componentes. Foi observado também que as curvas momento-rotação teóricas ficaram bastante próximas das curvas experimentais para as duas ligações estudadas.

Na Figura 1.1 está ilustrada a segunda ligação estudada por MIOTTO (2002), que foi solicitada a momento fletor em diferentes sentidos, ou seja, momento fletor positivo e negativo. Foi observado que o momento fletor resistente positivo foi da ordem de $20 \%$ do momento fletor resistente negativo.

Ainda segundo MIOTTO (2002), quando o modelo foi solicitado por momentos positivos, os valores observados de rigidez inicial foram considerados bons. Foi verificado também que quando a ligação foi fissurada, o que ocorreu a baixos valores de solicitação, os valores de rigidez sofreram uma acentuada redução. É oportuno lembrar 
que mesmo depois de fissurada, a ligação apresentou um comportamento dúctil sob a ação do momento fletor positivo, devido à presença do chumbador.

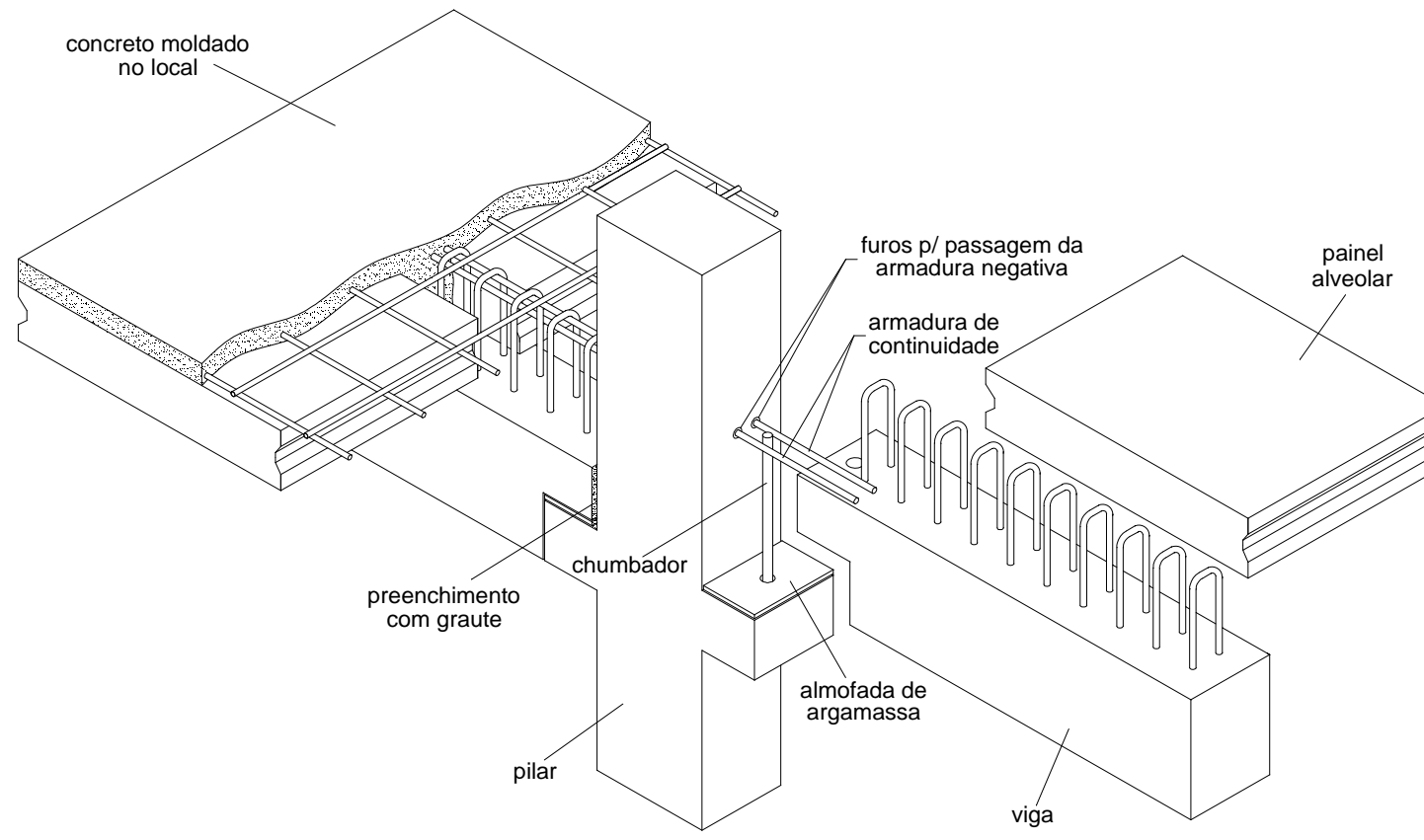

Figura 1.1: Ligação viga-pilar estudada por MIOTTO (2002)

Quando a ligação é submetida a momentos fletores negativos, a avaliação da transferência de esforços pode ser realizada com o auxílio da teoria do Concreto Armado, onde a armadura de continuidade é tracionada. Já quando a ligação é submetida a momentos fletores positivos, o desempenho da ligação depende do mecanismo resistente do chumbador.

Chumbadores dispostos verticalmente na ligação (Figura 1.1) apresentam como mecanismo resistente predominante o efeito de pino. A partir do momento em que o chumbador começa a ser inclinado, o mecanismo resistente sofre alterações, aparecendo também esforços de tração.

BALDISSERA (2006) estudou o comportamento de uma ligação viga-pilar semelhante à ligação estudada por MIOTTO (2002), composta por dois chumbadores inclinados e presos à viga por meio de chapas metálicas, porcas e arruelas. Foram confeccionados dois modelos físicos para o programa experimental da pesquisa, sendo um com pilar intermediário e outro com pilar de extremidade. 
Na Figura 1.2 está ilustrada a ligação estudada por BALDISSERA (2006), para o pilar intermediário, que também foi solicitada a momento fletor em diferentes sentidos. Foi observado que o momento fletor resistente positivo foi da ordem de $60 \%$ do momento fletor resistente negativo para o pilar intermediário e $85 \%$ para o pilar de extremidade.

Ainda segundo BALDISSERA (2006), a ligação com chumbadores inclinados, quando comparada com a de chumbadores retilíneos estudada por MIOTTO (2002), apresentou um acréscimo de 2 vezes na rigidez a momento fletor positivo e um acréscimo superior a 2,5 vezes no momento de plastificação. Como justificativa a essa alteração considerável de resultados, foi observado, com base nos resultados experimentais, que sobre o chumbador, além do efeito de tração, havia também indícios de uma parcela do efeito de pino, que não pôde ser devidamente comprovada.

Com base nos resultados experimentais obtidos por MIOTTO (2002) e BALDISSERA (2006), pode-se perceber que para o entendimento do comportamento da ligação é necessário o conhecimento do mecanismo resistente do chumbador.

Tanto MIOTTO (2002) como BALDISSERA (2006) utilizaram em suas pesquisas almofadas de apoio em argamassa, posicionadas entre o consolo do pilar e a viga, com o intuito de promover uma distribuição mais uniforme de tensões de contato, além de permitir movimentos de rotação entre os elementos.

Esse tipo de argamassa vem sendo estudado no Laboratório de Estruturas da EESC-USP desde o ano 2000, com algumas variações dos materiais utilizados. Dentre as pesquisas mais recentes pode-se citar a de SIQUEIRA (2007), que apresenta um estudo de uma argamassa modificada para uso como elemento de ligação entre elementos de concreto pré-moldado.

A argamassa estudada por SIQUEIRA (2007) foi obtida pela introdução de látex estireno-butadieno (SBR) e fibras de polipropileno a uma argamassa de cimento e areia. Foi observado que ocorreram mudanças em algumas propriedades mecânicas do compósito, proporcionando assim um aumento da deformabilidade por diminuição do módulo de elasticidade, conferindo-lhe assim características favoráveis ao uso como elemento de apoio para estruturas pré-moldadas de concreto.

Ainda segundo esse pesquisador, a capacidade das almofadas em absorver rotações pode ser considerada adequada. Os valores de rotações máximas medidas para o compósito foram da ordem de $25 \%$ maiores quando comparadas às argamassas convencionais. No tocante à espessura da almofada a ser utilizada, foi verificado por 
SIQUEIRA (2007) que as de $10 \mathrm{~mm}$ de espessura foram consideradas mais adequadas à absorção de rotações que as de $20 \mathrm{~mm}$, confeccionadas com o mesmo material.

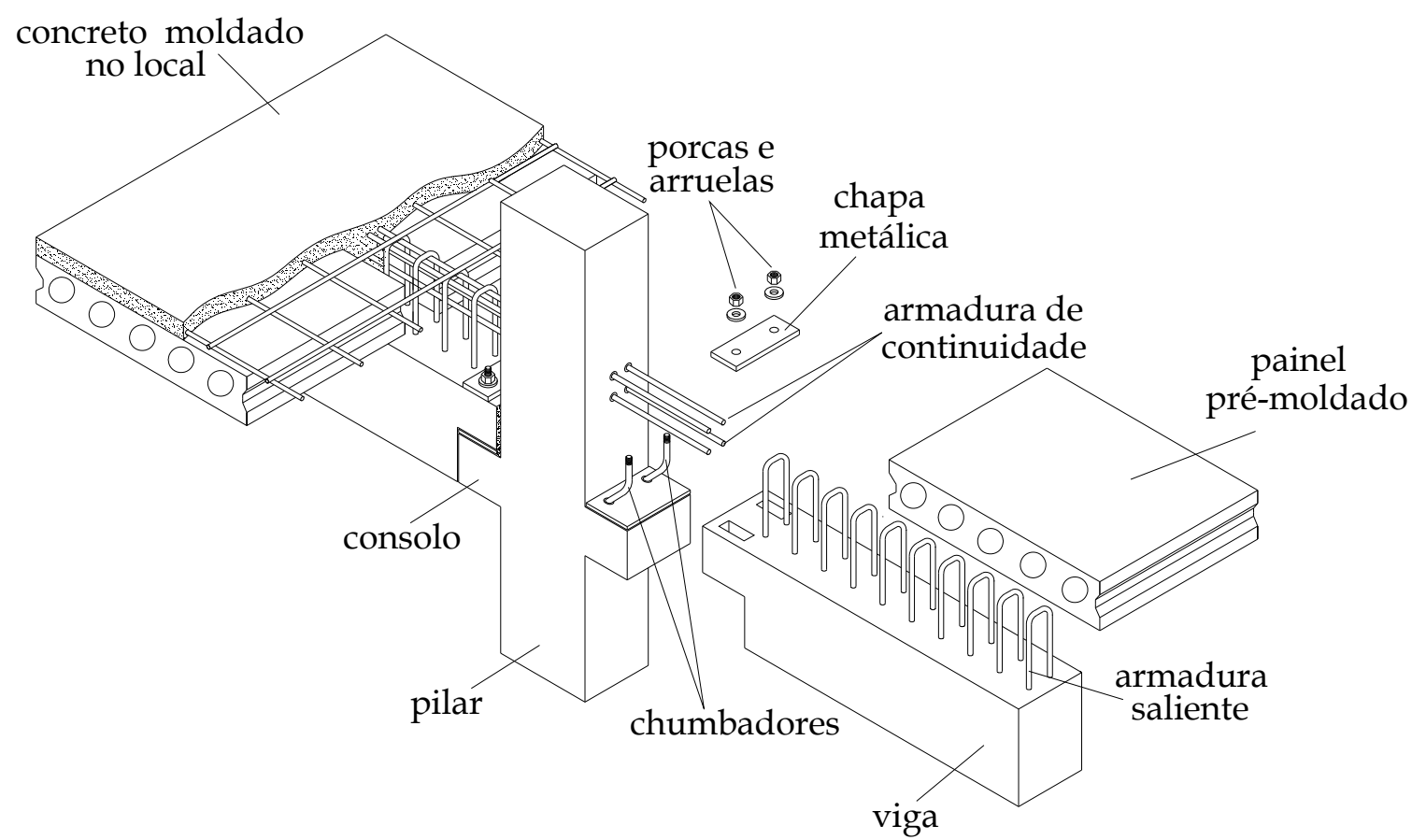

Figura 1.2: Ligação viga-pilar estudada por BALDISSERA (2006)

\subsection{OBJETIVOS}

O objetivo geral do presente trabalho consiste em fazer uma análise teórica e experimental dos chumbadores grauteados, focando principalmente o mecanismo resistente do chumbador para ligações viga-pilar parcialmente resistentes a momento fletor.

Entre os objetivos específicos estão:

i. Avaliar os mecanismos de resistência e de deformabilidade mobilizados com a alteração na inclinação dos chumbadores;

ii. Analisar a influência dos chumbadores no comportamento das ligações estudadas (modelos) mediante a aplicação do Método dos Elementos Finitos, e comparar com os resultados experimentais; 
iii. Propor modelos analíticos que consigam reproduzir a influência da inclinação dos chumbadores e que possam contribuir na análise do comportamento global da ligação.

\subsection{JUSTIFICATIVA}

A necessidade de se entender o comportamento das ligações, em especial as ligações semi-rígidas, passa a ser de fundamental importância para o desenvolvimento de um projeto estrutural econômico e que garanta a estabilidade global do sistema.

MOTA (2009) comenta que a contribuição da ligação semi-rígida na melhoria das condições de estabilidade cresce naturalmente com o aumento do grau de engastamento, definido pela razão entre o momento fletor na extremidade da viga considerando a ligação semi-rígida e o momento fletor de engastamento perfeito. Ainda segundo MOTA (2009), foi observado que a contribuição da ligação semi-rígida no comportamento global da estrutura é significativa mesmo para um grau de engastamento inferior a $20 \%$.

Uma das maneiras de se entender o comportamento das ligações é por meio do conhecimento dos seus componentes. A avaliação das características de deformação e de resistência de cada componente individualmente e a associação desses componentes para analisar o comportamento da ligação como um todo, constitui-se numa prática recomendável.

É oportuno lembrar que o conhecimento dos componentes das ligações é de fundamental importância quando se deseja propor modelos analíticos simplificados que representem o comportamento da ligação semi-rígida.

Dando continuidade à linha de pesquisa sobre ligações semi-rígidas, desenvolvida no Departamento de Estruturas da Escola de Engenharia de São Carlos, em particular a Tese de Doutorado de MIOTTO (2002) e a Dissertação de Mestrado BALDISSERA (2006), no presente trabalho é realizado um estudo teórico e experimental do comportamento de um componente fundamental da ligação viga-pilar que é o chumbador.

O chumbador pode ser entendido como um componente da ligação, inserido no concreto, capaz de transmitir esforços de cisalhamento entre elementos. Essa transferência de esforços gera um estado de tensões não-uniforme no concreto 
(Figura 1.3), submetendo o chumbador a um esforço de flexão máximo junto à interface.

Em função do estado de tensões apresentado e dependendo das dimensões, posicionamento e da resistência do chumbador, além também da resistência e aderência do concreto que o envolve, alguns modos de ruptura podem ser previstos. Dentre esses modos de ruptura, pode-se citar a formação de rótulas plásticas na seção de máximo esforço de flexão do chumbador (Figura 1.3).

O modelo teórico para a determinação da capacidade máxima do chumbador à flexão foi desenvolvido por HфJLUND-RASMUSSEN ${ }^{1}$ apud FIB (2007), com base na teoria da plasticidade, para chumbadores retilíneos. A formulação foi apresentada tendo como variáveis alguns parâmetros obtidos experimentalmente, e desta forma, a obtenção desses parâmetros ainda é objeto pertinente de pesquisas.
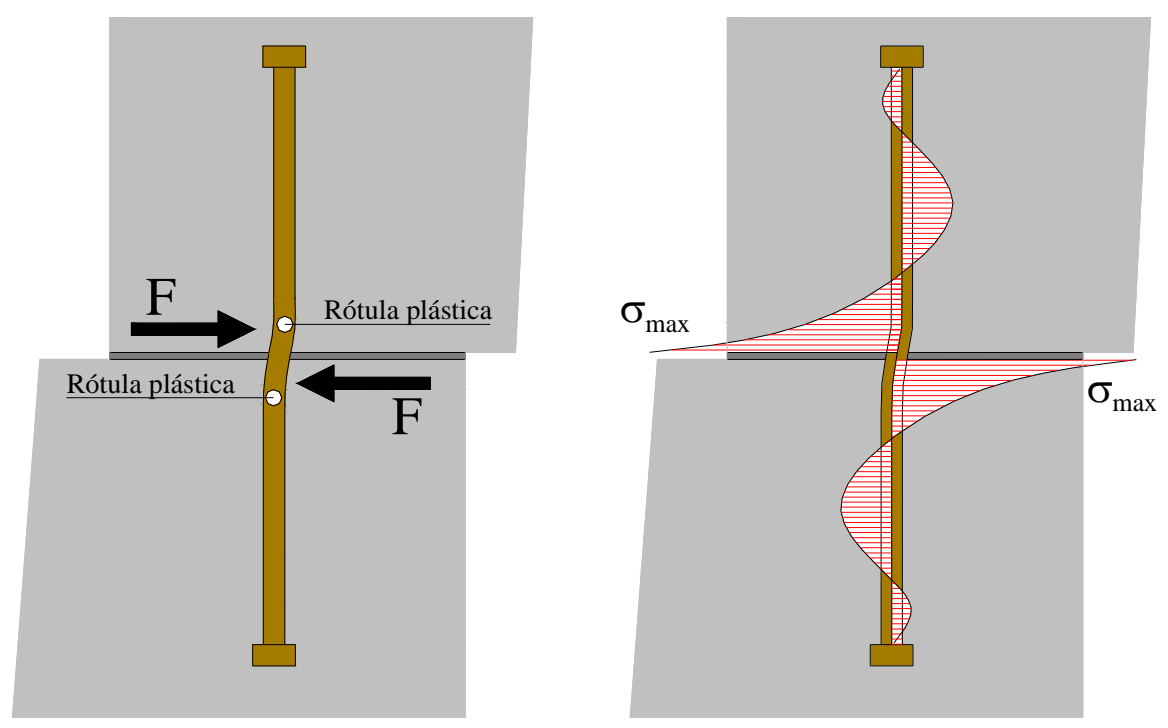

Figura 1.3: Estado de tensões não-uniforme no concreto

O estudo teórico-experimental realizado visa um aprofundamento na influência da inclinação dos chumbadores na determinação da resistência e da rigidez das ligações semi-rígidas de elementos pré-moldados, tendo como motivação o aumento de rigidez

1 HØJLUND-RASMUSSEN, B (1963). Betoninstöbte, tvaerbelastade boltes og dornes baereevne. (Resistance of embedded bolts and dowels loaded in shear. In Danish). 
das ligações estudadas por BALDISSERA (2006) quando comparadas aos resultados experimentais obtidos por MIOTTO (2002).

Outro ponto relevante é o fato de quase não haver estudos sobre chumbadores inclinados. Além de BALDISSERA (2006), foi encontrado na literatura apenas o estudo realizado por DULÁCSKA ${ }^{2}$ apud FIB (2007), apresentado no Capítulo 2 deste trabalho.

\subsection{METODOLOGIA DA PESQUISA}

Para alcançar os objetivos anteriormente descritos, foi utilizada a seguinte metodologia de trabalho:

a) Pesquisa bibliográfica

Na pesquisa bibliográfica foi realizado um levantamento dos estudos teóricos e experimentais existentes na literatura técnica, principalmente no que diz respeito ao comportamento dos chumbadores em concreto.

b) Programa experimental

Para a análise da influência da inclinação dos chumbadores no comportamento da ligação, foram idealizados modelos buscando priorizar a simplicidade de execução e análise.

Os modelos foram confeccionados e ensaiados no Laboratório de Estruturas da Escola de Engenharia de São Carlos - USP, onde foram trabalhadas variáveis como diâmetro e inclinação do chumbador, além da resistência à compressão do concreto. Durante a realização dos ensaios foi observado o comportamento dos mecanismos básicos de deformação e resistência dos chumbadores.

O programa experimental foi composto por 15 modelos, onde a apresentação de suas dimensões, detalhamento de armaduras, discriminação das variáveis avaliadas, instrumentação e procedimentos necessários à realização dos ensaios, estão apresentados no Capítulo 3 deste trabalho.

\footnotetext{
${ }^{2}$ DULÁCSKA, H. (1972). Dowel action of reinforcement crossing cracks in concrete. ACI Journal, Vol. 69, No. 12, 1972, pp. 754-757.
} 
b) Modelo numérico

Além da análise experimental descrita, foram realizadas também modelagens numéricas dos espécimes via Método dos Elementos Finitos (MEF), onde foram avaliadas as influências de diversos parâmetros no comportamento da ligação.

Numa modelagem numérica via MEF, podem ser simulados quase todos os fenômenos complexos existentes na ligação, dentre os quais se citam o atrito, o contato e a interação chumbador-concreto, entre outros. É oportuno lembrar que a elaboração de um modelo de elementos finitos capaz de representar de maneira precisa o comportamento real da ligação exige um esforço computacional muito grande, principalmente quando se leva em consideração a não-linearidade física do concreto.

Na etapa de modelagem numérica foi utilizado o programa computacional DIANA release 9.2, que tem o Método dos Elementos Finitos como base para o seu sistema de análise. Posteriormente os modelos numéricos foram calibrados com base nos resultados obtidos no programa experimental.

d) Análise dos resultados

Nesta etapa da pesquisa foram realizadas as análises dos resultados experimentais e das simulações numéricas, principalmente no tocante aos mecanismos de deformabilidade e de resistência do chumbador.

Em decorrência dessas análises, foram propostos modelos analíticos com o intuito de representar o mais fielmente possível o comportamento observado.

\subsection{APRESENTAÇÃO DO TRABALHO}

O presente trabalho foi dividido em sete capítulos, cujos conteúdos são resumidos como segue:

No Capítulo 1 é realizada uma breve introdução ao tema da pesquisa desenvolvida, sendo apresentados os objetivos do trabalho, a justificativa e a metodologia utilizada na pesquisa.

No Capítulo 2 é apresentada a revisão bibliográfica realizada, sendo enfocada a fundamentação teórica e os principais estudos relacionados ao tema, encontrados na literatura. 
O Capítulo 3 apresenta a definição do programa experimental realizado, onde estão descritas as características dos modelos, os materiais utilizados, a moldagem e montagem dos modelos, a instrumentação interna e externa utilizada e os procedimentos de ensaios.

O Capítulo 4 reúne todos os resultados experimentais dos modelos ensaiados, apresentando suas características observadas, além de uma análise prévia dos resultados individuais de cada modelo.

No Capítulo 5 são apresentadas as análises numéricas realizadas e os modelos analíticos propostos para a representação do comportamento dos chumbadores.

O Capítulo 6 traz a análise de resultados, onde são comparados os resultados experimentais com os resultados teóricos, obtidos por meio dos modelos analíticos e das simulações numéricas.

No Capítulo 7 são apresentadas as considerações finais, as conclusões do estudo realizado e ainda algumas sugestões para pesquisas futuras sobre o tema em questão. 


\section{REVISÃo BIBLIOGRÁFICA}

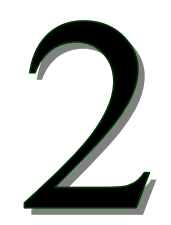

Capítulo

\subsection{GENERALIDADES}

É prática corriqueira em escritórios de cálculo de estruturas de concreto pré-moldado, o projetista especificar as ligações viga-pilar como articuladas. Tal procedimento subestima o desempenho das estruturas pré-moldadas, principalmente no que se refere à estrutura de múltiplos pavimentos.

Muitas das ligações típicas utilizadas em estruturas pré-moldadas, conforme evidenciado em várias investigações experimentais disponíveis na literatura técnica, apresentam comportamento semi-rígido.

Entende-se como comportamento semi-rígido, um comportamento intermediário entre o articulado (rotulado) e o rígido (engastamento perfeito), tendendo a se aproximar de uma das duas situações em função do grau de flexibilidade da ligação.

A consideração do grau de flexibilidade das ligações adquire relevância na análise estrutural, tendo em vista que a rigidez dos elementos que compõem a estrutura sofre modificação, promovendo assim uma redistribuição dos esforços e deslocamentos ao longo de toda a estrutura.

O estudo das ligações semi-rígidas é conhecido no campo das estruturas metálicas desde a primeira metade do século XX. LEON (1998) comenta que desde a década de 50 as ligações semi-rígidas ou de resistência parcial já eram incorporadas a projetos através do método simplificado permitido pelas normas AISC, American Institute of Steel Construction.

Segundo LEON (1998), naquela época as ligações eram supostas articuladas quando submetidas a carregamentos verticais (gravitacional) e supostas rígidas ou de 
resistência total quando submetidas a carregamentos horizontais (vento). Para análise em serviço as ligações eram consideradas rígidas.

Estudos comparando o método simplificado descrito por LEON (1998) com procedimentos rigorosos de análise estrutural para o Estado Limite de Serviço e o Estado Limite Último, comprovaram que tal método apresenta resultados perfeitamente satisfatórios.

Em estruturas de concreto pré-moldado, embora exista um grande número de trabalhos experimentais disponíveis na literatura técnica, ainda são poucos os modelos analíticos que permitam projetar as ligações viga-pilar levando em conta o seu comportamento semi-rígido. No Manual do PCI (1988) é preconizado que resultados experimentais obtidos em ensaios de ligações devam conduzir a equacionamentos para o cálculo e detalhamento de ligações típicas.

Talvez a forma mais usual para levar em consideração o comportamento semi-rígido de uma ligação de concreto pré-moldado, seja a utilização dos parâmetros de deformabilidade (ou de rigidez) e de resistência última, extraídos de curvas força $\mathrm{x}$ deslocamento.

Segundo EL DEBS (2000), a deformabilidade de uma ligação é definida como o deslocamento relativo entre os elementos que compõem a ligação, causado por um esforço unitário atuante na direção desse deslocamento. Assim, a deformabilidade ao momento fletor da ligação viga-pilar está associada à rotação da viga em relação à forma indeformada do nó, conforme apresentado na Figura 2.1.

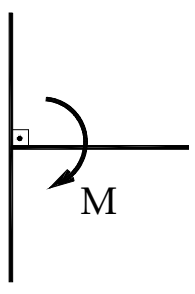

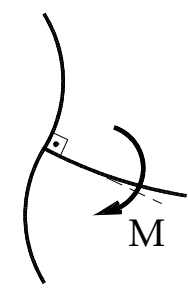

ligação indeformável

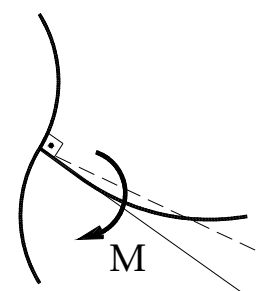

ligação deformável

Figura 2.1: Deformabilidade ao momento fletor em uma ligação viga-pilar Fonte:EL DEBS (2000). 
A deformabilidade, com base na definição apresentada e na Figura 2.1, pode ser matematicamente expressa por:

$$
D_{m}=\frac{\phi}{M}
$$

A rigidez é o inverso da deformabilidade e, portanto, pode ser matematicamente expressa por:

$$
K_{m}=\frac{M}{\phi}
$$

Sendo que:

$D_{m}$ - Deformabilidade (flexibilidade) ao momento fletor da ligação;

$K_{m}$ - Rigidez ao momento fletor da ligação;

$M$ - Momento fletor solicitante da ligação;

$\phi$ - Rotação relativa entre os elementos da ligação (Figura 2.1).

A rigidez de uma ligação pode ser obtida em função do comportamento do seu diagrama momento fletor $\mathrm{x}$ rotação, ou simplesmente diagrama momento x rotação. Assim, a rigidez $K_{m}$ da ligação é obtida pelo gradiente da curva momento x rotação, conforme ilustrado na Figura 2.2.

A resistência última de uma ligação pode ser entendida como a máxima combinação de esforços que a ligação pode suportar. Em projeto, caracteriza-se por ser o momento fletor em que ocorre a plastificação da ligação.

Na Figura 2.2 está ilustrado o comportamento não-linear de uma ligação, que consiste em uma característica da maioria das ligações semi-rígidas, sendo que " $\mathrm{M}_{\mathrm{u}}$ "é o máximo momento que a ligação pode suportar e " $\mathrm{M}_{\mathrm{i}}$ ", o momento elástico linear da ligação.

Segundo ELLIOT (1998), a rigidez inicial da ligação depende principalmente da sua geometria, em particular pela maneira na qual foi construída, e as tolerâncias admitidas. Ainda segundo ELLIOT (1998), a resistência última seria devida 
principalmente à resistência dos materiais que compõem a ligação, e a capacidade de rotação, em função da ductilidade, sendo que a geometria também exerce influência.

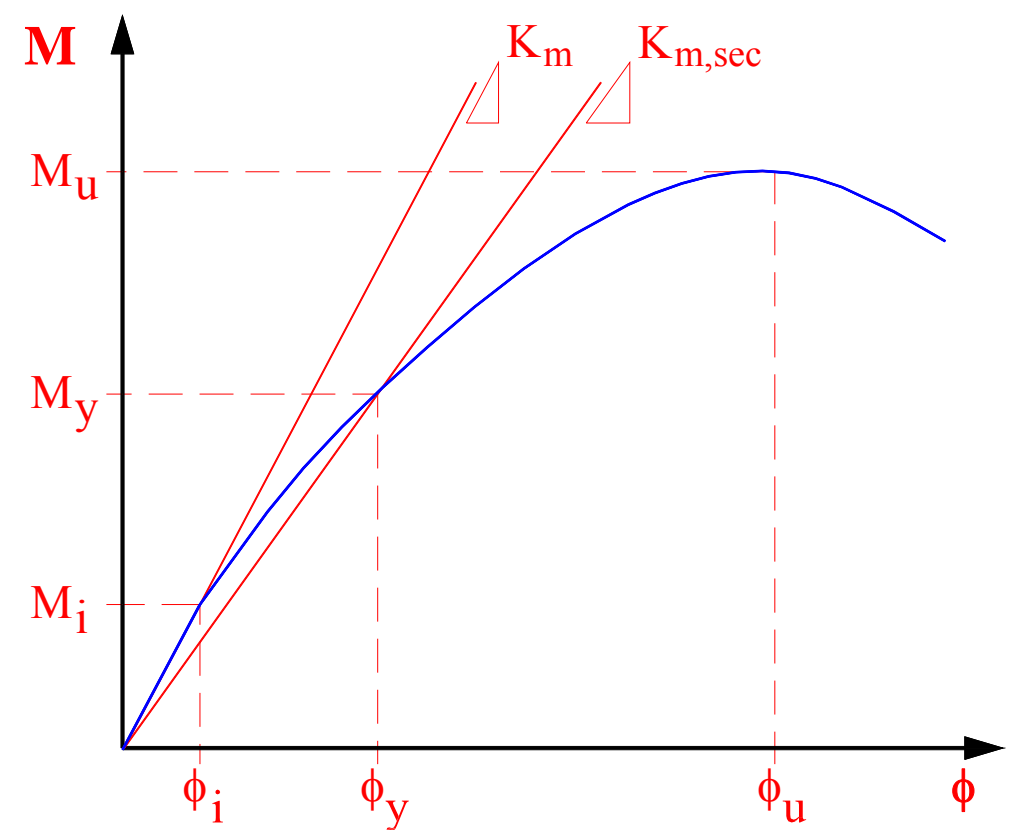

Figura 2.2: Curva momento-rotação para uma ligação

Por meio da rigidez de uma ligação é possível estimar a sua resistência com a utilização do método "Beam-Line", desenvolvido inicialmente para a aplicação no estudo de ligações semi-rígidas em estruturas metálicas de pórticos contraventados.

O método "Beam-Line" é na realidade um processo simplificado para estimar a resistência da ligação a partir da consideração da rigidez da ligação, sendo a resistência, compatível com o comportamento elástico da viga e com a rigidez da ligação.

A partir dos pontos que unem as situações de engastamento perfeito e de articulação perfeita nas extremidades da viga, a reta "Beam-Line" é definida. Na Figura 2.3, são apresentadas as extremidades da reta "Beam-Line", para $\mathrm{M}=\mathrm{M}_{\mathrm{p}}$ (Momento de engastamento perfeito) e para $\mathrm{M}=0$ (situação de articulação perfeita).

Conforme pode-se verificar na Figura 2.3, o ponto limite para o trabalho da ligação é definido pelo ponto "E", que corresponde a interseção da curva momento x rotação da ligação com a reta "Beam-Line". Como interpretação desse gráfico, pode-se afirmar que se a ruptura ocorrer no trecho abaixo do ponto "E" 
(Figura 2.3), ela se dará na região da ligação. Em caso contrário, a ruptura ocorrerá na região da viga, ou seja, se a ruptura ocorrer no trecho acima do ponto "E".

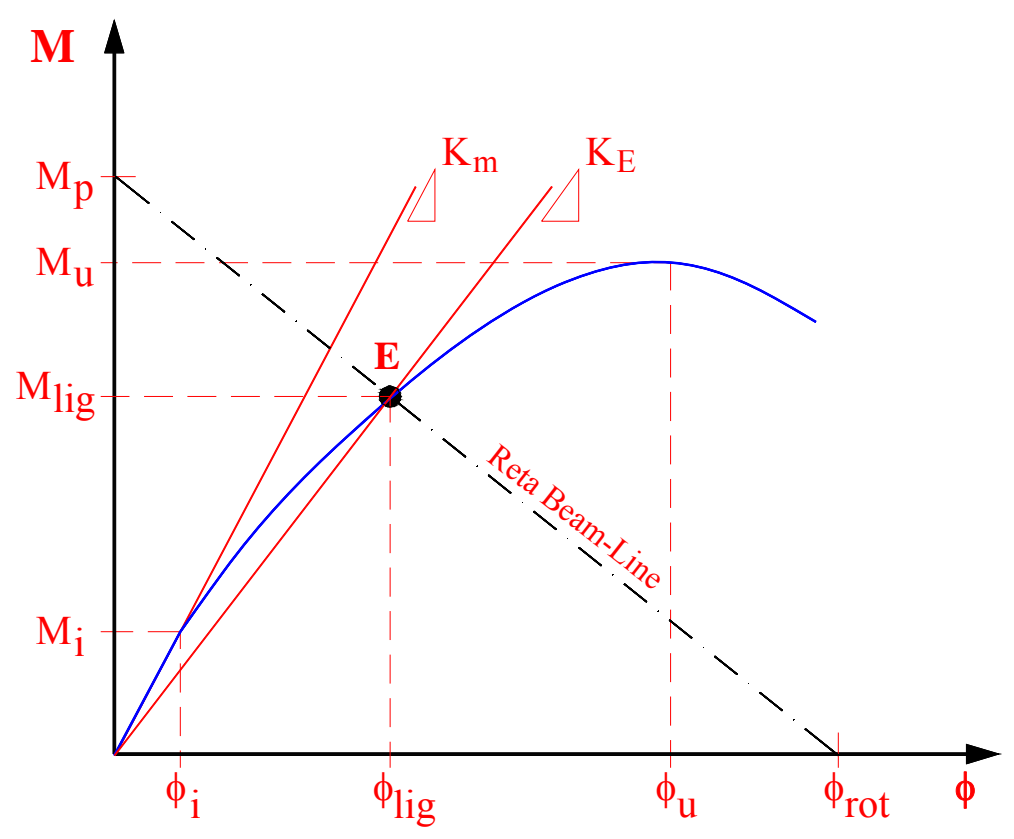

Figura 2.3: Reta Beam-Line com a curva momento-rotação da ligação Fonte:FERREIRA (1999).

ELLIOTT et al. (1998) propõem equações empíricas para as relações entre o momento máximo na ligação $\left(\mathrm{M}_{\mathrm{u}}\right)$ e o momento de engastamento perfeito $\left(\mathrm{M}_{\mathrm{p}}\right)$, escrita em função de rigidez equivalente $\left(\mathrm{K}_{\mathrm{s}}\right)$, para o caso da ligação em apenas um lado do pilar (Equação 2.3) e para o caso de duas ligações opostas sobre o pilar (Equação 2.4), dadas como segue:

$$
\begin{aligned}
& \frac{M_{u}}{M_{p}}=0,87 \sqrt{K_{s}} \\
& \frac{M_{u}}{M_{p}}=0,62 \sqrt{K_{s}}
\end{aligned}
$$




$$
K_{s}=\frac{K_{m} \cdot l}{4 \cdot E_{c} \cdot I}
$$

Sendo que:

$K_{m}$ - Rigidez ao momento fletor da ligação;

$\ell \quad$ - Vão efetivo da viga;

$E_{c}$ - Módulo de Elasticidade do concreto;

I - Momento de Inércia da viga;

FERREIRA (1999), analisando estas equações, concluiu que o efeito da rigidez das ligações é maior nos casos onde se têm duas vigas adjacentes conectadas a pilares centrais, onde há uma maior restrição aos giros nodais, e menor para as situações de vigas conectadas a pilares de extremidade, com uma maior liberdade aos giros nodais.

Conhecendo o momento máximo na ligação $\left(\mathrm{M}_{\mathrm{u}}\right)$ e o momento de engastamento perfeito $\left(\mathrm{M}_{\mathrm{p}}\right)$, pode-se obter uma rigidez equivalente $\left(\mathrm{K}_{\mathrm{s}}\right)$, e assim calcular o momento de projeto $\mathrm{M}_{\mathrm{E}}$ (momento da ligação), através da equação que segue.

$$
M_{E}=M_{p} \cdot\left(\frac{2 K_{s}}{2 K_{s}+1}\right)
$$

Com o objetivo de simplificação dos cálculos, ao se projetar estruturas de concreto pré-moldado, é comum promover uma linearização do diagrama momento $\mathrm{x}$ rotação. A partir do método "Beam-Line", pode-se construir um diagrama bi-linear que represente, de forma simplificada o comportamento momento x rotação da ligação (Figura 2.4). É oportuno lembrar que o trecho reto paralelo ao eixo das abscissas, representa a ruptura na região da viga.

Segundo CHEFDEBIEN (1998), que estudou ligação viga-pilar com diferentes materiais para almofada de apoio e preenchimento dos nichos dos chumbadores, as curvas momento-rotação apresentam-se quase bi-linear quando a almofada e o preenchimento desses nichos são feitos de materiais rígidos. Para as ligações cujas as almofadas e os nichos sejam preenchidos com materiais mais flexíveis, as curvas têm um comportamento não-linear. 


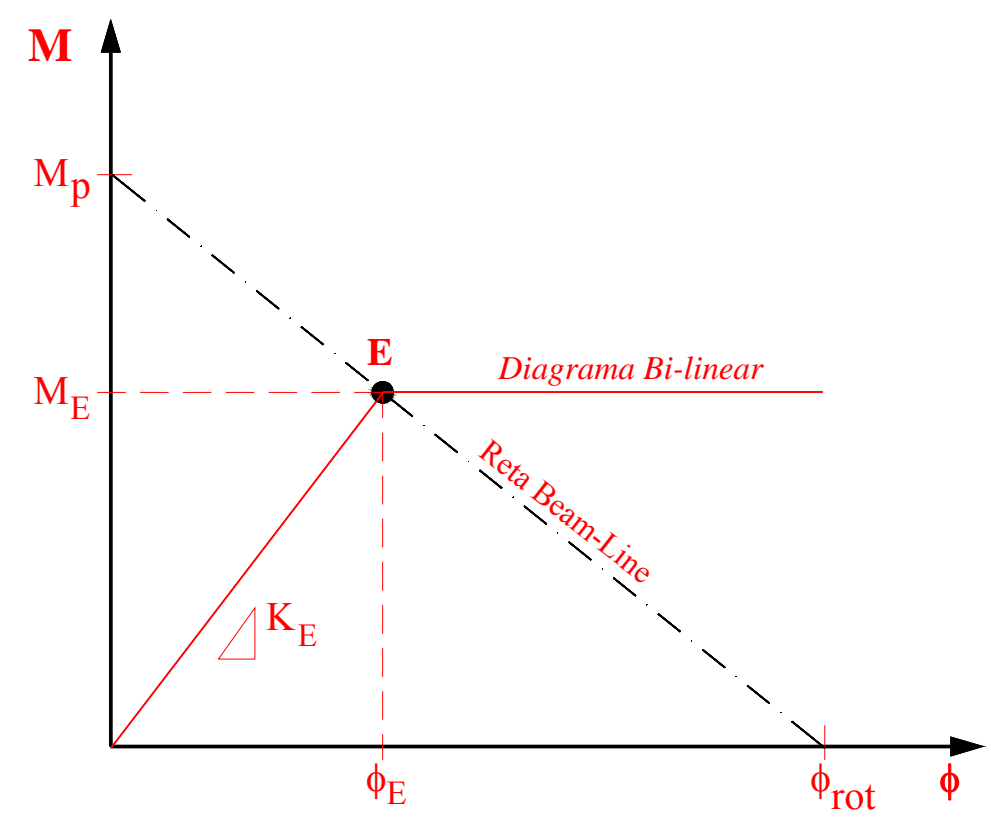

Figura 2.4: Diagrama Bi-Linear construído a partir do método "Beam-Line" Fonte:FERREIRA (1999).

A linearização do diagrama momento-rotação é um procedimento presente em Normas tanto de Estruturas de Concreto Pré-Moldado, quanto de Estruturas Metálicas. No PCI (1988) é apresentado um procedimento para a linearização do diagrama momento-rotação que é baseado no método "Beam-Line", visando a aplicação prática em escritórios de projeto de Estruturas de Concreto Pré-Moldado. Vale ressaltar que no EUROCODE 3 (2002), também são apresentados procedimentos para a linearização do diagrama momento-rotação, com ênfase em Estruturas Metálicas.

É oportuno registrar que a aplicação de procedimentos simplificados para a análise do comportamento momento x rotação, é limitada ao estudo de vigas submetidas a ações verticais. A falta de uma base de dados experimentais e de equacionamentos analíticos que possibilitem a determinação da rigidez das ligações, impossibilita muitas vezes a aplicação desses procedimentos simplificados.

\subsection{CLASSIFICAÇÃO DAS LIGAÇÕES}

As classificações das ligações aqui apresentadas são baseadas principalmente em pesquisas realizadas na área de Estruturas Metálicas, e têm como objetivo auxiliar na escolha do tipo de ligação, visando economia e desempenho estrutural. 
As ligações podem ser classificadas quanto à sua rigidez e quanto à sua resistência. Quanto à rigidez as ligações podem ser rígidas, articuladas ou semi-rígidas. Já quanto à resistência, as ligações podem ser articuladas, de resistência parcial ou de resistência total.

\subsubsection{Classificação quanto à rigidez}

Conforme já mencionado anteriormente, quanto à rigidez, as ligações são classificadas em rígidas, articuladas ou semi-rígidas.

Uma ligação rígida pode ser entendida como aquela que garante a continuidade da estrutura, restringindo totalmente as rotações relativas, permitindo assim a transmissão total de momento fletor da viga para o pilar.

Quando as rotações relativas não são restringidas e não existe transmissão de momento fletor da viga para o pilar, a ligação é dita articulada.

Já as ligações semi-rígidas, possuem um comportamento intermediário entre as rígidas e as articuladas (ou flexíveis). Assim, pode-se conceituar as ligações semi-rígidas como sendo aquelas capazes de restringir parcialmente as rotações relativas e de transmitir parcialmente momento fletor da viga para o pilar.

Na norma americana AISC/LFRD (1986), foi proposta uma modificação na classificação das ligações, onde são consideradas apenas duas classes:

i. Tipo FR (fully restrained) - ligações completamente restringidas. São consideradas aquelas nas quais é garantida a continuidade da estrutura e as rotações relativas são totalmente restringidas, ou admitem restrições no mínimo igual a 90\% da rotação teórica verificada sob condições de rótula ideal;

ii. Tipo PR (partially restrained) - ligações parcialmente restringidas. Neste grupo são reunidas todas as ligações cuja rigidez seja considerada insuficiente para manter inalterado o ângulo original entre os elementos conectados.

Já na norma americana AISC/ASD (1989), as ligações são classificadas em três classes, onde o limite de rotação de cada ligação também é especificado: 
i. Tipo 1: Ligações rígidas - consideradas as ligações onde o ângulo original entre os elementos conectados é mantido praticamente inalterado após solicitação, admitindo-se rotações relativas não superiores a $10 \%$ da correspondente à situação de perfeitamente articulada;

ii. Tipo 2: Ligações articuladas - consideradas as ligações onde a rotação relativa entre os elementos deve ser superior a $80 \%$ da correspondente à situação de ligação perfeitamente articulada;

iii. Tipo 3: Ligações semi-rígidas - consideradas as ligações onde há uma restrição parcial à rotação, com rotações relativas entre elementos de $10 \%$ a $80 \%$ da correspondente à situação de perfeitamente articulada.

A classificação do EUROCODE 3 (2002) é baseada na capacidade de carga dos elementos estruturais, levando-se em conta o comportamento global da estrutura, sendo a rigidez das ligações expressa como uma parcela da rigidez do elemento que está sendo conectado, ou seja, uma parcela da rigidez da viga.

Esta classificação contida no EUROCODE 3 (2002) pode ser melhor entendida, se for analisada a curva momento $\mathrm{x}$ rotação adimensional, onde o momento de plastificação da seção transversal na viga " $\mathrm{M}_{\mathrm{p}}$ " e sua respectiva rotação " $\theta_{\mathrm{p}}$ " são levados em consideração. Na Figura 2.5, são apresentados os limites para a classificação das ligações rígidas, semi-rígidas e articuladas (ou flexíveis), segundo esta norma.

Observando a Figura 2.5, pode-se estabelecer valores limite para a rigidez inicial da ligação $\left(\mathrm{K}_{\mathrm{m}}\right)$, como parcela da rigidez da viga. Tanto o EUROCODE 3 (2002) como o texto base da norma brasileira NBR 8800 (2003) trazem como limite para ligações articuladas $\mathrm{K}_{\mathrm{m}}<0,5 \mathrm{EI}_{\mathrm{v}} / \ell_{\mathrm{v}}$ e para ligações rígidas $\mathrm{K}_{\mathrm{m}}>\mathrm{k}_{\mathrm{v}} \mathrm{EI}_{\mathrm{v}} / \ell_{\mathrm{v}}$, sendo $\mathrm{k}_{\mathrm{v}}=8$ para $\mathrm{o}$ caso de estruturas contraventadas e $\mathrm{k}_{\mathrm{V}}=25$ para $\mathrm{o}$ caso de estruturas não contraventadas.

$\mathrm{Na}$ Tabela 2.1 são apresentados resumidamente os valores limites de classificação das ligações quanto à rigidez, preconizados pelo EUROCODE (2002), pelo texto base da NBR 8800 (2003) e o pelo AISC/ASD (1989). É importante registrar que essas formulações apresentadas são destinadas à avaliação de vigas, submetidas a ações verticais. 


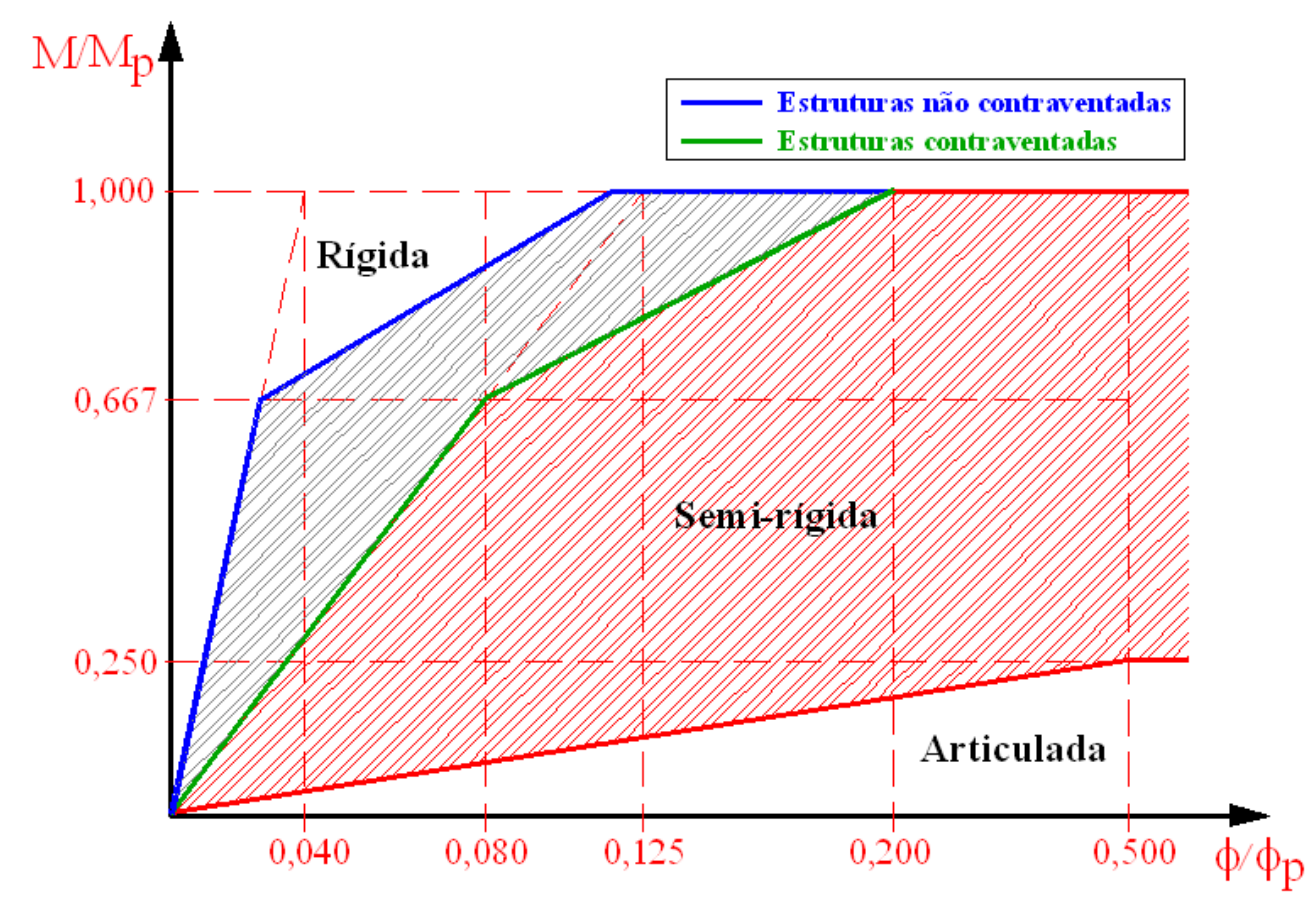

Figura 2.5: Classificação das ligações segundo o EUROCODE 3 (2002)

Tabela 2.1: Limite de classificação à rigidez estabelecido por normas

\begin{tabular}{|c|c|c|c|c|}
\hline \multicolumn{2}{|c|}{ NORMA } & \multicolumn{3}{|c|}{ TIPO DE LIGAÇÃO } \\
\hline & & Articulada & Semi-rígida & Rígida \\
\hline \multirow{2}{*}{ EUROCODE 3} & $\begin{array}{l}\text { Estruturas } \\
\text { contraventadas }\end{array}$ & $\mathrm{K}_{\mathrm{m}}<0,5 \mathrm{EI}_{\mathrm{v}} / \ell_{\mathrm{v}}$ & $0,5 \mathrm{EI}_{\mathrm{v}} / \ell_{\mathrm{v}}<\mathrm{K}_{\mathrm{m}}<8 \mathrm{EI}_{\mathrm{v}} / \ell_{\mathrm{v}}$ & $\mathrm{K}_{\mathrm{m}}>8 \mathrm{EI}_{\mathrm{v}} / \ell_{\mathrm{v}}$ \\
\hline & $\begin{array}{l}\text { Estruturas } \\
\text { não contravent. }\end{array}$ & $\mathrm{K}_{\mathrm{m}}<0,5 \mathrm{EI}_{\mathrm{v}} / \ell_{\mathrm{v}}$ & $0,5 \mathrm{EI}_{\mathrm{v}} / \ell_{\mathrm{v}}<\mathrm{K}_{\mathrm{m}}<25 \mathrm{EI}_{\mathrm{v}} / \ell_{\mathrm{v}}$ & $\mathrm{K}_{\mathrm{m}}>25 \mathrm{EI}_{\mathrm{v}} / \ell_{\mathrm{v}}$ \\
\hline \multirow{2}{*}{ NBR 8800} & $\begin{array}{l}\text { Estruturas } \\
\text { contraventadas }\end{array}$ & $\mathrm{K}_{\mathrm{m}}<0,5 \mathrm{EI}_{\mathrm{v}} / \ell_{\mathrm{v}}$ & $0,5 \mathrm{EI}_{\mathrm{v}} / \ell_{\mathrm{v}}<\mathrm{K}_{\mathrm{m}}<8 \mathrm{EI}_{\mathrm{v}} / \ell_{\mathrm{v}}$ & $\mathrm{K}_{\mathrm{m}}>8 \mathrm{EI}_{\mathrm{v}} / \ell_{\mathrm{v}}$ \\
\hline & $\begin{array}{l}\text { Estruturas } \\
\text { não contravent. }\end{array}$ & $\mathrm{K}_{\mathrm{m}}<0,5 \mathrm{EI}_{\mathrm{v}} / \ell_{\mathrm{v}}$ & $0,5 \mathrm{EI}_{\mathrm{v}} / \ell_{\mathrm{v}}<\mathrm{K}_{\mathrm{m}}<25 \mathrm{EI}_{\mathrm{v}} / \ell_{\mathrm{v}}$ & $\mathrm{K}_{\mathrm{m}}>25 \mathrm{EI}_{\mathrm{v}} / \ell_{\mathrm{v}}$ \\
\hline \multirow{2}{*}{ AISC-ASD } & $\begin{array}{l}\text { Estruturas } \\
\text { contraventadas }\end{array}$ & \multirow{2}{*}{$\begin{array}{c}\phi>80 \% \text { da ligação } \\
\text { perfeitamente } \\
\text { articulada }\end{array}$} & \multirow{2}{*}{$\begin{array}{c}10 \%<\phi<80 \% \text { da ligação } \\
\text { perfeitamente articulada }\end{array}$} & \multirow{2}{*}{$\begin{array}{c}\phi<10 \% \text { da } \\
\text { ligação } \\
\text { perfeitamente } \\
\text { articulada }\end{array}$} \\
\hline & $\begin{array}{l}\text { Estruturas } \\
\text { não contravent. }\end{array}$ & & & \\
\hline
\end{tabular}

$\mathrm{I}_{\mathrm{v}} / \ell_{\mathrm{v}}$ : Relação entre momento de inércia e comprimento da viga.

GOMES et al. (1998), em seu trabalho, reuniu algumas formulações apresentadas por diferentes pesquisadores para a classificação de ligações rígidas. $\mathrm{Na}$ 
Tabela 2.2 são apresentados os limites propostos, e diante desses valores, pode-se perceber claramente que ainda não existe um consenso geral sobre o assunto.

Tabela 2.2: Limite de classificação à rigidez estabelecido por outros pesquisadores. Fonte: GOMES et al (1998)

\begin{tabular}{|c|c|}
\hline AUTORES & $\begin{array}{c}\text { LIMITE PARA CLASSIFICAÇÃO COMO } \\
\text { LIGAÇÃO RÍGIDA }\end{array}$ \\
\hline BJORHOVDE et al. (1990) & $\mathrm{EI}_{\mathrm{v}} / 2 \mathrm{~d}$ \\
\hline BIJLAARD \& STEENHUIS (1992) & $\begin{array}{ll}\mathrm{EI}_{\mathrm{v}} / \mathrm{d} & \text { (Estruturas não contraventadas) } \\
\mathrm{EI}_{\mathrm{v}} / 2,5 \mathrm{~d} & \text { (Estruturas contraventadas) }\end{array}$ \\
\hline TSCHEMMERNEGG \& HUTER (1993) & $3 \mathrm{EI}_{\mathrm{v}} / 4 \mathrm{~d}$ \\
\hline MAZZOLANI et al. (1996) & $\mathrm{EI}_{\mathrm{v}} / \mathrm{d}$ \\
\hline TSCHEMMERNEGG \& HUBER (1998) & $\begin{array}{l}\text { (Estruturas não contraventadas) } \\
\text { (Estruturas contraventadas) }\end{array}$ \\
\hline
\end{tabular}

$\mathrm{d}$ : Altura da viga; $b_{\mathrm{j}}$ : Largura do pilar; $\mathrm{I}_{\mathrm{v}}=$ Momento de inércia da viga.

\subsubsection{Classificação quanto à resistência}

Para entender melhor a classificação das ligações quanto à resistência , pode-se tomar como base a classificação proposta por STARK \& BIJLAARD (1988). Segundo estes pesquisadores, a classificação das ligações depende da metodologia empregada no projeto das ligações, quanto à consideração ou não da não-linearidade física do material.

Assim, para dimensionamento considerando a não-linearidade física, as ligações são classificadas como segue:

i. Ligações articuladas - São as ligações projetadas para transferir somente forças normais e cortantes, admitindo-se que a ligação tenha uma capacidade de rotação que permita a formação de todas as rótulas plásticas necessárias ao estabelecimento do mecanismo de colapso;

ii. Ligações completamente resistentes - São as ligações que apresentam capacidade de resistir a momentos fletores superiores aos momentos de plastificação dos elementos conectados, resultando na formação de rótula plástica em um elemento adjacente à ligação. Para essa consideração, não é necessário que a ligação apresente, teoricamente, capacidade de rotação; 
iii. Ligações parcialmente resistentes - São as ligações que apresentam capacidade de resistir a momentos fletores inferiores aos momentos de plastificação dos elementos conectados. Neste caso, é necessária uma capacidade rotacional adequada, visto que a rótula plástica terá sua formação na ligação.

O Eurocode 3 (2002) define que as ligações podem ser classificadas em ligação articulada, de resistência parcial e resistência total comparando seu momento resistente com o momento resistente dos elementos que compõem a ligação.

Ligação articulada tem conceituação similar à da classificação pela rigidez. Ligações com resistência parcial apresentam resistência inferior à resistência dos elementos a ela conectados e a ligação com resistência total apresenta resistência igual ou superior à resistência dos elementos conectados.

Na Figura 2.6 estão ilustrados os limites para cada tipo de ligação de acordo com o EUROCODE 3 (2002), onde $\mathrm{M}_{\text {pl.Rd }}$ é o momento de plastificação de cálculo da viga conectada. Com base na figura, pode-se verificar que o limite máximo para a ligação ser considerada como articulada é de $0,25 . \mathrm{M}_{\mathrm{pl} . \mathrm{Rd}}$.

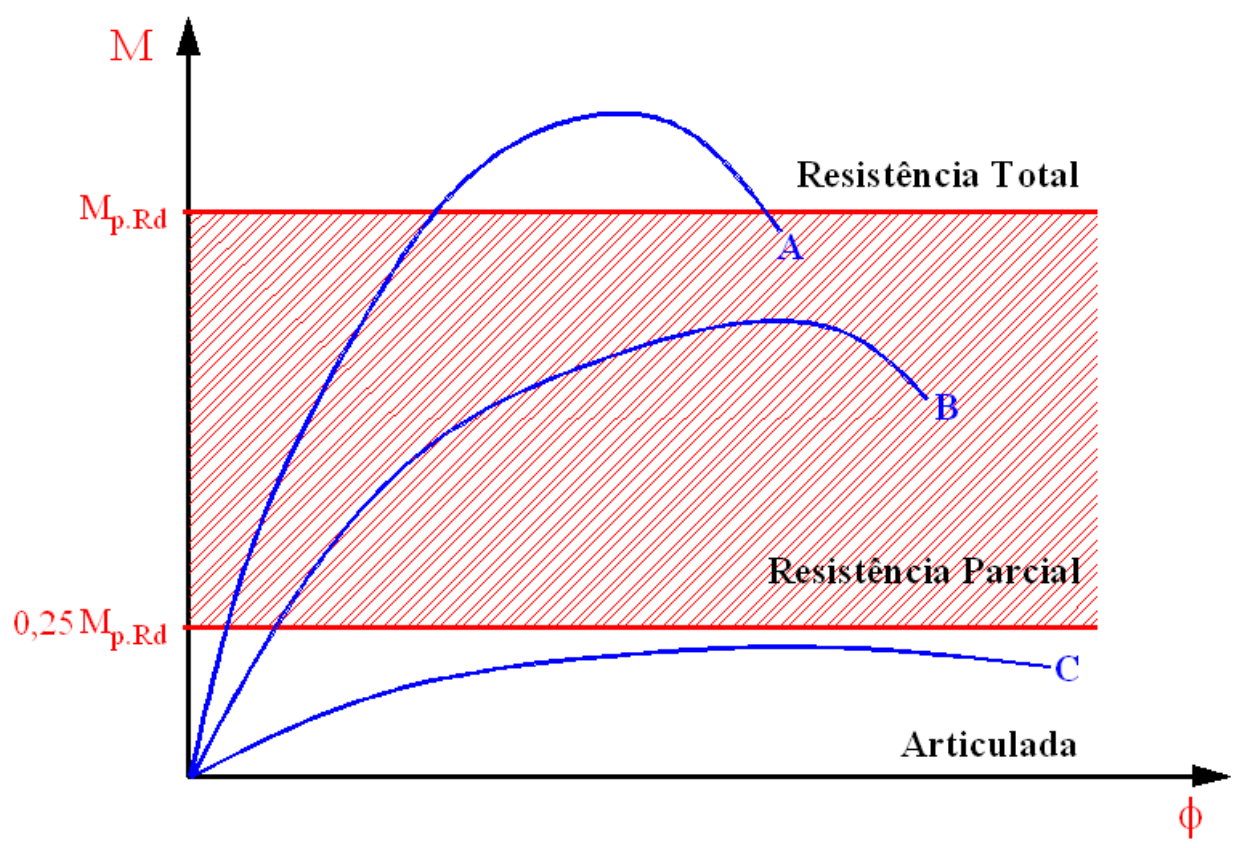

Figura 2.6: Classificação das ligações quanto à resistência 
A título de ilustração, na Figura 2.6 são representadas três curvas momento-rotação, onde a curva "A" representa uma ligação de resistência total; a curva “B”, uma ligação de resistência parcial, e finalmente, a curva "C", representa uma ligação articulada.

Assim como ocorreu na classificação das ligações quanto à rigidez, na classificação quanto à resistência também são observadas divergências nos limites propostos. Segundo TSCHEMMERNEGG et al. (1998) o limite máximo para a ligação ser considerada como articulada deve ser de $0,10 . \mathrm{M}_{\text {pl.Rd. }}$.

\subsection{COMPORTAMENTO DE LIGAÇÕES SEMI-RÍGIDAS}

\subsubsection{Determinação da relação momento-rotação}

A análise da deformabilidade de uma ligação pode ser realizada por meio de ensaios experimentais em modelos de escala 1:1 ou reduzida, por simulações numéricas ou por modelos analíticos adequados.

Dentre as formas de análise disponíveis, sem dúvidas a mais confiável é a realização de ensaios de laboratório. Porém, a realização de tais ensaios é na maioria das vezes restrita à atividades de pesquisas, tendo em vista o alto custo envolvido (equipamento, mão-de-obra especializada e tempo disponíveis) em tal atividade. Desta forma, para a aplicação em escritórios de cálculo, é de fundamental importância a aplicação de modelos analíticos adequados.

Segundo JASPART \& MAQUOI (1992), a maioria dos modelos matemáticos conhecidos podem ser classificados em:

i. Aproximação a uma curva (“curve fitting”): Esse método consiste na aproximação da curva momento x rotação da ligação, obtida de forma experimental ou por simulações numéricas, a uma representação matemática. A vantagem deste método é a fácil implementação em programas de análise estrutural, sendo que a curva tem aplicação restrita a ligações similares às utilizadas na calibração da curva;

ii. Análise via Método dos Elementos Finitos: A determinação da curva momento-rotação da ligação é realizada através de simulações 
numéricas com base no Método dos Elementos Finitos (MEF). A análise via MEF tem como vantagem a visualização do modelo nas fases linear e não-linear, podendo o projetista optar por análises em 2D ou 3D. A grande dificuldade dessa análise está na escolha de elementos e critérios que simulem adequadamente o comportamento real da ligação;

iii. Modelos mecânicos: Esse método consiste na representação da ligação através de modelos mecânicos baseados na associação de seus elementos componentes. A curva momento fletor-rotação da ligação é obtida através de uma combinação de elementos rígidos e deformáveis que representam o comportamento de cada componente da ligação, considerando que o comportamento global da ligação é o resultado da associação dos componentes isolados;

iv. Modelos analíticos simplificados: Nesse método a obtenção da curva momento-rotação da ligação é feita através de uma representação matemática baseada em seus principais valores característicos (deformabilidade inicial, momento resistente de projeto, momento de plastificação). Para isso é necessário o conhecimento das propriedades mecânicas e geométricas das ligações. Esse método é na realidade uma simplificação do método apresentado anteriormente.

Na utilização de métodos analíticos simplificados, o primeiro passo para avaliar a deformabilidade de uma ligação é idealizar a sua posição deformada. A partir dessa idealização é possível associar os mecanismos básicos de deformação.

O equacionamento do comportamento em conjunto dos mecanismos básicos de deformação é chamado de Método dos Componentes, e será melhor abordado na seqüência deste trabalho.

\subsubsection{Método dos Componentes}

Segundo o COST C1 - Composite steel-concrete joints in braced frames for buildings (1996), para a determinação do comportamento da ligação pelo modelo mecânico, é necessário que seja seguida a seguinte metodologia de análise: 
i. Listagem dos componentes da ligação: Nesta etapa são listados os componentes da ligação que possam contribuir no seu comportamento estrutural;

ii. Caracterização da deformação e da resistência dos componentes: Nesta estapa é realizada uma avaliação das características de deformação e resistência de cada componente individualmente;

iii. Associação dos componentes: Nesta etapa é feita a associação dos componentes individuais para a representação da ligação como um todo.

O Método dos Componentes, no "item ii", exige o conhecimento do comportamento dos componentes básicos da ligação. Várias são as técnicas que podem ser utilizadas para a caracterização dos componentes e para sua associação na ligação. As características relativas à rigidez, resistência e capacidade de deformação dos componentes podem ser obtidas através de modelos experimentais (ensaios de laboratório), simulações numéricas via Método dos Elementos Finitos ou por meio de modelos analíticos adequados.

As combinações apropriadas desses componentes propiciam a análise do comportamento de várias configurações de ligações, o que permite ao projetista de estruturas uma ferramenta de análise confiável e econômica.

Tanto as características como a associação dos componentes podem ser desenvolvidas com diferente grau de sofisticação, de acordo com os objetivos do projetista.

Quando uma ligação é solicitada, cada um dos seus componentes constituintes está sujeito a forças (F) de compressão, tração ou cisalhamento e a suas respectivas deformações $(\Delta)$. O comportamento real desses componentes pode então ser expresso com o auxílio de curvas F- $\Delta$ (não-lineares).

Para representar o comportamento da ligação, são aplicadas molas para simular a rigidez de cada componente. Obtém-se assim, uma representação física do comportamento local de cada um desses componentes, através da adoção do modelo de molas. Quando as características F- $\Delta$ de cada componente são conhecidas, todas as molas podem ser associadas para representar a configuração da ligação. 
Depois da associação das molas, um conjunto de forças é então aplicado às extremidades da viga e do pilar para a análise do comportamento da ligação. Submetendo a ligação a carregamentos incrementais, as forças se distribuem entre os componentes de acordo com a matriz de rigidez tangente da última configuração (configuração deformada do passo de carga anterior). Essa forma de avaliar o comportamento da ligação requer a aplicação de um computador para resolver as numerosas equações do processo iterativo.

Na Figura 2.7 está representado um modelo de ligação viga-pilar-laje para estrutura metálica, submetida a momento fletor, onde a configuração da ligação através de molas foi idealizada pelo Método dos Componentes.

Partindo da premissa de que as molas têm um comportamento linear correspondente a sua rigidez elástica, então as rigidezes iniciais elásticas da ligação podem ser desenvolvidas analiticamente. Assim, a rigidez inicial da ligação $\left(\mathrm{K}_{\mathrm{j}, \text { ini }}\right)$ é obtida a partir da rigidez elástica dos componentes. O comportamento elástico de cada componente é representado por uma mola. A relação força-deformação dessa mola é dada por:

$$
F_{i}=K_{i} \cdot E \cdot \Delta_{i}
$$

Sendo que:

$$
\begin{array}{ll}
F_{i} & \text { - Força na mola i; } \\
K_{i} & \text { - Coeficiente de rigidez do componente i; } \\
E & \text { - Módulo de elasticidade do material; } \\
\Delta_{i} & \text { - Deformação da mola i; }
\end{array}
$$

Na Figura 2.7a é indicado como o modelo de molas é adaptado para casos mais complicados, onde as forças de tração, resultantes do momento aplicado, são resistidas não apenas por uma única camada de armadura, mas por uma segunda linha de barras ou por parafusos pertencentes à ligação metálica.

As molas podem ser somadas em série ou em paralelo, diminuindo assim a complexibilidade do modelo, como mostra a Figura 2.7b e 2.7c. No caso da Figura 2.7c, $\mathrm{K}_{1}, \mathrm{~K}_{\mathrm{eq}}$ e $\mathrm{K}_{11}$ representam respectivamente a alma do pilar submetida ao cisalhamento, 
armadura longitudinal e parafusos, e a alma do pilar submetida à compressão em conjunto com a chapa de contato.

Ainda na Figura 2.7c, pode-se perceber como essas molas efetivas de cada linha de parafusos são substituídas por uma mola equivalente atuando a um nível z. O coeficiente de rigidez dessa mola efetiva é $\mathrm{K}_{\mathrm{eq}}$ que pode ser denominado de $\mathrm{K}_{10}$.

A força em cada mola é igual a $F_{1}, F_{10}$ e $F_{11}$, relacionadas respectivamente com os seguintes componentes: alma do pilar solicitada ao cisalhamento, armadura longitudinal tracionada e alma do pilar (não enrijecida) à compressão associada a uma chapa de contato.
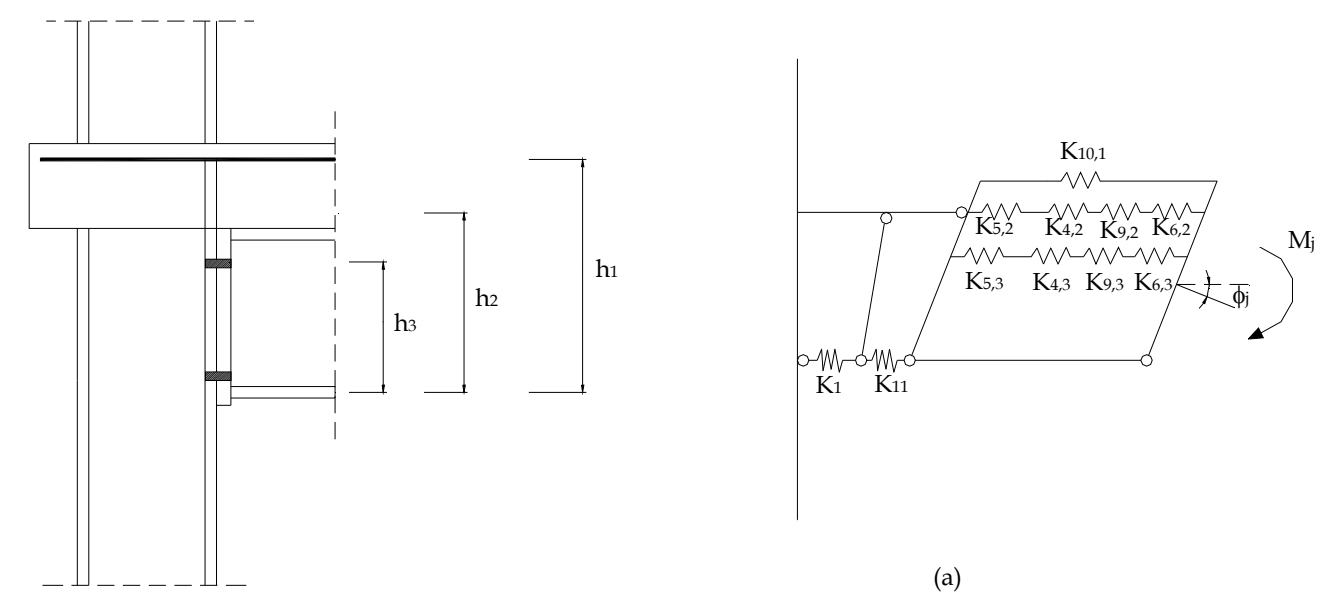

(a)
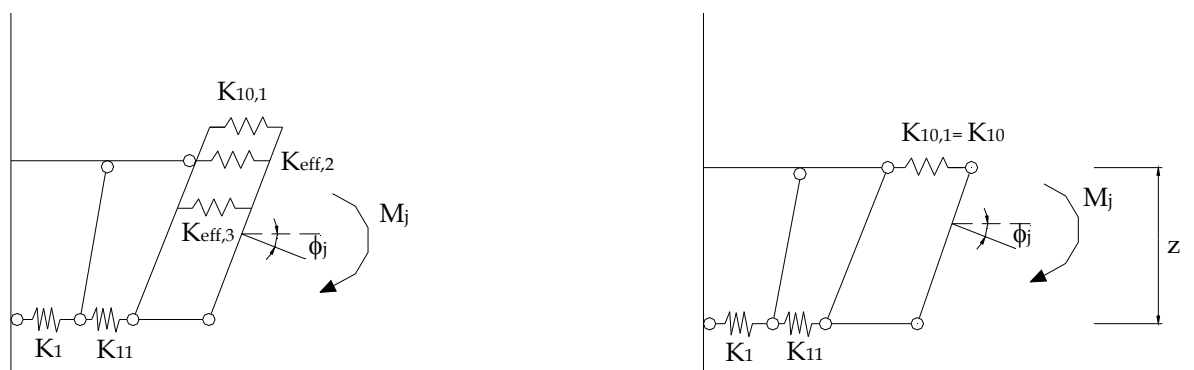

(b)

(c)

Figura 2.7: Modelo de molas para uma ligação viga-pilar-laje.

Fonte: COST C1 (1996)

$\mathrm{O}$ momento $\mathrm{M}_{\mathrm{j}}$ atuante no modelo é igual a $\mathrm{M}_{\mathrm{j}}=\mathrm{F} \cdot \mathrm{z}$, onde $\mathrm{z}$ é a distância entre o centro de tração, localizado no nível das barras da armadura, e o centro de 
compressão, considerado no centro da mesa inferior da viga. A rotação na ligação é dada pela Equação 2.8:

$$
\phi_{j}=\frac{\left(\Delta_{1}+\Delta_{11}+\Delta_{10}\right)}{Z}
$$

Sendo que:

$\Delta_{1} \quad$ - Deformação da molas 1;

$\Delta_{10} \quad$ - Deformação da molas 10;

$\Delta_{11}$ - Deformação da molas 11;

A rigidez inicial da ligação da Figura 2.7 pode ser determinada analiticamente através da Equação 2.9:

$$
\mathrm{K}_{\mathrm{j}, \text { ini }}=\frac{\mathrm{M}_{\mathrm{j}}}{\phi_{\mathrm{j}}}=\frac{\mathrm{F} \cdot \mathrm{z}}{\frac{\Delta_{1}}{\mathrm{z}}+\frac{\Delta_{11}}{\mathrm{z}}+\frac{\Delta_{10}}{\mathrm{z}}}=\frac{\mathrm{F} \cdot \mathrm{z}^{2}}{\frac{\mathrm{F}}{\mathrm{E}} \cdot\left(\frac{1}{\mathrm{~K}_{1}}+\frac{1}{\mathrm{~K}_{11}}+\frac{1}{\mathrm{~K}_{10}}\right)}=\frac{\mathrm{E} \cdot \mathrm{z}^{2}}{\sum \frac{1}{\mathrm{~K}_{\mathrm{i}}}}
$$

O Método dos Componentes é uma ferramenta que permite a junção do comportamento individual de cada elemento que compõe a ligação, para gerar o comportamento estrutural da ligação como um todo.

A facilidade de cálculo e a possibilidade de representar uma grande variedade de ligações, devido a inúmeras combinações dos elementos, tornam o Método dos Componentes viável para utilização em escritórios de projeto. É importante ressaltar que em ligações mais complexas, essa avaliação pode ser mais difícil e em geral com maior grau de simplificação.

\subsubsection{Mecanismos básicos de deformação}

Para a formulação de um modelo analítico qualquer de uma ligação, baseado no Método das Componentes, é necessário primeiramente o conhecimento dos mecanismos básicos de deformação no qual estão submetidos os elementos que compõem a ligação. Desta forma, neste item é promovida uma sucinta análise de apenas dois mecanismos de 
deformação, inerentes ao estudo dos chumbadores, necessários para a fundamentação da proposta apresentada neste trabalho.

\subsubsection{Mecanismo de deformação por tração de uma barra inserida no concreto}

No mecanismo de deformação por tração de uma barra inserida no concreto, pelo menos dois parâmetros adquirem grande relevância, são eles: a deformabilidade por alongamento da barra e a tensão de aderência.

A deformabilidade por alongamento da barra foi estudada por FERREIRA (1999), onde foi considerada apenas a fase linear do mecanismo de deformação por tração.

Segundo este pesquisador, para o desenvolvimento analítico do mecanismo de deformação à tração na fase linear, foi considerada a deformação axial de uma barra tracionada de comprimento $\ell_{\mathrm{s}}$, conforme indicado na Figura 2.8 .

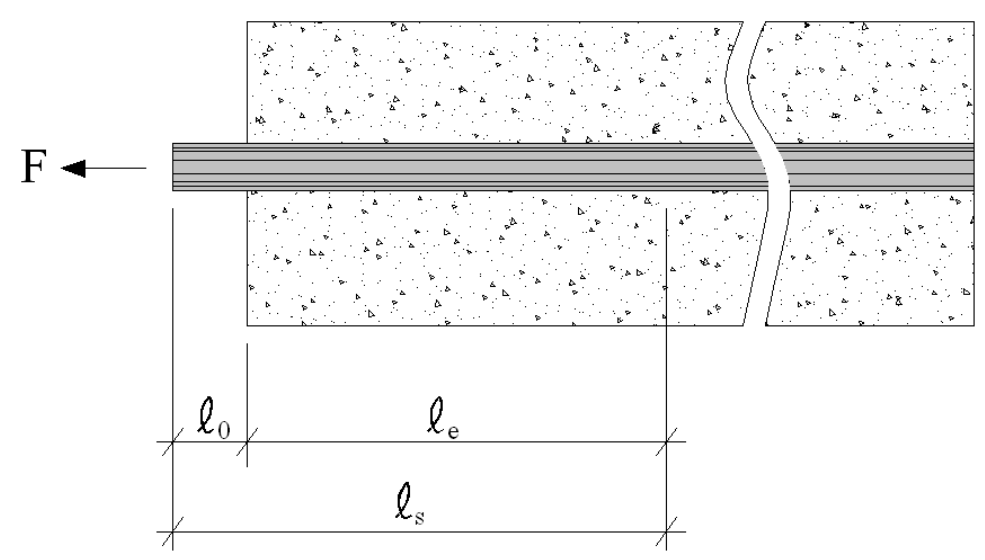

Figura 2.8: Comprimento efetivo de uma barra inserida em um elemento de concreto. Fonte: FERREIRA (1999)

A deformabilidade por alongamento da barra pode ser definida pela seguinte Equação:

$$
D_{t b}=\frac{\ell_{s}}{A_{s} \cdot E_{s}}
$$


$\ell_{s}=\ell_{0}+\ell_{e}$

Sendo que:

$D_{t b} \quad$ - Deformabilidade à tração da barra;

$\ell_{s}$ - Comprimento considerado para o calculo da deformabilidade;

$\ell_{0} \quad$ - Distância da face do elemento de concreto ao ponto considerado;

$\ell_{e}$ - Comprimento de ancoragem efetivo da barra no elemento de concreto.

FERREIRA (1999) recomenda que o comprimento efetivo para o cálculo da deformação à tração de uma barra, dado por $\ell_{\mathrm{e}}$, seja tomado como sendo a metade do comprimento de ancoragem $\ell_{\mathrm{b}}$.

Outro parâmetro importante para análise do mecanismo de deformação por tração de uma barra inserida no concreto é a tensão de aderência.

A transferência de forças de tração em barras envoltas em concreto é dada ao longo da interface concreto/aço através de tensões de aderência que não são uniformemente distribuídas, devido ao escorregamento em pontos da barra, mas que para efeito de cálculo podem ser consideradas uniformes. Na Figura 2.9 é apresentada a curva simplificada das tensões de aderência ao longo da barra.
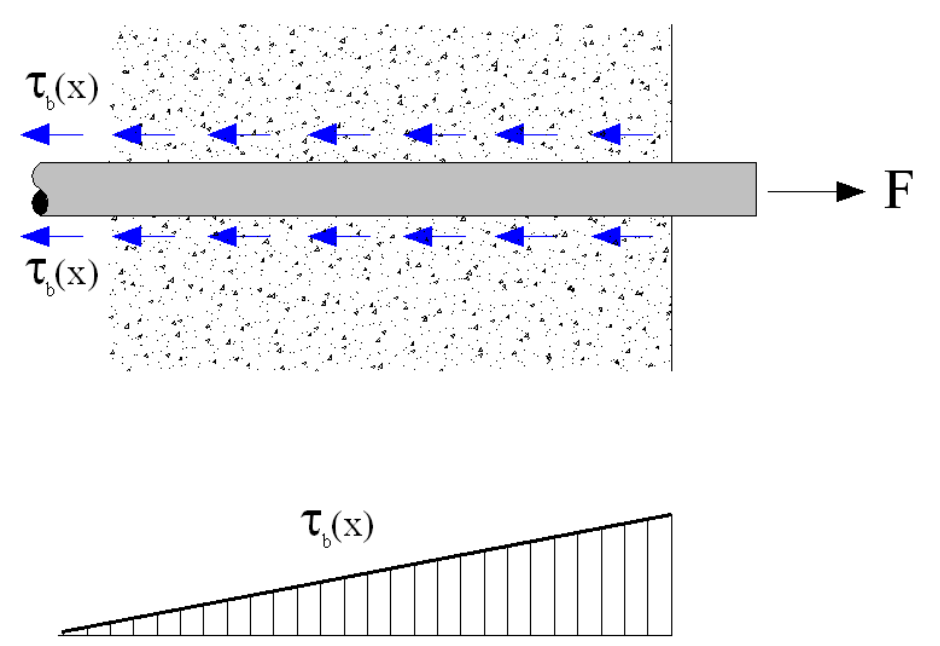

Figura 2.9: Distribuiçãosimplificada de tensões de aderência de barras tracionadas. 
Baseado em ensaios experimentais de arrancamento, no CEB/FIP (1990) foi definida a relação tensão de aderência x deslizamento indicado na Figura 2.10.

ENGSTROM (1992a) desenvolveu um modelo para determinar a relação força $\mathrm{x}$ deslocamento em ligações conectadas por tirantes, submetidas à tração. A teoria é fundamentada na hipótese de que a ligação entre os elementos de concreto pré-moldados adjacentes pode ser considerada fraca se comparada às outras seções transversais. Tendo em vista que a capacidade dos tirantes é geralmente pequena para produzir fissuras de tração nos elementos, as ligações podem ser tratadas analiticamente como um caso de uma única fissura em membros tracionados.

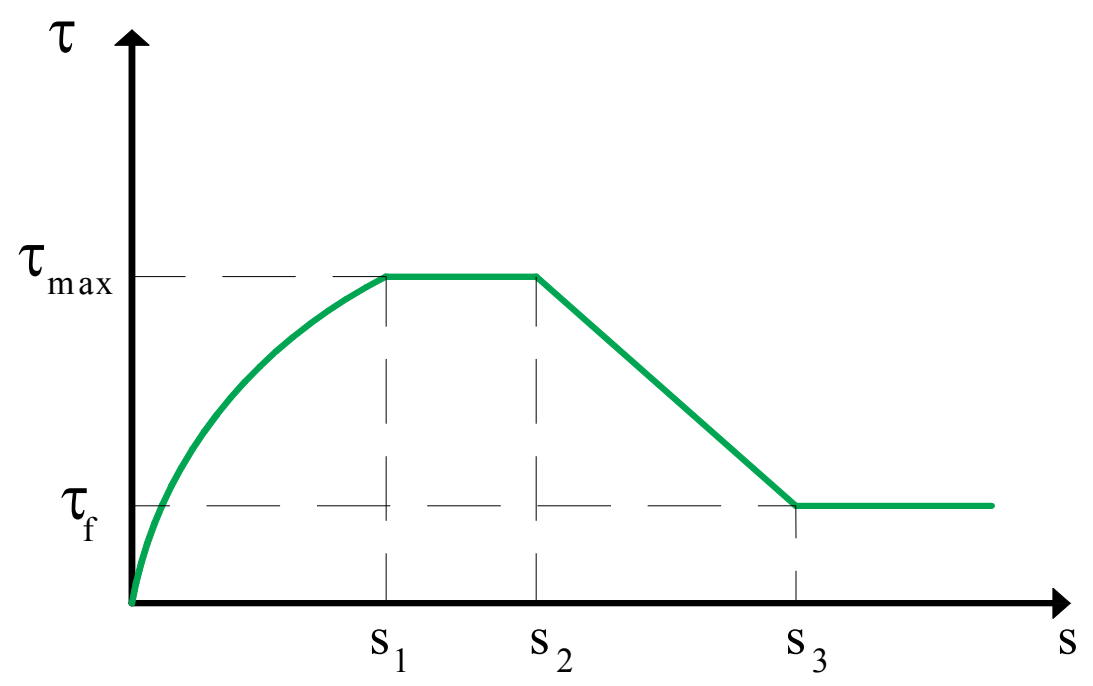

Figura 2.10: Relação entre tensão de aderência e deslizamento proposto pelo CEB. Fonte: FEB/FIP (1990)

O objetivo do estudo foi determinar o deslocamento relativo entre os elementos de concreto adjacentes, sendo que o referido deslocamento foi considerado igual à abertura global de fissura (w - global), conforme ilustrado na Figura 2.11.

Para o desenvolvimento do modelo, foram utilizados resultados de ensaios realizados em uma série de ligações atirantadas idealizadas, com barras corrugadas (com mossas) embutidas em elementos de concreto de grandes dimensões, conforme mostra a Figura 2.12. Nos ensaios foram medidas as forças aplicadas (N) e seus respectivos deslocamentos $(\mathrm{w})$. 


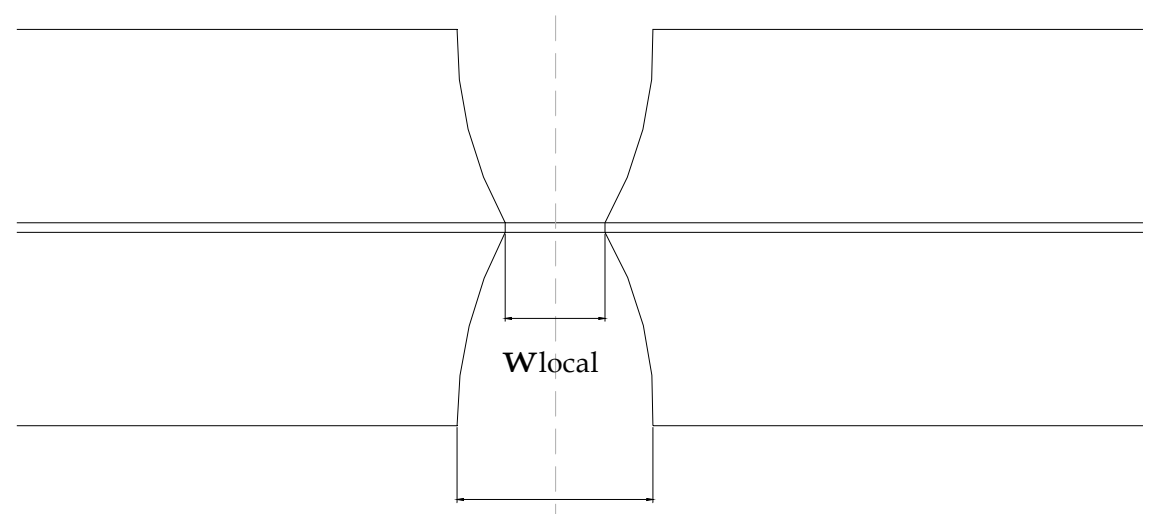

Wglobal

Figura 2.11 - Deslocamento entre dois elementos de concreto adjacentes Fonte: ENGSTROM (1992a)

Para descrever a relação tensão de aderência $\mathrm{x}$ deslocamento foram utilizados dois modelos: o primeiro é o modelo do CEB-FIP (1990) e o segundo é um modelo modificado, ambos representados na Figura 2.13. Sendo que:

$$
\begin{aligned}
& \mathrm{s}_{1}=1,0 \mathrm{~mm} \\
& \mathrm{~s}_{2}=3,0 \mathrm{~mm} \\
& \mathrm{~s}_{3}=\text { espaçamento livre entre as mossas } \\
& s_{4}=\frac{s_{3}}{2} \\
& \tau_{\max }=2,5 \cdot \sqrt{f_{c k}} \text { ou } \tau_{\max }=1,25 \cdot \sqrt{f_{c k}} \text { (boa ou má condição de aderência) } \\
& \tau_{f}=0,4 \cdot \tau_{\max } \\
& \tau_{f p l}=\frac{\tau_{f}}{2}
\end{aligned}
$$

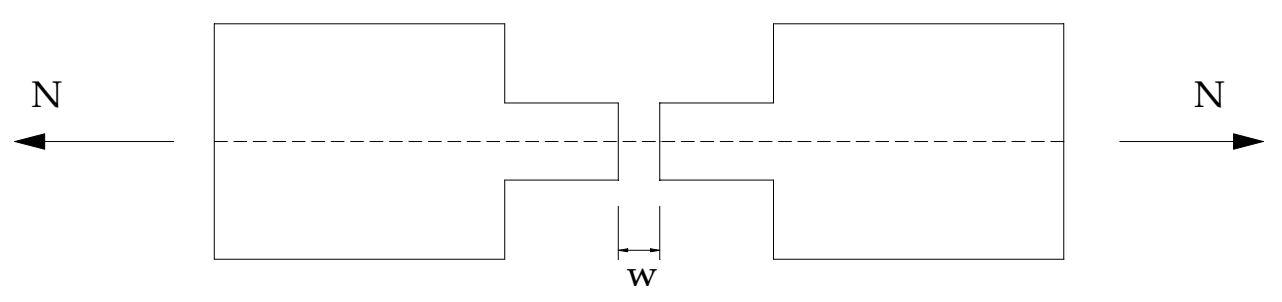

Figura 2.12 - Esquema dos ensaios de tração realizados por ENGSTROM (1992a). 
Baseado nos resultados experimentais observados, o modelo modificado proposto apresenta um ramo descendente logo após a tensão de aderência atingir a tensão de escorregamento da armadura (para $\tau=\tau_{\mathrm{y}}$ ), sendo mais adequado, segundo ENGSTROM (1992a), quando comparado ao modelo do CEB-FIP (1990).

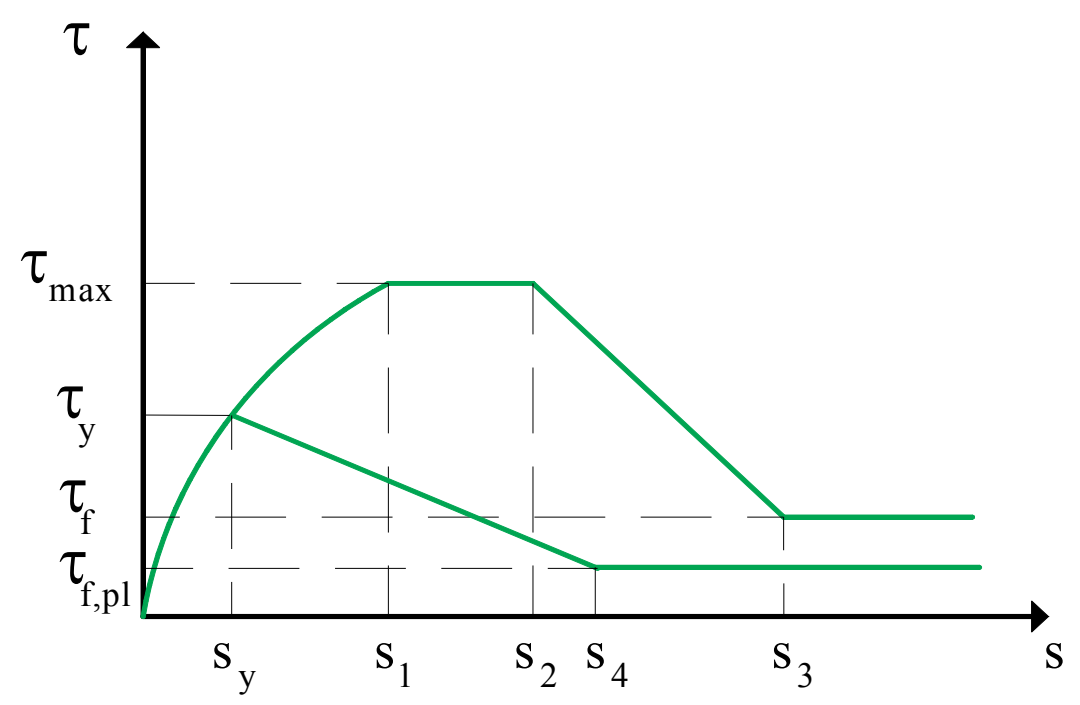

Figura 2.13: Tensão de aderência e deslizamento proposto por ENGSTROM (1992a)

Para as ligações ensaiadas, ENGSTROM (1992a) constatou que a deformação do concreto, ao longo do comprimento de transmissão era desprezível no cálculo da abertura da fissura global, especialmente em comparação com as incertezas na modelagem do comportamento aderência $\mathrm{x}$ deslocamento. Conseqüentemente, foi considerado que os elementos de concreto eram infinitamente rígidos nos cálculos.

Com os modelos do material e da relação tensão de aderência x deslocamento (Figura 2.13) foi desenvolvido um programa de computador para o calculo do deslocamento $\mathrm{w}$ a partir da força $\mathrm{N}$, ou seja, que determina a relação força $\mathrm{x}$ deslocamento dessas ligações. Através desse programa foi possível determinar também a distribuição de deformação do aço e os parâmetros a ela relacionados como: comprimento de transmissão, extensão da zona de plastificação e a tensão de aderência média na plastificação que também foram calculados e comparados com resultados experimentais. 
$\mathrm{Na}$ comparação dos resultados primeiramente foi utilizada a relação aderência x deslocamento do CEB-FIP (1990) nos cálculos numéricos. Durante a fase elástica houve uma boa semelhança entre os valores calculados e os observados experimentalmente. $\mathrm{Na}$ fase plástica, tanto a abertura da fissura como a extensão da zona plástica foram consideravelmente subestimadas pelo modelo do CEB-FIP (1990). Nessa fase, o deslocamento entre os elementos de concreto dependeram principalmente das deformações plásticas da barra.

ENGSTROM (1992a) verificou que no modelo do CEB-FIP (1990) são adotadas tensões de aderência muito altas na zona plástica. No entanto, devido ao escoamento, a deformação axial e a contração da barra aumentam significativamente, fazendo decrescer os efeitos de chave de cisalhamento das mossas e, conseqüentemente, reduzindo as tensões de aderência.

No modelo modificado proposto, o efeito do escoamento poderia ser considerado pela introdução de um ramo descendente na relação aderência $\mathrm{x}$ deformação no ponto $\left(\tau_{\mathrm{y}}, \mathrm{s}_{\mathrm{y}}\right)$ onde o escoamento é atingido. Quando o modelo modificado é adotado nos cálculos numéricos do deslocamento último, o comprimento de transmissão e a extensão da zona plástica em função da força de tração ficaram próximos aos obtidos experimentalmente.

ENGSTROM (1992a) sugere uma relação força-deslocamento tri-linear para ligações entre membros de concreto, com grandes dimensões, através de tirante de aço, como pode ser observado na Figura 2.14.

ENGSTROM (1992a) cita como as tensões principais de aderência no comprimento de transmissão podem ser calculadas com o uso de funções exponenciais de aderência x deslocamento. Este pesquisador recomenda a Equação 2.12 para o cálculo da abertura de fissura no instante de escoamento da barra ( $\left.\mathrm{w}_{\mathrm{y}}\right)$. A Equação 2.12 é válida quando a relação tensão de aderência $\mathrm{x}$ deslocamento é calculada pela Equação 2.13, sendo que "s" é o deslizamento medido e "s $\mathrm{s}_{1}$ " deve ser tomado como igual a $1 \mathrm{~mm}$.

$$
w_{y}=0,576 \cdot\left(\frac{\phi \cdot f_{y}{ }^{2}}{\tau_{\max } \cdot E_{s}}\right)^{0,714}+\left(\frac{f_{y} \cdot 4 \cdot \phi}{E_{s}}\right)
$$




$$
\tau=\tau_{\max }\left(\frac{s}{s_{1}}\right)^{2}
$$

Sendo que:

$\phi \quad$ - Diâmetro da armadura;

$f_{y} \quad$ - Tensão de escoamento do aço;

$E_{s} \quad$ - Módulo de elasticidade do aço.

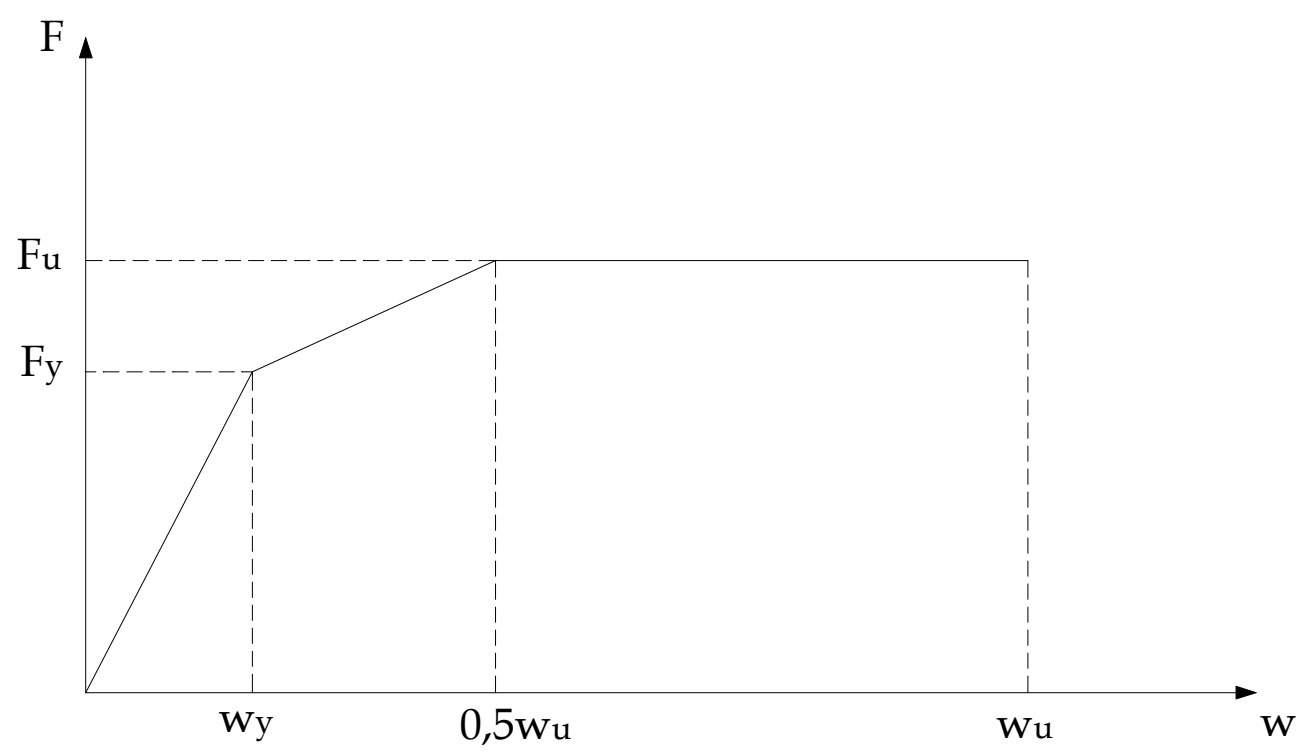

Figura 2.14: Relação força x deslocamento - aproximação trilinear.

\section{Fonte: ENGSTROM (1992a)}

Observando que a razão entre a tensão de aderência média na zona plástica e a tensão máxima de aderência $\tau_{\max }$ era quase a mesma para todos os testes, ENGSTROM (1992a) concluiu que a extensão última da zona plástica poderia ser determinada por uma condição de equilíbrio, apresentada na Equação 2.14.

$$
\begin{aligned}
& \ell_{t, p l}=\frac{\left(f_{u}-f_{y}\right)}{0,28 \cdot \tau_{\max }} \cdot \frac{\phi}{4} \\
& \tau_{\text {ader }}=\frac{F}{\pi \cdot \phi \cdot \ell_{t, p l}}
\end{aligned}
$$




$$
F=F_{u}-F_{y}=\frac{\pi \cdot \phi^{2}}{4} \cdot\left(f_{u}-f_{y}\right)
$$

Sendo que:

$$
\begin{array}{ll}
\ell_{\mathrm{t}, \mathrm{pl}} & - \text { Comprimento da zona plástica; } \\
f_{u} & - \text { Tensão última do aço; } \\
f_{y} & - \text { Tensão de escoamento do aço; }
\end{array}
$$

Dentro da zona plástica a tensão média de aderância pode ser estimada como $28 \%$ da tensão máxima ( $\tau_{\max }$ ), e a deformação média do aço pode ser estimada com $\varepsilon_{\mathrm{sm}, \mathrm{pl}} \cong 0,5 \varepsilon_{\mathrm{su}}$. O deslocamento último $\left(\mathrm{w}_{\mathrm{u}}\right)$ pode ser calculado pela Equação 2.17.

$$
w_{u}=\varepsilon_{s u} \cdot \ell_{t, p l}+w_{y}
$$

É oportuno comentar que a proposta de ENGSTROM (1992a) é apresentada pela FIB (2007) como alternativa para se estimar os valores de abertura de fissuras das ligações de barras tracionadas envoltas em concreto.

\subsubsection{Mecanismo de deformação por cisalhamento de uma barra inserida no concreto}

Uma das formas de se transmitir os esforços de cisalhamento entre elementos é através de barras transversais (chumbadores) inseridas em concreto submetidas a esforços horizontais. Essa transferência de forças provoca o surgimento de um estado de tensões não uniformes no concreto como mostra a Figura 2.15 e que submetem o chumbador à flexão com um momento fletor máximo próximo a interface.

Dependendo das dimensões, posição e resistência do chumbador, além da resistência do concreto que o envolve, diversos tipos de rupturas podem ser previstos. Os três modos principais são: resistência ao corte, lascamento do concreto e formação de rótulas plásticas na seção de máximo momento fletor.

O mecanismo de cisalhamento em um chumbador inserido em um elemento de concreto pode ser estimado por diferentes tipos de análise. Segundo 
DEI POLI et al. (1992), para esforços da ordem de até $40 \%$ da capacidade última do chumbador, os resultados experimentais demonstraram que a consideração de um comportamento linear se aproxima adequadamente ao comportamento real observado.

DEI POLI et al (1992) realizaram dois estudos importantes sobre o mecanismo de cisalhamento no chumbador. O primeiro estudo é referente ao comportamento do chumbador na fase elástica, onde foi utilizada a analogia de uma viga sob apoio elástico.

O segundo estudo é referente ao chumbador na sua posição crítica, com a formação de uma rótula plástica na seção de máximo momento fletor e com plastificação do concreto na face do elemento, conforme apresentado na Figura 2.16.

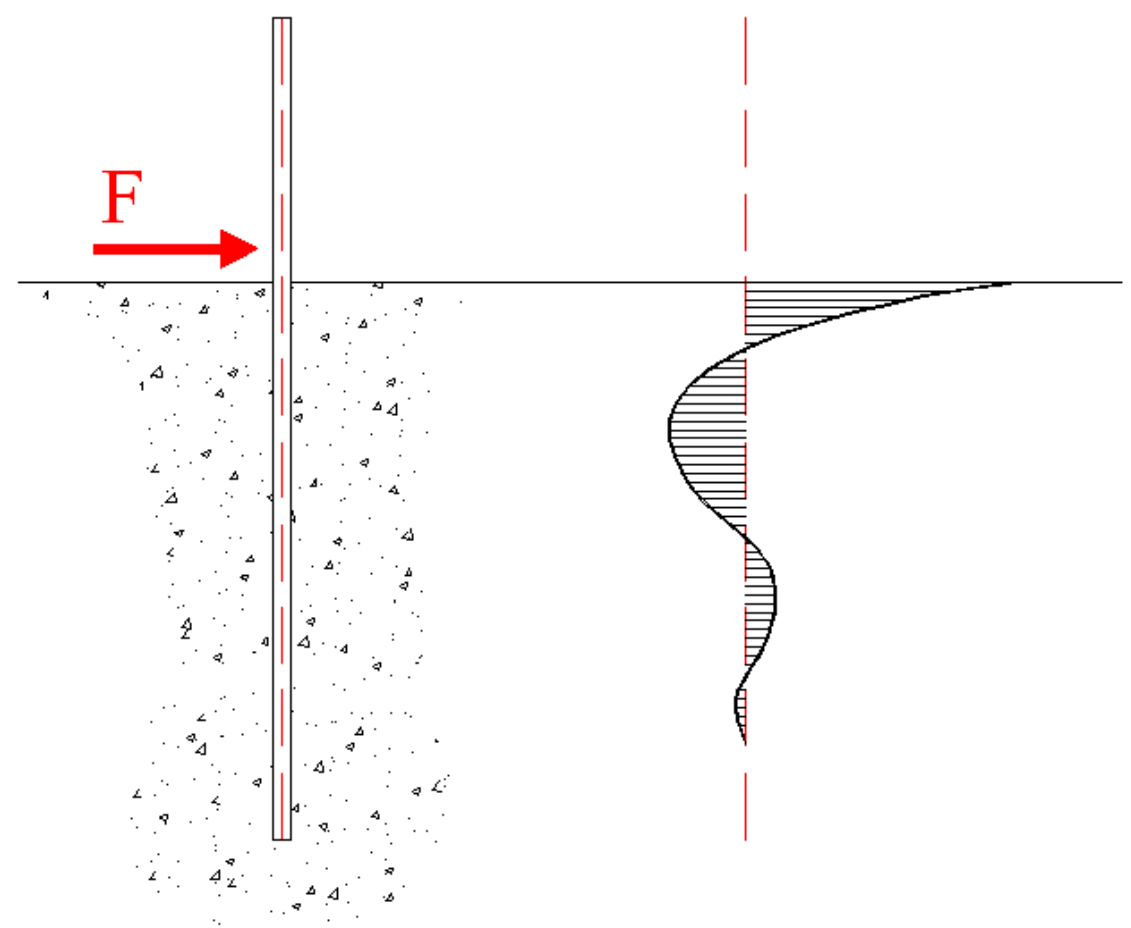

Figura 2.15: Tensões no concreto devido ao efeito de pino em análise linear Fonte: FIB (2007)

Com base em resultados experimentais, DEI POLI et al (1992) estabeleceu uma relação para a distância $\ell y$, dada pela Equação 2.18.

$$
\ell_{y}=(1,6 \quad a \quad 1,7) \cdot \phi_{b}
$$


Sendo que:

$\ell_{y} \quad$ - Distância da borda do concreto até a seção de máximo momento;

$\phi_{b} \quad$ - Diâmetro da barra do chumbador.

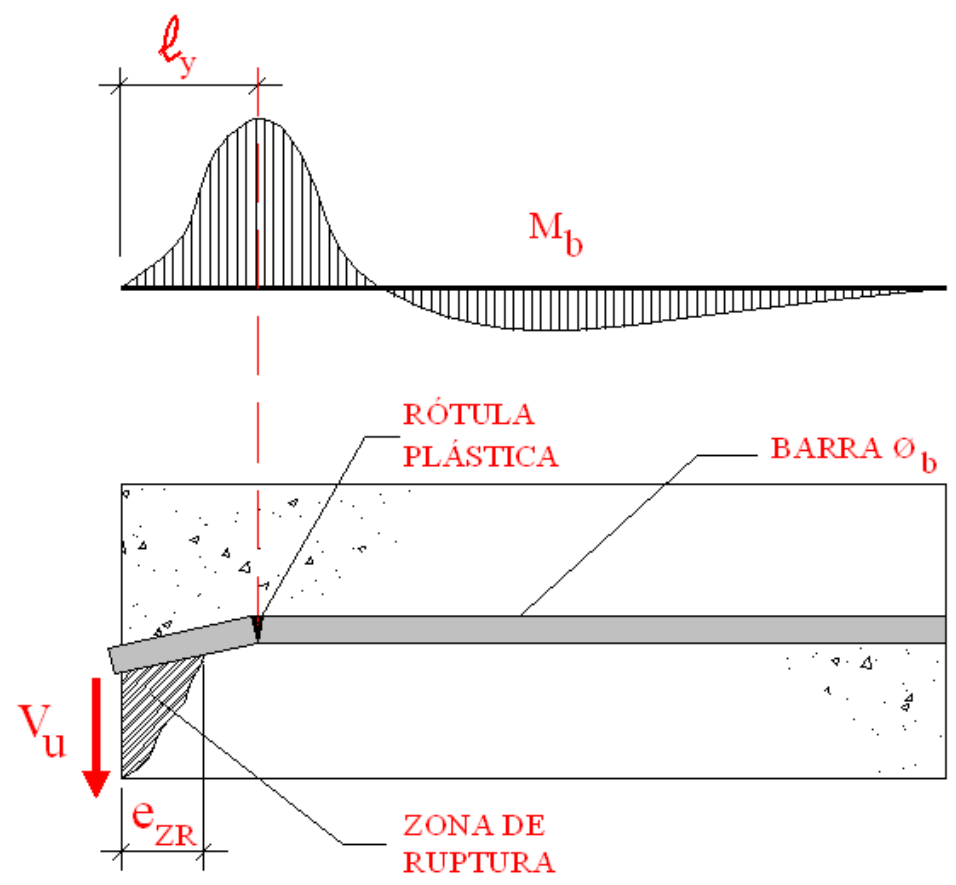

Figura 2.16: Formação de rótula plástica e zona de ruptura Fonte: DEI POLI et al. (1992)

DEI POLI et al (1992) verificou que a espessura da zona de ruptura, dada por “e $\mathrm{zr}_{\mathrm{zr}}$ (Figura 2.16), varia com o diâmetro da barra do chumbador, sugerindo as seguintes relações:

$$
\begin{array}{ll}
e_{Z R}=0,6 . \phi_{b} & \text { Para } \phi_{b}=12 \mathrm{~mm} \\
e_{Z R}=0,4 . \phi_{b} & \text { Para } \phi_{b}=25 \mathrm{~mm}
\end{array}
$$

Para o cálculo do deslocamento transversal do chumbador na borda do elemento de concreto, DEI POLI et al (1992) sugeriu a Equação 2.21. 


$$
\begin{aligned}
& w=\frac{V}{\left(2 \cdot \alpha^{3} \cdot E_{s} \cdot I_{b}\right)} \\
& \alpha=\sqrt[4]{\frac{K_{c} \cdot \phi_{b}}{4 \cdot E_{s} \cdot I_{b}}} \\
& K_{c}=127 \cdot \frac{\sqrt{f_{c}}}{\left(\phi_{b}\right)^{2 / 3}}
\end{aligned}
$$

\section{Sendo que:}

w - Deslocamento transversal na barra do chumbador;

$V \quad$ - Força cortante aplicada à barra do chumbador;

$K_{c}$ - Módulo de rigidez de referência para o concreto;

$f_{c}$ - Resistência à compressão do concreto;

$\phi_{b}$ - Diâmetro da barra do chumbador;

$E_{S}$ - Módulo de elasticidade do aço;

$I_{b}$ - Momento de inércia da barra do chumbador.

A deformabilidade ao cisalhamento na barra do chumbador, inserido em apenas um elemento de concreto, pode ser obtida a partir da Equação 2.24, sendo dada por:

$$
D_{t b}=\frac{1}{\left(2 \cdot \alpha^{3} \cdot E_{s} \cdot I_{b}\right)}
$$

Para o modo de ruptura através de formação de rótulas plásticas, quando se têm chumbadores inseridos em dois elementos haverá formação de rótulas plásticas em cada um destes elementos e a carga última será dada pela formação da segunda rótula plástica.

Essas rótulas podem ser formadas simultaneamente, quando as resistências dos elementos que envolvem o chumbador forem iguais, ou se formar em períodos diferentes para resistências distintas. Neste caso a primeira rótula plástica se forma no elemento de menor resistência enquanto que o elemento de maior resistência ainda está 
no regime elástico. Posteriormente forma-se a segunda rótula plástica no elemento mais resistente. Percebe-se, entretanto, que ao se formar a primeira rótula a rigidez da ligação é reduzida.

Na Figura 2.17 é apresentada a configuração do chumbador após a formação das rótulas plásticas para o caso de haver ou não uma altura livre entre os elementos.

O modelo para o cálculo da resistência ao cisalhamento em um chumbador inserido em um elemento de concreto, submetido à ação transversal, foi proposto originalmente por HOJLUND \& RASMUSSEN apud FIB (2007), sendo posteriormente aperfeiçoado por DULASKA apud FIB (2007), que, adotando a teoria de plasticidade, sugeriu para representar a força máxima que provoca o surgimento da rótula plástica e a distância desta força a interface do elemento respectivamente as Equações 2.25 e 2.26.

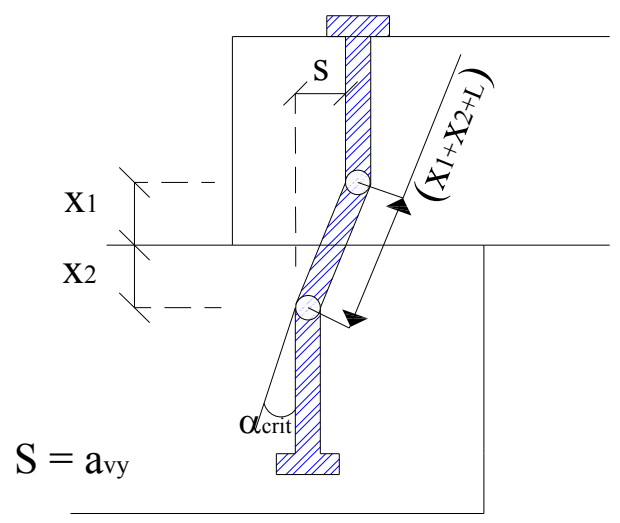

(a) Sem altura livre entre os elementos

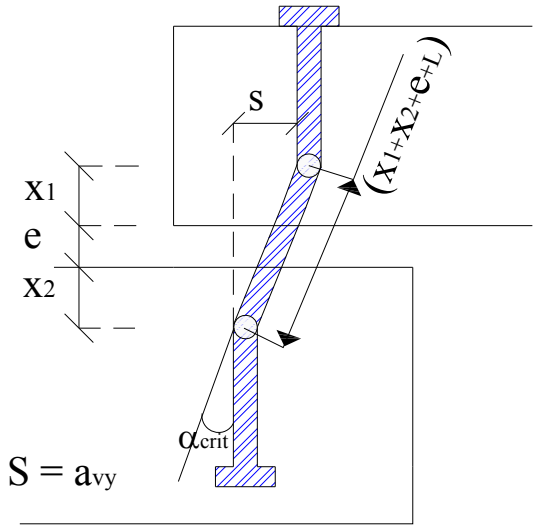

(b) Com altura livre entre os elementos

Figura 2.17: Formação de rótula plástica em chumbadores inseridos em dois elementos Fonte: FIB (2007)

$$
\begin{aligned}
& F_{p}=c_{1} \cdot \phi_{b}^{2} \cdot \sqrt{f_{y} \cdot f_{c c, \text { max }}} \\
& q_{c}=3 \cdot c_{1}^{2} \cdot f_{c c, \text { max }} \cdot \phi_{b} \\
& x=\frac{F_{p}}{q_{c}}=\frac{\sqrt{\frac{f_{y}}{f_{c c, \text { max }}}}}{3 \cdot c_{1}} \cdot \phi_{b}
\end{aligned}
$$


Sendo que:

$F_{p} \quad$ - Força de formação da segunda rótula plástica no chumbador;

$C_{1} \quad$ - Coeficiente para consideração do efeito de compressão tri-axial;

$\phi_{b} \quad$ - Diâmetro do chumbador;

$f_{y} \quad$ - Tensão de escoamento do aço;

$f_{c c, \max }$ - Maior resistência à compressão dentre os elementos de concreto.

No caso de haver uma restrição ao giro do chumbador na região da interface da ligação, tem-se a modificação no comportamento do chumbador, no trecho inserido no concreto. Em razão desta restrição, são formadas rotulas plásticas em ambos os lados restritos do chumbador. A condição de equilíbrio para tal mecanismo, fornece a força de escoamento da ligação, expressa por:

$$
F_{p}=c_{r} \cdot c_{1} \cdot \phi_{b}^{2} \cdot \sqrt{f_{y} \cdot f_{c c, \max }}
$$

\section{Sendo que:}

$c_{r}$ - Fator de restrição.

Segundo ENGSTROM (1992b), para o caso de se ter uma grande restrição ao giro do chumbador, próximo à face do concreto, o fator de restrição "c $\mathrm{c}_{\mathrm{r}}$ " pode ser adotado como sendo $c_{r}=\sqrt{2}$. Também para o caso de uma restrição parcial ao giro no chumbador, o fator de restrição deve variar entre $1<c_{r}<\sqrt{2}$.

Quando existe uma altura livre entre os dois elementos, devido à presença de almofadas de elastômero ou de outro aparelho de apoio, haverá uma excentricidade vertical entre as solicitações horizontais de cisalhamento no chumbador, nos trechos imersos ao concreto. Assim, no cálculo da força de escoamento, deverá ser incorporada uma redução por meio de um fator de excentricidade "c $\mathrm{e}_{\mathrm{e}}$ ", ficando a Equação 2.28 dada por:

$$
F_{p}=c_{e} \cdot c_{1} \cdot \phi_{b}^{2} \cdot \sqrt{f_{y} \cdot f_{c c, \text { max }}}
$$




$$
\begin{aligned}
& c_{e}=\sqrt{1+\left(\varepsilon \cdot c_{1}\right)^{2}}-\varepsilon \cdot c_{1} \\
& \varepsilon=\frac{3 \cdot e}{\phi_{b}} \cdot \sqrt{\frac{f_{c c, \text { max }}}{f_{y}}}
\end{aligned}
$$

Sendo que:

$c_{r}$ - Coeficiente para consideração de restrição ao deslocamento;

$c_{e}$ - Coeficiente para consideração da excentricidade da carga aplicada;

e - Excentricidade da carga aplicada no chumbador.

No caso de uma altura livre ocasionada pela presença de uma almofada de elastômero entre dois elementos de concreto, a excentricidade "e" deverá ser tomada como sendo a metade da altura livre entre os dois elementos, sendo e $\cong h_{n} / 2$, onde " $h_{n}$ " é a espessura da almofada de elastômero.

Em ENGSTROM ${ }^{1}$ apud FIB (2007), complementando os estudos de transferência de forças de cisalhamento em chumbadores inseridos em concreto, foi proposto que as rótulas plásticas se formam quando a inclinação total do chumbador atinja o valor crítico dado pela Equação 2.32. Esta inclinação crítica é proporcional à curvatura da seção crítica do chumbador quando seu escoamento é atingido.

$$
\begin{aligned}
& \alpha_{c r i t}=k \cdot \frac{f_{y}}{E_{s} \cdot \phi_{b}} \\
& \alpha_{c r i t}=\frac{a_{v y}}{x} \quad \text { (chumbador inserido em um único elemento de concreto) } \\
& \alpha_{c r i t}=\frac{a_{v y}}{l_{p p}} \text { (chumbador inserido em dois elementos de concreto) }
\end{aligned}
$$

\footnotetext{
1 Engström, B.(1990). Combined effects of dowel action and friction in bolted connections. Nordic Concrete Research, The Nordic Concrete Federation, Publication No. 9, Oslo 1990, pp. 14-33.
} 
$l_{p p}=x_{1}+x_{2}+h_{a}$

Sendo que:

$k \quad-1,75 \mathrm{~m}$, baseado em resultados experimentais de ENGSTROM (1992b);

$E_{s} \quad$ - Módulo de elasticidade do aço;

$\alpha_{c r i t}$ - Deformação angular crítica;

$a_{v y} \quad$ - Deslocamento horizontal relativo na ligação;

$h_{a} \quad$ - Altura livre entre os elementos de concreto que envolvem o chumbador.

Além do efeito de pino ao qual o chumbado está submetido, pode-se contabilizar o efeito do atrito entre as interfaces do concreto. ENGSTROM (1992b) observou que o atrito na interface da ligação atua positivamente, aumentando a resistência ao cisalhamento da ligação. Assim, a capacidade da ligação deve-se em parte à ação de pino e em parte à ação do atrito na interface da ligação. Assim, a capacidade total de cisalhamento da ligação será dada pela seguinte equação:

$$
\begin{aligned}
& F_{p}=c_{1} \cdot \phi_{b}^{2} \cdot \sqrt{f_{y, \text { red }} \cdot f_{c c, \max }}+\mu_{s} \cdot \sigma_{n} \cdot A_{s} \\
& f_{y, \text { red }}=f_{y}-\sigma_{n}
\end{aligned}
$$

Sendo que:

$\mu_{s}$ - Coeficiente de atrito na interface;

$\sigma_{n}$ - Tensão atuante no chumbador quando o mecanismo é formado;

$A_{s}$ - Área da seção transversal do chumbador.

Ainda segundo ENGSTROM (1992), o coeficiente de atrito " $\mu_{s}$ " varia de acordo com a superfície de contato na interface da ligação e pode ser tomado como “ 0,6 " para concreto-concreto; " 0,4 ” para aço-concreto e entre " 0,3 " e " 0,4 ”, para concreto-neoprene.

DULACSKA apud FIB (2003) estudou o comportamento de chumbadores inseridos em elementos de concreto inclinados de um ângulo $\theta$ com a superfície plana. 
Verificou-se que a capacidade resistente da ligação ao cisalhamento não mais era dada pela Equação 2.25, mas sim por:

$$
\begin{aligned}
& F_{p}=\gamma \cdot k \cdot \operatorname{sen}(\theta) \cdot f_{y} \cdot \phi_{b}^{2} \cdot\left[\sqrt{1+\frac{f_{c c}}{3 \cdot \gamma^{2} \cdot k \cdot \operatorname{sen}^{2} \theta \cdot f_{y}}}-1\right] \\
& k=3 \cdot c^{2}
\end{aligned}
$$

Sendo que:

$\theta$ - Ângulo de inclinação do chumbador com a superfície plana.

FERREIRA (1999) idealizou um diagrama tri-linear simplificado que relaciona a força normal atuante na viga com o deslocamento horizontal relativo entre os elementos de viga e pilar, conforme ilustrado na Figura 2.18. A proposta de FERREIRA (1999) foi idealizada com base no estudo desenvolvido em ENGSTRÖM (1992b), e teve como objetivo proporcionar uma representação gráfica para o comportamento de uma ligação viga-pilar articulada em apoio sobre consolo com almofada de elastômero não fretado e chumbador, estudada por este pesquisador.

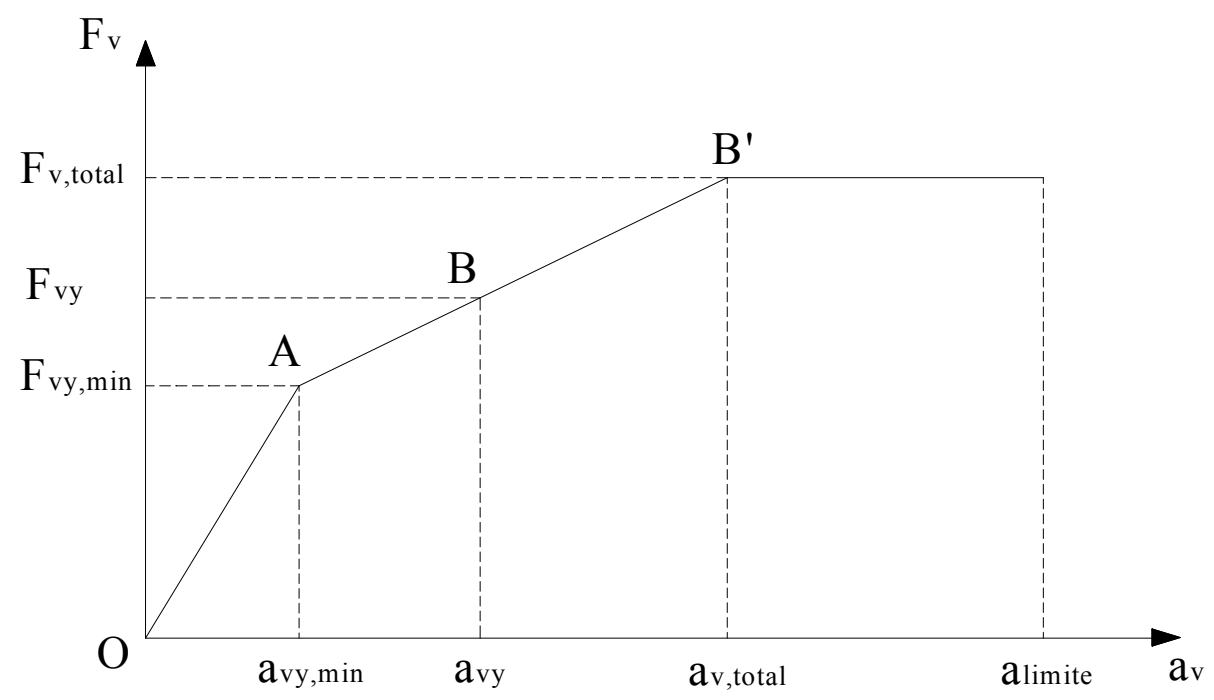

Figura 2.18: Modelo analítico proposto por FERREIRA (1999). 
A inclinação inicial do diagrama pode ser obtida a partir da deformabilidade ao cisalhamento da ligação, definida por $\left(\mathrm{D}_{\tau \operatorname{lig}}\right)$, conforme a Equação 2.40 .

$$
D_{\text {tlig }}=\left(\frac{1}{D_{m}}+\frac{1}{D_{t b l}+D_{t b i}}\right)^{-1}
$$

Para o cálculo da deformabilidade da ligação $\left(D_{\tau l i g}\right)$ na fase linear, FERREIRA (1999) utilizou o modelo apresentado em FERREIRA (1993). Para isso o autor considerou três mecanismos de deformação presentes na ligação. São eles:

i. Deformação ao cisalhamento do elastômero não fretado, associada à deformabilidade $\mathrm{D}_{\tau \mathrm{n}}$, dada pela expressão 2.41;

ii. Deformação ao cisalhamento de uma barra inserida no concreto, associada à deformabilidade $\mathrm{D}_{\tau b i}$, dada pela expressão 2.43;

iii. Deformação ao cisalhamento de uma barra bi-engastada em dois elementos de concreto com altura livre entre si, associada à deformabilidade $\mathrm{D}_{\tau b l}$, dada pela expressão 2.42 .

$\mathrm{Na}$ Figura 2.19 é apresentado o esquema de molas que representa os mecanismos de deformação considerados por FERREIRA (1999). As deformabilidades $\mathrm{D}_{\tau \mathrm{bi}}$ e $\mathrm{D}_{\tau b l}$ estão associadas em série, que por sua vez, estão associadas em paralelo à deformabilidade $\mathrm{D}_{\tau \mathrm{n}}$.

$$
D_{m}=\frac{h_{a}}{G_{a} \cdot A_{0}}
$$

Sendo que:

$\mathrm{h}_{\mathrm{a}} \quad$ - Espessura da almofada de apoio;

$\mathrm{A}_{0} \quad$ - Área da superfície de apoio efetiva do elastômero;

$\mathrm{G}_{\mathrm{a}}$ - Módulo de deformação transversal do elastômero. 


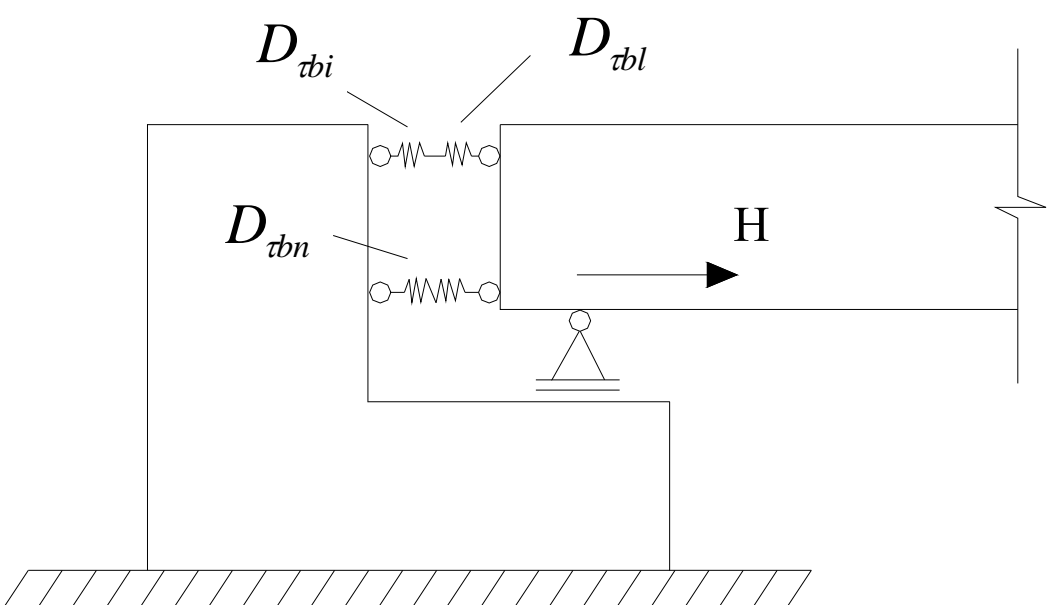

Figura 2.19: Mecanismo de deformação ao cisalhamento por meio de molas Fonte: FERREIRA (1999)

$D_{t b l}=\frac{16 \cdot\left(h_{a}+2 \cdot \phi_{b}\right)^{3}}{3 \cdot \pi \cdot E_{s} \cdot \phi_{b}{ }^{4}}$

Sendo que:

$\mathrm{E}_{\mathrm{s}} \quad$ - Módulo de elasticidade do aço;

$\phi_{b} \quad$ - Diâmetro do chumbador.

$D_{t b i}=\left(2 \cdot \alpha^{3} \cdot E_{s} \cdot I_{b}\right)^{-1}$

Sendo que:

$\mathrm{I}_{\mathrm{b}}$ - Momento de inércia da barra;

$f_{c}$ - Resistência à compressão do concreto (MPa);

$\alpha$ - Definido na Equação (2.22)

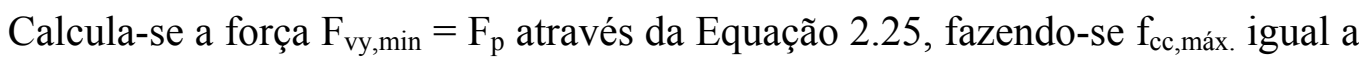
menor resistência dos concretos dos elementos conectados. Determina-se $\mathrm{a}_{\mathrm{vy}, \min }=\lambda_{\tau l i g} \cdot \mathrm{F}_{\mathrm{vy}, \min }$, obtendo-se o ponto A do gráfico (Figura 2.18). Calcula-se a força $\mathrm{F}_{\mathrm{vy}}$ através da Equação 2.25. O valor de $\mathrm{a}_{\mathrm{vy}}$ é determinado pelas Equações 2.33 e 2.34. Fica assim determinado o ponto $B$. Calcula-se $F_{v, t o t a l}=F_{p}$ através da Equação 2.36. $\mathrm{O}$ ponto $\mathrm{B}^{\prime}\left(\mathrm{a}_{\mathrm{v}, \text { total }} ; \mathrm{K}_{\mathrm{v}, \text { total }}\right)$ é definido pela interseção do prolongamento da reta $\mathrm{AB}$ com 
a reta $\mathrm{F}_{\mathrm{v}}=\mathrm{F}_{\mathrm{v} \text {,total. }} \mathrm{O}$ valor limite para o deslocamento horizontal da ligação, dado por $\mathrm{a}_{\text {lim }}$, foi definido por FERREIRA (1999) como sendo um valor inferior ao da ordem do diâmetro da barra do chumbador.

Ao comparar os resultados teóricos com os experimentais, FERREIRA (1999) constatou que o procedimento proposto por ENGSTROM (1992b) forneceu uma boa estimativa para a resistência ao cisalhamento das ligações ensaiadas. Desta forma, o modelo proposto por FERREIRA (1999), e apresentado na Figura 2.18, pode ser considerado satisfatório.

\subsection{PRINCIPAIS ESTUDOS RELACIONADOS}

Como visto no capítulo de introdução deste trabalho, diversos estudos foram desenvolvidos para análise do comportamento das ligações em elementos pré-moldados.

Em seu trabalho DOLAN et al. (1987) apresentam resumidamente os resultados do programa PCI 1/4 desenvolvido nos Estados Unidos para análise do comportamento da ligação de elementos pré-moldados mais usuais.

Foram realizados testes individuais em oito tipos de ligações, mostradas na Figura 2.20, submetidas a carregamentos gravitacionais, forças laterais ou carregamentos cíclicos equivalentes. Os resultados mostraram que:

i. As ligações BC15, BC16A, BC25, BC26, BC28 e BC 29 tiveram sua resistência última no mínimo igual à prevista para o momento negativo;

ii. A ligação $\mathrm{BC} 16 \mathrm{~A}$ possui uma capacidade resistente a momento fletor positivo da ordem de $30 \%$ da capacidade a momento fletor negativo;

iii. A ligação BC15 apresenta uma capacidade resistente a momento fletor positivo da ordem de $65 \%$ da capacidade a momento fletor negativo;

iv. As ligações $\mathrm{BC} 25$ e $\mathrm{CC} 1$ apresentaram capacidades resistentes a momento negativo próximas às capacidades a momento positivo;

v. As ligações $\mathrm{BC} 28$ e $\mathrm{BC} 29$ suportaram pequenos momentos e sofreram grandes deformações;

vi. A presença de fios pós-tracionados na ligação BC27 promoveu boa rigidez inicial, equivalendo-se a um concreto de $\mathrm{E}_{\mathrm{c}}=51000 \mathrm{MPa}$. 
$\mathrm{BC} 15$

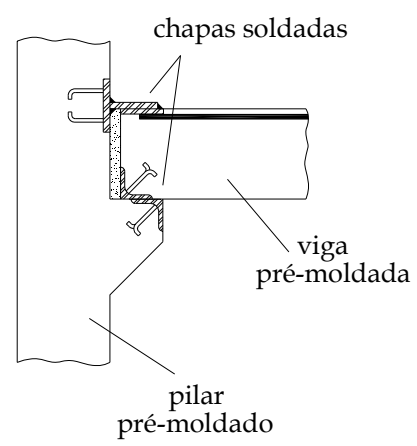

BC26

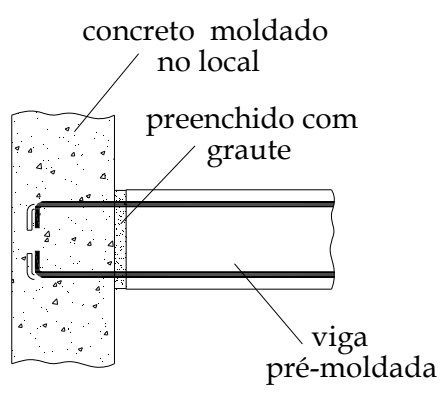

$\mathrm{BC} 27$

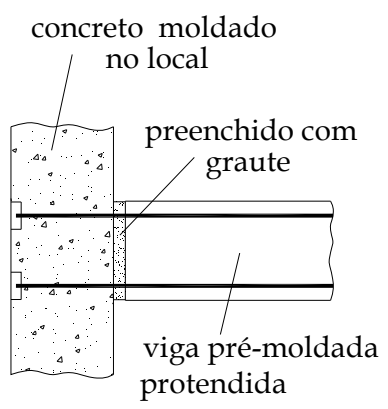

BC16A

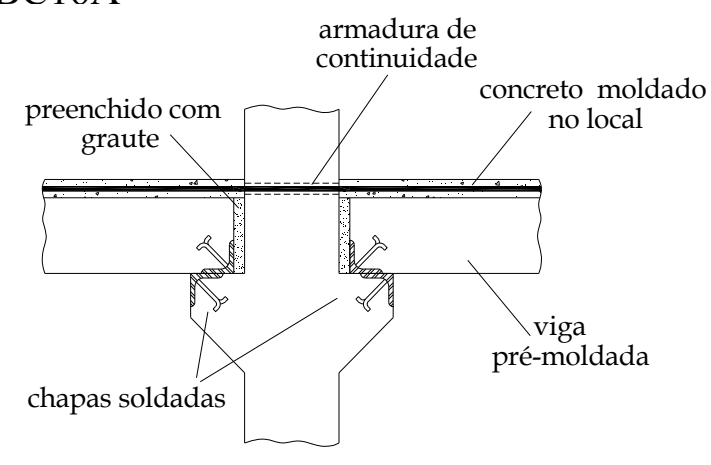

$\mathrm{CC} 1$ e $\mathrm{BC} 25$

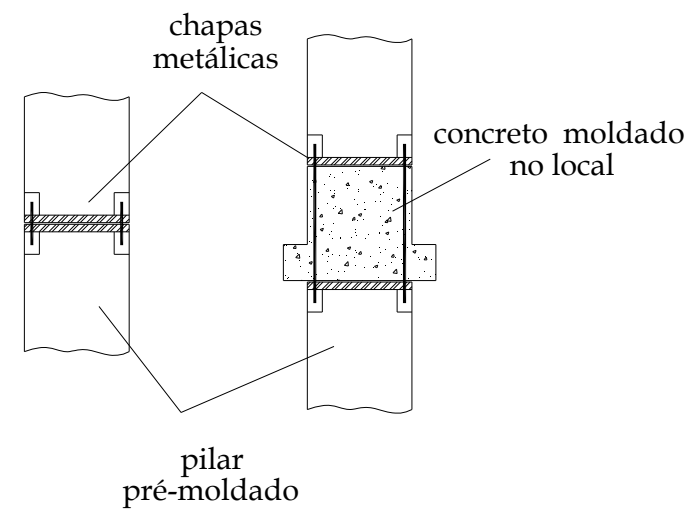

BC28 E BC29

chumadores grauteados

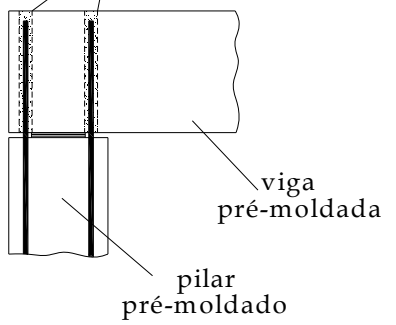

Figura 2.20: Ligações ensaiadas por DOLAN et al (1987) 
Tabela 2.3: Resumo dos momentos previstos e suportados pelas ligações

Fonte: DOLAN et al (1987)

\begin{tabular}{|c|c|c|c|c|c|c|}
\hline \multirow{2}{*}{$\begin{array}{l}\text { Tipo de } \\
\text { ligação }\end{array}$} & \multicolumn{3}{|c|}{ Momento negativo } & \multirow{2}{*}{$\begin{array}{c}\text { Momento } \\
\text { positivo }\end{array}$} & \multicolumn{2}{|c|}{ Máxima rotação } \\
\hline & $\begin{array}{c}\text { Momento } \\
\text { de projeto } \\
(\mathrm{kN} . \mathrm{m})\end{array}$ & $\begin{array}{c}\text { Capacidade } \\
\text { prevista } \\
(\mathrm{kN} . \mathrm{m})\end{array}$ & $\begin{array}{c}\text { Capacidade } \\
\text { medida } \\
(\mathrm{kN} . \mathrm{m})\end{array}$ & & $\begin{array}{l}\text { Negativo } \\
(\mathrm{rad} / 100)\end{array}$ & $\begin{array}{l}\text { Positivo } \\
(\mathrm{rad} / 100)\end{array}$ \\
\hline $\mathrm{BC} 15$ & 161,34 & 215,12 & 246,87 & 163,82 & 3,7 & 1,20 \\
\hline BC16A & 161,34 & 215,12 & 395,44 & 137,61 & 10,0 & 4,00 \\
\hline $\mathrm{BC} 25$ & 179,30 & 281,10 & 512,38 & 4777,69 & 4,0 & 4,00 \\
\hline $\mathrm{CC} 1$ & 115,24 & 184,39 & 172,07 & 177,95 & 4,0 & 3,65 \\
\hline BC26 & 161,34 & 215,12 & 350,25 & ------ & 12,5 & ------ \\
\hline $\mathrm{BC} 27$ & 235,68 & 290,93 & 269,80 & ------ & 8,3 & ------ \\
\hline $\mathrm{BC} 28$ & 32,87 & 45,08 & 65,07 & --- & 4,1 & ------ \\
\hline $\mathrm{BC} 29$ & 32,87 & 45,08 & 61,01 & 35,92 & 3,9 & 3,75 \\
\hline
\end{tabular}

LIN (1991) realizou ensaios de ligação viga-pilar com almofada de elastômero e chumbador, onde foi analisado o efeito do atrito na interface entre os elementos na ligação. Segundo esse pesquisador, o coeficiente de atrito é inversamente proporcional à espessura da almofada. LIN (1991) observou que para almofadas espessas, o coeficiente de atrito " $\mu$ " foi da ordem de 0,27 . Para ligações com almofadas finas, o coeficiente de atrito observado foi da ordem de 0,30 . No caso de ligações que não possuíam algum componente na interface entre os elementos de concreto, os coeficientes de atrito variaram de 0,60 a 0,94 .

Em KERONEN (1996) são apresentados os resultados de uma pesquisa realizada na Universidade Tecnológica de Tampere, na Finlândia. A pesquisa trata do comportamento semi-rígido de ligações viga-pilar de estruturas reticulares de concreto pré-moldado, com um ou mais pavimentos. O objetivo da pesquisa é viabilizar o uso da rigidez parcial das ligações viga-pilar na análise das estruturas de concreto pré-moldado. Isso conduz a uma economia de material (em pilares, ligações pilar-fundação e fundações) e de tempo de construção, e portanto, a uma estrutura mais competitiva.

KERONEN (1996) apresenta os resultados de ensaios realizados em escala natural em uma estrutura aporticada tipo "trave", com o objetivo de estudar na prática, o efeito do comportamento semi-rígido das ligações viga-pilar no deslocamento e no 
momento na base do pilar. Esse tipo de estrutura vem sido estudado na Universidade de Tampere desde 1983. Foram estudados 8 tipos diferentes de ligações, conforme ilustra a Figura 2.21
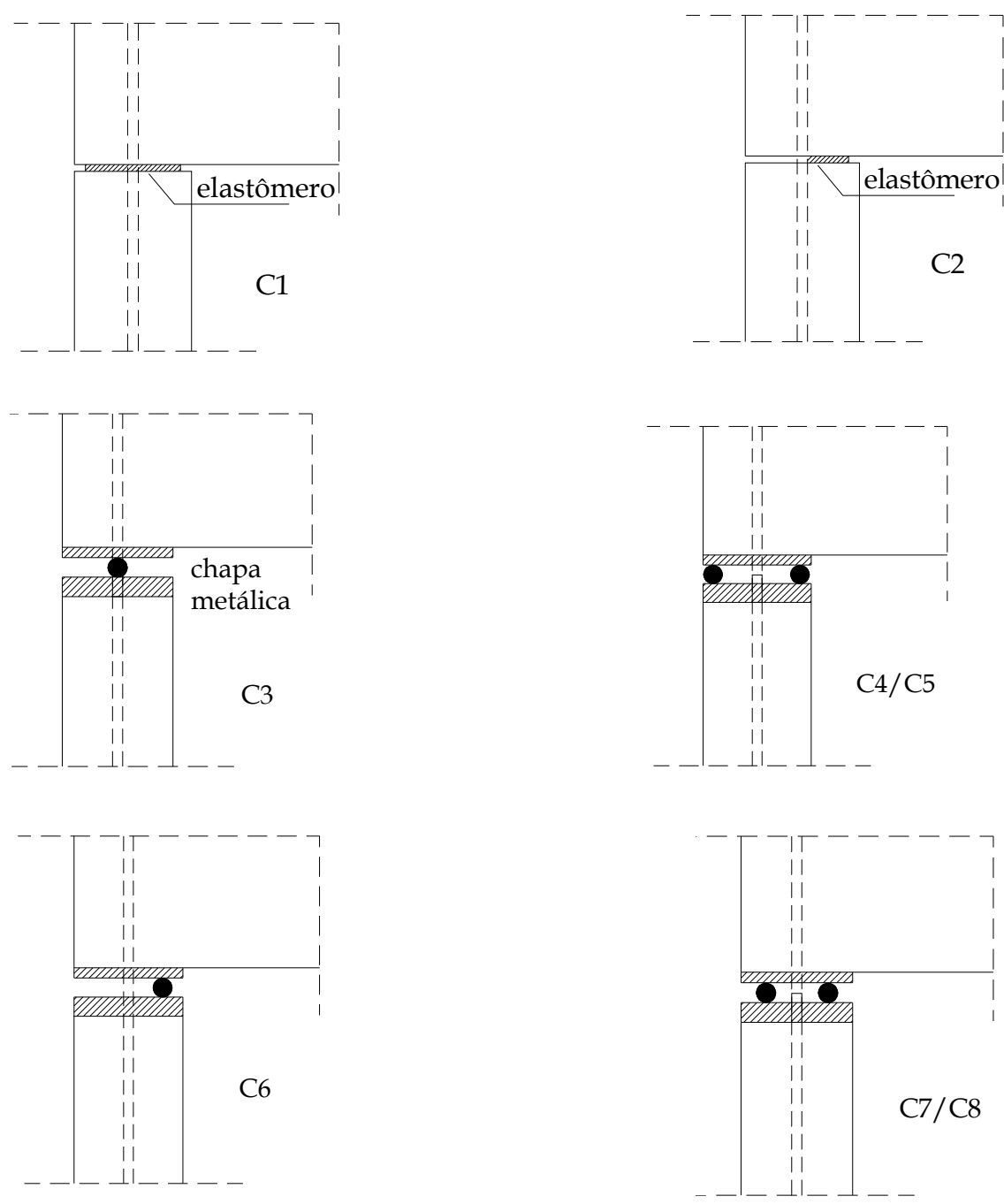

Onde: C4, C5 - sem e com protensão do chumbador, respectivamente $\mathrm{C} 7, \mathrm{C} 8$ - sem e com protensão do chumbador, respectivamente

Figura 2.21: Ligações viga-pilar ensaiadas por KERONEN (1996).

Com base nos resultados, o autor constatou que as ligações com componentes metálicos (C4 e C5) foram as mais rígidas: os deslocamentos foram reduzidos em $90 \% \mathrm{e}$ o momento na base do pilar em 70\% em comparação com as articulações (C3 e C6). Observou-se também que uma ligação viga-pilar provida de elastômero em toda a sua extensão apresenta uma redução significativa em seus deslocamentos (aproximadamente $60 \%$ ) e no momento fletor na base dos pilares (aproximadamente 40\%). Esses 
resultados indicam que o aparelho de apoio deve ser o maior possível, pois no caso de um aparelho de apoio que abrange somente a metade da extensão da ligação, a redução foi de apenas 30\% nos deslocamentos e de $20 \%$ no momento na base do pilar em comparação aos casos de articulações.

Segundo KERONEN (1996) se o aparelho de apoio puder ser substituído por uma placa metálica ou por rolos metálicos, a rigidez da estrutura poderia ser até duplicada. Protendendo o chumbador também se aumenta a rigidez da estrutura. Mas na prática, de acordo com este pesquisador, é mais econômico otimizar o tamanho da ligação metálica (C4 e C7) do que protender o chumbador.

Inserido no projeto promovido pelo CERIB "Study and Research Center of the French Precast Concrete Industry", CHEFDEBIEN (1998) apresenta em seu trabalho os resultados de dois modelos de ligações viga-pilar usualmente utilizados na França com o propósito de estudar os seus comportamentos semi-rígidos, uma vez que em projetos elas são consideradas articuladas.

As ligações estudadas são mostradas na Figura 2.22 e consistem de almofada de apoio, chumbadores e capa de concreto moldado no local com resistência de $25 \mathrm{MPa}$. A resistência dos elementos pré-moldados foi de $60 \mathrm{MPa}$.

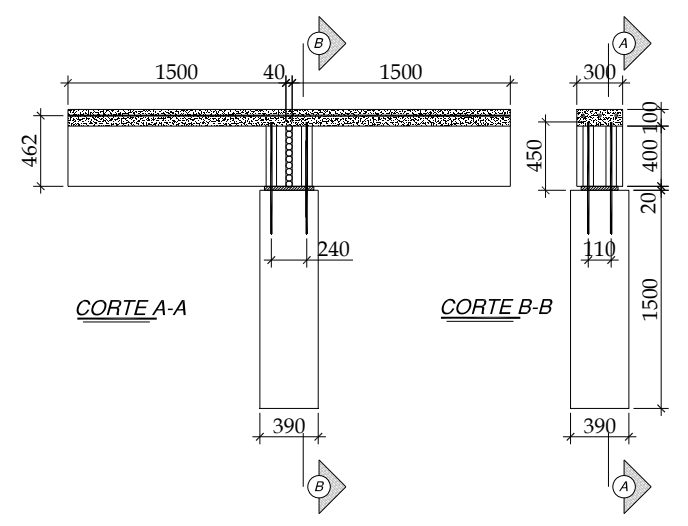

(a)

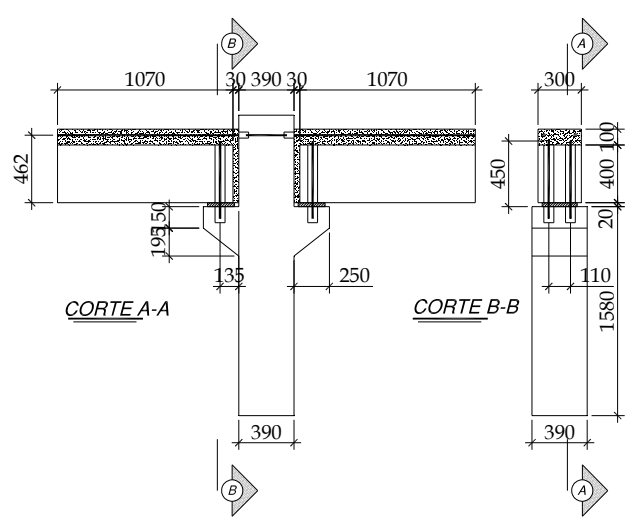

(b)

Figura 2.22: Ligações viga-pilar estudada por CHEFDEBIEN (1998)

Para entender melhor a influência de cada componente da ligação variou-se o material da almofada de apoio, preenchimento vertical e quantidade de armadura da capa de concreto para cada um dos seis modelos como mostra a Tabela 2.4 
Tabela 2.4: Características dos modelos ensaiados por CHEFDEBIEN (1998)

\begin{tabular}{|c|c|c|c|}
\hline Modelo & Almofada de apoio & $\begin{array}{c}\text { Preenchimento } \\
\text { vertical (chumbador) }\end{array}$ & $\begin{array}{c}\text { Armadura de } \\
\text { continuidade }\end{array}$ \\
\hline BC1 & Argamassa & Concreto & $3 \phi 12$ \\
\hline BC2 \& BC5 & Argamassa & Concreto & $3 \phi 16$ \\
\hline BC3 & Neoprene & Poliestireno & $3 \phi 16$ \\
\hline BC4 & Argamassa & Poliestireno & $3 \phi 16$ \\
\hline BC6 & Argamassa & Concreto & $2 \phi 16$ \\
\hline
\end{tabular}

Os modelos foram carregados simetricamente através de 2 atuadores hidráulicos com controle de força como mostra a Figura 2.23. Foi aplicado um carregamento vertical de $200 \mathrm{kN}$ sobre o topo da ligação nos modelos BC1, BC2, BC3 e BC5 com o objetivo de simular o carregamento de andares superiores da estrutura. As rotações foram medidas através de transdutores posicionados próximos à face do pilar e sob os pontos de carregamento. Para o modelo BC6 foram locados transdutores adicionais no pilar para medição das rotações da viga.

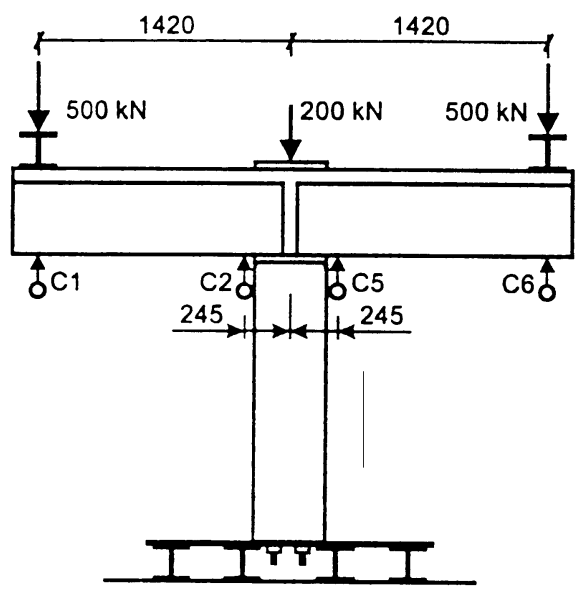

Ligação dos modelos BC 1 a BC 5

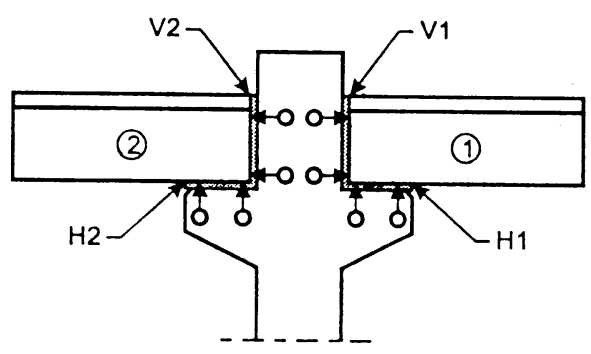

Ligação do modelo BC 6

Figura 2.23: Instrumentação dos modelos ensaiados por CHEFDEBIEN (1998)

Para todos os ensaios observaram-se fissuras verticais na interface da viga com o pilar. A ruptura iniciou-se com o escoamento da armadura presente na capa de concreto. Os resultados do experimento são mostrados na Tabela 2.5. 
Tabela 0.5: Resultados característicos das ligações de CHEFDEBIEN (1998)

\begin{tabular}{|c|c|c|c|c|}
\hline Modelo & $\mathrm{M}_{\mathrm{y}}(\mathrm{kN} . \mathrm{m})$ & $\mathrm{K}_{\mathrm{sy}}(\mathrm{MN} . \mathrm{m} / \mathrm{rad})$ & $\mathrm{M}_{\mathrm{r}}(\mathrm{kN} . \mathrm{m})$ & $\theta_{\mathrm{r}}(\mathrm{rad})$ \\
\hline BC1 & 104 & 91,6 & 137 & \\
\hline BC2 & 163 & 108 & 210 & \\
\hline BC3 & 72 & 11,3 & 189 & 0.064 \\
\hline BC4 & 124 & 30 & 195 & \\
\hline BC5 & 159 & 11,97 & 233 & 0.084 \\
\hline BC6 & 104 & 41,3 & 153 & 0.038 \\
\hline
\end{tabular}

$\mathrm{M}_{\mathrm{y}}=$ Momento de escoamento; $\mathrm{K}_{\mathrm{sy}}=$ Rigidez secante correspondente ao $\mathrm{M}_{\mathrm{y}}$ $\mathrm{M}_{\mathrm{r}}=$ Momento resistente $; \theta_{\mathrm{r}}=$ Rotação correspondente ao $\mathrm{M}_{\mathrm{r}}$.

Através da curva momento fletor-rotação mostrada na Figura 2.24 percebem-se dois comportamentos distintos. Para os modelos que possuíam almofadas de apoio e preenchimento vertical com material rígido, as curvas foram quase bi-linear enquanto que os modelos que possuíam materiais flexíveis apresentaram comportamentos não-lineares.

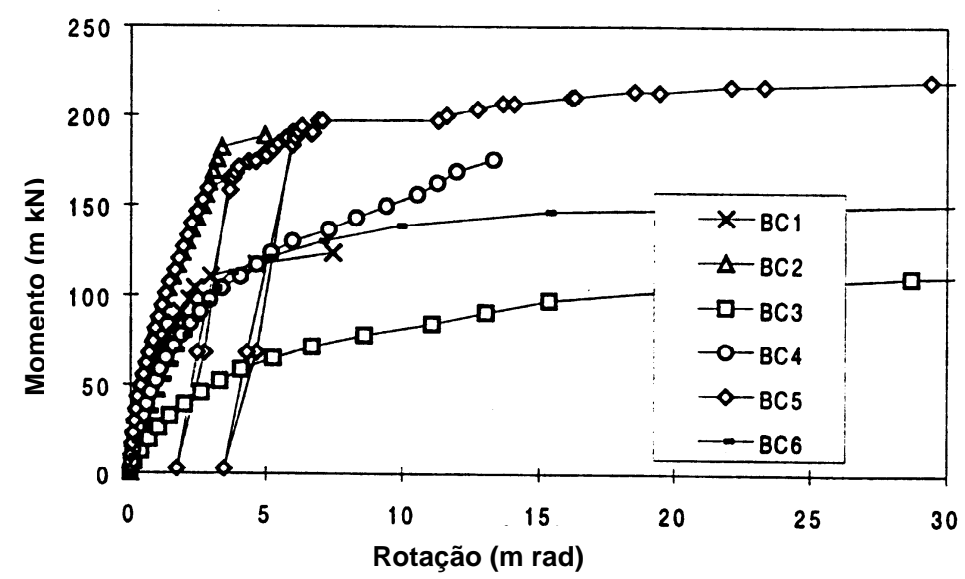

Figura 2.24: Curva momento fletor-rotação dos modelos de CHEFDEBIEN (1998)

ELLIOTT et al (1998) apresentam os ensaios experimentais de ligações viga-pilar semi-rígidas de concreto pré-moldado com o objetivo de determinar o comportamento estrutural destas, verificando a relação entre a resistência e a rigidez das 
ligações à flexão variando-se o tipo de conector, a geometria da subestrutura e a forma de carregamento.

Para este trabalho foram estudados 3 tipos de ligação mais usuais na Inglaterra e criados 28 modelos para ensaio. Estas ligações são mostradas na Figura 2.25.

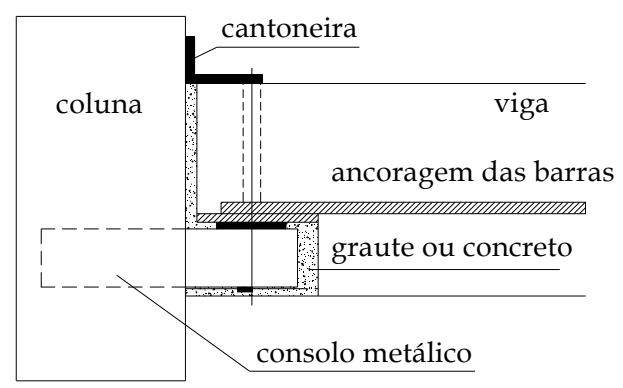

(a)

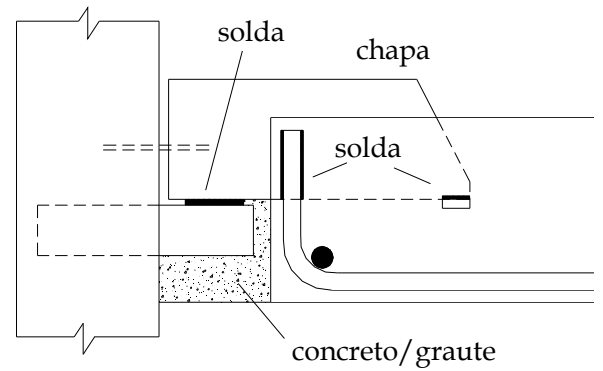

(b)

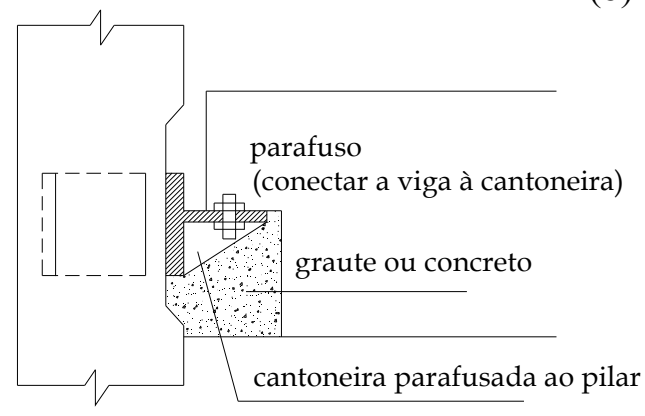

(c)

Figura 2.25 - Ligações viga-pilar utilizadas na Inglaterra Fonte: ELLIOTT et al. (1998)

Para os ensaios experimentais, as dimensões do pilar se mantiveram constantes (300mm x 300mm), porém as dimensões das vigas variaram de acordo com o tipo de conector utilizado (de $300 \mathrm{~mm}$ x $300 \mathrm{~mm}$ a $600 \mathrm{~m}$ x $300 \mathrm{~mm}$ ). Em alguns modelos foram colocadas lajes alveolares de $200 \mathrm{~mm}$ x $1200 \mathrm{~mm}$ protentidas e armaduras longitudinais de $25 \mathrm{~mm}$.

Com base no estudo descrito, ELLIOTT et al. (1998) concluíram que a rigidez e resistência das ligações de concreto pré-moldado dependem, em ordem de importância:

i. Tipo do conector - Chapas soldadas mostraram se mais eficientes

ii. Geometria da subestrutura - Ligações simétricas geram comportamentos melhores que estruturas assimétricas 
iii. Forma de carregamento - Carregamentos gravitacionais permitem a estrutura suportar maiores momentos que sob carregamentos horizontais.

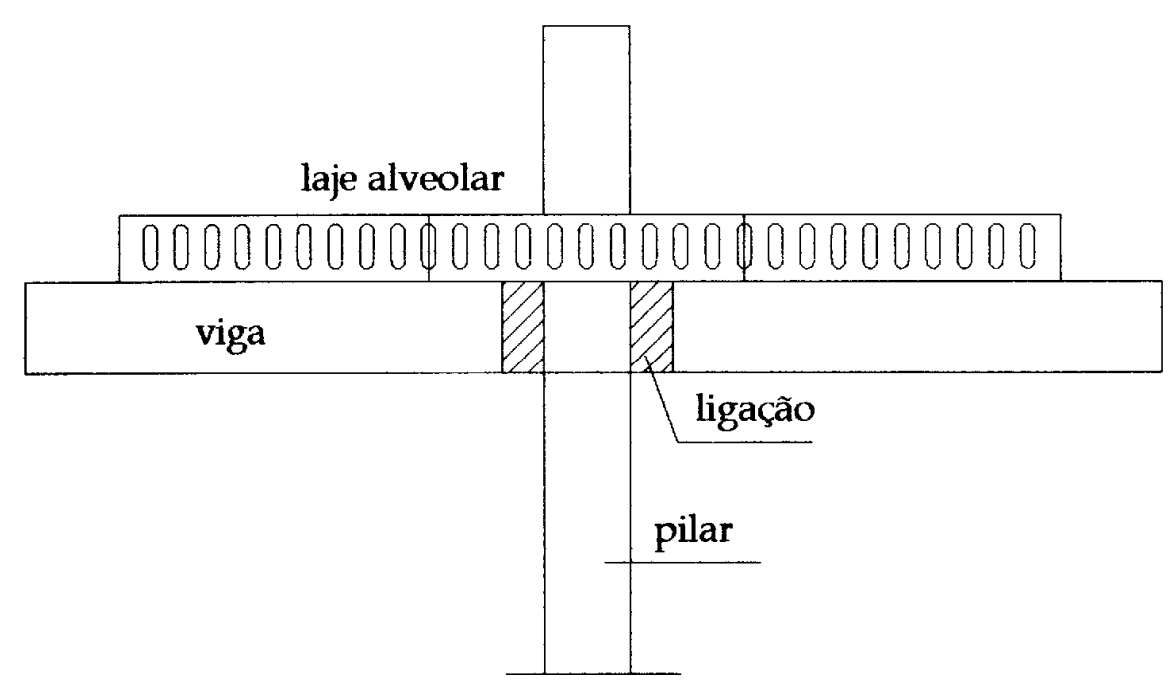

Figura 2.26 - Esquema dos modelos ensaiados por ELLIOTT et al. (1998).

As pesquisas de MIOTTO (2002) e de BALDISSERA (2006), realizados no Laboratório de Estruturas da Escola de Engenharia de São Carlos da Universidade de São Paulo servirão de base para a análise realizada ao longo de todo este trabalho. No capítulo anterior foi discutida a motivação do trabalho, onde foi relatado de forma resumida os resultados obtidos por estes pesquisadores.

MIOTTO (2002) relata os resultados experimentais de dois modelos de uma ligação viga-pilar, apresentada na Tabela 2.6, e propõe um modelo analítico para representar os momentos de plastificação e rigidezes da ligação.

A ligação estudada é composta por um chumbador retilíneo, almofada de apoio à base de argamassa e uma capa de concreto com armadura longitudinal dentro do pilar. O esquema de ensaio dos modelos está apresentado nas Figura 2.27 e 2.28.

MIOTTO (2002) também propôs um modelo analítico baseado no Método dos Componentes, onde para a determinação dos momentos negativos e positivos foi adotado um diagrama tri-linear da curva momento-rotação. 
Tabela 2.6 - Resumo do programa experimental - ligação $n^{0} 2$.

Fonte: MIOTTO (2002)

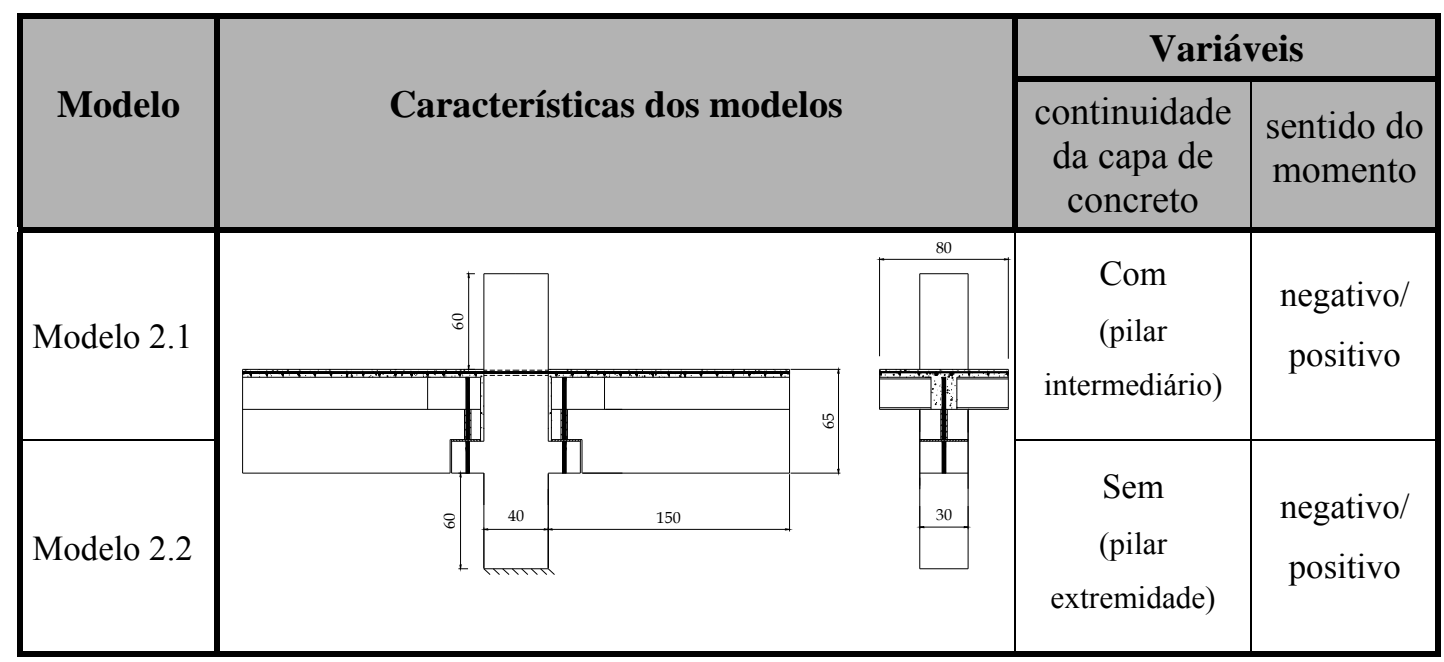

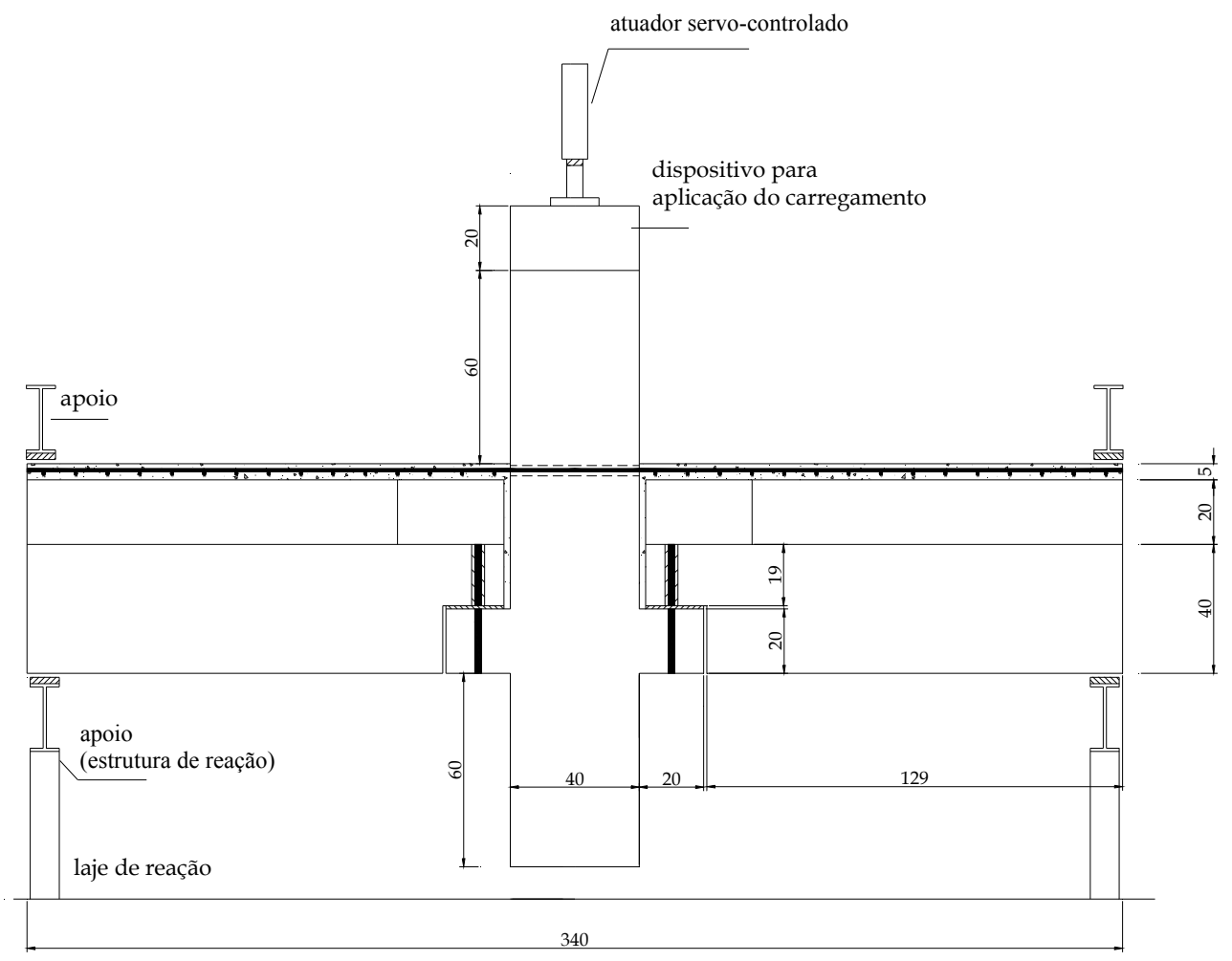

Figura 2.27 - Esquema dos ensaios dos modelos 2.1 e 2.2 (dimensões em cm).

Fonte: MIOTTO (2002) 


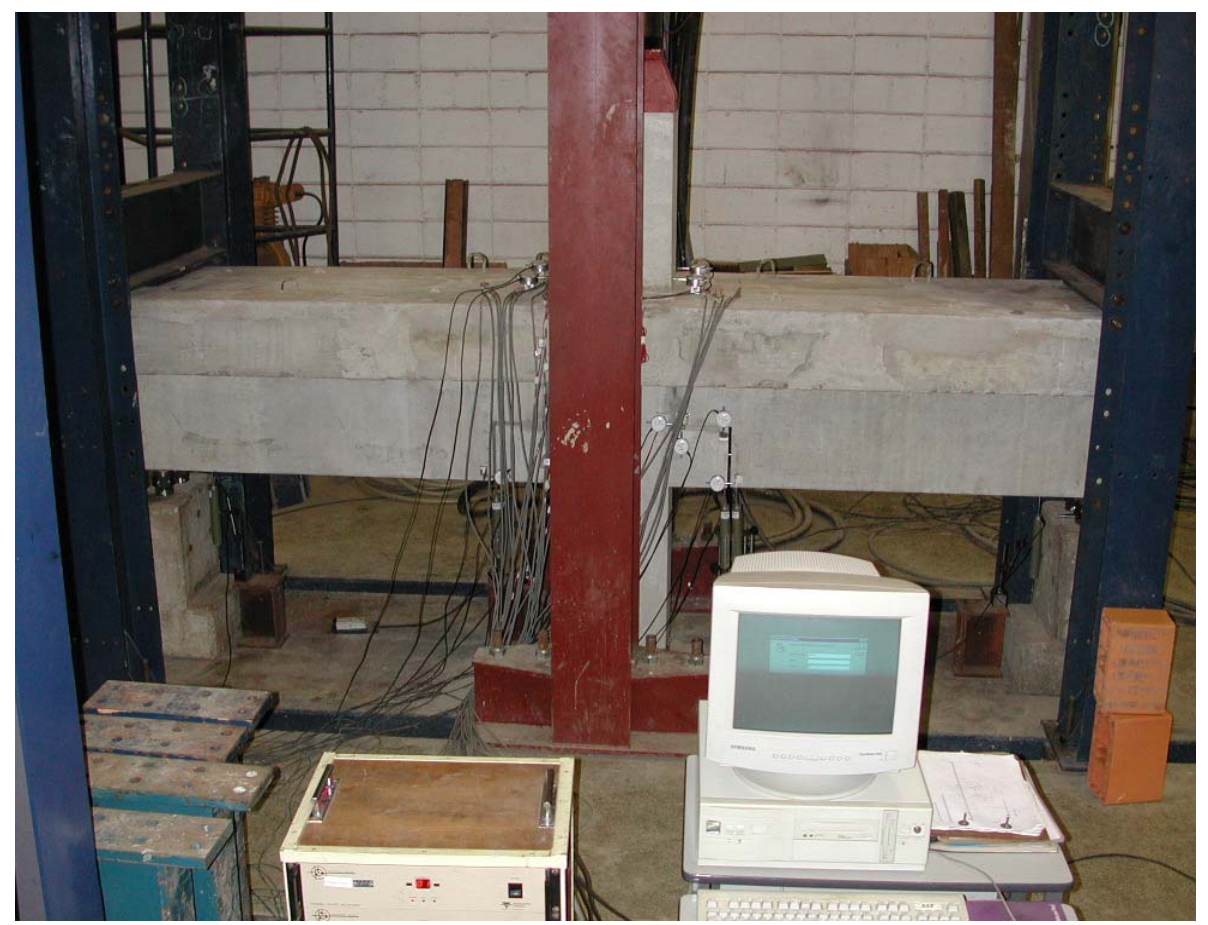

Figura 2.28 - Esquema de ensaio - ilustração (modelo 2.1)

Fonte: MIOTTO (2002)

$\mathrm{Na}$ Tabela 2.7 são apresentados os resultados experimentais obtidos por MIOTTO (2002), para os dois modelos ensaiados.

Tabela 2.7: Resumo dos resultados experimentais Fonte: MIOTTO (2002)

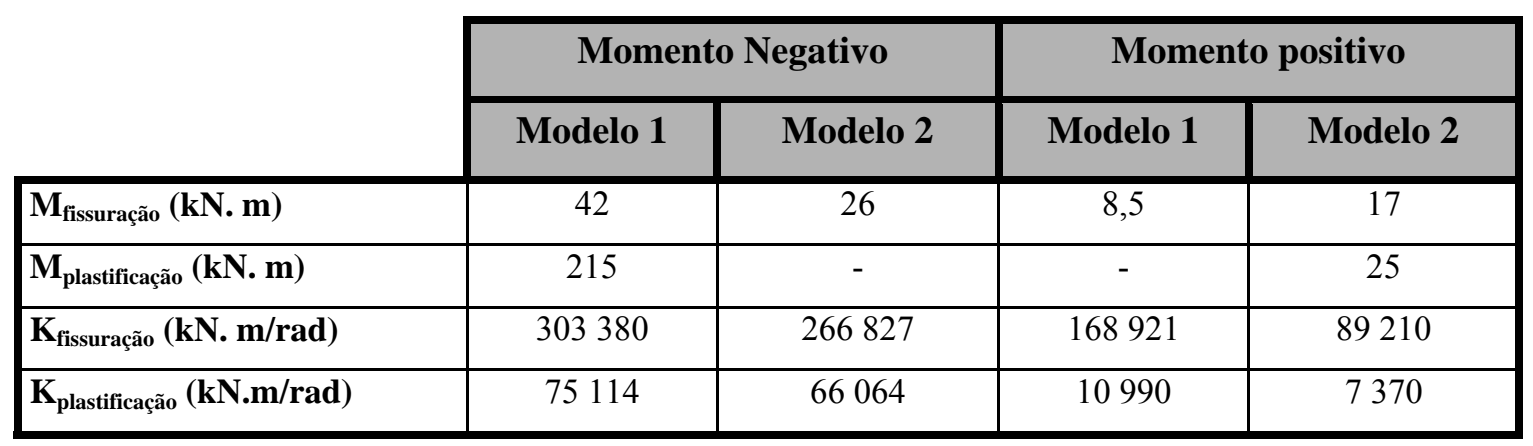

Nas Figuras 2.29 e 2.30 estão apresentadas as curvas momento-rotação experimentais e analíticas, obtidas para o modelo 2.1, para momento negativo e positivo respectivamente. 


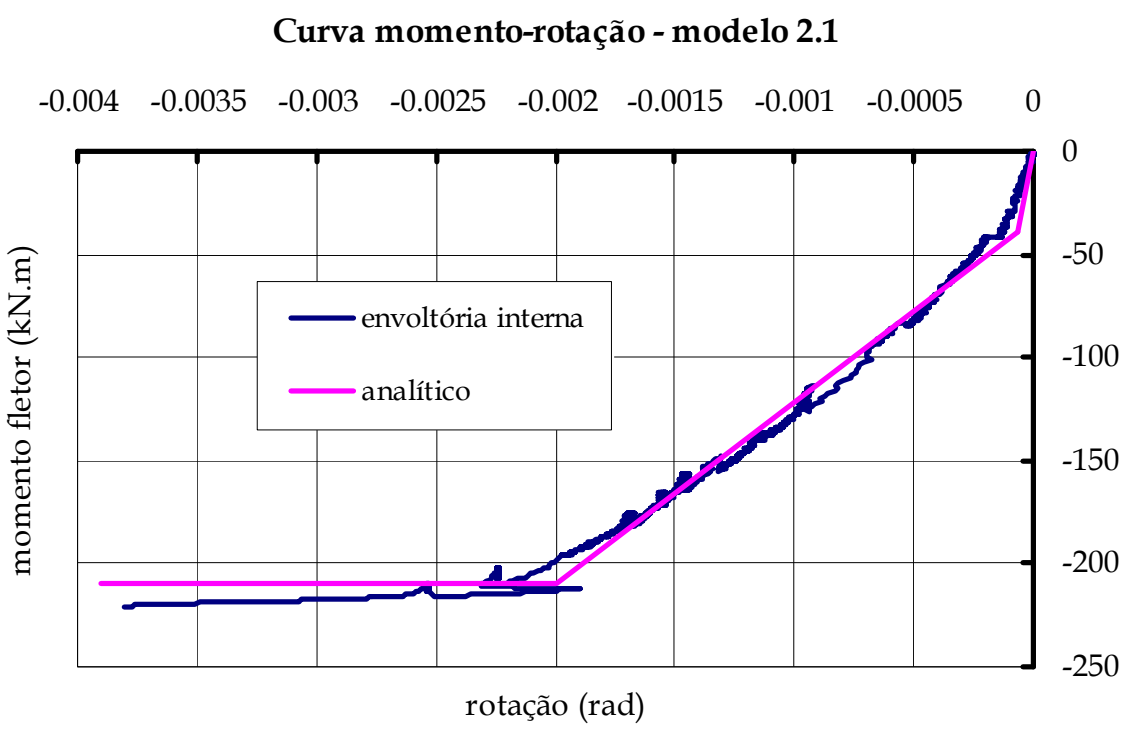

Figura 2.29: Curva momento-rotação do modelo 2.1 para momento negativo Fonte: MIOTTO (2002)

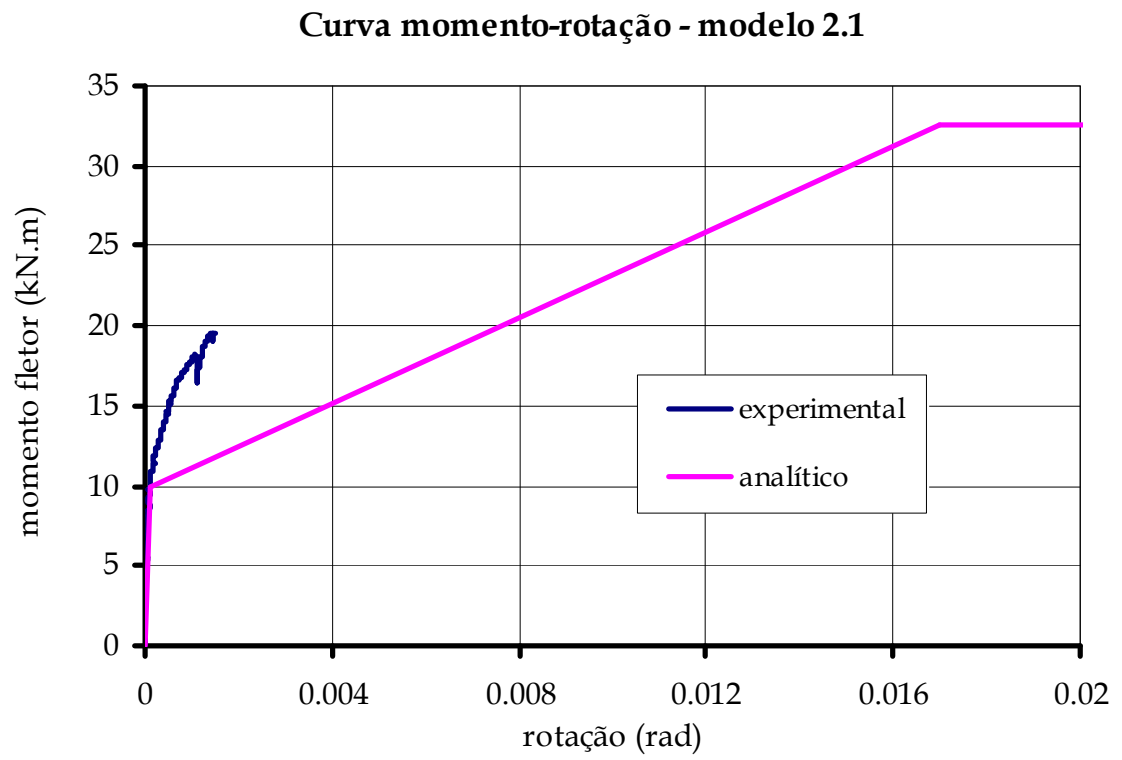

Figura 2.30: Curva momento-rotação do modelo 2.1 para momento positivo Fonte: MIOTTO (2002)

As principais conclusões do trabalho de MIOTTO (2002) são descritas a seguir:

i. Para o mesmo sentido de momento, as curvas momento-rotação dos modelos de pilar interno e externo têm formatos semelhantes. Porém percebeu-se a diferença de resistência para os diferentes sentidos de momento aplicados; 
ii. O momento fletor resistente positivo é da ordem de $20 \%$ do momento fletor resistente negativo;

iii. Para a situação de momentos positivos os valores de rigidez inicial são bons, porém sofrem acentuada redução depois da peça ter fissurado;

iv. Pode se afirmar que o modelo analítico proposto baseado no método dos componentes representa adequadamente o comportamento da ligação estudada.

BALDISSERA (2006), com o intuito de melhorar o comportamento da ligação a momento fletor positivo de MIOTTO (2002), propôs uma alteração na configuração do chumbador. O chumbador retilíneo utilizado em MIOTTO (2002) foi substituído por um chumbador inclinado a $45^{\circ}$.

Na Figura 2.31 está ilustrado o modelo I, que representa um pilar intermediário, e compõe um dos dois modelos ensaiados no programa experimental realizado por BALDISSERA (2006). O outro modelo ensaiado foi o modela E, e representa um pilar de extremidade.
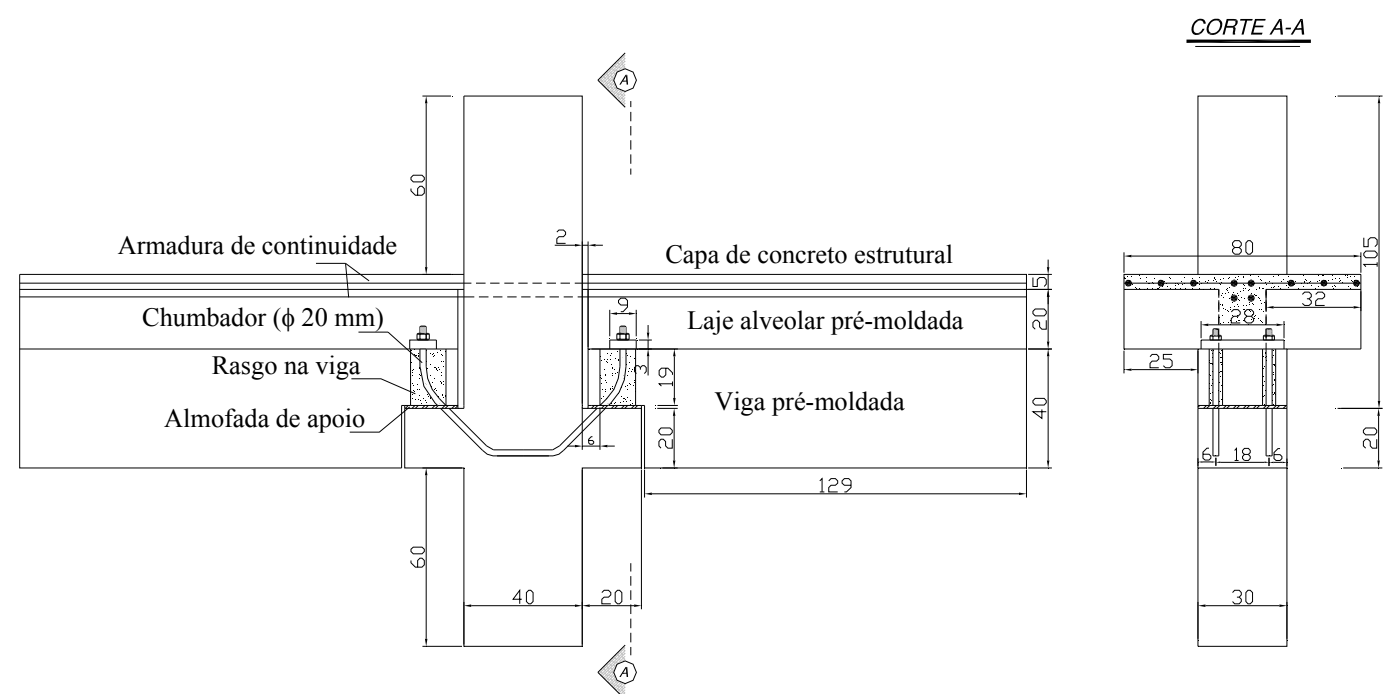

Figura 2.31: Características geométricas do modelo I de BALDISSERA (2006) Fonte: BALDISSERA (2006)

O esquema de ensaio utilizado por BALDISSERA (2006) está representado nas Figuras 2.32 e 2.33 , onde foram aplicados ao modelo, momentos fletores positivos e negativos. 


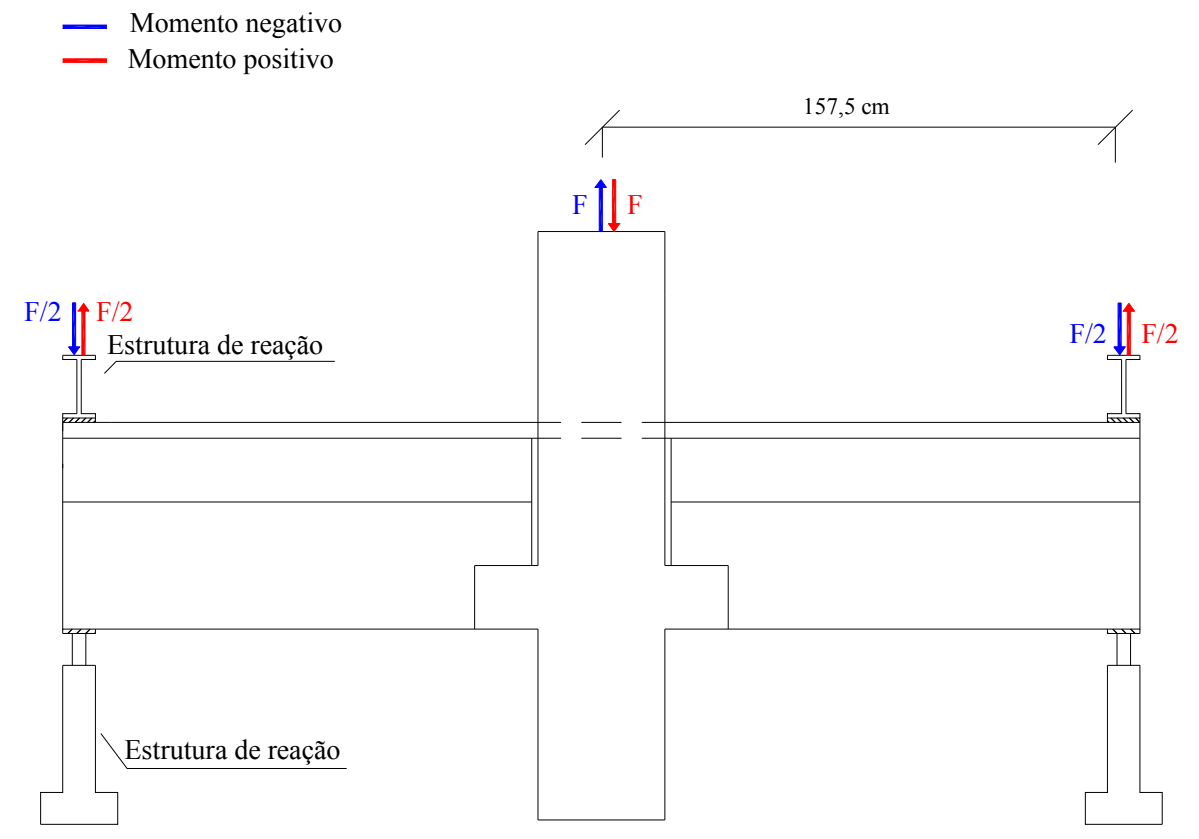

Figura 2.32: Esquema de ensaio do modelo I de BALDISSERA (2006)

Fonte: BALDISSERA (2006)

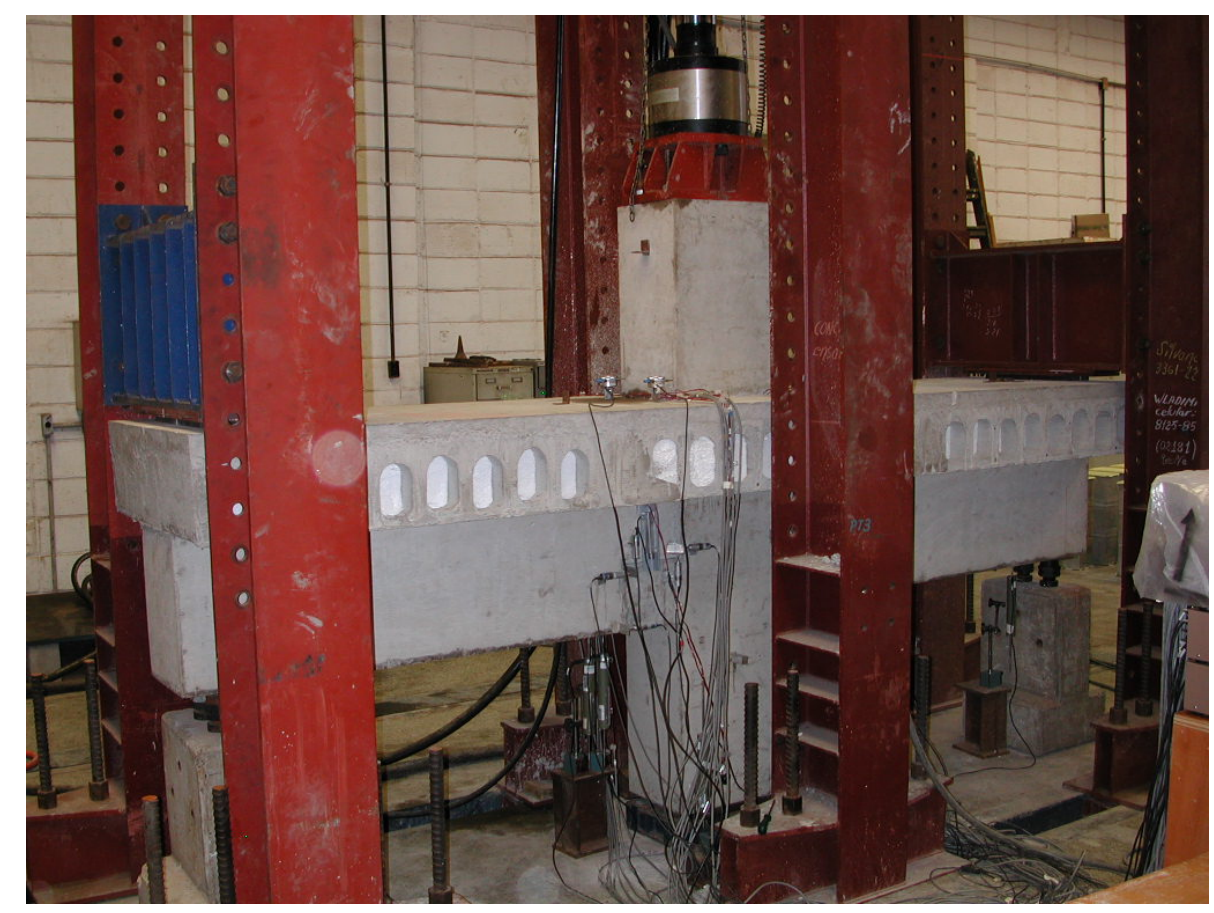

Figura 2.33: Vista do ensaio do modelo I de BALDISSERA (2006)

Fonte: BALDISSERA (2006) 
BALDISSERA (2006) verificou que a ruptura da ligação ocorreu por escoamento da armadura da capa. Os momentos máximos atuantes em cada modelo estão apresentados na Tabela 2.8. O resumo das rigidezes obtidas para ambos os modelos estão apresentadas na Tabela 2.9.

Tabela 2.8: Momentos máximos atuantes em cada modelo

Fonte: BALDISSERA (2006)

\begin{tabular}{|l|c|c|}
\cline { 2 - 3 } \multicolumn{1}{c|}{} & Momento Negativo & Momento positivo \\
\hline Modelo I (kN. m) & $-227,0$ & 144,1 \\
\hline Modelo E (kN. m) & $-162,2$ & 139,3 \\
\hline
\end{tabular}

Tabela 2.9: Resumo das rigidezes dos modelos I e E

Fonte: BALDISSERA (2006)

\begin{tabular}{|l|c|c|}
\multicolumn{1}{c|}{} & Fonte: BALDISSERA (2006) \\
\cline { 2 - 3 } \multicolumn{1}{c|}{} & Momento Negativo & Momento positivo \\
\hline Rigidez modelo I (MN.m/rad) & 79,6 & 28,8 \\
\hline \multirow{2}{*}{ Rigidez modelo E (MN.m/rad) } & 20,4 (direito) & $22,8 \quad$ (direito) \\
& 40,7 (esquerdo) & 28,0 (esquerdo) \\
\hline
\end{tabular}

As principais conclusões do trabalho de BALDISSERA (2006) são descritas a seguir:

i. A ligação viga-pilar estudada possui uma boa capacidade de transmissão a momento fletor negativo, devido à presença de armaduras de continuidade, e a momento fletor positivo, possui um comportamento bastante dúctil;

ii. O momento resistente positivo é da ordem de $60 \%$ do momento negativo para o pilar intermediário e $85 \%$ para o pilar de extremidade;

iii. Quando comparados os momentos de plastificação de ambos os modelos, percebe-se que para momento fletor negativo a ligação do modelo I é capaz de suportar momentos $30 \%$ maiores que a do modelo E, enquanto que para o momento positivo a ligação possui praticamente o mesmo momento resistente;

iv. Na ligação estudada, quando comparada à ligação similar, porém com chumbadores retilíneos, com uma extrapolação de resultados, foi 
observado um acréscimo superior a 3,5 vezes nos momentos de plastificação e de 2,5 vezes na rigidez a momento fletor positivo.

Para que pudesse ser realizada a comparação entre os resultados obtidos por MIOTTO (2002) e BALDISSERA (2006), foi necessária uma extrapolação de resultados, uma vez que MIOTTO (2002) usou em seus modelos apenas um chumbador de $25 \mathrm{~mm}$ de diâmetro, contra dois chumbadores de $20 \mathrm{~mm}$ de diâmetro usados por BALDISSERA (2006). Além disso, a resistência de escoamento nominal passou de $250 \mathrm{MPa}$ para $500 \mathrm{MPa}$, respectivamente. Os detalhes da comparação realizada são apresentados em EL DEBS \& BALDISSERA (2008).

KATAOKA (2007) estudou a continuidade em ligações laje-viga-pilar em estruturas pré-moldadas de concreto com a realização de uma investigação experimental quanto à contribuição da parcela de armadura nas laterais do pilar e na capa da laje, tanto para a rigidez à flexão quanto para o controle de fissuração.

A ligação viga-pilar estudada (Figura 2.34) era composta de consolo de concreto com dois chumbadores de $20 \mathrm{~mm}$ de diâmetro e armadura de continuidade passante no pilar por meio de bainhas lisas preenchidas com graute.

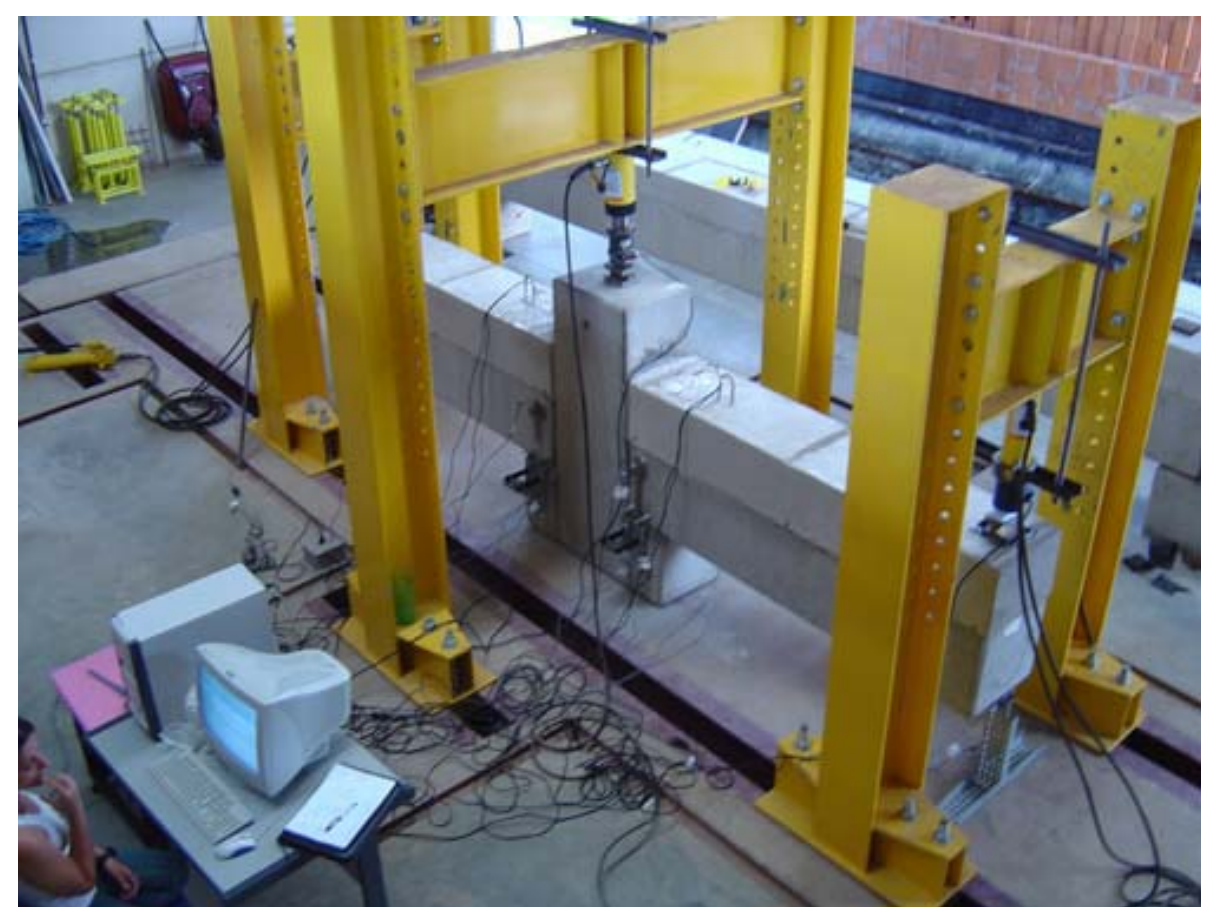

Figura 2.34: Vista do ensaio realizado por KATAOKA (2007) 
KATAOKA (2007) realizou ensaios em dois modelos, sendo o primeiro com $100 \%$ das armaduras de continuidade passando dentro do pilar (Figura 2.35), e o segundo com 50\% dentro do pilar e 50\% nas laterais (Figura 2.36).
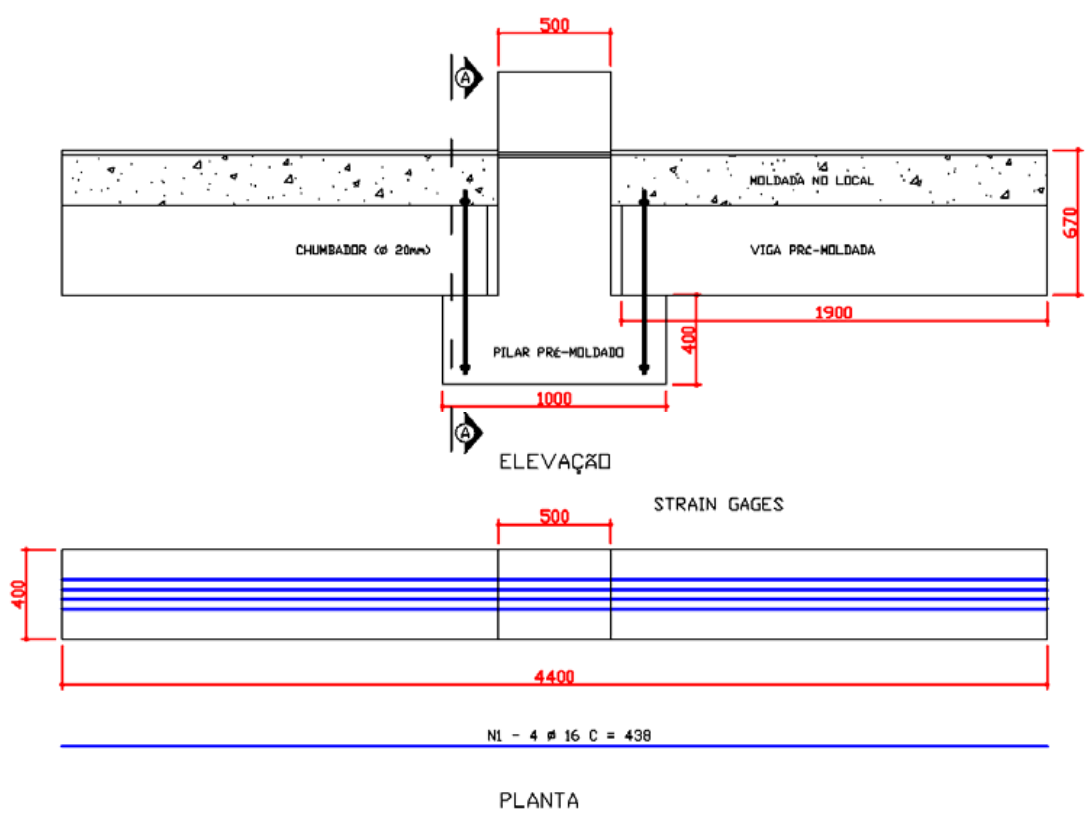

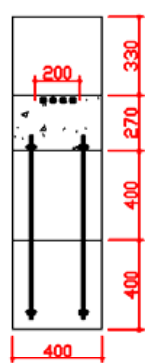

CDRTE AA

Figura 2.35: Detalhe da armadura de continuidade do modelo 1 de KATAOKA (2007)

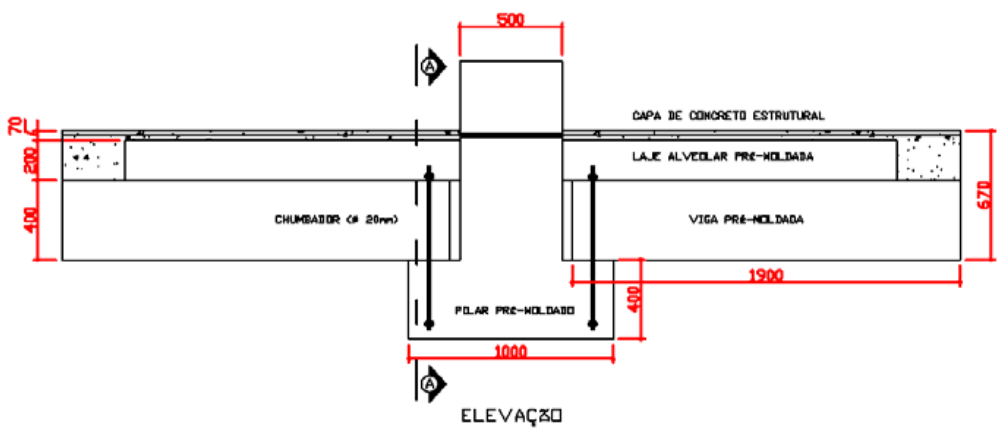

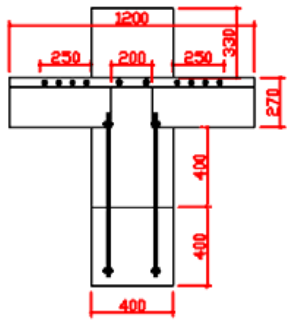

CDRTE AA

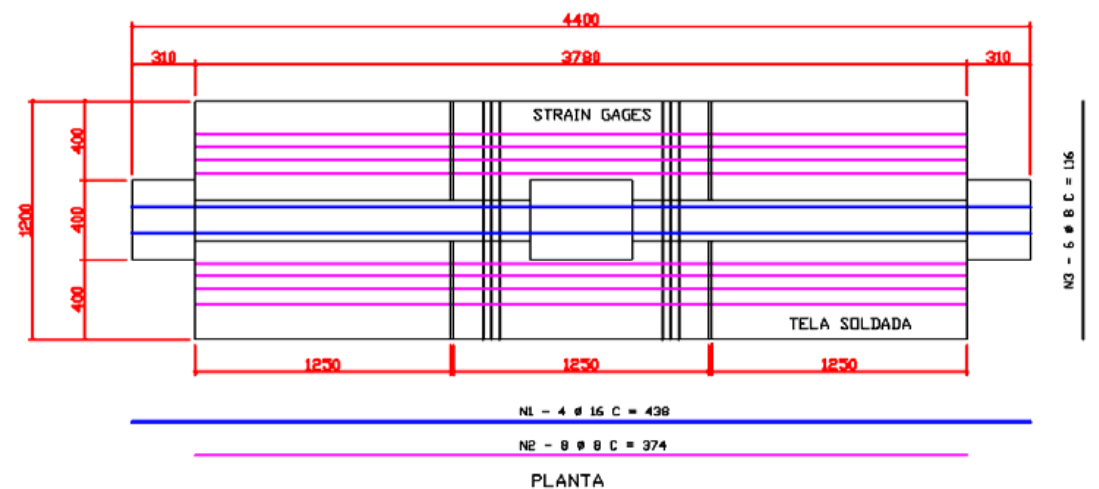

Figura 2.36: Detalhe da armadura de continuidade do modelo 2 de KATAOKA (2007) 
Os resultados experimentais mostraram que as barras laterais ao pilar contribuíram para o aumento da rigidez à flexão, principalmente na fase de serviço, inferior à carga de projeto. Entretanto as rotações relativas ao início da plastificação para a relação momento x rotação foram próximas para os dois modelos.

Embora as ligações estudadas por KATAOKA (2007) terem sido confeccionadas com o uso de chumbadores verticais, o objetivo da pesquisa não contemplou a análise deste componente da ligação. 


\section{PROGRAMA EXPERIMENTAL}

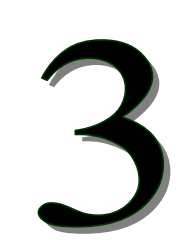

Capítulo

\subsection{GENERALIDADES}

O programa experimental descrito nesta seção consiste no estudo de 15 (quinze) modelos idealizados para o estudo do comportamento do chumbador nas ligações.

O objetivo da análise é estudar especificamente a influência do chumbador no comportamento da ligação. Para isso, foi montado um programa experimental onde foram analisadas três inclinações para os chumbadores, onde foi avaliada também a variável “diâmetro do chumbador”. As inclinações analisadas foram de $0^{\circ}$, que representa o chumbador normal à interface entre o consolo e o pilar, $45^{\circ}$ e $60^{\circ}$. Os diâmetros estudados foram de $16 \mathrm{~mm}$, $20 \mathrm{~mm}$ e $25 \mathrm{~mm}$.

O programa experimental foi dividido em duas fases, sendo a primeira fase definida como programa experimental piloto (composto por três modelos), e a segunda fase definida como programa experimental final (composto por 12 modelos).

O termo programa experimental piloto aqui descrito, refere-se na realidade a um programa experimental preliminar, tendo em vista que todos os resultados obtidos nesta fase foram aproveitados nas análises finais.

Na tabela 3.1 está representado o programa experimental inicialmente proposto, onde a influência da inclinação do chumbador e a influência da força de atrito mobilizada pela reação de apoio da viga sobre o consolo ligado ao pilar, também foram variáveis analisadas.

A reação de apoio da viga sobre o consolo foi simulada no modelo com a aplicação de uma força de compressão na ligação. Para verificar a influência da resistência à compressão do concreto no comportamento do chumbador, os modelos 
foram confeccionados com concretos de classe C35 (35 MPa) e C50 (50 MPa), definidos no programa experimental final.

O projeto da ligação, confecção do modelo, montagem, caracterização dos materiais, instrumentação e procedimentos de ensaios, estão discriminados nos tópicos que seguem.

Tabela 3.1: Programa experimental inicialmente proposto

\begin{tabular}{|c|c|c|c|c|}
\hline \multirow{2}{*}{$\begin{array}{l}\text { Diâmetro do } \\
\text { chumbador }\end{array}$} & \multicolumn{3}{|c|}{ Inclinação do chumbador } & \multirow{2}{*}{ Concreto } \\
\hline & $0^{\circ}$ & $45^{\circ}$ & $60^{\circ}$ & \\
\hline \multicolumn{5}{|c|}{ Sem força de compressão na ligação } \\
\hline $16 \mathrm{~mm}$ & Modelo 01 & & Modelo 02 & \multirow{3}{*}{ C35 } \\
\hline $20 \mathrm{~mm}$ & Modelo 03 & Modelo 04 & Modelo 05 & \\
\hline $25 \mathrm{~mm}$ & Modelo 06 & Modelo 07 & & \\
\hline \multicolumn{5}{|c|}{ Com força de compressão na ligação } \\
\hline $16 \mathrm{~mm}$ & & & & \multirow{3}{*}{ C35 } \\
\hline $20 \mathrm{~mm}$ & Modelo 08 & Modelo 09 & Modelo 10 & \\
\hline $25 \mathrm{~mm}$ & & & & \\
\hline \multicolumn{5}{|c|}{ Sem força de compressão na ligação } \\
\hline $16 \mathrm{~mm}$ & Modelo 11 & & & \multirow{3}{*}{ C50 } \\
\hline $20 \mathrm{~mm}$ & Modelo 12 & Modelo 13 & Modelo 14 & \\
\hline $25 \mathrm{~mm}$ & Modelo 15 & & & \\
\hline
\end{tabular}

Nota: Os modelos do programa experimental piloto estão destacados em vermelho.

\subsection{DESCRIÇÃO DOS MODELOS}

Para estudar o comportamento do chumbador na ligação viga-pilar, procurou-se reduzir as interferências que pudessem comprometer a análise. Para isso, foi desenvolvido um modelo na tentativa de simular o mais próximo possível o comportamento do chumbador isoladamente. Na Figura 3.1 está ilustrada a parte da ligação viga-pilar na qual o modelo proposto tentou reproduzir.

A hipótese, adotada inicialmente, para a idealização do modelo proposto para a realização dos ensaios, foi que a ligação viga-pilar da Figura 3.1 não apresentasse continuidade da viga com o pilar por armaduras dispostas na capa de concreto. Assim, quando a ligação for submetida a momento fletor, a transferência de esforços se dará pelo chumbador grauteado. 


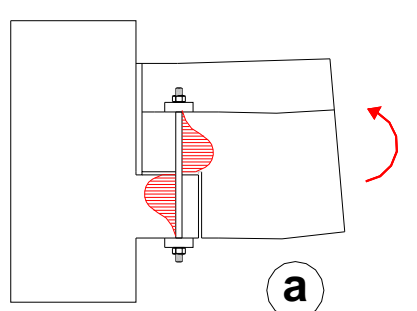

a

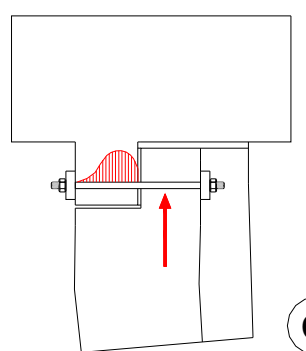

C

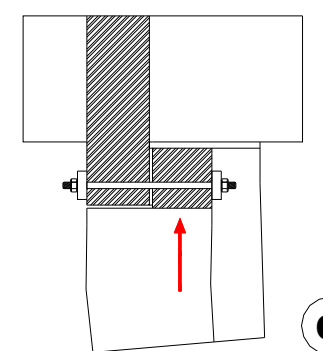

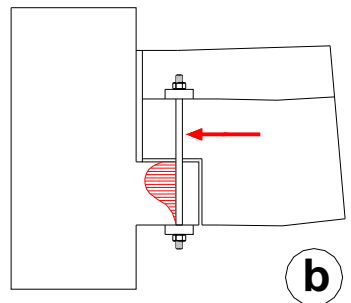

b

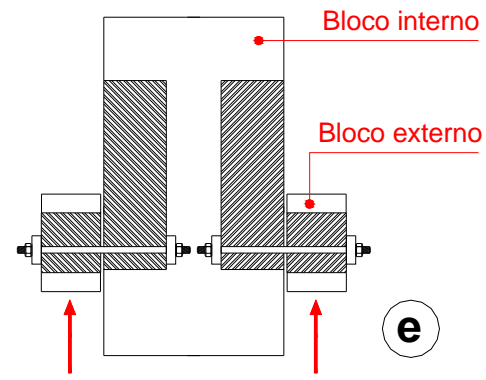

Figura 3.1: Comportamento isolado do chumbador e montagem do modelo

Quando essa ligação é submetida a momento fletor, tensões são mobilizadas ao longo do chumbador, conforme ilustra a Figura 3.1-a. Estas tensões podem ser substituídas por forças resultantes capazes que gerar deslocamentos horizontais e rotações (Figura 3.1-b). Se a ligação for rotacionada (Figura 3.1-c), a força que atua no chumbador passa a ser vertical, o que facilita sua reprodução em laboratório. Isolando os elementos adjacentes ao chumbador (Figura 3.1-d), pode-se criar um modelo mais simplificado para a simulação do comportamento da ligação em laboratório (Figura 3.1-e).

Partindo do modelo apresentado na Figura 3.1-e, foram desenvolvidos os modelos do programa experimental proposto, adaptando as dimensões do modelo às dimensões usuais empregadas em peças pré-moldadas de concreto. Na Figura 3.2 estão ilustrados os modelos adotados no programa experimental para o chumbador inclinado e para o chumbador retilíneo.

Tendo em vista alguns problemas encontrados nos ensaios piloto, descritos em AGUIAR \& EL DEBS (2008) e oportunamente ao longo deste trabalho, houve a necessidade de alterar o programa experimental inicialmente proposto, sendo o programa experimental adotado apresentado na Tabela 3.2, onde os modelos pilotos estão em destaque.

O Modelo 03 (Tabela 3.2), pertencente ao programa experimental piloto, não apresentou resultados confiáveis a priori, exigindo assim a repetição do ensaio com a 
confecção de um novo modelo (Modelo 04). Assim, também com base nos resultados obtidos nos outros dois modelos ensaiados, foi definido o programa experimental final, conforme a Tabela 3.2 .

Inicialmente estava previsto também a aplicação de carregamentos alternados, em ciclos de curta duração, de forma que na ligação fossem simuladas forças mobilizadas por momentos fletores positivos e negativos. O Modelo 03 (Tabela 3.2) foi então submetido ao ensaio de carregamento alternado, onde foi observado já nos primeiros ciclos, folgas entre o consolo e o pilar devido à falta de uma armadura de continuidade (Figura 3.1), o que conduziu à repetição do ensaio com a confecção de um novo modelo.

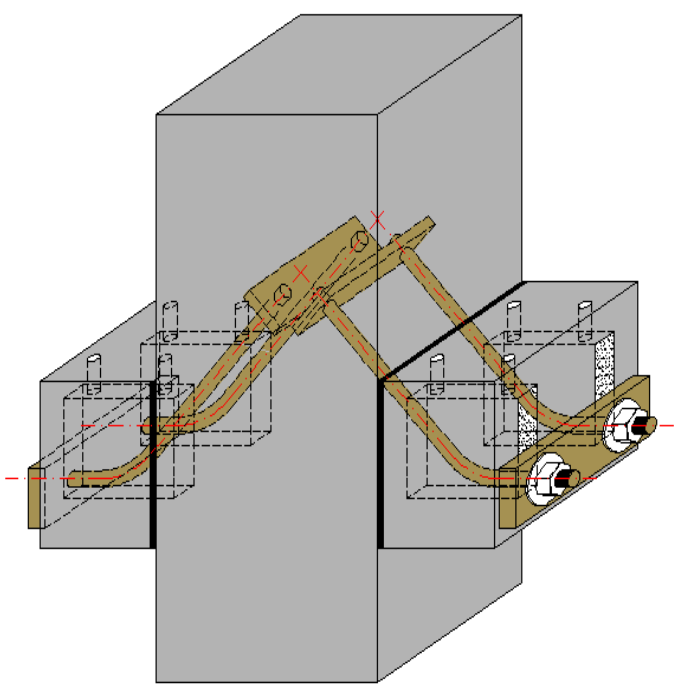

a- Modelo chumbador inclinado

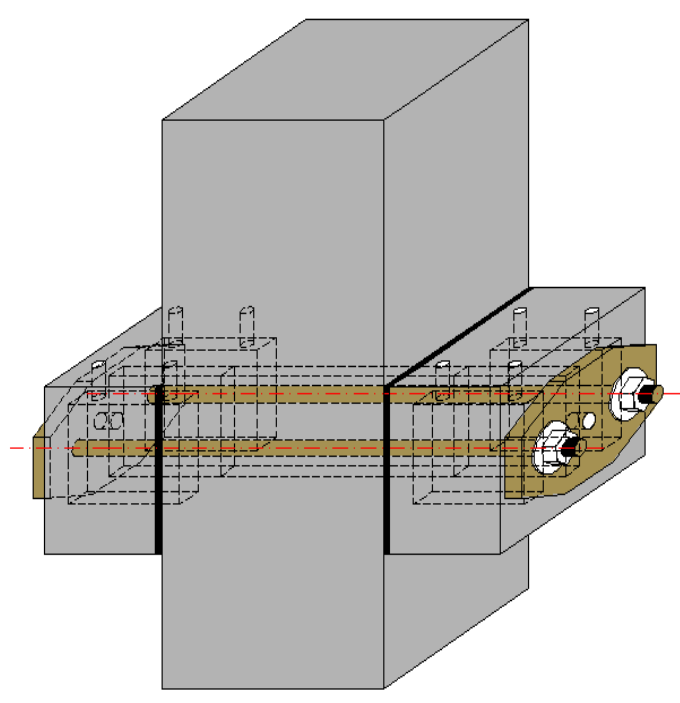

b- Modelo chumbador retilíneo

Figura 3.2: Perspectiva dos modelos utilizados no programa experimental piloto

Para facilitar a visualização das características inerentes a cada modelo apresentado, procurou-se definir uma nomenclatura de identificação que contemplasse o nome do modelo (M01, M02...), a inclinação do chumbador (i00, i45...), o diâmetro do chumbador (D16, D20...), a resistência do concreto à compressão (C35, C50) e existência de força de compressão aplicada (-FC). Assim, o Modelo 08, por exemplo, passa a ser identificado por M08 i00 D20 C35-FC, ou seja, Modelo 08 com inclinação de chumbador de $0^{\circ}$ (retilíneo), diâmetro do chumbador de $20 \mathrm{~mm}$, resistência do concreto a compressão de 35MPa e força de compressão aplicada. 
Tabela 3.2: Resumo do programa experimental efetuado

\begin{tabular}{|c|c|c|c|c|}
\hline \multirow{2}{*}{$\begin{array}{l}\text { Diâmetro do } \\
\text { chumbador }\end{array}$} & \multicolumn{3}{|c|}{ Inclinação do chumbador } & \multirow{2}{*}{ Concreto } \\
\hline & $0^{\circ}$ & $45^{\circ}$ & $60^{\circ}$ & \\
\hline \multicolumn{5}{|c|}{ Sem força de compressão na ligação } \\
\hline $16 \mathrm{~mm}$ & $\begin{array}{c}\text { Modelo } 01 \\
\text { M01 i00 D16 C35 }\end{array}$ & & & \multirow{3}{*}{ C35 } \\
\hline $20 \mathrm{~mm}$ & & $\begin{array}{c}\text { Modelo } 02 \\
\text { M02 i45 D20 C35 }\end{array}$ & $\begin{array}{c}\text { Modelo } 03 \\
\text { M03 i60 D20 C35 } \\
\text { Modelo } 04 \\
\text { M04 i60 D20 C35 }\end{array}$ & \\
\hline $25 \mathrm{~mm}$ & $\begin{array}{c}\text { Modelo } 05 \\
\text { M05 ioo D25 C35 }\end{array}$ & $\begin{array}{c}\text { Modelo } 06 \\
\text { M06 i45 D25 C35 }\end{array}$ & & \\
\hline \multicolumn{5}{|c|}{ Com força de compressão na ligação } \\
\hline $16 \mathrm{~mm}$ & \begin{tabular}{|c|} 
Modelo 07 \\
M07 i00 D16 C35-FC \\
\end{tabular} & & & \multirow{3}{*}{ C35 } \\
\hline $20 \mathrm{~mm}$ & \begin{tabular}{c|} 
Modelo 08 \\
M08 i00 D20 C35-FC \\
\end{tabular} & \begin{tabular}{c|} 
Modelo 09 \\
M09 i45 D20 C35-FC
\end{tabular} & \begin{tabular}{c|} 
Modelo 10 \\
M10 i60 D20 C35-FC \\
\end{tabular} & \\
\hline $25 \mathrm{~mm}$ & $\begin{array}{c}\text { Modelo } 11 \\
\text { M11 ioo D25 C35-FC } \\
\end{array}$ & & $\begin{array}{c}\text { Modelo } 12 \\
\text { M12 i60 D25 C35-FC } \\
\end{array}$ & \\
\hline \multicolumn{5}{|c|}{ Sem força de compressão na ligação } \\
\hline $16 \mathrm{~mm}$ & & & & \multirow{3}{*}{ C50 } \\
\hline $20 \mathrm{~mm}$ & & $\begin{array}{c}\text { Modelo } 13 \\
\text { M13 i45 D20 C50 }\end{array}$ & $\begin{array}{c}\text { Modelo } 14 \\
\text { M14 i60 D20 C50 }\end{array}$ & \\
\hline $25 \mathrm{~mm}$ & & $\begin{array}{c}\text { Modelo } 15 \\
\text { M15 i45 D25 C50 }\end{array}$ & & \\
\hline
\end{tabular}

Nota: Os modelos do programa experimental piloto estão destacados em vermelho.

Nas Figuras 3.3; 3.4 e 3.5 estão ilustradas as dimensões dos modelos com chumbadores de eixo retilíneo (Modelo 08), eixo inclinado a $45^{\circ}$ (Modelo 02) e 60 (Modelo 03) respectivamente, utilizados na definição do programa experimental piloto.

No caso específico do Modelo 08 (Figura 3.3), com o objetivo de simular a reação de apoio da viga sobre o consolo uma ligação viga-pilar, foram previstos nichos nos blocos externos e no bloco interno para a passagem de uma cordoalha engraxada onde seria aplicada uma força de protensão de $180 \mathrm{kN}$. O valor da força aplicada foi calculado tomando-se como base uma estrutura de concreto pré-moldado usual com lajes de vãos de $6 \mathrm{~m}$ x $6 \mathrm{~m}$, solicitadas por um carregamento último de $10 \mathrm{kN} / \mathrm{m}^{2}$. 


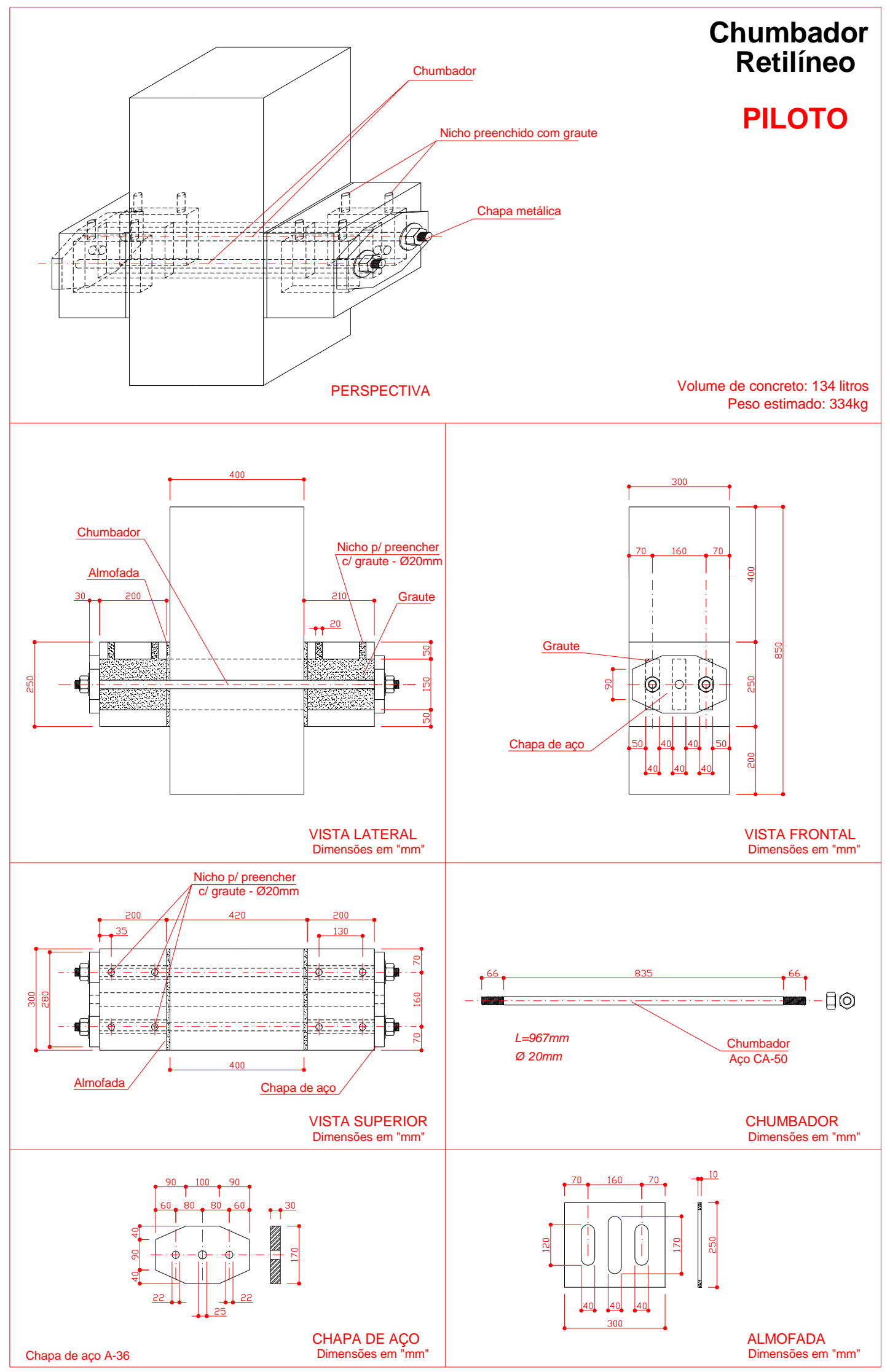

Figura 3.3: Dimensões e detalhes do modelo piloto com chumbador retilíneo 


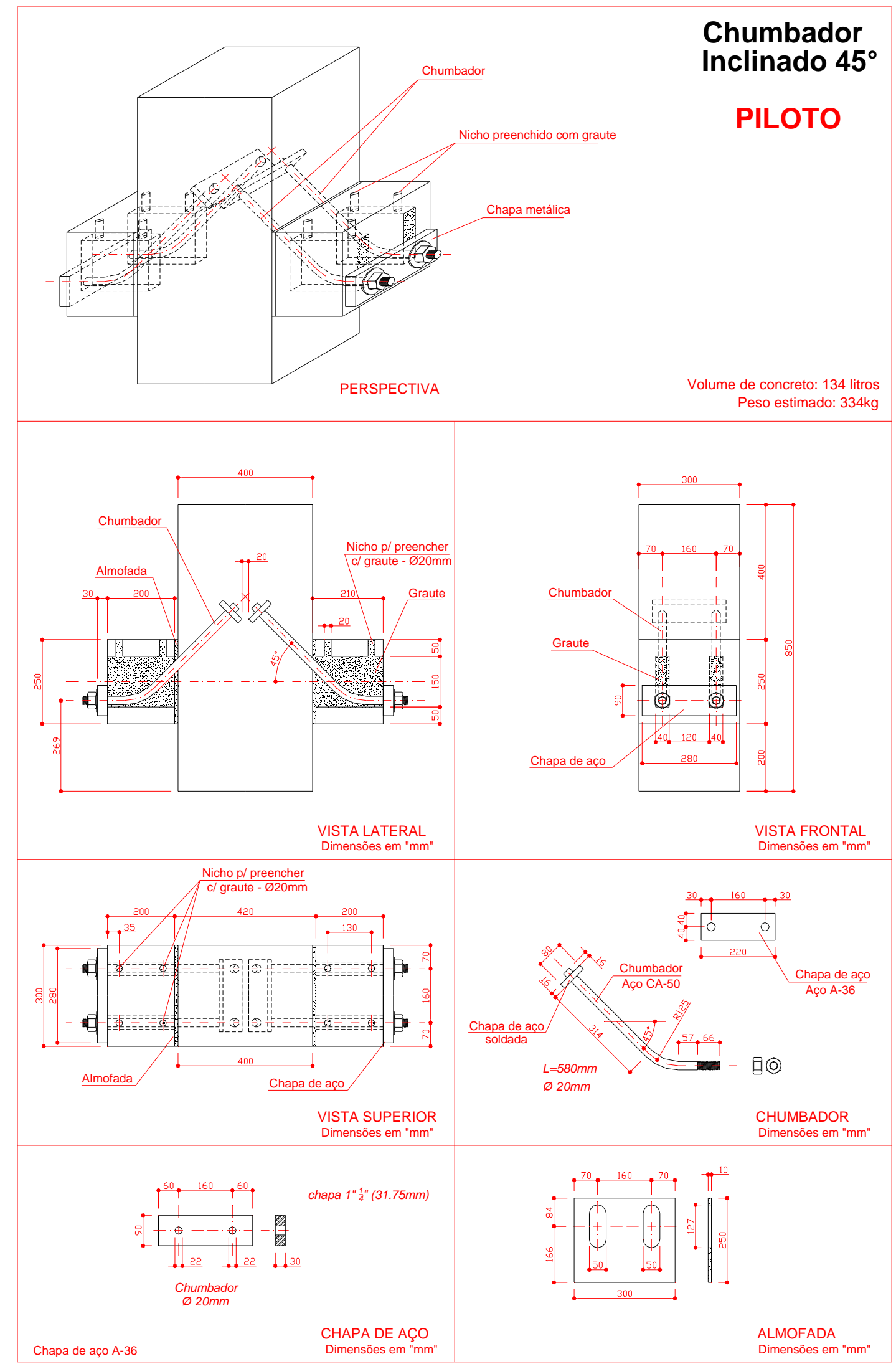

Figura 3.4: Dimensões e detalhes do modelo piloto com chumbador inclinado a $45^{\circ}$ 


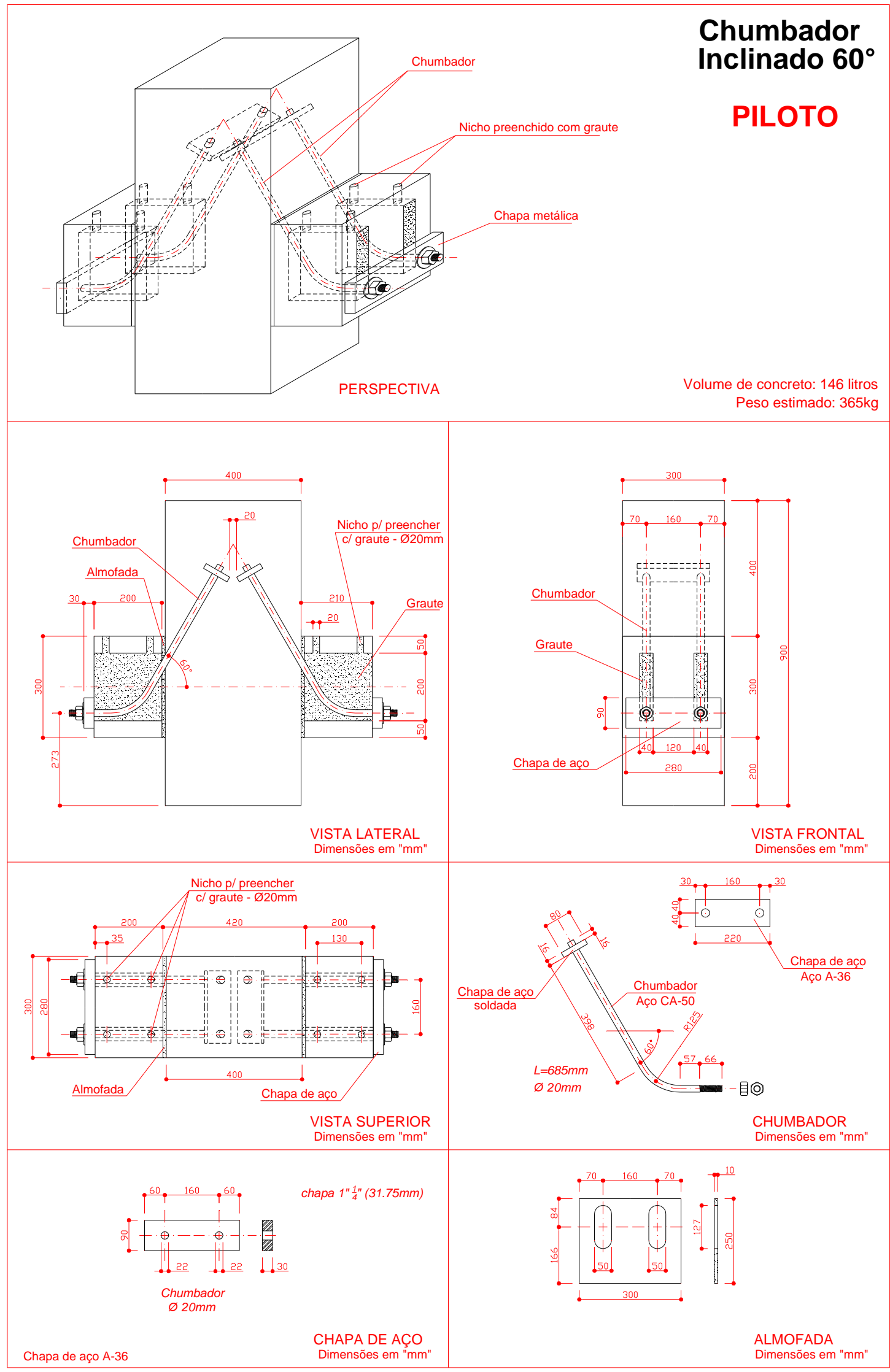

Figura 3.5: Dimensões e detalhes do modelo piloto com chumbador inclinado a $60^{\circ}$ 
A protensão utilizada no modelo 08 foi inicialmente prevista com cordoalha engraxada de diâmetro de 15,2 mm. Como os equipamentos disponíveis no Laboratório de Estruturas do SET/EESC/USP eram destinados à utilização em cordoalhas de 12,7 mm, tentou-se fazer adaptações sem êxito.

Assim, para o modelo piloto, foi utilizada uma cordoalha de $12,7 \mathrm{~mm}$, onde a força de protensão inicialmente planejada não pôde ser alcançada. É importante lembrar que os problemas ocorridos durante o ensaio desse modelo serão abordados ao longo deste capítulo.

A limitação do uso das cordoalhas de $12,7 \mathrm{~mm}$ e a necessidade de alcançar uma força de compressão aplicada próxima a $180 \mathrm{kN}$ (valor estimado da reação de apoio da viga sobre o consolo), conduziram à utilização de duas cordoalhas para protensão nos modelos que necessitaram simular o efeito da reação de apoio.

A utilização de duas cordoalhas gerou a necessidade de mais espaço no nicho inicialmente projetado, o que conduziu a mudanças nas dimensões dos modelos. Assim, houve a necessidade de se aumentar a altura dos blocos externos, levando em consideração a distância necessária, entre as cordoalhas, para a colocação de blocos de ancoragem e células de carga.

As dimensões utilizadas nos modelos com força de compressão aplicada foram também adotadas nos demais modelos, facilitando assim a confecção de formas e armaduras.

Nas Figuras 3.6; 3.7 e 3.8 estão ilustradas as dimensões dos modelos com chumbadores de eixo retilíneo, eixo inclinado a $45^{\circ}$ e $60^{\circ}$ respectivamente, utilizados na definição do programa experimental definitivo.

Os modelos sem força de compressão aplicada foram confeccionados sem nicho para a passagem de cordoalhas, porém com as mesmas dimensões e detalhamento de armaduras.

A altura dos blocos internos também foram alteradas. Optou-se por adotar a altura constante e igual a $80 \mathrm{~cm}$ em todos os modelos que compõem o programa experimental definitivo. O objetivo da redução na altura do bloco interno foi tentar compensar o acréscimo de altura nos blocos externos, mantendo assim o consumo de concreto e o peso dos modelos próximos aos observados no programa experimental piloto. 


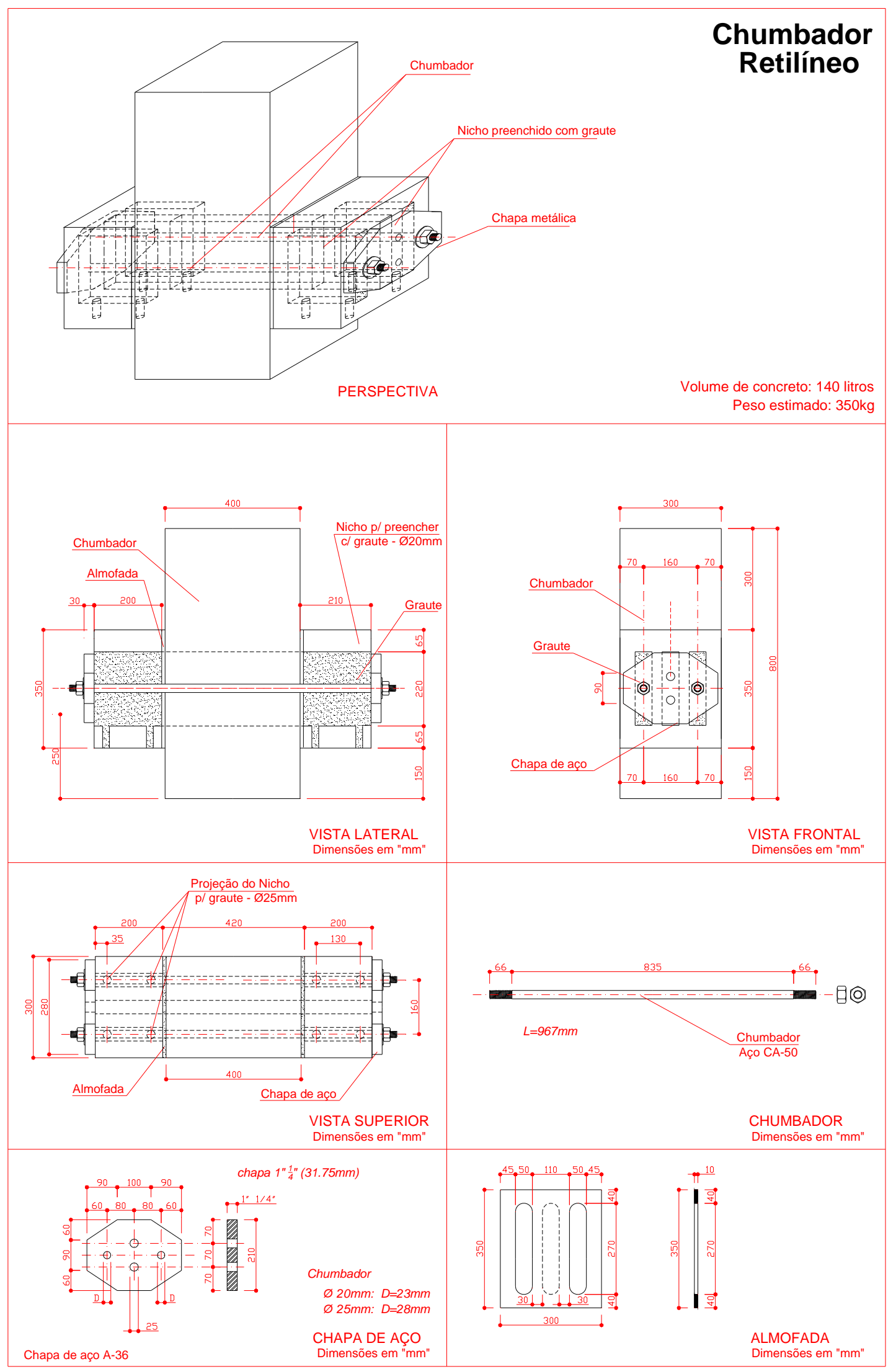

Figura 3.6: Dimensões e detalhes do modelo com chumbador retilíneo 


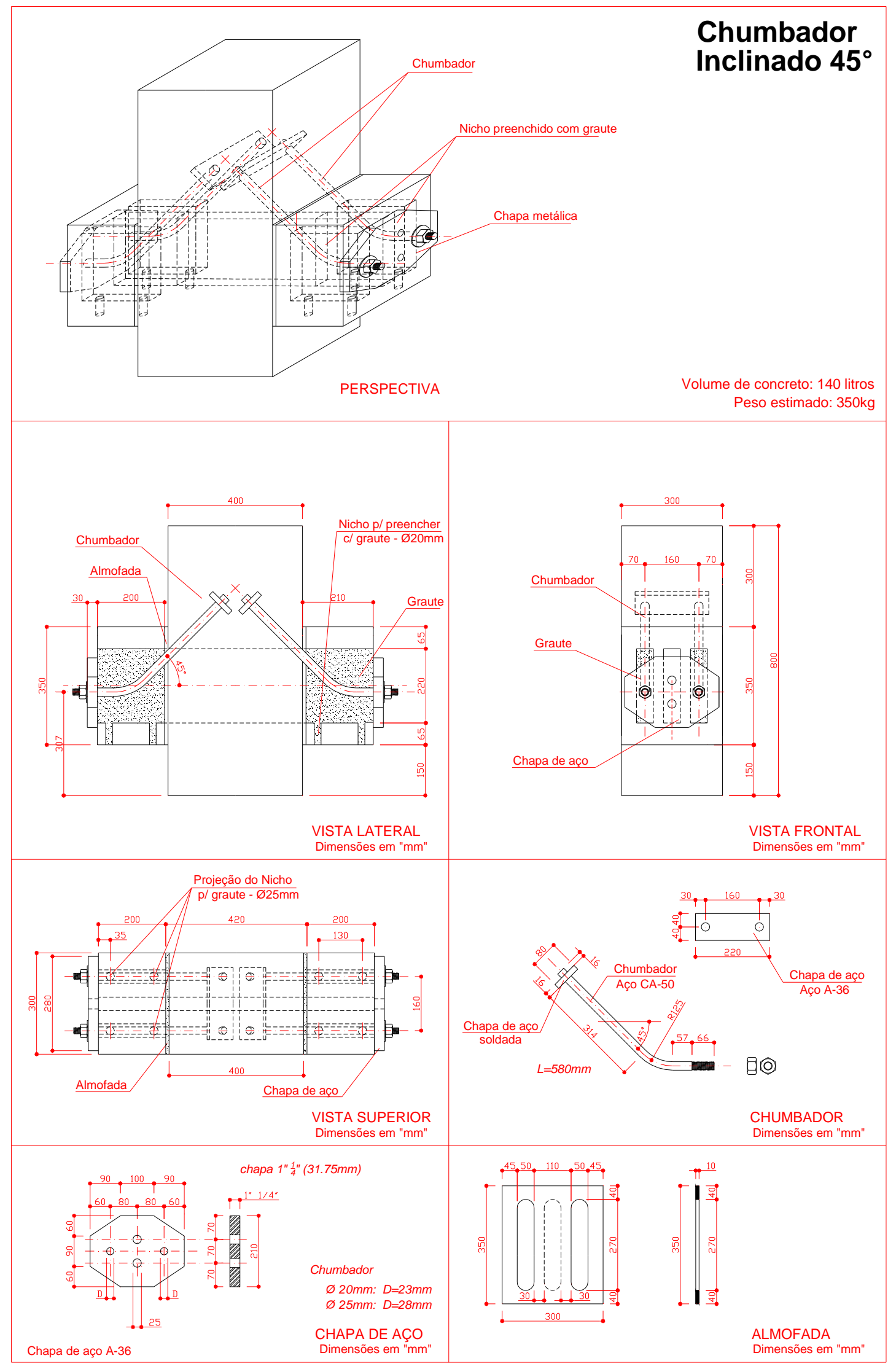

Figura 3.7: Dimensões e detalhes do modelo com chumbador inclinado a $45^{\circ}$ 


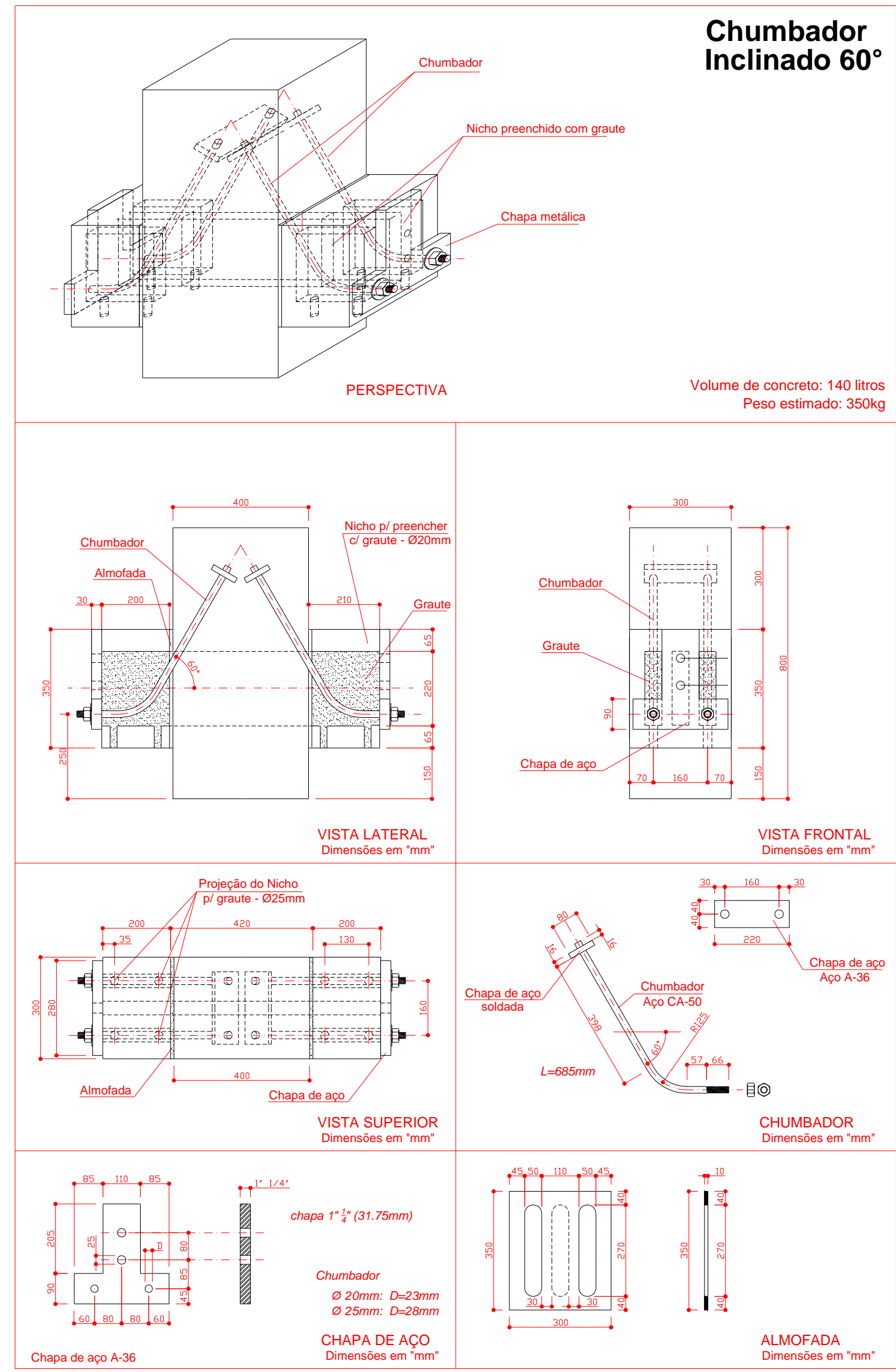

Figura 3.8: Dimensões e detalhes do modelo com chumbador inclinado a $60^{\circ}$ 


\subsubsection{Especificação do concreto}

Para a confecção dos modelos, conforme apresentado na Tabela 3.2, foram especificados dois valores diferentes de resistência característica à compressão do concreto. Para os modelos 13, 14 e 15 a resistência característica à compressão especificada foi de $50 \mathrm{MPa}$. Para os demais modelos, o valor especificado foi de 35 MPa.

\subsubsection{Armadura de projeto}

O aço utilizado para a confecção dos modelos foi o CA -50, cujos diâmetros variaram entre 6,3 e 25 mm. As armaduras foram adquiridas já cortadas e dobradas, sendo que a montagem dos modelos foi realizada por funcionários do Laboratório de estruturas do SET/EESC/USP.

A armadura adotada foi baseada na armadura utilizada por MIOTTO (2002) nos seus modelos confeccionados em escala 1:1, semelhante às armaduras praticadas em estruturas usuais de concreto pré-moldado com vãos de seis metros de comprimento.

Os chumbadores foram confeccionados em aço CA-50, dobrados a frio, respeitando os limites de curvatura baseado na norma NBR 6118:2003 e no manual CPCA Concrete Design Handbook da Associação Canadense de Cimento Portland. A ancoragem foi garantida com a soldagem de chapas de aço MR-250 (A-36) nas extremidades concretadas no modelo, conforme ilustrado na Figura 3.9.
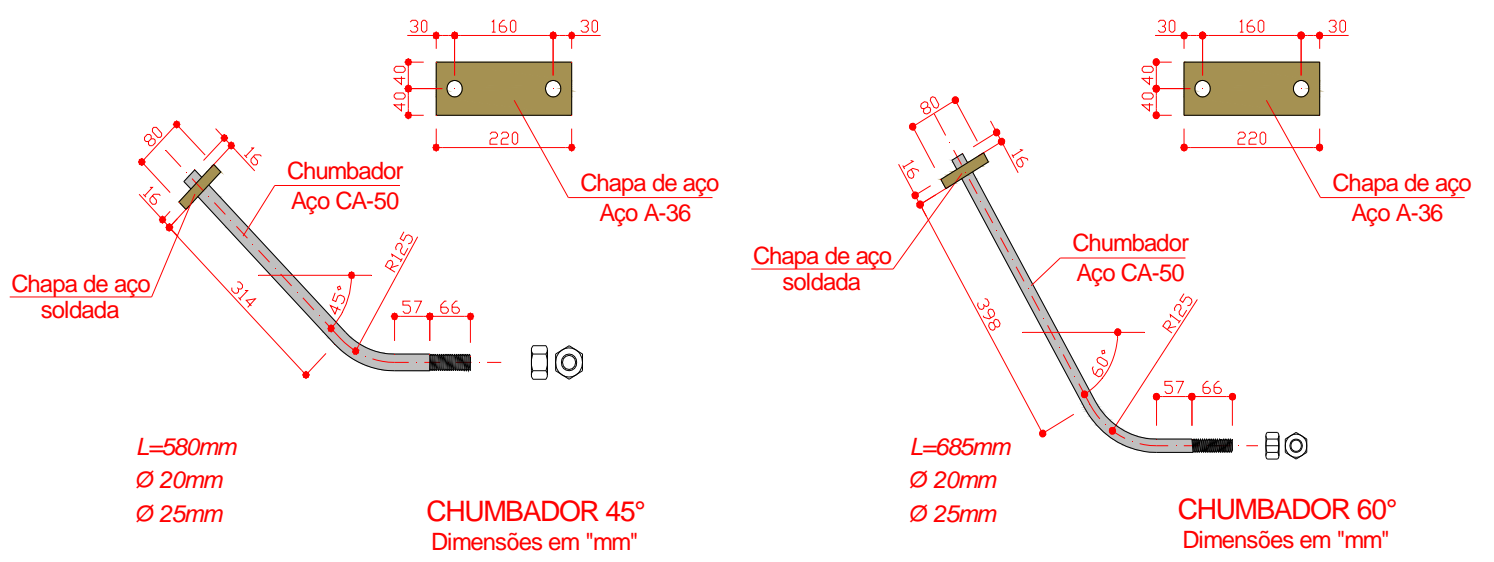

Figura 3.9: Detalhe dos chumbadores inclinados 
Nas Figuras 3.10; 3.11 e 3.12, estão ilustradas as armaduras adotadas nos modelos com chumbador retilíneo, chumbador inclinado a $45^{\circ}$ e a $60^{\circ}$, respectivamente, utilizados no programa experimental piloto.

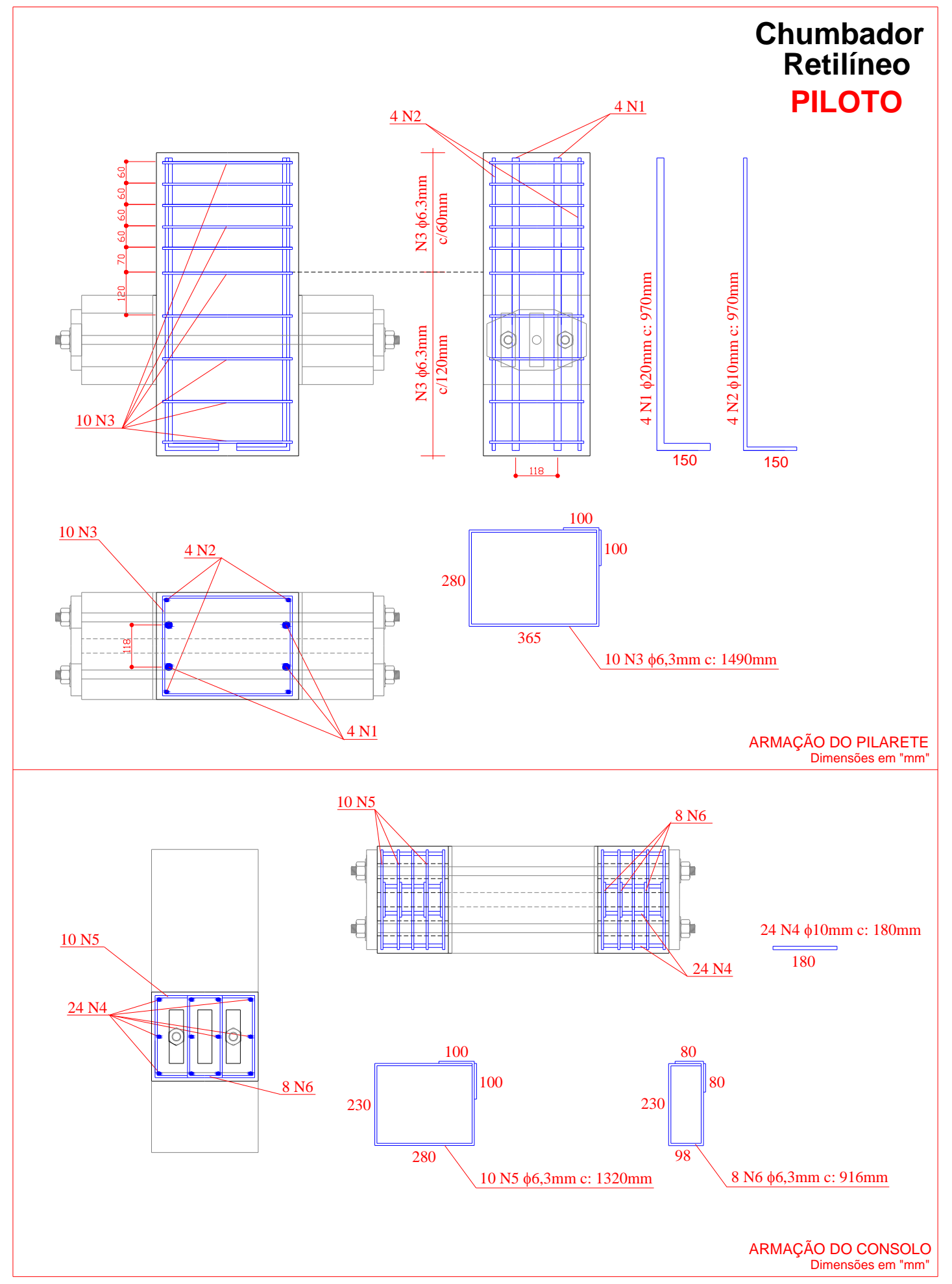

Figura 3.10: Armadura adotada no modelo piloto com chumbador retilíneo 


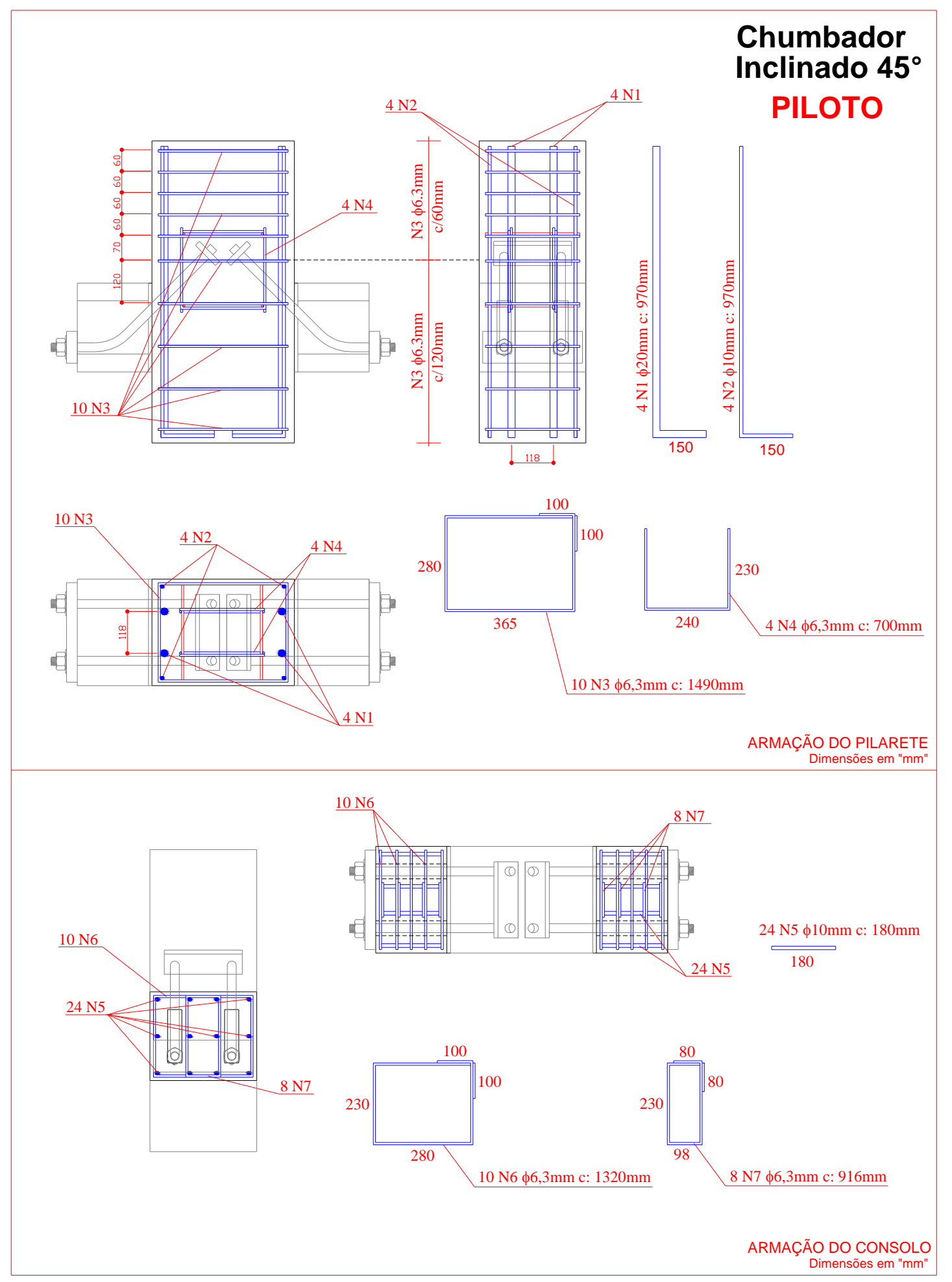

Figura 3.11: Armadura adotada no modelo piloto com chumbador inclinado a $45^{\circ}$

No modelo piloto com chumbador inclinado a $60^{\circ}$ (Modelo 03), como era previsto a realização de ensaio com reversão de carregamento, foi necessário criar um 
prolongamento da armadura do bloco interno (Figura 3.12) para a fixação do modelo no atuador servo-controlado utilizado no ensaio.

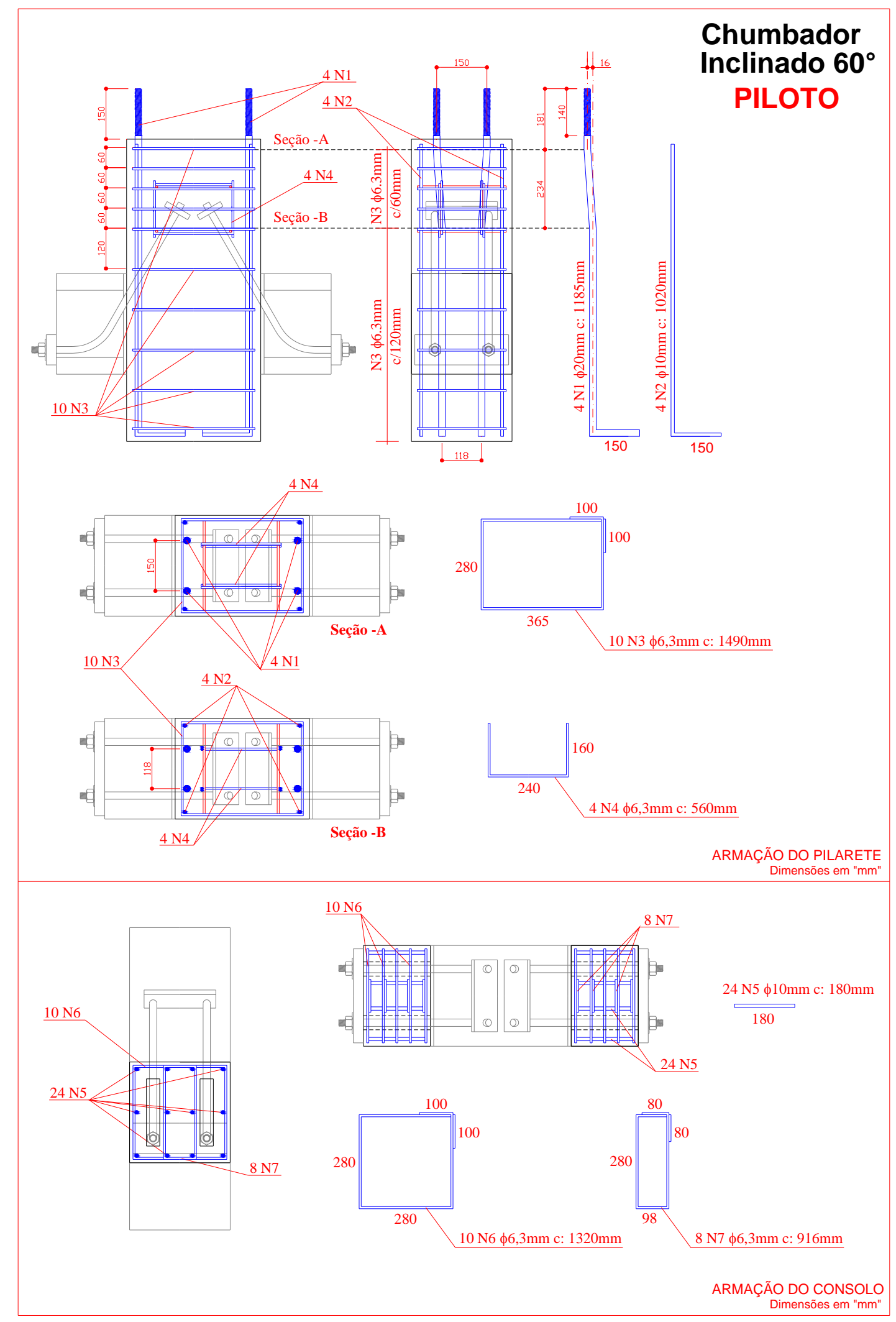

Figura 3.12: Armadura adotada no modelo piloto com chumbador inclinado a $60^{\circ}$ 
Para os modelos que compõem o programa experimental final, procurou-se padronizar as armaduras, sendo o detalhamento utilizado para os chumbadores retilíneos igual ao usado nos chumbadores inclinados.

Na Figura 3.13 é apresentado o detalhamento de armaduras utilizado nos 12 modelos confeccionados para a realização do programa experimental final.

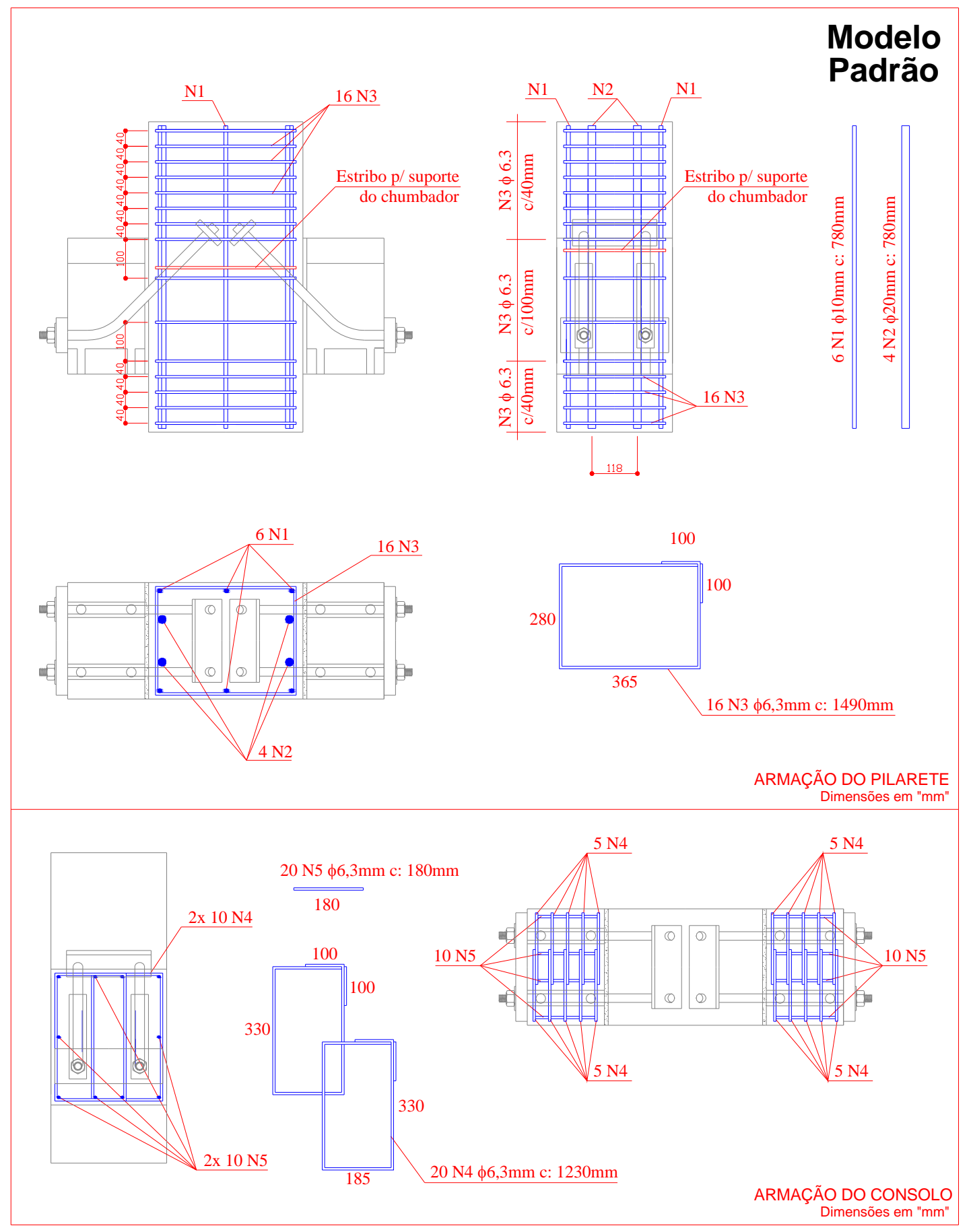

Figura 3.13: Armadura dos modelos que compõem o programa experimental final 


\subsubsection{Graute}

Para o preenchimento dos nichos dos blocos externos, foi especificado um graute auto adensável, com retração compensada e resistência à compressão similar a do concreto pré-moldado, ou seja, de 35MPa.

\subsubsection{Almofada de apoio}

As almofadas de apoio foram confeccionadas com uma argamassa modificada, obtida pela introdução de látex estireno-butadieno (SBR) e fibras de polipropileno a uma argamassa de cimento e areia. Este material foi desenvolvido no SET/EESC/USP por SIQUEIRA (2007), e apresentou desempenho satisfatório para a aplicação em elementos pré-moldados.

Na Figura 3.14 estão ilustradas as dimensões das almofadas utilizadas para a confecção dos modelos do ensaio experimental piloto (modelos 02, 03 e 08) e do ensaio experimental final, onde estão ilustradas as almofadas dos modelos sem força de compressão aplicada e dos modelos com força de compressão aplicada.
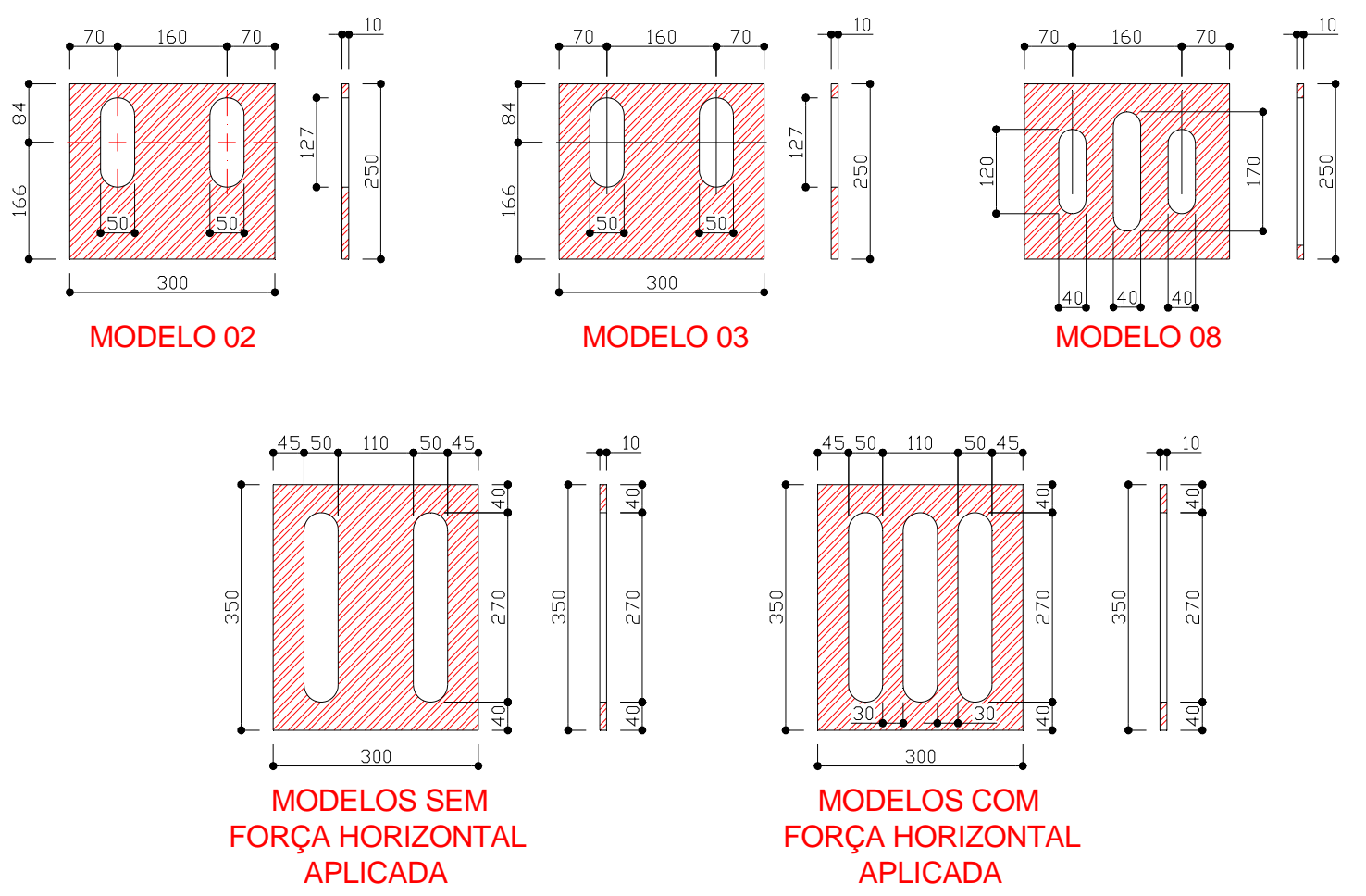

Figura 3.14: Dimensões das almofadas utilizadas nos modelos do ensaio piloto 


\subsection{CONFECÇÃO DOS ELEMENTOS}

\subsubsection{Fôrma}

As fôrmas foram todas confeccionadas no LAMEM/SET/EESC/USP, onde foi utilizada madeira compensada plastificada de $17 \mathrm{~mm}$ de espessura. Toda a forma foi montada com parafusos e porcas, visando a facilidade de desforma e um maior reaproveitamento do material.

Todas as formas foram cuidadosamente projetadas para que houvesse o máximo aproveitamento de capa chapa de madeira compensada de 110 x 220 cm. Na Figura 3.15 está representada a forma de detalhamento utilizada.

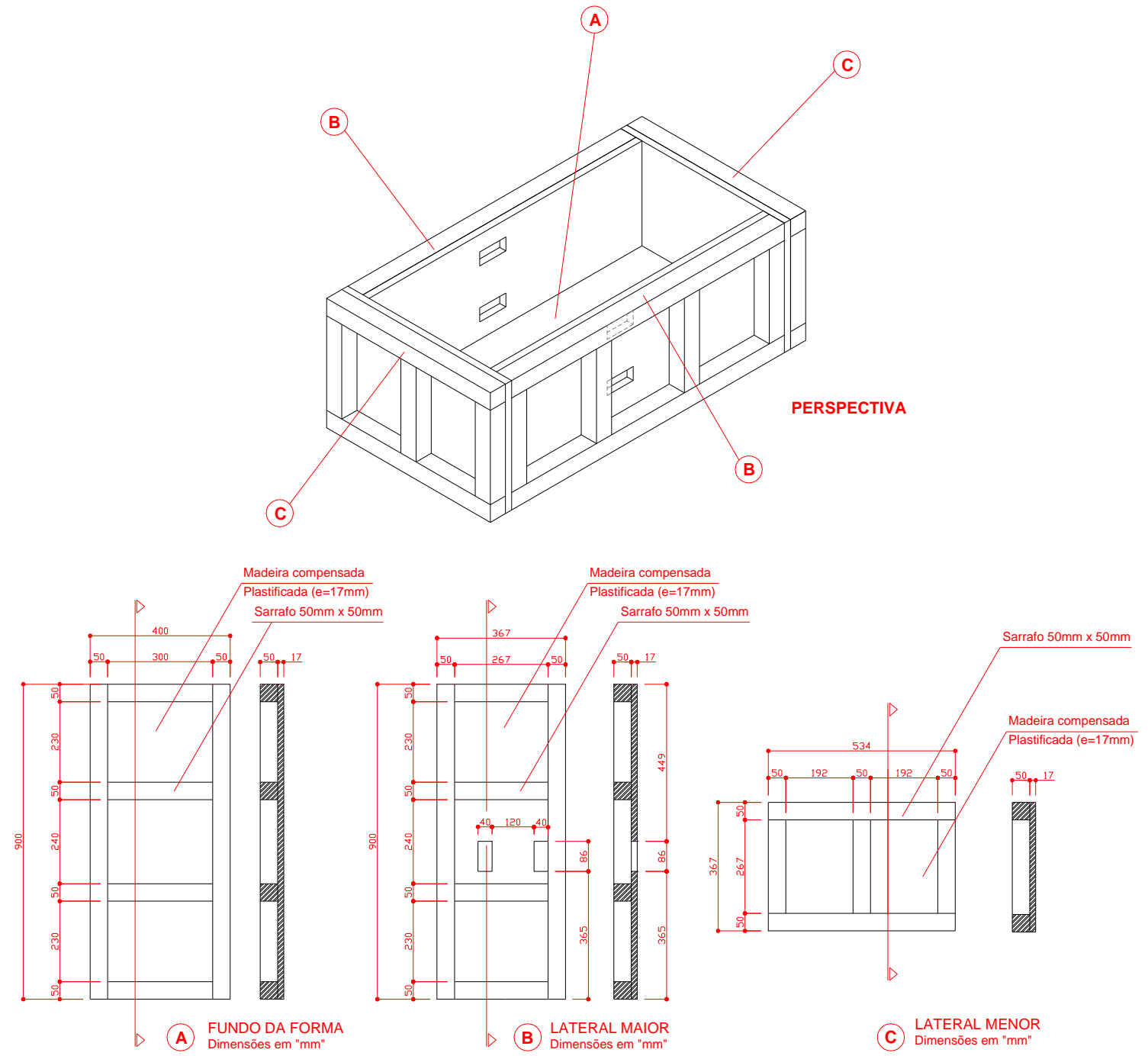

Figura 3.15: Detalhamento das formas utilizadas 
Na Figura 3.16 está ilustrada uma seqüência de etapas utilizadas para a confecção das formas de madeira.
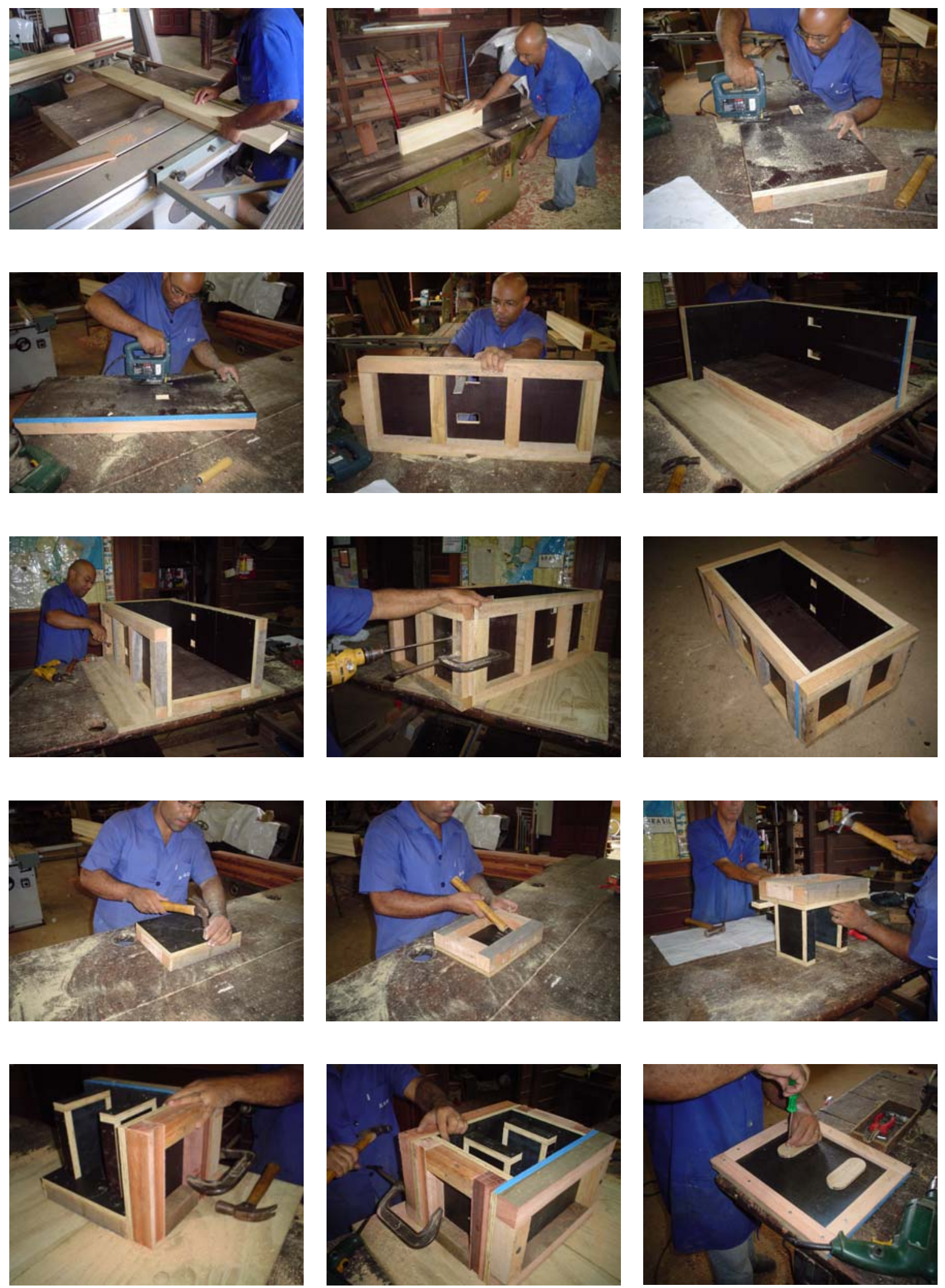

Figura 3.16: Seqüência de execução das formas de madeira 


\subsubsection{Confecção dos chumbadores}

A confecção dos chumbadores usados nos modelos foi realizada na Oficina de serviços mecânicos do Departamento de Química de São Carlos - USP, cujos materiais empregados foram discriminados no item 3.2.2. Na Figura 3.17 está ilustrada a seqüência de montagem dos chumbadores.
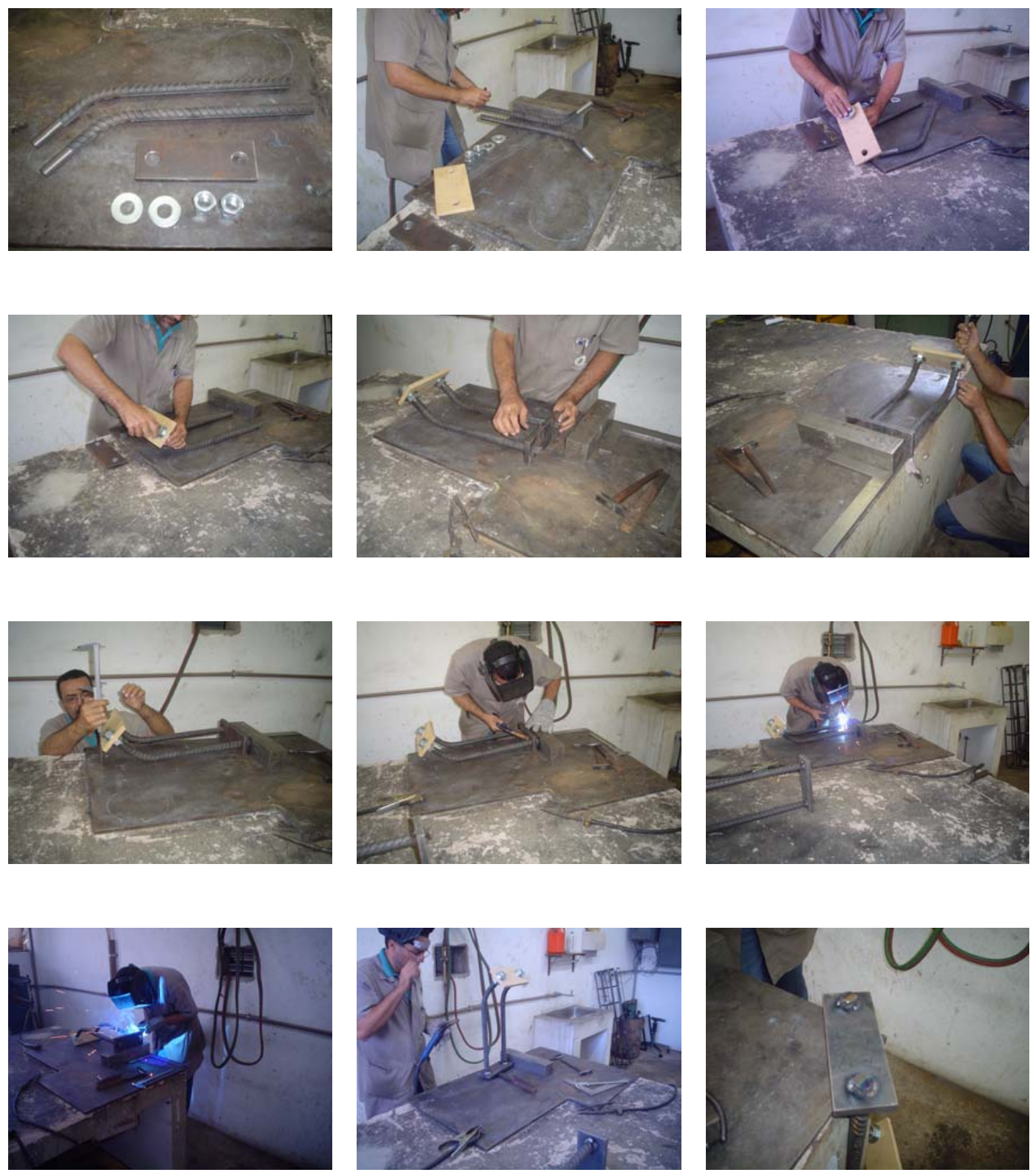

Figura 3.17: Confecção dos chumbadores usados nos modelos 


\subsubsection{Armação dos modelos}

Conforme comentado anteriormente, toda a montagem das armaduras dos modelos foi realizada no Laboratório de Estruturas do SET/EESC/USP. Na Figura 3.18 está ilustrada a seqüência de montagem dessas armaduras.
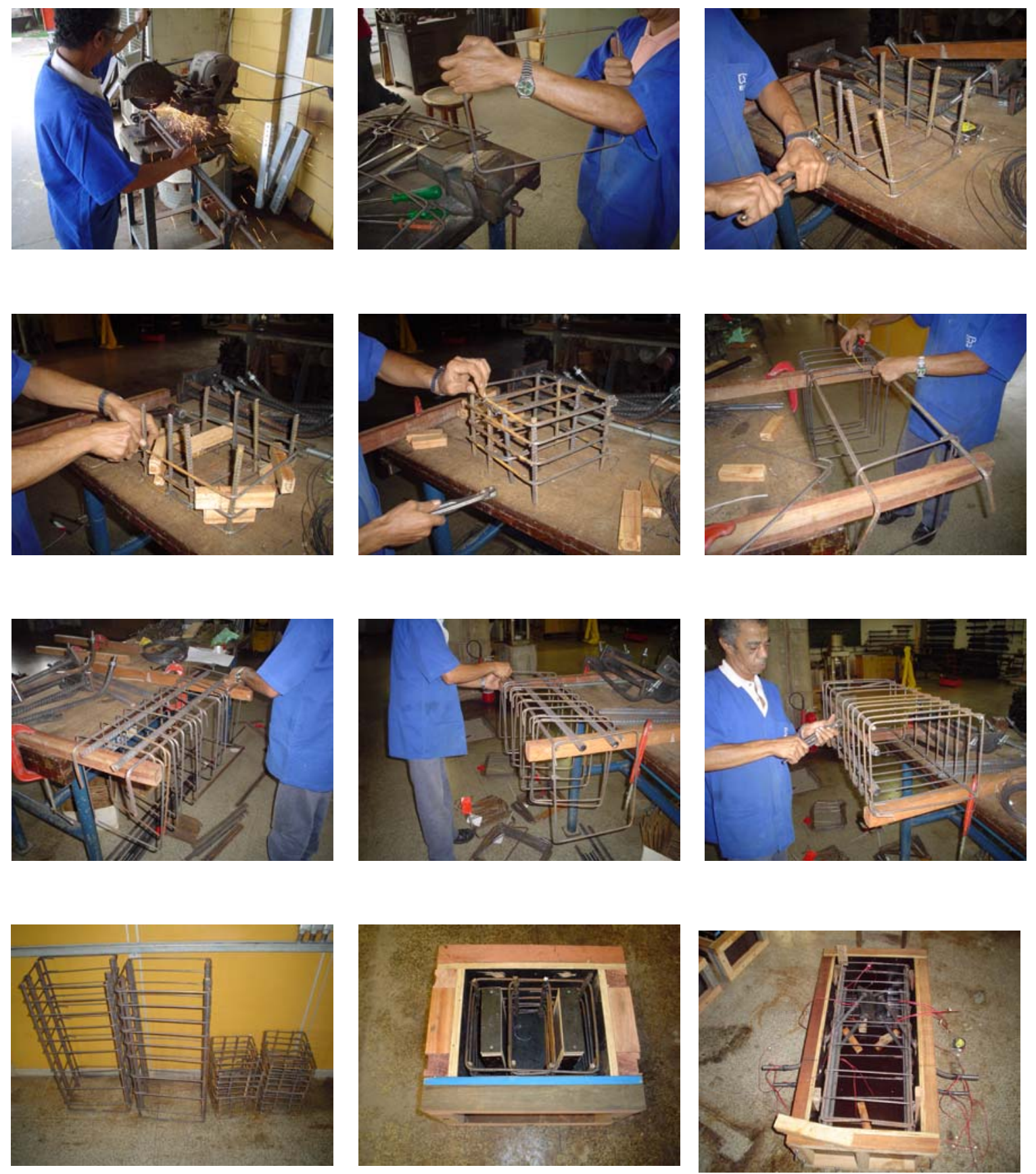

Figura 3.18: Seqüência de montagem das armaduras 


\subsubsection{Moldagem dos modelos}

A maior parte do concreto utilizado nos modelos foi confeccionado no Laboratório de Estruturas do SET/EESC/USP. Foram elaborados dois traços para o concreto, tendo como objetivo alcançar a resistência característica à compressão de $35 \mathrm{MPa}$ (C 35) e $50 \mathrm{MPa}$ (C 50), com um slump de $10 \pm 1$.

O traço utilizado foi elaborado com base no estudo realizado por LIMA JÚNIOR (2003), para dosagem de concreto de alta resistência. Na Tabela 3.3 estão apresentados os traços utilizados, especificados em massa, para as classes C 35 e C 50.

Tabela 3.3: Traço do concreto usado na confecção dos modelos

\begin{tabular}{|c|c|c|}
\hline \multirow{2}{*}{ MATERIAL } & \multicolumn{2}{|c|}{ CONSUMO DE MATERIAL $\left(\mathbf{k g} / \mathbf{m}^{\mathbf{3}}\right)$} \\
\cline { 2 - 3 } & C 35 & C 50 \\
\hline Cimento CP V ARI Plus & 396 & 516 \\
\hline Areia seca & 695 & 671 \\
\hline Brita 1 & 1042 & 877 \\
\hline Água & 198 & 258 \\
\hline Relação a/c & 0,5 & 0,5 \\
\hline Traço em massa & $1: 1,76: 2,63$ & $1: 1,30: 1,70$ \\
\hline
\end{tabular}

Os materiais utilizados estavam disponíveis no Laboratório de Estruturas, estocados adequadamente. Fez-se necessário para a confecção do traço, a caracterização desses materiais. Para a caracterização da brita, foi utilizado o ensaio de proveta para a determinação da massa específica, que foi de $2,78 \mathrm{~kg} / \mathrm{dm}^{3}$.

Para a areia, foi utilizado o método descrito na NBR 6508 (1984) para a determinação da massa específica, que foi de $2,644 \mathrm{~kg} / \mathrm{dm}^{3}$. O ensaio para a caracterização da areia foi realizado no Laboratório de Solos do Departamento de Transportes (STT/EESC/USP). A obtenção da massa específica pelo método descrito na NBR 6508 (1984) é mais precisa que pela utilização do “frasco de Chapman”, pois no método escolhido, consegue-se reduzir bastante o ar incorporado. Na Figura 3.19 está ilustrado o ensaio realizado.

Os modelos foram concretados em datas diferentes, devido ao volume de concreto utilizado. Após a mistura, foi realizado o ensaio de abatimento do tronco de cone, e depois o concreto foi transportado com o auxílio de carriolas até o local da concretagem. 

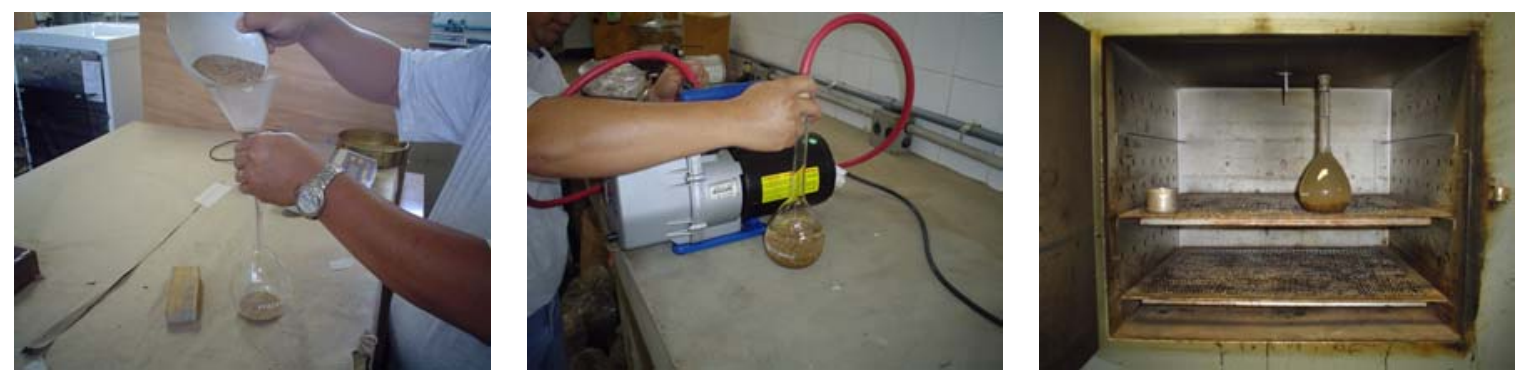

Figura 3.19: Ensaio de caracterização da areia

O lançamento do concreto nas formas foi feito com o auxílio de pás, e o adensamento foi realizado com vibrador de imersão de agulha de $25 \mathrm{~mm}$ de diâmetro. Duas horas após a concretagem, foi realizado o acabamento da superfície concretada com o auxílio de uma desempenadeira.

Na Figura 3.20 está ilustrada uma seqüência de concretagem de um dos modelos (modelo 03) utilizado no programa experimental.

Além do concreto confeccionado no Laboratório de Estruturas do SET/EESC/USP, também foi utilizado concreto usinado, conforme ilustrado na Figura 3.21, na confecção dos modelos 07, 10, 13 e 15. A opção por concreto usinado se deu pela rapidez na concretagem, uma vez que o traço não necessitaria ser executado nas dependências do Laboratório de Estruturas.

Para o concreto usinado, o transporte também se deu com o auxílio de carriolas até o local da concretagem, sendo o lançamento nas formas realizado com o auxílio de pás. Os procedimentos de concretagem e acabamento seguiram a mesma metodologia empregada nos demais modelos.

O traço utilizado na elaboração do concreto usinado não foi disponibilizado pela empresa responsável. A resistência característica à compressão aos 28 dias do concreto usinado havia sido especificada com o valor de 50 MPa e slump de $10 \pm 1$.

Os modelos 07 e 10 haviam sido inicialmente especificados com concreto de classe C35 (Tabela 3.2), porém optou-se por utilizar concreto de classe C50. A mudança pode ser justificada pela necessidade de possuir, dentre os modelos com força de compressão aplicada, amostras com concreto de resistência superior ao C35. 

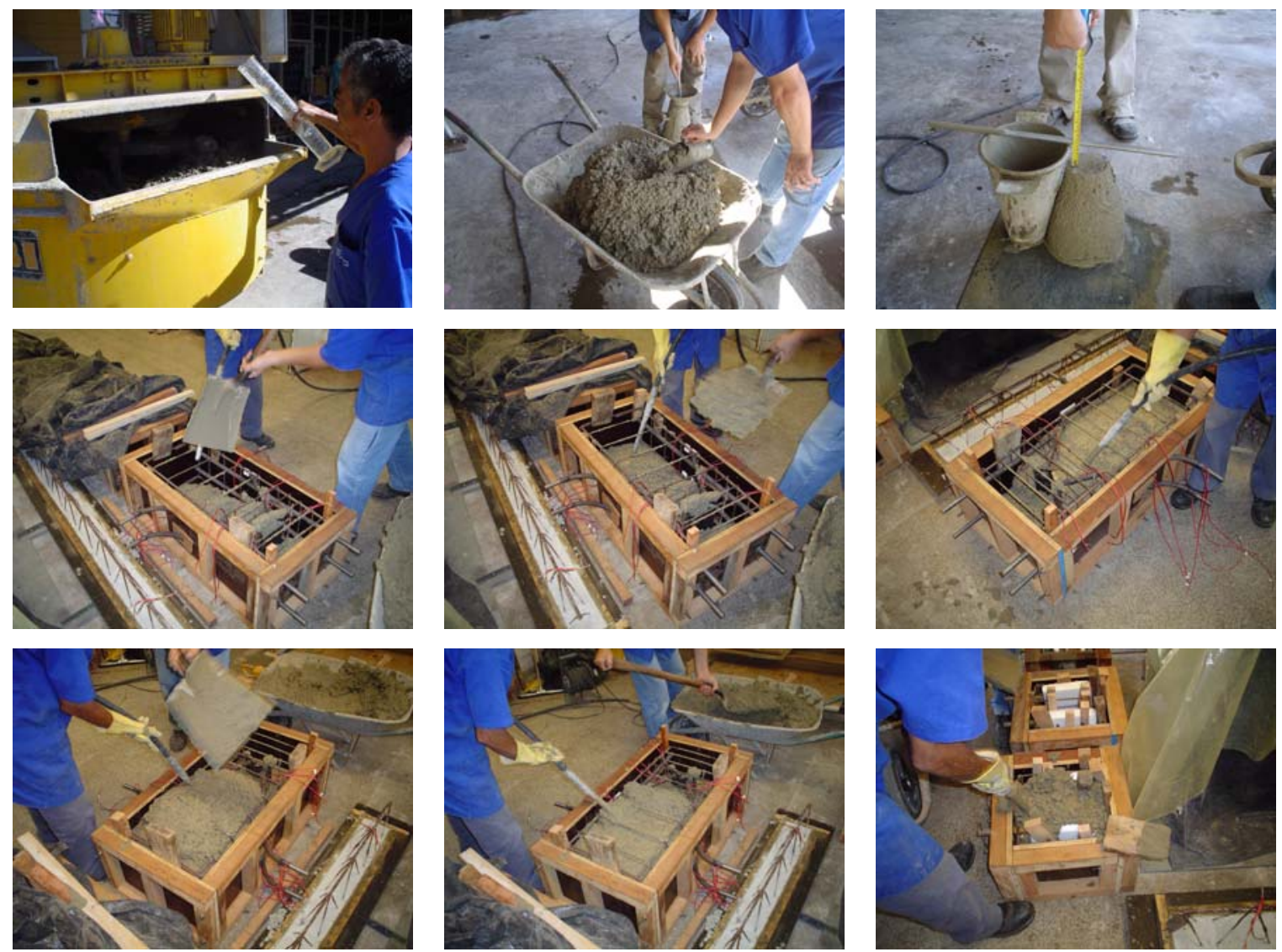

Figura 3.20: Concretagem do modelo 03.
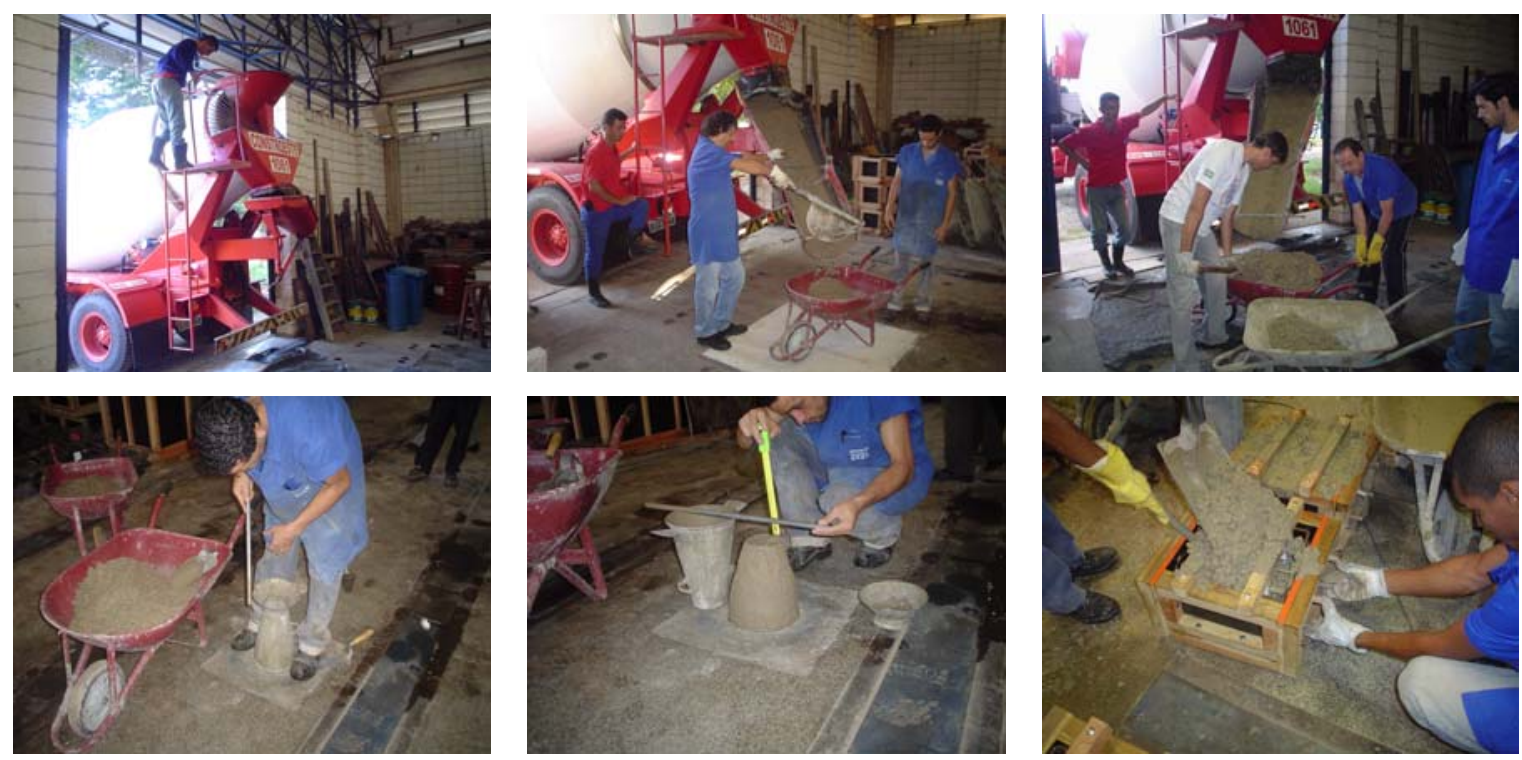

Figura 3.21: Concreto usinado utilizado na confecção dos modelos 07, 10, 13 e 15. 


\subsubsection{Graute}

Para o preenchimento dos nichos dos chumbadores, nos modelos pilotos, foi utilizado o graute da QUARTZOLIT-WEBER, denominado de “graute fácil”. O produto consiste em um concreto fluido pronto, com consumo de $2000 \mathrm{~kg} / \mathrm{m}^{3}$.

A composição do graute, segundo o fabricante, é de cimento, agregados minerais e aditivos químicos não tóxicos, inclusive fluidificantes. O graute possui densidade aparente de $1,7 \mathrm{~g} / \mathrm{cm}^{3}$.

O graute utilizado no programa experimental piloto não apresentou comportamento satisfatório, comentado oportunamente ao longo deste texto, o que conduziu à mudança do produto.

Para o programa experimental final, foi utilizado o graute da FOSROC, denominado FOSGROUT PLUS, com densidade aparente de $2,2 \mathrm{~g} / \mathrm{cm}^{3}$, consumo de $2200 \mathrm{~kg} / \mathrm{m}^{3}$ e aditivos compensadores de retração.

\subsubsection{Almofada de apoio}

O traço escolhido para a composição da almofada de apoio consiste em cimento, areia, vermiculita, látex estireno-butadieno, fibras polipropileno, aditivo superplastificante e água, conforme apresentado na Tabela 3.4.

Segundo SIQUEIRA (2007), a quantidade de látex adotada deve ser de 30\% do volume, pois quantidades maiores que estas, proporcionam queda significativa de resistência para a argamassa e, em quantidades muito menores, não apresentam modificações significativas nas propriedades do compósito.

Tabela 3.4: Traço utilizado na confecção das almofadas

Fonte: SIQUEIRA (2007)

\begin{tabular}{|c|c|c|c|c|c|c|}
\hline Cimento & Areia & Vermiculita & Látex & Fibras & Água & Aditivo \\
\hline 1 & 0,27 & 0,03 & 0,3 & $3,50 \%$ & 0,1 & 0,01 \\
\hline
\end{tabular}

Na Figura 3.22 são apresentadas fotos ilustrativas da mistura dos materiais, lançamento da argamassa e preparação para cura, respectivamente. 

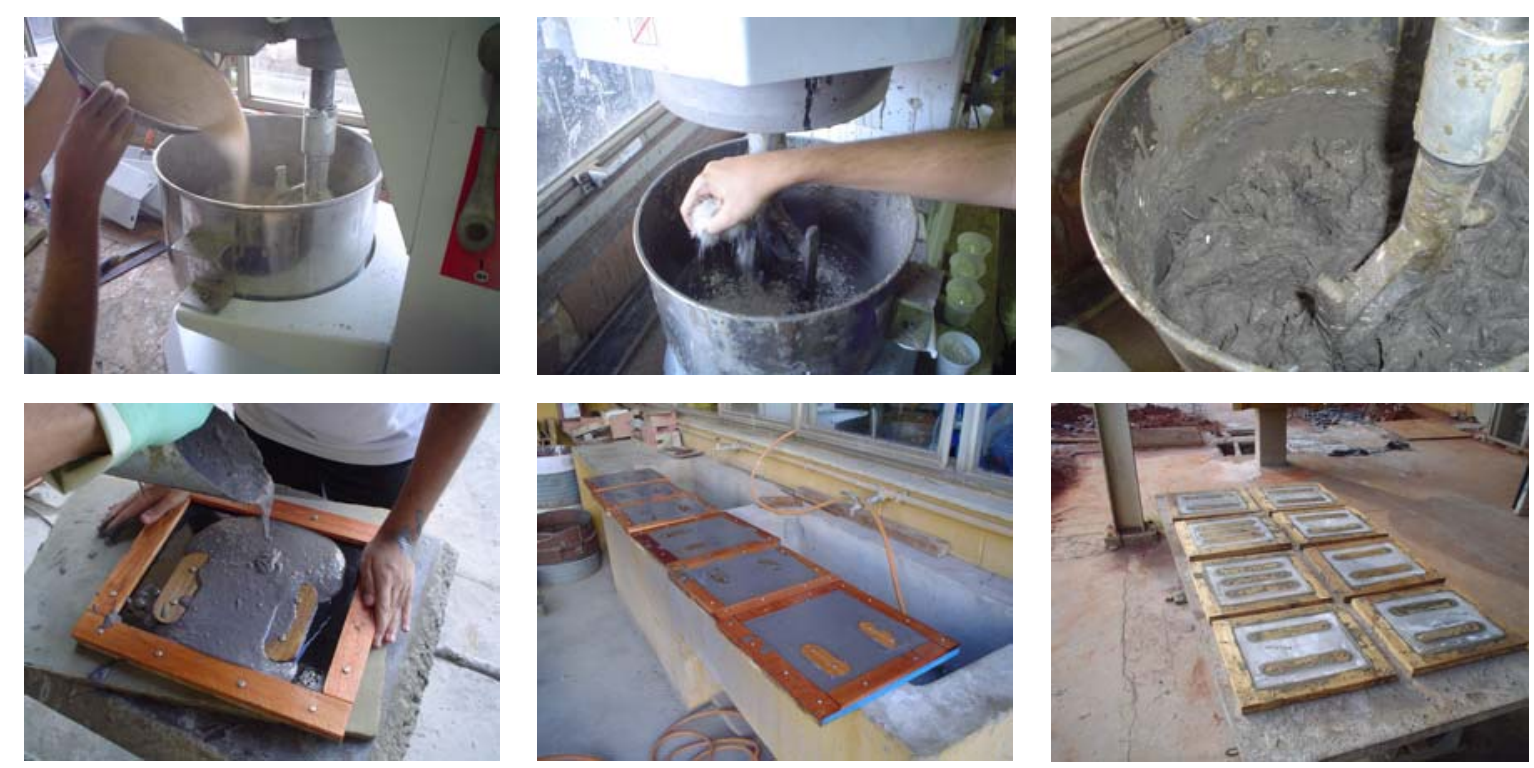

Figura 3.22: confecção das almofadas de apoio

\subsection{MONTAGEM DOS MODELOS}

Para a montagem dos modelos foi obedecida a posição dos blocos externos em relação à base dos blocos internos. Foi especificado nos modelos pilotos que as bases dos blocos externos ficariam a $200 \mathrm{~mm}$ da base do bloco interno (Figuras 3.3, 3.4 e 3.5), e nos demais modelos essa altura seria de $150 \mathrm{~mm}$ (Figuras 3.6, 3.7 e 3.8). Entre os blocos externos e o bloco interno foram posicionadas as almofadas de apoio, obedecendo o mesmo posicionamento dos blocos externos.

Após o posicionamento, os chumbadores foram solidarizados por meio de chapas de aço, fixas no modelo com o auxílio de porcas e arruelas. Na Figura 3.23 está ilustrada uma seqüência de montagem dos modelos.

Na tentativa de aplicar o mesmo torque no aperto das porcas, foi utilizado um torquímetro. A operação de uso do torquímetro (Figura 3.24) não obteve êxito, pois foi necessário aplicar torques superiores à capacidade do equipamento para que o modelo não apresentasse folgas aparentes.

Nos modelos com força de compressão aplicada, além do procedimento descrito, foram posicionadas cordoalhas de concreto protendido de 12,7 mm de diâmetro, que após protendidas, simularam a reação de apoio que a viga exerce sobre o consolo na ligação viga-pilar (Figura 3.25). 

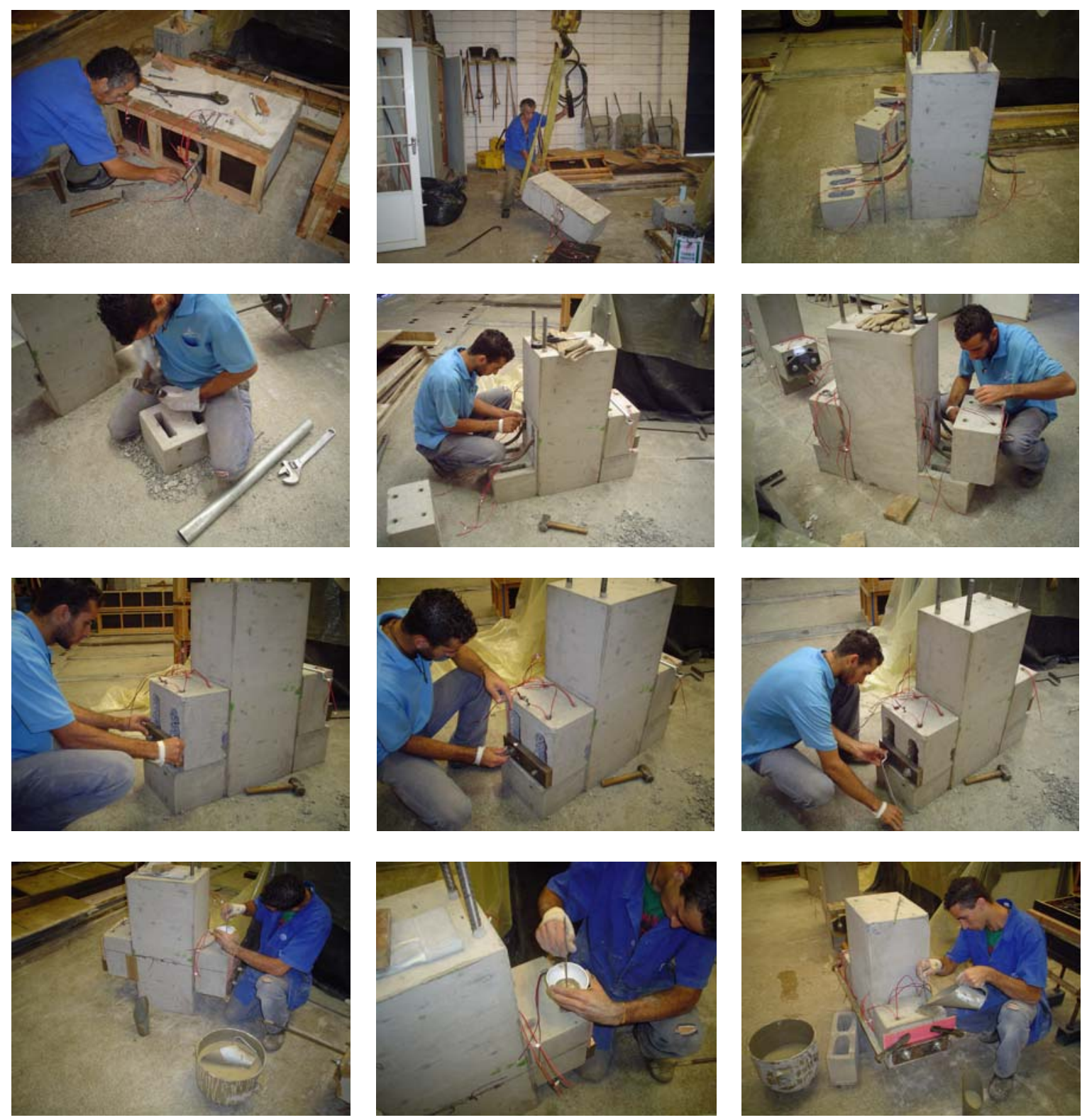

Figura 3.23: Seqüência de montagem dos modelos
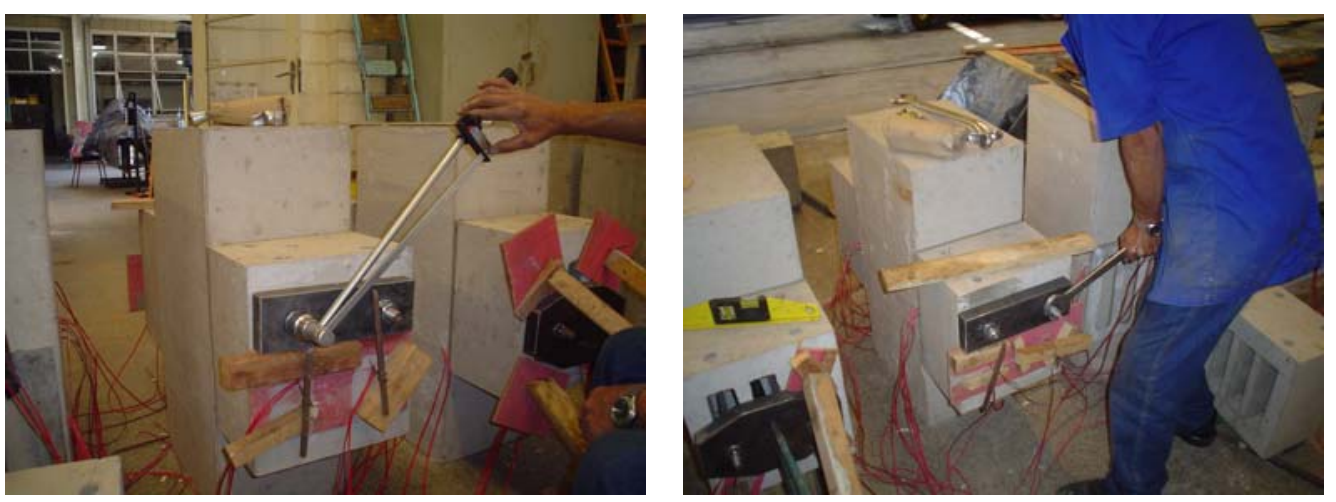

Figura 3.24: Aperto das porcas na montagem dos blocos externos 

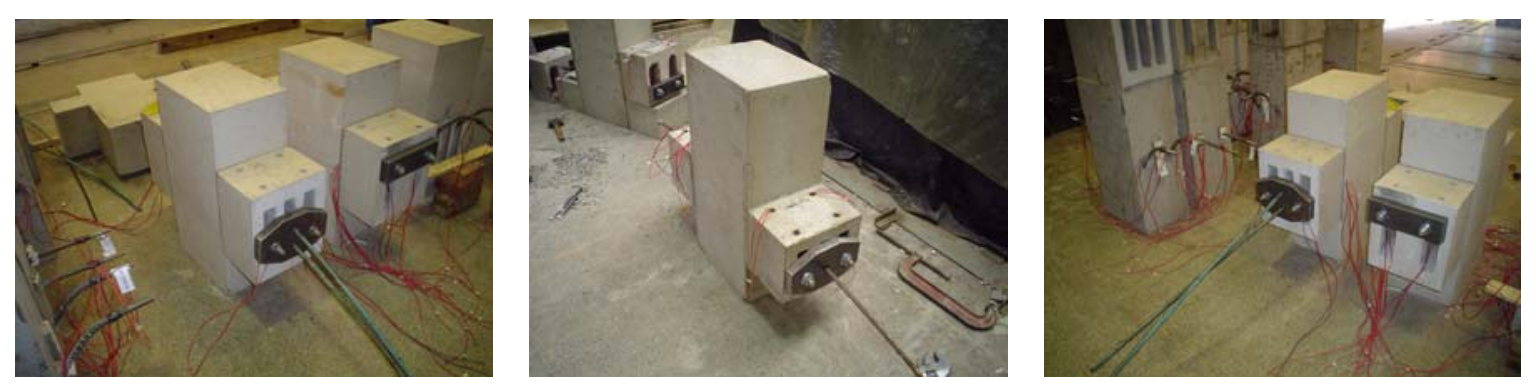

Figura 3.25: vista dos modelos com força de compressão aplicada

\subsection{PROPRIEDADES MECÂNICAS DOS MATERIAIS}

\subsubsection{Concreto}

As propriedades mecânicas do concreto aqui apresentadas, referem-se às obtidas com o concreto utilizado na confecção dos modelos destinados ao programa experimental, e foram obtidas por meio de corpos-de-prova cilíndricos de 150 mm x 300 mm, desformados um dia após a concretagem, e mantidos na câmera úmida até a data dos ensaios.

Para a determinação da resistência à compressão, no programa experimental piloto, foram empregados dois corpos-de-prova de concreto por cada data de rompimento. Para o traço empregado, a resistência foi medida aos 3, 7, 21 e 28 dias, apenas para o primeiro modelo concretado (modelo 02). Para a data do ensaio dos modelos, foram reservados três corpos-de-prova para a determinação da resistência à compressão, três para a determinação do módulo de elasticidade e mais três para o ensaio de tração por compressão diametral.

Os valores das resistências à compressão dos corpos-de-prova foram calculados de acordo com a expressão (3.1).

$$
f_{c j}=\frac{N}{A}
$$

Sendo que:

$f_{c j}$ - Resistência à compressão dos corpos-de-prova na data “j” dias;

$N$ - Força;

A - Área da seção transversal do corpo-de-prova. 
Para o cálculo da resistência à tração por compressão diametral dos corpos-de-prova, foi utilizada a expressão (3.2). O módulo de elasticidade tangente foi obtido de acordo com o que preconiza a NBR 8522:1984.

$$
f_{c t, s p}=\frac{2 F_{j}}{\pi \cdot d_{j} \cdot h} \cdot 0,85
$$

Sendo que:

$f_{c t, s p}$ - Resistência à tração por compressão diametral;

$F_{j} \quad$ - Força máxima;

$d_{j} \quad$ - Diâmetro do corpo-de-prova;

$h$ - Comprimento do corpo-de-prova.

O ensaio de compressão foi realizado no Laboratório de Estruturas do SET/EESC/USP, na máquina de ensaio ELE-AUTOTEST 2000, onde a carga foi aplicada com velocidade constante de 5,30 kN/segundo para corpos-de-prova de $150 \mathrm{~mm}$ x 300mm; 2,40 kN/segundo para corpos-de-prova de $100 \mathrm{~mm}$ x 200mm e 0,50 kN/segundo para corpos-de-prova de 50mm x 100mm.

Na Figura 3.26 são apresentadas as fotos dos corpos-de-prova em câmara úmida, assim como o ensaio de rompimento realizado.
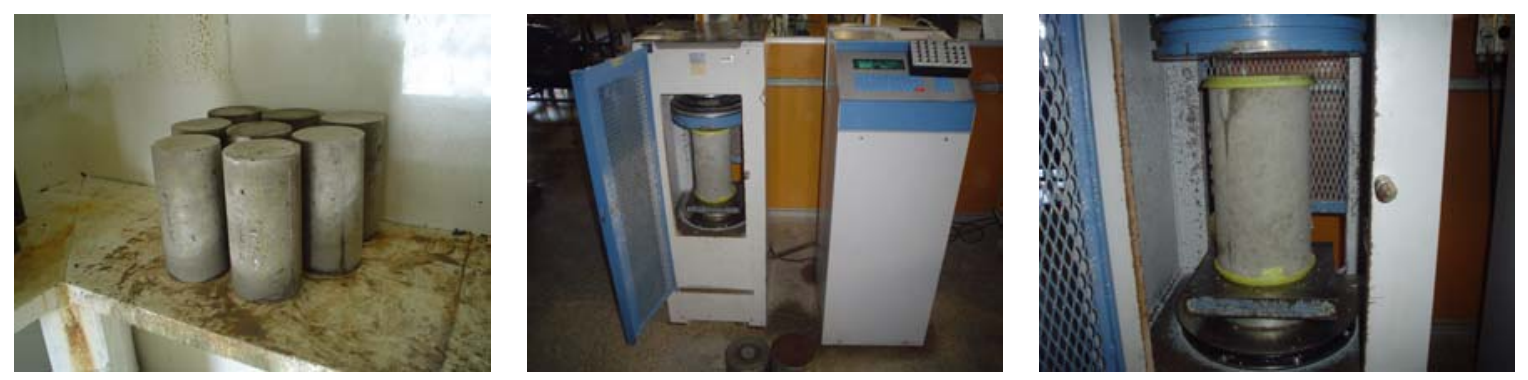

Figura 3.26: Cura e rompimento dos corpos-de-prova

A evolução da resistência média nas primeiras idades observada nos corpos-de-prova para o concreto C35, lançado no Modelo 02, estão apresentadas na Tabela 3.5. 
Tabela 3.5: Evolução da resistência à compressão nas primeiras idades (Modelo 02)

\begin{tabular}{|c|c|c|c|}
\hline Corpo-de-Prova & Idade & Tensão & Tensão média \\
\hline CP-01 & \multirow[b]{2}{*}{3 dias } & 32,31 MPa & \multirow[b]{2}{*}{ 31,59 MPa } \\
\hline CP-02 & & 30,87 MPa & \\
\hline CP-03 & \multirow[b]{2}{*}{7 dias } & 37,19 MPa & \multirow[b]{2}{*}{ 37,26 MPa } \\
\hline CP-04 & & 37,32 MPa & \\
\hline CP-05 & \multirow[b]{2}{*}{21 dias } & $44,12 \mathrm{MPa}$ & \multirow[b]{2}{*}{ 44,90 MPa } \\
\hline CP-06 & & 45,67 MPa & \\
\hline CP-07 & \multirow[b]{2}{*}{28 dias } & 47,20 MPa & \multirow[b]{2}{*}{ 47,92 MPa } \\
\hline CР-08 & & 48,63 MPa & \\
\hline
\end{tabular}

Na Tabela 3.6 são apresentadas as resistências à compressão medidas nos corpos-de-prova na data da realização dos ensaios de cada modelo, assim como os slumps medidos durante a concretagem.

Tabela 3.6: Resistência à compressão do concreto na data dos ensaios dos modelos

\begin{tabular}{|c|c|c|c|c|}
\hline MODELO & $\begin{array}{l}\text { Corpo-de- } \\
\text { Prova }\end{array}$ & $\begin{array}{l}\text { slump } \\
\text { (cm) }\end{array}$ & $\begin{array}{l}\text { Tensão } \\
\text { (MPa) }\end{array}$ & $\begin{array}{c}\text { Tensão } \\
\text { média (MPa) }\end{array}$ \\
\hline \multirow{3}{*}{$\begin{array}{c}01 \\
\text { C35 }\end{array}$} & CP-01 & \multirow{3}{*}{7,5} & 58,71 & \multirow{3}{*}{55,86} \\
\hline & CP-02 & & 54,81 & \\
\hline & CP-03 & & 54,07 & \\
\hline \multirow{3}{*}{$\begin{array}{c}02 \\
\text { C35 }\end{array}$} & CP-01 & \multirow{3}{*}{8,9} & 56,51 & \multirow{3}{*}{56,25} \\
\hline & CP-02 & & 56,51 & \\
\hline & CP-03 & & 55,72 & \\
\hline \multirow{3}{*}{$\begin{array}{c}03 \\
\text { C35 }\end{array}$} & CP-01 & \multirow{3}{*}{6,5} & 65,03 & \multirow{3}{*}{62,64} \\
\hline & CP-02 & & 60,63 & \\
\hline & CP-03 & & 62,26 & \\
\hline \multirow{3}{*}{$\begin{array}{c}04 \\
\text { C35 }\end{array}$} & CP-01 & \multirow{3}{*}{8,0} & 47,17 & \multirow{3}{*}{47,67} \\
\hline & CP-02 & & 49,16 & \\
\hline & CP-03 & & 46,68 & \\
\hline \multirow{3}{*}{$\begin{array}{c}05 \\
\text { C35 }\end{array}$} & CP-01 & \multirow{3}{*}{8,0} & 47,17 & \multirow{3}{*}{47,67} \\
\hline & CP-02 & & 49,16 & \\
\hline & CP-03 & & 46,68 & \\
\hline \multirow{3}{*}{$\begin{array}{c}06 \\
\text { C35 }\end{array}$} & CP-01 & \multirow{3}{*}{7,5} & 58,71 & \multirow{3}{*}{55,86} \\
\hline & CP-02 & & 54,81 & \\
\hline & CP-03 & & 54,07 & \\
\hline \multirow{3}{*}{$\begin{array}{c}07 \\
\text { C35 }\end{array}$} & CP-01 & \multirow{3}{*}{6,5} & 59,71 & \multirow{3}{*}{59,91} \\
\hline & CP-02 & & 60,61 & \\
\hline & CP-03 & & 59,41 & \\
\hline \multirow{3}{*}{$\begin{array}{c}08 \\
\text { C35 }\end{array}$} & CP-01 & \multirow{3}{*}{4,5} & 50,52 & \multirow{3}{*}{53,67} \\
\hline & CP-02 & & 53,12 & \\
\hline & CP-03 & & 57,36 & \\
\hline
\end{tabular}

\begin{tabular}{|c|c|c|c|c|}
\hline MODELO & $\begin{array}{l}\text { Corpo-de- } \\
\text { Prova }\end{array}$ & $\begin{array}{l}\text { slump } \\
\text { (cm) }\end{array}$ & $\begin{array}{l}\text { Tensão } \\
\text { (MPa) }\end{array}$ & $\begin{array}{c}\text { Tensão } \\
\text { média (MPa) }\end{array}$ \\
\hline \multirow{3}{*}{$\begin{array}{c}09 \\
\text { C35 }\end{array}$} & CP-01 & \multirow{3}{*}{7,5} & 58,71 & \multirow{3}{*}{55,86} \\
\hline & CP-02 & & 54,81 & \\
\hline & CP-03 & & 54,07 & \\
\hline \multirow{3}{*}{$\begin{array}{c}10 \\
\text { C35 }\end{array}$} & CP-01 & \multirow{3}{*}{6,7} & 59,71 & \multirow{3}{*}{59,91} \\
\hline & CP-02 & & 60,61 & \\
\hline & CP-03 & & 59,41 & \\
\hline \multirow{3}{*}{$\begin{array}{c}11 \\
\text { C35 }\end{array}$} & CP-01 & \multirow{3}{*}{8,9} & 47,17 & \multirow{3}{*}{47,67} \\
\hline & CP-02 & & 49,16 & \\
\hline & CP-03 & & 46,68 & \\
\hline \multirow{3}{*}{$\begin{array}{c}12 \\
\text { C35 }\end{array}$} & CP-01 & \multirow{3}{*}{8,9} & 47,17 & \multirow{3}{*}{47,67} \\
\hline & CР-02 & & 49,16 & \\
\hline & CP-03 & & 46,68 & \\
\hline \multirow{3}{*}{$\begin{array}{c}13 \\
\text { C50 }\end{array}$} & CP-01 & \multirow{3}{*}{6,7} & 59,71 & \multirow{3}{*}{59,91} \\
\hline & CP-02 & & 60,61 & \\
\hline & CP-03 & & 59,41 & \\
\hline \multirow{3}{*}{$\begin{array}{c}14 \\
\text { C50 }\end{array}$} & CP-01 & \multirow{3}{*}{5,8} & 64,06 & \multirow{3}{*}{64,24} \\
\hline & CP-02 & & 61,69 & \\
\hline & CP-03 & & 66,97 & \\
\hline \multirow{3}{*}{$\begin{array}{l}15 \\
\text { C50 }\end{array}$} & CР-01 & \multirow{3}{*}{6,7} & 59,71 & \multirow{3}{*}{59,91} \\
\hline & CP-02 & & 60,61 & \\
\hline & CP-03 & & 59,41 & \\
\hline \multicolumn{5}{|c|}{$\begin{array}{l}\text { Os modelos } 02,03 \text { e } 08 \text { pertencem ao programa } \\
\text { experimental piloto. }\end{array}$} \\
\hline
\end{tabular}

Foi medida também a resistência à tração por compressão diametral na data dos ensaios dos modelos. Os valores obtidos estão apresentados na Tabela 3.7. 
O ensaio de tração também foi realizado no Laboratório de Estruturas do SET/EESC/USP, na máquina de ensaio ELE-AUTOTEST 2000, onde a carga foi aplicada a uma velocidade constante de $2,10 \mathrm{kN} /$ segundo.

Tabela 3.7: Resistência à tração do concreto na data dos ensaios dos modelos

\begin{tabular}{|c|c|c|c|c|}
\hline MODELO & $\begin{array}{l}\text { Corpo-de- } \\
\text { Prova }\end{array}$ & $\begin{array}{l}\text { slump } \\
\text { (cm) }\end{array}$ & $\begin{array}{l}\text { Tensão } \\
\text { (MPa) }\end{array}$ & $\begin{array}{c}\text { Tensão } \\
\text { média (MPa) }\end{array}$ \\
\hline \multirow{3}{*}{$\begin{array}{c}01 \\
\text { C35 }\end{array}$} & CP-01 & \multirow{3}{*}{7,5} & 2,97 & \multirow{3}{*}{2,90} \\
\hline & CP-02 & & 3,02 & \\
\hline & CP-03 & & 2,72 & \\
\hline \multirow{3}{*}{$\begin{array}{c}02 \\
\text { C35 }\end{array}$} & CP-01 & \multirow{3}{*}{8,9} & 3,16 & \multirow{3}{*}{3,27} \\
\hline & CP-02 & & 3,30 & \\
\hline & CP-03 & & 3,36 & \\
\hline \multirow{3}{*}{$\begin{array}{c}03 \\
\text { C35 }\end{array}$} & CP-01 & \multirow{3}{*}{6,5} & 3,15 & \multirow{3}{*}{3,34} \\
\hline & CP-02 & & 3,10 & \\
\hline & CP-03 & & 3,78 & \\
\hline \multirow{3}{*}{$\begin{array}{c}04 \\
\text { C35 }\end{array}$} & CP-01 & \multirow{3}{*}{8,0} & 2,99 & \multirow{3}{*}{2,54} \\
\hline & CP-02 & & 2,52 & \\
\hline & CP-03 & & 2,10 & \\
\hline \multirow{3}{*}{$\begin{array}{c}05 \\
\text { C35 }\end{array}$} & CP-01 & \multirow{3}{*}{8,0} & 2,99 & \multirow{3}{*}{2,54} \\
\hline & CP-02 & & 2,52 & \\
\hline & CP-03 & & 2,10 & \\
\hline \multirow{3}{*}{$\begin{array}{c}06 \\
\text { C35 }\end{array}$} & CP-01 & \multirow{3}{*}{7,5} & 2,97 & \multirow{3}{*}{2,90} \\
\hline & CP-02 & & 3,02 & \\
\hline & CP-03 & & 2,72 & \\
\hline \multirow{3}{*}{$\begin{array}{c}07 \\
\text { C35 }\end{array}$} & CP-01 & \multirow{3}{*}{6,5} & 3,01 & \multirow{3}{*}{3,37} \\
\hline & CP-02 & & 3,93 & \\
\hline & CP-03 & & 3,17 & \\
\hline \multirow{3}{*}{$\begin{array}{c}08 \\
\text { C35 }\end{array}$} & CP-01 & \multirow{3}{*}{4,5} & 4,54 & \multirow{3}{*}{4,55} \\
\hline & CP-02 & & 4,69 & \\
\hline & CP-03 & & 4,42 & \\
\hline
\end{tabular}

\begin{tabular}{|c|c|c|c|c|}
\hline MODELO & $\begin{array}{l}\text { Corpo-de- } \\
\text { Prova }\end{array}$ & $\begin{array}{c}\text { slump } \\
(\mathrm{cm})\end{array}$ & $\begin{array}{l}\text { Tensão } \\
\text { (MPa) }\end{array}$ & $\begin{array}{c}\text { Tensão } \\
\text { média (MPa) }\end{array}$ \\
\hline \multirow{3}{*}{$\begin{array}{c}09 \\
\text { C35 }\end{array}$} & CP-01 & \multirow{3}{*}{7,5} & 2,97 & \multirow{3}{*}{2,90} \\
\hline & CP-02 & & 3,02 & \\
\hline & CP-03 & & 2,72 & \\
\hline \multirow{3}{*}{$\begin{array}{c}10 \\
\text { C35 }\end{array}$} & СР-01 & \multirow{3}{*}{6,7} & 3,01 & \multirow{3}{*}{3,37} \\
\hline & CP-02 & & 3,93 & \\
\hline & CP-03 & & 3,17 & \\
\hline \multirow{3}{*}{$\begin{array}{c}11 \\
\text { C35 }\end{array}$} & CP-01 & \multirow{3}{*}{8,9} & 2,99 & \multirow{3}{*}{2,54} \\
\hline & CP-02 & & 2,52 & \\
\hline & CP-03 & & 2,10 & \\
\hline \multirow{3}{*}{$\begin{array}{c}12 \\
\text { C35 }\end{array}$} & CP-01 & \multirow{3}{*}{8,9} & 2,99 & \multirow{3}{*}{2,54} \\
\hline & CP-02 & & 2,52 & \\
\hline & CP-03 & & 2,10 & \\
\hline \multirow{3}{*}{$\begin{array}{l}13 \\
\text { C50 }\end{array}$} & CP-01 & \multirow{3}{*}{6,7} & 3,01 & \multirow{3}{*}{3,37} \\
\hline & CP-02 & & 3,93 & \\
\hline & CP-03 & & 3,17 & \\
\hline \multirow{3}{*}{$\begin{array}{c}14 \\
\text { C50 }\end{array}$} & CP-01 & \multirow{3}{*}{5,8} & 3,15 & \multirow{3}{*}{3,34} \\
\hline & CP-02 & & 3,10 & \\
\hline & CP-03 & & 3,78 & \\
\hline \multirow{3}{*}{$\begin{array}{l}15 \\
\text { C50 }\end{array}$} & CP-01 & \multirow{3}{*}{6,7} & 3,01 & \multirow{3}{*}{3,37} \\
\hline & CP-02 & & 3,93 & \\
\hline & CP-03 & & 3,17 & \\
\hline \multicolumn{5}{|c|}{$\begin{array}{l}\text { Os modelos } 02,03 \text { e } 08 \text { pertencem ao programa } \\
\text { experimental piloto. }\end{array}$} \\
\hline
\end{tabular}

Na Tabela 3.8 são apresentados os valores obtidos nos ensaios de módulos de elasticidade (Figura 3.27) para os modelos ensaiados.
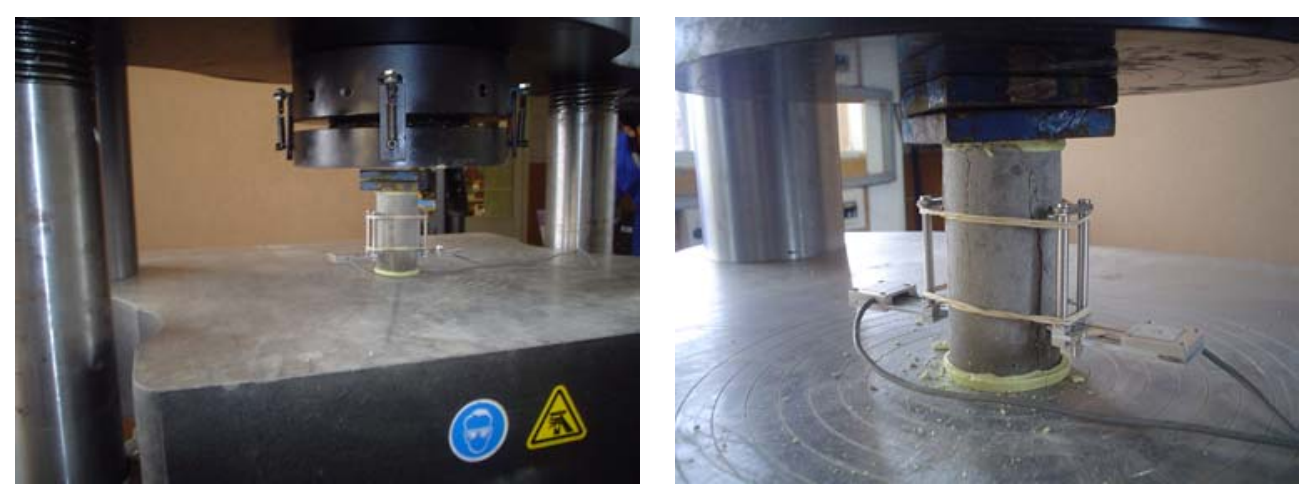

Figura 3.27: Ensaios para a determinação do módulo de elasticidade 
Tabela 3.8: Módulo de elasticidade do concreto para os modelos

\begin{tabular}{|c|c|c|c|}
\hline MODELO & $\begin{array}{c}\text { Corpo-de- } \\
\text { Prova }\end{array}$ & $\begin{array}{c}\text { Módulo de } \\
\text { Elasticidade } \\
\text { (GPa) }\end{array}$ & $\begin{array}{c}\mathrm{E}_{\mathrm{C}} \\
\text { média } \\
(\mathrm{GPa})\end{array}$ \\
\hline \multirow{3}{*}{$\begin{array}{c}01 \\
\text { C35 }\end{array}$} & CP-01 & 30,1 & \multirow{3}{*}{30,5} \\
\hline & CP-02 & 30,9 & \\
\hline & CP-03 & 30,5 & \\
\hline \multirow{3}{*}{$\begin{array}{c}02 \\
C 35\end{array}$} & CP-01 & 31,8 & \multirow{3}{*}{32,0} \\
\hline & CP-02 & 32,5 & \\
\hline & CP-03 & 31,6 & \\
\hline \multirow{3}{*}{$\begin{array}{c}03 \\
\text { C35 }\end{array}$} & CP-01 & 34,6 & \multirow{3}{*}{34,6} \\
\hline & CP-02 & 35,2 & \\
\hline & CP-03 & 33,9 & \\
\hline \multirow{3}{*}{$\begin{array}{c}04 \\
C 35\end{array}$} & CP-01 & 34,2 & \multirow{3}{*}{34,1} \\
\hline & CP-02 & 35,2 & \\
\hline & CP-03 & 32,9 & \\
\hline \multirow{3}{*}{$\begin{array}{c}05 \\
\text { C35 }\end{array}$} & CP-01 & 34,2 & \multirow{3}{*}{34,1} \\
\hline & CP-02 & 35,2 & \\
\hline & CP-03 & 32,9 & \\
\hline \multirow{3}{*}{$\begin{array}{c}06 \\
\text { C35 }\end{array}$} & CP-01 & 30,1 & \multirow{3}{*}{30,5} \\
\hline & CP-02 & 30,9 & \\
\hline & CP-03 & 30,5 & \\
\hline \multirow{3}{*}{$\begin{array}{c}07 \\
\text { C35 }\end{array}$} & CP-01 & 39,2 & \multirow{3}{*}{38,8} \\
\hline & CP-02 & 37,8 & \\
\hline & CP-03 & 39,5 & \\
\hline \multirow{3}{*}{$\begin{array}{c}08 \\
\text { C35 }\end{array}$} & CP-01 & 38,7 & \multirow{3}{*}{39,3} \\
\hline & CP-02 & 39,0 & \\
\hline & CP-03 & 40,2 & \\
\hline
\end{tabular}

\begin{tabular}{|c|c|c|c|}
\hline MODELO & $\begin{array}{l}\text { Corpo-de- } \\
\text { Prova }\end{array}$ & $\begin{array}{l}\text { Módulo de } \\
\text { Elasticidade } \\
\text { (GPa) }\end{array}$ & $\begin{array}{c}\mathrm{E}_{\mathrm{C}} \\
\text { média } \\
(\mathrm{GPa})\end{array}$ \\
\hline \multirow{3}{*}{$\begin{array}{c}09 \\
\text { C35 }\end{array}$} & CP-01 & 30,1 & \multirow{3}{*}{30,5} \\
\hline & CP-02 & 30,9 & \\
\hline & CP-03 & 30,5 & \\
\hline \multirow{3}{*}{$\begin{array}{c}10 \\
\text { C35 }\end{array}$} & CP-01 & 39,2 & \multirow{3}{*}{38,8} \\
\hline & CP-02 & 37,8 & \\
\hline & CP-03 & 39,5 & \\
\hline \multirow{3}{*}{$\begin{array}{c}11 \\
C 35\end{array}$} & CP-01 & 34,2 & \multirow{3}{*}{34,1} \\
\hline & $\overline{\mathrm{CP}-02}$ & 35,2 & \\
\hline & CP-03 & 32,9 & \\
\hline \multirow{3}{*}{$\begin{array}{c}12 \\
C 35\end{array}$} & CP-01 & 34,2 & \multirow{3}{*}{34,1} \\
\hline & CP-02 & 35,2 & \\
\hline & CP-03 & 32,9 & \\
\hline \multirow{3}{*}{$\begin{array}{c}13 \\
\text { C50 }\end{array}$} & CP-01 & 39,2 & \multirow{3}{*}{38,8} \\
\hline & CP-02 & 37,8 & \\
\hline & CP-03 & 39,5 & \\
\hline \multirow{3}{*}{$\begin{array}{l}14 \\
\text { C50 }\end{array}$} & CP-01 & 35,2 & \multirow{3}{*}{35,6} \\
\hline & CP-02 & 35,4 & \\
\hline & CP-03 & 36,3 & \\
\hline \multirow{3}{*}{$\begin{array}{l}15 \\
\mathrm{C} 50\end{array}$} & CP-01 & 39,2 & \multirow{3}{*}{38,8} \\
\hline & CP-02 & 37,8 & \\
\hline & CР-03 & 39,5 & \\
\hline \multicolumn{4}{|c|}{$\begin{array}{l}\text { Os modelos } 02,03 \text { e } 08 \text { pertencem ao programa } \\
\text { experimental piloto. }\end{array}$} \\
\hline
\end{tabular}

\subsubsection{Armadura}

O aço utilizado foi do tipo CA-50, e as barras ensaiadas foram as de $\phi 6,3 \mathrm{~mm}$; $\phi 10 \mathrm{~mm} ; \phi 16 \mathrm{~mm} ; \phi 20 \mathrm{~mm}$ e $\phi 25 \mathrm{~mm}$.

As propriedades mecânicas do aço foram obtidas na máquina servo-controlada INSTRON 8506 para todos os diâmetros utilizados. A velocidade de aplicação da solicitação foi de $0,05 \mathrm{~mm} /$ segundos.

Na Figura 3.28 é apresentado o aspecto geral do ensaio, realizado no Laboratório de Estruturas do SET/EESC/USP. 

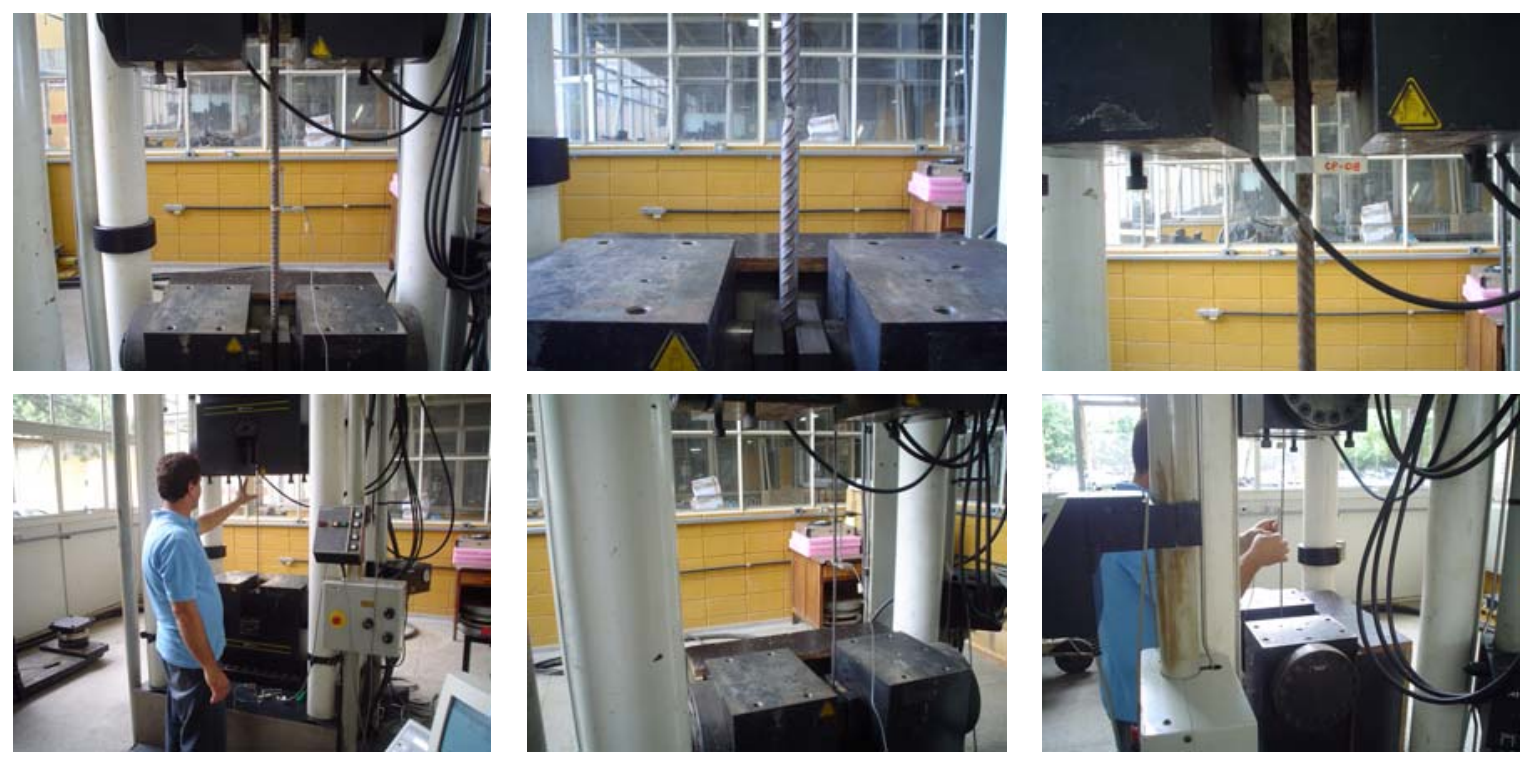

Figura 3.28: Ensaio de caracterização do aço.

Na tabela 3.9 estão indicados os valores da tensão de escoamento $\left(\mathrm{f}_{\mathrm{y}}\right)$ e ruína $\left(\mathrm{f}_{\mathrm{u}}\right)$ para cada diâmetro. Foram ensaiadas três amostras do mesmo diâmetro por cada lote. O módulo de elasticidade não foi determinado no ensaio, sendo adotado como igual a $210 \mathrm{GPa}$.

Tabela 3.9: Propriedades mecânicas dos aços

\begin{tabular}{|c|c|c|c|}
\hline Diâmetro & Corpo-de-prova & $f_{y}(M P a)$ & $f_{u}(M P a)$ \\
\hline \multirow{4}{*}{$6,3 \mathrm{~mm}$} & CP 1 & 706 & 850 \\
\hline & CP 2 & 742 & 876 \\
\hline & CP 3 & 738 & 894 \\
\hline & Média & 729 & 873 \\
\hline \multirow{4}{*}{$10 \mathrm{~mm}$} & CP 4 & 644 & 740 \\
\hline & CP 5 & 626 & 736 \\
\hline & CP 6 & 648 & 746 \\
\hline & Média & 639 & 741 \\
\hline \multirow{4}{*}{$16 \mathrm{~mm}$} & CP 7 & 612 & 744 \\
\hline & CP 8 & 609 & 739 \\
\hline & CP 9 & 618 & 748 \\
\hline & Média & 613 & 744 \\
\hline \multirow{4}{*}{$20 \mathrm{~mm}$} & CP 7 & 614 & 741 \\
\hline & CP 8 & 607 & 738 \\
\hline & CP 9 & 612 & 743 \\
\hline & Média & 611 & 741 \\
\hline \multirow{4}{*}{$25 \mathrm{~mm}$} & $\mathrm{CP} 7$ & 607 & 732 \\
\hline & CP 8 & 604 & 729 \\
\hline & СР 9 & 601 & 731 \\
\hline & Média & 604 & 731 \\
\hline
\end{tabular}




\subsubsection{Graute}

As características mecânicas do graute empregado nos modelos estão apresentadas na Tabela 3.10. Para a determinação de tais características, foram moldados corpos-de-prova de 50mm x 100mm, que ficaram em câmara úmida até a data do ensaio.

Foi utilizado um fator água/graute de 0,200 em todos os modelos. O objetivo era de aumentar a fluidez e facilitar assim o grauteamento dos nichos. $\mathrm{O}$ fator recomendado pelo fabricante é de 0,126.

Tabela 3.10: Características mecânicas do graute empregado

\begin{tabular}{|c|c|c|c|}
\hline MODELO & $\begin{array}{l}\text { Resistência à } \\
\text { Tração } \\
\text { (MPa) }\end{array}$ & $\begin{array}{c}\text { Resistência à } \\
\text { Compressão } \\
\text { (MPa) }\end{array}$ & $\begin{array}{l}\text { Módulo de } \\
\text { Elasticidade } \\
\text { (GPa) }\end{array}$ \\
\hline \multirow{3}{*}{01} & 3,85 & 41,83 & 26,7 \\
\hline & 3,22 & 43,72 & 26,4 \\
\hline & 3,33 & 42,97 & 25,9 \\
\hline Média & 3,47 & 42,84 & 26,3 \\
\hline \multirow{3}{*}{02} & 2,28 & 26,02 & 27,1 \\
\hline & 2,51 & 29,07 & 24,9 \\
\hline & 2,43 & 38,96 & 25,5 \\
\hline Média & 2,41 & 31,35 & 25,8 \\
\hline \multirow{3}{*}{03} & 3,03 & 45,70 & 28,1 \\
\hline & 2,51 & 39,22 & 29,6 \\
\hline & 2,11 & 43,68 & 27,7 \\
\hline Média & 2,55 & 42,87 & 28,5 \\
\hline \multirow{3}{*}{04} & 2,28 & 26,02 & 27,1 \\
\hline & 2,51 & 29,07 & 24,9 \\
\hline & 2,43 & 38,96 & 25,5 \\
\hline Média & 2,41 & 31,35 & 25,8 \\
\hline \multirow{3}{*}{05} & 3,03 & 45,70 & 28,1 \\
\hline & 2,51 & 39,22 & 29,6 \\
\hline & 2,11 & 43,68 & 27,7 \\
\hline Média & 2,55 & 42,87 & 28,5 \\
\hline \multirow{3}{*}{06} & 3,85 & 41,83 & 26,7 \\
\hline & 3,22 & 43,72 & 26,4 \\
\hline & 3,33 & 42,97 & 25,9 \\
\hline Média & 3,47 & 42,84 & 26,3 \\
\hline \multirow{3}{*}{07} & 2,25 & 38,12 & 32,0 \\
\hline & 3,43 & 42,36 & 33,4 \\
\hline & 3,21 & 41,08 & 29,9 \\
\hline Média & 2,96 & 40,52 & 31,8 \\
\hline \multirow{3}{*}{08} & 2,28 & 26,02 & 27,1 \\
\hline & 2,51 & 29,07 & 24,9 \\
\hline & 2,43 & 38,96 & 25,5 \\
\hline Média & 2,41 & 31,35 & 25,8 \\
\hline
\end{tabular}

\begin{tabular}{|c|c|c|c|}
\hline MODELO & $\begin{array}{l}\text { Resistência à } \\
\text { Tração } \\
\text { (MPa) }\end{array}$ & $\begin{array}{l}\text { Resistência à } \\
\text { Compressão } \\
\text { (MPa) }\end{array}$ & $\begin{array}{l}\text { Módulo de } \\
\text { Elasticidade } \\
\text { (GPa) }\end{array}$ \\
\hline \multirow{3}{*}{09} & 3,37 & 39,70 & 27,9 \\
\hline & 3,34 & 41,02 & 28,4 \\
\hline & 3,11 & 40,29 & 29,1 \\
\hline Média & 3,27 & 40,34 & 28,5 \\
\hline \multirow{3}{*}{10} & 3,37 & 39,70 & 27,9 \\
\hline & 3,34 & 41,02 & 28,4 \\
\hline & 3,11 & 40,29 & 29,1 \\
\hline Média & 3,27 & 40,34 & 28,5 \\
\hline \multirow{3}{*}{11} & 3,03 & 45,70 & 28,1 \\
\hline & 2,51 & 39,22 & 29,6 \\
\hline & 2,11 & 43,68 & 27,7 \\
\hline Média & 2,55 & 42,87 & 28,5 \\
\hline \multirow{3}{*}{12} & 3,37 & 39,70 & 27,9 \\
\hline & 3,34 & 41,02 & 28,4 \\
\hline & 3,11 & 40,29 & 29,1 \\
\hline Média & 3,27 & 40,34 & 28,5 \\
\hline \multirow{3}{*}{13} & 2,25 & 38,12 & 32,0 \\
\hline & 3,43 & 42,36 & 33,4 \\
\hline & 3,21 & 41,08 & 29,9 \\
\hline Média & 2,96 & 40,52 & 31,8 \\
\hline \multirow{3}{*}{14} & 3,85 & 41,83 & 26,7 \\
\hline & 3,22 & 43,72 & 26,4 \\
\hline & 3,33 & 42,97 & 25,9 \\
\hline Média & 3,47 & 42,84 & 26,3 \\
\hline \multirow{3}{*}{15} & 2,25 & 38,12 & 32,0 \\
\hline & 3,43 & 42,36 & 33,4 \\
\hline & 3,21 & 41,08 & 29,9 \\
\hline Média & 2,96 & 40,52 & 31,8 \\
\hline \multicolumn{4}{|c|}{$\begin{array}{l}\text { Os modelos } 02,03 \text { e } 08 \text {, pertencentes ao programa } \\
\text { experimental piloto, usaram graute QUARTZOLIT. } \\
\text { Os demais modelos usaram FOSGROUT. }\end{array}$} \\
\hline
\end{tabular}

\subsubsection{Almofada de apoio}

As características mecânicas da almofada de apoio empregado nos modelos estão apresentadas na Tabela 3.11. Para a determinação de tais características, foram moldados corpos-de-prova de 50mm x 100mm. 
Tabela 3.11: Características mecânicas da almofada de apoio

\begin{tabular}{|c|c|c|c|}
\hline MODELO & $\begin{array}{l}\text { Resistência à } \\
\text { Tração } \\
\text { (MPa) }\end{array}$ & $\begin{array}{c}\text { Resistência à } \\
\text { Compressão } \\
\text { (MPa) }\end{array}$ & $\begin{array}{c}\text { Módulo de } \\
\text { Elasticidade } \\
\text { (GPa) }\end{array}$ \\
\hline \multirow{3}{*}{01} & 3,58 & 35,22 & 9,1 \\
\hline & 3,68 & 34,67 & 9,4 \\
\hline & 3,52 & 34,18 & 9,3 \\
\hline Média & 3,59 & 34,69 & 9,3 \\
\hline \multirow{3}{*}{02} & 2,44 & 22,29 & 6,1 \\
\hline & 2,24 & 19,70 & 6,2 \\
\hline & 2,27 & 20,97 & 5,9 \\
\hline Média & 2,32 & 20,99 & 6,1 \\
\hline \multirow{3}{*}{03} & 2,44 & 22,29 & 6,1 \\
\hline & 2,24 & 19,70 & 6,2 \\
\hline & 2,27 & 20,97 & 5,9 \\
\hline Média & 2,32 & 20,99 & 6,1 \\
\hline \multirow{3}{*}{04} & 2,82 & 33,49 & 8,6 \\
\hline & 2,91 & 27,68 & 8,7 \\
\hline & 3,14 & 34,47 & 8,9 \\
\hline Média & 2,96 & 31,88 & 8,7 \\
\hline \multirow{3}{*}{05} & 2,82 & 33,49 & 8,6 \\
\hline & 2,91 & 27,68 & 8,7 \\
\hline & 3,14 & 34,47 & 8,9 \\
\hline Média & 2,96 & 31,88 & 8,7 \\
\hline \multirow{3}{*}{06} & 3,58 & 35,22 & 9,1 \\
\hline & 3,68 & 34,67 & 9,4 \\
\hline & 3,52 & 34,18 & 9,3 \\
\hline Média & 3,59 & 34,69 & 9,3 \\
\hline \multirow{3}{*}{07} & 3,56 & 37,93 & 11,9 \\
\hline & 4,45 & 46,86 & 9,8 \\
\hline & 3,64 & 45,62 & 12,3 \\
\hline Média & 3,88 & 43,47 & 11,3 \\
\hline \multirow{3}{*}{08} & 2,44 & 22,29 & 6,1 \\
\hline & 2,24 & 19,70 & 6,2 \\
\hline & 2,27 & 20,97 & 5,9 \\
\hline Média & 2,32 & 20,99 & 6,1 \\
\hline
\end{tabular}

\begin{tabular}{|c|c|c|c|}
\hline MODELO & $\begin{array}{c}\text { Resistência à } \\
\text { Tração } \\
\text { (MPa) }\end{array}$ & $\begin{array}{c}\text { Resistência à } \\
\text { Compressão } \\
\text { (MPa) }\end{array}$ & $\begin{array}{l}\text { Módulo de } \\
\text { Elasticidade } \\
\text { (GPa) }\end{array}$ \\
\hline \multirow{3}{*}{09} & 3,58 & 35,22 & 9,1 \\
\hline & 3,68 & 34,67 & 9,4 \\
\hline & 3,52 & 34,18 & 9,3 \\
\hline Média & 3,59 & 34,69 & 9,3 \\
\hline \multirow{3}{*}{10} & 3,56 & 37,93 & 11,9 \\
\hline & 4,45 & 46,86 & 9,8 \\
\hline & 3,64 & 45,62 & 12,3 \\
\hline Média & 3,88 & 43,47 & 11,3 \\
\hline \multirow{3}{*}{11} & 2,82 & 33,49 & 8,6 \\
\hline & 2,91 & 27,68 & 8,7 \\
\hline & 3,14 & 34,47 & 8,9 \\
\hline Média & 2,96 & 31,88 & 8,7 \\
\hline \multirow{3}{*}{12} & 2,82 & 33,49 & 8,6 \\
\hline & 2,91 & 27,68 & 8,7 \\
\hline & 3,14 & 34,47 & 8,9 \\
\hline Média & 2,96 & 31,88 & 8,7 \\
\hline \multirow{3}{*}{13} & 3,56 & 37,93 & 11,9 \\
\hline & 4,45 & 46,86 & 9,8 \\
\hline & 3,64 & 45,62 & 12,3 \\
\hline Média & 3,88 & 43,47 & 11,3 \\
\hline \multirow{3}{*}{14} & 3,58 & 35,22 & 9,1 \\
\hline & 3,68 & 34,67 & 9,4 \\
\hline & 3,52 & 34,18 & 9,3 \\
\hline Média & 3,59 & 34,69 & 9,3 \\
\hline \multirow{3}{*}{15} & 3,56 & 37,93 & 11,9 \\
\hline & 4,45 & 46,86 & 9,8 \\
\hline & 3,64 & 45,62 & 12,3 \\
\hline Média & 3,88 & 43,47 & 11,3 \\
\hline \multicolumn{4}{|c|}{$\begin{array}{l}\text { Os modelos } 02,03 \text { e } 08 \text { pertencem ao programa } \\
\text { experimental piloto. }\end{array}$} \\
\hline
\end{tabular}

O processo de cura utilizada para as almofadas de apoio foi o descrito em SIQUEIRA (2007), ou seja, cura de 48 horas com umidade de $100 \%$, sendo que 24 horas com cura em forma mantendo a amostra sob espuma saturada de água, e 24 horas em câmara úmida. Após as 48 horas as almofadas foram submetidas a cura ao ar até a realização dos ensaios.

\subsection{EQUIPAMENTOS E INSTRUMENTAÇÃO}

Os equipamentos e instrumentos de medição utilizados para a realização dos ensaios estão descritos na Tabela 3.12. São discriminadas a marca, o modelo, as características e a função de cada equipamento.

A instrumentação aqui apresentada está dividida em instrumentação interna e instrumentação externa. A instrumentação interna utilizada é destinada à medição das 
deformações em pontos específicos dos chumbadores. Já a instrumentação externa, é destinada à medição de deslocamentos no modelo.

Tabela 3.12: Equipamentos e instrumentação usados

\begin{tabular}{|c|c|c|c|c|c|}
\hline $\begin{array}{l}\text { Equipamentol } \\
\text { Instrumento }\end{array}$ & Marca & Modelo & \multicolumn{2}{|c|}{ Características } & Função \\
\hline $\begin{array}{c}\text { Sistema de } \\
\text { aquisição de dados } \\
\text { de extensômetria }\end{array}$ & $\begin{array}{l}\text { Vishay } \\
\text { Measurements } \\
\text { Group, Inc. }\end{array}$ & SYSTEM 5000 & \multicolumn{2}{|c|}{$\begin{array}{l}\text { Sistema de aquisição de } \\
\text { dados }\end{array}$} & $\begin{array}{l}\text { Aquisição automática } \\
\text { de dados. }\end{array}$ \\
\hline $\begin{array}{l}\text { Atuador servo- } \\
\text { controlado }\end{array}$ & INSTRON & A1891Y & \multicolumn{2}{|c|}{$\begin{array}{l}\text { Capacidade nominal de } 500 \\
\text { kN }\end{array}$} & $\begin{array}{l}\text { Aplicação de força com } \\
\text { controle de } \\
\text { deslocamento. }\end{array}$ \\
\hline $\begin{array}{l}\text { Extensômetro } \\
\text { elétrico de } \\
\text { resistência }\end{array}$ & KYOWA & $\begin{array}{c}\mathrm{KFG}-5-120- \\
\mathrm{C} 1-11\end{array}$ & \multicolumn{2}{|c|}{$\begin{array}{c}\mathrm{GF}=2.12 \\
\text { Base } 5 \mathrm{~mm}\end{array}$} & $\begin{array}{l}\text { Medição das } \\
\text { deformações. }\end{array}$ \\
\hline \multirow{5}{*}{$\begin{array}{l}\text { Transdutor de } \\
\text { deslocamento }\end{array}$} & & Tipo & $\begin{array}{l}\text { Curso } \\
(\mathrm{mm})\end{array}$ & Resolução (mm) & \multirow{5}{*}{$\begin{array}{l}\text { Medição dos } \\
\text { deslocamenentos. }\end{array}$} \\
\hline & & DT-100A & 100 & 0,040 & \\
\hline & & DT-10D & 10 & 0,003 & \\
\hline & & DTH-A-10 & 10 & 0,001 & \\
\hline & KYOWA & DTH-A-20 & 20 & 0,002 & \\
\hline $\begin{array}{l}\text { Máquina de ensaio } \\
\text { servo - controlada }\end{array}$ & INSTRON & 8506 & \multicolumn{2}{|c|}{ Capacidade de $2500 \mathrm{kN}$} & $\begin{array}{l}\text { Caracterização dos } \\
\text { materiais e aplicação } \\
\text { de força com controle } \\
\text { de deslocamento. }\end{array}$ \\
\hline
\end{tabular}

\subsubsection{Instrumentação interna}

A instrumentação interna dos modelos corresponde aos extensômetros elétricos fixados exclusivamente nos chumbadores. Nas Figuras 3.29; 3.30 e 3.31, estão apresentados os pontos de fixação dos extensômetros utilizados nos chumbadores de eixo reto e inclinados a $45^{\circ}$ e $60^{\circ}$, respectivamente.

Toda a instrumentação utilizada foi confeccionada pelos técnicos do Laboratório de Estruturas do SET/EESC/USP. Na Figura 3.32 estão apresentadas algumas fotos que ilustram a instrumentação realizada. 

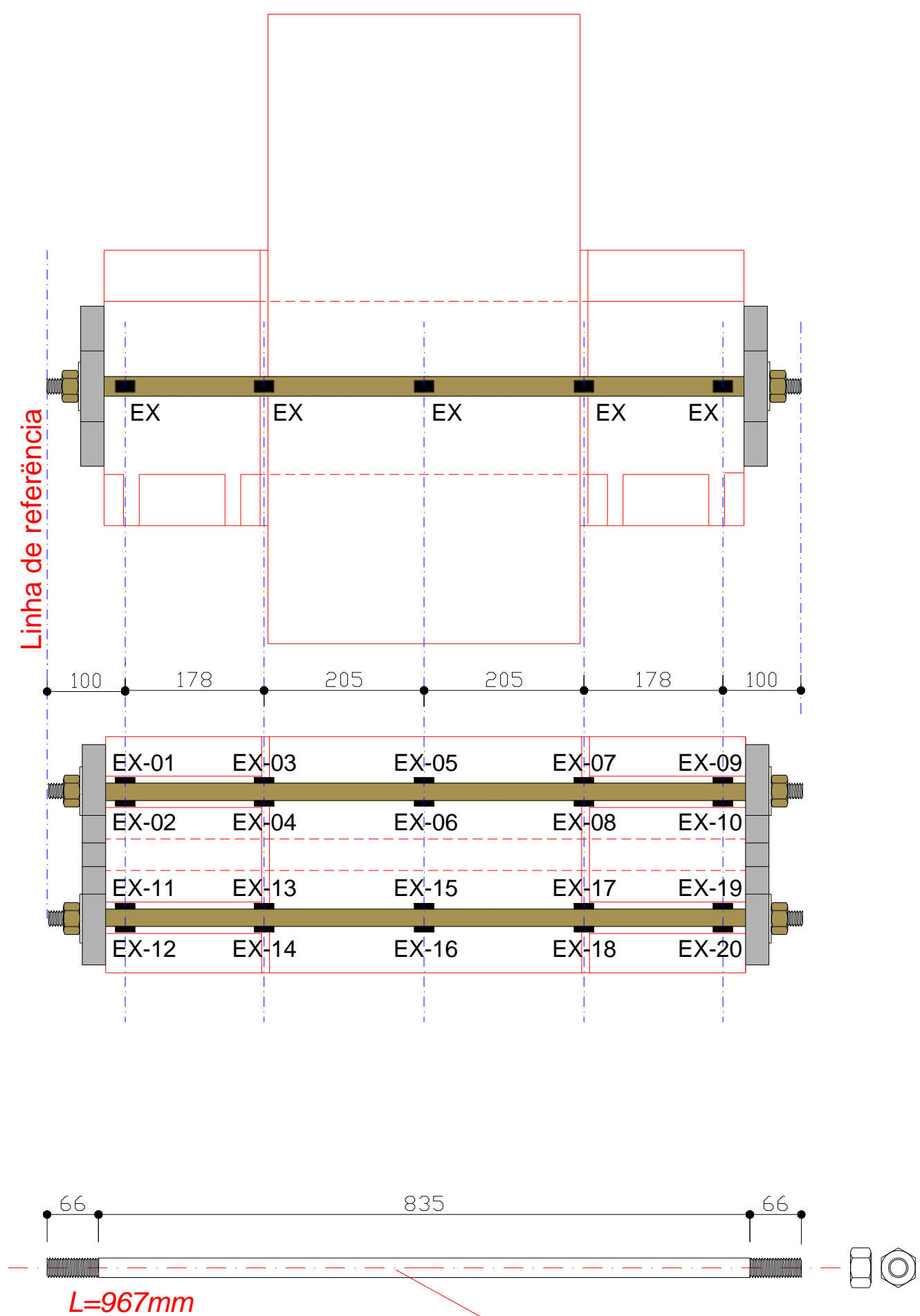

Chumbador

Aço CA-50

Figura 3.29: Instrumentação do chumbador de eixo reto 

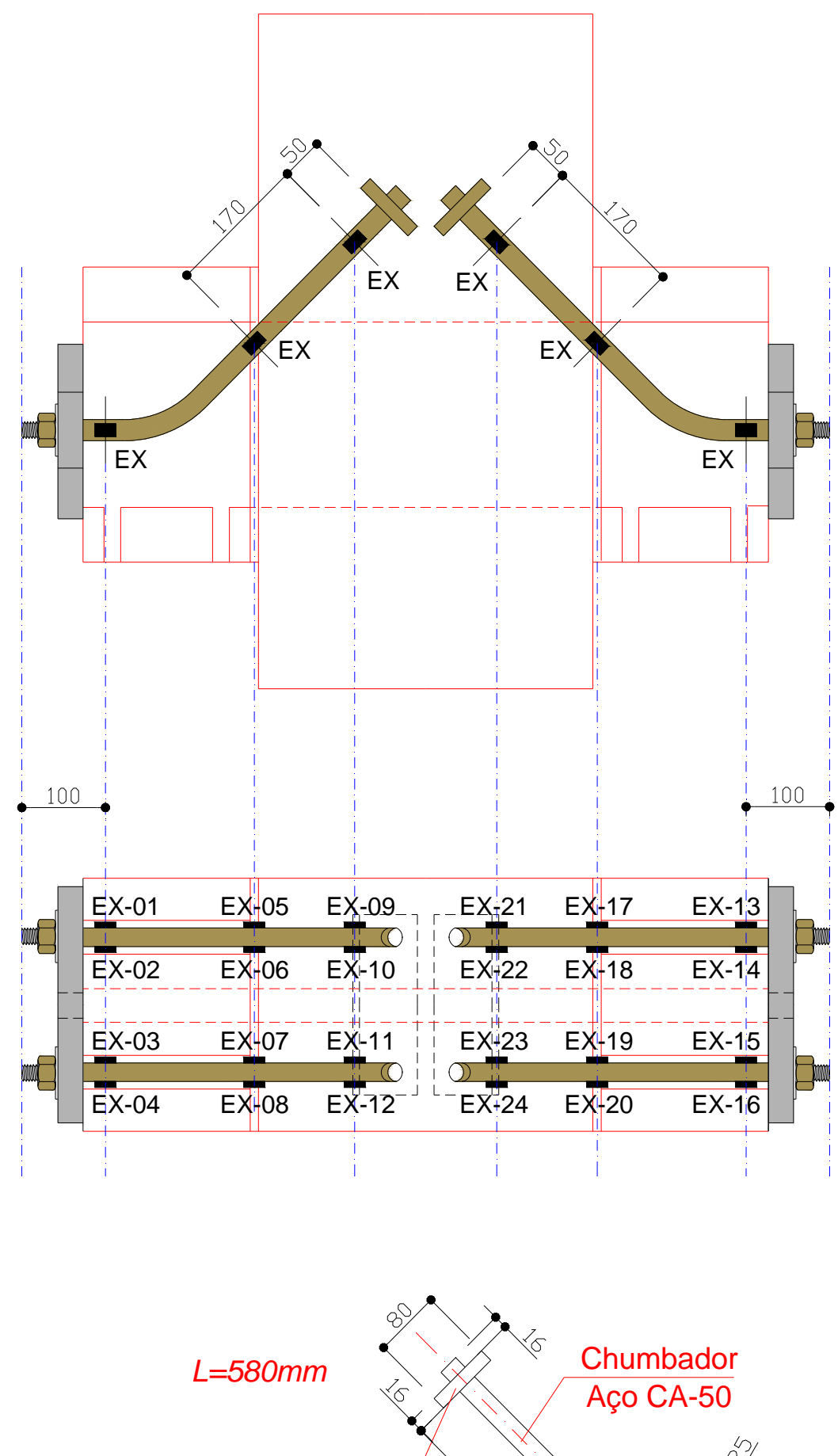

Chapa de aço soldada

Figura 3.30: Instrumentação do chumbador inclinado a $45^{\circ}$ 


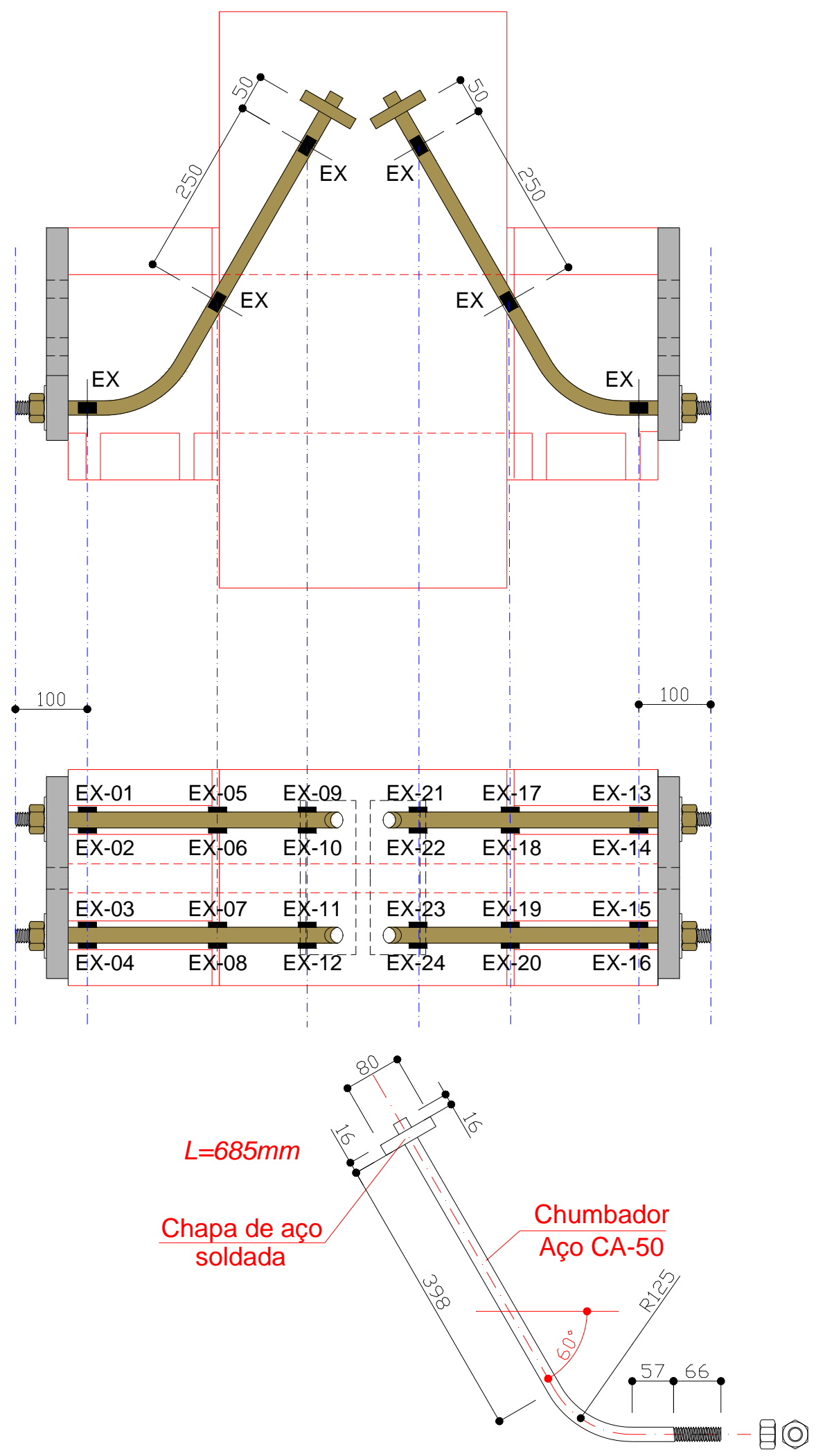

Figura 3.31: Instrumentação do chumbador inclinado a $60^{\circ}$. 

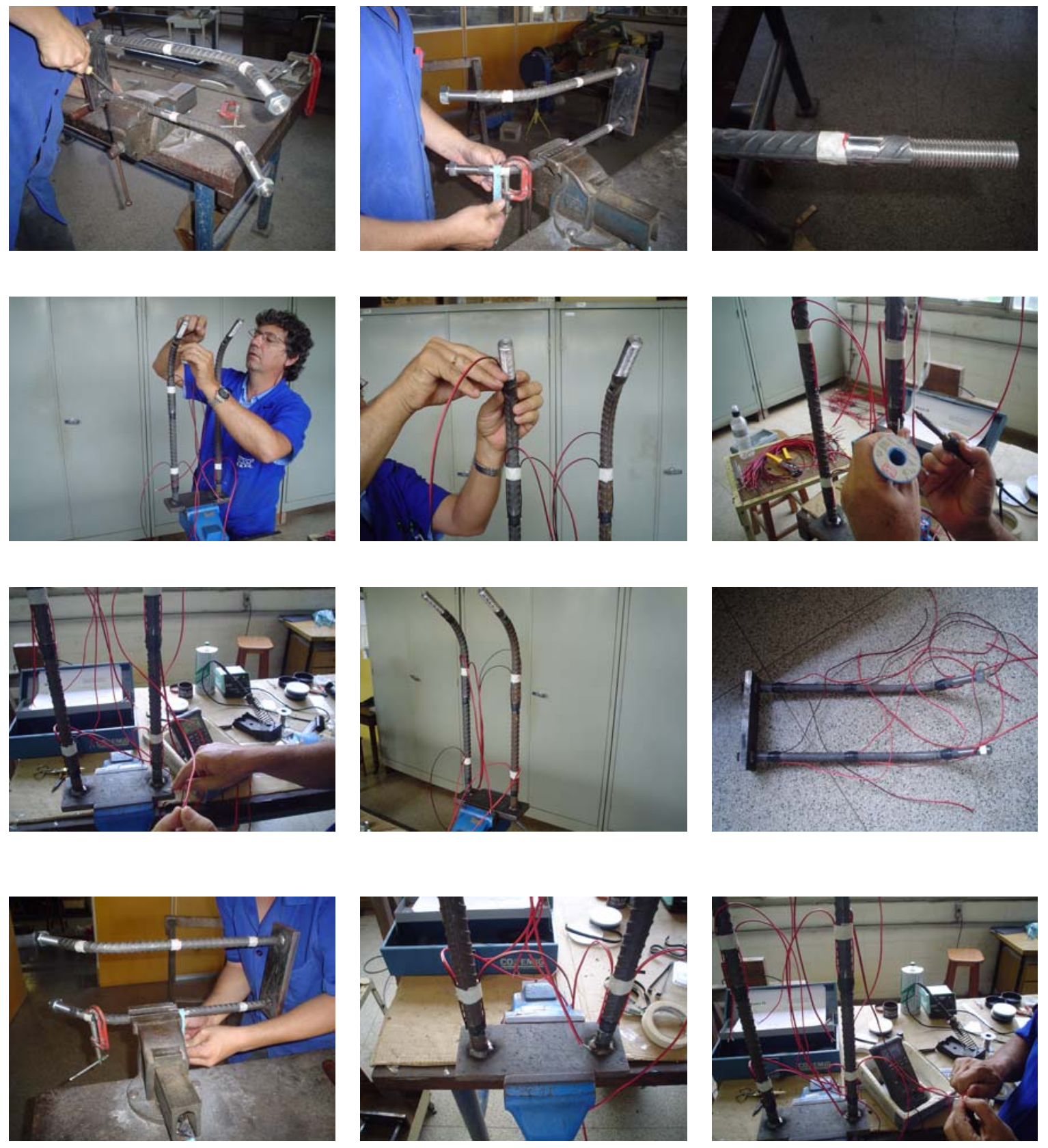

Figura 3.32: Etapas de instrumentação dos chumbadores

\subsubsection{Instrumentação externa}

A instrumentação externa é destinada à medição dos deslocamentos do modelo. Foram utilizados transdutores de deslocamentos (TD), sendo a disposição da instrumentação externa repetida em todos os modelos (Figura 3.33). 
Os transdutores de deslocamentos foram utilizados para a obtenção do deslocamento relativo entre as partes componentes do modelo, ou seja, entre o bloco interno e os blocos externos.
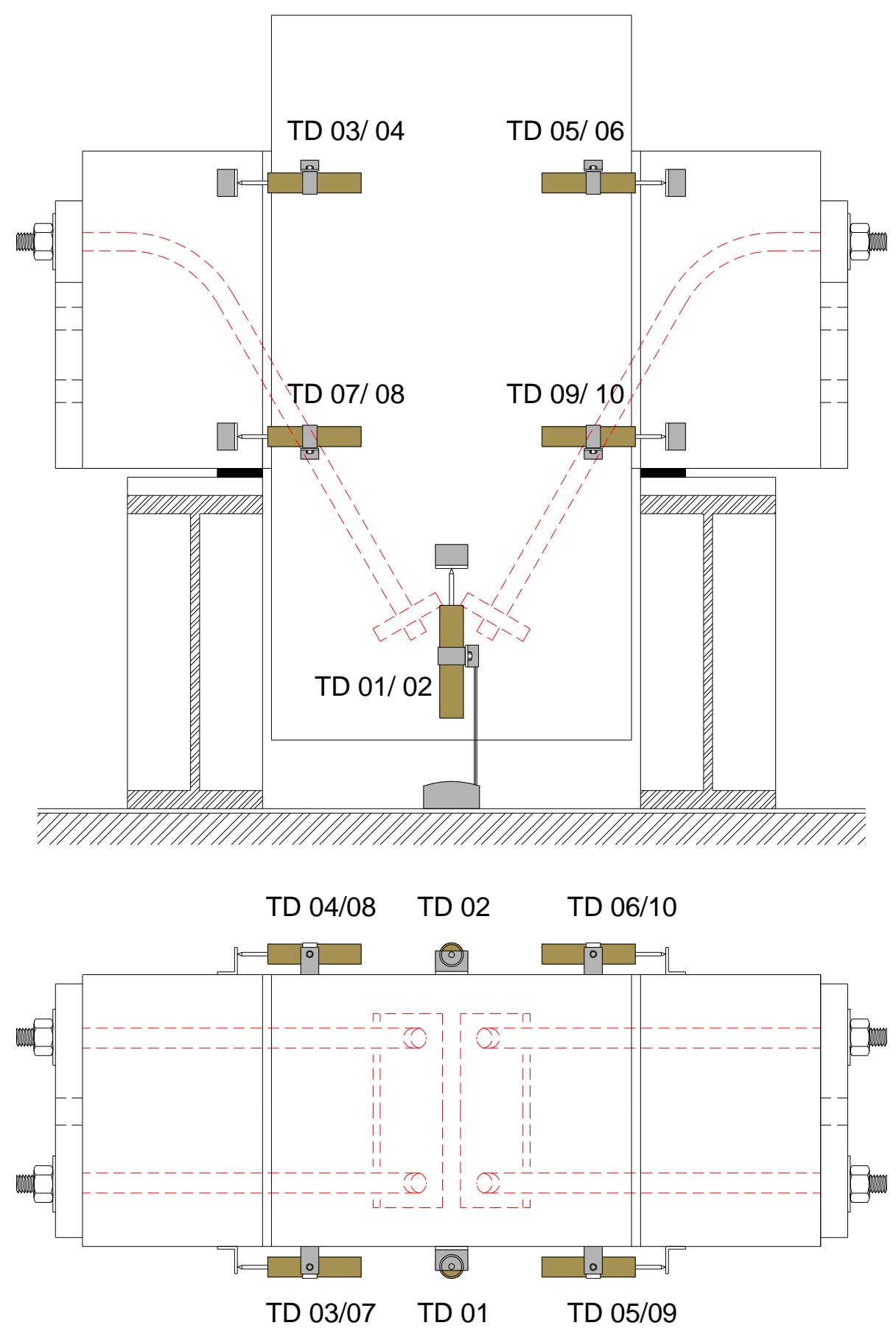

Figura 3.33: Instrumentação externa do modelo 


\subsection{PROCEDIMENTO DE ENSAIO}

Os ensaios foram realizados no Laboratório de Estruturas do SET/EESC/USP, com aplicação de carregamentos com ciclos de carga e descarga, com e sem reversão de sinal. Para a aplicação do carregamento sem reversão de sinal, foi utilizada a máquina INSTRON 8506, esquematizada na Figura 3.34. Para a realização dos ensaios com reversão de carregamento, foi utilizado o ATUADOR SERVO-CONTROLADO A1891Y, instalado em pórtico metálico sobre a laje de reação do laboratório, conforme ilustra a Figura 3.35.

O ensaio com reversão de carregamento só foi realizado no programa experimental piloto, no modelo 03, não sendo repetido no programa experimental final. Na realização do referido ensaio, não houve êxito, pois com a reversão de carregamento ocorreu o aparecimento de folgas consideráveis entre o bloco interno e o bloco externo, o que inviabilizou a continuação do ensaio.

Para ciclos de carga e descarga sem reversão de sinal, optou-se por usar a máquina INSTRON 8506, pois a capacidade de carga dos modelos superava a capacidade de carga real do ATUADOR SERVO-CONTROLADO A1891Y.

Entende-se por capacidade real, a capacidade máxima de carga que o atuador pode aplicar sobre o modelo. No caso do ATUADOR SERVO-CONTROLADO $\boldsymbol{A 1 8 9 1 Y}$, a capacidade teórica é de $500 \mathrm{kN}$, porém a capacidade real do equipamento é cerca de $430 \mathrm{kN}$.

Antes de iniciar o procedimento de carregamento propriamente dito, foi realizado o procedimento de escorvamento, que consiste na aplicada de uma carga de $5 \%$ do valor de ruptura esperado. A finalidade de tal procedimento é a verificação do funcionamento dos equipamentos e possibilitar as acomodações do modelo.

Na Tabela 3.13, são apresentadas as cargas de ruptura previstas para cada modelo ensaiado. A capacidade de carga dos modelos sem força de compressão aplicada, foi calculada de acordo com a Equação (2.28), para os modelos confeccionados com chumbadores retilíneos. Para os modelos confeccionados com chumbadores de eixo inclinado, foi utilizada a Equação (2.36), que embora não leve em consideração o efeito da inclinação do chumbador, considera o efeito do atrito entre as faces de concreto, que a princípio parecia ser mais atuante em modelos com chumbadores de eixo inclinado. 
Para modelos com força de compressão aplicada, acrescentou-se a parcela relativa à força de atrito mobilizada pela força normal aplicada. O coeficiente de atrito adotado foi $\mu=0,3$. Por falta de valores de referência na literatura técnica, optou-se por adotar 50\% do valor do coeficiente de atrito definido para as superfícies de contato entre concreto-concreto, que é igual a 0,6 de acordo com ENGSTROM (1992b).

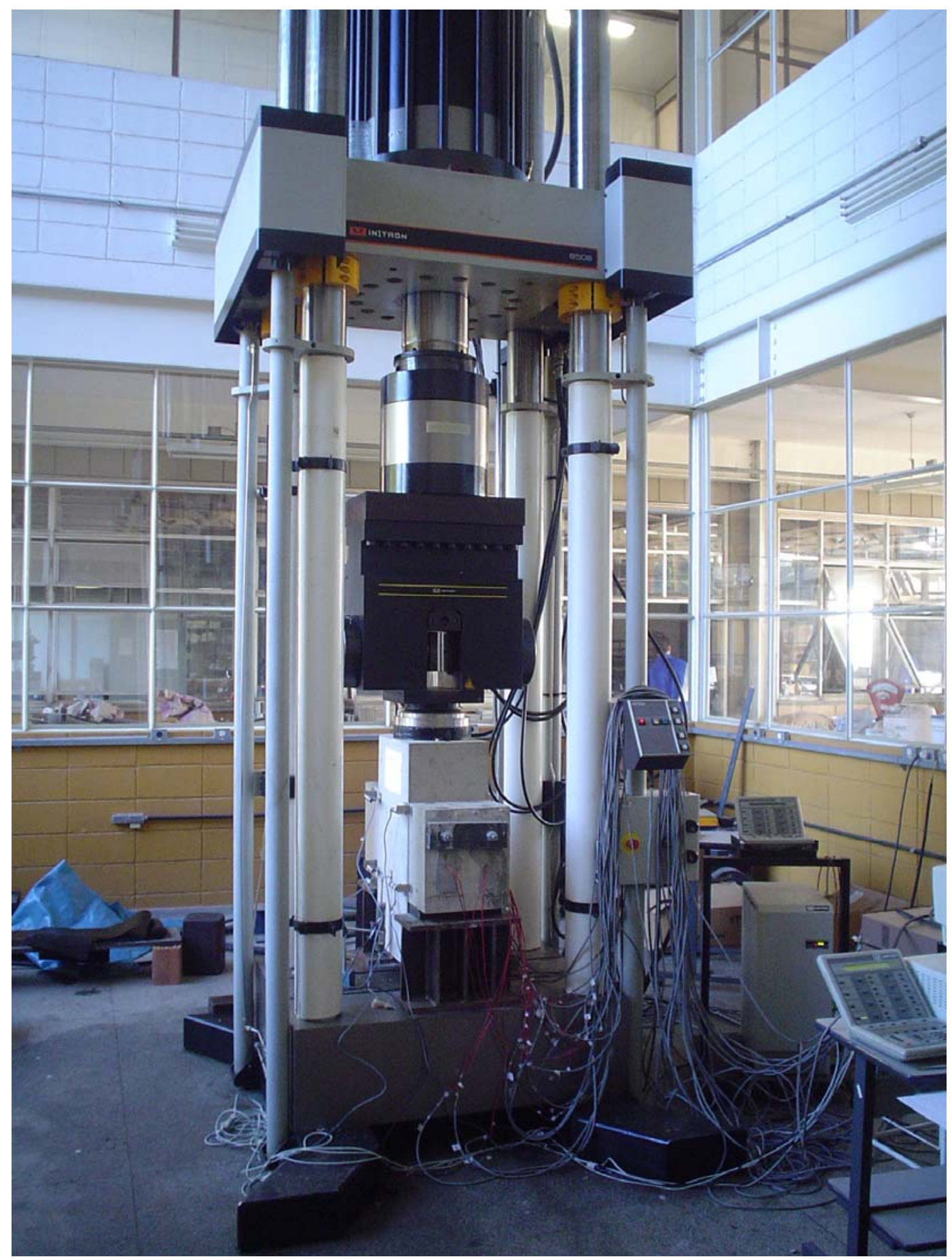

Figura 3.34: esquema de ensaio na máquina INSTRON 8506 


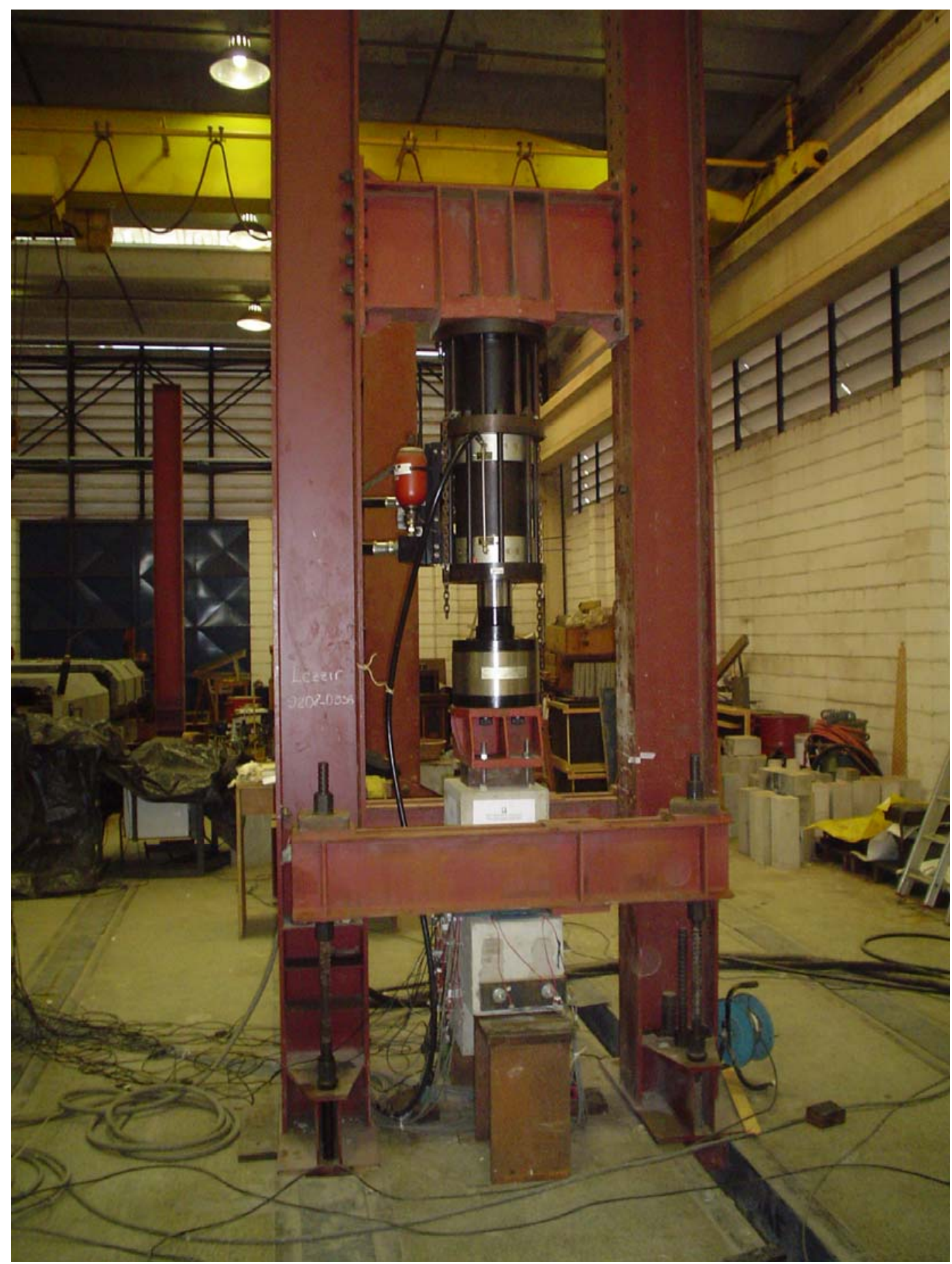

Figura 3.35: esquema de ensaio no atuador A1891Y

No modelo 08, para simular o efeito da reação de apoio que a viga exerce sobre o pilar, foi realizada inicialmente a protensão em um cabo de $15,2 \mathrm{~mm}$ na tentativa de aplicar uma força de $180 \mathrm{kN}$. Como o equipamento disponível, assim como os acessórios necessários eram destinados à utilização em cabos de até 12,7 mm, tentou-se fazer adaptações sem êxito. 
Como as cunhas disponíveis, assim como as ancoragens, não eram compatíveis com o diâmetro do cabo utilizado, houve o rompimento do cabo por tensões excessivas exercidas pelas cunhas (Figura 3.36).

No caso específico do modelo 08, foi então utilizada apenas uma cordoalha de protensão, onde foi aplicada a força de $100 \mathrm{kN}$, medida em célula de carga instalada.
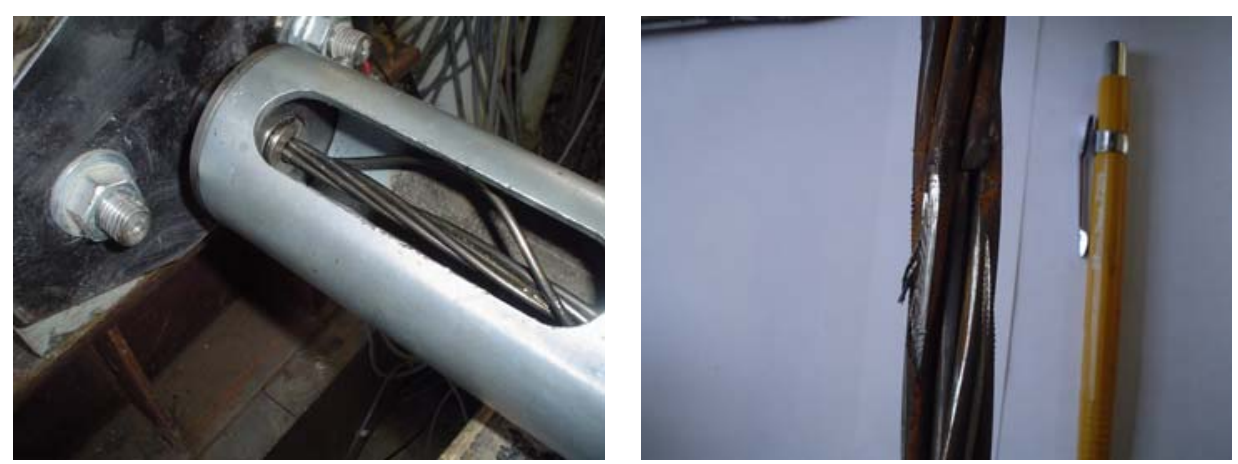

Figura 3.36: Aspecto do cabo de protensão de 15,2 mm

Para os demais modelos com força de compressão aplicada, foram utilizadas duas cordoalhas de 12,7mm, o que proporcionou uma força aplicada média de $200 \mathrm{kN}$. Na Figura 3.37 são apresentados aspectos dos modelos protendidos com duas cordoalhas.
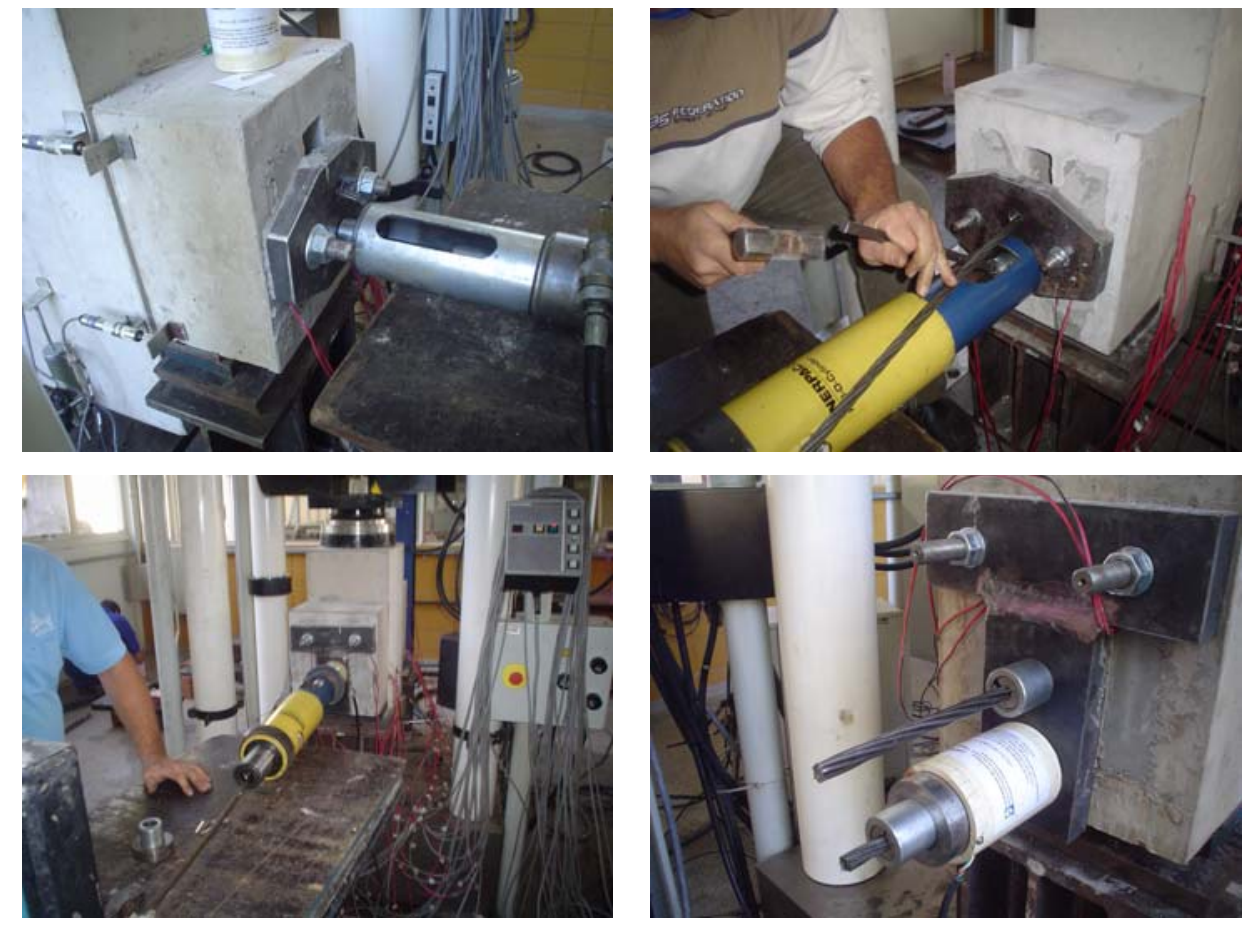

Figura 3.37: Aspecto dos modelos com duas cordoalhas de 12,7mm 
Tabela 3.13: Previsão de carga dos modelos

\begin{tabular}{|c|c|c|c|c|}
\hline \multicolumn{2}{|c|}{ MODELO } & \multirow{2}{*}{$\begin{array}{c}\begin{array}{c}\text { Força de } \\
\text { Ruptura } \\
\text { (kN) }\end{array} \\
336\end{array}$} & \multirow{2}{*}{$\begin{array}{c}\begin{array}{c}\text { Força de } \\
\text { Escorvamento } \\
(\mathrm{kN})\end{array} \\
17\end{array}$} & \multirow{2}{*}{$\begin{array}{c}\begin{array}{c}\text { Força de } \\
\text { Utilização } \\
\text { (kN) }\end{array} \\
202\end{array}$} \\
\hline \multirow[b]{5}{*}{ eixo reto } & Modelo 01 & & & \\
\hline & Modelo 05 & 753 & 38 & 452 \\
\hline & Modelo 07 & 359 & 18 & 215 \\
\hline & Modelo 08 & 525 & 26 & 315 \\
\hline & Modelo 11 & 764 & 38 & 458 \\
\hline \multirow[b]{5}{*}{ inclinado $45^{\circ}$} & Modelo 02 & 589 & 29 & 353 \\
\hline & Modelo 06 & 851 & 43 & 511 \\
\hline & Modelo 09 & 482 & 24 & 289 \\
\hline & Modelo 13 & 591 & 30 & 355 \\
\hline & Modelo 15 & 858 & 43 & 515 \\
\hline \multirow{5}{*}{ inclinado $60^{\circ}$} & Modelo 03 & 593 & 30 & 356 \\
\hline & Modelo 04 & 586 & 29 & 352 \\
\hline & Modelo 10 & 483 & 24 & 290 \\
\hline & Modelo 12 & 684 & 34 & 410 \\
\hline & Modelo 14 & 594 & 30 & 356 \\
\hline
\end{tabular}

De modo geral, os modelos foram carregados em várias etapas. Cada etapa de carregamento foi denominada de “ciclo”. Os modelos foram submetidos a 19 ciclos de carga e descarga após o escorvamento. Do ciclo 1 ao 10 os modelos atingiram $40 \%$ da carga prevista; do ciclo 11 ao 18 os modelos foram submetidos a $60 \%$ da carga prevista (valor estimado como carga de utilização) e, finalmente, no ciclo 19 o modelo foi levado à ruptura.

A velocidade de aplicação do carregamento variou em cada ciclo de carga e descarga. Para o escorvamento (5\% da carga prevista de ruptura), a velocidade de aplicação da carga, medida em deslocamento, foi de $0,005 \mathrm{~mm} / \mathrm{s}$. No primeiro ciclo, após o escorvamento, a velocidade foi de $0,01 \mathrm{~mm} / \mathrm{s}$. Do ciclo 2 ao 18 , a velocidade de aplicação foi de $0,08 \mathrm{~mm} / \mathrm{s}$, e no último ciclo, a velocidade foi de $0,01 \mathrm{~mm} / \mathrm{s}$ até a ruptura do modelo. Na Figura 3.38 é apresentado graficamente um esquema dos ciclos de carregamento e descarregamento aplicados em cada modelo, sendo a velocidade de descarregamento igual à de carregamento. 


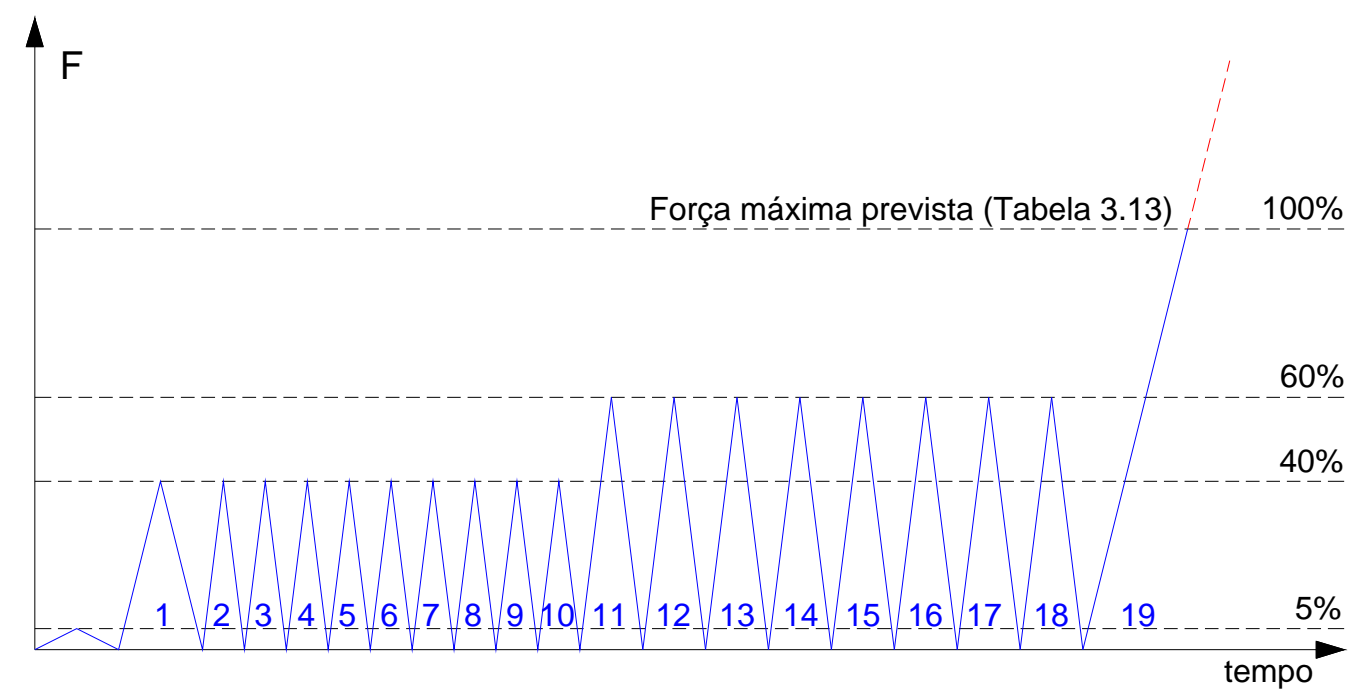

Figura 3.38: Ciclos de carregamento e descarregamento aplicados nos modelos.

Após a etapa de escorvamento, representada na Figura 3.38 como o primeiro ciclo de carregamento e descarregamento, todo o sistema de aquisição de dados foi zerado para o início dos ensaios (aplicação do ciclo 1).

O sistema de aquisição de dados, SYSTEM 5000, registrou o comportamento dos modelos a cada segundo de aplicação do carregamento. Cada ensaio, após escorvamento, durou em média 45 minutos, sendo os resultados apresentados no capítulo que segue. 


\section{RESULTADOS EXPERIMENTAIS}

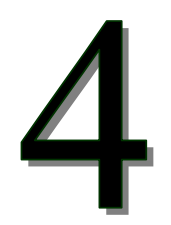

Capítulo

\subsection{GENERALIDADES}

Neste capítulo são apresentados os resultados obtidos no programa experimental piloto e no programa experimental final. Para cada modelo ensaiado foi determinada a curva força $\mathrm{x}$ deslocamento vertical e também a curva força $\mathrm{x}$ deformação do chumbador no ponto de junção do bloco externo com o bloco interno do modelo.

Para visualizar a relação entre a deformação do chumbador no ponto de junção do bloco externo com o bloco interno e o deslocamento vertical do modelo, foram geradas curvas deformação $\mathrm{x}$ deslocamento. Para todos os modelos, os resultados experimentais mostraram respostas não-lineares.

Os modelos foram ensaiados a cisalhamento, onde se procurou ao máximo reduzir os efeitos da flexão gerada no ensaio. Para isso, foi utilizada uma chapa de apoio de $8 \mathrm{~cm}$ de largura, faceando o bloco externo na junção com a almofada (Figura 4.1), permitindo assim o deslocamento também da almofada.

As leituras realizadas nos transdutores horizontais (TD 3 ao TD 10), apresentados na Figura 3.33, confirmaram que os deslocamentos gerados por flexão foram mínimos, podendo ser desprezados. Os deslocamentos horizontais foram utilizados na análise como verificação de desaprumos do modelo, garantindo assim um deslocamento vertical uniforme do bloco interno.

Para a determinação do deslocamento vertical, utilizou-se a média aritmética das leituras dos transdutores TD 1 e TD 2 (Figura 3.33). Já para a determinação da deformação do chumbador na junção do bloco interno com o bloco externo, foram 
usadas as expressões 4.1 e 4.2 para os chumbadores de eixo reto (Figura 3.29) e inclinados (Figuras 3.30 e 3.31) respectivamente.
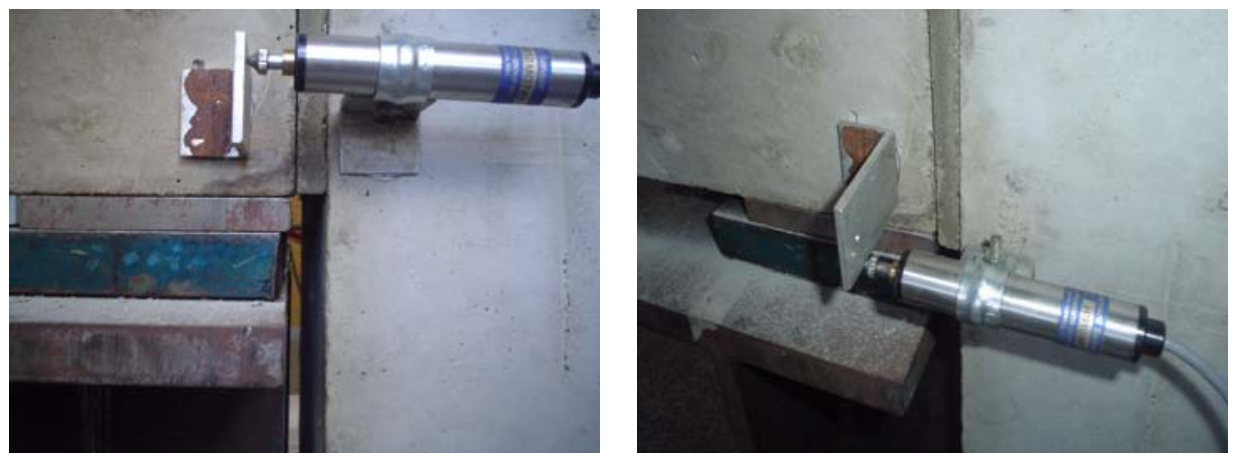

Figura 4.1: Detalhe do apoio utilizado nos modelos

$$
\begin{aligned}
& \varepsilon_{s}^{\text {reto }}=\frac{(E X 03+E X 04+E X 13+E X 14)+(E X 07+E X 08+E X 17+E X 18)}{8} \\
& \varepsilon_{s}^{\text {incl }}=\frac{(E X 05+E X 06+E X 07+E X 08)+(E X 17+E X 18+E X 19+E X 20)}{8}
\end{aligned}
$$

Sendo que:

$\varepsilon_{s}^{\text {reto }}$ - Deformação do chumbador de eixo reto na junção entre o bloco interno e o bloco externo;

$\varepsilon_{s}^{\text {incl }}$ - Deformação do chumbador de eixo inclinado na junção entre o bloco interno e o bloco externo;

$E X$ - Leitura do extensômetro na posição indicada.

A força aplicada nos ensaios é aqui apresentada para cada chumbador. Assim, a capacidade de carga do modelo é igual à capacidade de carga do chumbador multiplicado por quatro, pois em cada modelo existem quatro seções de corte.

Nos itens que seguem são apresentados os resultados obtidos para os 15 modelos ensaiados a cisalhamento, sendo realizada também uma análise prévia dos resultados individuais de cada modelo.

Os modelos foram divididos em grupos, sendo apresentados os modelos pilotos; os modelos sem força de compressão aplicada, pertencentes ao grupo de concreto de classe C35; os com força de compressão aplicada também da classe C35, e finaliza-se com a apresentação dos modelos sem força aplicada, pertencentes à classe C50. 


\subsection{MODELOS PILOTOS}

\subsubsection{Modelo 02}

O modelo 02, com chumbador de $20 \mathrm{~mm}$ de diâmetro, apresentou o comportamento força por barra $x$ deslocamento ilustrado na Figura 4.2. A capacidade máxima alcançada por barra foi de $247 \mathrm{kN}$, o que totalizou uma capacidade de carga do modelo de $988 \mathrm{kN}$. A carga de ruptura real do modelo superou a carga de ruptura prevista (Tabela 3.13) em 68\%.

Na Figura 4.2 são apresentados os resultados experimentais observados para o modelo 02. A rigidez inicial no último ciclo de carregamento foi de 49,33 kN/mm. Após a força por barra atingir $100 \mathrm{kN}$, a rigidez reduziu para 32,10 kN/mm, e atingiu 4,63 kN/mm quando a força por barra superou $200 \mathrm{kN}$.

A deformação no chumbador (Figura 4.2b) não apresentou mudanças bruscas ao longo do carregamento, sendo que as leituras dos extensômetros deixaram de ser registradas quando a deformação superou 7\%.
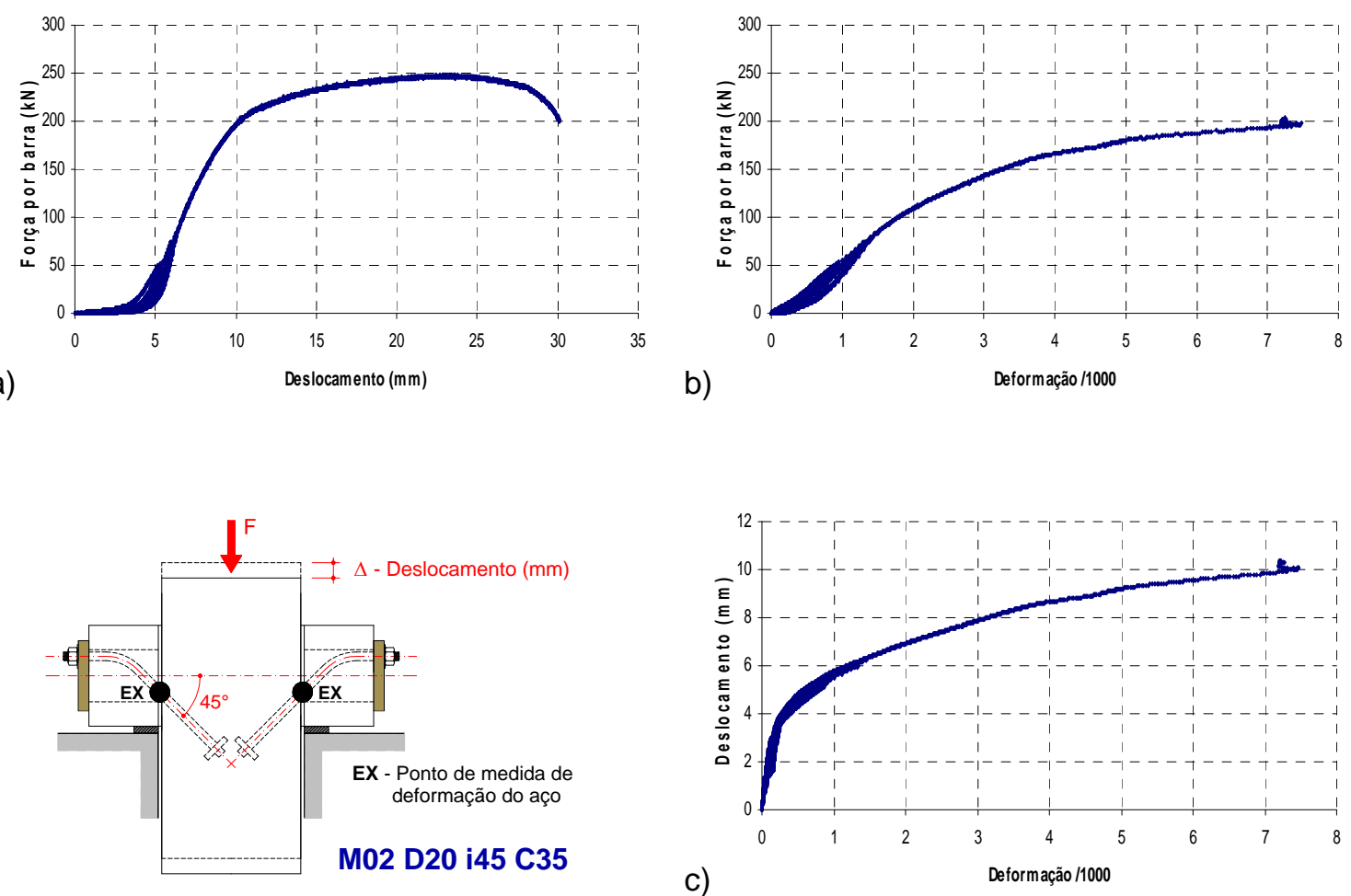

Figura 4.2: Resumo dos resultados experimentais do modelo 02 
Na Figura 4.3 é apresentado um aspecto geral do ensaio realizado, onde inicialmente o modelo obteve um comportamento compatível com o esperado.

Após o modelo sofrer fissuração nas regiões dos blocos externos e do bloco interno, apresentar translações consideráveis e, com carga atuante próximo à carga real de ruptura, ocorreu a ruptura brusca do modelo com a deformação excessiva do chumbador por tração.
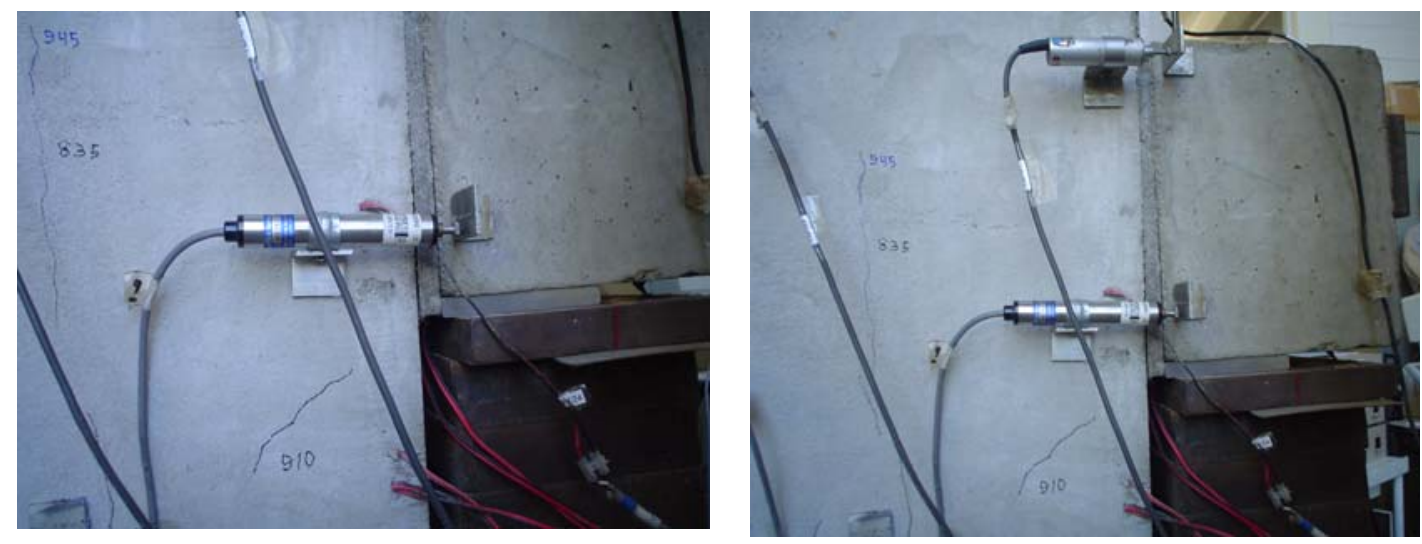

Figura 4.3: Ensaio experimental do modelo 02

Na realidade ocorreu uma redução na área transversal do chumbador até o seu rompimento, causando assim uma ruptura brusca do modelo. Na Figura 4.4 está ilustrado o aspecto do chumbador após a ruptura brusca.
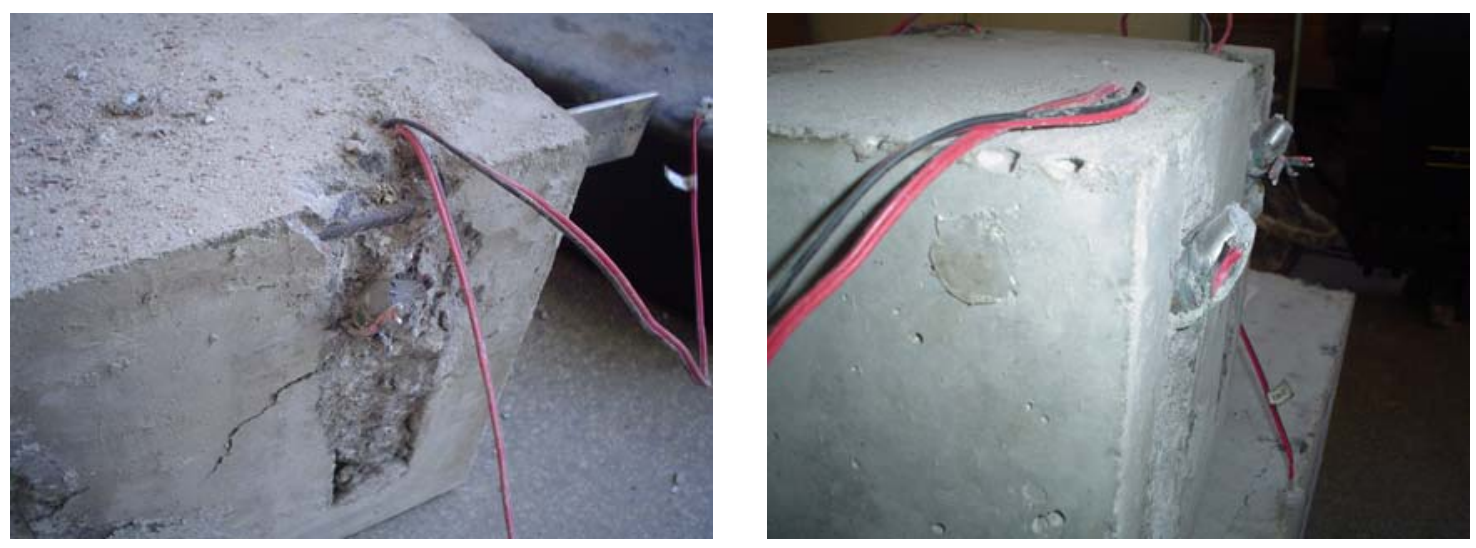

Figura 4.4: Aspecto da ruptura da seção transversal do chumbador

Para uma melhor visualização do aspecto do chumbador, todo o cobrimento de concreto adjacente foi removido, e o chumbador foi pintado de amarelo (Figura 4.5). A 
partir de tal procedimento, percebeu-se que havia também um início de redução da seção transversal do chumbador no lado direito do bloco interno.
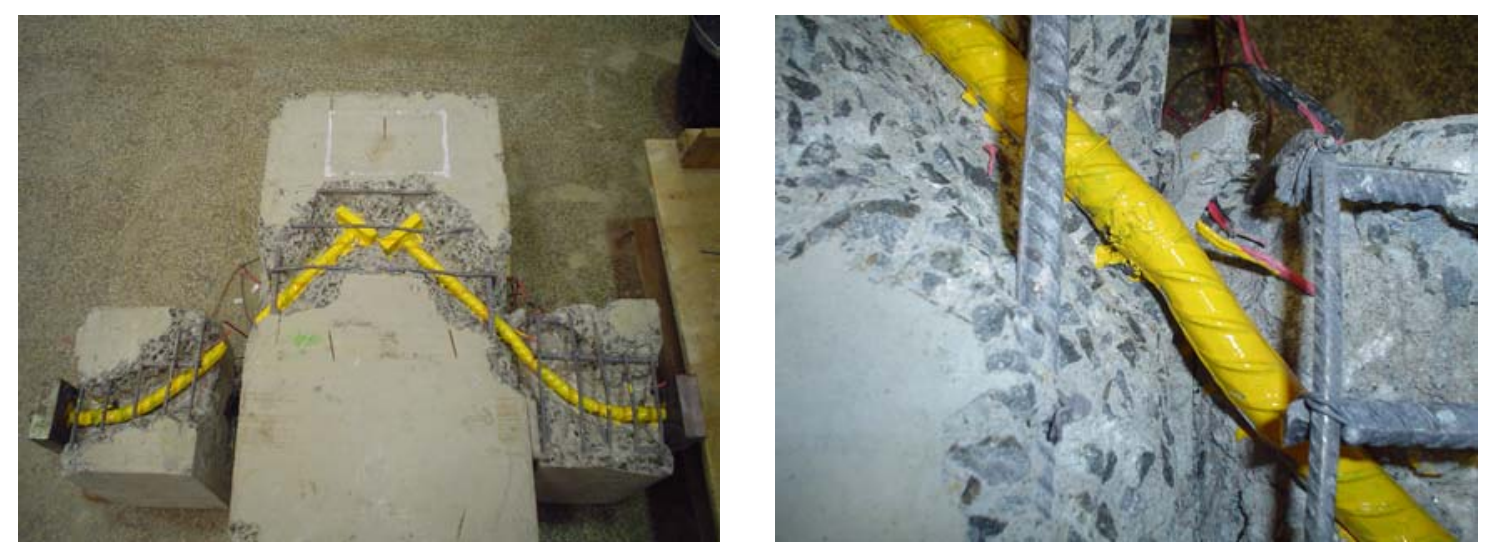

Figura 4.5: Detalhe do chumbador após a ruptura

Na Figura 4.6 é apresentada a distribuição das deformações ao longo do comprimento do chumbador, onde a porcentagem apresentada refere-se à capacidade máxima alcançada pelo modelo.

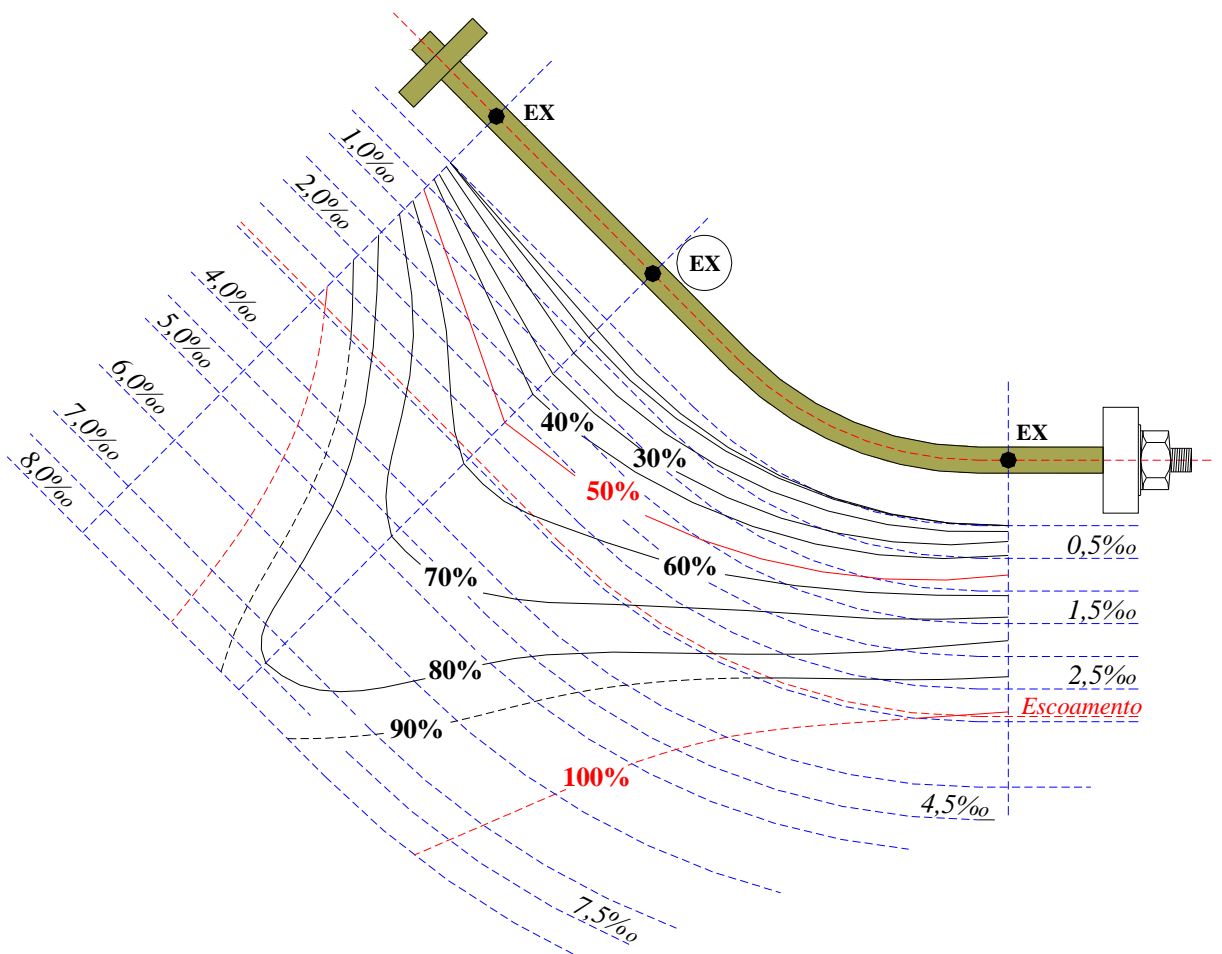

Figura 4.6: Deformação dos pontos de extensometria ao longo do chumbador 
É importante registrar que a distribuição de deformações apresentada na Figura 4.6 tem o intuito de ilustrar uma possível configuração, pois só foram medidas as deformações em três pontos, podendo as curvas apresentadas assumirem outras configurações.

Acredita-se que o fenômeno de redução na seção transversal do chumbador até sua ruptura, esteja representado na Figura 4.2a pela perda de rigidez ocorrida após os $25 \mathrm{~mm}$ de deslocamento.

\subsubsection{Modelo 03}

O Modelo 03 foi ensaiado inicialmente no atuador A1891Y, obedecendo à proposta de ensaio de ciclos de carga e descarga com reversão de sinal. Na Figura 4.7 é apresentado um panorama geral do ensaio.
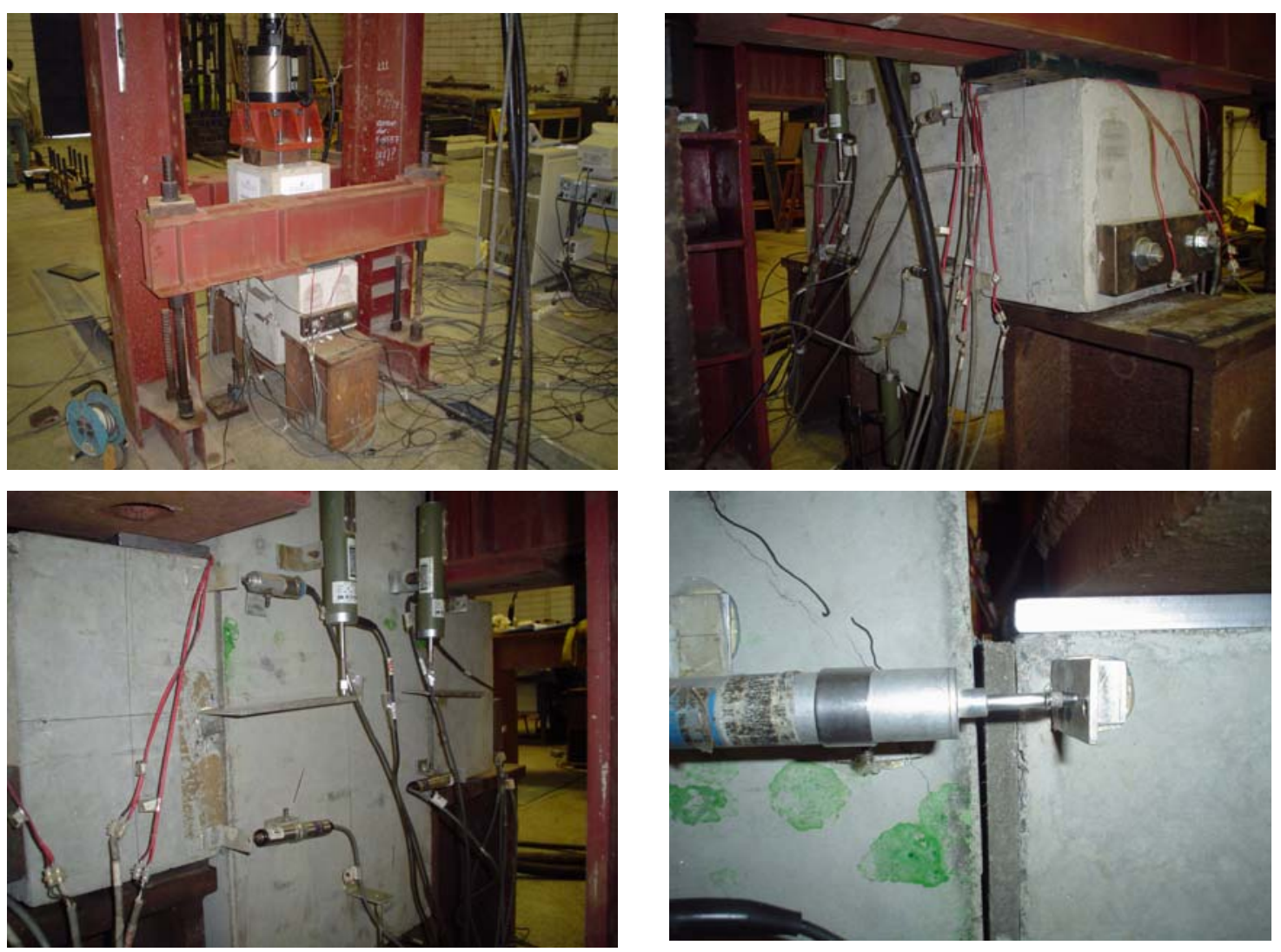

Figura 4.7: Ensaio experimental do modelo 03

A reversão de sinal no carregamento do modelo provocou folgas consideráveis entre o bloco externo e o bloco interno (Figura 4.7), o que inviabilizou a continuação do 
ensaio e o aproveitamento dos dados. Como a capacidade de carga do atuador A1891Y era inferior à capacidade do modelo, resolveu-se paralisar os ensaios e descartar os dados obtidos.

Após a paralisação, o modelo foi transportado até a máquina INSTRON 8506 (Figura 4.8), para que fosse carregado até a ruptura. Como o modelo foi inicialmente ensaiado no atuador A1891Y e já possuía folgas, resolveu-se aplicar a carga até a ruptura do modelo em um único ciclo.

Alguns extensômetros e os transdutores de deslocamentos verticais foram novamente ligados, sendo descartados os transdutores de deslocamentos dispostos na horizontal.

Como esse modelo também obteve comportamento semelhante ao modelo 02, caracterizou-se sua capacidade limite no ponto em que a carga aplicada permaneceu constante por alguns segundos. Assim, temendo outra ruptura brusca, o modelo foi então descarregado.

Na Figura 4.8, é apresentado um panorama da fissuração ocorrida no ensaio realizado na máquina INSTRON 8506.
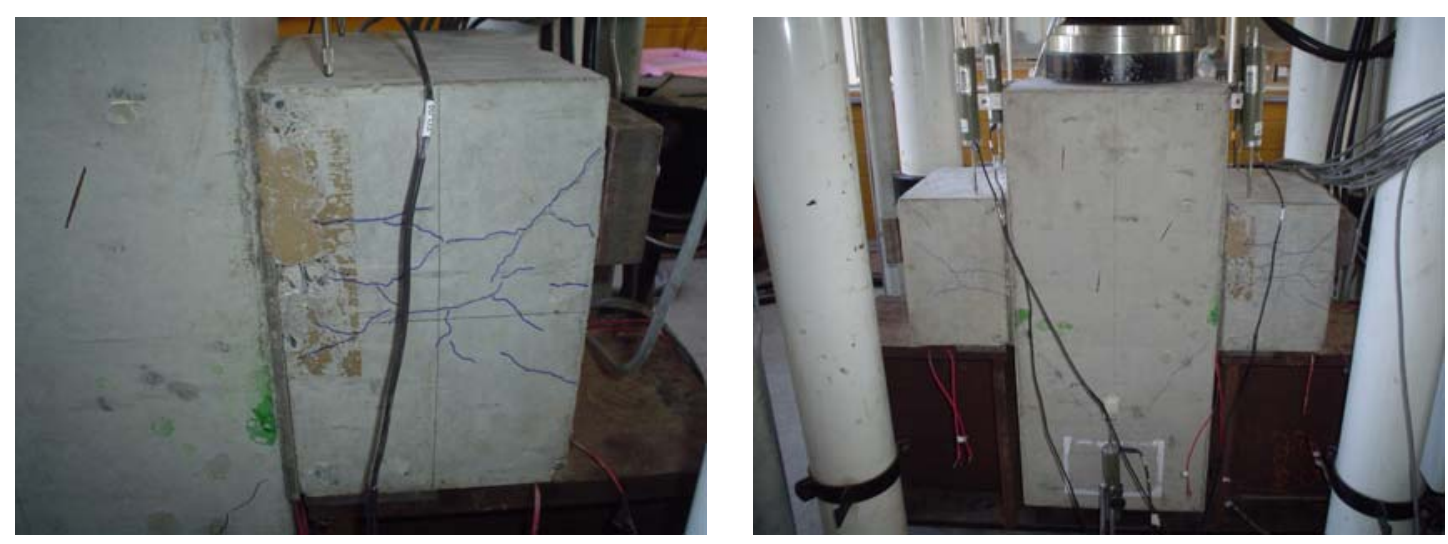

Figura 4.8: Aspecto da fissuração do modelo 03

A capacidade máxima alcançada por barra foi de 256 kN, o que totalizou uma capacidade de carga do modelo de $1024 \mathrm{kN}$. A carga de ruptura real do modelo superou a carga de ruptura prevista (Tabela 3.13) em 73\%.

Na Figura 4.9 são apresentados os resultados experimentais observados para o modelo 03. A rigidez inicial no carregamento foi de $54,60 \mathrm{kN} / \mathrm{mm}$. Após a força por barra atingir $200 \mathrm{kN}$, a rigidez reduziu consideravelmente para 6,00 kN/mm. 
No modelo, como não houve ciclos de carga e descarga, e todos os transdutores foram zerados antes do início do ensaio, não foi observado folgas no gráfico da Figura 4.9a.

Na Figura 4.9b, pode ser observado que não houve mudanças bruscas no comportamento do chumbador.

Como o modelo já havia sido ensaiado inicialmente no atuador A1891Y, não se conseguiu estimar o nível de deformações residuais do chumbador e o nível de precisão dos extensômetros, o que gerou dúvidas nos resultados obtidos.

Alguns extensômetros foram danificados no percurso e não foram ligados quando o modelo foi transferido para a máquina INSTRON 8506. Os demais extensômetros foram cuidadosamente ligados e lidos com êxito.

A solução encontrada foi repetir os ensaios realizados no modelo 03 , com a confecção de um novo modelo: o modelo 04.

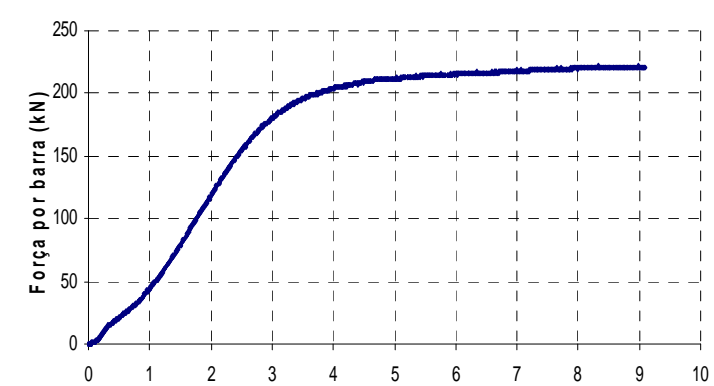

a)

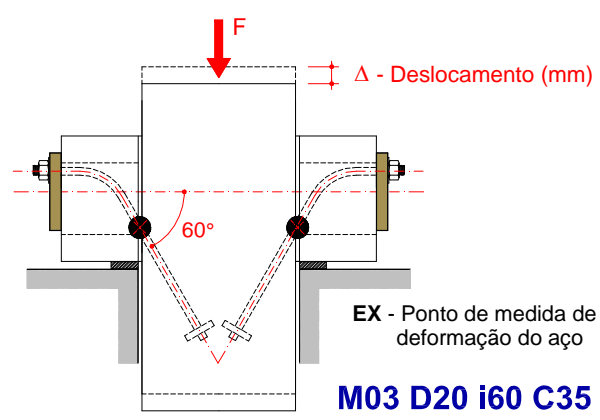

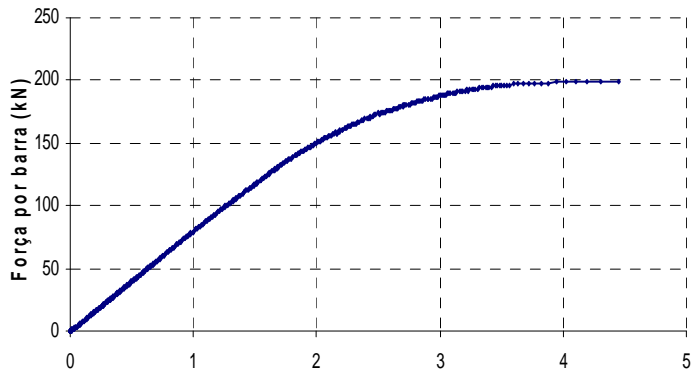

b)

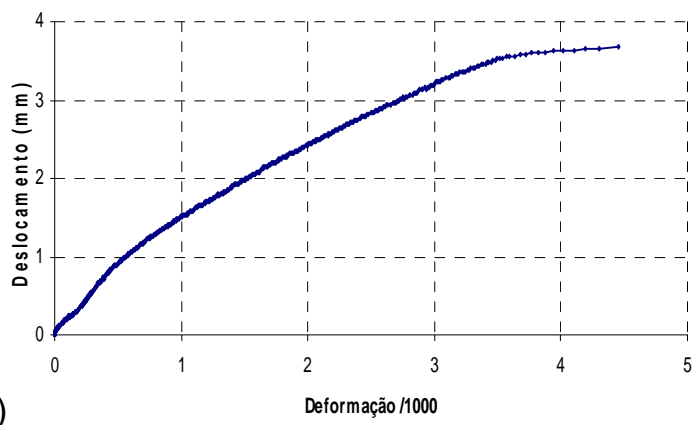

C)

Figura 4.9: Resumo dos resultados experimentais do modelo 03 


\subsubsection{Modelo 08}

O Modelo 08 foi ensaiado na máquina INSTRON 8506, obedecendo também aos ciclos de carregamento descritos na Figura 3.38. O Aspecto geral do ensaio é mostrado na Figura 4.10.

Nesse modelo foi realizado inicialmente uma protensão em um cabo de 15,2 mm, para simular o efeito da reação de apoio que a viga exerce sobre o pilar. Como o equipamento disponível, assim como os acessórios necessários eram destinados à utilização em cabos de até 12,7 mm, tentou-se fazer adaptações sem êxito.

A solução encontrada foi a utilização de um cabo de $12,7 \mathrm{~mm}$, na qual foi aplicada inicialmente uma força de protensão de 15 toneladas. Porém, após o encunhamento, esta força foi reduzida para 10 toneladas.
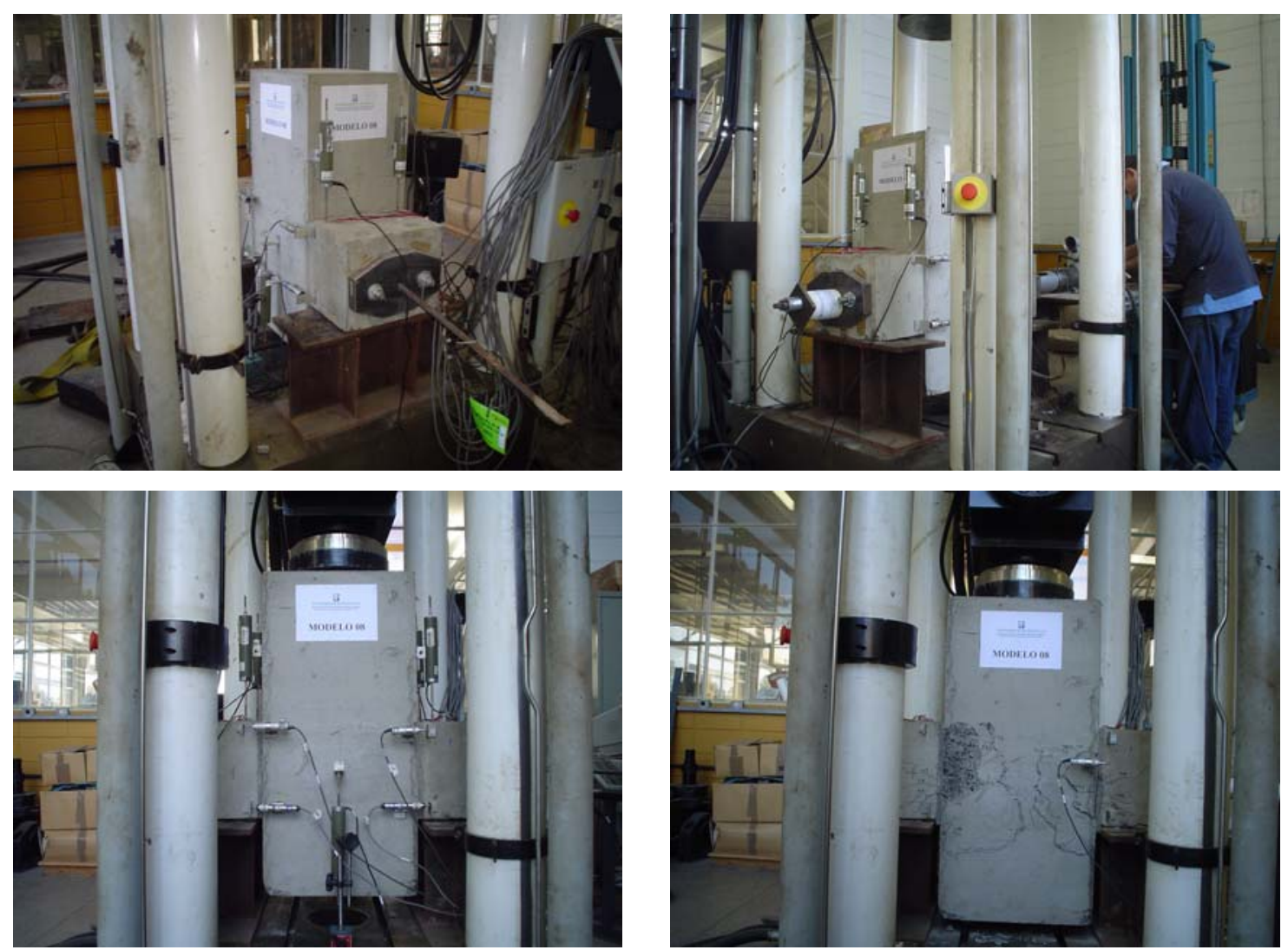

Figura 4.10: Aspecto do ensaio experimental do modelo 08

A capacidade máxima alcançada por barra foi de 169 kN (Figura 4.11), o que totalizou uma capacidade de carga do modelo de $676 \mathrm{kN}$. Assim, a carga de ruptura real do modelo superou a carga de ruptura prevista em $29 \%$. 
A rigidez inicial no último ciclo de carregamento foi de $142 \mathrm{kN} / \mathrm{mm}$. Após a força por barra atingir 83 kN, a rigidez do modelo sofreu uma redução brusca, atingindo $1,10 \mathrm{kN} / \mathrm{mm}$. Após a força por barra superar $90 \mathrm{kN}$, a rigidez aumentou, atingindo o valor de $2,59 \mathrm{kN} / \mathrm{mm}$.

As leituras dos extensômetros deixaram de ser registradas quando a força por barra atingiu o valor de 91 kN, sendo registrada a deformação de 3,82\%o (Figura 4.11b).

Conforme apresentado na Figura 4.11a, mesmo com a aplicação da protensão foi observado folgas após a aplicação dos ciclos de carga e descarga. Com base na Figura 4.11c, a folga do modelo foi da ordem de $2 \mathrm{~mm}$.

Foi observado também nesse modelo que quando o deslocamento do bloco interno em relação aos blocos externos atingiu valores próximos a $2 \mathrm{~mm}$, a almofada de apoio sofreu a primeira fissura externa.

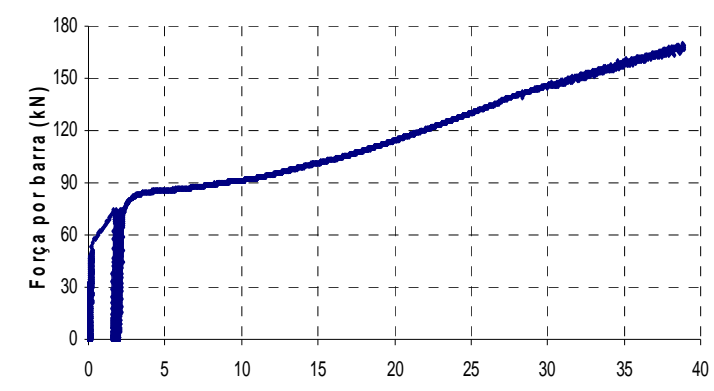

a)

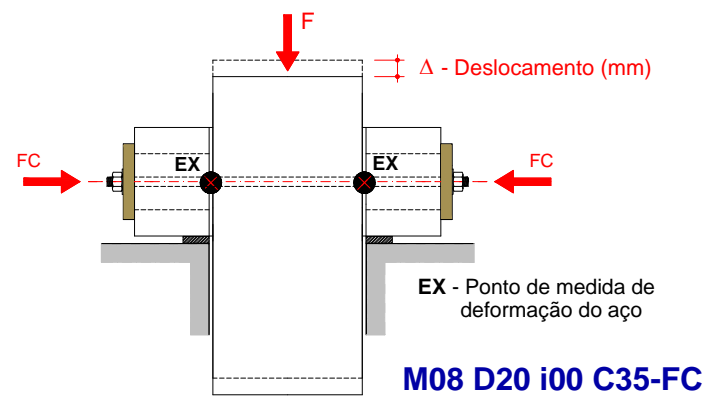

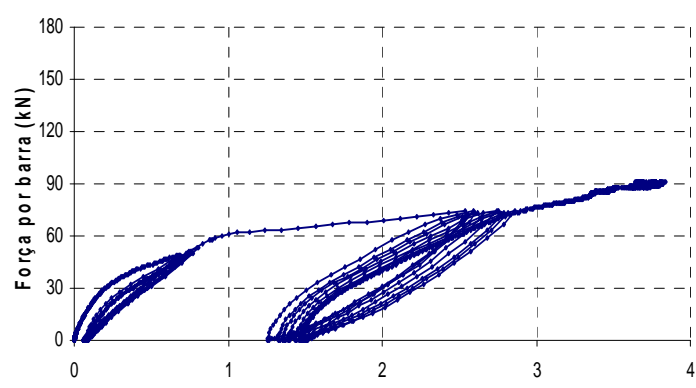

b)

Deformação /1000

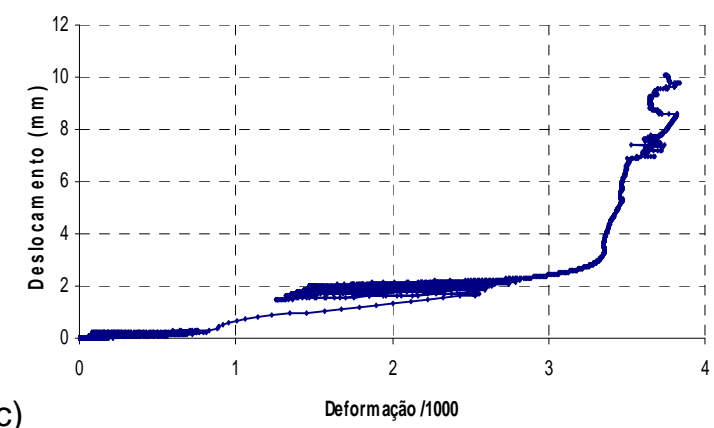

c)

Figura 4.11: Resumo dos resultados experimentais do modelo 08

Após a ruptura do modelo, foi efetuada a remoção do cobrimento de concreto adjacente ao chumbador, para verificar sua posição deformada (Figura 4.12).

Tanto DEI POLI et al. (1992) quanto ENGSTROM (1992b) propuseram expressões para estimar a posição da rótula plástica no chumbador. Baseado nas 
expressões 2.18 e 2.27, propostas por estes pesquisadores respectivamente, foi calculada a posição da rótula e comparada com o valor medido no modelo (Figura 4.12).

Na Figura 4.12 também pode ser observado claramente a formação de rótulas plásticas no chumbador, na região adjacente à almofada de apoio. A posição da rótula foi medida e comparada com valores teóricos.
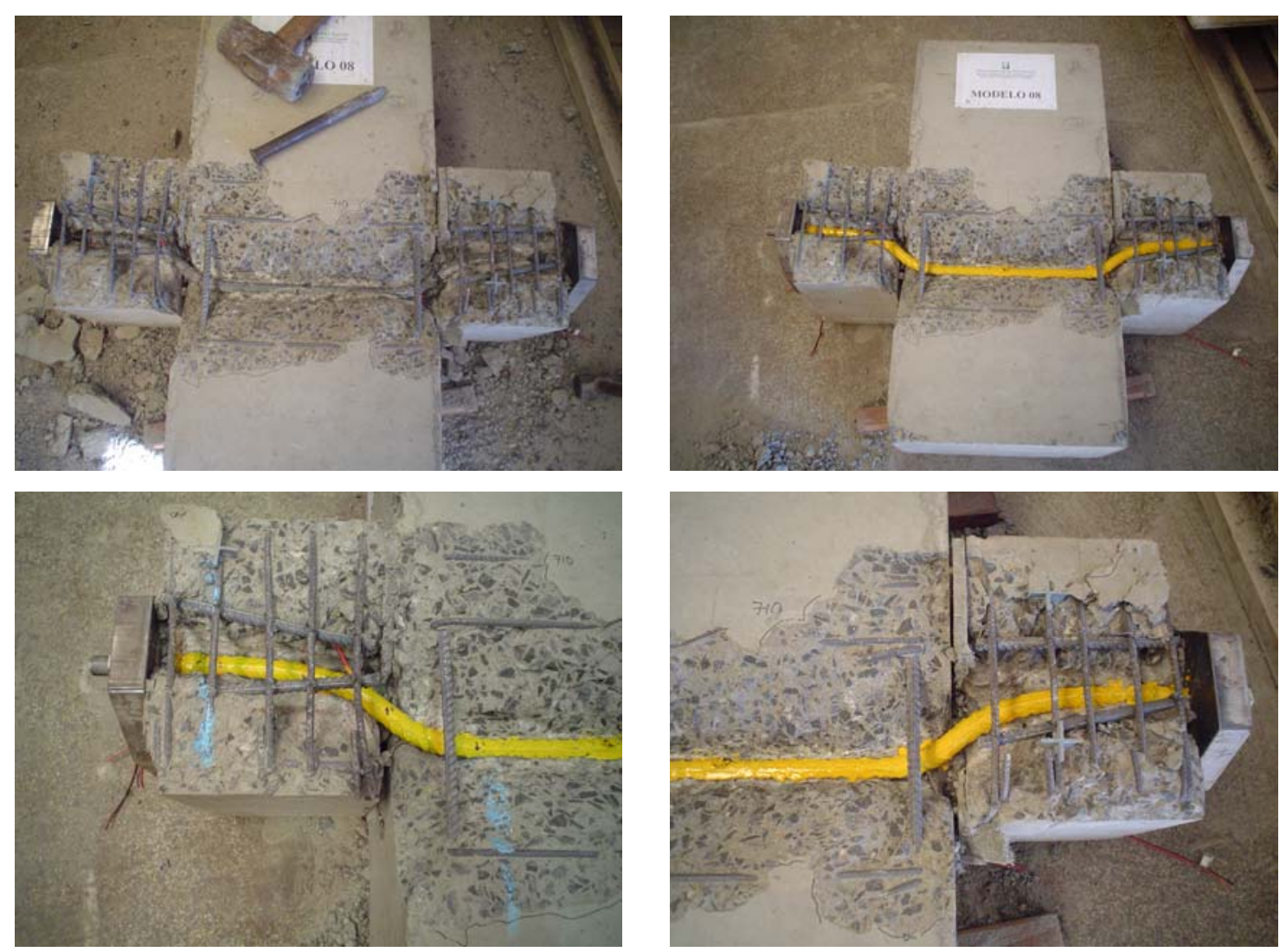

Figura 4.12: Deformada do chumbador do modelo 08

Os valores experimentais e teóricos da posição da rótula plástica são apresentados na Figura 4.13.

A expressão proposta por DEI POLI et al. (1992) subestimou a posição da rótula plástica tanto no bloco externo como no bloco interno.

Do lado esquerdo do modelo, pela expressão de ENGSTROM (1992b), chegouse a $67 \%$ do valor experimental do lado do bloco externo, e a $87 \%$ do lado do bloco interno. Pelo lado direito, chegou-se a $86 \%$ do valor experimental do lado do bloco externo, e a 95\% do lado do bloco interno. Estas diferenças do lado dos blocos externos podem ser atribuídas ao graute utilizado, que não garantiu uma boa aderência com o 
chumbador. Por esta razão optou-se pela mudança do produto descrita no item 3.3.5 deste trabalho.

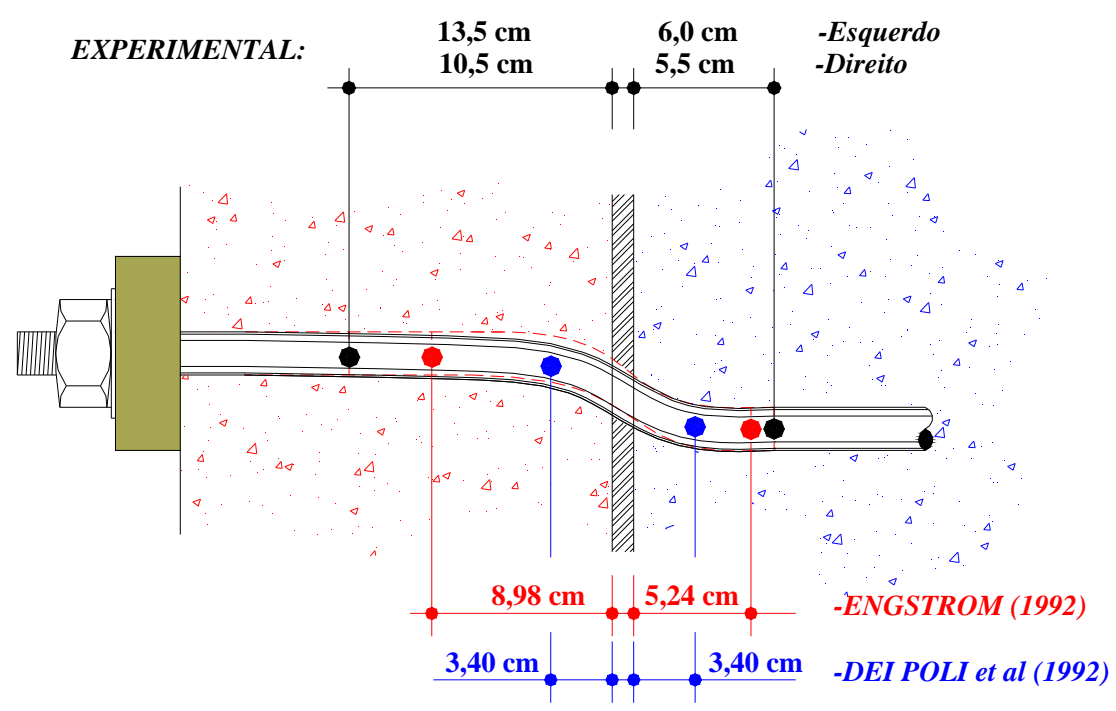

Figura 4.13: Posição experimental e teórica da rótula plástica no modelo 08

\subsection{MODELOS SEM FORÇA DE COMPRESSÃO - CLASSE C35}

\subsubsection{Modelo 01}

O modelo 01, com chumbador de $16 \mathrm{~mm}$ de diâmetro, apresentou o comportamento força por barra x deslocamento ilustrado na Figura 4.14. A capacidade máxima alcançada por barra foi de 149 kN, o que totalizou uma capacidade de carga do modelo de $596 \mathrm{kN}$. A carga de ruptura real do modelo superou a carga de ruptura prevista (Tabela 3.13) em 77\%.

Para este modelo, foi verificado grandes deslocamentos e grandes deformações na seção do chumbador. Na Figura 4.14b pode ser observado que as leituras dos extensômetros deixaram de ser registradas quando a força por barra ficou próxima de $110 \mathrm{kN}$.

Observando as Figuras 4.14b e 4.14c, verifica-se que o chumbador sofre uma mudança brusca de rigidez quando atinge a deformação de 1\%o, e cerca de $80 \mathrm{kN}$.

Na Figura 4.14a pode ser observada também a existência de folga no modelo de quase $5 \mathrm{~mm}$ entre o primeiro e o ultimo ciclo de carregamento. Esta folga se dá pela falta da aplicação de uma força de compressão. 
A rigidez no último ciclo de carregamento foi de $40,91 \mathrm{kN} / \mathrm{mm}$ na fase inicial de carregamento, sendo reduzida bruscamente para 2,60 kN/mm próximo de $80 \mathrm{kN}$ de força aplicada por barra.
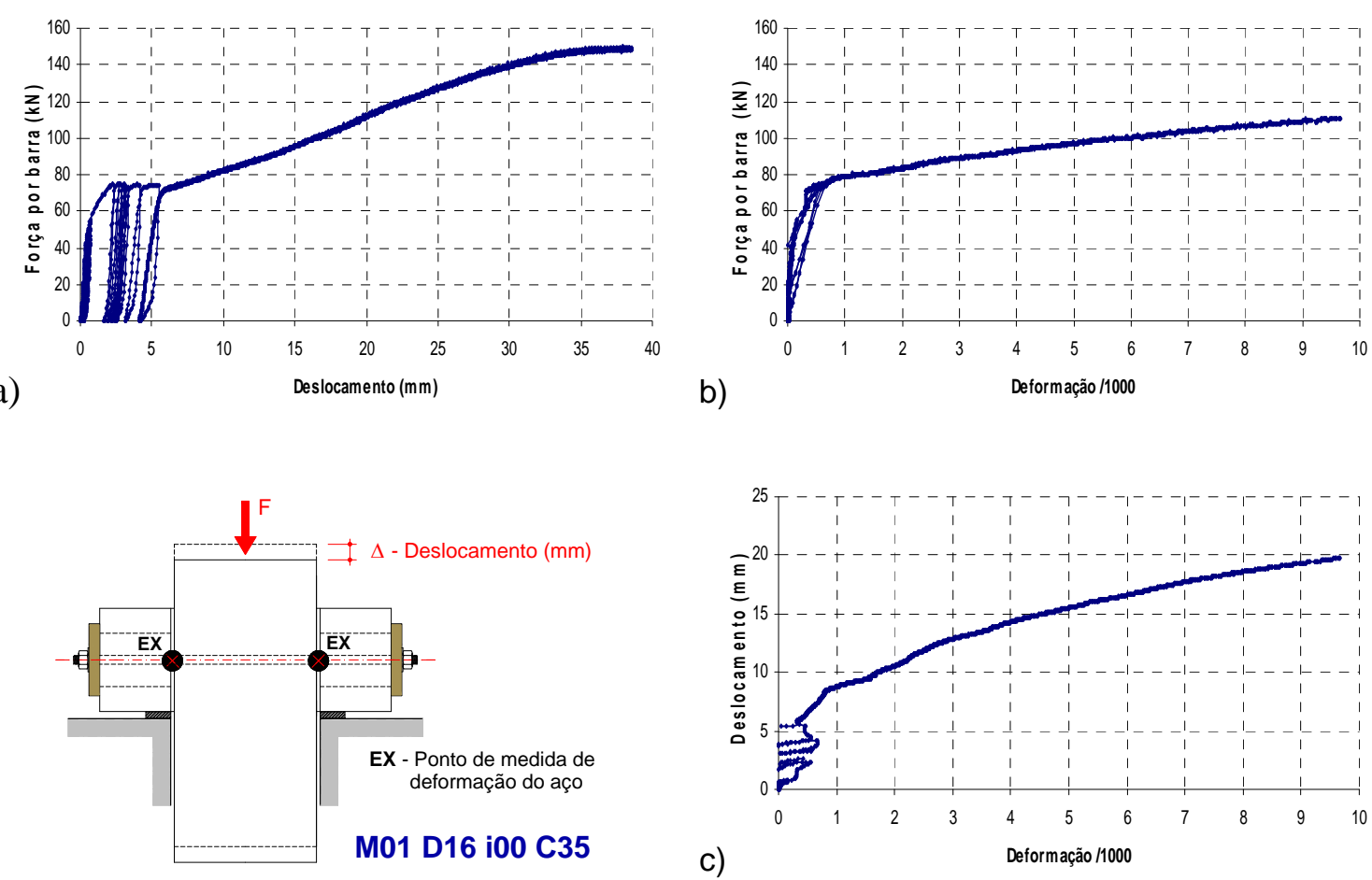

Figura 4.14: Resumo dos resultados experimentais do modelo 01

Na Figura 4.15 é apresentado o aspecto da fissuração do modelo na região de junção do bloco interno e o bloco externo. Foi observado que a almofada de apoio apresentou a primeira fissura quando o deslocamento medido no modelo alcançava valores da ordem de $2 \mathrm{~mm}$.
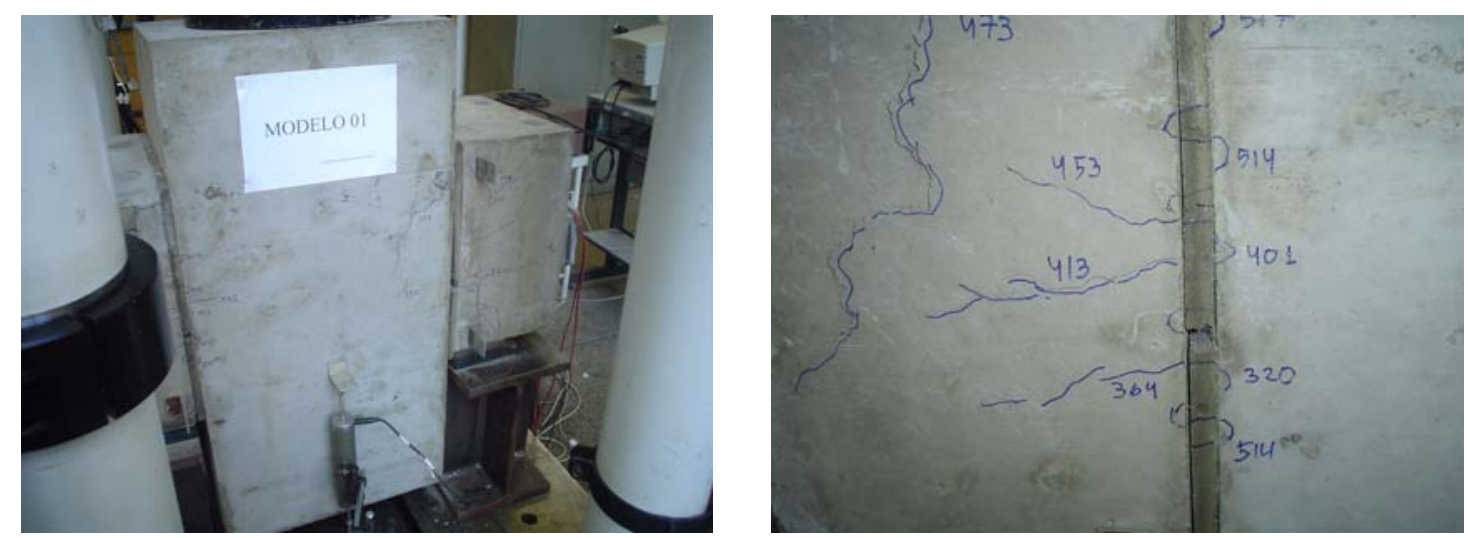

Figura 4.15: Aspecto da fissuração do modelo 01 


\subsubsection{Modelo 04}

O modelo 04, apresentou o comportamento força por barra $x$ deslocamento ilustrado na Figura 4.16. A capacidade máxima alcançada por barra foi de $253 \mathrm{kN}$, o que totalizou uma capacidade de carga do modelo de $1012 \mathrm{kN}$. A carga de ruptura real do modelo superou a carga de ruptura prevista (Tabela 3.13) em 73\%.

A rigidez após a força por barra atingir $100 \mathrm{kN}$, no último ciclo de carregamento, foi de 57,07 kN/mm. Após a força por barra atingir $200 \mathrm{kN}$, a rigidez reduziu consideravelmente para 9,48 kN/mm. Se levarmos em consideração o trecho em que a força por barra varia entre $40 \mathrm{kN}$ e $90 \mathrm{kN}$, a rigidez alcançada foi de $152,39 \mathrm{kN} / \mathrm{mm}$.

Nas Figuras 4.16b e 4.16c, pode ser verificado que não houve mudanças bruscas no comportamento do chumbador. Foi observada uma deformação residual no chumbador de $0,6 \%$ antes da aplicação do último ciclo de carregamento.

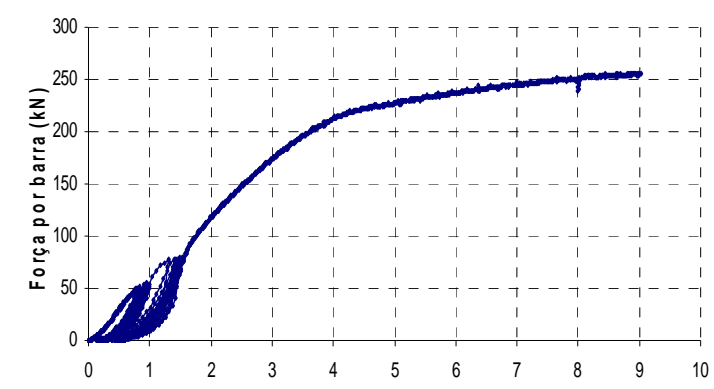

a)

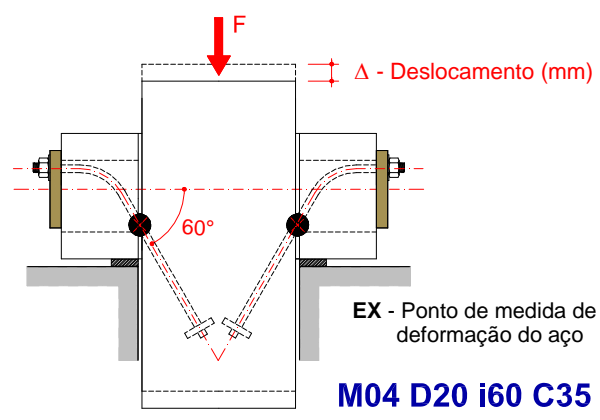

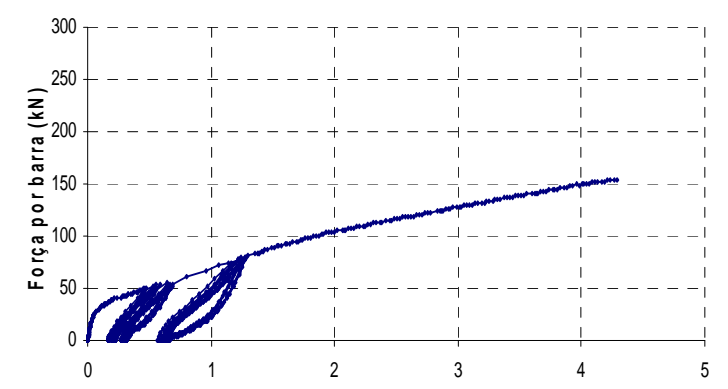

b)

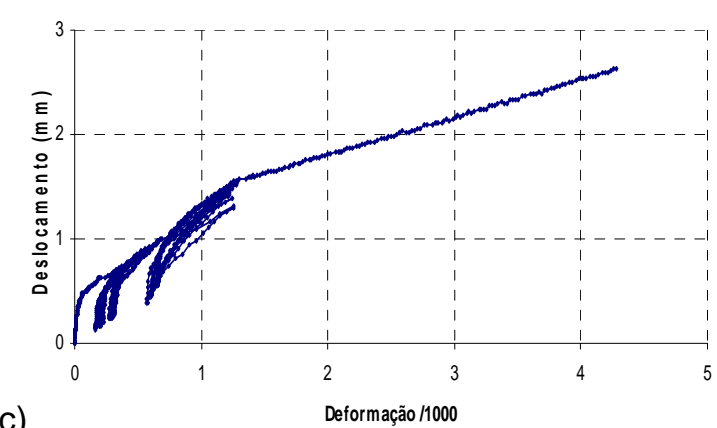

Figura 4.16: Resumo dos resultados experimentais do modelo 04

Na Figura 4.17 é apresentado um panorama geral do ensaio realizado na máquina INSTRON 8506. 

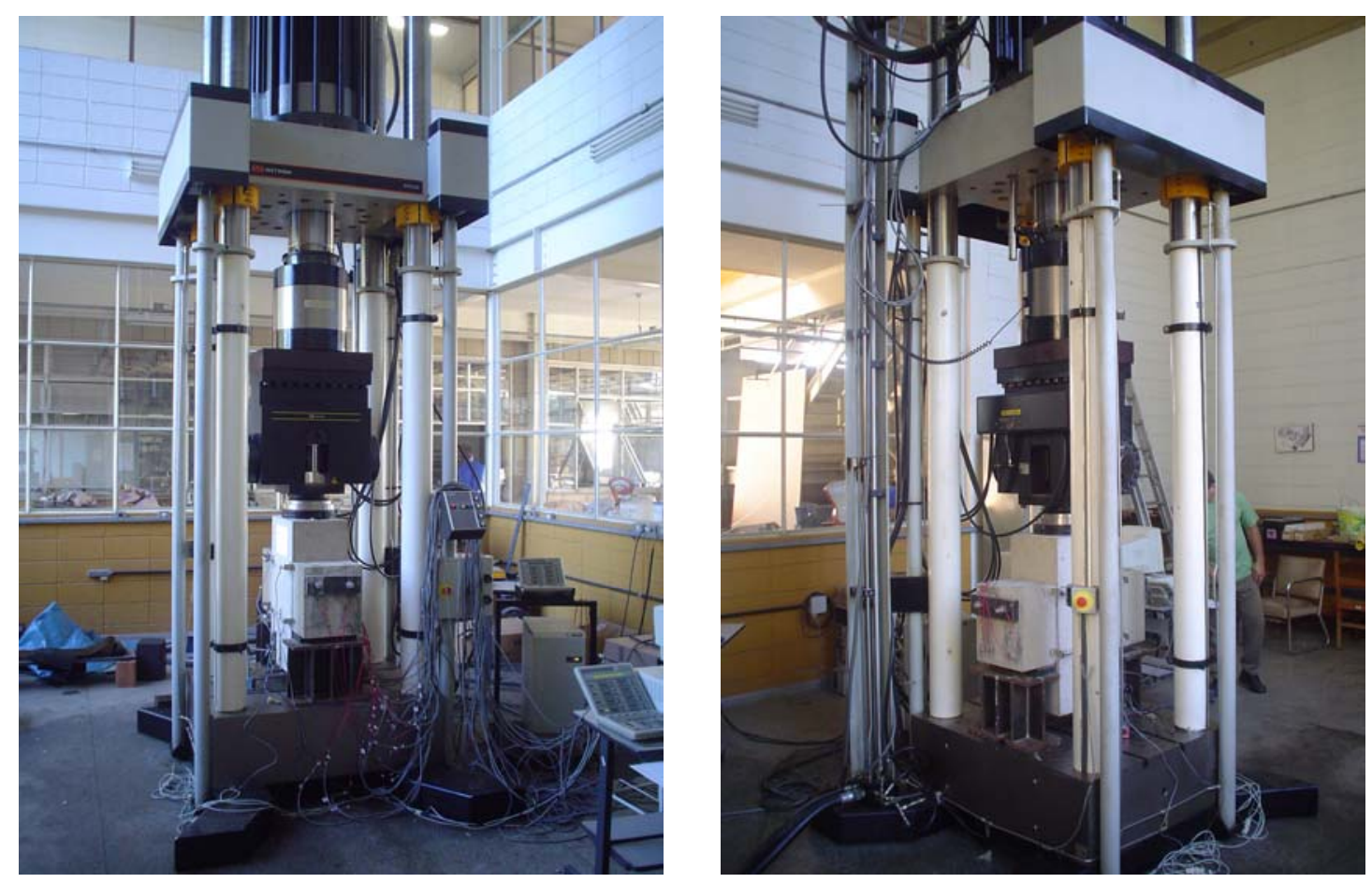

Figura 4.17: Esquema do ensaio experimental do modelo 04

\subsubsection{Modelo 05}

A capacidade máxima alcançada por barra foi de $202 \mathrm{kN}$ (Figura 4.18), o que totalizou uma capacidade de carga do modelo de $808 \mathrm{kN}$. A carga de ruptura real do modelo superou a carga de ruptura prevista em apenas 7\%.

A rigidez inicial no último ciclo de carregamento foi de $115,14 \mathrm{kN} / \mathrm{mm}$. Após a força por barra atingir $150 \mathrm{kN}$, a rigidez reduziu consideravelmente para 1,66 kN/mm.

Nas Figuras 4.18b e 4.18c, verifica-se mudanças no comportamento do chumbador quando a deformação ultrapassa 4\%. Após superado esse valor, percebe-se uma acentuada redução na rigidez do modelo.

Na Figura 4.19 é apresentado um panorama geral da fissuração observada no modelo. Foi verificado que a almofada de apoio apresentou a primeira fissura quando o deslocamento vertical do bloco interno se aproximou de $2 \mathrm{~mm}$.

Para este modelo, foi verificado que a configuração de aparecimento das fissuras nos dois blocos externos foram bem semelhantes, sendo que o surgimento de tais fissuras ocorreu quando a carga por barra superou $150 \mathrm{kN}$. 


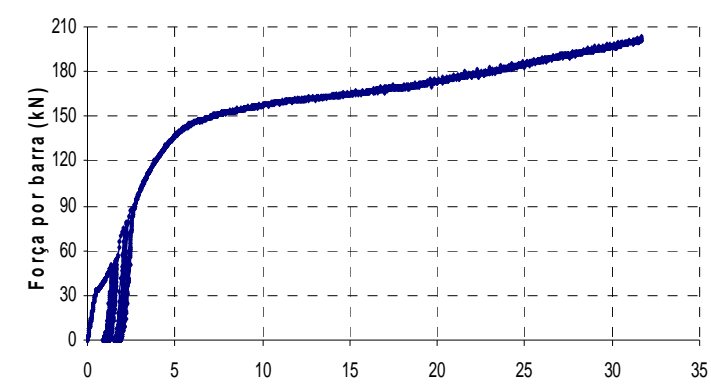

a)

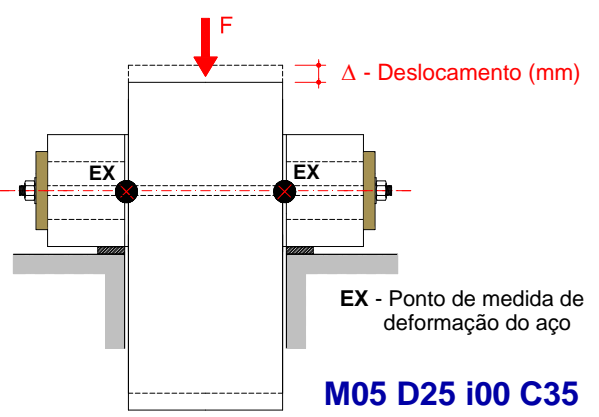

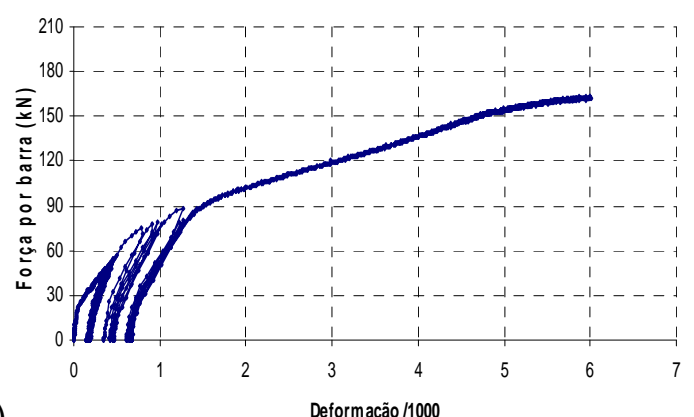

b)

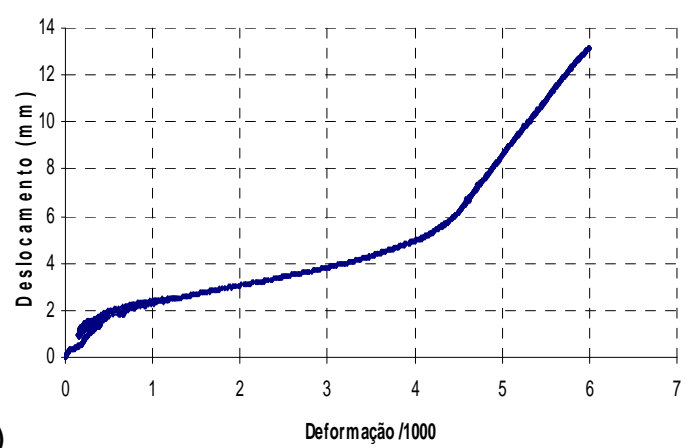

c)

Figura 4.18: Resumo dos resultados experimentais do modelo 05
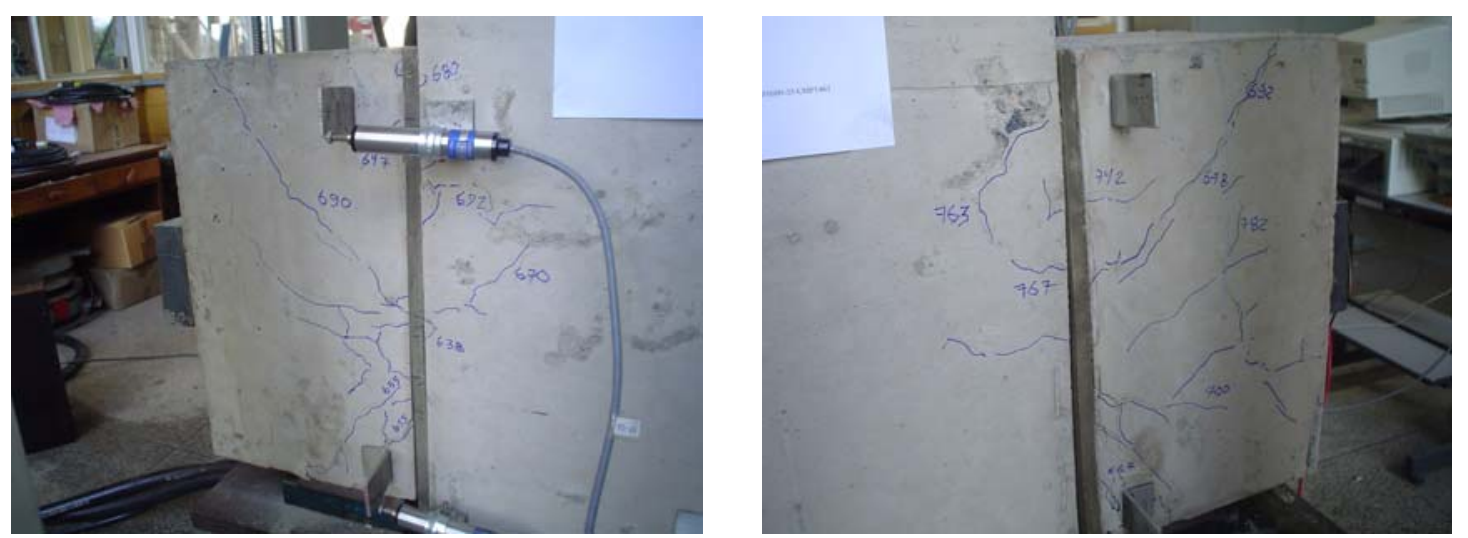

Figura 4.19: Aspecto da fissuração dos blocos externos do modelo 05

\subsubsection{Modelo 06}

Para o modelo 06, a capacidade máxima alcançada por barra foi de $308 \mathrm{kN}$ (Figura 4.20), o que totalizou uma capacidade de carga do modelo de $1232 \mathrm{kN}$. Assim, a carga de ruptura real do modelo superou a carga de ruptura prevista em $45 \%$. 


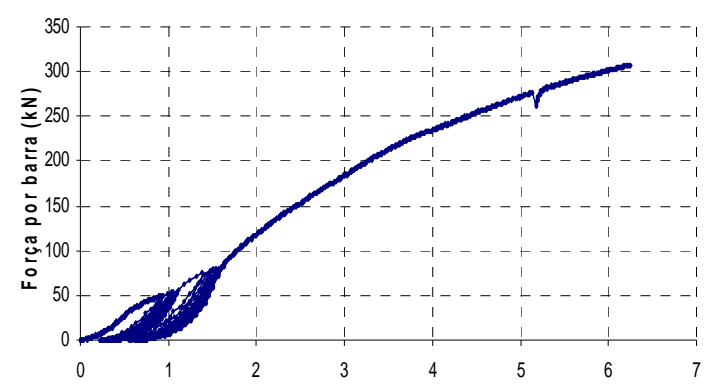

a)

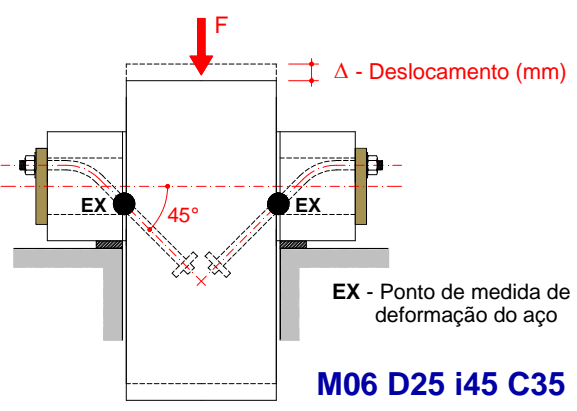

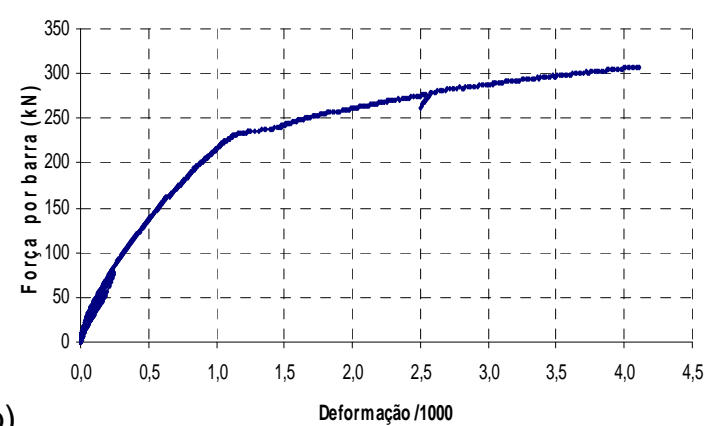

b)

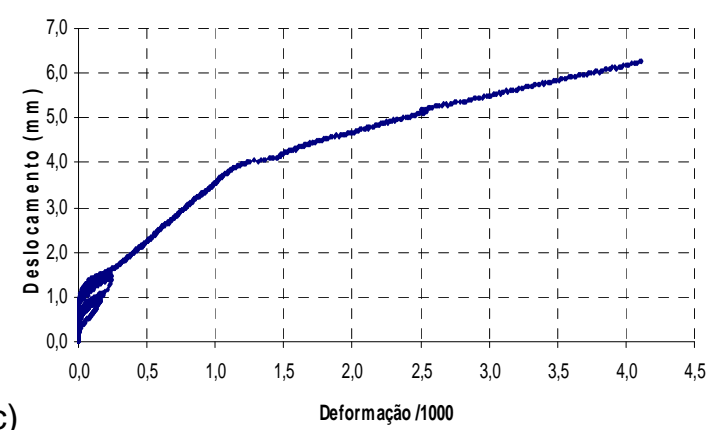

c)

Figura 4.20: Resumo dos resultados experimentais do modelo 06

A rigidez inicial no último ciclo de carregamento foi de 96,97 kN/mm. Após a força por barra atingir $110 \mathrm{kN}$, a rigidez do modelo reduziu para 65,90 kN/mm.

Conforme apresentado na Figura 4.20b, os extensômetros conseguiram registrar as deformações dos chumbadores até o final do ensaio.

Com base nas Figuras 4.20b e 4.20c, quando a força por barra alcançou 236 kN, houve uma mudança no comportamento do chumbador, o que caracterizou uma pequena redução na rigidez do modelo quando o deslocamento vertical do bloco interno ultrapassou o valor de $4 \mathrm{~mm}$. Tal fenômeno pode ser interpretado pela perda de aderência aço-concreto, podendo ser a abertura de uma fissura ou escorregamento da barra.

Na Figura 4.21 é apresentado o ensaio do modelo 06 realizado na máquina INSTRON 8506.

Após o fim do ensaio, o modelo foi transportado para a área externa do Laboratório de Estruturas do SET/EESC/USP e, com o auxílio de um martelete pneumático, foi removido todo o concreto adjacente ao chumbador até sua visualização plena (Figura 4.22).

Após a superfície ser lavada e devidamente seca, o chumbador foi pintado na cor amarela para uma melhor visualização (Figura 4.22). 

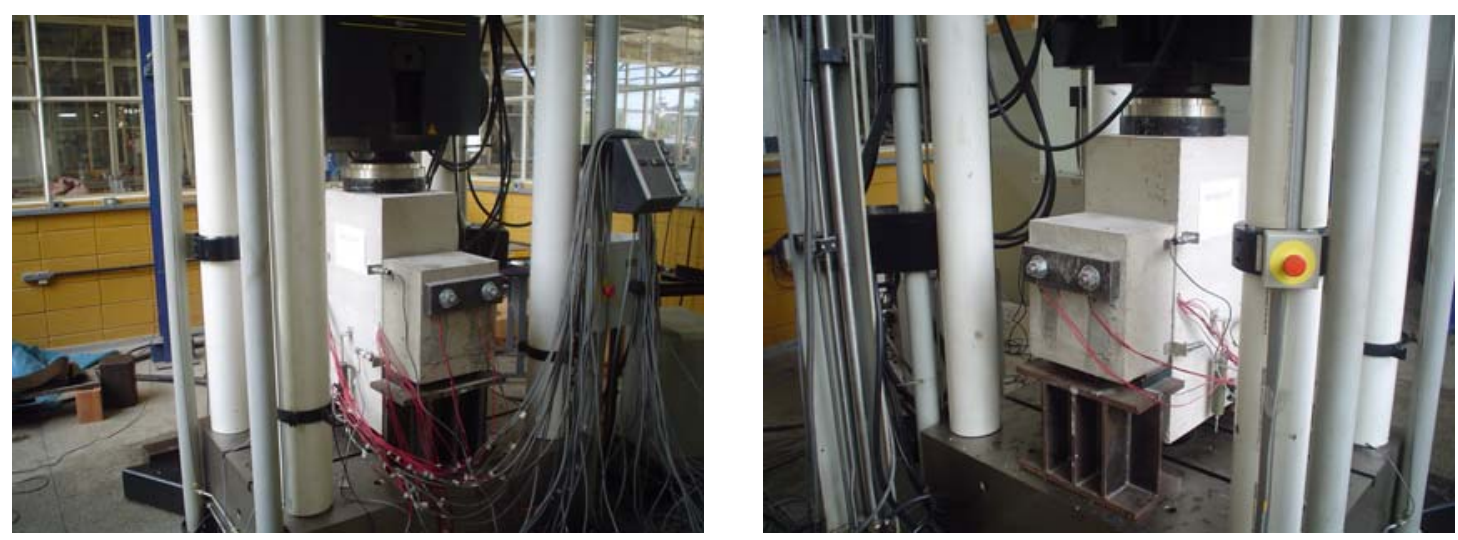

Figura 4.21: Vista do ensaio realizado no modelo 06

Analisando os chumbadores após a realização do ensaio, percebeu-se que houve uma leve tendência de retificação da sua parte curva, posicionada na região do bloco externo. Isso deu indícios da existência de esforços de tração atuando no chumbador.
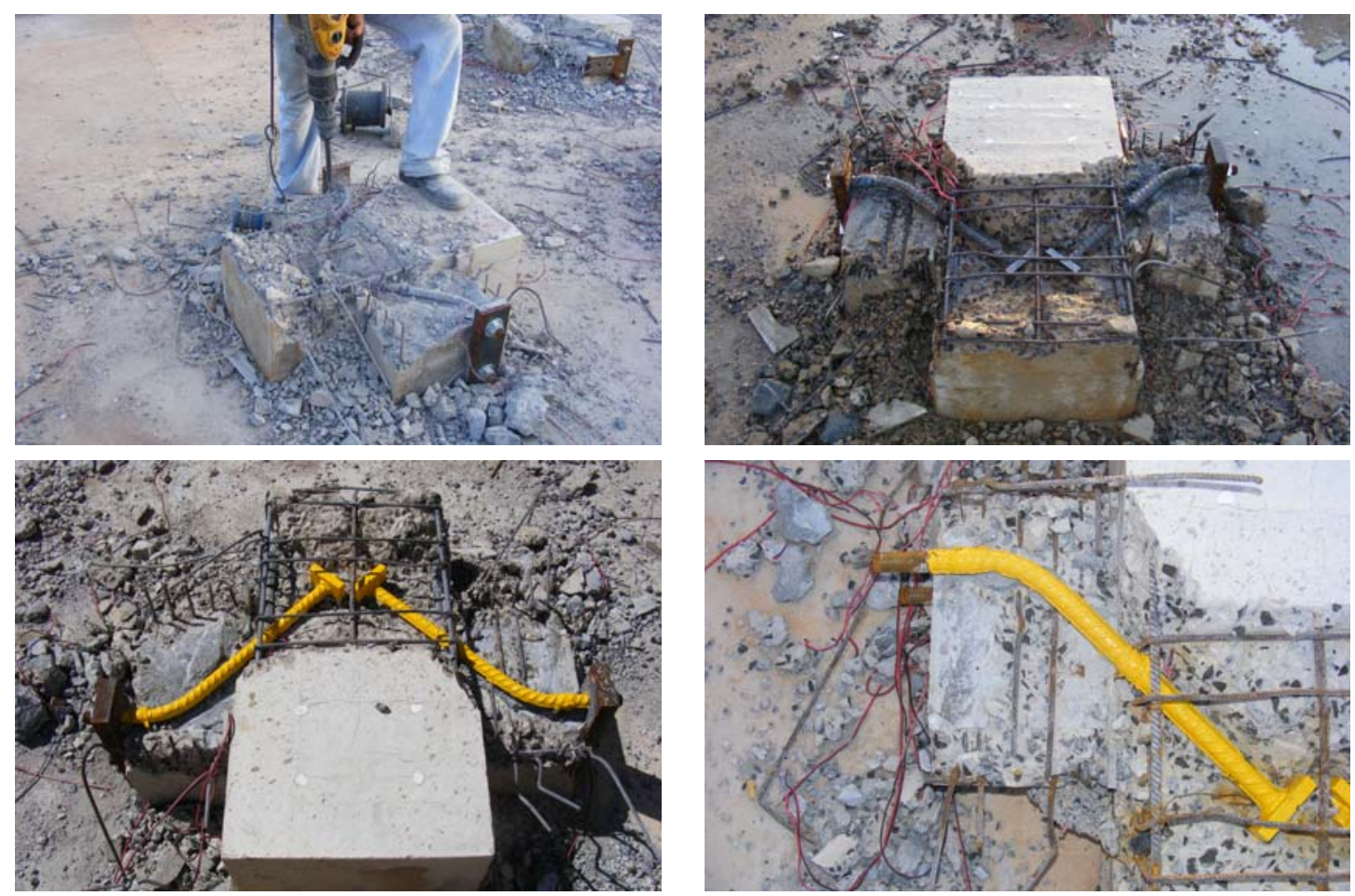

Figura 4.22: Visualização do chumbador do modelo 06 após a ruptura.

\subsection{MODELOS COM FORÇA DE COMPRESSÃO - CLASSE C35}




\subsubsection{Modelo 07}

No modelo 07 foi aplicada a força de compressão (protensão) para simular o efeito da reação de apoio da viga sobre o bloco externo. Foram utilizados duas cordoalhas engraxadas de 12,7mm, cuja força final de protensão totalizou 205,94 kN. As forças horizontais finais aplicadas foram de 95,06 kN e 110,88 kN para os cabos 1 e 2, respectivamente (Figura 4.23). Após a etapa de protensão, deu-se o início do ensaio.
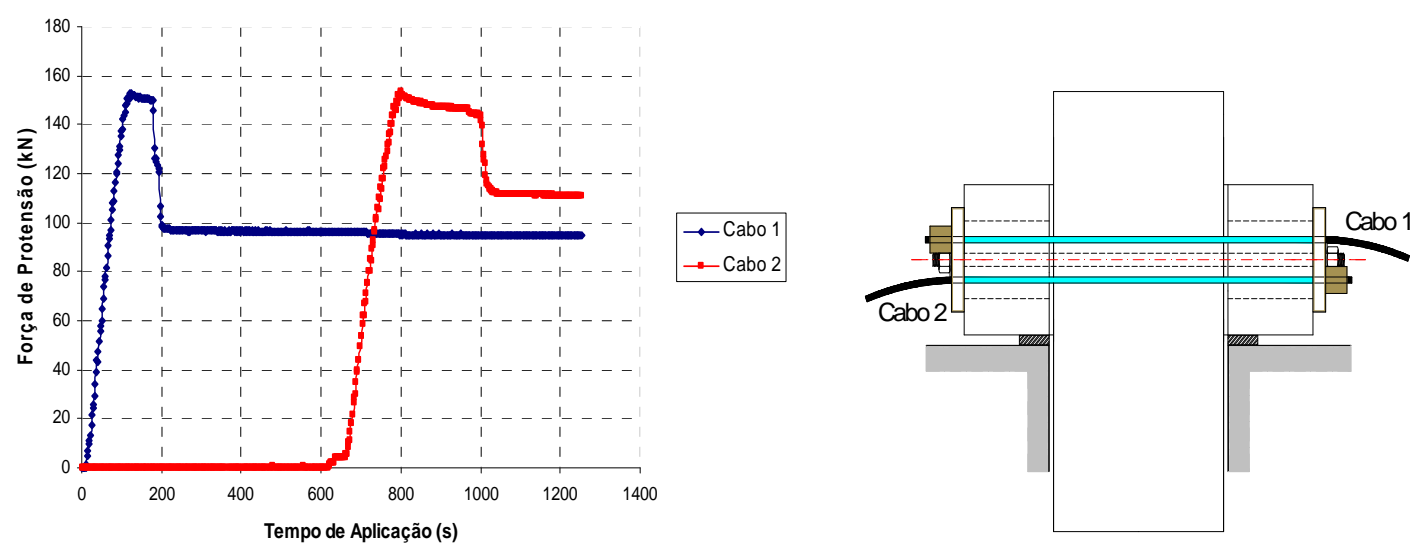

Figura 4.23: Força de protensão aplicada no modelo 07

Para o modelo 07, a capacidade máxima alcançada por barra foi de $185 \mathrm{kN}$ (Figura 4.24), o que totalizou uma capacidade de carga do modelo de $740 \mathrm{kN}$. Assim, a carga de ruptura real do modelo superou a carga de ruptura prevista em 106\%.

A rigidez inicial no último ciclo de carregamento foi de $134 \mathrm{kN} / \mathrm{mm}$. Após a força por barra atingir $100 \mathrm{kN}$, a rigidez do modelo sofreu uma redução brusca, atingindo $4,39 \mathrm{kN} / \mathrm{mm}$.

A leitura dos extensômetros deixaram de ser registradas quando a força por barra atingiu o valor de $113 \mathrm{kN}$, sendo registrada a deformação de 2,03\% (Figura 4.24b).

Conforme apresentado na Figura 4.24, não foi observado folgas após a aplicação dos ciclos de carga e descarga. Essa ausência de folgas deu-se por conta da protensão aplicada no modelo. 


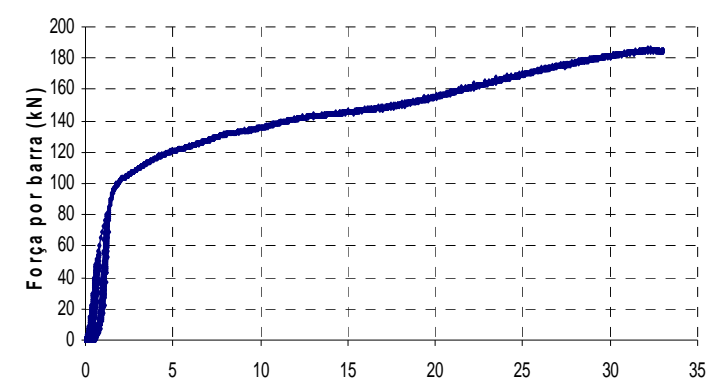

a)

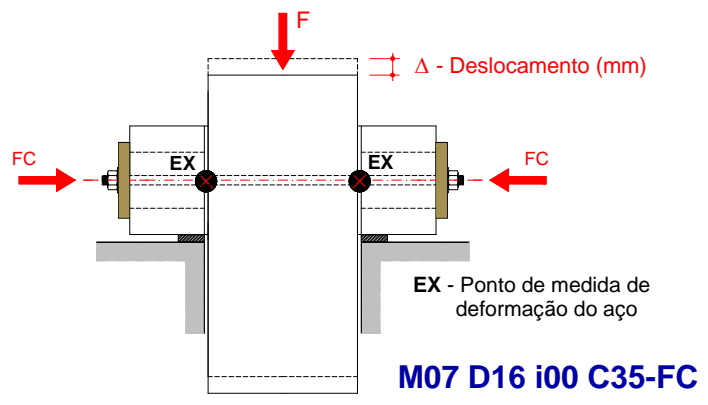

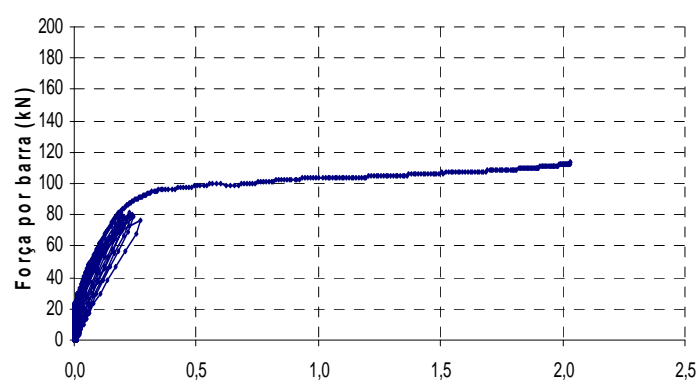

b)

Deformação $/ 1000$

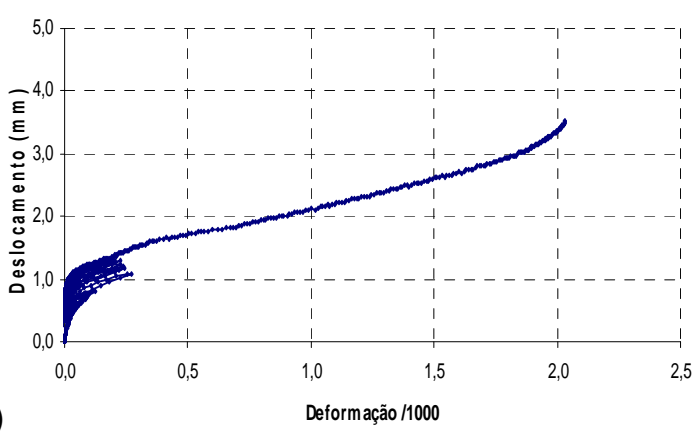

c)

Figura 4.24: Resumo dos resultados experimentais do modelo 07

Na Figura 4.25 é apresentado o aspecto da fissuração do bloco externo, onde foi observado já na fase final de carregamento o desprendimento parcial da capa de concreto. Foi observado também grandes deslocamentos (verticais) do bloco interno em relação aos blocos externos.
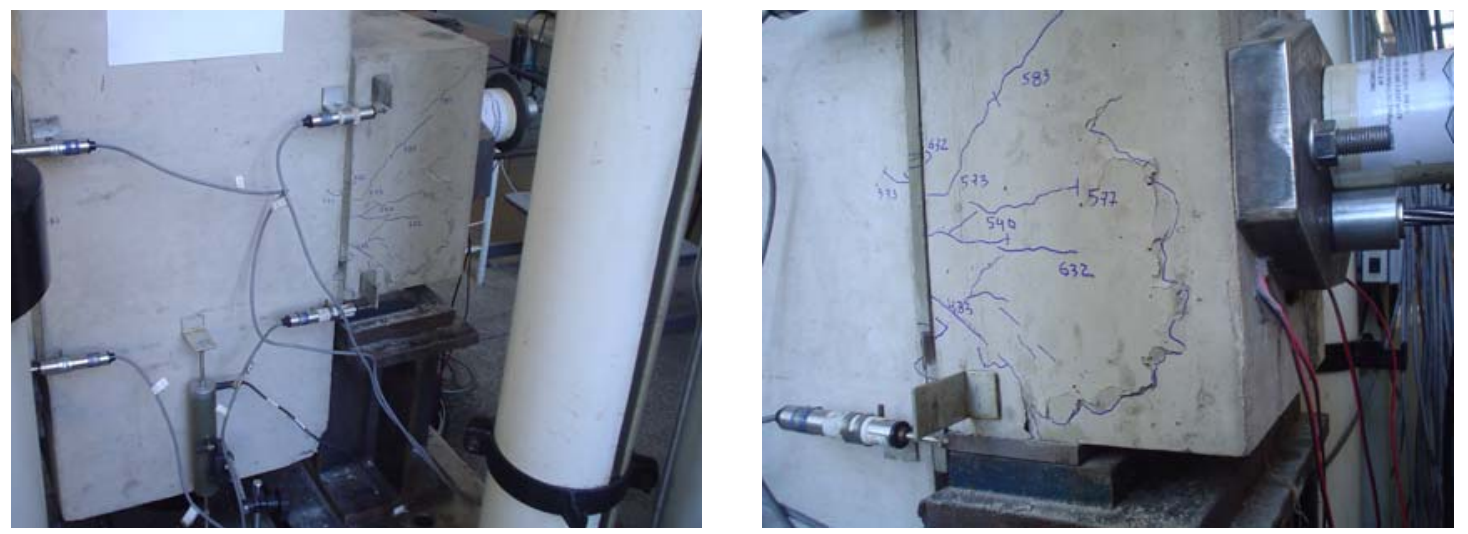

Figura 4.25: Aspecto da fissuração do bloco externo do modelo 07

Após a realização dos ensaios, o concreto adjacente ao chumbador foi removido, seguindo o mesmo procedimento descrito no modelo 06, para que pudesse ser avaliada a configuração deformada do chumbador (Figura 4.26). 

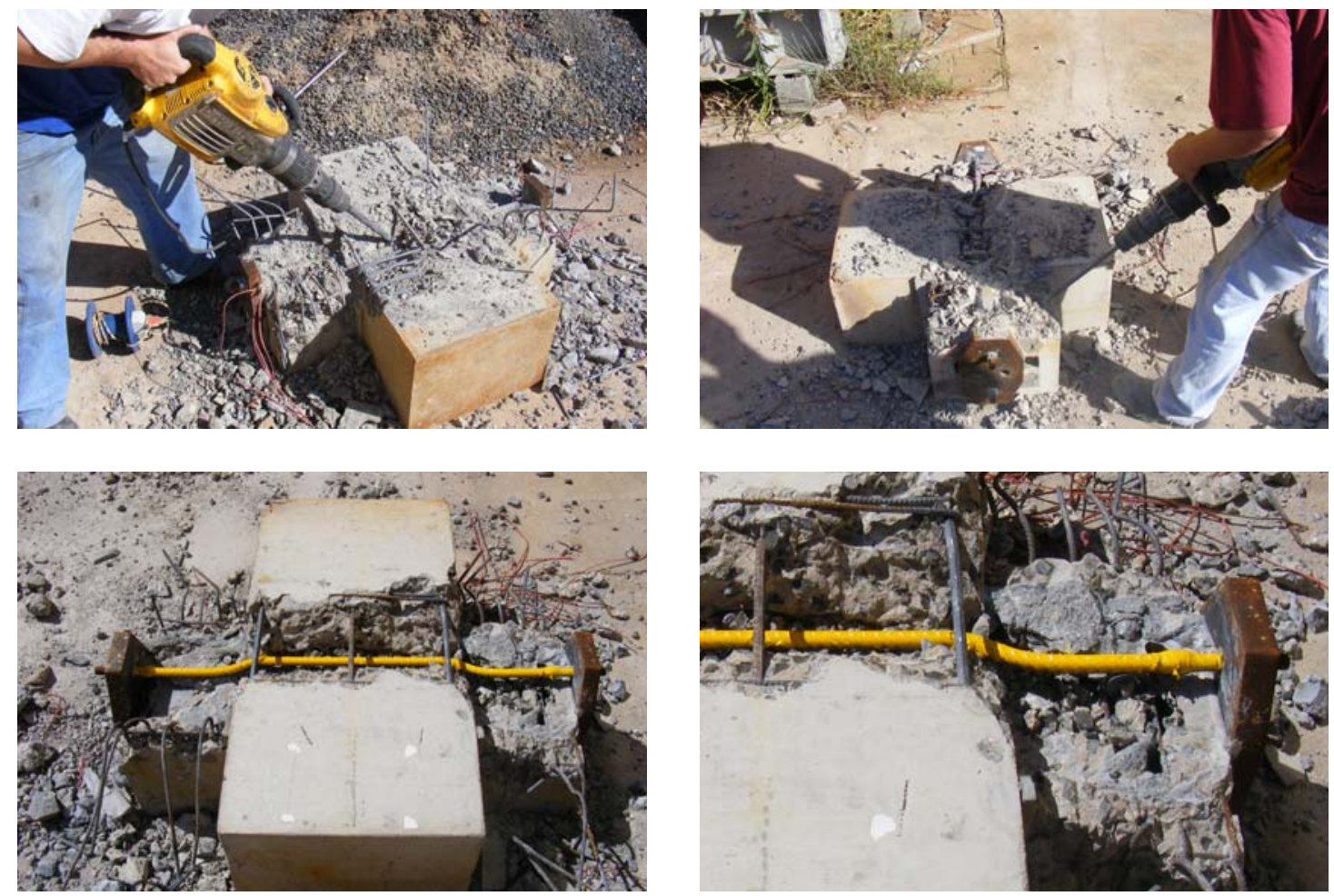

Figura 4.26: Visualização do chumbador do modelo 07 após a ruptura.

Na Figura 4.26 observa-se claramente a formação de rótulas plásticas no chumbador, na região adjacente à almofada de apoio, conforme descrito no item 2.3.3.2 deste trabalho.

Os valores experimentais e teóricos da posição da rótula plástica são apresentados na Figura 4.27. São apresentados os valores experimentais para a junção bloco externo - bloco interno tanto do lado esquerdo quanto do lado direito do modelo.

A expressão proposta por DEI POLI et al. (1992) subestimou a posição da rótula plástica tanto no bloco externo como no bloco interno. Já a proposta de ENGSTROM (1992b) conduziu a valores mais próximos dos obtidos experimentalmente. Do lado esquerdo, a expressão de ENGSTROM (1992b) superestimou a posição da rótula em 9\% do lado do bloco externo e em 10\% do lado do bloco interno. Do lado direito, a posição foi superestimada em 6\% do lado do bloco externo e em $8 \%$ do lado do bloco interno. 


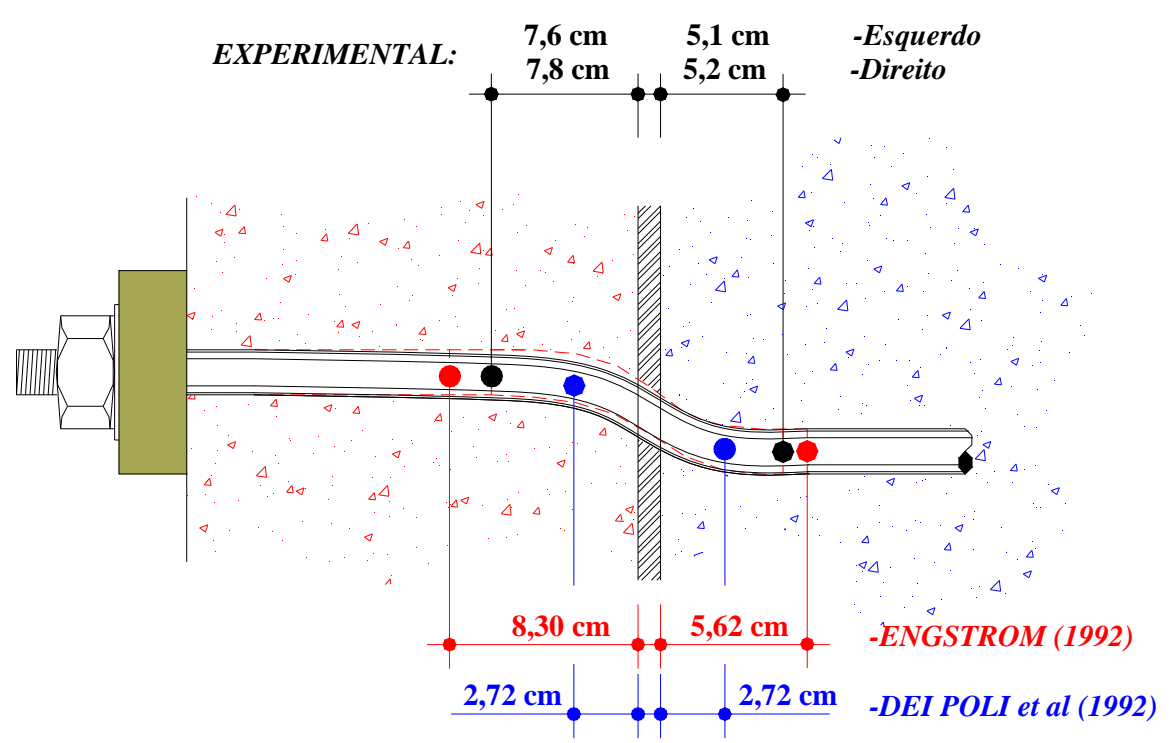

Figura 4.27: Posição experimental e teórica da rótula plástica no modelo 07

\subsubsection{Modelo 09}

No modelo 09 foi aplicada a força de compressão com a utilização de duas cordoalhas engraxadas de $12,7 \mathrm{~mm}$, cuja força final de protensão totalizou $210 \mathrm{kN}$. As forças horizontais finais aplicadas foram de $100 \mathrm{kN}$ e $110 \mathrm{kN}$ para os cabos 1 e 2, respectivamente (Figura 4.28).
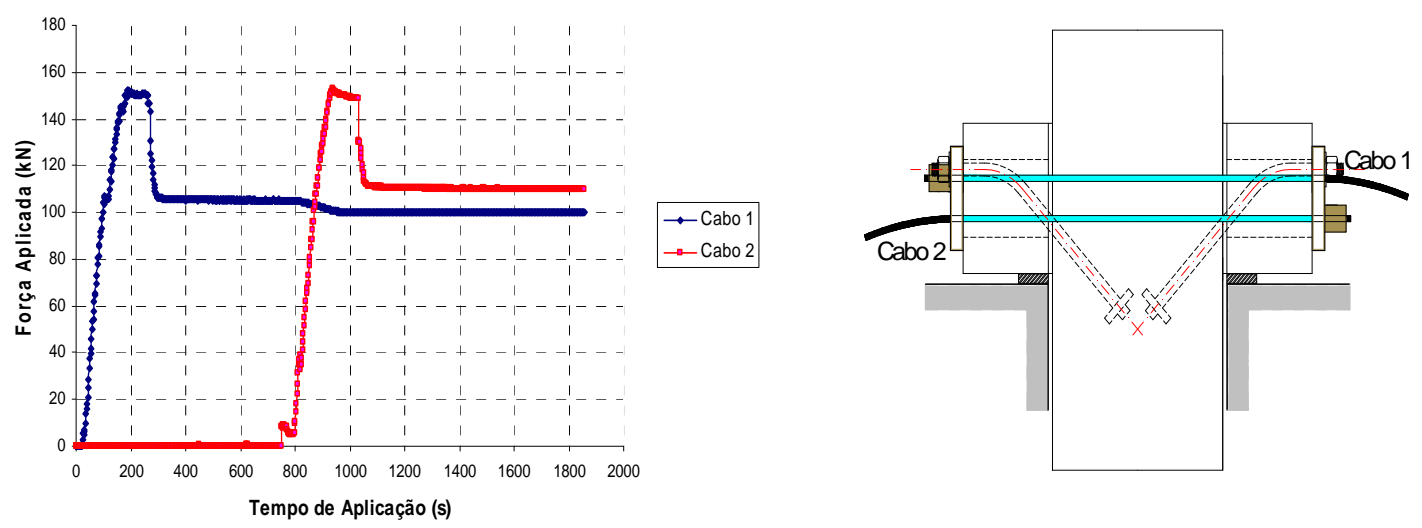

Figura 4.28: Força de protensão aplicada no modelo 09

A capacidade máxima alcançada por barra foi de 312,3 kN (Figura 4.29), o que totalizou uma capacidade de carga do modelo de 1249,2 kN. Assim, a carga de ruptura real do modelo superou a carga de ruptura prevista em 159\%. 
A rigidez inicial no último ciclo de carregamento foi de $83 \mathrm{kN} / \mathrm{mm}$, após a força por barra ter atingido $100 \mathrm{kN}$. Não foram observadas reduções bruscas na rigidez do modelo ao longo do ensaio.

As leituras dos extensômetros deixaram de ser registradas quando a força por barra atingiu o valor de $282 \mathrm{kN}$, sendo registrada a deformação de 5,93\%o (Figura 4.29b).
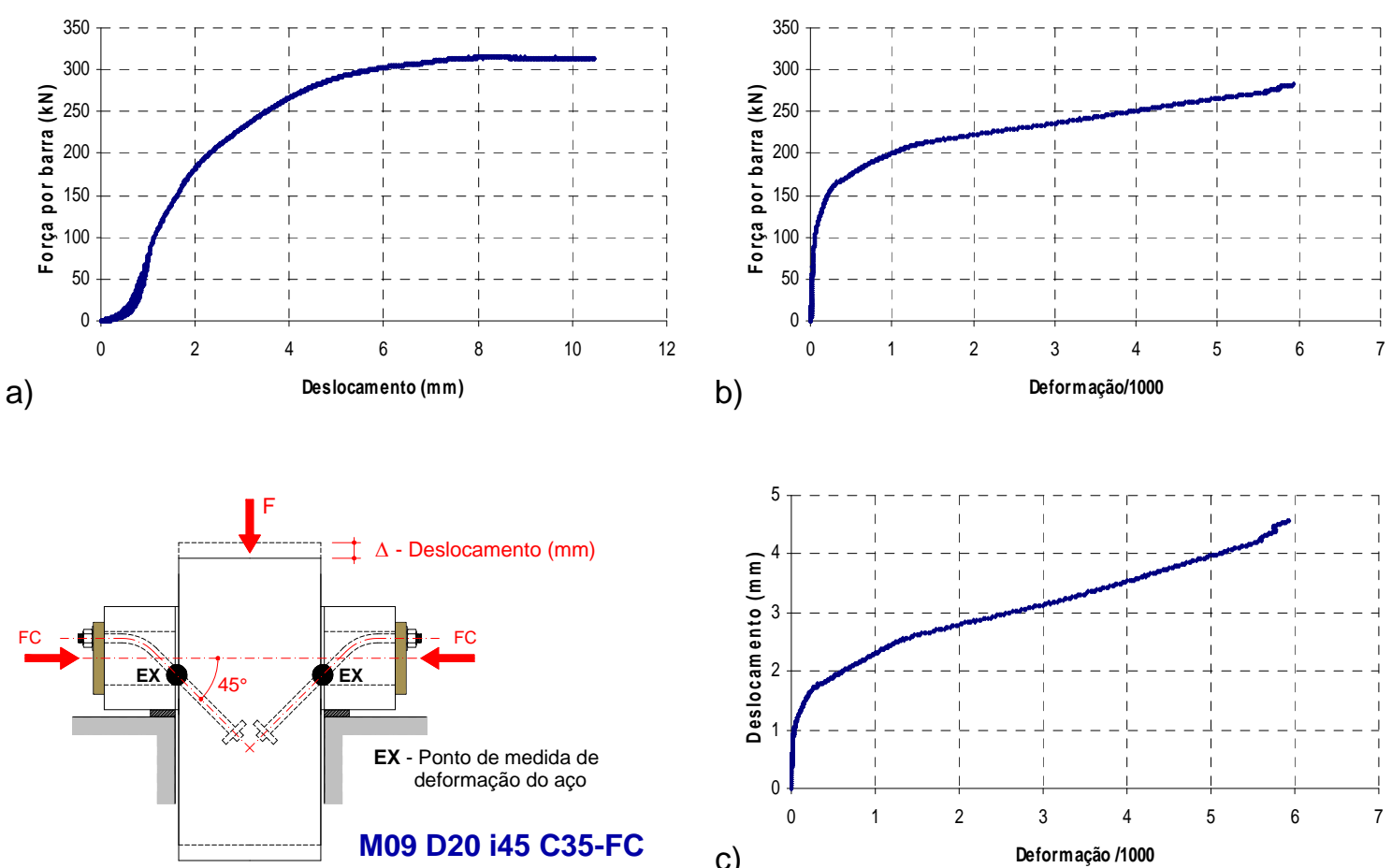

Figura 4.29: Resumo dos resultados experimentais do modelo 09

Na Figura 4.30 é apresentado um panorama geral da fissuração observada na região dos blocos externos. Foi verificado que a primeira fissura externa na região da almofada de apoio também surgiu quando o deslocamento do bloco interno em relação aos blocos externos atingiu valor próximo a $2 \mathrm{~mm}$.

Após a ruptura do modelo, foi realizada a remoção do cobrimento de concreto adjacente ao chumbador, para a verificação de sua posição deformada (Figura 4.31).

Analisando os chumbadores após a realização do ensaio percebeu-se a mesma tendência de retificação da parte curva já comentada no modelo 06, o que reforçou a idéia de predominância de esforços de tração atuando no chumbador. 

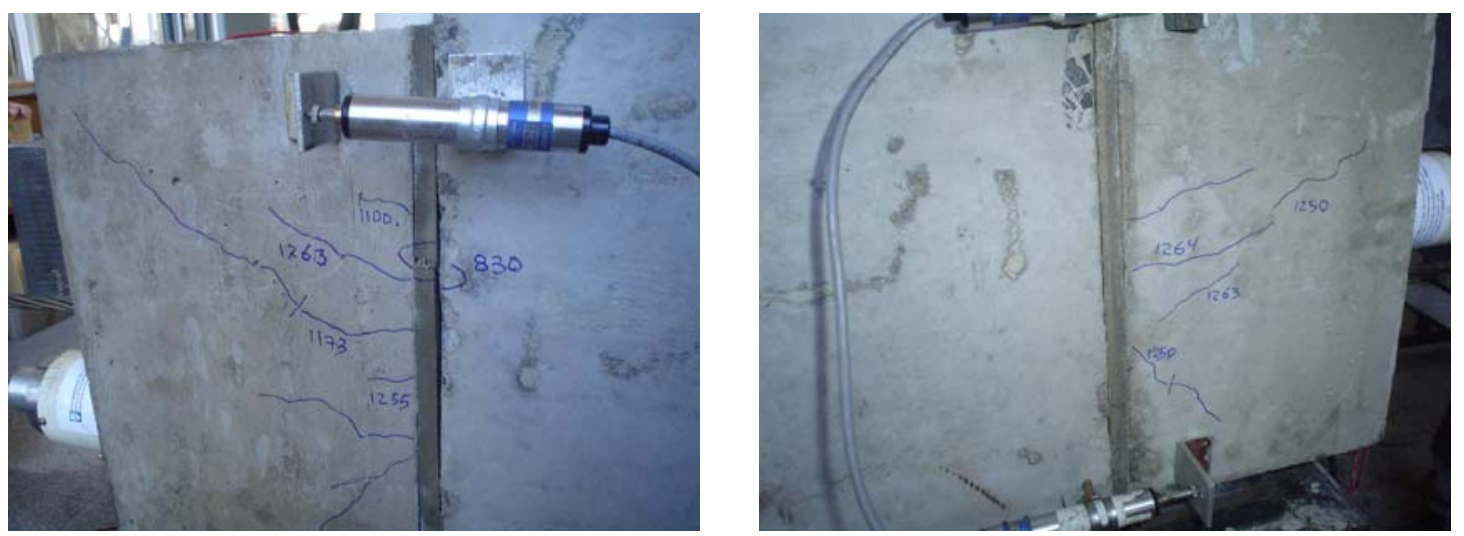

Figura 4.30: Aspecto da fissuração dos blocos externos do modelo 09.
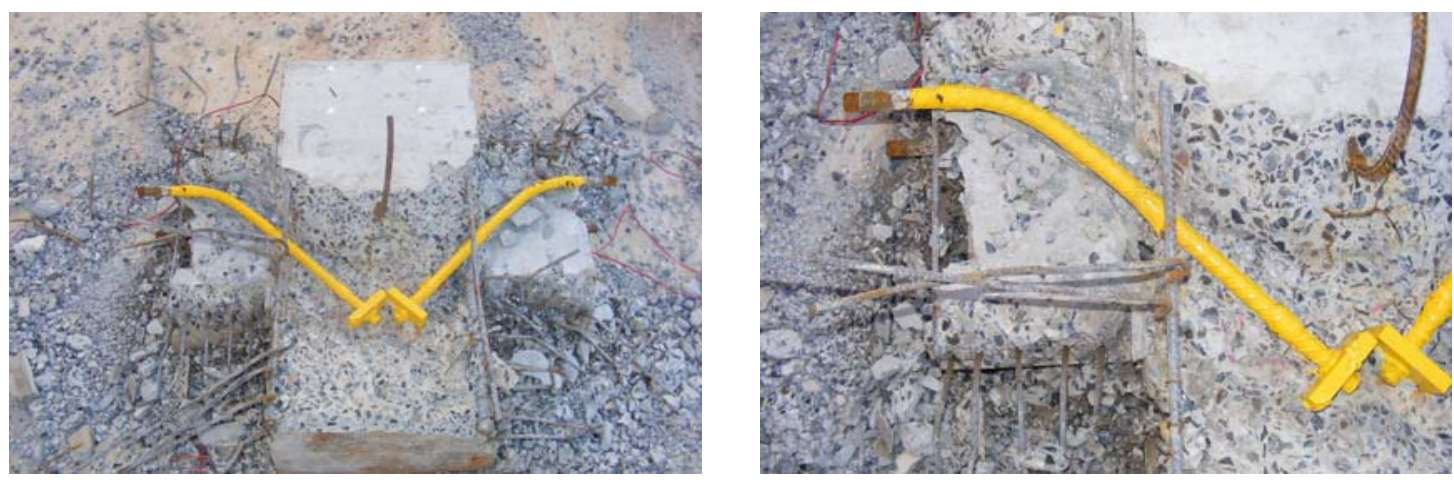

Figura 4.31: Deformada do chumbador do modelo 09

\subsubsection{Modelo 10}

No modelo 10 a força final de protensão totalizou 214,2 kN. As forças horizontais finais aplicadas foram de $98,2 \mathrm{kN}$ e $116 \mathrm{kN}$ para os cabos 1 e 2, respectivamente (Figura 4.32).

A capacidade máxima alcançada por barra foi de $252 \mathrm{kN}$ (Figura 4.34), o que totalizou uma capacidade de carga do modelo de 1008 kN. Assim, a carga de ruptura real do modelo superou a carga de ruptura prevista em 109\%.

A rigidez inicial no último ciclo de carregamento foi de $158 \mathrm{kN} / \mathrm{mm}$. Após a força por barra ter atingido 135 kN, a rigidez sofreu uma redução, atingindo o valor de 42 kN/mm. Não foram observadas reduções bruscas na rigidez do modelo ao longo do ensaio. 

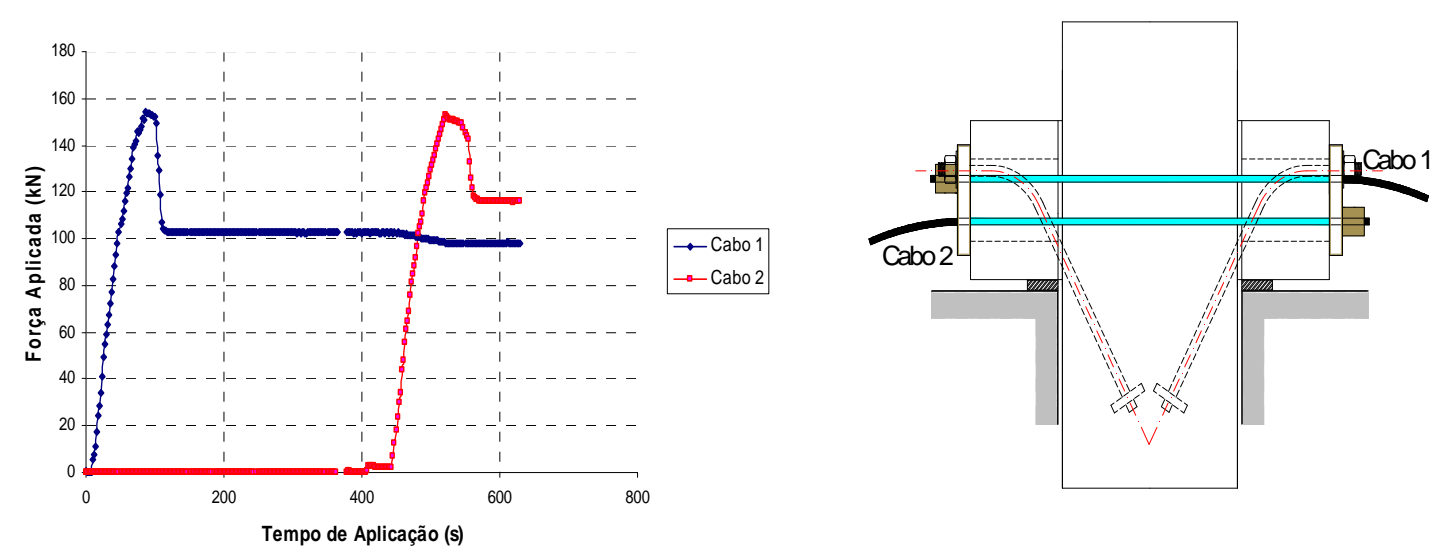

Figura 4.32: Força de protensão aplicada no modelo 10

Na Figura 4.33 é apresentado o esquema do ensaio realizado e o detalhe de ancoragem utilizado no sistema de protensão adotado.
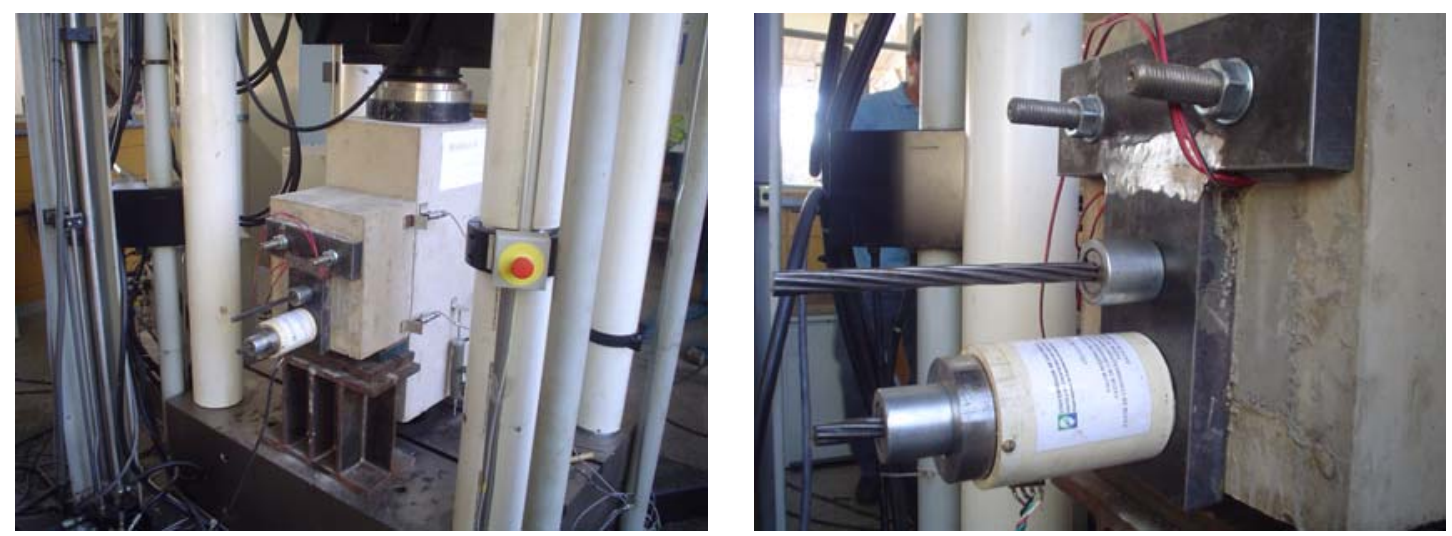

Figura 4.33: Aspecto da protensão realizada no modelo 10

Quando a força aplicada por barra atingiu 214,4 $\mathrm{kN}$ as leituras dos extensômetros deixaram de ser registradas, sendo 4,79\%o a última deformação do chumbador registrada na interface bloco externo - bloco interno.

Nas Figuras 4.34b e 4.34c pode-se perceber uma mudança no comportamento do chumbador quando a força por barra atinge 100 kN. Tal mudança dá indícios de redução da aderência causada pela formação de fissuras ou acomodações do modelo.

Após a ruptura do modelo, foi realizada a remoção do cobrimento de concreto adjacente ao chumbador, para a verificação de sua posição deformada (Figura 4.35).

Analisando os chumbadores após a realização do ensaio percebeu-se que a tendência de retificação da parte curva foi mais evidenciada nesse modelo. 

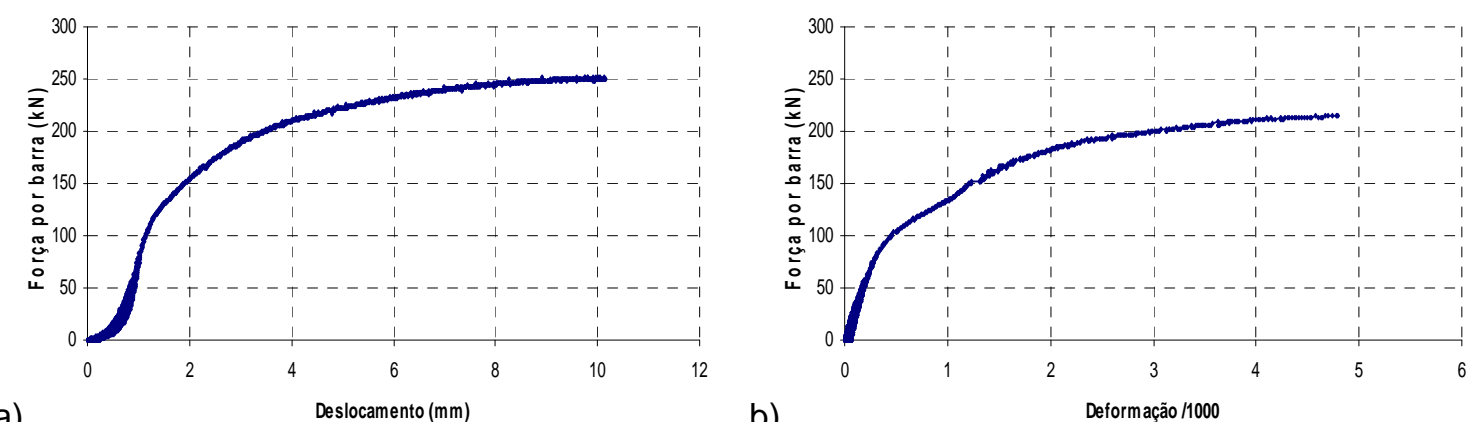

a)

b)
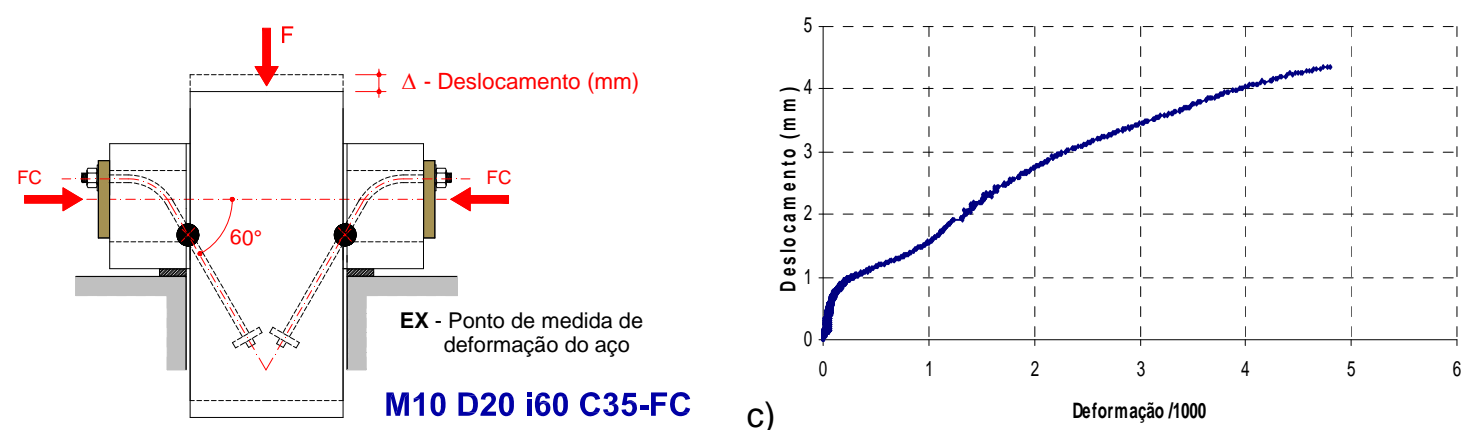

Figura 4.34: Resumo dos resultados experimentais do Modelo 10
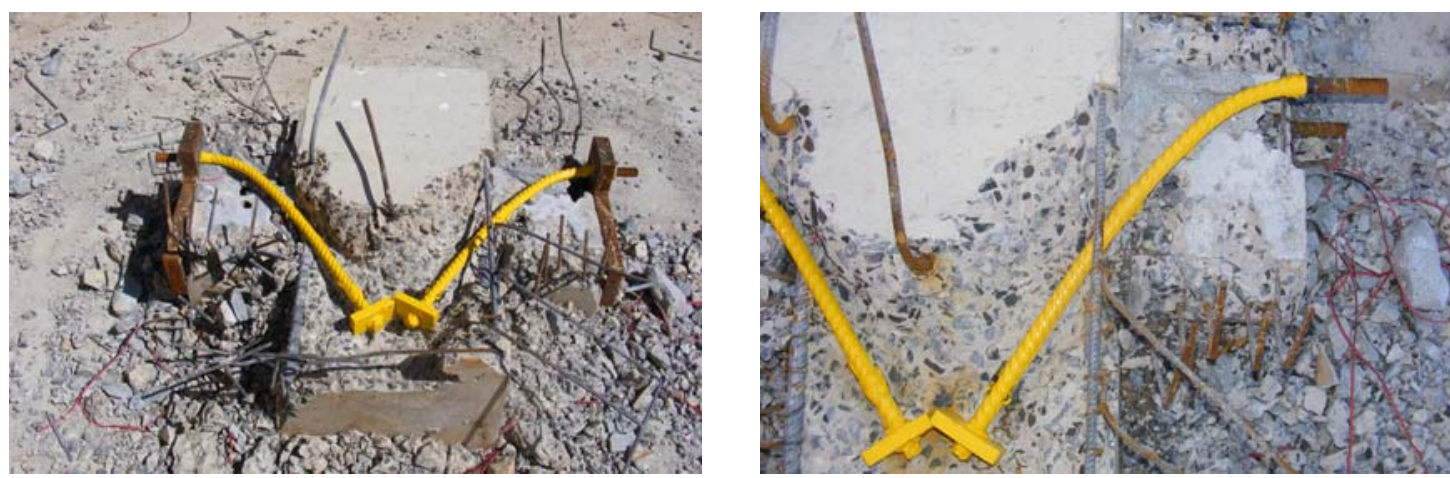

Figura 4.35: Deformada do chumbador do modelo 10.

\subsubsection{Modelo 11}

No modelo 11 a força final de protensão totalizou 187,3 kN. As forças horizontais finais aplicadas foram de $96,8 \mathrm{kN}$ e $90,5 \mathrm{kN}$ para os cabos 1 e 2, respectivamente (Figura 4.36). 
O valor final da força de protensão ficou bem próximo do valor estimado como reação de apoio da viga em uma ligação viga-pilar com dimensões usuais (180 kN).

Conforme ilustrado na Figura 4.36, o modelo 11 apresentou dificuldades para ancoragem dos cabos, havendo perdas de protensão superiores às observadas nos outros modelos já apresentados. Assim, o procedimento adotado foi protender novamente cada cabo até que a força final atingisse valor superior a $90 \mathrm{kN}$.
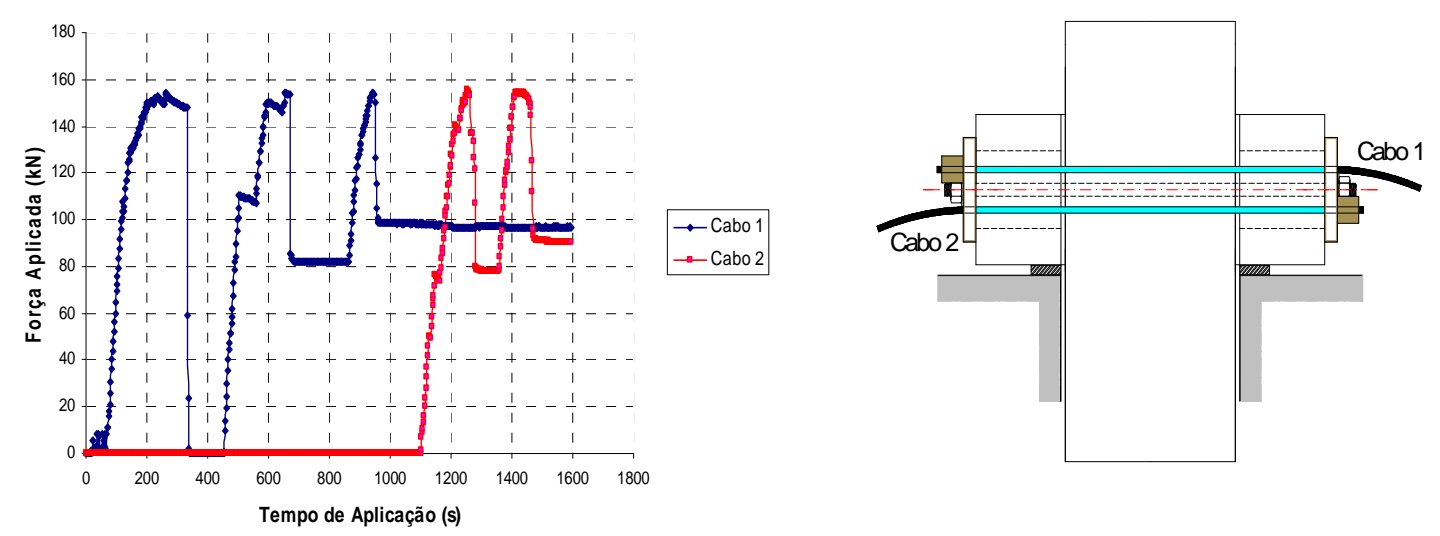

Figura 4.36: Força de protensão aplicada no modelo 11

A capacidade máxima alcançada por barra foi de $181 \mathrm{kN}$ (Figura 4.37), o que totalizou uma capacidade de carga do modelo de $724 \mathrm{kN}$. Assim, a carga de ruptura real do modelo foi inferior a carga de ruptura prevista (764 kN).

A rigidez inicial no último ciclo de carregamento foi de $153 \mathrm{kN} / \mathrm{mm}$. Após a força por barra ter atingido $80 \mathrm{kN}$, a rigidez sofreu uma redução, atingindo o valor de $23 \mathrm{kN} / \mathrm{mm}$. Para o deslocamento de 8,24 mm o modelo começou a perder capacidade de carga até se estabilizar com rigidez nula.

Nas Figuras 4.37b e 4.37c, observam-se mudanças buscas no comportamento do chumbador quando a força máxima foi alcançada. O chumbador entrou em escoamento até o ponto em que os extensômetros foram perdidos.

Acredita-se que neste modelo, o ponto de formação da rótula plástica se deu quando a força por barra alcançou o valor de $171 \mathrm{kN}$, com deformação registrada no chumbador de 1,38\%o. Tal hipótese pode ser justificada pela descontinuidade apresentada na Figura 4.37c. 


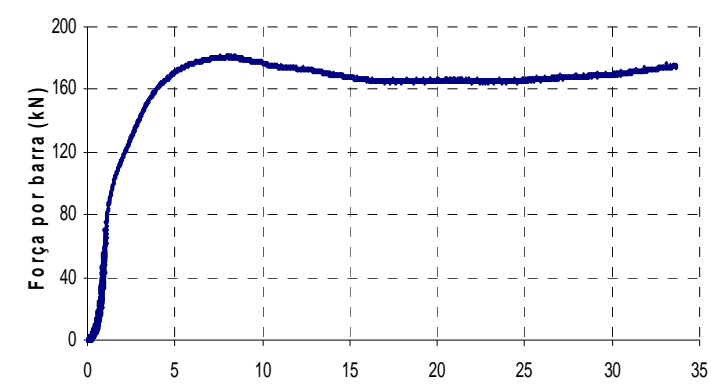

a)

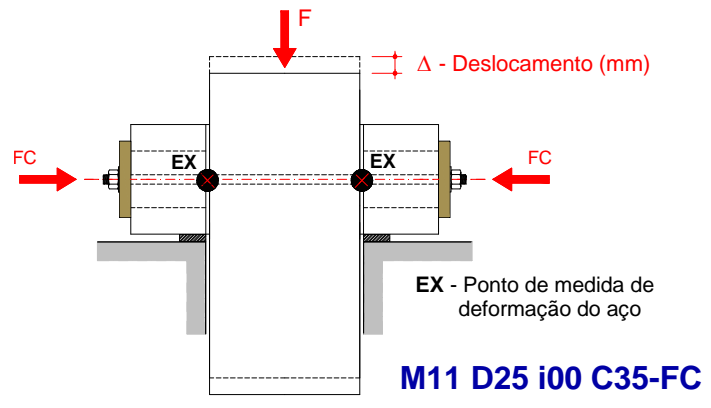

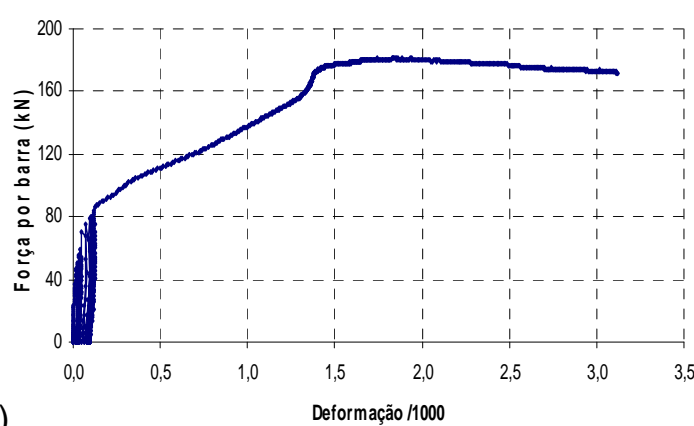

b)

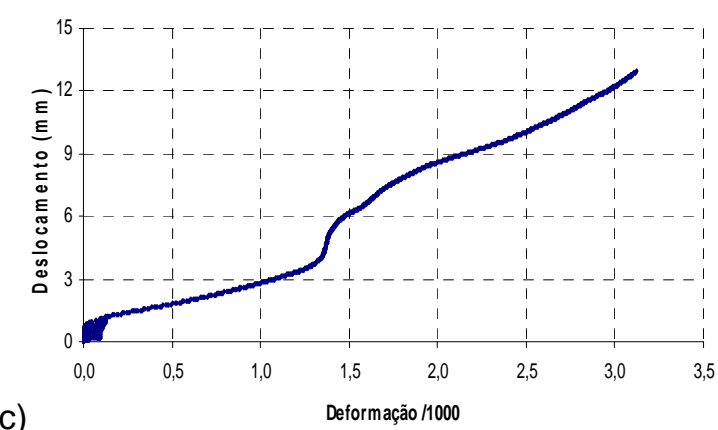

c)

Figura 4.37: Resumo dos resultados experimentais do modelo 11

Foram observadas fissuras nos blocos externos com desprendimento da capa de concreto (Figura 4.38), o que caracterizou a perda de rigidez após o pico. A almofada de apoio também apresentou a primeira fissura externa quando o deslocamento vertical do bloco interno em relação ao bloco externo alcançou $2 \mathrm{~mm}$.
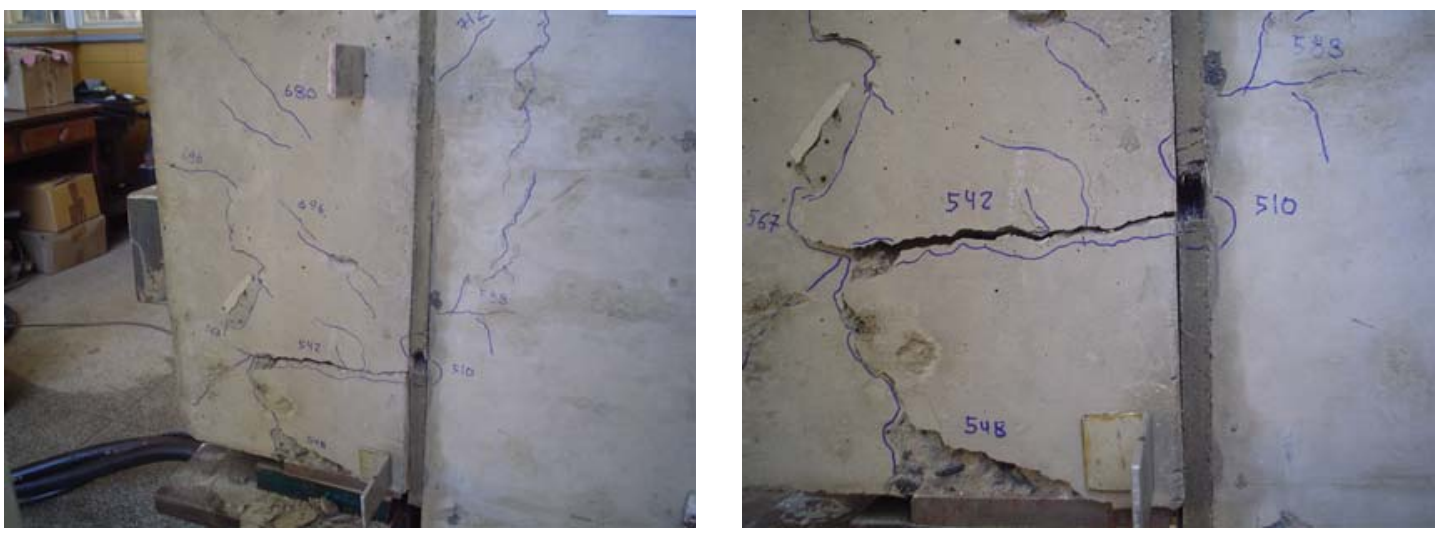

Figura 4.38: Estado de fissuração do bloco externo do modelo 11

Após a ruptura do modelo, foi realizada a remoção do cobrimento de concreto adjacente ao chumbador, para a verificação de sua posição deformada (Figura 4.39). 

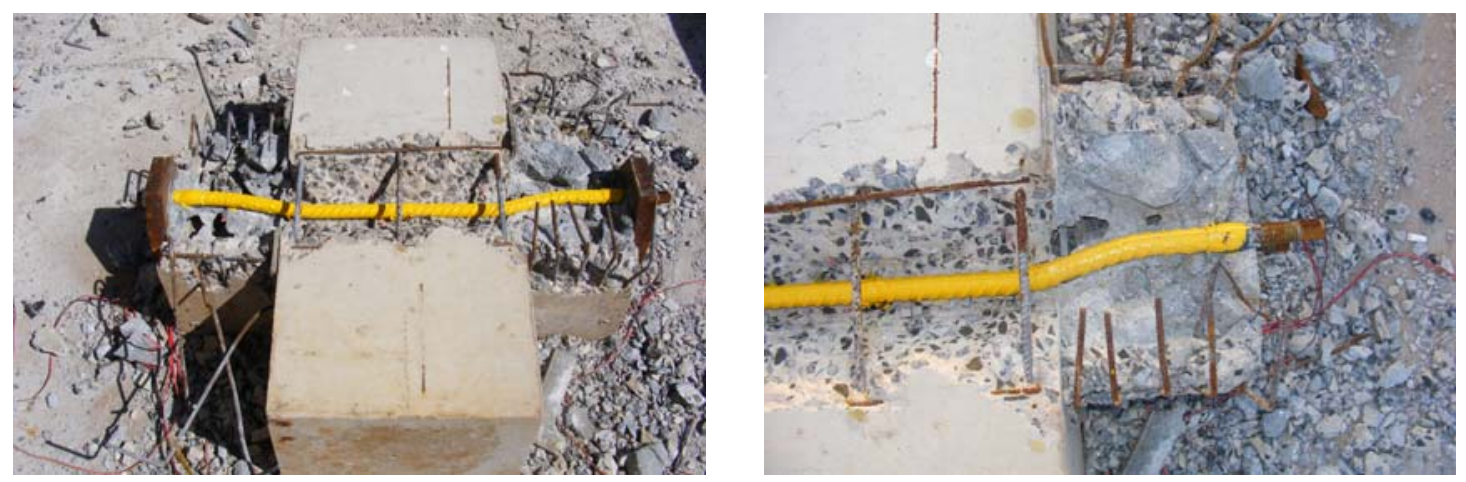

Figura 4.39: Deformada do chumbador do modelo 11.

Do lado do bloco interno percebe-se claramente a formação da rótula plástica. Já do lado do bloco externo, observa-se que houve a formação de uma rótula, porém o eixo do chumbador não permaneceu perpendicular à chapa de fixação após a ruptura do modelo. Tal comportamento dá indícios de má aderência entre o graute e o chumbador, o que pode ter gerado um escorregamento e conseqüente perda da capacidade de carga do modelo.

Seguindo o mesmo procedimento descrito anteriormente, a posição da rótula foi medida e comparada com valores teóricos (Figura 4.40).

A expressão proposta por DEI POLI et al. (1992) subestimou a posição da rótula plástica do lado do bloco externo. Do lado do bloco interno, a expressão conduziu a valores $1 \%$ e $3 \%$ superiores aos obtidos experimentalmente do lado esquerdo e direito, respectivamente.

Pela expressão de ENGSTROM (1992b), do lado esquerdo do modelo, chegouse a $54 \%$ do valor experimental do lado do bloco externo, e a $120 \%$ do lado do bloco interno. Pelo lado direito, chegou-se a 52\% do valor experimental do lado do bloco externo, e a $123 \%$ do lado do bloco interno.

Estas diferenças do lado dos blocos externos podem ser atribuídas a uma provável má aderência entre o graute e o chumbador. 


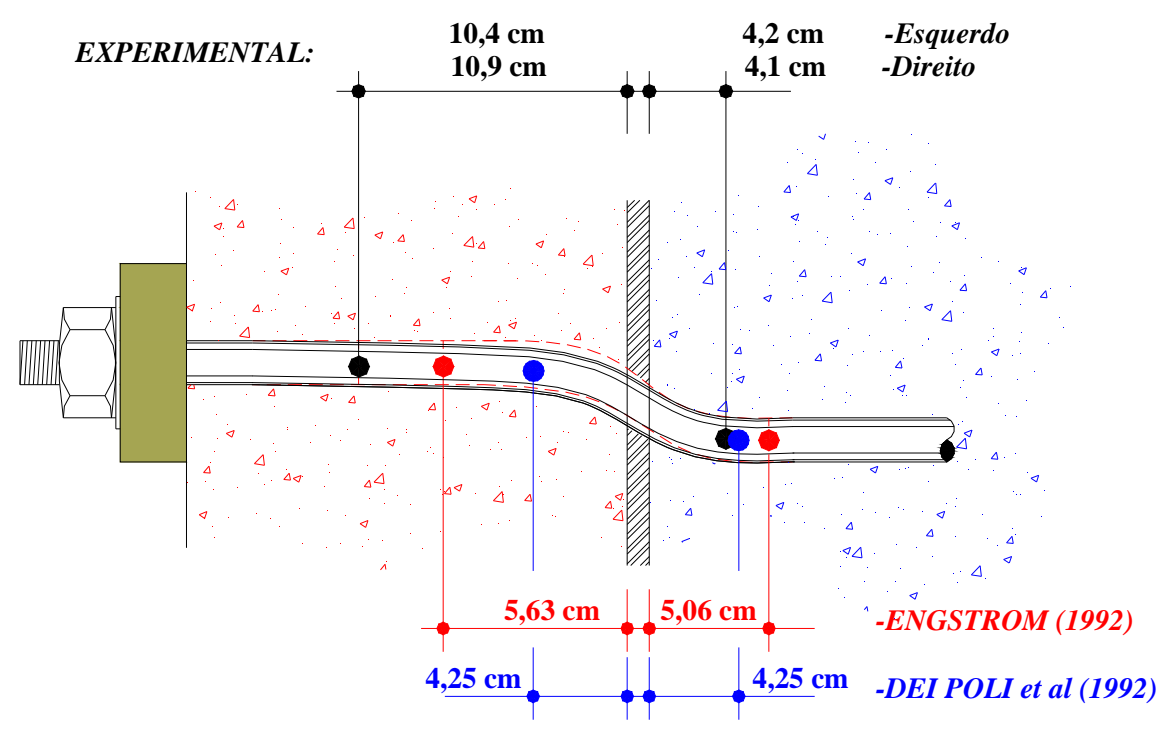

Figura 4.40: Posição experimental e teórica da rótula plástica no modelo 11

\subsubsection{Modelo 12}

A força final de protensão no modelo 12 totalizou 188,8 kN. As forças horizontais finais aplicadas foram de $92,0 \mathrm{kN}$ e $96,8 \mathrm{kN}$ para os cabos 1 e 2, respectivamente (Figura 4.41).
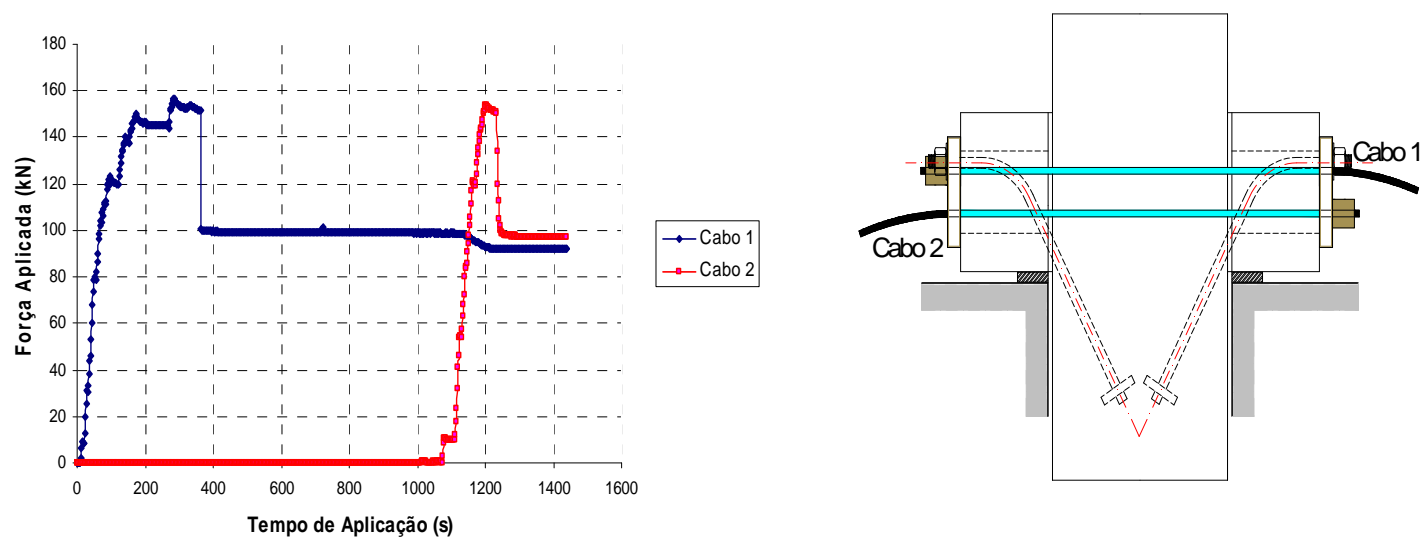

Figura 4.41: Força de protensão aplicada no modelo 12

Nesse modelo, a capacidade máxima alcançada por barra foi de $313 \mathrm{kN}$ (Figura 4.42), o que totalizou uma capacidade de carga do modelo de 1252 kN. Assim, a carga de ruptura real do modelo superou a carga de ruptura prevista em 83\%. 
A rigidez inicial no último ciclo de carregamento foi de $218 \mathrm{kN} / \mathrm{mm}$. Após a força por barra ter atingido $150 \mathrm{kN}$, a rigidez sofreu uma redução, atingindo o valor de $62 \mathrm{kN} / \mathrm{mm}$. Para o deslocamento de $5 \mathrm{~mm}$ o modelo começou estabilizar sua capacidade de carga, mantendo-a próximo de $300 \mathrm{kN}$ até sua ruptura.

As leituras dos extensômetros deixaram de ser registradas quando a força por barra atingiu o valor de $297 \mathrm{kN}$, sendo registrada a deformação de 5,11\%o (Figura 4.42b).

Embora não tenha sido realizada a remoção do cobrimento de concreto adjacente ao chumbador para a verificação de sua posição deformada, supõe-se que houve uma tendência de retificação da parte curva do chumbador, caracterizada pela mudança brusca no comportamento do diagrama força por barra x deformação (Figura 4.42b). Tal comportamento é evidenciado na Figura 4.41c, pois quando o chumbador atingiu a deformação de 1,72\%, o deslocamento do modelo aumentou sendo que os acréscimos de deformações foram desprezíveis.

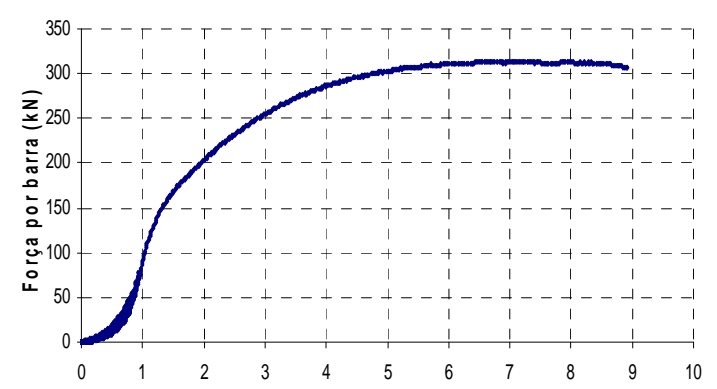

a)

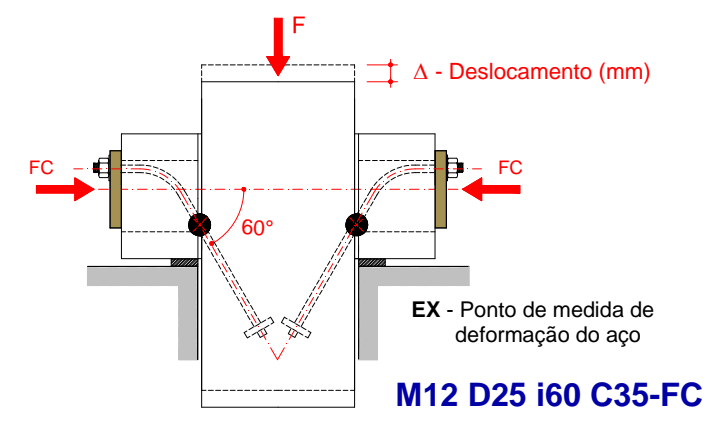

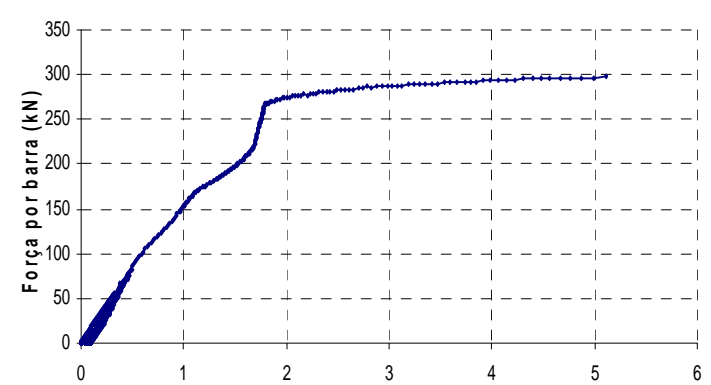

b)

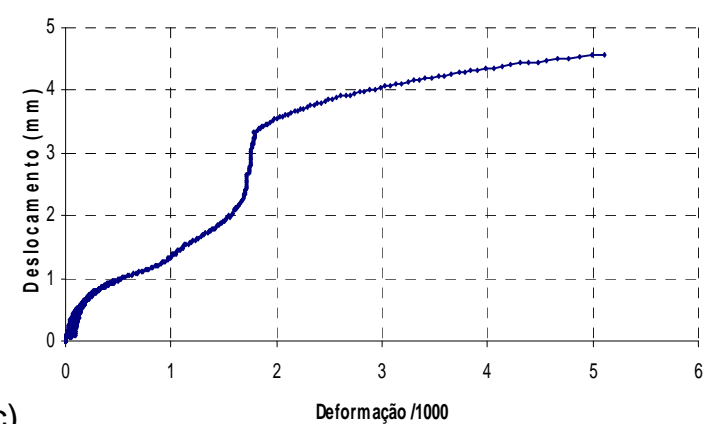

c)

Figura 4.42: Resumo dos resultados experimentais do modelo 12

Na Figura 4.43 é apresentado o baixo nível de fissuração da região da interface bloco externo - bloco interno. Foi observado nesse modelo que a almofada de apoio 
apresentou a primeira fissura externa quando o deslocamento do bloco interno em relação ao bloco externo alcançou valores próximos a $3 \mathrm{~mm}$.
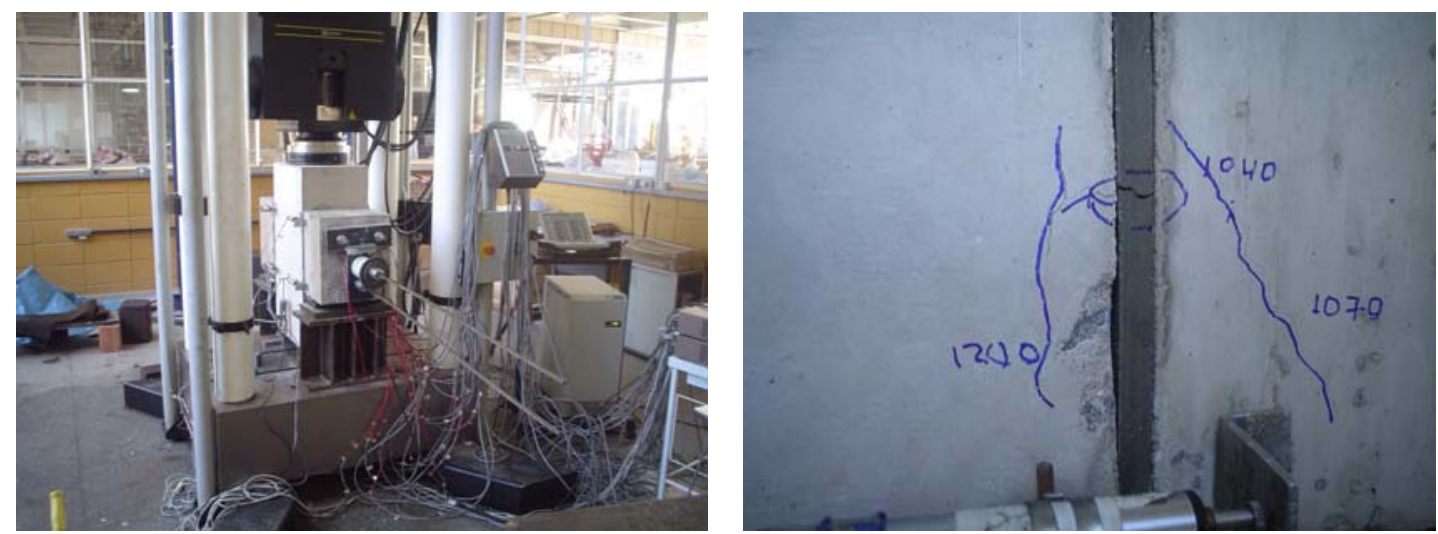

Figura 4.43: Aspecto do ensaio do modelo 12

\subsection{MODELOS SEM FORÇA DE COMPRESSÃO - CLASSE C50}

\subsubsection{Modelo 13}

O modelo 13, pertencente ao grupo de modelos com concreto de classe C50, foi ensaiado seguindo os mesmos procedimentos adotados nos demais modelos. Na Figura 4.44 é apresentado um panorama geral do ensaio realizado na máquina INSTRON 8506.
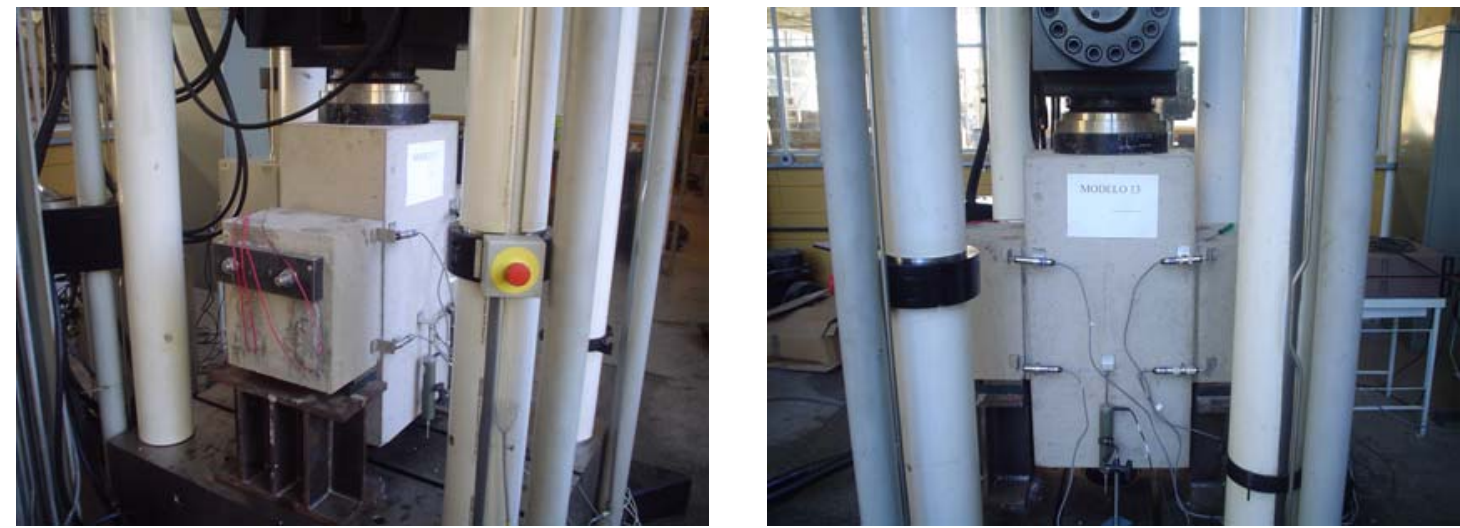

Figura 4.44: Aspecto do ensaio experimental do modelo 13 
Os resultados experimentais obtidos no ensaio são apresentados na Figura 4.45. A capacidade máxima alcançada por barra foi de $241 \mathrm{kN}$, o que totalizou uma capacidade de carga do modelo de $964 \mathrm{kN}$. Assim, a carga de ruptura real do modelo superou a carga de ruptura prevista em $63 \%$.

A rigidez inicial no último ciclo de carregamento foi de $195 \mathrm{kN} / \mathrm{mm}$. Após a força por barra atingir $83 \mathrm{kN}$, a rigidez reduziu para $55 \mathrm{kN} / \mathrm{mm}$, e atingiu 19,4 kN/mm quando a força por barra superou $200 \mathrm{kN}$.

A deformação no chumbador (Figura 4.45b) não apresentou mudanças bruscas ao longo do carregamento, sendo que as leituras dos extensômetros deixaram de ser registradas quando a deformação atingiu 5,28 \%. A força medida na deformação máxima registrada foi de $214 \mathrm{kN}$.

Após os ciclos de carga e descarga realizados, foi observada uma folga no modelo de 1,46 mm antes da aplicação do último ciclo.

O nível de fissuração do modelo foi considerado baixo, uma vez que apresentou poucas e espaçadas fissuras. Quanto à almofada de apoio, o aparecimento da primeira fissura externa ocorreu quando o deslocamento entre o bloco interno e os blocos externos atingiu valores próximos a $2 \mathrm{~mm}$.
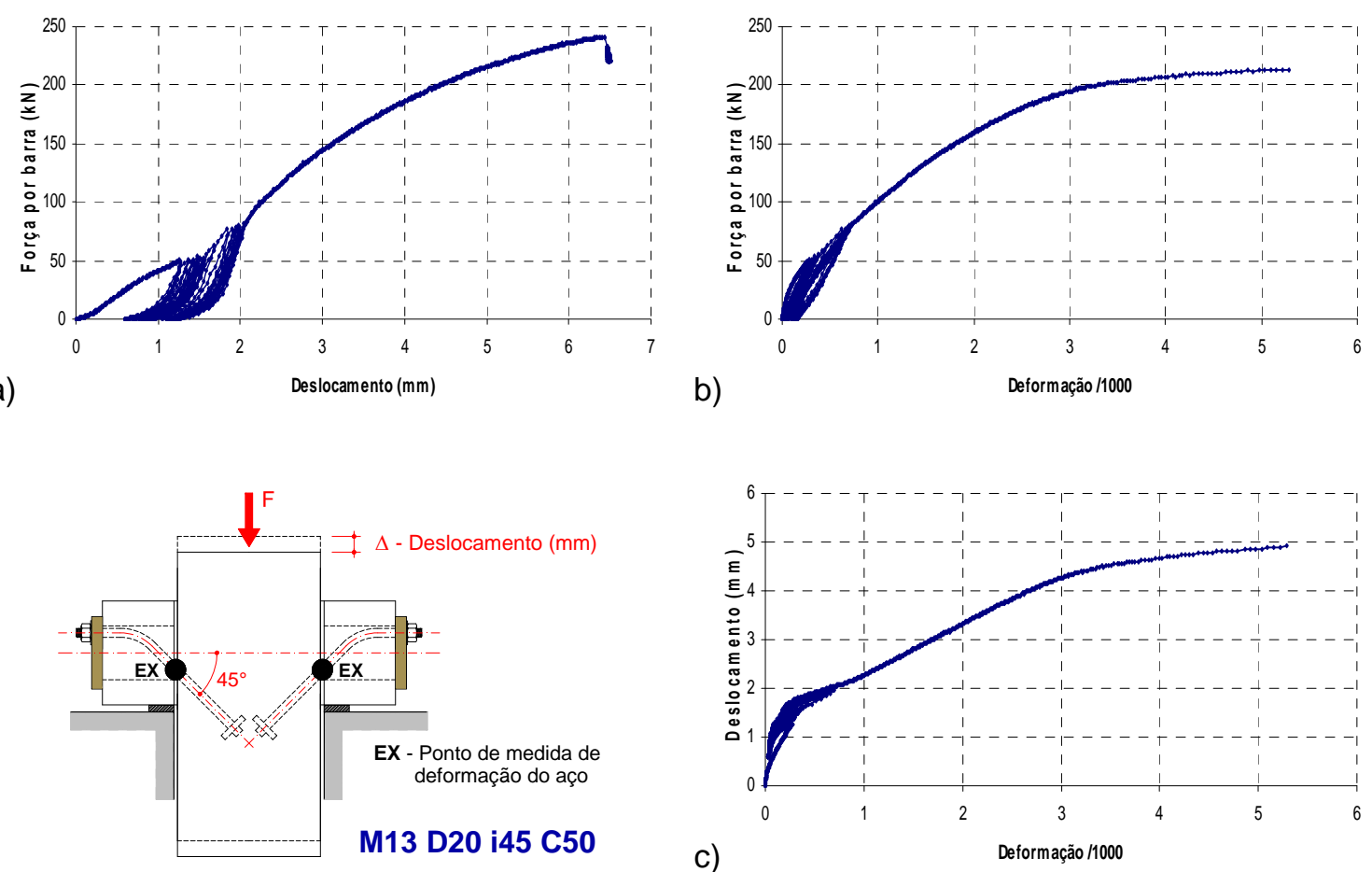

Figura 4.45: Resumo dos resultados experimentais do modelo 13 


\subsubsection{Modelo 14}

A capacidade máxima alcançada por barra foi de $255 \mathrm{kN}$, o que totalizou uma capacidade de carga do modelo de $1020 \mathrm{kN}$. Assim, a carga de ruptura real do modelo superou a carga de ruptura prevista em $72 \%$.

A rigidez inicial no último ciclo de carregamento foi de $189 \mathrm{kN} / \mathrm{mm}$. Após a força por barra superar $100 \mathrm{kN}$, a rigidez reduziu para $56 \mathrm{kN} / \mathrm{mm}$, e atingiu $8,6 \mathrm{kN} / \mathrm{mm}$ quando a força por barra alcançou $218 \mathrm{kN}$ (Figura 4.46)

Nas Figuras 4.46b e 4.46c, pode-se observar mudanças bruscas no comportamento do chumbador ao longo do carregamento. Quando a força por barra atingiu $90 \mathrm{kN}$, o chumbador sofreu uma redução brusca em sua rigidez, o que pode caracterizar redução da aderência do chumbador ou simplesmente uma acomodação do modelo.

As leituras dos extensômetros deixaram de ser registradas quando a deformação atingiu 9,39 \%. A força medida na deformação máxima registrada foi de 161 kN.

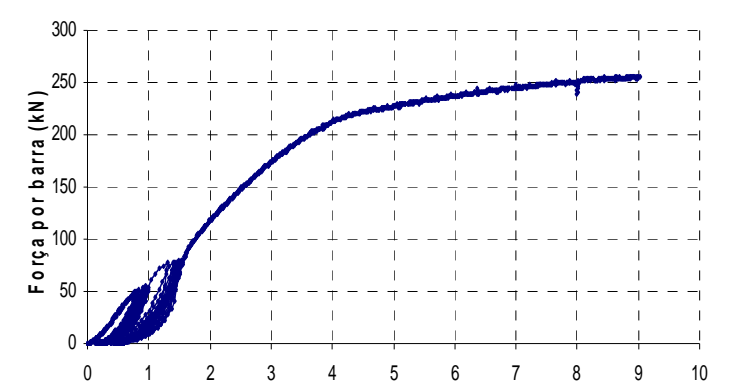

a)

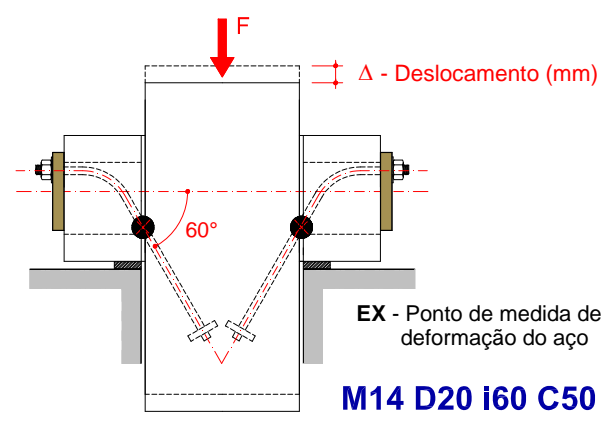

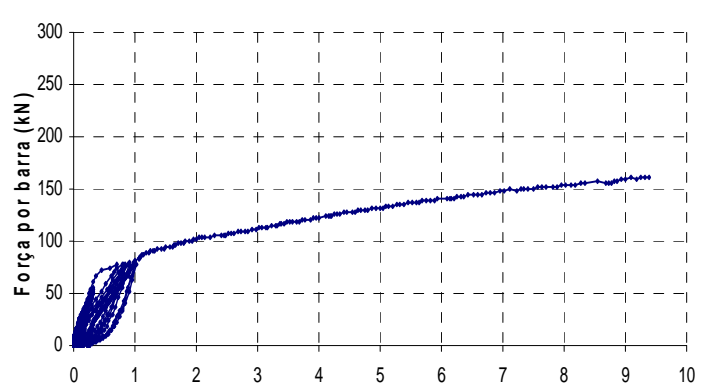

b)

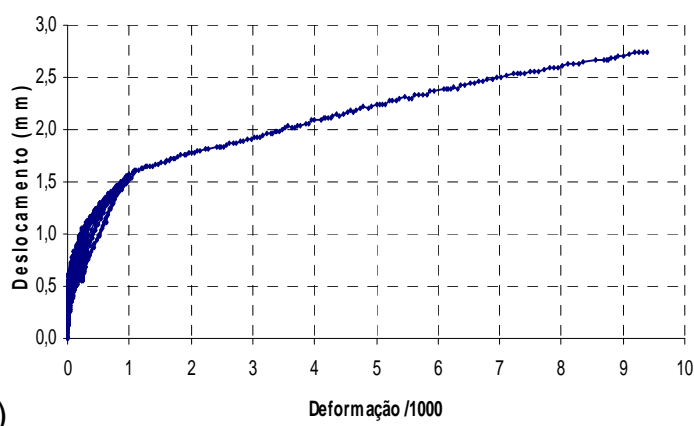

C)

Figura 4.46: Resumo dos resultados experimentais do modelo 14

Para o modelo 14 não houve registros de fissuras aparentes nos blocos externos e no bloco interno (Figura 4.47). Quanto à almofada de apoio, o aparecimento da 
primeira fissura externa ocorreu quando o deslocamento entre o bloco interno e os blocos externos atingiu valores próximos a 2,7 mm.

A ruptura do modelo foi caracterizada pela estabilização da capacidade de carga alcançada após o deslocamento do bloco interno, em relação aos blocos externos, ter alcançado $7 \mathrm{~mm}$. Temendo a ocorrência de acidentes, o ensaio foi então paralisado.
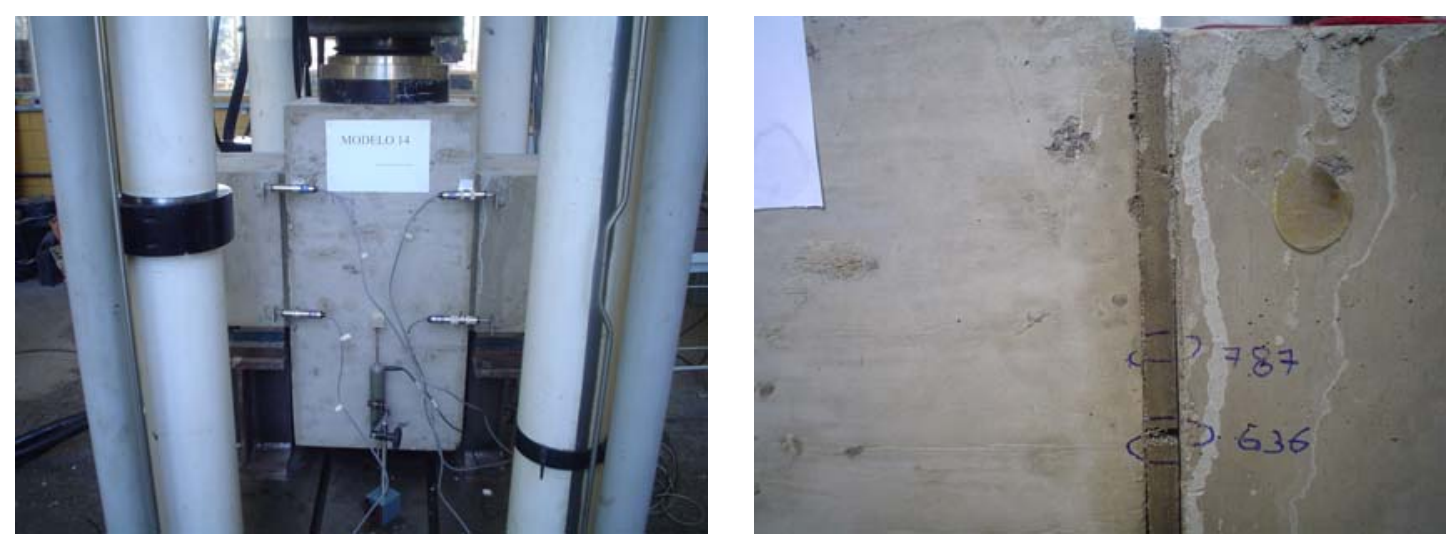

Figura 4.47: Aspecto do ensaio do modelo 14

\subsubsection{Modelo 15}

Para o último modelo do programa experimental adotado, a capacidade máxima alcançada por barra foi de 309,2 kN, o que totalizou uma capacidade de carga do modelo de 1236,8 kN. Assim, a carga de ruptura real superou a carga de ruptura prevista em $44 \%$.

A rigidez inicial no último ciclo de carregamento foi de $205 \mathrm{kN} / \mathrm{mm}$. Após a força por barra superar $100 \mathrm{kN}$, a rigidez reduziu para $63 \mathrm{kN} / \mathrm{mm}$, e atingiu $39 \mathrm{kN} / \mathrm{mm}$ quando a força por barra alcançou $226 \mathrm{kN}$ (Figura 4.48).

A deformação máxima do chumbador antes das leituras dos extensômetros deixarem de ser registradas foi de 4,36 \% (Figura 4.48b). A força por barra alcançada no instante do último registro de deformação foi de $294 \mathrm{kN}$.

Pela Figura 4.48c observa-se um comportamento quase linear, sendo as deformações do chumbador proporcionais ao deslocamento do modelo. O comportamento apresentado dá indícios de uma boa aderência chumbador-graute. 


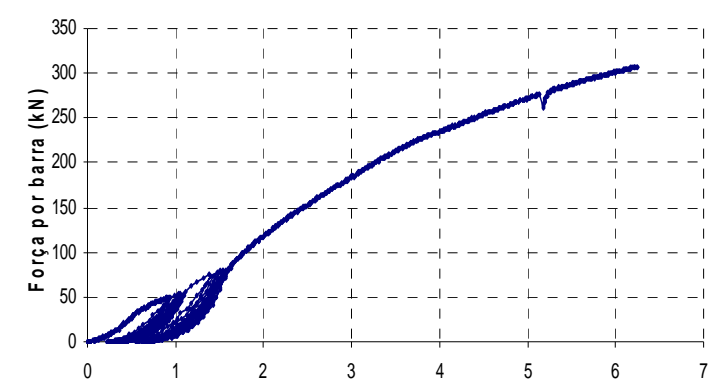

a)

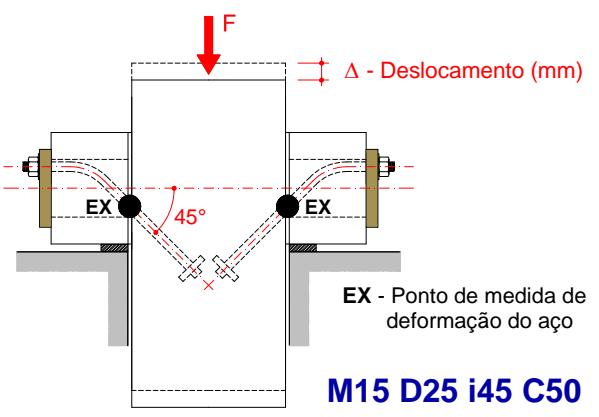

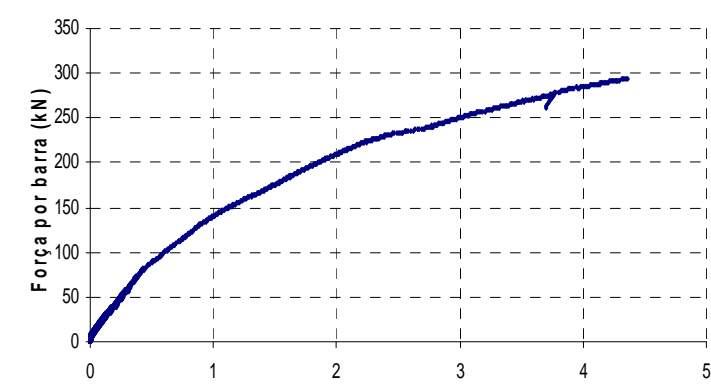

b)

Deformação $/ 1000$

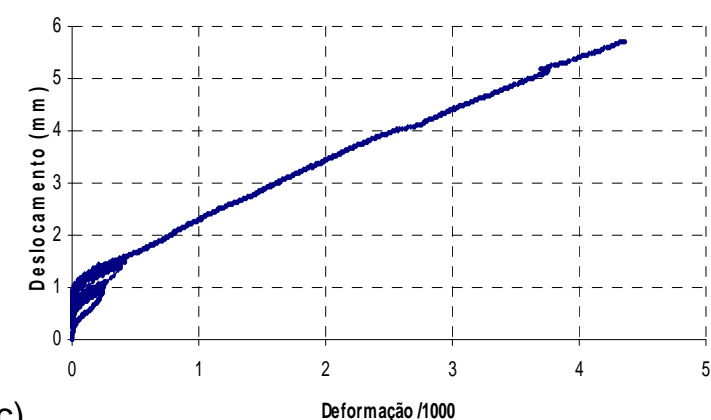

C)

Figura 4.48: Resumo dos resultados experimentais do modelo 15

Na Figura 4.49 é apresentado um panorama da fissuração observada no modelo. O nível de fissuração do modelo pode ser considerado baixo, uma vez que apresentou poucas e espaçadas fissuras. Quanto à almofada de apoio, conforme verificado na maioria dos modelos ensaiados, o aparecimento da primeira fissura externa ocorreu quando o deslocamento entre o bloco interno e os blocos externos atingiu valores próximos a $2 \mathrm{~mm}$.
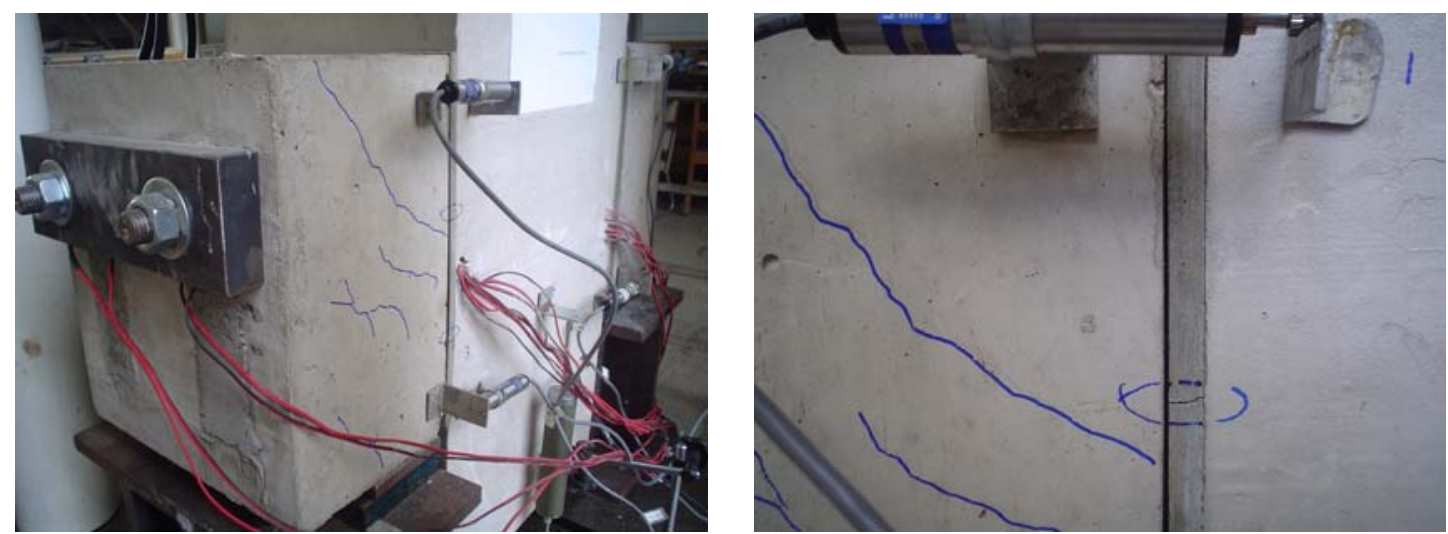

Figura 4.49: Aspecto da fissuração no modelo 15 


\subsection{RESUMO DOS RESULTADOS}

Neste item são apresentados resumidamente os resultados obtidos no programa experimental realizado.

A força de ruptura prevista para cada modelo, a força máxima alcançada por cada modelo, a força máxima alcançada por chumbador, e a rigidez inicial no último ciclo de carregamento, constituem os dados apresentados na Tabela 4.1.

Os resultados foram separados de acordo com a inclinação dos chumbadores, sendo destacados os grupos dos modelos pilotos (MP), dos modelos sem força de compressão - classe C35 (SFC-C35), dos modelos com força de compressão - classe C35 (CFC-C35) e dos modelos sem força de compressão - classe C50 (SFC-C50).

Tabela 4.1: Resumo dos principais resultados experimentais

\begin{tabular}{|c|c|c|c|c|c|c|}
\hline \multirow{2}{*}{\multicolumn{2}{|c|}{ MODELO }} & \multirow{3}{*}{$\begin{array}{c}\begin{array}{c}\text { Força por } \\
\text { chumbador } \\
(\mathrm{kN})\end{array} \\
149\end{array}$} & \multicolumn{3}{|c|}{ Força por Modelo (kN) } & \multirow{3}{*}{$\begin{array}{c}\begin{array}{c}\text { Rigidez } \\
\text { (kN /mm) }\end{array} \\
41\end{array}$} \\
\hline & & & \multirow{2}{*}{\begin{tabular}{|c|} 
Prevista \\
336
\end{tabular}} & \multirow{2}{*}{$\frac{\text { Alcançada }}{596}$} & \multirow{2}{*}{$\begin{array}{c}\begin{array}{c}\text { Alcançada } I \\
\text { Prevista }\end{array} \\
1,77\end{array}$} & \\
\hline \multirow[b]{5}{*}{ eixo reto } & Modelo 01 (SFC-C35) & & & & & \\
\hline & Modelo 05 (SFC-C35) & 202 & 753 & 808 & 1,07 & 115 \\
\hline & Modelo 07 (CFC-C35) & 185 & 359 & 740 & 2,06 & 134 \\
\hline & Modelo 08 (CFC-C35) & 169 & 525 & 676 & 1,29 & 142 \\
\hline & Modelo 11 (CFC-C35) & 181 & 764 & 724 & 0,95 & 153 \\
\hline \multirow[b]{5}{*}{ inclinado $45^{\circ}$} & Modelo 02 (SFC-C35) & 247 & 589 & 988 & 1,68 & 49 \\
\hline & Modelo 06 (SFC-C35) & 308 & 851 & 1232 & 1,45 & 97 \\
\hline & Modelo 09 (CFC-C35) & 312 & 482 & 1248 & 2,59 & 83 \\
\hline & Modelo 13 (SFC-C50) & 241 & 591 & 964 & 1,63 & 195 \\
\hline & Modelo 15 (SFC-C50) & 309 & 858 & 1236 & 1,44 & 205 \\
\hline \multirow[b]{5}{*}{ inclinado $60^{\circ}$} & Modelo 03 (SFC-C35) & 256 & 593 & 1024 & 1,73 & 55 \\
\hline & Modelo 04 (SFC-C35) & 253 & 586 & 1012 & 1,73 & 152 \\
\hline & Modelo 10 (CFC-C35) & 252 & 483 & 1008 & 2,09 & 158 \\
\hline & Modelo 12 (CFC-C35) & 313 & 684 & 1252 & 1,83 & 218 \\
\hline & Modelo 14 (SFC-C50) & 255 & 594 & 1020 & 1,72 & 189 \\
\hline
\end{tabular}





\section{MODELOS NUMÉRICO E ANALÍTICO}

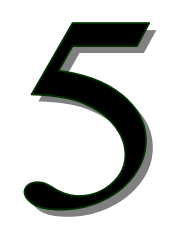

Capítulo

\subsection{GENERALIDADES}

Neste capítulo é apresentado o modelo analítico proposto para simular o comportamento dos chumbadores de eixo reto e inclinado. O modelo é baseado no comportamento de vigas apoiadas sobre base elástica, sendo levado em consideração a não-linearidade geométrica do chumbador.

Para auxiliar o desenvolvimento do modelo analítico, foram realizadas inicialmente simulações numéricas em alguns modelos via Método dos Elementos Finitos, por meio do programa computacional DIANA versão 9.2.

Os critérios utilizados para a simulação numérica também são descritos neste capítulo, onde também é apresentada uma proposta para determinação de parâmetros inerentes à interface bloco externo-bloco interno a serem adotados.

\subsection{MODELO NUMÉRICO}

A simulação numérica foi iniciada na Universidade do Minho, campus de Azurém (Guimarães - Portugal), como parte das atividades desenvolvidas no programa de Doutorado sanduíche pela CAPES, e concluída no Departamento de Estruturas da Escola de Engenharia de São Carlos.

O programa computacional utilizado foi o DIANA, que consiste em um programa via método dos elementos finitos, desenvolvido por engenheiros civis da TNO 
Building and Construction Research, com ênfase no comportamento do concreto armado.

O programa DIANA dispõe de modelos desenvolvidos especialmente para simular a mecânica não-linear do concreto, podendo ser analisados fenômenos complexos inerentes ao concreto armado como exemplo a fissuração.

\subsubsection{Elementos finitos utilizados}

Os modelos foram simulados em duas dimensões tendo em vista o baixo custo computacional associado. Como o modelo utilizado é formado por uma associação de sólidos prismáticos com simetria de carga e forma, a opção por modelagem em duas dimensões não conduz a resultados menos confiáveis, quando comparados aos obtidos em modelagens tridimensionais.

Para a modelagem do bloco interno, bloco externo e almofadas de apoios, foi utilizado o elemento finito estrutural plano CQ 16M (Figura 5.1). Esse elemento finito é isoparamétrico de oito nós com interpolação quadrática.

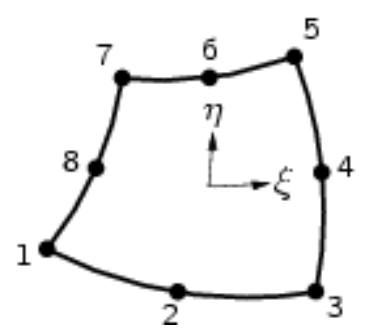

Figura 5.1: Elemento finito plano CQ 16M

Fonte: DIANA (2005)

O polinômio de deslocamentos do elemento finito CQ 16M é apresentado na Equação 5.1.

$$
u_{i}(\xi, \eta)=a_{0}+a_{1} \xi+a_{2} \eta+a_{3} \xi \eta+a_{4} \xi^{2}+a_{5} \eta^{2}+a_{6} \xi^{2} \eta+a_{7} \xi \eta^{2}
$$

Como os elementos que compõem o modelo foram moldados separadamente e depois montados, sentiu-se a necessidade de lançar elementos de interface para a ligação dos elementos finitos CQ 16M. Assim, foram lançados elementos de interface 
entre o bloco interno e a almofada de apoio e entre a almofada de apoio e o bloco externo.

O elemento de interface utilizado foi o CL 12I, constituído de seis nós. O elemento também utiliza interpolação quadrática para os deslocamentos e é compatível com o elemento plano CQ $16 \mathrm{M}$.
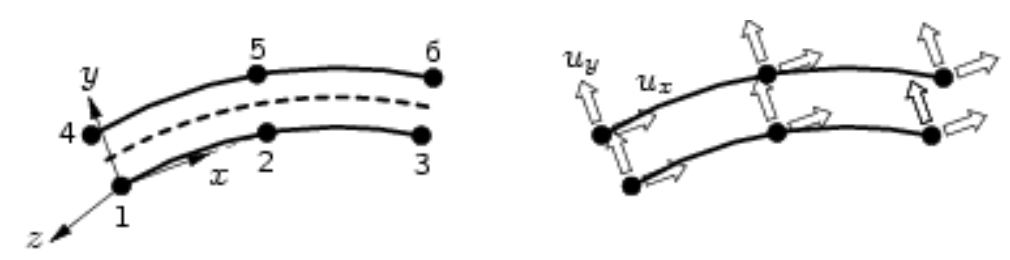

Figura 5.2: Tipologia e deslocamentos do elemento de interface CL 12I

Fonte: DIANA (2005)

Para a utilização dos elementos de interface é necessário definir valores para o módulo de rigidez normal e transversal, o que constitui uma das maiores dificuldades da análise.

O módulo de rigidez normal é a relação entre a tração normal e o deslocamento na direção normal. Já o módulo de rigidez transversal é a relação entre a tração causada pelo cisalhamento e seu deslocamento correspondente.

A simulação numérica foi realizada para $1 / 4$ do modelo, aproveitando a simetria de carga e forma existente. Assim, os valores de força atuante obtidos na análise são referentes à força por barra ou força por chumbador.

Na região do apoio e na região do graute a malha de elementos finitos foi mais densa com o intuito de uma análise mais criteriosa. Na Figura 5.3 é apresentado o modelo com a malha de elementos finitos adotada, sendo a discretização realizada apenas na região em que a simulação foi realizada.

Para simular a armadura e o chumbador foi utilizado um elemento pertencente à biblioteca do DIANA denominado reinforcement bar, que consiste em um elemento linear cujas tensões e deformações são medidas no sentido do seu próprio eixo de inserção (direção axial). Esse elemento funciona como enrijecedor dos elementos finitos aos quais estão conectados, denominados como mother elements. A aderência entre a armadura e o concreto é considerada perfeita. 


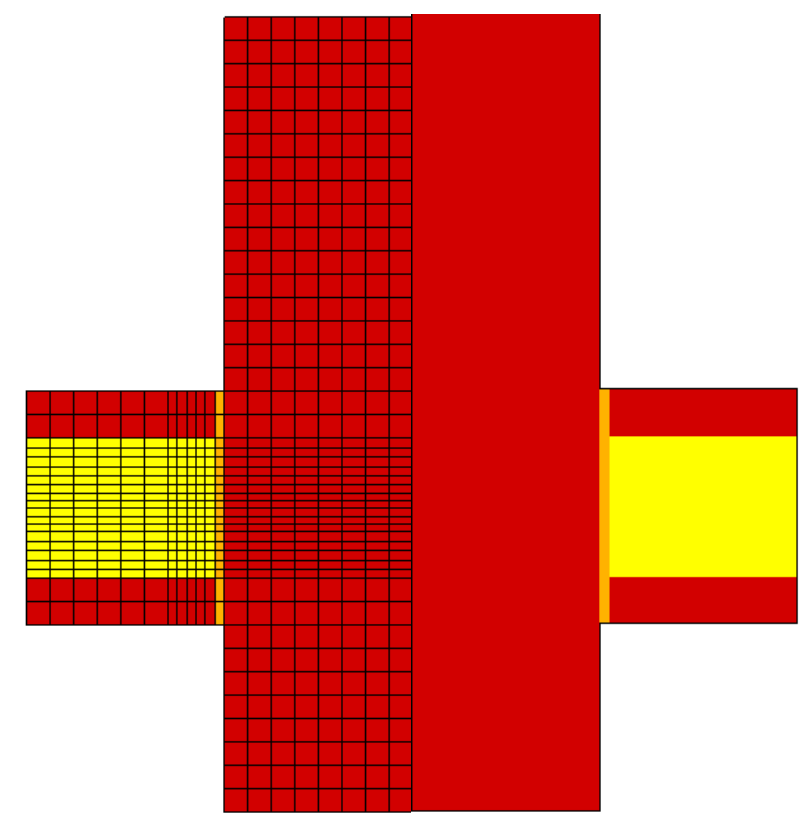

Figura 5.3: Malha em Elementos Finitos adotada para os modelos

Na Figura 5.4 é apresentada a inserção das armaduras e dos chumbadores nos modelos da simulação numérica.

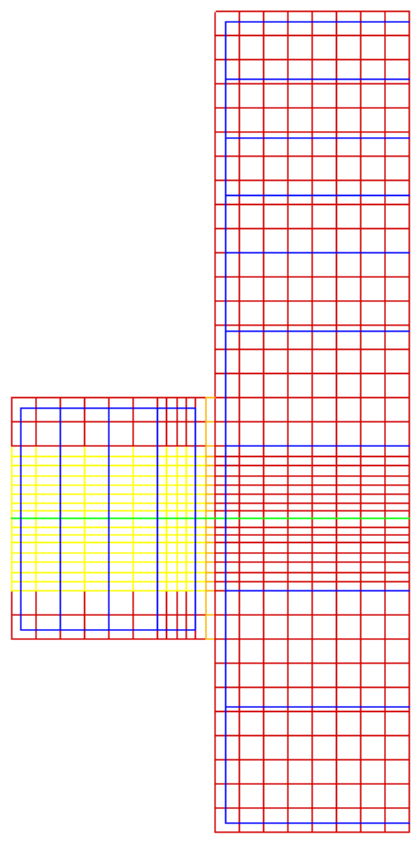

Chumbador de eixo reto

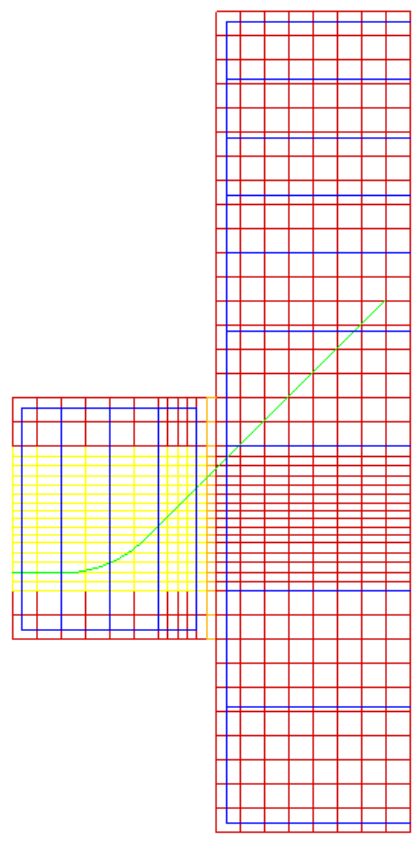

Chumbador de eixo inclinado

Figura 5.4: Disposição das armaduras nos modelos numéricos 


\subsubsection{Modelos constitutivos}

Para o concreto dos blocos externos e blocos internos, assim como para o graute, foi utilizado o modelo constitutivo denominado Total Strain Crack Model, pertencente à biblioteca do DIANA.

O programa DIANA dispõe de dois modelos possíveis de serem utilizados para prever a propagação de fissuras no concreto, sendo eles o Total Strain Fixed Crack e o Total Strain Rotate Crack. No Total Strain Rotate Crack é permitida a mudança da direção da fissura durante a sua propagação. No Total Strain Fixed Crack só é permitida que a variação do ângulo de fissuração seja de $90^{\circ}$ em relação ao ângulo inicial.

No Total Strain Fixed Crack, supõe-se que uma fissura se forma na direção perpendicular à direção da máxima tensão principal de tração quando a tensão principal excede a resistência à tração do material e que a orientação da fissura não se altera com o processo de carregamento. Segundo CHEN (1982) ${ }^{1}$ apud CRUZ et al. (2004), devido ao efeito de engrenamento dos agregados ( “aggregate interlock”) e à ação de pino da armadura ("dowel action”) as tensões principais podem mudar sua orientação durante o carregamento permitindo que a resistência à tração seja novamente excedida. Por esse motivo, segundo CRUZ et al. (2004), os modelos de fissuras fixas tendem a prever respostas mais rígidas que a resposta experimental.

O Total Strain Rotate Crack também assume que a fissura se forme na direção perpendicular à direção da tensão principal de tração quando a tensão principal atinge a resistência à tração do material. Entretanto, a orientação do plano da fissura é ajustada a cada passo de carregamento para permanecer ortogonal à direção atual da tensão principal máxima. A investigação experimental desenvolvida por VECCHIO \& COLLINS (1986) em painéis armados ortotropicamente comprovou a possibilidade de rotação das fissuras durante o carregamento da estrutura. Com isso, constatou-se que quanto maior o grau de ortotropia em termos de armaduras, maior era a rotação das tensões e deformações principais. Esses perquisadores observaram ainda que as fissuras possuíam uma orientação bastante próxima à direção das tensões principais.

O programa DIANA possui em sua biblioteca diversas leis constitutivas para descrever o comportamento dos materiais à tração e compressão. Essas leis são baseadas na energia de fraturamento, que consiste na energia necessária para causar um

\footnotetext{
${ }^{1}$ CHEN, W. F., Plasticity in reinforced concrete, McGraw Hill, New York, 1982.
} 
dano irreversível no material. Nas Figuras 5.5 e 5.6 são apresentados os modelos de tração e de compressão, respectivamente, disponíveis no programa DIANA para o Total Strain Crack Model.

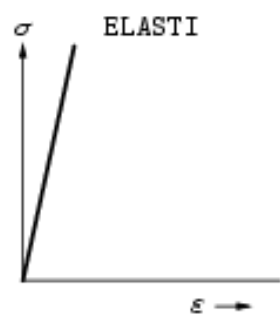

(a) elastic

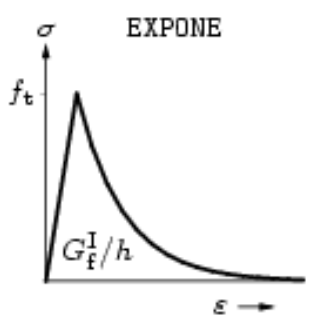

(e) exponential

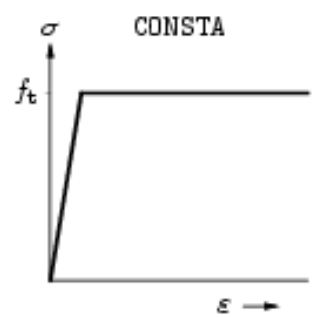

(b) ideal

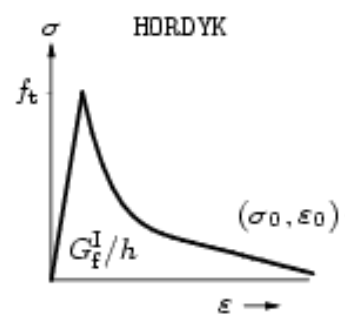

(f) Hor dijk

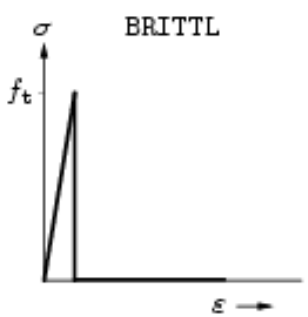

(c) brittle

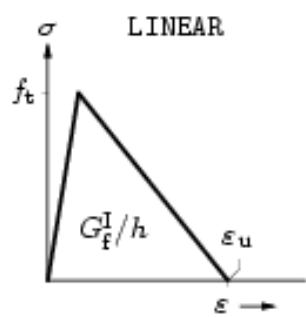

(d) linear

Figura 5.5: Modelos constitutivos à tração no Total Strain Crack Model.

Fonte: Fonte: DIANA (2005)
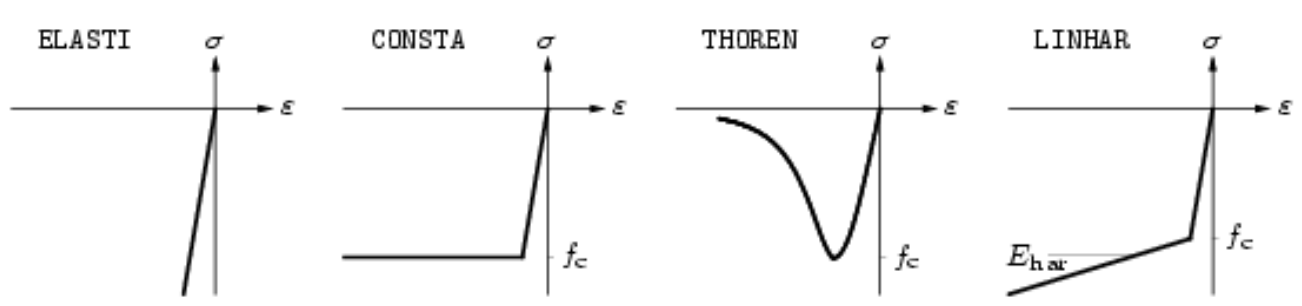

(a) elastic

(b) ideal

(c) Thorenfeldt

(d) linear

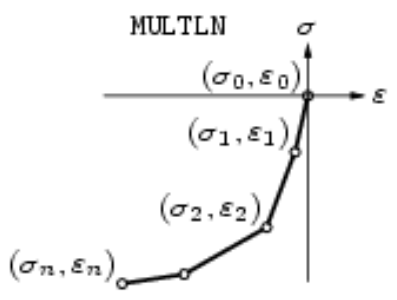

(e) multi-linear

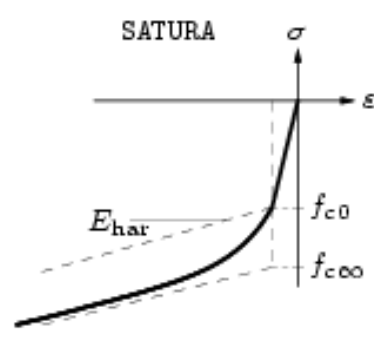

(f) saturation type

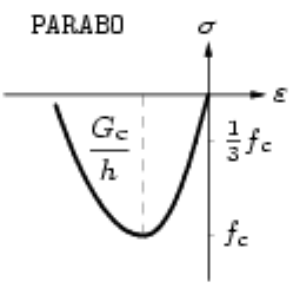

(g) parabolic

Figura 5.6: Modelos constitutivos à compressão no Total Strain Crack Model.

Fonte: Fonte: DIANA (2005) 
Para a análise numérica realizada, o modelo constitutivo à tração utilizado foi o modelo exponencial (Figura 5.5e), por apresentar melhores resultados para o caso específico do modelo analisado. Para a compressão foi utilizado o modelo multi-linear (Figura 5.6e). Para o modelo multi-linear é necessário que se forneça pontos com tensões e suas respectivas deformações.

Foi utilizado como base para o modelo multi-linear o diagrama tensão-deformação definido pelo CEB-FIP Model Code (1990) para o comportamento à compressão do concreto.

Para a utilização do modelo exponencial foi necessário estimar a energia de fraturamento do material, pois não foram realizados ensaios experimentais para a determinação dessa propriedade mecânica.

A energia de fraturamento pode ser estimada com o uso das Equações 5.2 e 5.3, com base no que preconiza o CEB-FIP Model Code (1990), tendo como variáveis envolvidas a resistência à compressão e o tamanho máximo do agregado.

$$
\begin{aligned}
& G_{f}=G_{f 0}\left(\frac{f_{c m}}{f_{c m 0}}\right)^{0,7} \\
& f_{c m}=f_{c k}+8
\end{aligned}
$$

Sendo que:

$G_{f} \quad$ - Energia de fraturamento na tração, em N.mm/mm²;

$G_{f 0} \quad$ - Parâmetro que depende do tamanho do agregado, conforme Tabela 5.1;

$f_{c k} \quad$ - Resistência característica à compressão do concreto, em N/mm²;

$f_{c m 0} \quad$ - Valor constante e igual a $10 \mathrm{~N} / \mathrm{mm}^{2}$.

Tabela 5.1: Valores de $G_{f 0}$ em função do tamanho do agregado.

Fonte: CEB-FIP Model Code (1990)

\begin{tabular}{|c|c|}
\hline $\mathbf{G}_{\mathbf{f} 0}\left(\mathbf{N} \cdot \mathbf{m m} / \mathbf{m m}^{2}\right)$ & $\mathbf{d}_{\max }(\mathbf{m m})$ \\
\hline 0,025 & 8 \\
\hline 0,030 & 16 \\
\hline 0,058 & 32 \\
\hline
\end{tabular}


MAEKAWA et al. (2004) recomenda a utilização das Equações 5.4 e 5.5 para o cálculo da energia de fraturamento. Segundo estes pesquisadores, a Equação 5.2 não é adequada para o uso em concretos de alta resistência, superestimando o valor da energia de fraturamento.

$$
\begin{aligned}
& G_{f}=\alpha_{f}\left(f_{c k}\right)^{1 / 3} \\
& \alpha_{f}=10\left(d_{\text {max }}\right)^{1 / 3}
\end{aligned}
$$

Para a simulação numérica realizada, as equações recomendadas por MAEKAWA et al. (2004) conduziram a resultados mais satisfatórios que os obtidos pelo modelo do CEB-FIP Model Code (1990).

Em virtude do efeito da fissuração, pode ocorrer uma redução no módulo de elasticidade transversal do material, que deve ser considerada por meio de um parâmetro definido como coeficiente de retenção ao cisalhamento, ou simplesmente coeficiente $\beta$. O valor do coeficiente $\beta$ deve ser tomado entre 0 e 1 . Nos casos onde o cisalhamento é um esforço preponderante no modo de ruptura da estrutura, o valor deve ficar próximo a zero. Para os modelos ensaiados, o valor adotado foi 0,001.

Na implantação do elemento de interface é necessário conhecer o módulo de rigidez normal $\left(D_{11}\right)$ e o módulo de rigidez transversal $\left(D_{22}\right)$, já definidos no item anterior.

Os valores dos módulos de rigidez normal e transversal são geralmente obtidos por tentativas. No caso específico dos modelos simulados nesta pesquisa, foi observado que os resultados finais eram bastante influenciados pelos valores adotados.

Após várias simulações realizadas, e com base nos resultados experimentais obtidos, foi observado que tanto o módulo de rigidez normal quanto o transversal eram influenciados pelo diâmetro do chumbador e pela resistência à tração dos materiais associados à interface. Para o módulo de rigidez transversal, a folga medida após os ciclos de carga e descarga do modelo também exerceu influência.

Face à sensibilidade apresentada nos modelos numéricos aos parâmetros inerentes à interface, tornou-se necessário desenvolver uma proposta que contemplasse as influências observadas. Assim, foram desenvolvidas equações empíricas, baseadas nas análises de resultados obtidas com a variação de cada parâmetro. Os parâmetros 
foram simulados separadamente, onde foi observada sua influência no comportamento força x deslocamento do modelo. Assim, após a realização de várias simulações foram obtidas equações empíricas para a determinação do módulo de rigidez normal $\left(\mathrm{D}_{11}\right)$ e 0 módulo de rigidez transversal $\left(\mathrm{D}_{22}\right)$, apresentadas nas Equações 5.6 e 5.7, respectivamente.

$$
\begin{aligned}
& D_{11}=\frac{1}{100}\left(a \cdot k_{1}^{2}+b \cdot k_{1}+c\right) \\
& D_{22}=\frac{1}{100}\left(d \cdot k_{2}+e\right) \\
& k_{1}=\phi \cdot f_{t} \\
& k_{2}=\frac{\phi}{f_{t} \cdot \delta_{c h}}
\end{aligned}
$$

Sendo que:

$D_{11} \quad$ - Módulo de rigidez normal em $\mathrm{N} / \mathrm{mm}^{3}$;

$D_{22} \quad$ - Módulo de rigidez transversal em $\mathrm{N} / \mathrm{mm}^{3}$;

$\phi \quad$ - Diâmetro do chumbador em mm;

$\delta_{c h} \quad-$ Folga do modelo após os ciclos de carga e descarga, sendo $\geq 1 \mathrm{~mm}$;

$f_{t} \quad$ - Menor resistência à tração entre os materiais adjacentes à interface.

$a, b, c, d, e$ - Coeficientes que dependem da inclinação do chumbador, dados na Tabela 5.2.

Tabela 5.2: Coeficientes propostos para ajuste dos modelos

\begin{tabular}{|l|r|r|r|r|c|}
\hline \multirow{2}{*}{ TIPO DE CHUMBADOR } & \multicolumn{5}{|c|}{ COEFICIENTES DE AJUSTE DOS MODELOS } \\
\cline { 2 - 6 } & \multicolumn{1}{c|}{ a } & \multicolumn{1}{c|}{ b } & \multicolumn{1}{c|}{ c } & \multicolumn{1}{c|}{ d } & \multicolumn{1}{c|}{ e } \\
\hline eixo reto & 0,99 & $-83,75$ & 1780,0 & 36,62 & 292,43 \\
\hline eixo inclinado a $45^{\circ}$ & $-1,57$ & 215,52 & $-6275,1$ & 80,43 & 289,53 \\
\hline eixo inclinado a $60^{\circ}$ & 2,19 & $-203,73$ & 5030,3 & 39,61 & 665,16 \\
\hline
\end{tabular}


Os valores obtidos nas simulações numéricas com o uso das expressões propostas conduziram a resultados satisfatórios quando comparados aos valores experimentais, conforme apresentado no capítulo 06 deste trabalho.

Para as armaduras e o chumbador, foi utilizado o modelo constitutivo elasto-plástico perfeito com o critério de plastificação de Von-Mises.

Na Tabela 5.3 são apresentados os dados do diagrama tensão-deformação do aço utilizado na simulação numérica. Foi adotado um diagrama tri-linear, sendo o último trecho (trecho 2-3) apenas um artifício usado para que o processamento do modelo, via DIANA, não fosse interrompido caso a armadura ou o chumbador atingissem a tensão última $\left(\mathrm{f}_{\mathrm{u}}\right)$.

O módulo de elasticidade do aço foi obtido experimentalmente no Laboratório de Estruturas da EESC-USP, sendo que seus valores não puderam ser aproveitados por se apresentarem muito elevados. A solução encontrada foi adotar para o aço o valor de 210 GPa, sendo também adotado o valor de 10\%o para sua deformação última $\left(\varepsilon_{\mathrm{u}}\right)$.

Tabela 5.3: Propriedades mecânicas do aço usadas na simulação numérica.

\begin{tabular}{|c|c|c|c|c|c|}
\hline$f_{u}^{\sigma}$ & $\frac{1}{\varepsilon_{y}}$ & 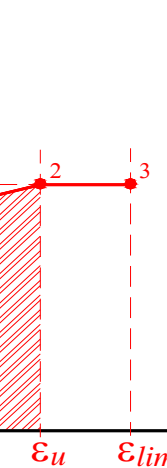 & 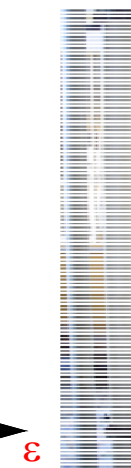 & 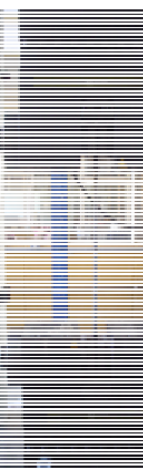 & 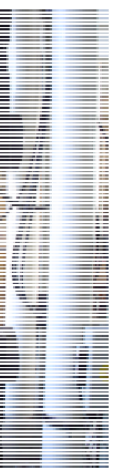 \\
\hline Diâmetro & $\mathrm{f}_{\mathrm{y}}(\mathrm{MPa})$ & $f_{u}(M P a)$ & $\varepsilon_{y}(\%)$ & $\mathcal{E}_{\mathrm{u}}(\%)$ & $\mathcal{E}_{\lim }(\%)$ \\
\hline $6,3 \mathrm{~mm}$ & 729 & 873 & 3,47 & 10 & 15 \\
\hline $10 \mathrm{~mm}$ & 639 & 741 & 3,04 & 10 & 15 \\
\hline $16 \mathrm{~mm}$ & 613 & 744 & 2,92 & 10 & 15 \\
\hline $20 \mathrm{~mm}$ & 611 & 741 & 2,91 & 10 & 15 \\
\hline $25 \mathrm{~mm}$ & 604 & 731 & 2,88 & 10 & 15 \\
\hline
\end{tabular}

\subsubsection{Resultados preliminares da simulação numérica}

A simulação numérica foi realizada em 10 dos 15 modelos ensaiados experimentalmente, onde foram utilizadas as Equações 5.6 e 5.7 para a determinação do 
módulo de rigidez normal $\left(\mathrm{D}_{11}\right)$ e $\mathrm{o}$ módulo de rigidez transversal $\left(\mathrm{D}_{22}\right)$, respectivamente.

Os resultados obtidos foram considerados satisfatórios, uma vez que o modelo numérico conseguiu reproduzir de forma aproximada o comportamento experimental do modelo no que diz respeito ao diagrama força por barra x deslocamento.

Como resultados preliminares, usados na calibração do modelo numérico, são apresentadas as simulações realizadas em dois modelos confeccionados com chumbadores de eixo reto. São eles: o modelo 01 (M01 i00 D16 C35) e o modelo 05 (M05 i00 D25 C35).

Na Figura 5.7 é apresentado o comportamento do modelo 01 obtido na simulação numérica realizada, onde pode ser observada a formação de um pico na força máxima do trecho elástico do diagrama força por barra x deslocamento.

Segundo MAEKAWA et al. (2004), a formação desse pico ocorre quando a área de concreto onde está inserida a barra de aço (chumbador) é superior à área máxima de aderência efetiva, calculada pela Equação 5.10.

$$
A_{c, \text { max }}=\frac{A_{s} \cdot f_{y}}{f_{c t}}
$$

Sendo que:

$$
\begin{aligned}
& A_{c, \max } \quad \text { - Área máxima de aderência efetiva do concreto; } \\
& A_{s} \quad \text { - Área da barra de aço inserida no concreto; } \\
& f_{y} \quad \text { - Tensão de escoamento do aço; } \\
& f_{c t} \quad \text {-Resistência à tração do concreto; }
\end{aligned}
$$

Comparando os resultados obtidos na simulação com os resultados experimentais (Figura 5.8), observa-se que o modelo numérico conseguiu representar o comportamento real até o deslocamento de $10 \mathrm{~mm}$ (valor máximo obtido na análise numérica).

A força máxima obtida na análise numérica foi inferior à registrada no programa experimental. Comparando a força obtida no deslocamento máximo alcançado pelo modelo numérico $(10 \mathrm{~mm})$ com a registrada experimentalmente para o mesmo deslocamento, verificou-se que o modelo numérico conduziu a uma força $15 \%$ superior. 

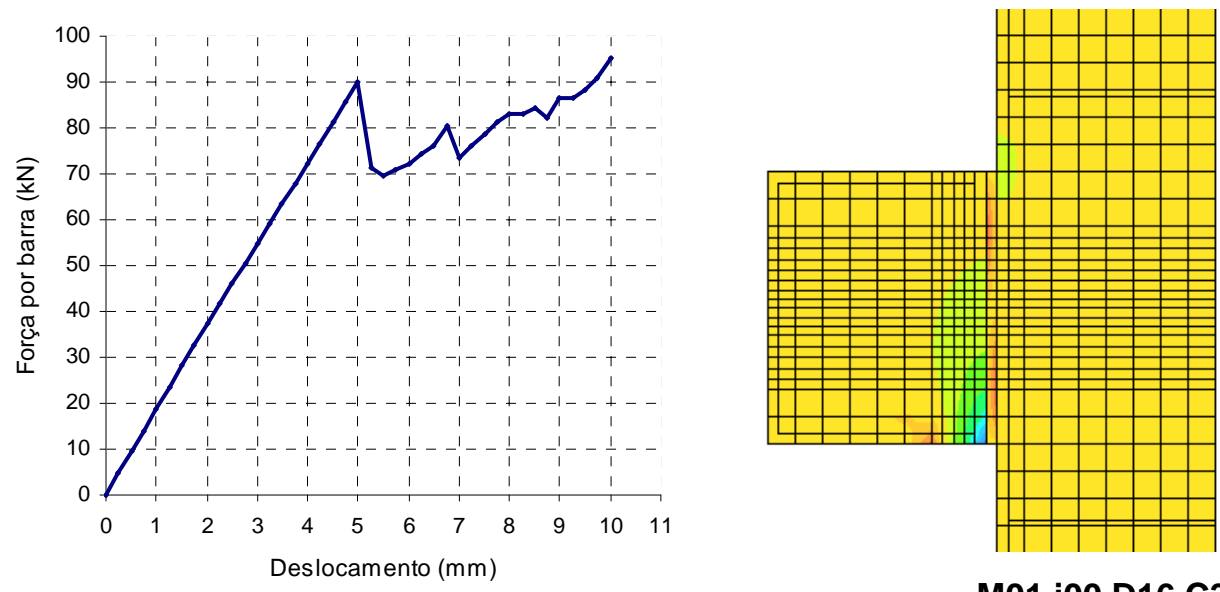

M01 i00 D16 C35

Figura 5.7: Resultado da simulação numérica do modelo 01.

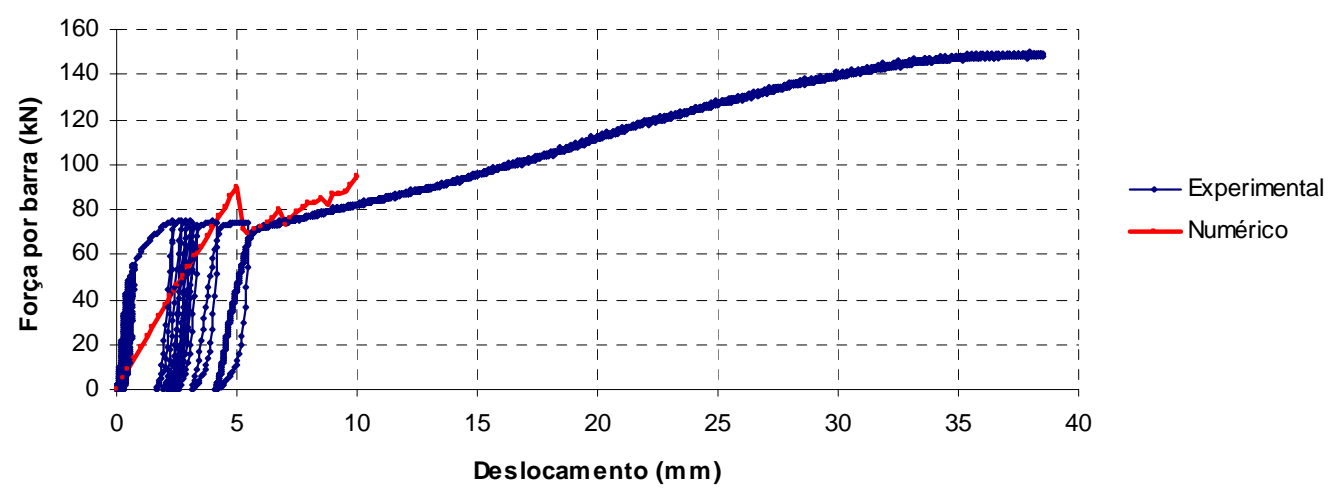

Figura 5.8: Comparação entre resultado numérico e experimental para o modelo 01.

Com o intuito de verificar a influência do diâmetro do chumbador na resposta força x deslocamento, foi escolhido o modelo 05 para uma nova simulação, cujo resultado é apresentado na Figura 5.9.

Observou-se que nesse caso também houve a formação de um pico na força máxima do trecho elástico do diagrama força por barra x deslocamento, porém menos acentuado quando comparado ao modelo 01. A redução do pico pode ser justificada pelo aumento da área da seção transversal do chumbador. Quanto maior for a seção transversal da barra, maior será a área máxima de aderência efetiva do concreto.

Para o modelo 05, a força máxima obtida na análise numérica também foi inferior à registrada no programa experimental (Figura 5.10). 
Seguindo o mesmo procedimento adotado no modelo 01, foi também realizada a comparação entre a força obtida no deslocamento máximo alcançado pelo modelo numérico (9 mm), com a registrada no programa experimental para o mesmo deslocamento. Foi observado que o modelo numérico conduziu a uma força 10,8\% superior à registrada no programa experimental.
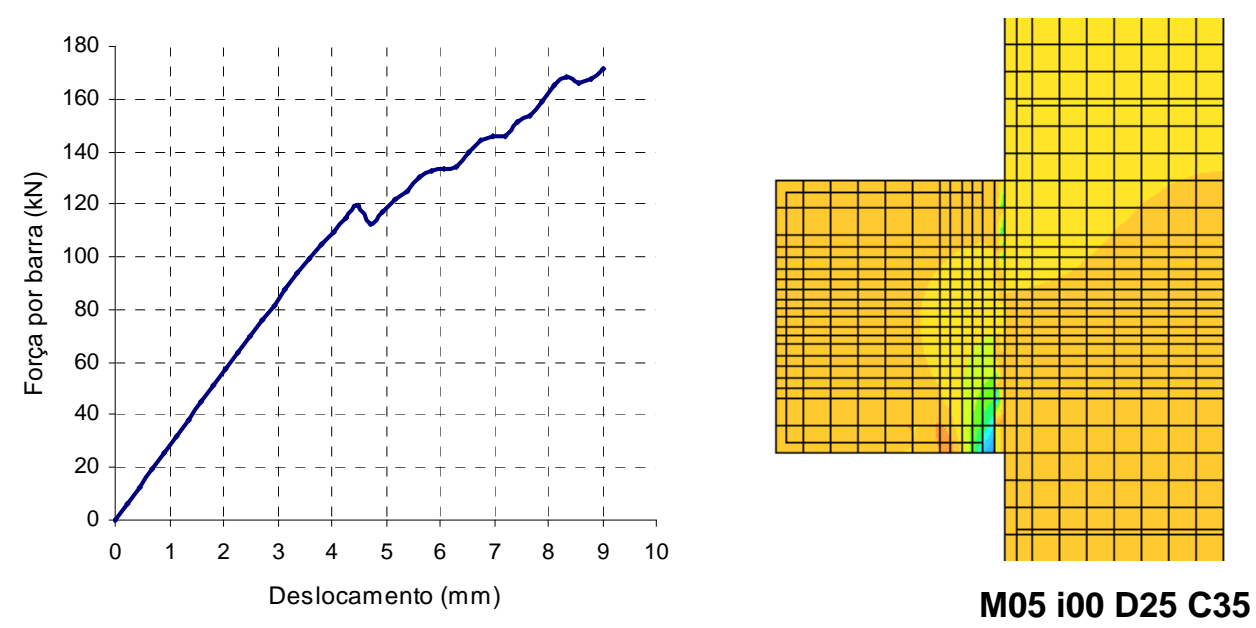

Figura 5.9: Resultado da simulação numérica do modelo 05.

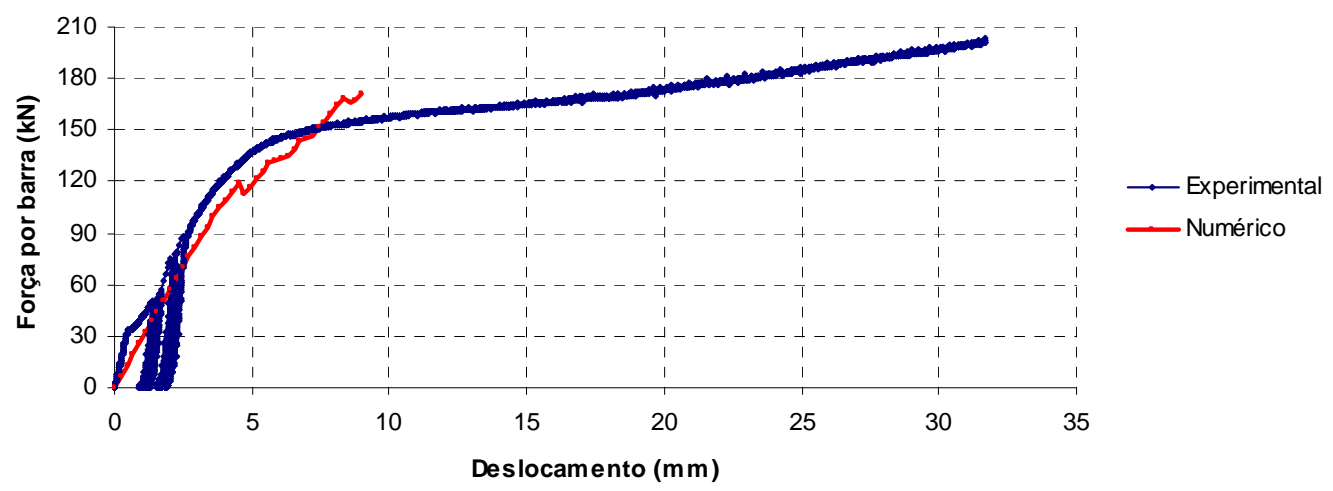

Figura 5.10: Comparação entre resultado numérico e experimental para o modelo 05.

É importante registrar que nos dois modelos apresentados, a simulação numérica conseguiu atingir o trecho do diagrama força por barra $\mathrm{x}$ deslocamento em que os modelos sofreram reduções bruscas em suas rigidezes. Essas reduções bruscas podem caracterizar a perda de aderência do chumbador ou o aparecimento de fissuras. 
O fenômeno da perda de aderência não pôde ser simulada pelo programa DIANA, tendo em vista o modelo utilizado para representar as armaduras e o chumbador considerar a aderência perfeita entre o aço e o concreto (Figura 5.11).

A opção de modelar o chumbador como elemento de barra não conduziu a resultados satisfatórios, talvez pela dificuldade encontrada na definição dos parâmetros do elemento de contato entre o concreto e o chumbador.
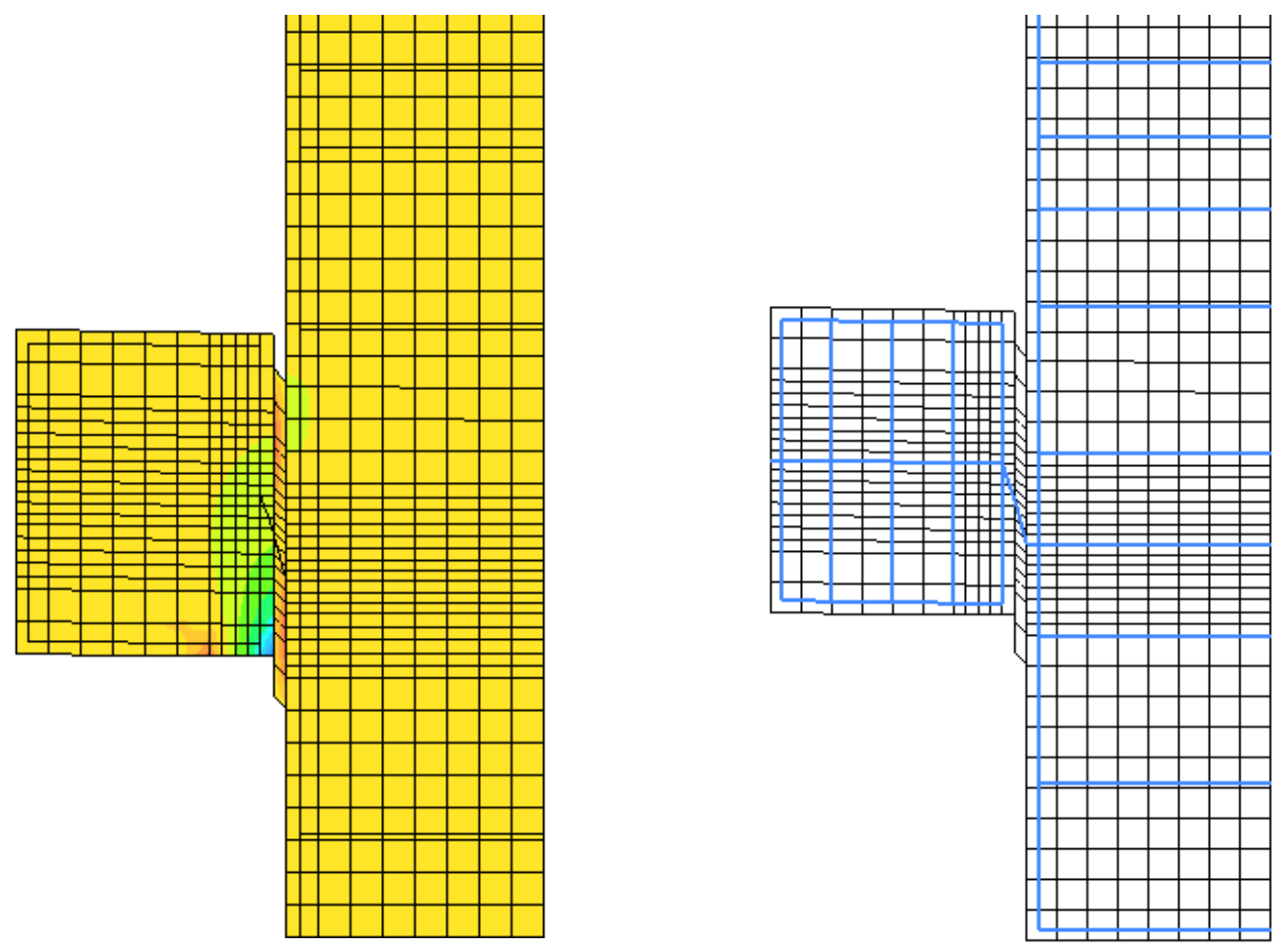

Figura 5.11: Deformação do chumbador na simulação numérica (modelo 01)

Na Figura 5.12 é apresentada uma comparação entre o comportamento dos modelos 01 e 05, obtidos numericamente, onde pode ser observado o aumento de rigidez com a mudança do diâmetro do chumbador de 16 mm (modelo 01) para 25 mm (modelo 05).

Os resultados das simulações numéricas realizadas nos modelos pertencentes aos grupos de chumbadores inclinados $\left(45^{\circ}\right.$ e $\left.60^{\circ}\right)$, assim como os outros modelos com chumbadores retilíneos, são apresentados no Capítulo 06 deste trabalho. 


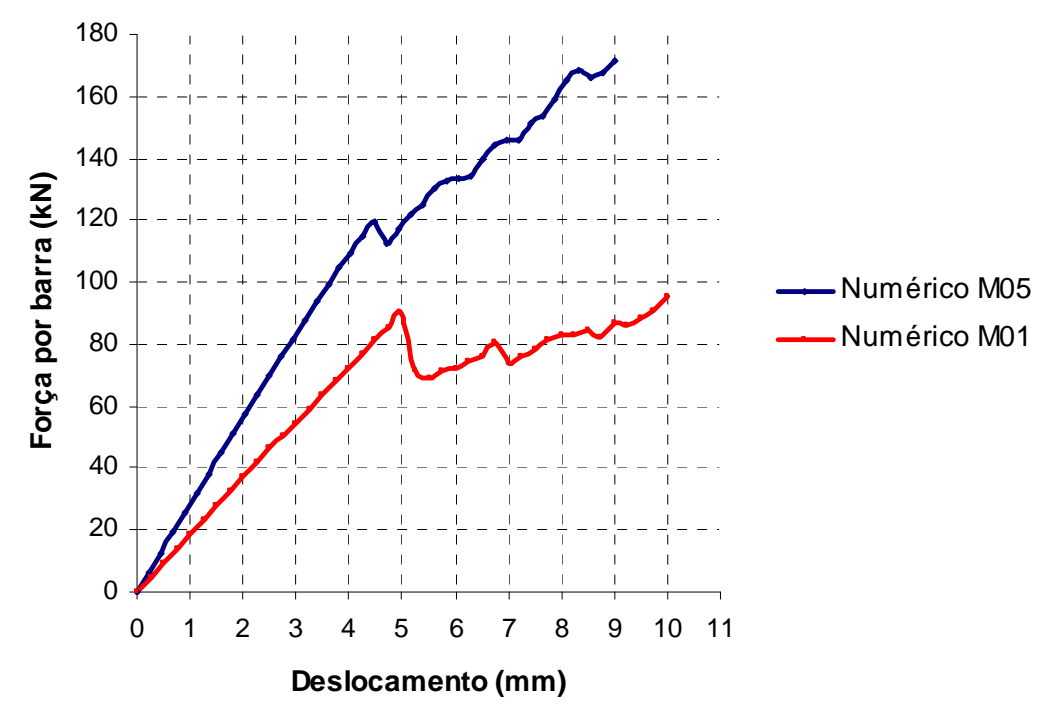

Figura 5.12: Comparação entre resultados numéricos para os modelos 01 e 05

\subsection{PROPOSTA DE MODELO ANALÍTICO}

A proposta de modelo analítico aqui apresentada é fundamentada nas propostas de HOJLUND \& RASMUSSEN (1963) apud FIB (2007), ENGSTROM (1992) e DEI POLI et al (1992).

Baseado nos resultados experimentais, nas simulações numéricas e na revisão bibliográfica realizada, foi possível levantar algumas hipóteses para a materialização da proposta. São elas:

a. Existe a formação de rótula plástica em chumbadores de eixo retilíneo;

b. Em chumbadores de eixo inclinado o efeito da força normal é predominante;

c. A formação de rótulas plásticas em chumbadores de eixo inclinado não é confirmada, porém pode ocorrer na fase inicial de carregamento e ser “camuflada” pelo alongamento causado devido à força normal predominante no chumbador;

d. O chumbador está inserido em um material com comportamento inicialmente elástico; 
e. A capacidade máxima do chumbador deve ser determinada levando em consideração sua posição inicial de equilíbrio e sua posição deformada;

f. Na ocasião da formação da rótula plástica, de acordo com FIB (2007), o deslocamento relativo entre as superfícies interligadas pelo chumbador pode ser estimado como 10\% de seu diâmetro, valor compatível com os resultados experimentais obtidos.

Assim, a proposta contempla duas fases distintas de cálculo da capacidade de carga do chumbador: a fase inicial de equilíbrio e a fase deformada, onde há a consideração da força normal. Após o estudo das duas fases é apresentada a formulação geral da capacidade de carga.

\subsubsection{Fase inicial de equilíbrio}

Na fase inicial de equilíbrio o chumbador é considerado como sendo uma viga apoiada sobre base elástica (Figura 5.13), pois na fase inicial do carregamento os materiais adjacentes ao chumbador apresentam respostas elásticas.
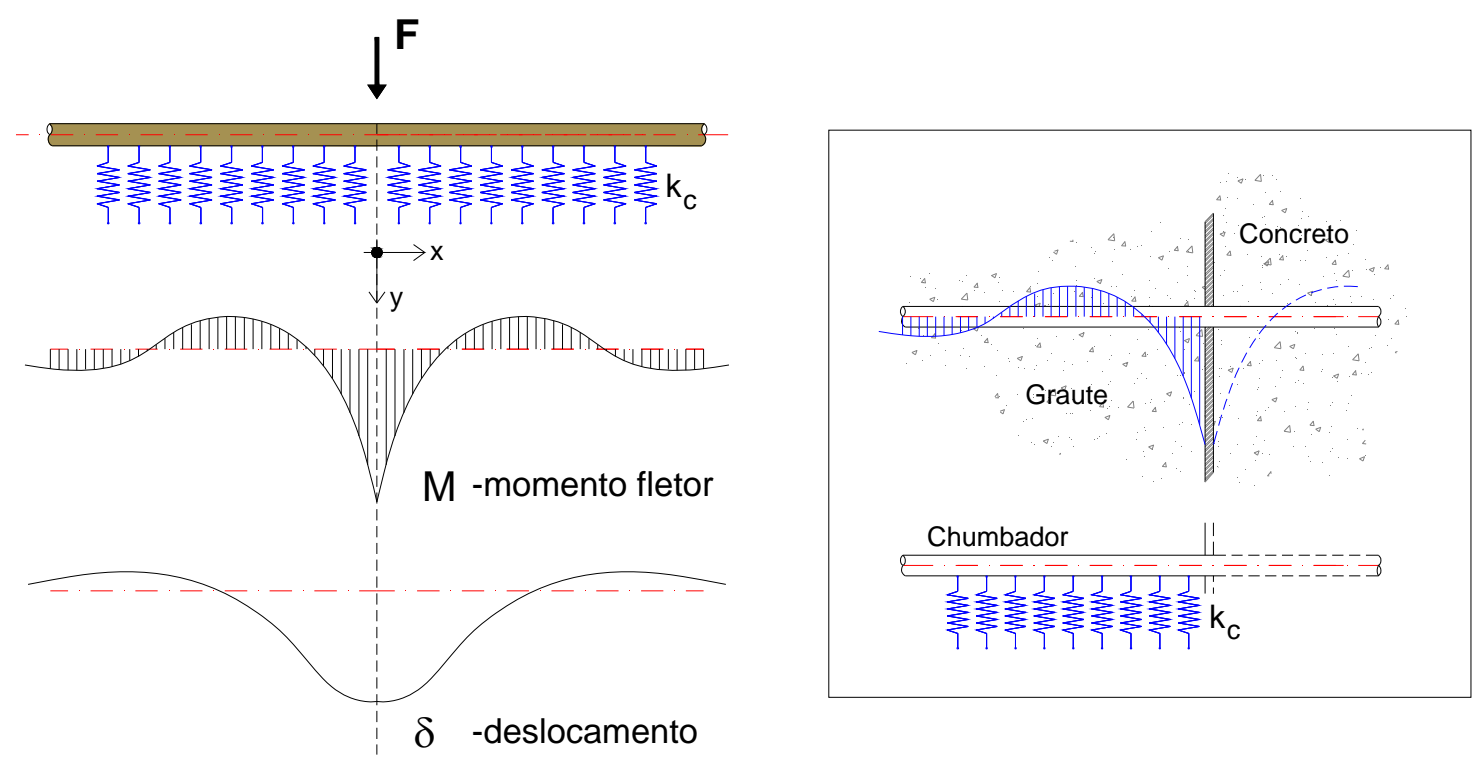

Figura 5.13: Chumbador considerado como viga sobre base elástica. 
Pela teoria de viga sobre apoio elástico, o momento fletor no ponto de aplicação da força $\mathrm{F}(\mathrm{x}=0)$ é dado pela Equação 5.11.

$$
M=\frac{F}{4 . \alpha}
$$

DEI POLI et al. (1992), baseado na mesma teoria, apresentou o seguinte equacionamento para “ $\alpha$ ”:

$$
\begin{aligned}
& \alpha=\sqrt[4]{\frac{k_{c} \cdot \phi}{4 \cdot E_{s} \cdot I_{b}}} \\
& k_{c}=127 \cdot \frac{\sqrt{f_{c}}}{(\phi)^{2 / 3}}
\end{aligned}
$$

Sendo que:

$$
\begin{array}{ll}
k_{c} & \text { - Módulo de rigidez de referência para o concreto; } \\
\phi & \text { - Diâmetro da barra (chumbador); } \\
E_{s} & \text { - Módulo de elasticidade do aço; } \\
I_{b} & \text { - Momento de inércia da barra (chumbador); } \\
f_{c} & \text { - Resistência do concreto à compressão. }
\end{array}
$$

Quando o chumbador é solicitado por uma força F (Figura 5.13), as tensões normais à seção transversal do chumbador, geram um momento resistente em relação ao seu centro de gravidade. Esse momento é máximo quando a seção é totalmente plastificada (Figura 5.14).

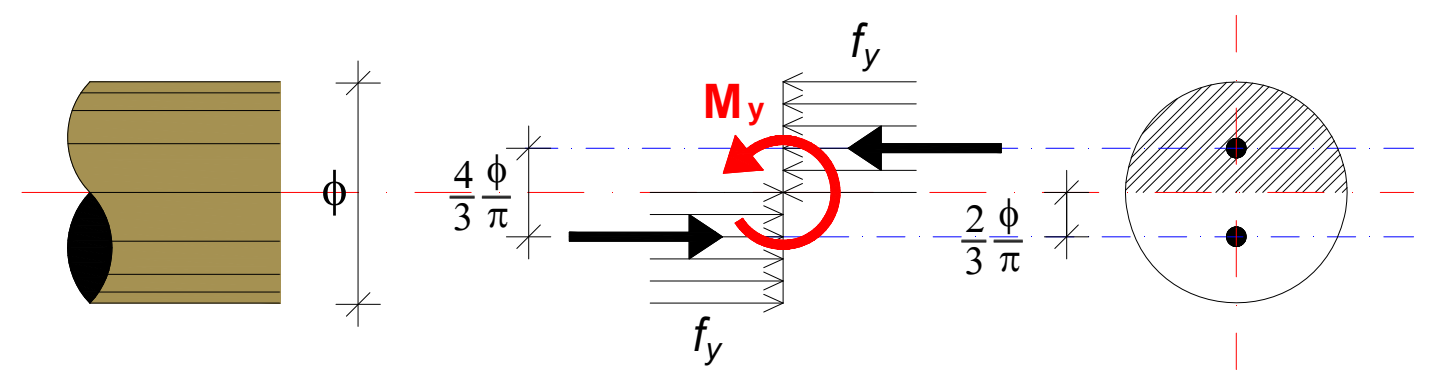

Figura 5.14: Tensões atuantes na seção plastificada do chumbador 
O momento resistente da seção plastificada é dado por:

$$
M_{y}=f_{y} \cdot\left(\frac{\pi \cdot \phi^{2}}{8}\right) \cdot \frac{4 \cdot \phi}{3 \pi}=f_{y} \cdot \frac{\phi^{3}}{6}
$$

Igualando o momento fletor da Equação (5.11) ao momento resistente da seção plastificada do chumbador, Equação (5.14), determina-se a força responsável pela formação da rótula plástica. Assim, tem-se:

$$
F=4 \cdot \alpha \cdot f_{y} \cdot \frac{\phi^{3}}{6}
$$

Substituindo as Equações (5.12) e (5.13) em (5.15), tem-se:

$$
F=\frac{4}{3} \cdot \phi^{2} \cdot f_{y} \cdot \sqrt[4]{\frac{127 \cdot \sqrt{f_{c}} \cdot \phi^{1 / 3}}{\pi \cdot E_{s}}}
$$

Considerando o módulo de elasticidade do aço igual a $210 \mathrm{GPa}$, a Equação (5.16) pode ser reescrita como segue:

$$
F=0,157 \cdot \phi^{2,083} \cdot f_{y} \cdot f_{c}^{0,125}
$$

Sendo que:

$$
\begin{array}{ll}
F & \text { - Parcela da força resistente, em } \mathrm{N} ; \\
\phi & \text { - Diâmetro da barra (chumbador), em mm; } \\
f_{y} & \text { - Tensão de escoamento do chumbador, em N/mm²; } \\
f_{c} & \text { - Resistência do concreto à compressão, em N/mm². }
\end{array}
$$

A Equação (5.17) representa uma parcela da formulação analítica proposta, sendo a outra parcela relativa à fase deformada do chumbador, onde há a consideração da força normal. 


\subsubsection{Consideração da força normal}

Na fase deformada é analisado o chumbador na ocorrência de deslocamento relativo entre o bloco interno e o bloco externo. No instante em que o deslocamento ocorre, o chumbador sofre mudanças de posição no seu eixo axial, mudando sua inclinação original.

\subsubsection{Chumbadores de eixo reto}

No caso dos chumbadores de eixo reto, na fase deformada surgirão pequenas inclinações que irão conduzir ao aparecimento de componentes normais de esforços, conforme apresentado na Figura 5.15.

O comprimento do trecho de análise (Figura 5.15) seguiu o que recomenda BLJUGER (1988) para barras inseridas em dois elementos de concreto com uma altura livre referente à almofada de apoio.

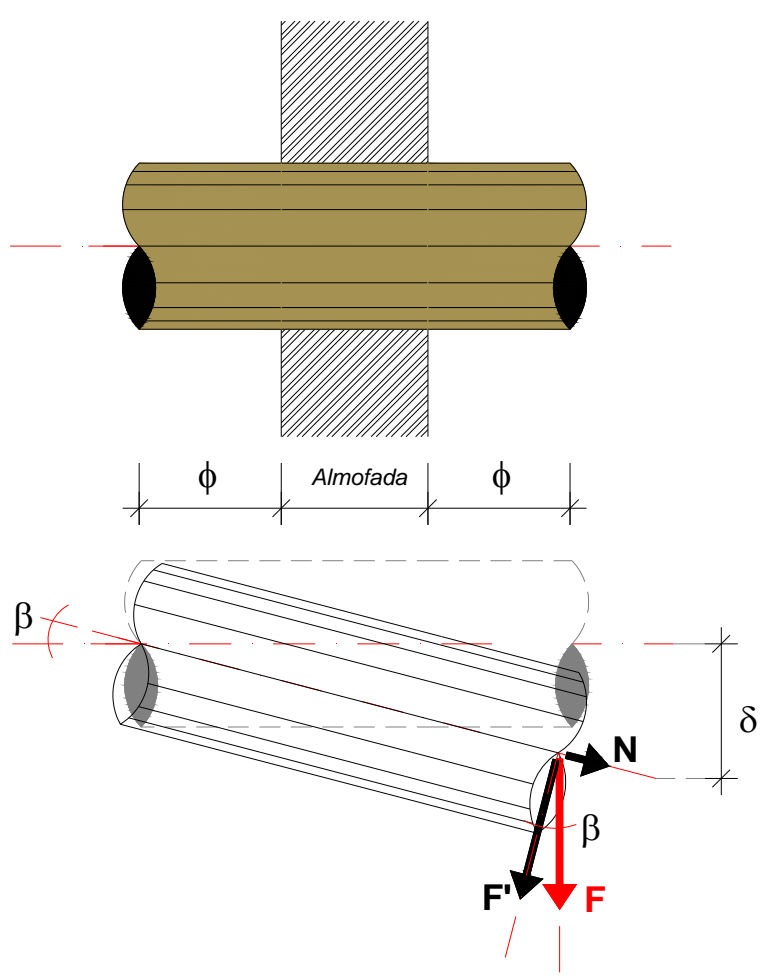

Figura 5.15: Geometria e esforços na posição deformada para chumbadores retos 
A força F, perpendicular ao eixo do chumbador na posição de equilíbrio inicial, após o deslocamento $\delta$ passa a ser decomposta em duas outras forças, sendo uma ainda perpendicular ao eixo do chumbador ( $\left.\mathrm{F}^{\prime}\right)$ e a outra paralela ao eixo do chumbador $(\mathrm{N})$.

A força $\mathrm{F}^{\prime}$ continua exercendo no chumbador o mesmo tipo de esforço capaz de gerar a plastificação da seção por flexão, descrita no item 5.3.1 deste trabalho. Já a força $\mathrm{N}$ atua como força normal de tração, capaz de aumentar as deformações da seção transversal já plastificada por tração (diagrama A, Figura 5.16) e desfazer a plastificação ocorrida por compressão (diagrama B, Figura 5.16).

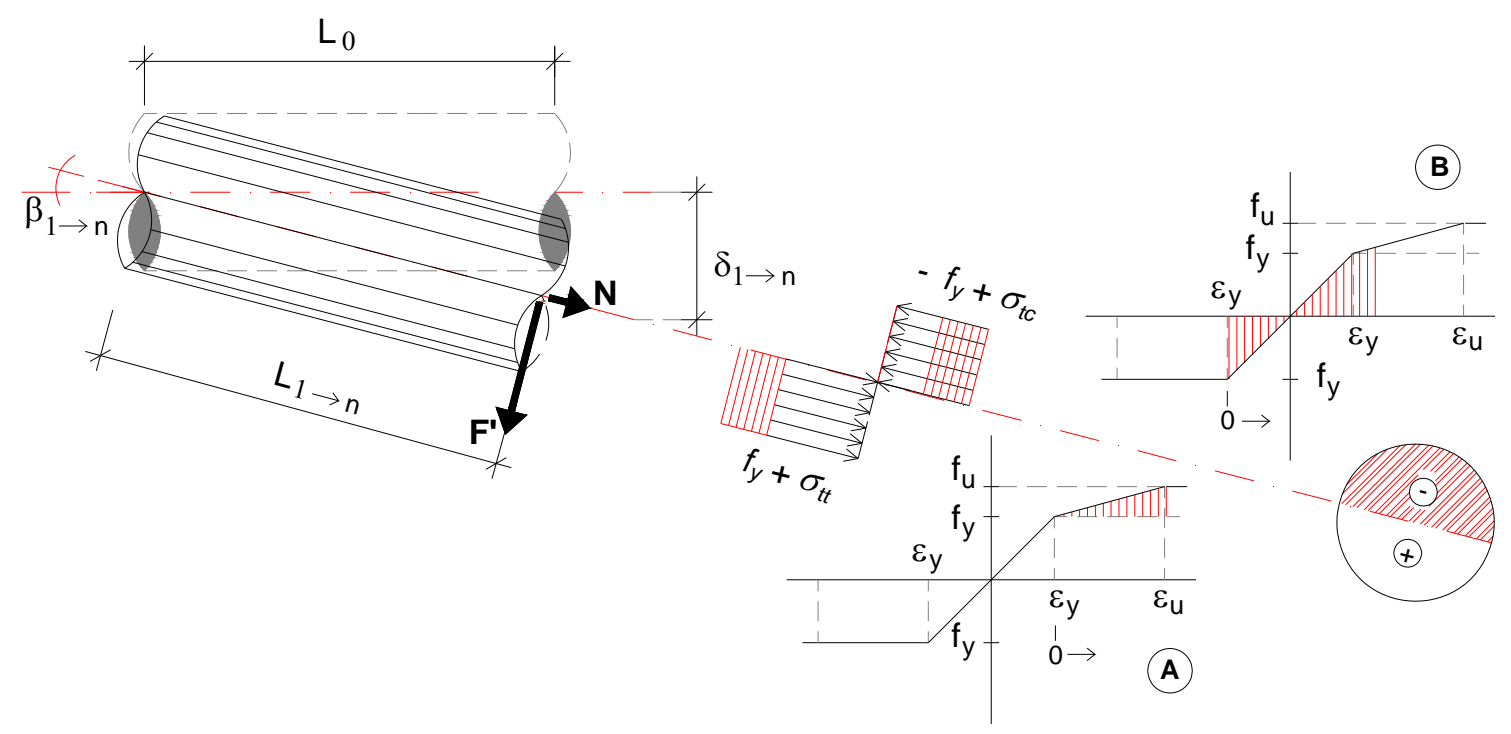

Figura 5.16: Influência do esforço normal na seção transversal do chumbador.

Assim, para cada acréscimo de deslocamento $\delta$, a barra sofrerá um alongamento que por sua vez irá gerar acréscimos de tensões na parte tracionada $\left(\sigma_{\mathrm{tt}}\right)$ e na parte comprimida da barra $\left(\sigma_{\mathrm{tc}}\right)$.

Para a determinação da força $\mathrm{N}$, é necessário seguir os seguintes passos:

Passo 1: Impor um deslocamento $\delta_{1}$, que inicialmente pode ser igual ao deslocamento preconizado por FIP (2007) na ocasião da formação da rótula plástica - 0,1申;

Passo 2: Calcular o ângulo $\beta_{1}$ formado na ocasião do deslocamento imposto, dado por: 


$$
\begin{aligned}
& \beta_{1}=\arctan \left(\frac{\delta_{1}}{L_{0}}\right) \\
& L_{0}=e_{\text {alm }}+2 . \phi
\end{aligned}
$$

Sendo que:

$e_{a l m} \quad$ - Espessura da almofada de apoio.

Passo 3: Calcular o comprimento $\mathrm{L}_{1}$ do chumbador, após a imposição do deslocamento, dado por:

$$
L_{1}=\frac{\left(e_{a l m}+2 . \phi\right)}{\cos \beta_{1}}
$$

Passo 4: Calcular a variação de comprimento $\Delta \mathrm{L}_{1}$ do chumbador, após a imposição do deslocamento, dado por:

$$
\Delta L_{1}=L_{1}-\left(e_{a l m}+2 . \phi\right)
$$

Passo 5: Calcular a deformação $\varepsilon_{1}$ do chumbador, após a imposição do deslocamento, dado por:

$$
\varepsilon_{1}=\frac{\Delta L_{1}}{\left(e_{a l m}+2 . \phi\right)}
$$

Passo 6: Calcular o acréscimo da tensão de tração na área tracionada $\sigma_{\mathrm{tt}}$, dado por:

$$
\sigma_{t t}=\left(\frac{f_{u}-f_{y}}{\varepsilon_{u}-\varepsilon_{y}}\right) \cdot \varepsilon_{1}
$$

Passo 7: Calcular a tensão de tração na área comprimida $\sigma_{\mathrm{tc}}$, para $\varepsilon_{1} \leq 2 . \varepsilon_{\mathrm{y}}$, dado por:

$$
\sigma_{t c}=E_{s} \cdot \varepsilon_{1}
$$


Passo 8: Calcular a força normal N, dada por:

$$
N=\sigma_{t t} \cdot\left(\frac{\pi \cdot \phi^{2}}{8}\right)+\sigma_{t c} \cdot\left(\frac{\pi \cdot \phi^{2}}{8}\right)
$$

Ou seja:

$$
N=\left[\left(\frac{f_{u}-f_{y}}{\varepsilon_{u}-\varepsilon_{y}}\right)+E_{s}\right]\left(\frac{\pi \cdot \phi^{2}}{8}\right) \cdot \varepsilon_{1}
$$

Após determinada a força $\mathrm{N}$ para o deslocamento $\delta_{1}$, deve ser imposto o deslocamento $\delta_{2}, \delta_{3} \ldots \delta_{\mathrm{n}}$, sendo calculado o valor de $\mathrm{N}$ para cada deslocamento imposto, seguindo os passos anteriormente descritos. A capacidade máxima do chumbador será atingida quando a deformação $\varepsilon_{\mathrm{n}}$ (obtida no deslocamento $\delta_{\mathrm{n}}$ ) alcançar a deformação $\varepsilon_{\mathrm{u}}$ do diagrama “A” da Figura 5.16.

\subsubsection{Chumbadores de eixo inclinado}

Para o chumbador inclinado a $\theta^{\circ}$, segue-se o mesmo procedimento anteriormente descrito, porém com a geometria da posição deformada apresentada na Figura 5.17.

Para os chumbadores inclinados não existe uma recomendação de comprimento do trecho de análise na literatura técnica. O uso do comprimento recomendado por BLJUGER (1988) não conduziu a resultados satisfatórios, uma vez que a formação de rótula plástica não pôde ser confirmada.

Conforme apresentado no Capítulo 04 deste trabalho, foi observado nos chumbadores inclinados uma tendência de retificação da sua parte curva. Essa tendência gerou a hipótese de que boa parte do comprimento do chumbador é solicitado. Assim, para o desenvolvimento do modelo analítico foi utilizado como comprimento de análise o comprimento projetado do chumbador no eixo horizontal ( $\left.\mathrm{L}_{\mathrm{proj}}\right)$.

Após a realização de várias tentativas para a determinação do comprimento analítico adequado, recomenda-se usar um valor não inferior a $16 \phi$ para chumbadores 
inclinados. O uso de comprimentos inferiores ao recomendado induz, pela proposta analítica aqui apresentada, à superação da capacidade de tração da barra em poucos incrementos de deslocamento.
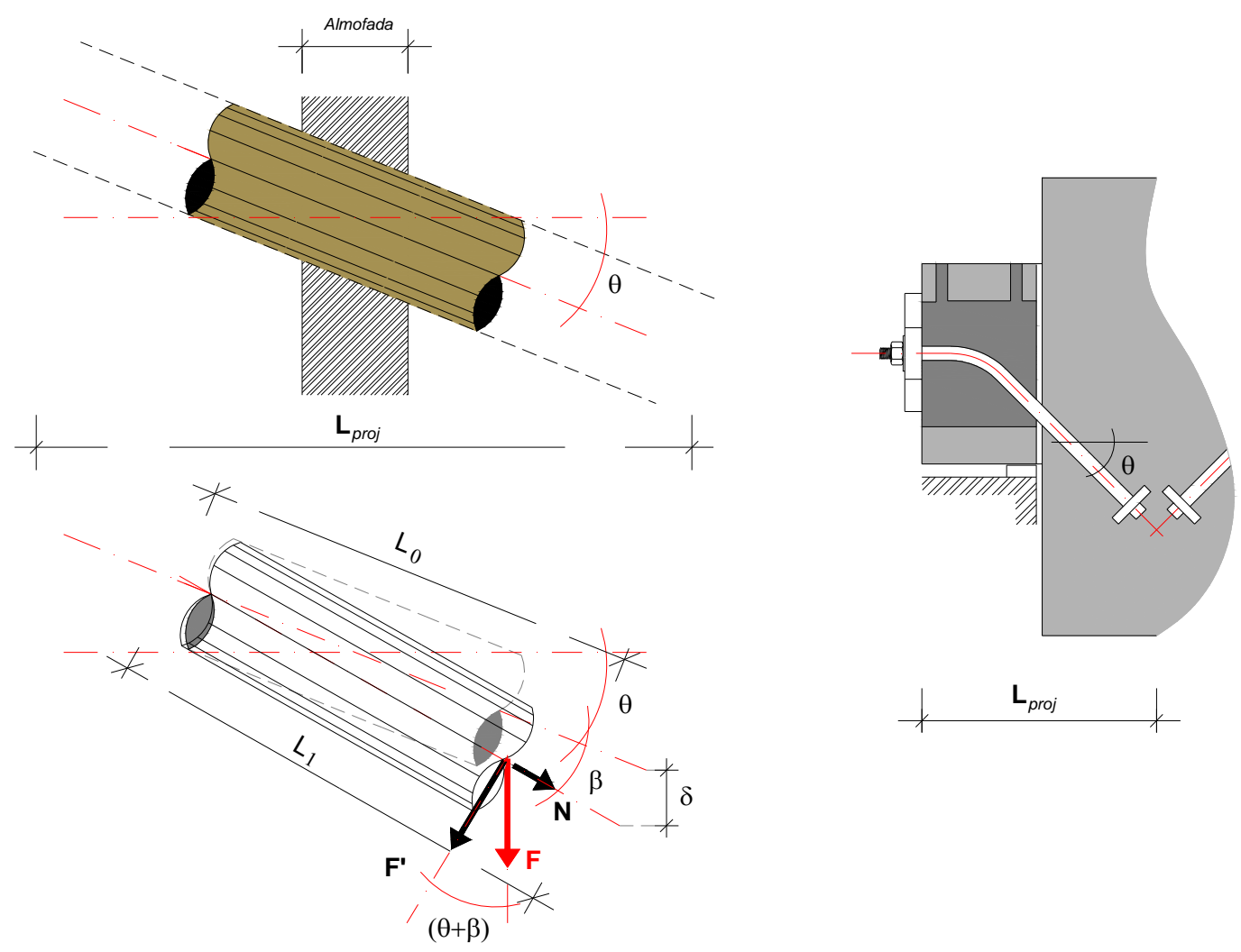

Figura 5.17: Geometria e esforços na posição deformada para chumbadores inclinados

Tomando como base o deslocamento de 0,1申, que de acordo com FIP (2007) ocorre na ocasião da formação da rótula plástica em chumbadores de eixo reto, pode-se determinar o valor da força $\mathrm{N}$ como segue:

$$
\begin{aligned}
& L_{0}=\frac{L_{\text {proj }}}{\cos \theta} \\
& (\theta+\beta)=\arctan \left[\frac{\left(L_{\text {proj }}\right) \cdot \tan \theta+0,1 . \phi}{L_{\text {proj }}}\right] \\
& L_{1}=\frac{L_{\text {proj }}}{\cos (\theta+\beta)}
\end{aligned}
$$




$$
\begin{aligned}
& \Delta L_{1}=\frac{L_{\text {proj }}}{\cos (\theta+\beta)}-\frac{L_{\text {proj }}}{\cos \theta} \\
& \varepsilon_{1}=\frac{\Delta L_{1}}{L_{\text {proj }}} \cdot \cos \theta
\end{aligned}
$$

Assim, a força N pode ser determinada pela Equação (5.26).

\subsubsection{Formulação geral da capacidade de carga}

Considera-se como capacidade de carga do chumbador no instante da formação da rótula plástica, a soma das parcelas relativas às forças $\mathrm{F}^{\prime}$ e $\mathrm{N}$, conforme ilustrado na Figura 5.17.

As parcelas relativas a $\mathrm{F}^{\prime}$ e $\mathrm{N}$ são consideradas na forma de componentes projetadas no eixo do deslocamento $\delta$ (eixo “y”). Assim a capacidade de carga do chumbador é dada pela seguinte expressão:

$$
F_{p}=F^{\prime} \cdot \cos (\beta+\theta)+N \cdot \operatorname{sen}(\beta+\theta)
$$

Substituindo na Equação (5.32) o valor de $\mathrm{F}^{\prime}$ dado na Equação (5.17) e o valor de $\mathrm{N}$ dado na Equação (5.26), tem-se:

$$
F_{p}=0,157 \cdot \phi^{2,083} \cdot f_{y} \cdot f_{c}^{0,125} \cdot \cos (\beta+\theta)+\left[\left(\frac{f_{u}-f_{y}}{\varepsilon_{u}-\varepsilon_{y}}\right)+E_{s}\right]\left(\frac{\pi \cdot \phi^{2}}{8}\right) \cdot \varepsilon_{1} \cdot \operatorname{sen}(\beta+\theta)
$$

Com base nos ensaios de tração do aço realizados no Laboratório de Estruturas da EESC-USP, foi verificado que a tensão última do aço $\left(f_{u}\right)$ é cerca de $21 \%$ superior à tensão de escoamento $\left(f_{y}\right)$ verificada.

Outra simplificação possível de ser realizada é a determinação do valor de $\varepsilon_{1}$ para o deslocamento $\delta=0,1 . \phi$. Substituindo a Equação (5.30) em (5.31), tem-se: 


$$
\varepsilon_{1}=\frac{\left(\frac{L_{p r o j}}{\cos (\theta+\beta)}-\frac{L_{p r o j}}{\cos \theta}\right)}{L_{\text {proj }}} \cdot \cos \theta
$$

Ou seja:

$$
\varepsilon_{1}=\left[\frac{\cos \theta}{\cos (\theta+\beta)}-1\right]
$$

Substituindo a Equação (5.35) em (5.33), tem-se a expressão final proposta, sendo que para chumbadores de eixo reto, o valor de $\theta$ é igual a zero.

$$
F_{p}=0,157 \cdot \phi^{2,083} \cdot f_{y} \cdot f_{c}^{0,125} \cdot \cos (\beta+\theta)+0,393 \cdot \phi^{2} \cdot\left[\left(\frac{0,21 \cdot f_{y}}{0,01-\frac{f_{y}}{E_{s}}}\right)+E_{s}\right] \cdot\left[\frac{\cos \theta}{\cos (\beta+\theta)}-1\right] \cdot \operatorname{sen}(\beta+\theta)
$$

Sendo que:

$F_{p} \quad$ - Força no chumbador na formação da rótula plástica ou quando o deslocamento relativo entre as superfícies interligadas pelo chumbador atingir $0,1 \phi(\mathrm{N})$;

$\theta \quad$ - Inclinação do chumbador sem carregamento;

$\beta$ - Inclinação quando o chumbador sofre plastificação, Equação (5.28);

$e_{\text {alm }} \quad$ - Espessura da almofada (mm);

$f_{y} \quad$ - Tensão de escoamento do chumbador $\left(\mathrm{N} / \mathrm{mm}^{2}\right)$;

$f_{c} \quad$ - Resistência do concreto à compressão $\left(\mathrm{N} / \mathrm{mm}^{2}\right)$;

$\phi \quad$ - Diâmetro do chumbador (mm);

$E_{s} \quad$ - Módulo de elasticidade do aço $\left(\mathrm{N} / \mathrm{mm}^{2}\right)$.

A primeira parcela da Equação (5.36), em chumbadores de eixo reto, pode ser substituída pela Equação (2.28), por se tratar de uma equação clássica e já consagrada no meio técnico. Para concretos com resistência à compressão próximo dos valores obtidos nesta pesquisa, as duas expressões apresentam valores compatíveis. 
Com base na Equação (5.36), para o deslocamento de 0,1申, pode-se estimar as parcelas relativas à formação da rótula plástica e à contribuição da força normal. Para chumbadores retilíneos (inclinação de $0^{\circ}$ ), a parcela relativa à formação da rótula plástica é em média $98 \%$ da força total $\left(F_{p}\right)$.

Para chumbadores inclinados a $45^{\circ}$, foi observado que a parcela relativa à formação da rótula plástica é em média $45 \%$ da força total $\left(F_{p}\right)$. Já nos chumbadores inclinados a $60^{\circ}$, essa parcela representa em média 35\% da força total $\left(F_{p}\right)$. Assim, verifica-se que a contribuição da força normal em chumbadores inclinados representa uma parcela importante de sua capacidade de carga.

Com o auxílio de uma planilha eletrônica, pode-se a partir do ponto de formação da rótula plástica, fornecer incrementos de deslocamentos e traçar o diagrama analítico de força por barra $\mathrm{x}$ deslocamento.

Na Figura 5.18 são apresentados diagramas força por barra x deslocamento para os modelos 01, 05 e 08, pertencentes ao grupo de chumbadores retos. Os pontos obtidos são referentes a incrementos sucessivos de $0,25 \mathrm{~mm}$ no deslocamento de formação da rótula plástica. A título de comparação, foi considerada a folga existente no modelo, sendo considerado como origem do diagrama analítico, o ponto referente ao último ciclo de carregamento

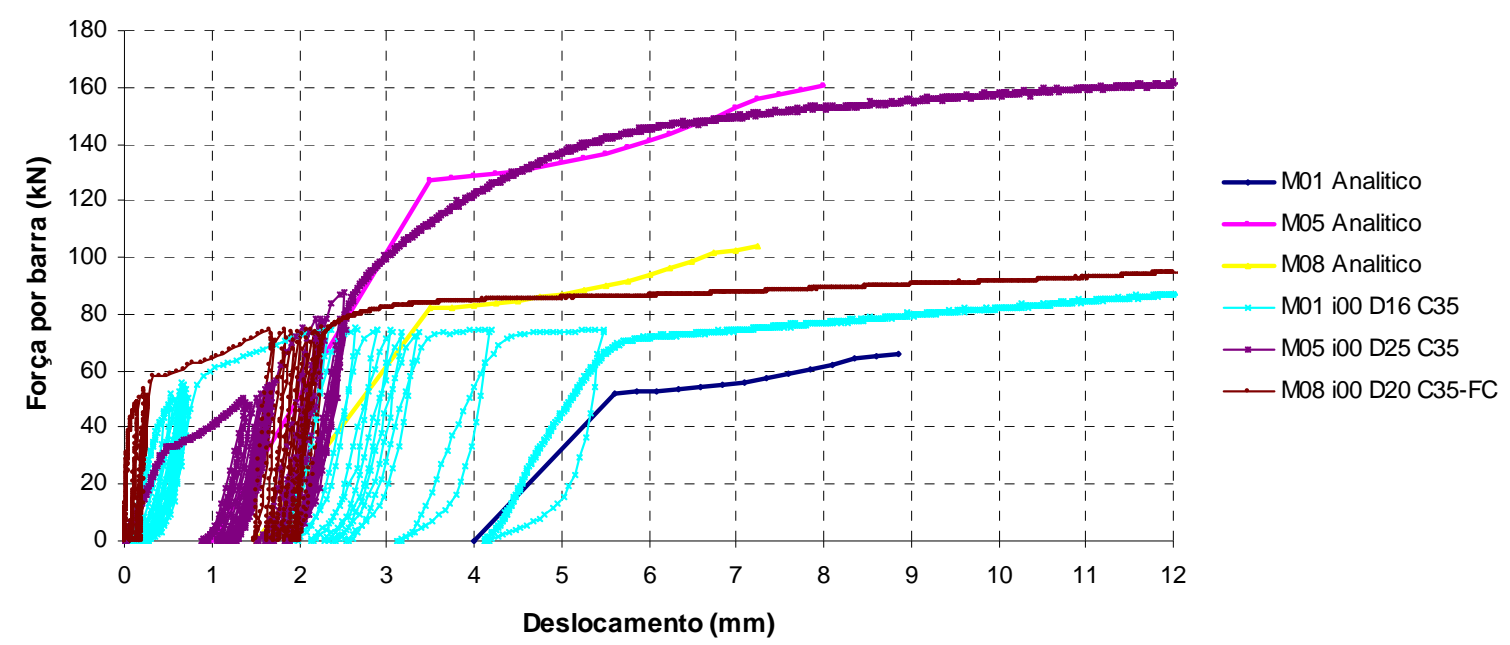

Figura 5.18: Comparação de resultados experimentais e analíticos - chumbadores retos

Para os chumbadores pertencentes ao grupo de eixo inclinado a $45^{\circ}$, o comportamento força por barra x deslocamento é apresentado na Figura 5.19. Foram 
simulados os comportamentos dos modelos 13 e 15, e comparados com os resultados experimentais.

Os pontos obtidos são referentes a incrementos sucessivos de 0,25 mm no deslocamento de 0,1.申. A origem do diagrama analítico foi o ponto de início do último ciclo de carregamento do modelo experimental.

Por fim foi realizado o mesmo procedimento para os chumbadores pertencentes ao grupo de eixo inclinado a $60^{\circ}$. O comportamento força por barra x deslocamento é apresentado na Figura 5.20, onde foram simulados os comportamentos dos modelos 10 e 12, e comparados com os resultados experimentais obtidos.

Não foi contemplado no modelo analítico proposto o efeito da força de protensão. Com base nos resultados experimentais, observou-se que a força de protensão exerceu papel importante na redução das folgas existentes no modelo, aumentando assim a rigidez, principalmente nos primeiros ciclos de carregamento. A partir do momento em que o modelo começa a sofrer deslocamentos, o efeito do atrito gerado pela protensão começa a perder eficiência.

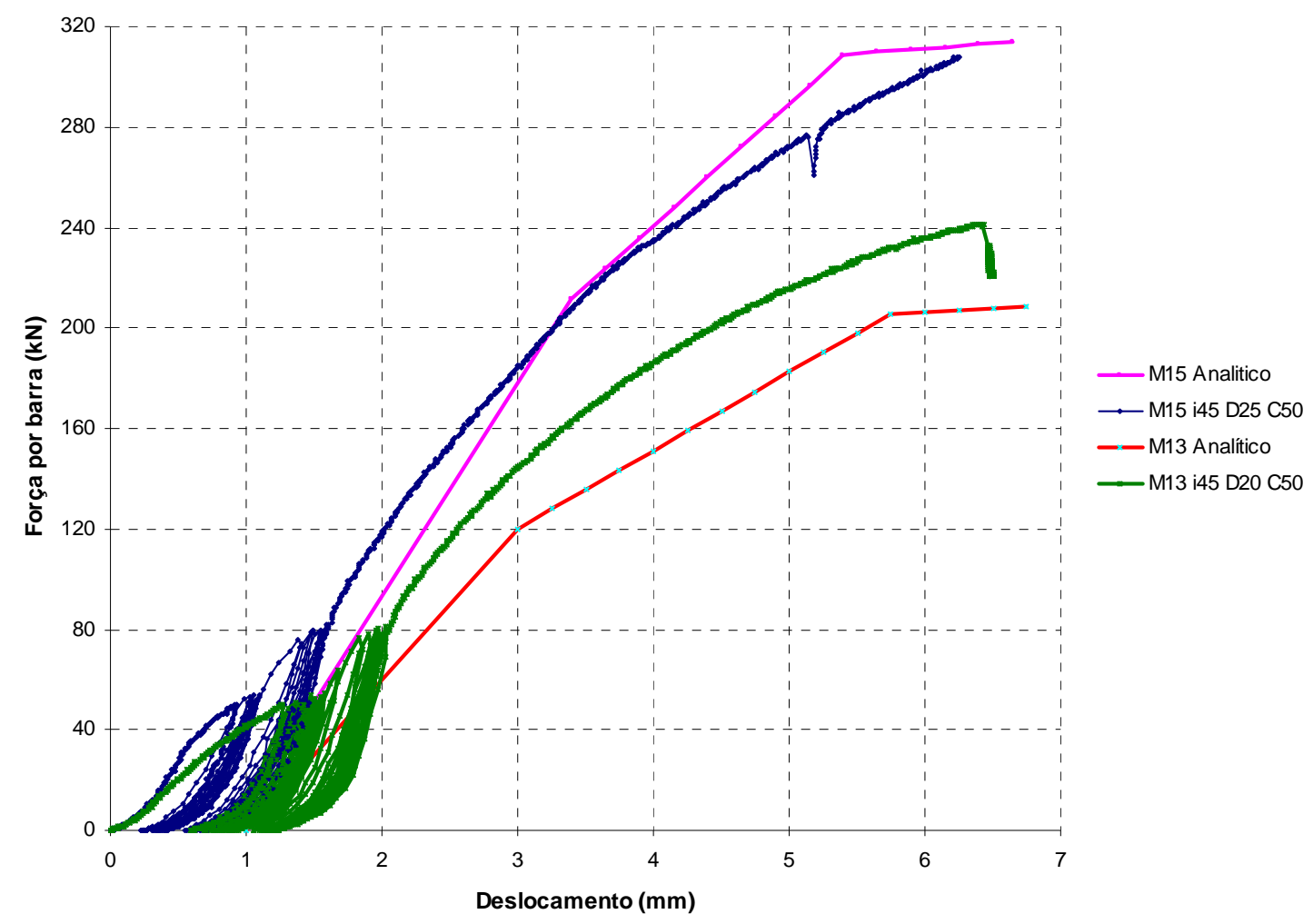

Figura 5.19: Comparação de resultados experimentais e analíticos - chumbadores a $45^{\circ}$ 


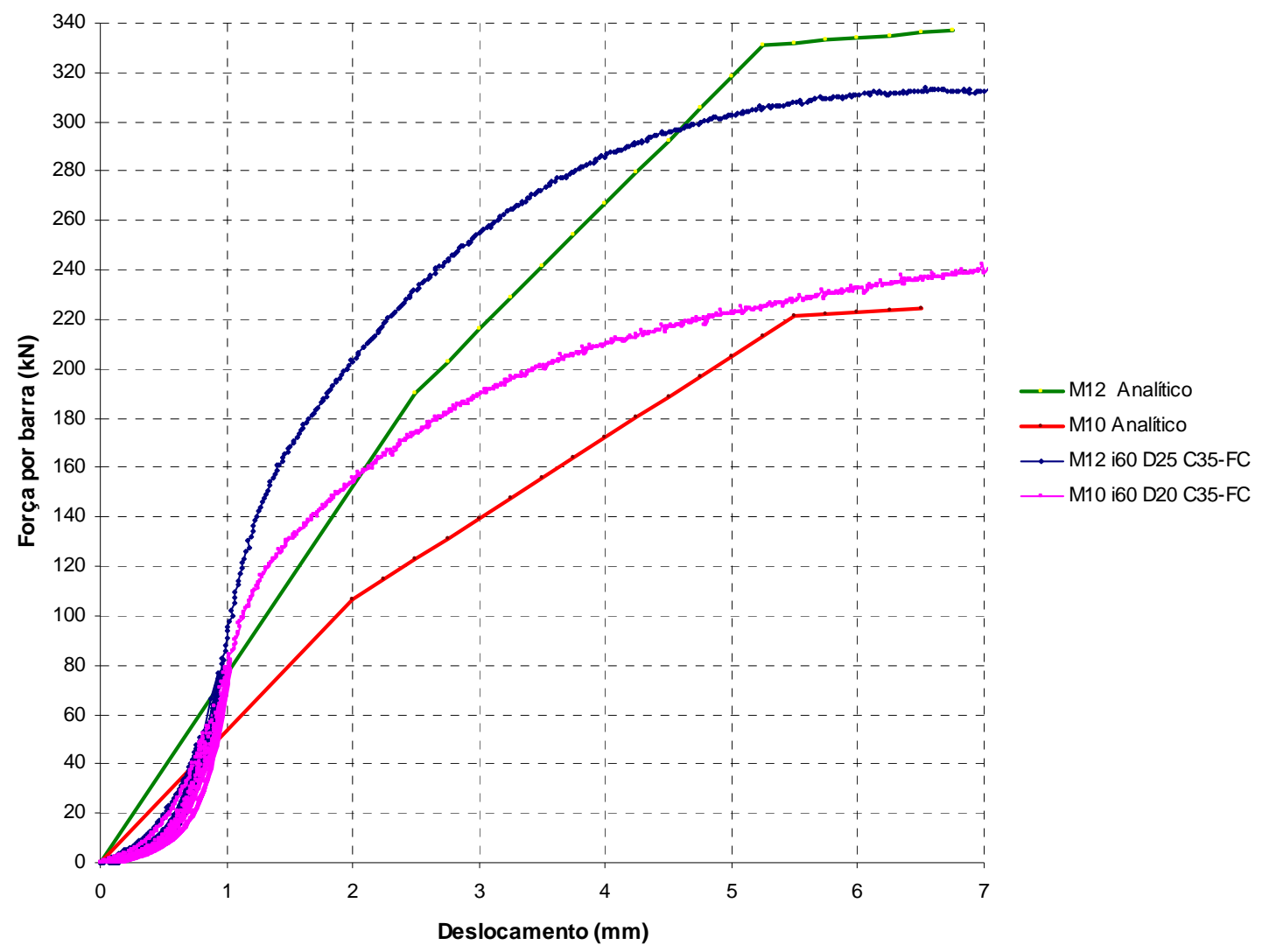

Figura 5.20: Comparação de resultados experimentais e analíticos - chumbadores a $60^{\circ}$

É importante registrar que a formulação proposta apresentada na Equação (5.36) não contempla modos de ruptura localizados, sendo considerado o chumbador como inserido em uma massa de concreto onde devem ser obedecidas dimensões mínimas previstas nos códigos vigentes.

\subsubsection{Proposta de diagrama analítico força por barra $\mathrm{x}$ deslocamento}

Baseado nos resultados obtidos analiticamente, foi observada a tendência tri-linear de resposta do diagrama força por barra x deslocamento. Tal resposta é bem acentuada para os chumbadores de eixo inclinado, onde a deformação angular do chumbador pouco altera a inclinação inicial.

No último trecho do diagrama analítico, referente à força máxima alcançada, observa-se uma tendência de horizontalidade, mais evidente nos chumbadores de eixo inclinado. 
Foram realizadas simulações analíticas variando as inclinações e diâmetros dos chumbadores, além da resistências à compressão do concreto, sendo observado os valores alcançados tanto para a força última como para o deslocamento máximo alcançado.

Expressando a força última alcançada em relação à força $F_{p}$ (Equação 5.33) e os deslocamentos observados em relação ao diâmetro analisado, chega-se a um diagrama tri-linear que pode ser usado para estimar o comportamento força por barra $\mathrm{x}$ deslocamento do chumbador.

Na Figura 5.21 é apresentada a proposta de diagrama analítico para os chumbadores de eixo reto. Foi observada a mesma tendência de comportamento independente do diâmetro utilizado.

Como proposta, optou-se por adotar o trecho 2-3 do diagrama (Figura 5.21) como horizontal, tendo em vista que o ganho de capacidade de carga nesse trecho pode ser considerado pequeno (Figura 5.18).

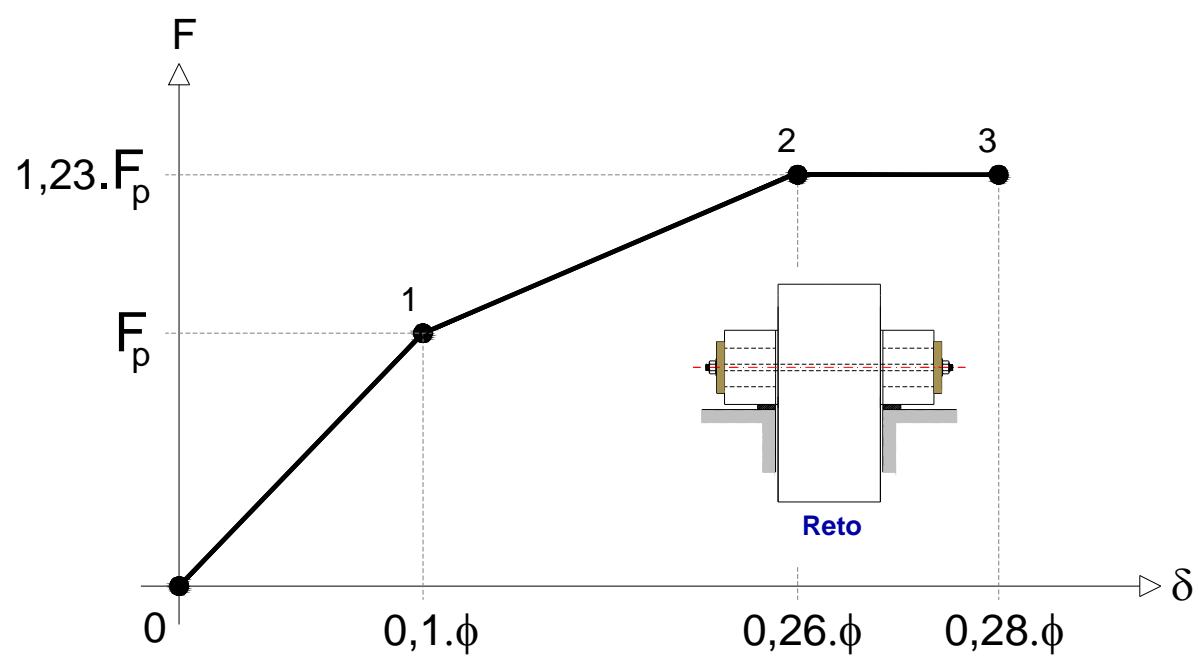

Figura 5.21: Proposta de diagrama analítico para chumbadores de eixo reto

Na Figura 5.22 é apresentada a proposta de diagrama analítico para os chumbadores de eixo inclinado.

Para esse grupo de chumbadores, foi observada que a resposta força por barra $\mathrm{x}$ deslocamento variava com o diâmetro e a inclinação, não sendo possível obter uma relação de simplificação dos resultados. 


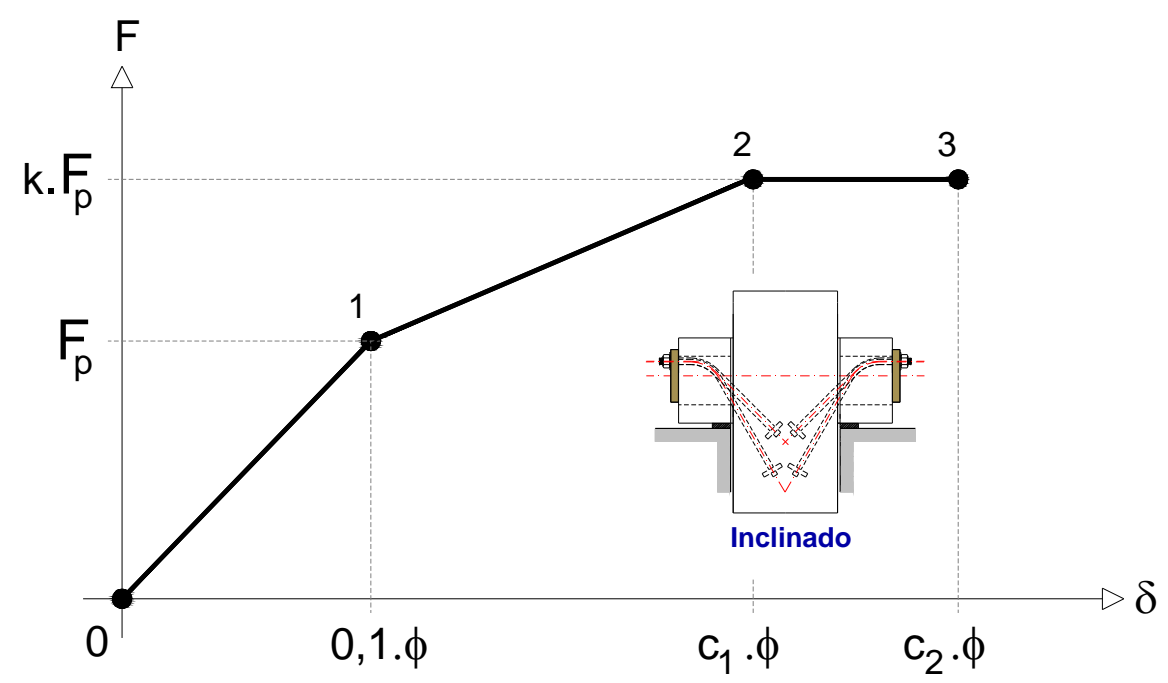

Figura 5.22: Proposta de diagrama analítico para chumbadores de eixo inclinado

Assim, a força máxima e os deslocamentos foram expressos na forma de coeficientes, apresentados na Tabela 5.4, que variam de acordo com o diâmetro e a inclinação do chumbador analisado.

Tabela 5.4: Coeficientes propostos para diagrama de chumbadores de eixo inclinado

\begin{tabular}{|c|c|c|c|c|}
\hline \multirow{2}{*}{$\begin{array}{c}\text { INCLINAÇÃO DO } \\
\text { CHUMBADOR }\end{array}$} & \multirow{2}{*}{$\begin{array}{c}\text { DIÂMETRO DO } \\
\text { CHUMBADOR }\end{array}$} & \multicolumn{3}{|c|}{ COEFICIENTES PROPOSTOS } \\
\hline & & $\mathbf{K}$ & $\mathrm{C}_{1}$ & $C_{2}$ \\
\hline \multirow{3}{*}{$45^{\circ}$} & $16 \mathrm{~mm}$ & 1,88 & 0,29 & 0,35 \\
\hline & $20 \mathrm{~mm}$ & 1,71 & 0,24 & 0,29 \\
\hline & $25 \mathrm{~mm}$ & 1,46 & 0,18 & 0,23 \\
\hline \multirow{3}{*}{$60^{\circ}$} & $16 \mathrm{~mm}$ & 2,32 & 0,33 & 0,41 \\
\hline & $20 \mathrm{~mm}$ & 2,08 & 0,28 & 0,33 \\
\hline & $25 \mathrm{~mm}$ & 1,73 & 0,21 & 0,27 \\
\hline
\end{tabular}

Com base nos valores propostos na Tabela 5.4, observa-se que a força máxima alcançada é em média $68 \%$ maior que a força $F_{p}$ (Equação 5.33) para chumbadores inclinados a $45^{\circ}$, e $104 \%$ maior para chumbadores inclinados a $60^{\circ}$.

A comparação entre os diagramas analíticos propostos e os diagramas obtidos experimentalmente é apresentada no Capítulo 06 deste trabalho. 


\section{ANÁLISE DOS RESULTADOS}

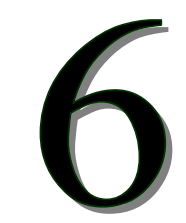

Capítulo

\subsection{GENERALIDADES}

Neste capítulo são apresentadas as análises dos resultados obtidos experimentalmente e dos resultados teóricos (analítico e numérico), sendo enfocados os fatores que influenciam o comportamento força x deslocamento do chumbador.

A influência do diâmetro e da força de compressão aplicada é apresentada separadamente para cada grupo de chumbadores (eixo reto e inclinados a $45^{\circ}$ e $60^{\circ}$ ). A influência da resistência à compressão do concreto também é abordada, finalizando com a apresentação da análise da inclinação do chumbador na resposta força x deslocamento dos modelos.

\subsection{CHUMBADORES DE EIXO RETO}

Para os chumbadores de eixo reto, são abordadas as influências do diâmetro do chumbador e da força de compressão aplicada.

\subsubsection{Influência do diâmetro do chumbador}

O diâmetro do chumbador exerce grande influência no comportamento força $\mathrm{x}$ deslocamento do modelo. Quanto maior o diâmetro, maior será a capacidade de carga a ele associada. 
Na Figura 6.1 são apresentados os resultados experimentais obtidos para os modelos 01 e 05. A força máxima alcançada pelo modelo 05 foi 35,6\% superior à alcançada pelo modelo 01. Comparando a rigidez no último ciclo de carregamento, apresentada no Capítulo 04 deste trabalho, o modelo 05 apresentou valor 181\% superior ao modelo 01 .

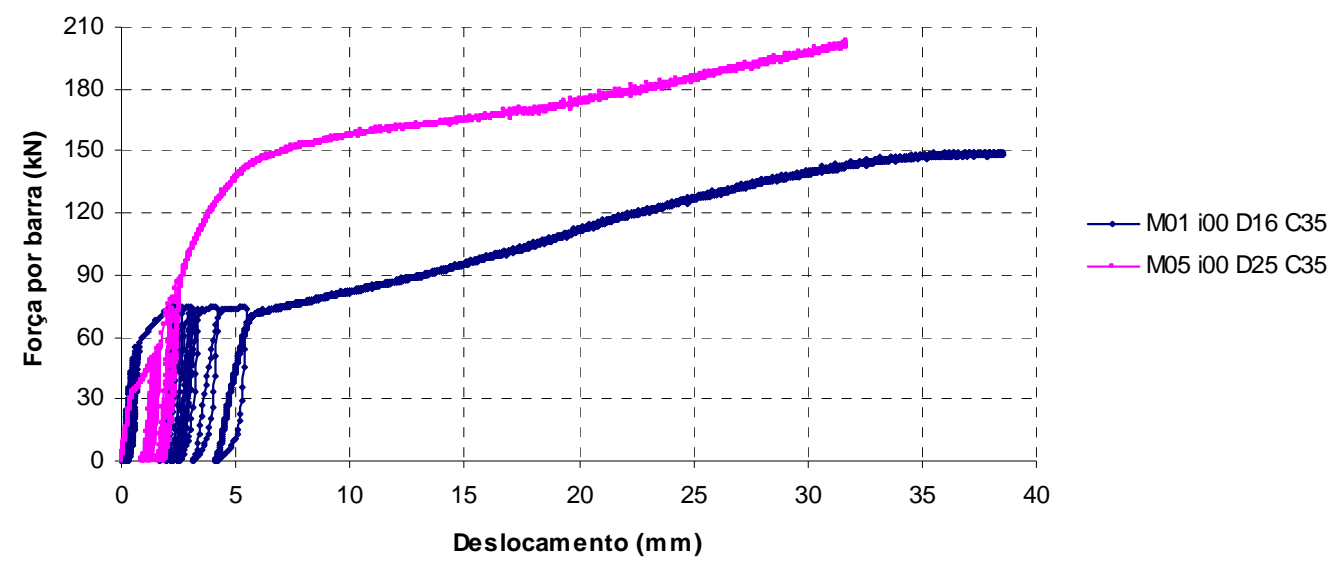

Figura 6.1: Resultados experimentais para os modelos 01 e 05

Os resultados obtidos segundo o modelo analítico proposto são apresentados na Figura 6.2. Para efeito de comparação foi levada em consideração a folga existente nos modelos, sendo considerado o último ciclo de carregamento.

A proposta analítica conseguiu reproduzir de forma satisfatória o comportamento força por barra x deslocamento dos chumbadores.

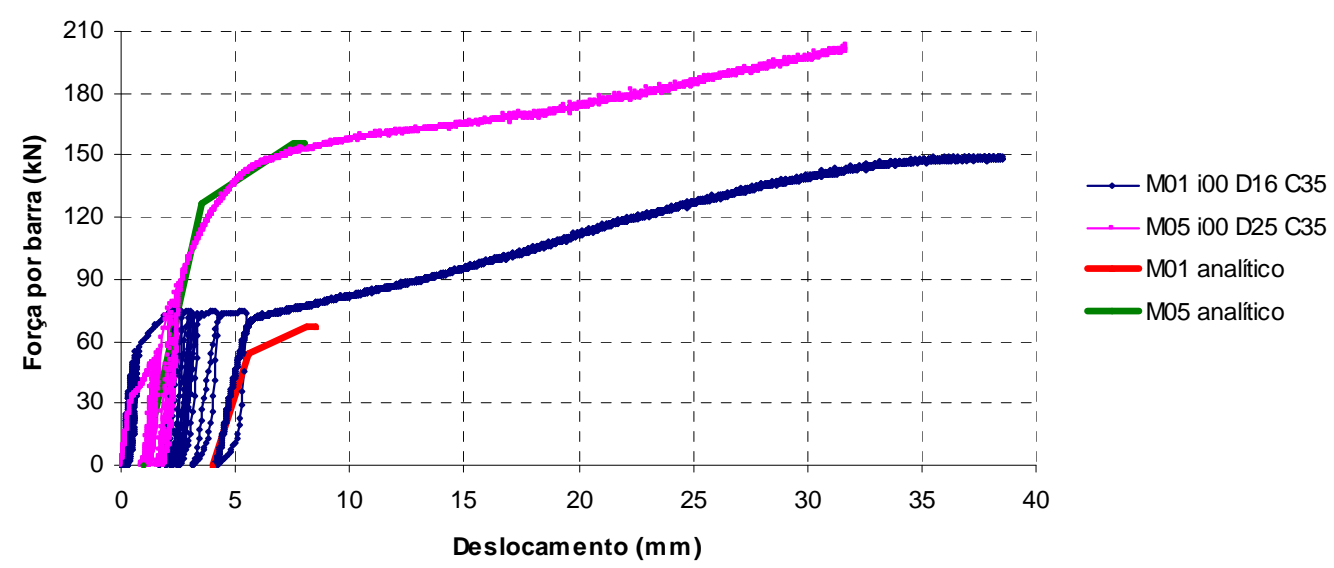

Figura 6.2: Resultados experimentais e analíticos dos modelos 01 e 05 
As relações entre a força experimental $\left(\mathrm{F}_{\text {exp }}\right)$ alcançada no ponto de deslocamento máximo previsto pela proposta analítica $\left(\delta_{\text {ana }}\right)$ com a força máxima obtida na proposta analítica $\left(\mathrm{F}_{\text {ana}}\right)$, foram de 1,16 e 0,98 para os modelos 01 e 05 respectivamente.

Na Figura 6.3 são apresentados os resultados da simulação numérica realizada, onde pode ser observada uma concordância também satisfatória com os resultados experimentais.

As relações entre a força experimental $\left(\mathrm{F}_{\text {exp }}\right)$ alcançada no ponto de deslocamento máximo previsto pela proposta numérica $\left(\delta_{\text {num }}\right)$ com a força máxima obtida na proposta numérica $\left(F_{\text {num }}\right)$, foram de 0,86 e 0,90 para os modelos 01 e 05 respectivamente.

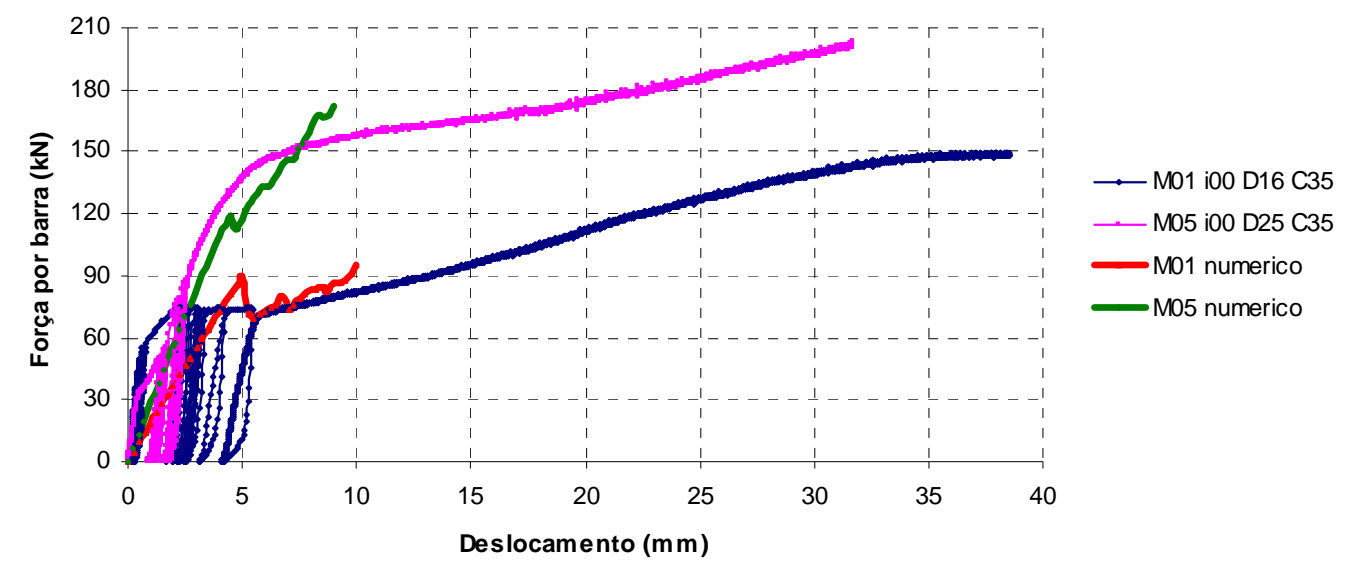

Figura 6.3: Resultados experimentais e numéricos dos modelos 01 e 05

Os resultados obtidos para os modelos 01 e 05 são apresentados na Tabela 6.1, onde a força máxima prevista inicialmente $\left(F_{\text {prev }}\right)$, de acordo com a Equação (2.34), é especificada.

Tabela 6.1: Comparação entre resultados para os modelos 01 e 05

\begin{tabular}{|c|c|c|c|c|c|c|c|c|c|c|c|}
\hline \multirow{2}{*}{ MODELO } & \multicolumn{4}{|c|}{ FORÇA MÁXIMA (kN) } & \multicolumn{3}{|c|}{ DESLOC. MÁXIMO (mm) } & \multirow{2}{*}{$\begin{array}{l}F_{\text {exp }} / \\
F_{\text {num }}\end{array}$} & \multirow{2}{*}{$\begin{array}{l}\mathrm{F}_{\text {exp }} / \\
\mathrm{F}_{\text {ana }}\end{array}$} & \multirow{2}{*}{$\begin{array}{c}\mathrm{F}_{\text {exp }}\left(\delta_{\text {num }}\right) / \\
\mathrm{F}_{\text {num }}\end{array}$} & \multirow{2}{*}{$\begin{array}{c}\mathrm{F}_{\exp }\left(\delta_{\text {ana }}\right) / \\
\mathrm{F}_{\text {ana }}\end{array}$} \\
\hline & $F_{\text {prev }}$ & $F_{\text {exp }}$ & $F_{\text {num }}$ & $F_{\text {ana }}$ & $\delta_{\exp }$ & $\delta_{\text {num }}$ & $\delta_{\text {ana }}$ & & & & \\
\hline Modelo 01 & 84,00 & 149,00 & 95,11 & 66,85 & 38,53 & 10,00 & 8,48 & 1,57 & 2,23 & 0,86 & 1,16 \\
\hline Modelo 05 & 188,25 & 202,00 & 171,70 & 156,20 & 31,70 & 9,00 & 8,00 & 1,18 & 1,29 & 0,90 & 0,98 \\
\hline
\end{tabular}


Além dos modelos 01 e 05, também foram realizadas comparações entre os resultados obtidos nos modelos 08 e 11, pertencentes ao grupo de chumbadores com força de compressão aplicada.

Foi observada a mesma tendência de aumento da capacidade de carga com o aumento do diâmetro do chumbador (Figura 6.4). A força máxima alcançada pelo modelo 11 foi 7,1\% superior à alcançada pelo modelo 08. Comparando a rigidez no último ciclo de carregamento, o modelo 11 foi 8\% superior ao modelo 08 .

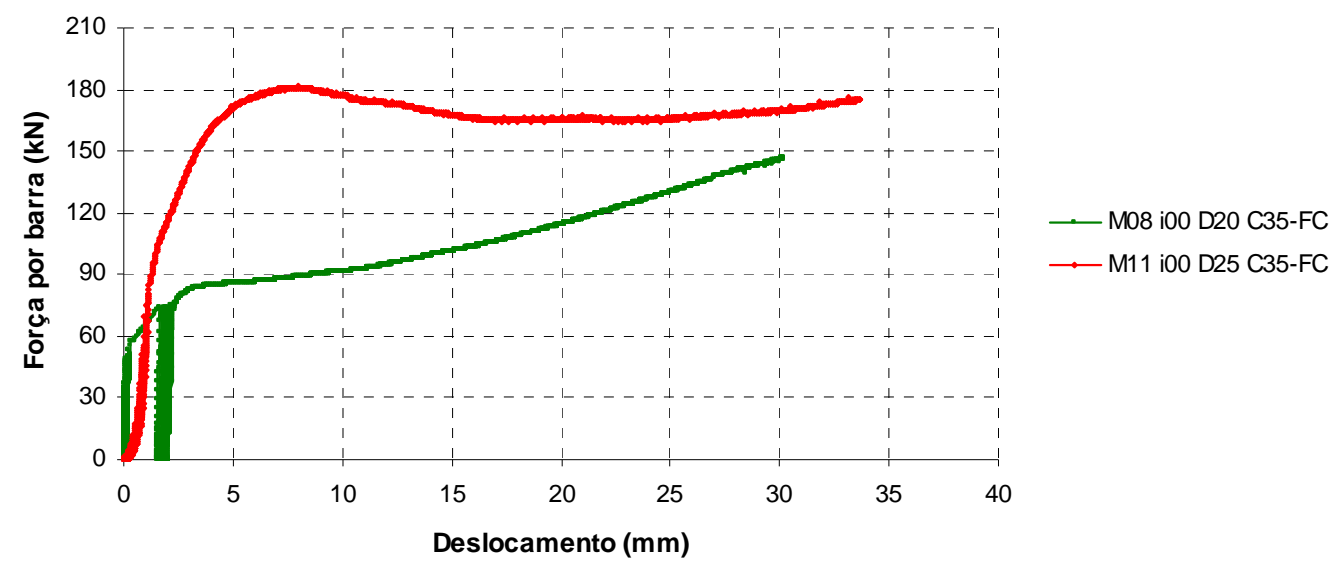

Figura 6.4: Resultados experimentais para os modelos 08 e 11

A proposta analítica também conseguiu representar de forma satisfatória o comportamento experimental do chumbador (Figura 6.5), principalmente se desconsiderarmos o pico registrado no modelo 11.

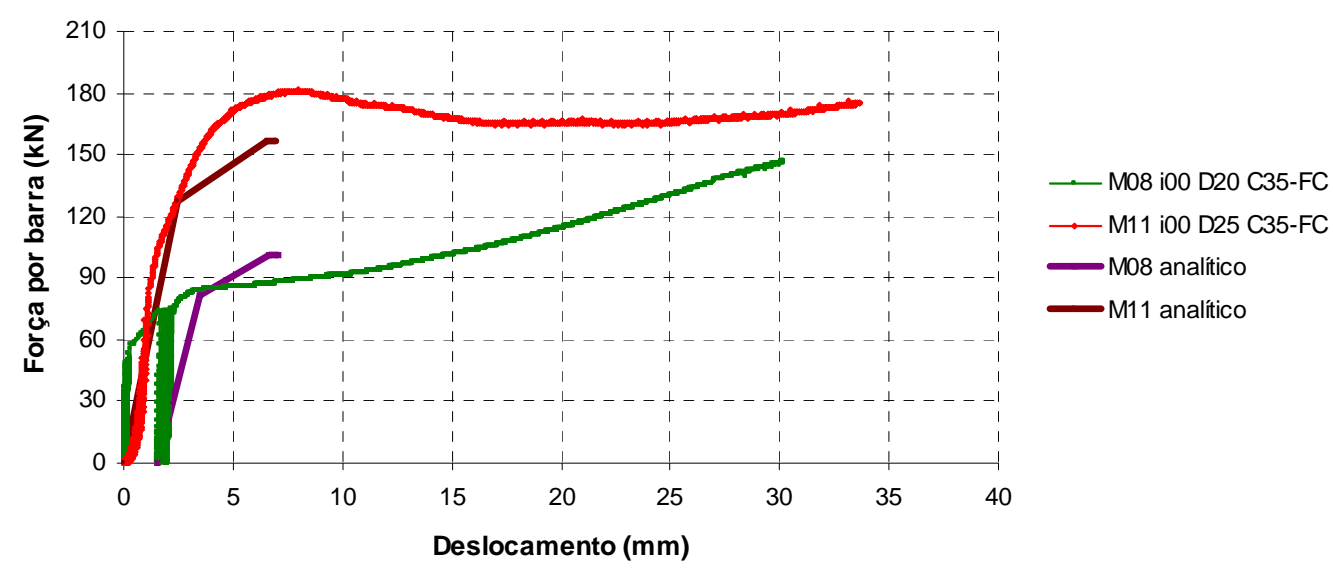

Figura 6.5: Resultados experimentais e analíticos dos modelos 08 e 11 
As relações entre a força experimental $\left(\mathrm{F}_{\text {exp }}\right)$ alcançada no ponto de deslocamento máximo previsto pela proposta analítica $\left(\delta_{\text {ana }}\right)$ com a força máxima obtida na proposta analítica $\left(\mathrm{F}_{\text {ana }}\right)$, foram de 0,87 e 1,15 para os modelos 08 e 11 respectivamente.

Na Figura 6.6 é apresentado o resultado da simulação numérica realizada para o modelo 08, onde pode ser observada uma concordância também satisfatória com o resultado experimental. A relação entre a força experimental $\left(\mathrm{F}_{\text {exp }}\right)$ alcançada no ponto de deslocamento máximo previsto pela proposta numérica $\left(\delta_{\text {num }}\right)$ com a força máxima obtida na proposta numérica $\left(F_{\text {num }}\right)$, foi de 0,79 .

Com relação ao modelo 08, tanto a proposta analítica quanto a numérica superestimaram a capacidade de carga do modelo no deslocamento analítico máximo e no deslocamento numérico máximo, respectivamente.

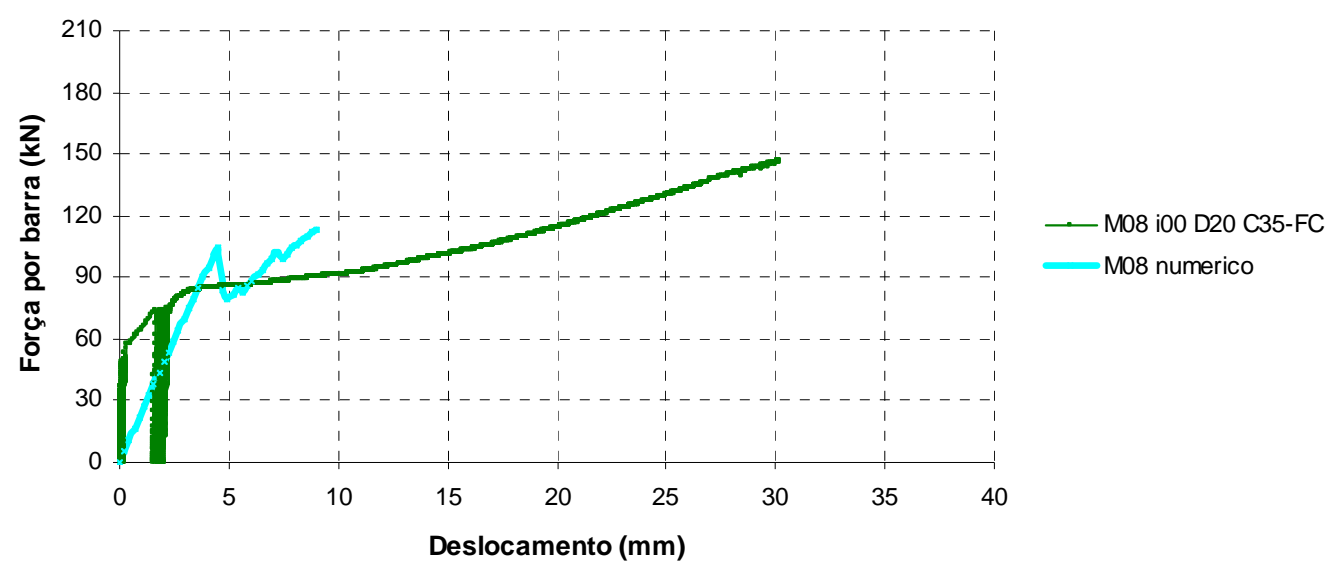

Figura 6.6: Resultado experimental e numérico do modelo 08

Na Tabela 6.2 são apresentados os resultados experimentais e analíticos observados para os modelos 08 e 11, e numéricos para o modelo 08. A força máxima prevista inicialmente $\left(\mathrm{F}_{\text {prev }}\right)$, de acordo com a Equação (2.34), também é especificada para os dois modelos.

Tabela 6.2: Comparação entre resultados para os modelos 08 e 11

\begin{tabular}{|c|c|c|c|c|c|c|c|c|c|c|c|}
\hline \multirow{2}{*}{ MODELO } & \multicolumn{4}{|c|}{ FORÇA MÁXIMA (kN) } & \multicolumn{3}{c|}{ DESLOC. MÁXIMO (mm) } & $F_{\text {exp }} /$ & $F_{\text {exp }} /$ & $F_{\text {exp }}\left(\delta_{\text {num }}\right) /$ & $F_{\text {exp }}\left(\delta_{\text {ana }}\right) /$ \\
$n^{*}$ & $F_{\text {prev }}$ & $F_{\text {exp }}$ & $F_{\text {num }}$ & $F_{\text {ana }}$ & $\delta_{\text {exp }}$ & $\delta_{\text {num }}$ & $\delta_{\text {ana }}$ & $F_{\text {num }}$ & $F_{\text {ana }}$ & $F_{\text {num }}$ & $F_{\text {ana }}$ \\
\hline Modelo 08 & 131,25 & 169,00 & 113,50 & 100,89 & 30,19 & 9,00 & 7,10 & 1,49 & 1,68 & 0,79 & 0,87 \\
\hline Modelo 11 & 191,00 & 181,00 & - & 156,20 & 33,66 & - & 7,00 & - & 1,16 & - & 1,15 \\
\hline
\end{tabular}




\subsubsection{Influência da força de compressão aplicada}

A força de compressão aplicada exerce influência principal na redução da folga existente no modelo. Na Figura 6.7 são apresentados os resultados experimentais para os modelos 05 e 11, onde a força de protensão aplicada não possibilitou o aparecimento de folgas no modelo 11 . No modelo 05 , sem força de compressão aplicada, a folga medida após os ciclos de carga e descarga foi de aproximadamente $2 \mathrm{~mm}$.

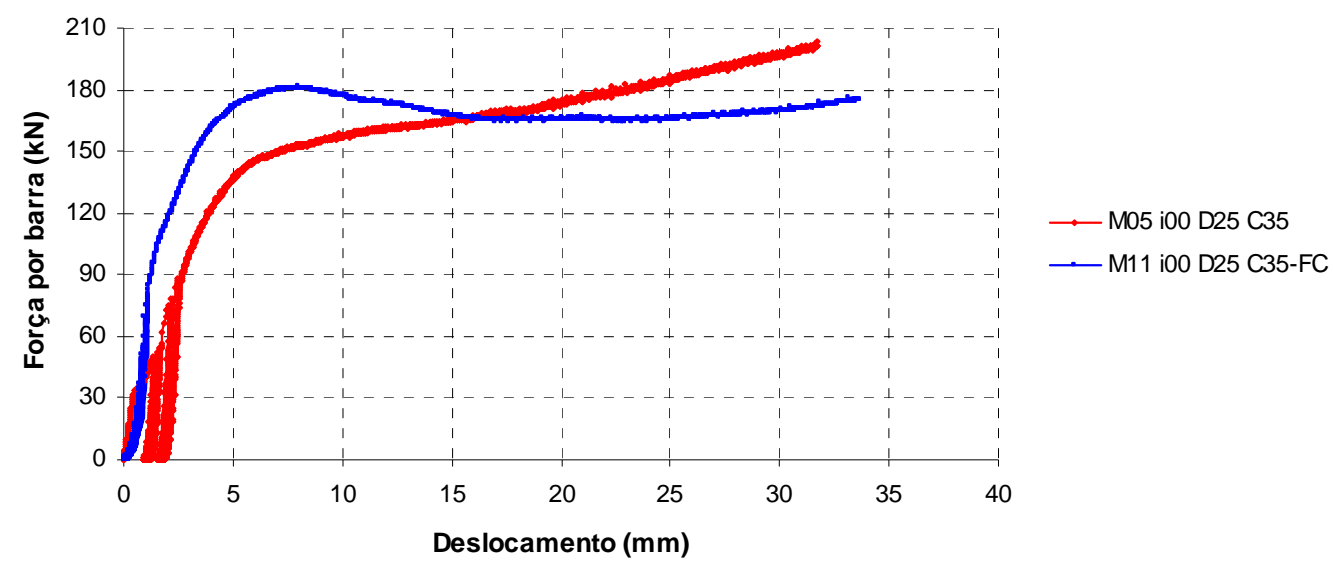

Figura 6.7: Resultados experimentais para os modelos 05 e 11

Nos modelos 01 e 07 (Figura 6.8), a influência na redução da folga também foi observada. No modelo 01, sem força de compressão aplicada, a folga medida após os ciclos de carga e descarga foi de aproximadamente $4 \mathrm{~mm}$.

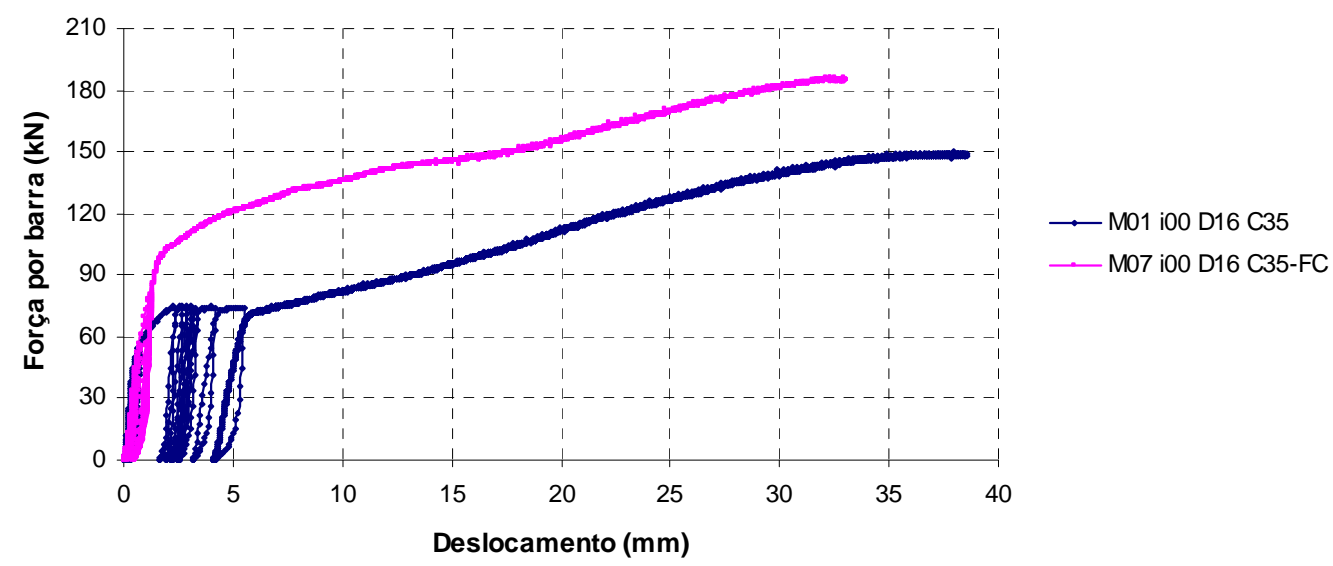

Figura 6.8: Resultados experimentais para os modelos 01 e 07 
Outra influência que também pode ser destacada é o aumento da capacidade de carga do modelo devido à força de atrito mobilizada. A intensidade da força de atrito (por chumbador) para os modelos analisados é de até $6 \mathrm{kN}$, se levarmos em consideração que o coeficiente de atrito entre as partes solidarizadas pelo chumbador seja de 0,6 - valor estimado por ENGSTROM (1992b) para atrito concreto-concreto.

No caso do modelo 07 (Figura 6.8), a força de protensão também promoveu um aumento na capacidade de carga do modelo, porém muito superior ao esperado. O fenômeno gerador de tal aumento não pôde ser identificado, pois os resultados experimentais (Capítulo 04) não apresentaram indícios de irregularidades.

É importante comentar que a influência da força de compressão aplicada também foi investigada nos modelos com chumbadores inclinados (item 6.3.2), onde foi observado o mesmo comportamento aqui apresentado.

\subsection{CHUMBADORES DE EIXO INCLINADO A $45^{\circ}$}

Para os chumbadores de eixo inclinado a $45^{\circ}$ foi seguida a mesma metodologia apresentada nos chumbadores de eixo reto, sendo abordadas as influências do diâmetro do chumbador e da força de compressão aplicada.

\subsubsection{Influência do diâmetro do chumbador}

Para os chumbadores de eixo inclinado a $45^{\circ}$ também foi observada a mesma tendência de aumento da capacidade de carga do modelo com o aumento do diâmetro do chumbador.

Na Figura 6.9 são apresentados os resultados experimentais obtidos para os modelos 02 e 06. A força máxima alcançada pelo modelo 06 foi $24,7 \%$ superior à alcançada pelo modelo 02. Na realidade a força máxima possível de ser aplicada no modelo 06 pode ser maior que a força aqui apresentada, uma vez que os ensaios de modelos com chumbadores inclinados eram todos interrompidos quando a máquina INSTRON 8506 registrava demora na aplicação de carregamento. Tal procedimento foi uma medida para prevenir a ocorrência de acidente semelhante ao do modelo 03.

Comparando a rigidez no último ciclo de carregamento, o modelo 06 apresentou valor 96,6\% superior ao modelo 02. 


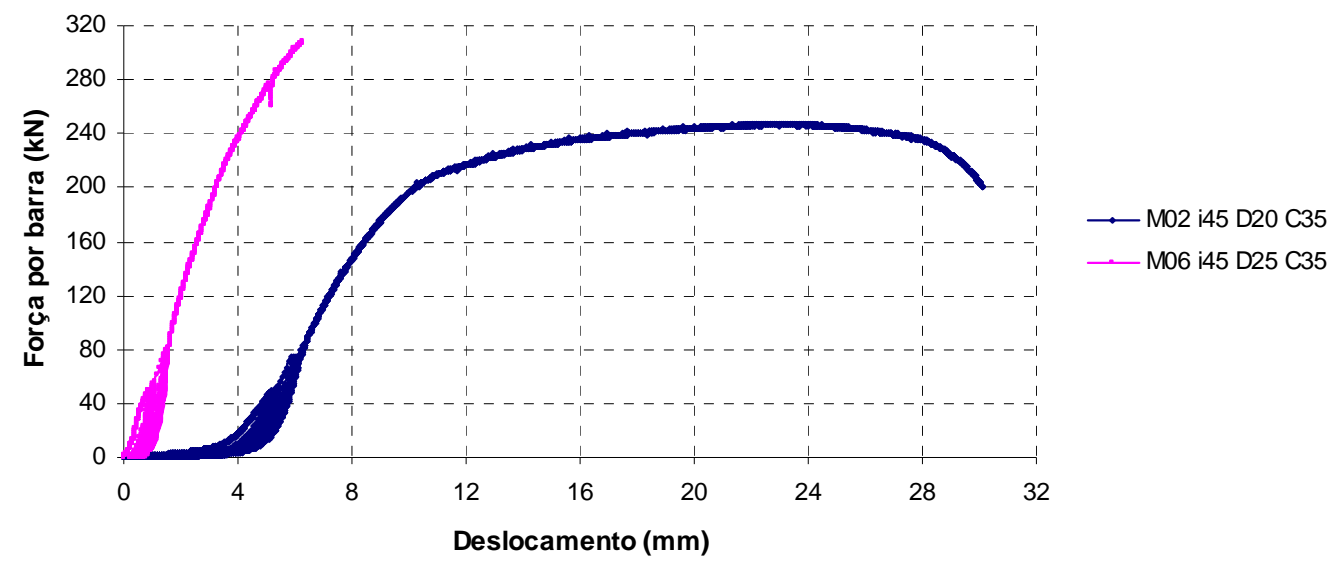

Figura 6.9: Resultados experimentais para os modelos 02 e 06

Para os chumbadores inclinados a $45^{\circ}$, também foram gerados diagramas força por barra x deslocamento baseado na proposta analítica. Na Figura 6.10 são apresentados os resultados analíticos confrontados aos resultados experimentais, onde pode ser observada uma concordância satisfatória, caso a origem do diagrama analítico coincida com o diagrama experimental no último ciclo de carregamento.

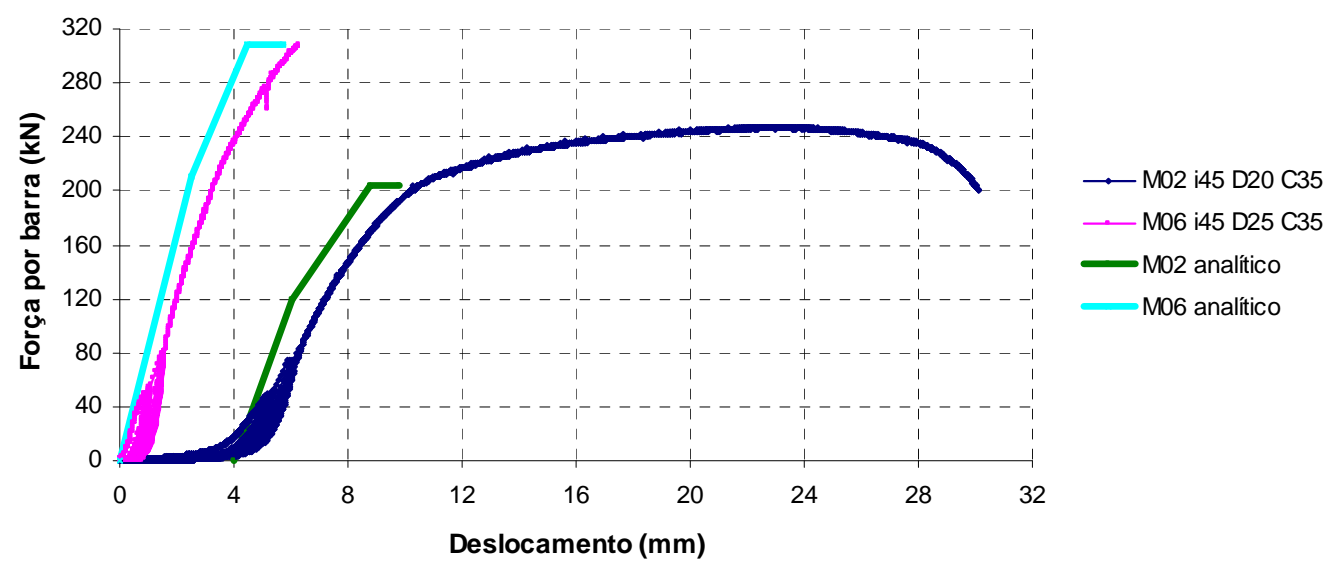

Figura 6.10: Resultados experimentais e analíticos dos modelos 02 e 06

As relações entre a força experimental $\left(F_{\exp }\right)$ alcançada no ponto de deslocamento máximo previsto pela proposta analítica $\left(\delta_{\text {ana }}\right)$ com a força máxima obtida na proposta analítica $\left(\mathrm{F}_{\text {ana }}\right)$, foram de 0,94 e 0,96 para os modelos 02 e 06 respectivamente. 
Na Figura 6.11 são apresentados os resultados das simulações numéricas realizadas para os modelos 02 e 06, onde pode ser observada uma concordância satisfatória, para o modelo 06, com o resultado experimental. No modelo 02, como a proposta de módulo de rigidez do elemento de interface (Capítulo 05) contempla a variável “folga”, os resultados no início do carregamento não foram semelhantes.

A relação entre a força experimental $\left(\mathrm{F}_{\text {exp }}\right)$ alcançada no ponto de deslocamento máximo previsto pela proposta numérica $\left(\delta_{\text {num }}\right)$ com a força máxima obtida na proposta numérica $\left(F_{\text {num }}\right)$, foi de 0,95 para o modelo 02. Para o modelo 06, o deslocamento alcançado no numericamente foi superior ao experimental.

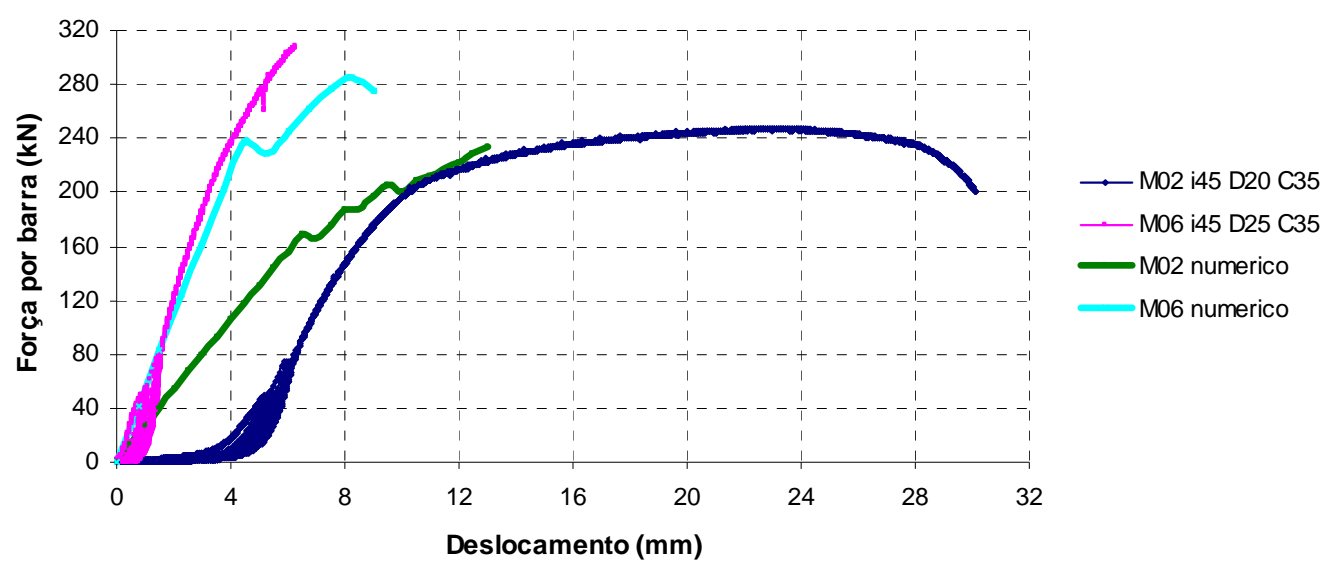

Figura 6.11: Resultados experimentais e numéricos dos modelos 02 e 06

Na Tabela 6.3 são apresentados os resultados das análises experimentais, numéricas e analíticas para os modelos 02 e 06.

Tabela 6.3: Comparação entre resultados para os modelos 02 e 06

\begin{tabular}{|c|c|c|c|c|c|c|c|c|c|c|c|}
\hline \multirow[b]{2}{*}{ MODELO } & \multicolumn{4}{|c|}{ FORÇA MÁXIMA (kN) } & \multicolumn{3}{|c|}{ DESLOC. MÁXIMO (mm) } & \multirow{2}{*}{$\begin{array}{l}F_{\text {exp }} / \\
F_{\text {num }} \\
\end{array}$} & \multirow{2}{*}{$\begin{array}{l}F_{\text {exp }} / \\
F_{\text {ana }}\end{array}$} & \multirow{2}{*}{$\begin{array}{c}F_{\text {exp }}\left(\delta_{\text {num }}\right) / \\
F_{\text {num }} \\
\end{array}$} & \multirow{2}{*}{$\begin{array}{c}\mathrm{F}_{\exp }\left(\delta_{\text {ana }}\right) / \\
\mathrm{F}_{\text {ana }}\end{array}$} \\
\hline & $F_{\text {prev }}$ & $F_{\text {exp }}$ & $F_{\text {num }}$ & $F_{\text {ana }}$ & $\delta_{\exp }$ & $\delta_{\text {num }}$ & $\delta_{\text {ana }}$ & & & & \\
\hline Modelo 02 & 147,25 & 247,00 & 234,10 & 204,62 & 30,10 & 13,00 & 9,80 & 1,06 & 1,21 & 0,95 & 0,94 \\
\hline Modelo 06 & 212,75 & $\mid 308,00$ & 286,00 & 308,03 & 6,25 & 9,00 & 5,75 & 1,08 & 1,00 & - & 0,96 \\
\hline
\end{tabular}

Além dos modelos 02 e 06, foram também analisados os modelos 13 e 15, pertencentes ao grupo de chumbadores confeccionados com concreto de classe C50, onde foi observado comportamento semelhante. 
Na Figura 6.12 são apresentados os resultados experimentais dos modelos 13 e 15, onde pode ser observado o aumento da capacidade do modelo com o aumento do diâmetro do chumbador.

A força máxima alcançada pelo modelo 15 foi 45,2\% superior à alcançada pelo modelo 13. Comparando a rigidez no último ciclo de carregamento, o modelo 15 apresentou valor 5\% superior ao modelo 13.

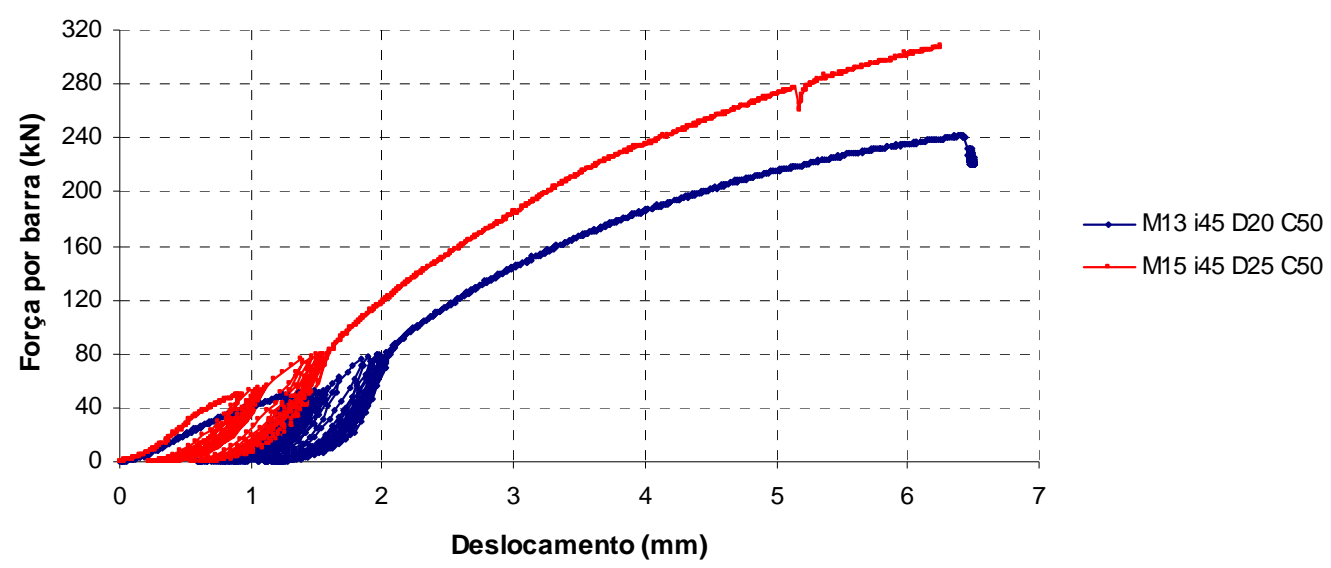

Figura 6.12: Resultados experimentais para os modelos 13 e 15

Na Figura 6.13 são apresentados os resultados analíticos confrontados aos resultados experimentais, onde pode ser observada uma concordância também satisfatória, sendo a proposta analítica capaz de prever o comportamento real do modelo.

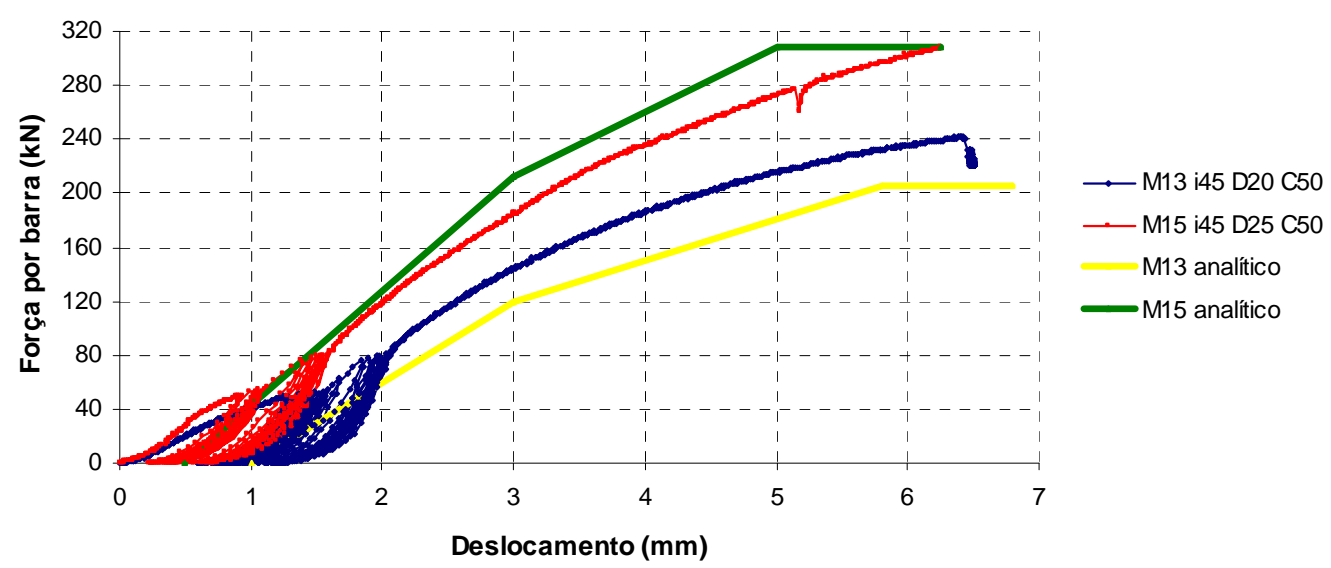

Figura 6.13: Resultados experimentais e analíticos dos modelos 13 e 15 
Comparando os resultados analíticos com os experimentais, observa-se que as relações entre a força experimental $\left(\mathrm{F}_{\mathrm{exp}}\right)$ alcançada no ponto de deslocamento máximo previsto pela proposta analítica $\left(\delta_{\text {ana }}\right.$ ) com a força máxima obtida na proposta analítica ( $\left.\mathrm{F}_{\text {ana }}\right)$, foram de 1,17 e 1,00 para os modelos 13 e 15 respectivamente.

Na Figura 6.14 é apresentado o resultado da simulação numérica realizada para o modelo 15, onde pode ser observada uma concordância satisfatória, embora o deslocamento máximo alcançado na proposta numérica tenha sido cerca de 67\% superior ao experimental.

A relação entre a força experimental ( $\left.\mathrm{F}_{\text {exp }}\right)$ máxima e a força obtida na proposta numérica $\left(\mathrm{F}_{\text {num }}\right)$, quando alcançado o ponto de deslocamento experimental $\left(\delta_{\exp }\right)$ máximo, foi de 1,15.

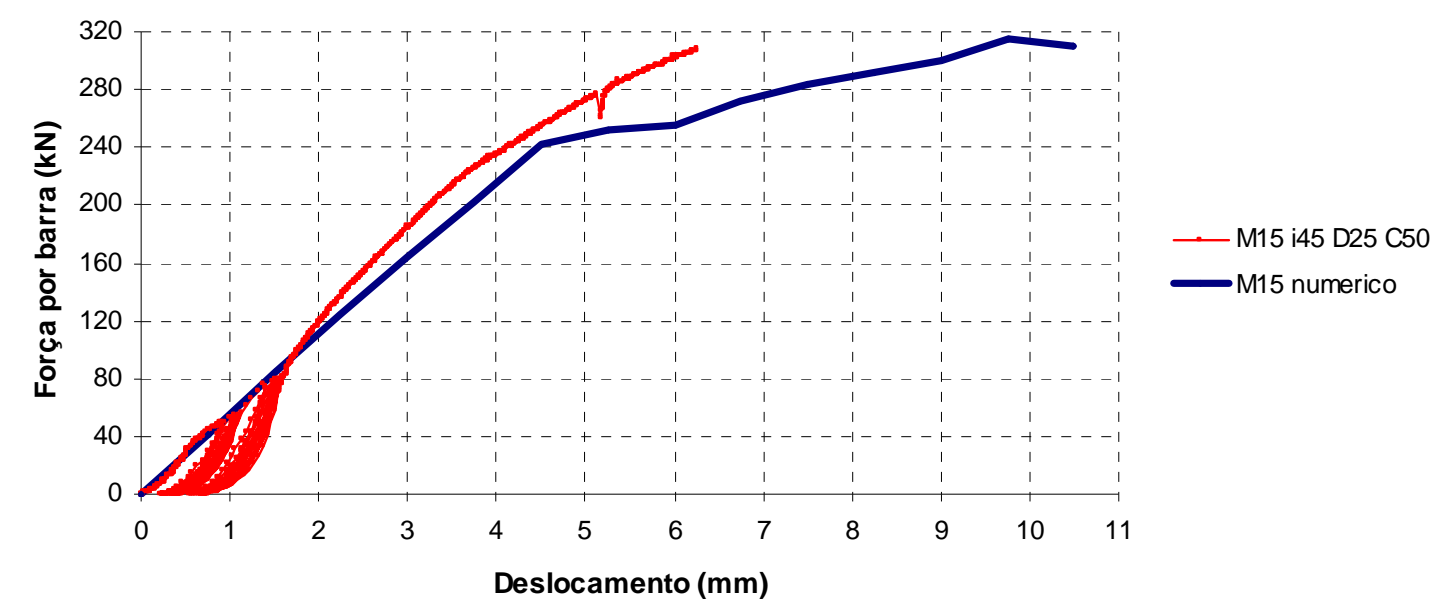

Figura 6.14: Resultado experimental e numérico dos modelo 15

Na Tabela 6.4 são apresentados os resultados experimentais e analíticos observados para os modelos 13 e 15, e numéricos para o modelo 15 .

Tabela 6.4: Comparação entre resultados para os modelos 13 e 15

\begin{tabular}{|c|c|c|c|c|c|c|c|c|c|c|c|}
\hline \multirow{2}{*}{ MODELO } & \multicolumn{4}{|c|}{ FORÇA MÁXIMA (kN) } & \multicolumn{3}{|c|}{ DESLOC. MÁXIMO (mm) } & \multirow{2}{*}{$\begin{array}{l}F_{\text {exp }} / \\
F_{\text {num }}\end{array}$} & \multirow{2}{*}{$\begin{array}{l}F_{\text {exp }} / \\
F_{\text {ana }}\end{array}$} & \multirow{2}{*}{$\begin{array}{c}F_{\exp } / \\
F_{\text {num }}\left(\delta_{\exp }\right)\end{array}$} & \multirow{2}{*}{$\begin{array}{c}F_{\text {exp }} / \\
F_{\text {ana }}\left(\delta_{\text {exp }}\right)\end{array}$} \\
\hline & $F_{\text {prev }}$ & $F_{\text {exp }}$ & $F_{\text {num }}$ & $F_{\text {ana }}$ & $\delta_{\exp }$ & $\delta_{\text {num }}$ & $\delta_{\text {ana }}$ & & & & \\
\hline Modelo 13 & 147,75 & 241,00 & - & 205,41 & 6,49 & - & 6,80 & - & 1,17 & - & 1,17 \\
\hline Modelo 15 & 214,50 & 309,20 & 315,70 & 309,18 & 6,26 & 10,50 & 6,25 & 0,98 & 1,00 & 1,15 & 1,00 \\
\hline
\end{tabular}




\subsubsection{Influência da força de compressão aplicada}

Para os modelos com chumbadores inclinados a $45^{\circ}$ foi observada a mesma tendência de redução da folga existente no modelo, quando a força de compressão é aplicada.

Na Figura 6.15 são apresentados os resultados experimentais para os modelos 02, 09 e 13, onde a força de protensão aplicada não possibilitou o aparecimento de folgas no modelo 09 .

No modelo 02, pertencente ao programa experimental piloto, a folga medida após os ciclos de carga e descarga foi de aproximadamente 4,5 mm. No modelo 13 a folga foi de aproximadamente $1,5 \mathrm{~mm}$.

A diferença entre as forças máximas alcançadas nos modelos 09 e 13 não pode ser atribuída à força de protensão aplicada, uma vez que o ensaio realizado no modelo 13 foi interrompido por razões já descritas.

Foi observado no modelo 09 um ganho de rigidez em relação ao modelo 13, que pode ser atribuído à força de compressão aplicada.

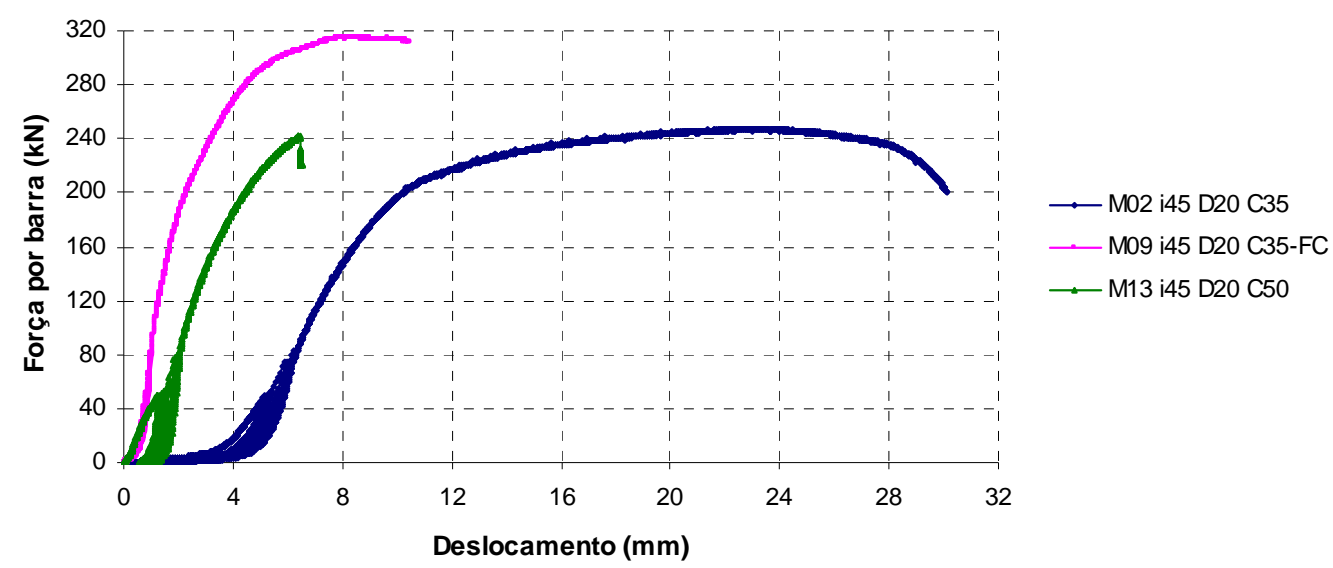

Figura 6.15: Resultados experimentais para os modelos 02, 09 e 13

\subsection{CHUMBADORES DE EIXO INCLINADO A 60}

Para os chumbadores de eixo inclinado a $60^{\circ}$ são abordadas as influências do diâmetro do chumbador, da força de compressão aplicada e da resistência à compressão do concreto. 


\subsubsection{Influência do diâmetro do chumbador}

Para os chumbadores de eixo inclinado a $60^{\circ}$ foi mantida a mesma tendência de aumento da capacidade de carga do modelo com o aumento do diâmetro do chumbador. Na Figura 6.16 são apresentados os resultados experimentais obtidos para os modelos 10 e 12, pertencentes ao grupo de chumbadores com força de compressão aplicada. A força máxima alcançada pelo modelo 12 foi 24,2\% superior à alcançada pelo modelo 10.

Comparando a rigidez no último ciclo de carregamento, o modelo 12 apresentou valor $38 \%$ superior ao modelo 10.

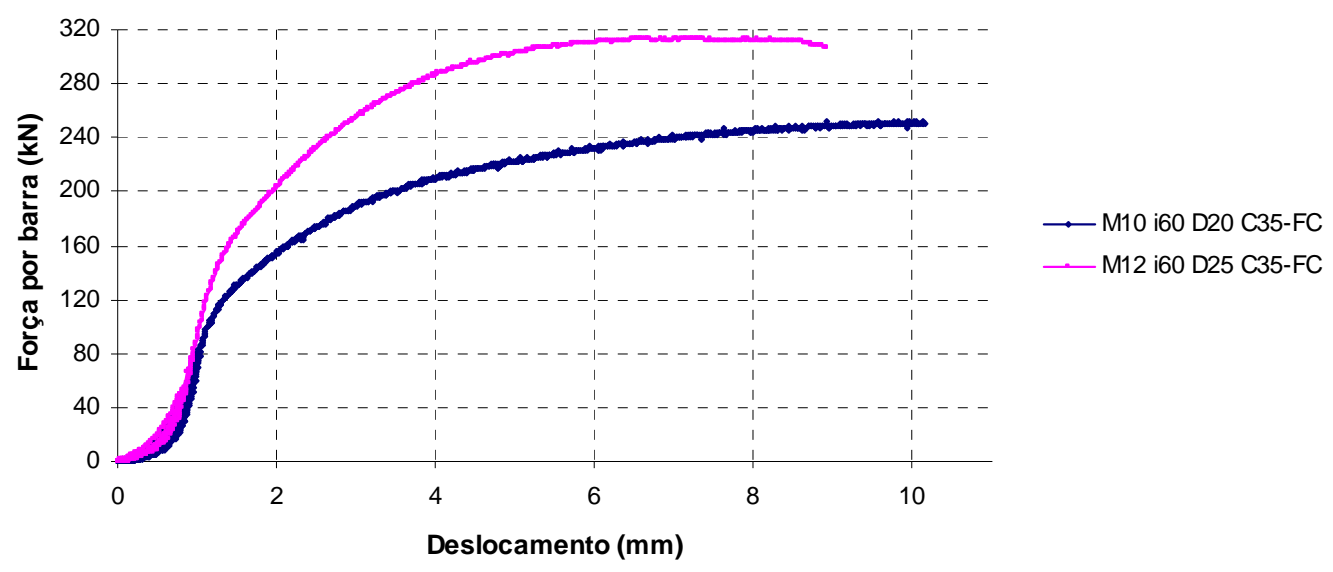

Figura 6.16: Resultados experimentais para os modelos 10 e 12

Na Figura 6.17 são apresentados os resultados analíticos confrontados aos resultados experimentais, onde pode ser observado que não houve concordância no início do carregamento. A proposta analítica conseguiu prever de forma satisfatória a carga máxima alcançada pelos modelos.

Comparando os resultados analíticos com os experimentais, observa-se que as relações entre a força experimental $\left(\mathrm{F}_{\mathrm{exp}}\right)$ alcançada no ponto de deslocamento máximo previsto pela proposta analítica $\left(\delta_{\text {ana }}\right)$ com a força máxima obtida na proposta analítica $\left(F_{\text {ana }}\right)$, foram de 1,06 e 0,95 para os modelos 10 e 12, respectivamente.

Na Figura 6.18 são apresentados os resultados da simulação numérica realizada, onde pode ser observada que não houve uma concordância satisfatória com os resultados experimentais obtidos no início do carregamento. A proposta numérica conseguiu prever de forma satisfatória a carga máxima alcançada pelos modelos. 


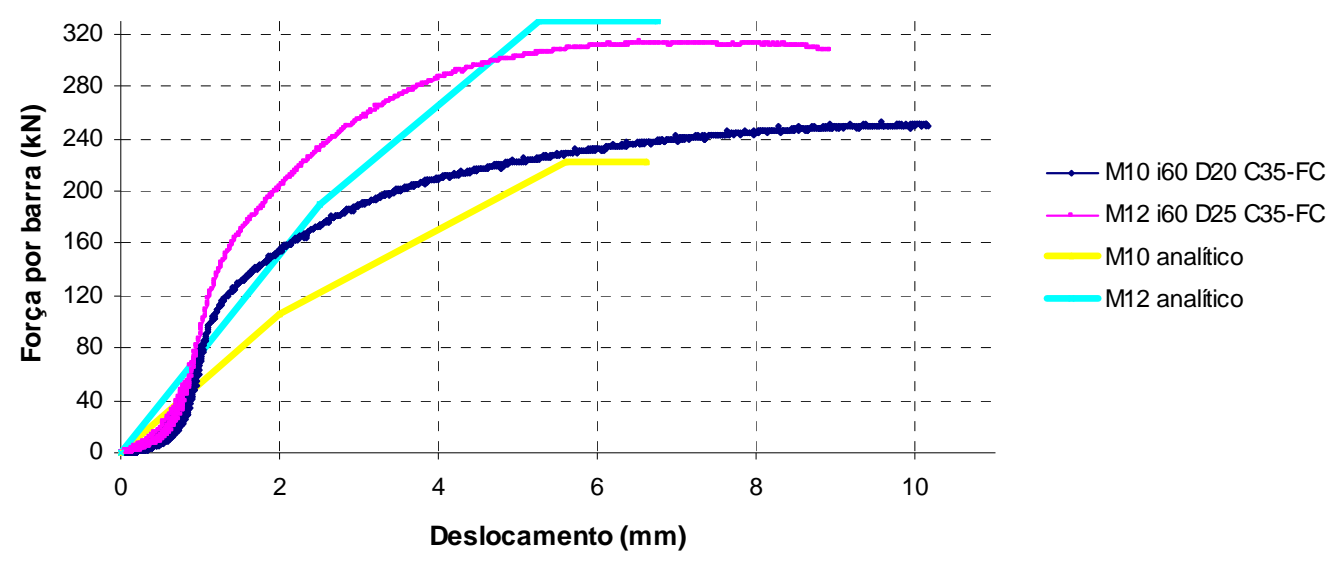

Figura 6.17: Resultados experimentais e analíticos dos modelos 10 e 12

As relações entre a força experimental $\left(\mathrm{F}_{\mathrm{exp}}\right)$ no ponto de deslocamento máximo previsto pela proposta numérica $\left(\delta_{\text {num }}\right)$ com a força máxima obtida na proposta numérica $\left(F_{\text {num }}\right)$, foram de 0,92 e 0,96 para os modelos 10 e 12 respectivamente.

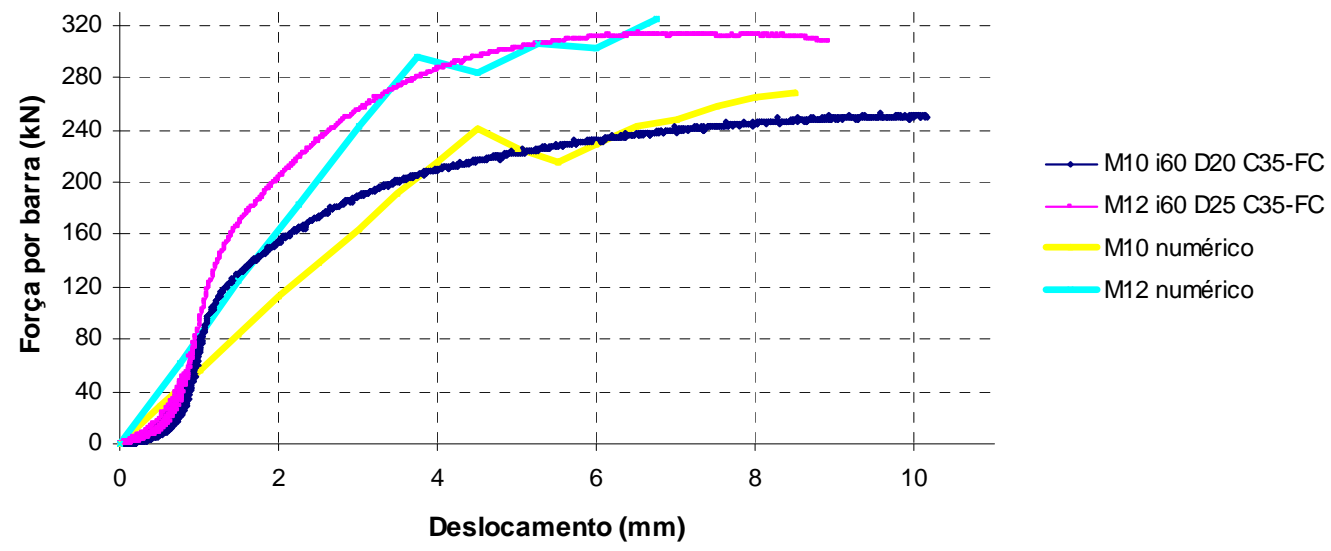

Figura 6.18: Resultados experimentais e numéricos dos modelos 10 e 12

Na Tabela 6.5 são apresentados os resultados experimentais e analíticos observados para os modelos 10 e 12 .

Tabela 6.5: Comparação entre resultados para os modelos 10 e 12

\begin{tabular}{|c|c|c|c|c|c|c|c|c|c|c|c|}
\hline \multirow{2}{*}{ MODELO } & \multicolumn{3}{|c|}{ FORÇA MÁXIMA (kN) } & \multicolumn{3}{c|}{ DESLOC. MÁXIMO (mm) } & $F_{\text {exp }} /$ & $F_{\text {exp }} /$ & $F_{\text {exp }}\left(\delta_{\text {num }}\right) /$ & $F_{\text {exp }}\left(\delta_{\text {ana }}\right) /$ \\
$n^{*}$ & $F_{\text {prev }}$ & $F_{\text {exp }}$ & $F_{\text {num }}$ & $F_{\text {ana }}$ & $\delta_{\text {exp }}$ & $\delta_{\text {num }}$ & $\delta_{\text {ana }}$ & $F_{\text {num }}$ & $F_{\text {ana }}$ & $F_{\text {num }}$ & $F_{\text {ana }}$ \\
\hline Modelo 10 & 120,75 & 252,00 & 269,30 & 221,98 & 10,16 & 8,50 & 6,60 & 0,94 & 1,14 & 0,92 & 1,06 \\
\hline Modelo 12 & 171,00 & 313,00 & 324,40 & 329,30 & 8,92 & 6,75 & 6,75 & 0,96 & 0,95 & 0,96 & 0,95 \\
\hline
\end{tabular}




\subsubsection{Influência da força de compressão aplicada}

Para os modelos com chumbadores inclinados a $60^{\circ}$, assim como nos chumbadores retos e inclinados a $45^{\circ}$, foi observada a mesma tendência de redução da folga existente no modelo, quando a força de compressão é aplicada.

Na Figura 6.19 é apresentada uma comparação entre os modelos 04, 10 e 14, onde pode ser observado que o modelo com força horizontal de protensão possui uma folga menor que os outros dois modelos. Por meio da comparação realizada, pode ser observado também que não houve ganho de capacidade de carga devido à protensão.

A força de compressão aplicada proporcionou um ganho de rigidez no modelo 10, quando comparado com os modelos 04 e 14. Tal comportamento também foi observado nos modelos com chumbadores inclinados a $45^{\circ}$.

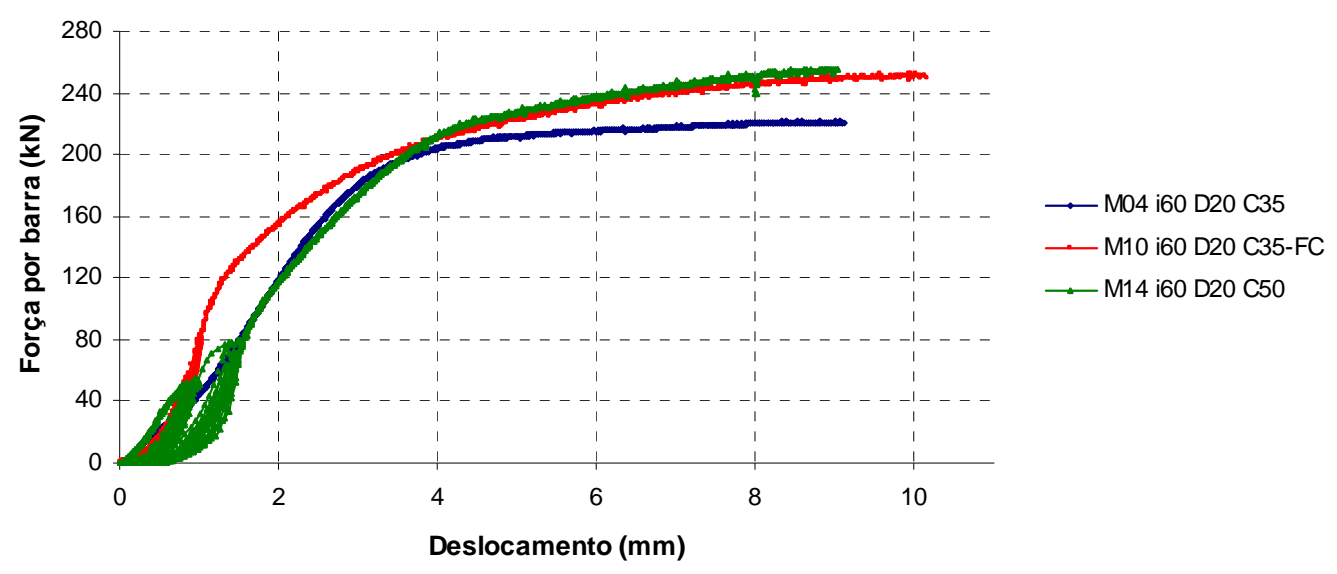

Figura 6.19: Resultados experimentais para os modelos 04, 10 e 14

\subsubsection{Influência da resistência à compressão do concreto}

A resistência à compressão do concreto não exerceu influência significativa no comportamento dos chumbadores inclinados a $60^{\circ}$.

Na Figura 6.20 é realizada uma comparação entre os modelos 04 e 14, onde pode ser observado que a variação da força última alcançada pelos modelos foi de $15 \%$. No início do carregamento, até atingir a força de $200 \mathrm{kN}$, os valores de força alcançados nos dois modelos foram praticamente coincidentes.

Resistência à compressão do concreto usada no modelo 04 foi de 47,67 MPa, enquanto que no modelo 14 foi de 64,24 MPa. 


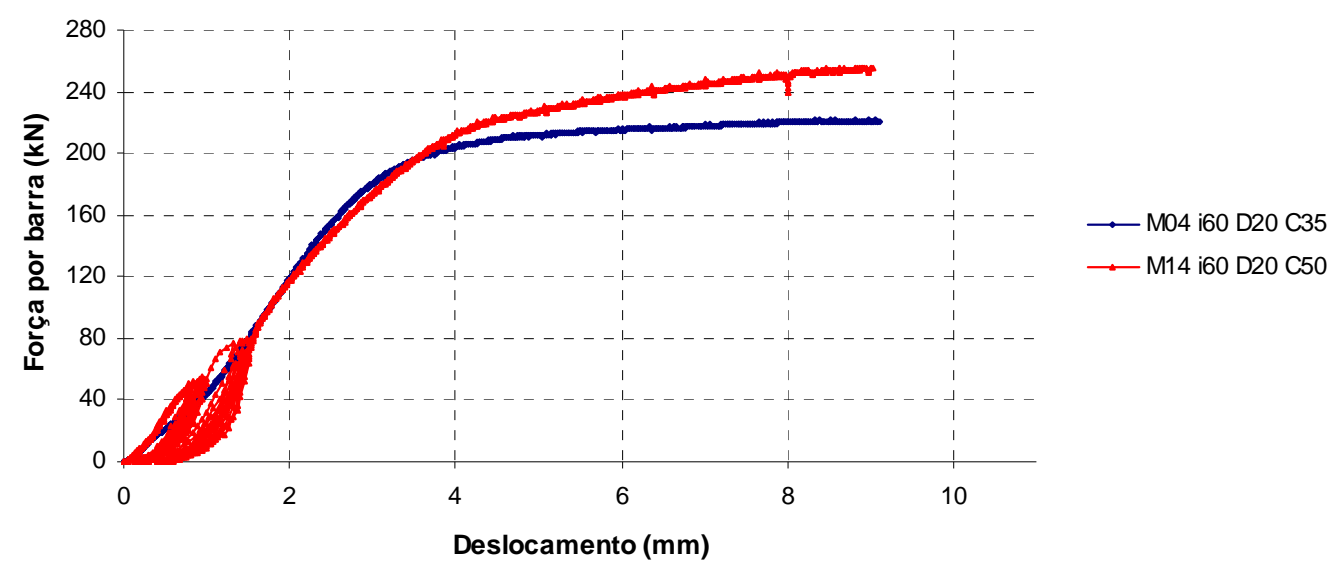

Figura 6.20: Resultados experimentais para os modelos 04 e 14

A influência da resistência à compressão do concreto também foi simulada analiticamente, sendo o resultado apresentado na Figura 6.21.

Pode ser observado que os dois modelos analíticos podem ser considerados coincidentes, e conseguiram representar de forma satisfatória o comportamento dos chumbadores no início e no fim do carregamento.

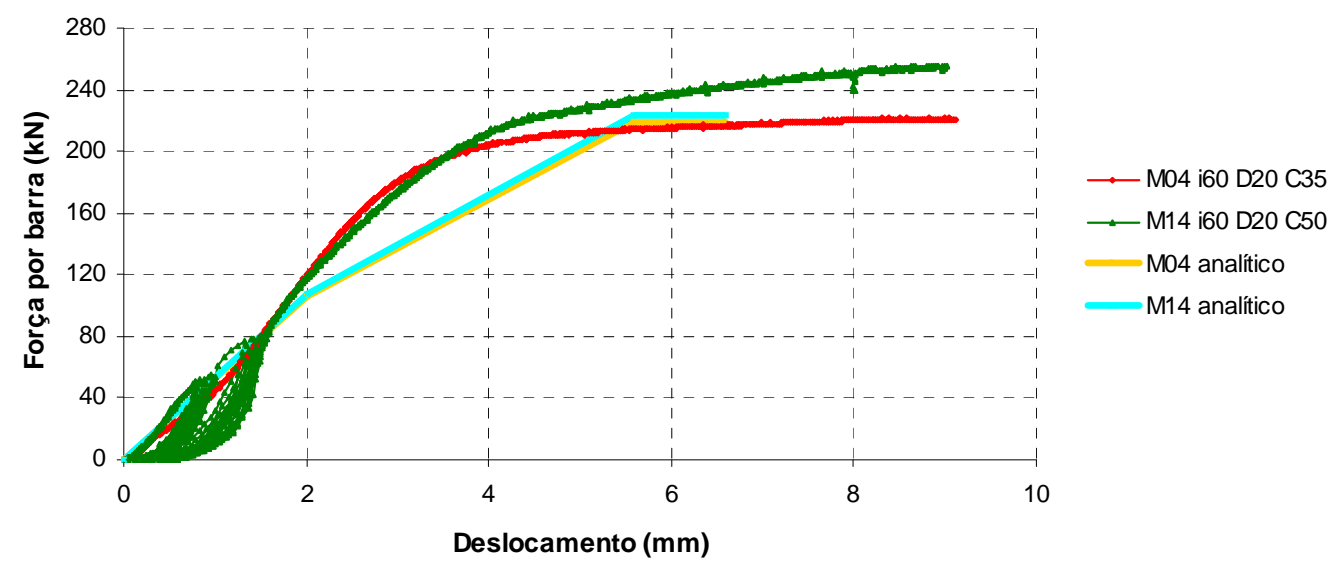

Figura 6.21: Resultados experimentais e analíticos dos modelos 04 e 14

Comparando os resultados analíticos com os experimentais, observa-se que as relações entre a força experimental $\left(\mathrm{F}_{\exp }\right)$ alcançada no ponto de deslocamento máximo previsto pela proposta analítica $\left(\delta_{\text {ana }}\right.$ ) com a força máxima obtida na proposta analítica ( $F_{\text {ana }}$ ), foram de 0,98 e 1,09 para os modelos 04 e 14, respectivamente. 
Na Figura 6.22 é apresentado o resultado da simulação numérica realizada para o modelo 04, onde pode ser observada uma concordância satisfatória tanto com os resultados experimentais do modelo 04 como com os do modelo 14.

A relação entre a força experimental $\left(\mathrm{F}_{\exp }\right)$ no ponto de deslocamento máximo previsto pela proposta numérica $\left(\delta_{\text {num }}\right)$ com a força máxima obtida na proposta numérica ( $\left.F_{\text {num }}\right)$, foi de 0,89 para o modelo 04, e 1,02 se comparado com o modelo 14.

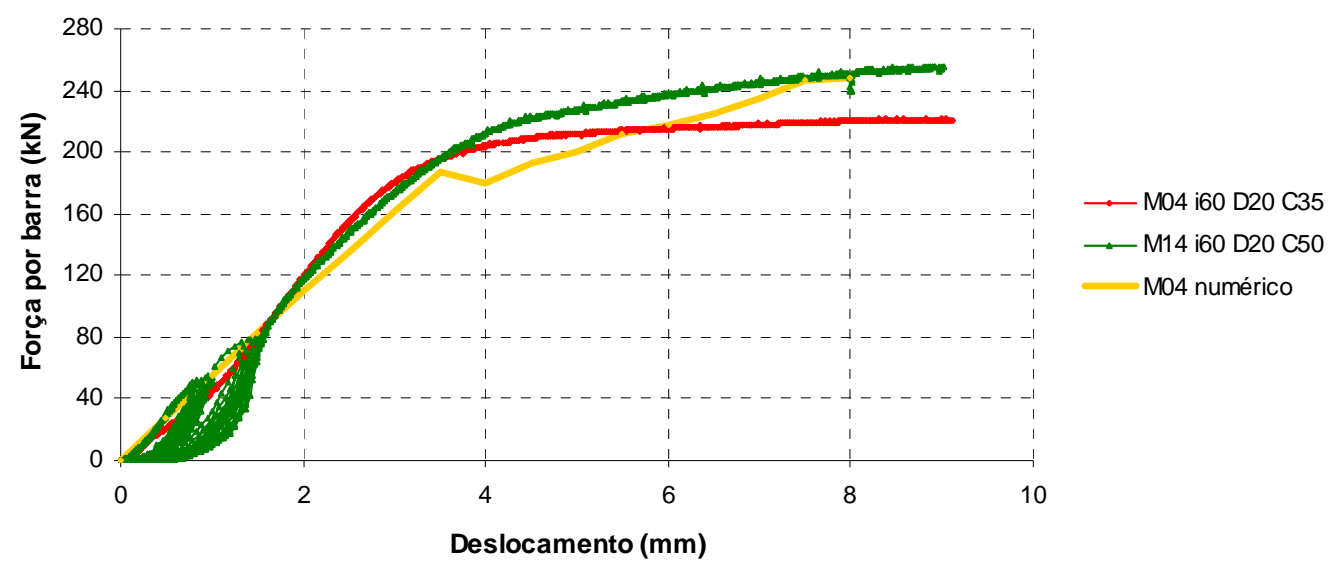

Figura 6.22: Resultado experimental e numérico do modelo 04 junto ao modelo 14

Na Tabela 6.6 são apresentados os resultados experimentais e analíticos observados para os modelos 04 e 14, e numéricos para o modelo 04.

Tabela 6.6: Comparação entre resultados para os modelos 04 e 14

\begin{tabular}{|c|c|c|c|c|c|c|c|c|c|c|c|}
\hline \multirow{2}{*}{ MODELO } & \multicolumn{4}{|c|}{ FORÇA MAXIMA (kN) } & \multicolumn{3}{c|}{ DESLOC. MAXIMO $(\mathrm{mm})$} & $\mathrm{F}_{\text {exp }} /$ & $\mathrm{F}_{\text {exp }} /$ & $\mathrm{F}_{\text {exp }}\left(\delta_{\text {num }}\right) /$ & $\mathrm{F}_{\text {exp }}\left(\delta_{\text {ana }}\right) /$ \\
\cline { 2 - 12 } & $\mathrm{F}_{\text {prev }}$ & $\mathrm{F}_{\text {exp }}$ & $\mathrm{F}_{\text {num }}$ & $\mathrm{F}_{\text {ana }}$ & $\delta_{\text {exp }}$ & $\delta_{\text {num }}$ & $\delta_{\text {ana }}$ & $\mathrm{F}_{\text {num }}$ & $\mathrm{F}_{\text {ana }}$ & $\mathrm{F}_{\text {num }}$ & $\mathrm{F}_{\text {ana }}$ \\
\hline Modelo 04 & 146,50 & 253,00 & 247,50 & 219,60 & 9,11 & 8,00 & 6,60 & 1,02 & 1,15 & 0,89 & 0,98 \\
\hline Modelo 14 & 148,50 & 255,00 & - & 222,73 & 9,03 & - & 6,60 & - & 1,14 & - & 1,09 \\
\hline
\end{tabular}

\subsection{INFLUÊNCIA DA INCLINAÇÃO DO CHUMBADOR}

Neste item são realizadas as comparações entre os modelos com chumbadores retos e inclinados, sendo avaliada a influência da inclinação na resposta força por barra x deslocamento dos modelos. 
Na Figura 6.23 são confrontados os resultados experimentais dos modelos 05 e 06, onde pode ser observado que a capacidade de carga do modelo 06 é $110 \%$ maior que a do modelo 05 , sendo ambos medidos no ponto de deslocamento máximo registrado para o modelo 06 .

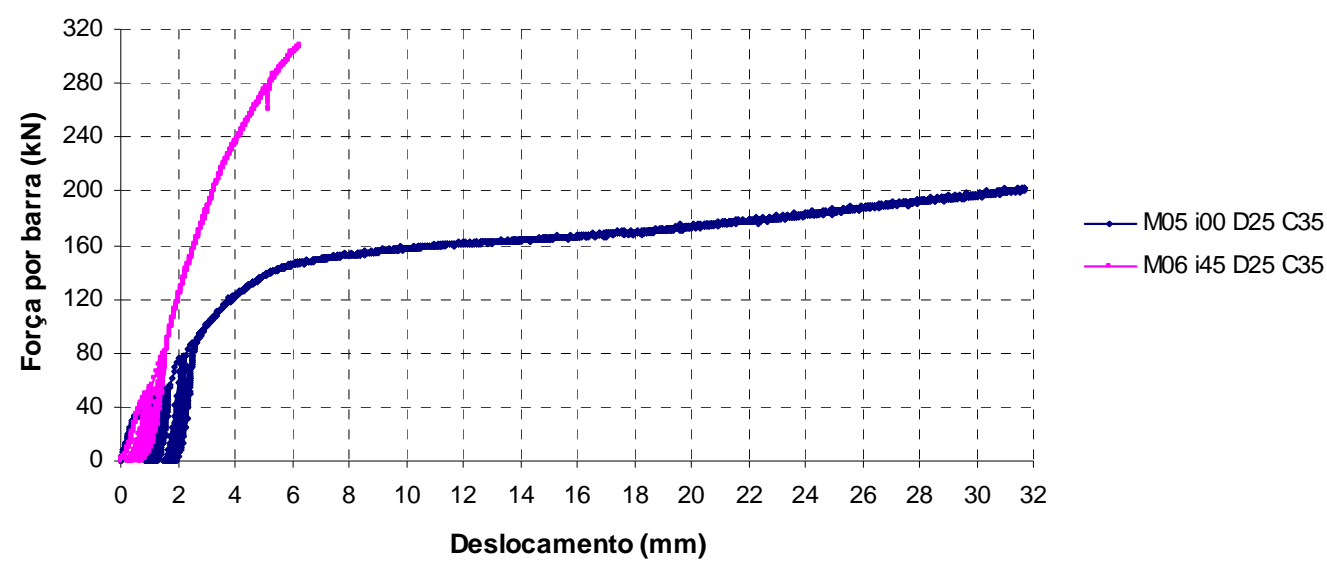

Figura 6.23: Resultados experimentais para os modelos 05 e 06

A influência da inclinação também foi simulada analiticamente e comparada com os resultados experimentais, conforme apresentado na Figura 6.24. Pode ser observada que a proposta analítica conseguiu simular satisfatoriamente o comportamento força x deslocamento tanto do modelo 05, quanto do modelo 06.

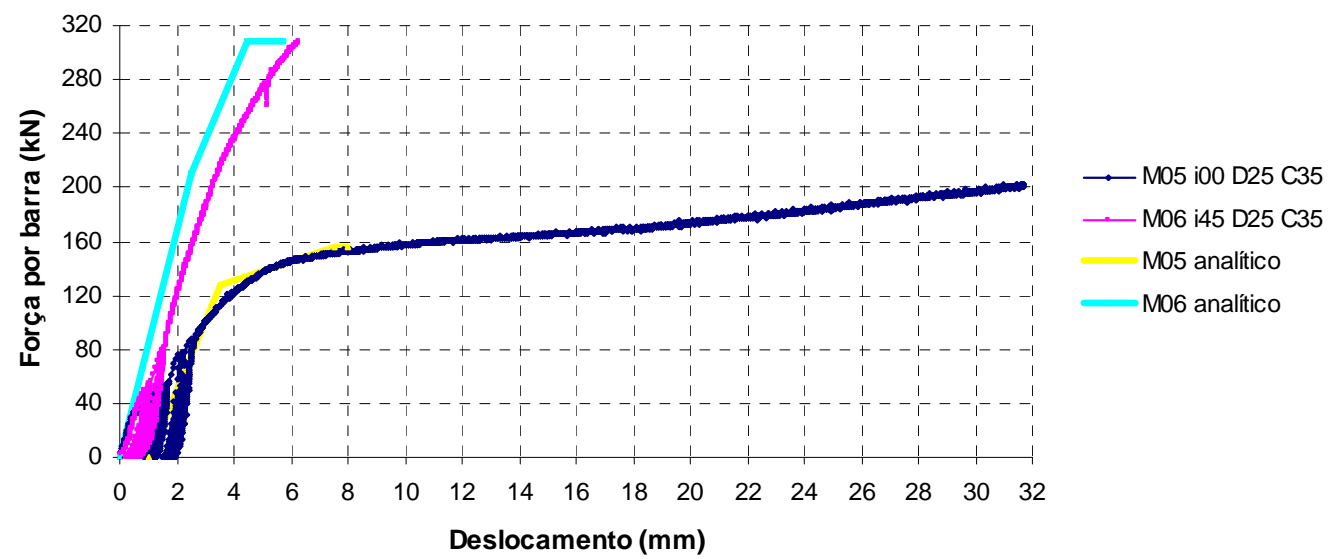

Figura 6.24: Resultados experimentais e analíticos dos modelos 05 e 06 
A variação da inclinação de $0^{\circ}$ para $60^{\circ}$ também foi comparada e apresentada na Figura 6.25, onde pode ser observada que a capacidade de carga do modelo 12 é $73 \%$ maior que a do modelo 11 , sendo ambos medidos no ponto de pico (força máxima alcançada) para o modelo 12.

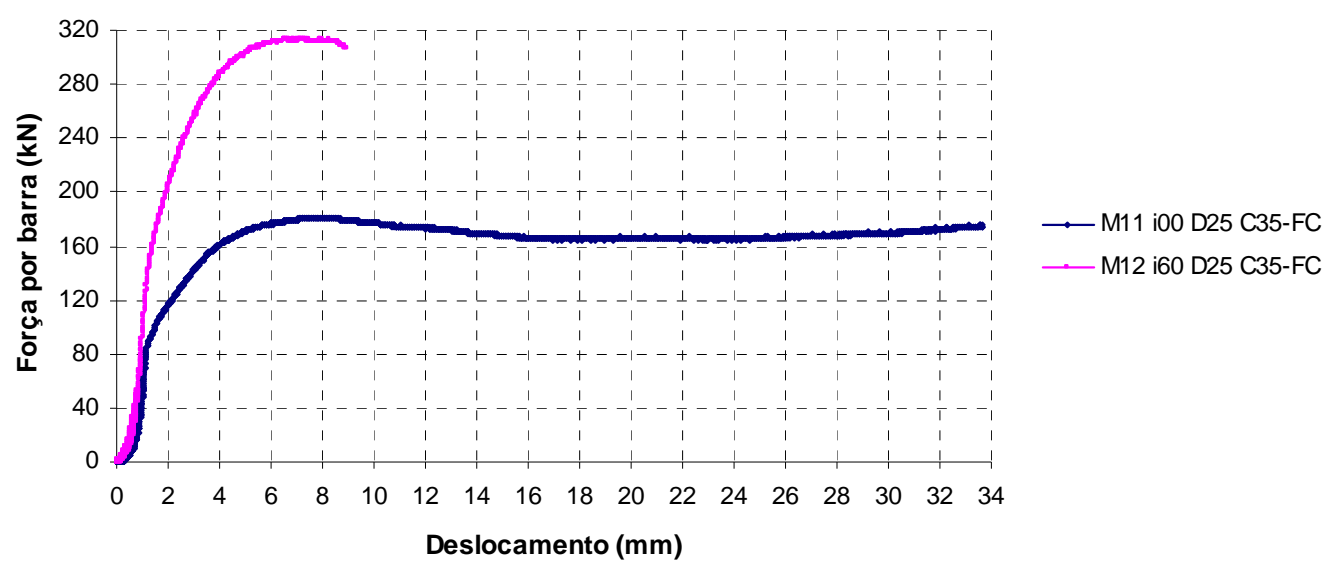

Figura 6.25: Resultados experimentais para os modelos 11 e 12

A influência da inclinação também foi simulada analiticamente e comparada com os resultados experimentais, conforme apresentado na Figura 6.26. Pode ser observada que a proposta analítica conseguiu também simular satisfatoriamente o comportamento força x deslocamento tanto do modelo 11, quanto do modelo 12.

A relação entre a força experimental de pico e a força máxima analítica foi de 0,95 para o modelo 12, e 1,15 para o modelo 11 .

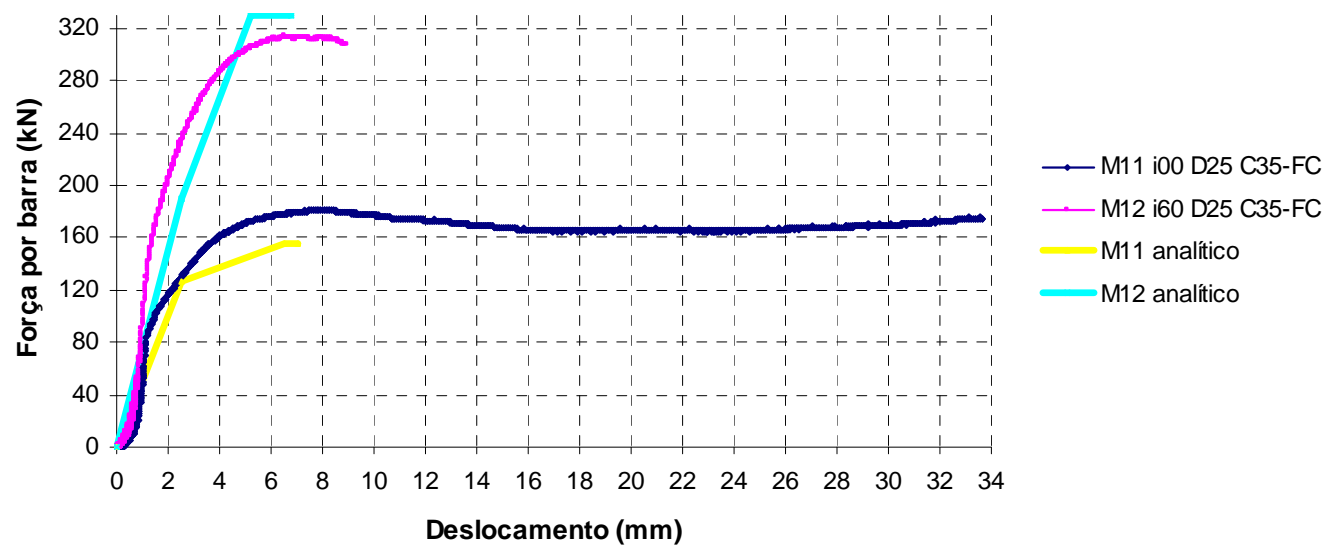

Figura 6.26: Resultados experimentais e analíticos dos modelos 11 e 12 
A mudança de inclinação de $45^{\circ}$ para $60^{\circ}$ também foi analisada e é apresentada na Figura 6.27, onde pode ser observado que quase não há diferença de resultados se desconsiderarmos a folga existente no modelo 13.

O modelo 13 apresentou uma rigidez 3\% superior à do modelo 14 , sendo que o modelo 14 atingiu um deslocamento máximo cerca de 38\% maior que o do modelo 13.

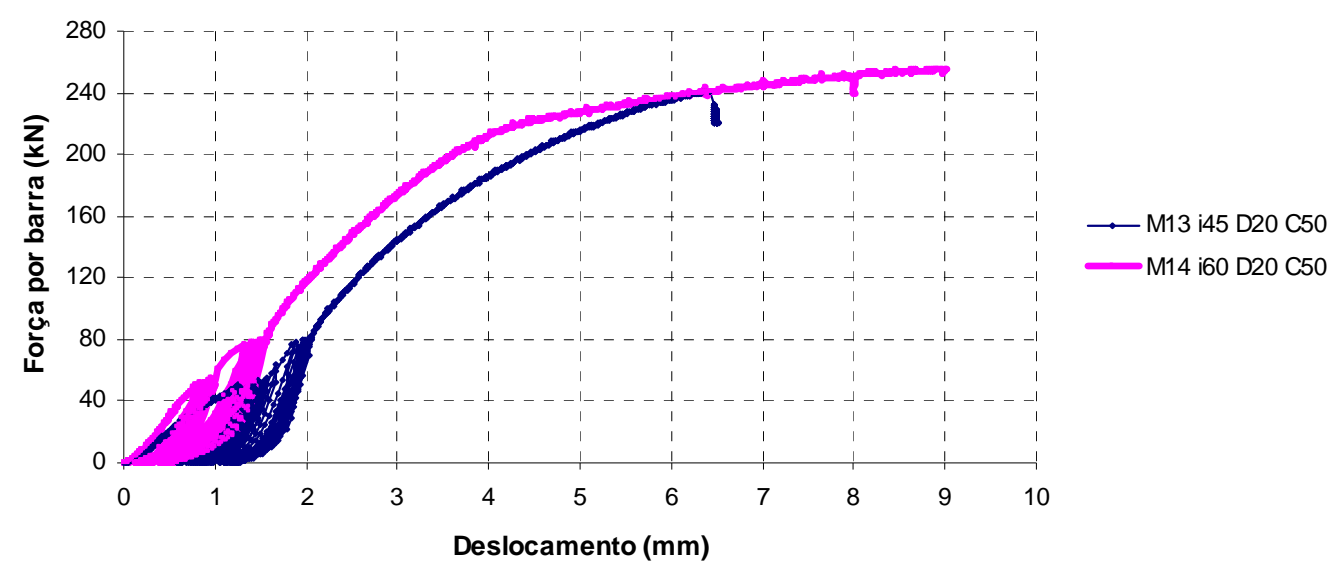

Figura 6.27: Resultados experimentais para os modelos 13 e 14

A influência da inclinação também foi simulada analiticamente e comparada com os resultados experimentais, conforme apresentado na Figura 6.28. Pela proposta analítica, desconsiderando a folga existente, o modelo 14 consegue atingir um deslocamento superior ao do modelo 13 , e a rigidez do modelo 13 é superior à do modelo 14, conforme observado experimentalmente.

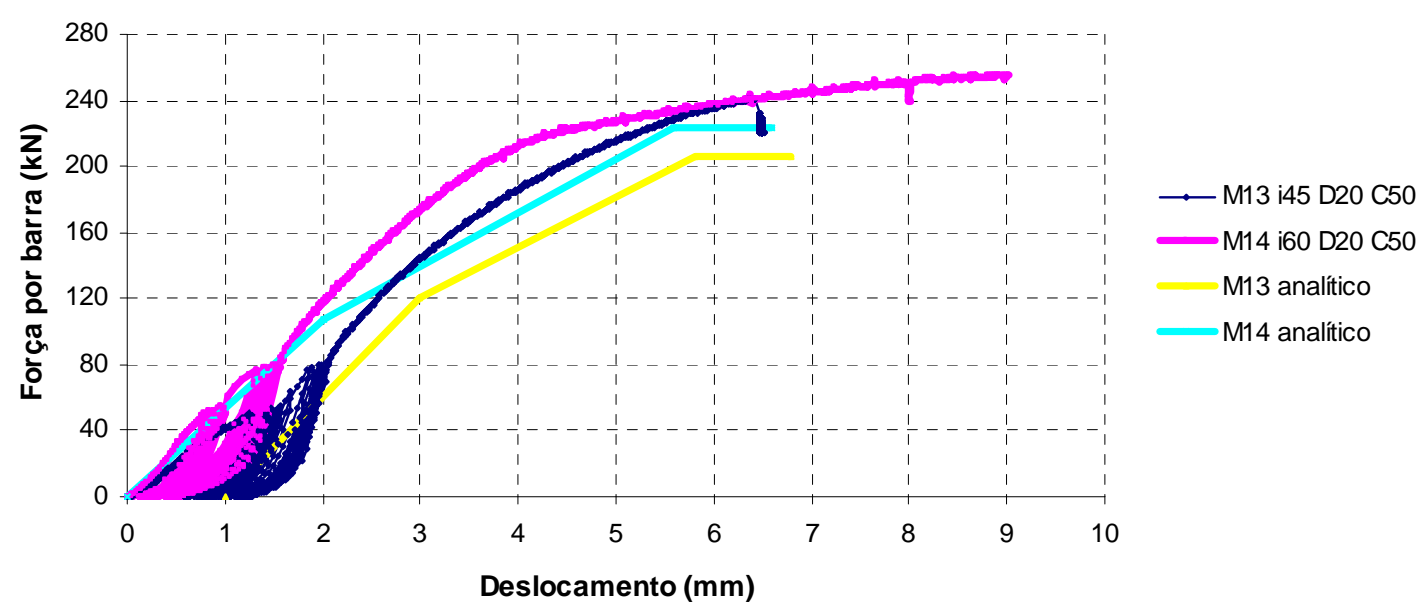

Figura 6.28: Resultados experimentais e analíticos dos modelos 13 e 14 
A comparação entre as três inclinações diferentes para os chumbadores é apresentada na Figura 6.29, onde pode ser observado o aumento da capacidade de carga do modelo com o aumento da inclinação. Para o modelo 09, com inclinação de $45^{\circ}$, o resultado apresentado não é compatível com os resultados observado nos outros modelos analisados.

No caso do modelo 09, a força de protensão promoveu um aumento na capacidade de carga do modelo, porém muito superior ao esperado. Analisando as Figuras 4.29b e 4.29c (Capítulo 04), foi verificado que deformação no chumbador foi nula até ser atingida a força próximo de $100 \mathrm{kN}$, situação atípica, o que denota uma aderência excelente entre o chumbador e o concreto.

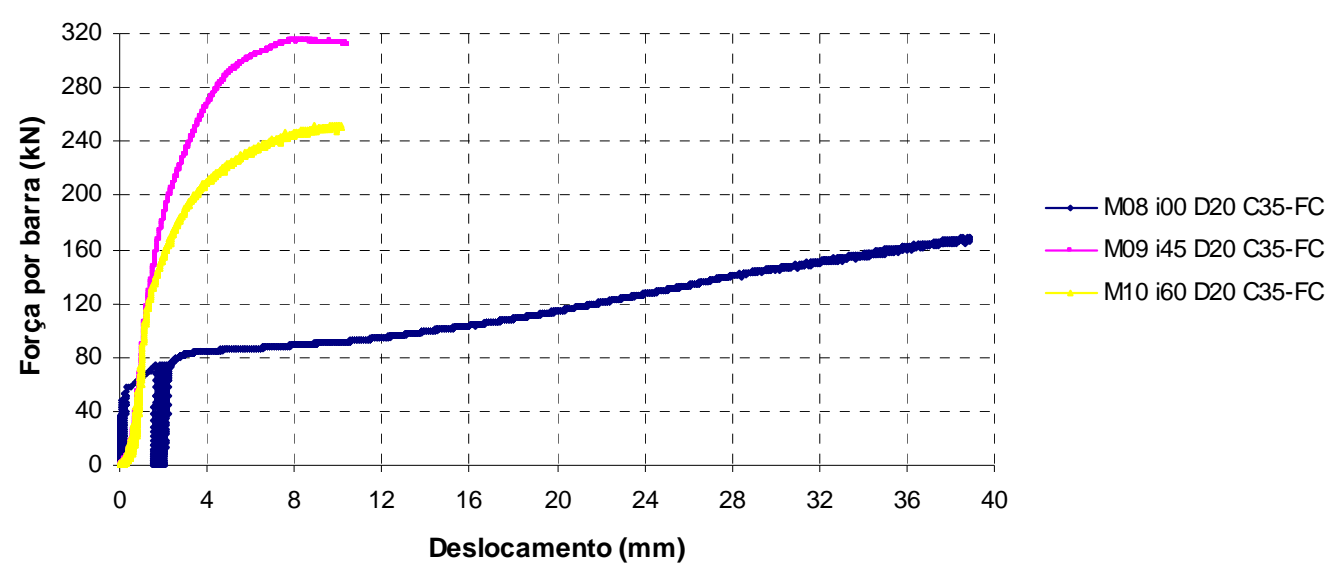

Figura 6.29: Resultados experimentais para os modelos 08, 09 e 10

Na Figura 6.30 é apresentada uma simulação analítica para os modelos 09 e 10, com o intuito de prever qual seria a posição da força máxima atingida pelo modelo 09 caso não ocorresse o fenômeno descrito anteriormente.

Comparando os resultados analíticos com os experimentais, observa-se que as relações entre a força experimental $\left(\mathrm{F}_{\mathrm{exp}}\right)$ alcançada no ponto de deslocamento máximo previsto pela proposta analítica $\left(\delta_{\text {ana }}\right.$ ) com a força máxima obtida na proposta analítica ( $F_{\text {ana }}$ ), foram de 1,47 e 1,06 para os modelos 09 e 10, respectivamente.

Na Figura 6.31 é apresentado o resultado da simulação numérica realizada também para os dois modelos. 


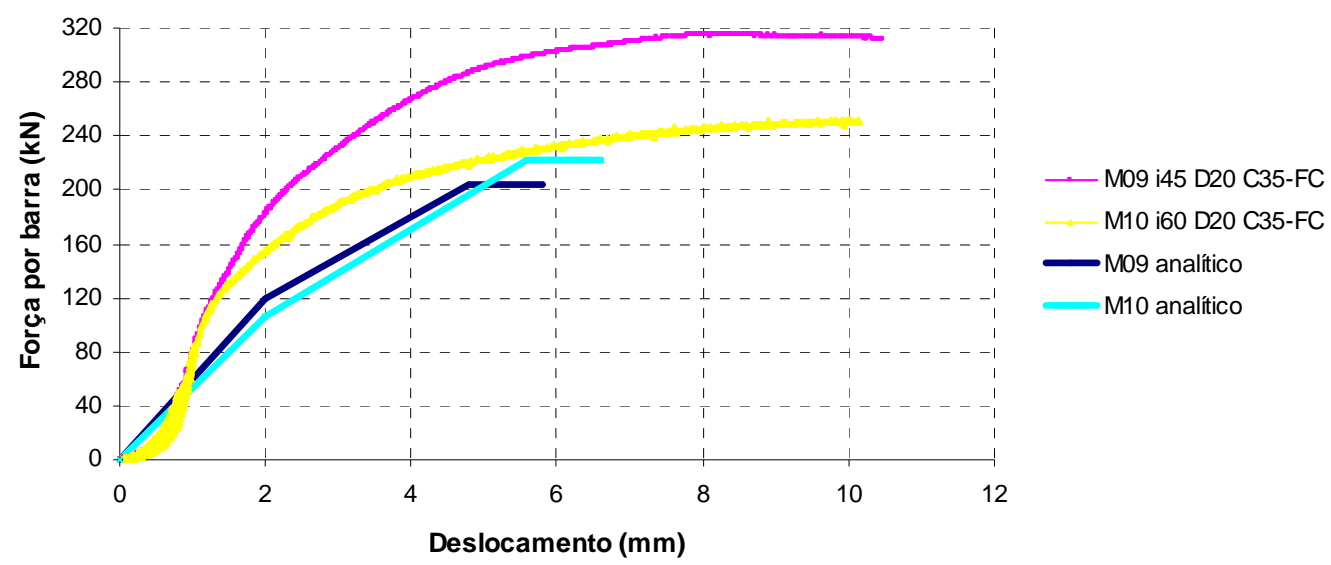

Figura 6.30: Resultados experimentais e analíticos dos modelos 09 e 10

A relação entre a força experimental $\left(\mathrm{F}_{\text {exp }}\right)$ no ponto de deslocamento máximo previsto pela proposta numérica $\left(\delta_{\text {num }}\right)$ com a força máxima obtida na proposta numérica $\left(F_{\text {num }}\right)$, foi de 1,20 e 0,92 para os modelos 09 e 10, respectivamente.

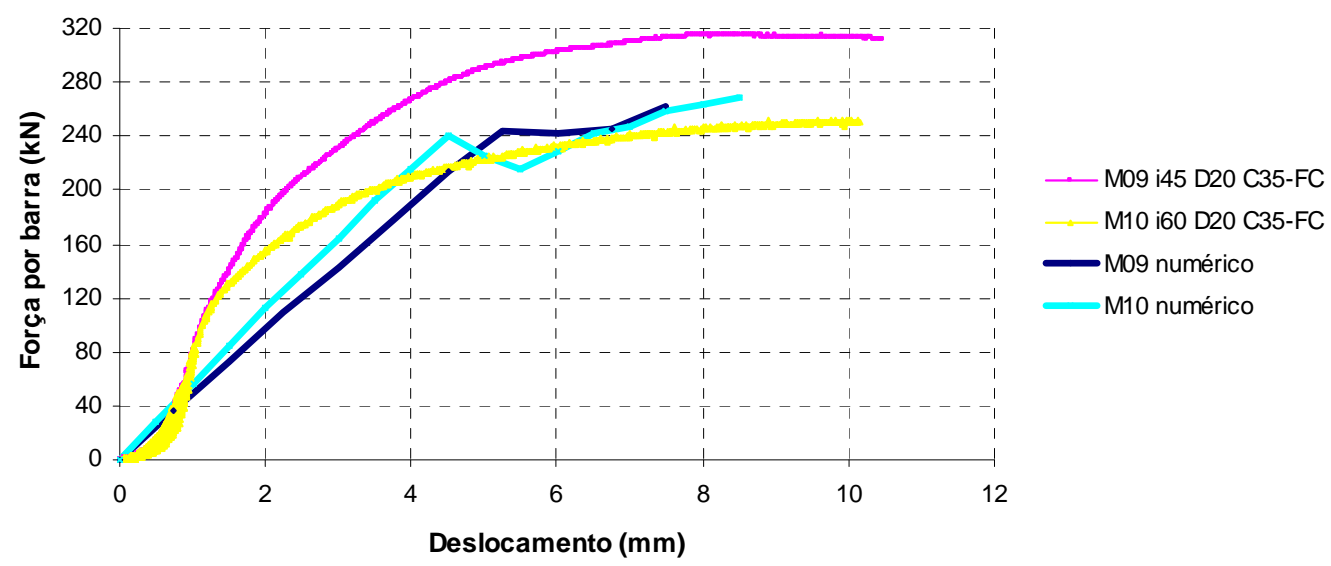

Figura 6.31: Resultados experimentais e numéricos dos modelos 09 e 10

Na Tabela 6.7 são apresentados os resultados experimentais e analíticos observados para os modelos 09 e 10.

Tabela 6.7: Comparação entre resultados para os modelos 09 e 10

\begin{tabular}{|c|c|c|c|c|c|c|c|c|c|c|c|}
\hline \multirow{2}{*}{ MODELO } & \multicolumn{4}{|c|}{ FORÇA MAXIMA (kN) } & \multicolumn{3}{c|}{ DESLOC. MAXIMO $(\mathrm{mm})$} & $\mathrm{F}_{\text {exp }} /$ & $\mathrm{F}_{\text {exp }} /$ & $\mathrm{F}_{\text {exp }}\left(\delta_{\text {num }}\right) /$ & $\mathrm{F}_{\text {exp }}\left(\delta_{\text {ana }}\right) /$ \\
& $F_{\text {prev }}$ & $F_{\text {exp }}$ & $F_{\text {num }}$ & $F_{\text {ana }}$ & $\delta_{\exp }$ & $\delta_{\text {num }}$ & $\delta_{\text {ana }}$ & $F_{\text {num }}$ & $F_{\text {ana }}$ & $F_{\text {num }}$ & $F_{\text {ana }}$ \\
\hline Modelo 09 & 120,50 & 312,30 & 261,20 & 204,53 & 10,47 & 7,50 & 5,80 & 1,20 & 1,53 & 1,20 & 1,47 \\
\hline Modelo 10 & 120,75 & 252,00 & 269,30 & 221,98 & 10,16 & 8,50 & 6,60 & 0,94 & 1,14 & 0,92 & 1,06 \\
\hline
\end{tabular}


Os valores das relações $\mathrm{F}_{\exp }\left(\delta_{\text {ana }}\right) / \mathrm{F}_{\text {ana }}$ e $\mathrm{F}_{\text {exp }}\left(\delta_{\text {num }}\right) / \mathrm{F}_{\text {num }}$ apresentados na Tabela 6.7, reforçam a idéia que o modelo 09 apresentou resultados superiores aos esperados.

Pela análise realizada e pelos resultados experimentais apresentados nas Figuras 4.29b e 4.29c (Capítulo 04), pode-se estimar que o valor da resistência máxima apresentada no modelo 09 deve ser reduzida em cerca de $80 \mathrm{kN}$, tornando-se compatível com os outros modelos aqui apresentados.

Em suma, consideram-se as propostas analítica e numérica adequadas para representar o comportamento de chumbadores retos e inclinados, tendo em vista o grau de complexidade envolvido no comportamento desse elemento estrutural. 



\section{CONSIDERAÇÓES PINAIS E CONCLUSÖES}

O presente trabalho destinou-se ao estudo do comportamento de chumbadores grauteados de ligações viga-pilar parcialmente resistentes a momento fletor, com ênfase no mecanismo resistente do chumbador inclinado. Este estudo está inserido na linha de pesquisa de estruturas de concreto pré-moldado que vem sendo desenvolvida no Departamento de Engenharia de Estruturas da Escola de Engenharia de São Carlos EESC-USP

O programa experimental realizado foi constituído de 15 modelos físicos, onde foram avaliadas as influências da inclinação do chumbador, do diâmetro, da resistência do concreto adjacente e da força de compressão no mecanismo resistente do chumbador.

Além do programa experimental, foram realizadas simulações numéricas, via Método dos Elementos Finitos, onde foi observado que os resultados obtidos eram bastante influenciados pelos módulos de rigidez normal e transversal, inerentes às interfaces almofada - bloco interno e almofada - bloco externo do modelo.

Baseado nos resultados experimentais e nas simulações numéricas realizadas, foi proposto um modelo analítico para representar o comportamento força x deslocamento do chumbador. O modelo proposto foi desenvolvido para a aplicação tanto em chumbadores de eixo reto quanto em chumbadores de eixo inclinado.

Baseado nos resultados obtidos apresenta-se de forma sintética as principais conclusões deste trabalho:

\section{a) Sobre a influência da inclinação dos chumbadores}

Foi verificado no programa experimental que em chumbadores de eixo retilíneo (inclinação de $0^{\circ}$ ) as formações de rótulas plásticas foram evidenciadas tanto do lado do bloco externo quanto do lado do bloco interno dos modelos. 
Nos chumbadores de eixo inclinado a formação de rótulas plásticas não pôde ser detectada após a ruína dos modelos, podendo ter ocorrido na fase inicial do carregamento e ter sido camuflada pelo alongamento causado devido à força normal, que é predominante nesse tipo de chumbador.

Foi verificada uma tendência de retificação da parte curva dos chumbadores inclinados, o que gerou a hipótese de que boa parte do comprimento do chumbador foi solicitado. Tal tendência de retificação também deu indícios da predominância do esforço normal nesse tipo de chumbador.

A capacidade resistente do chumbador também foi alterada com a mudança de inclinação. Baseado na análise de resultados foi observado um aumento na capacidade de carga quando a inclinação do chumbador foi alterada de $0^{\circ}$ para $45^{\circ}$ e de $0^{\circ}$ para $60^{\circ}$.

Para modelos com chumbadores de diâmetro de 25 mm, foi verificado um aumento de $73 \%$ na capacidade de carga quando a inclinação foi alterada de $0^{\circ}$ (modelo 11) para $60^{\circ}$ (modelo 12).

Quando a inclinação do chumbador foi alterada de $45^{\circ}$ para $60^{\circ}$ foi observado que quase não houve diferença de resultados.

A mudança de inclinação de $0^{\circ}$ (modelo 11) para $60^{\circ}$ (modelo 12) também proporcionou aos modelos um aumento de rigidez inicial de $42 \%$. Já a mudança de $45^{\circ}$ (modelo 13) para 60 (modelo 14) quase não alterou o valor da rigidez, sendo observado que o modelo 13 apresentou rigidez 3\% superior ao modelo 14 .

Outro ponto observado foi a redução em $100 \%$ da folga do modelo no último ciclo de carregamento com a mudança de inclinação do chumbador de $0^{\circ}$ (modelo 05) para $45^{\circ}$ (modelo 06).

\section{b) Sobre a influência do diâmetro dos chumbadores}

A influência do diâmetro do chumbador foi analisada separadamente para os três grupos de inclinações de chumbadores ensaiados. Em todos os três grupos foi verificado aumento da capacidade resistente do chumbador com o aumento do diâmetro. Assim, quanto maior o diâmetro, maior será a capacidade de carga.

Nos chumbadores de eixo reto, a mudança do diâmetro de 16 mm (modelo 01) para $25 \mathrm{~mm}$ (modelo 05) proporcionou um aumento de 35,6\% da força máxima alcançada.

Para o caso dos chumbadores inclinados a $45^{\circ}$, a mudança de diâmetro de 20 mm (modelo 02) para 25 mm (modelo 06) proporcionou um aumento de 24,7\% da força 
máxima. Já nos chumbadores inclinados a $60^{\circ}$, com a mudança do diâmetro de 20 mm (modelo 10) para $25 \mathrm{~mm}$ (modelo 12) foi verificado um aumento de 24,2\% na força máxima alcançada.

Foi verificado também um aumento na rigidez inicial com o aumento do diâmetro do chumbador. Comparando os modelos 01 e 05, por exemplo, foi verificado um aumento de $181 \%$ na rigidez inicial no último ciclo de carregamento. Já comparando os modelos 02 e 06 , com chumbadores inclinados a $45^{\circ}$, esse aumento foi de $96,6 \%$.

\section{c) Sobre a influência da resistência do concreto adjacente ao chumbador}

Experimentalmente a análise desta variável só foi realizada em chumbadores inclinados a $60^{\circ}$, tendo em vista que esse grupo apresentou a maior diferença de resistência à compressão do concreto. Assim foi observado que a resistência à compressão não exerceu influência significativa no comportamento do modelo.

Em simulações numéricas e analíticas realizadas, foi verificado que a resistência do concreto à compressão não exerce grande influência na capacidade de carga do chumbador. Por outro lado, a resistência à compressão passa a ser relevante no tocante à ancoragem do chumbador, que deve ser garantida.

\section{d) Sobre a força de compressão aplicada}

Com base nos resultados experimentais, observou-se que a força de protensão exerceu papel importante na redução das folgas existentes no modelo, aumentando assim a rigidez, principalmente nos primeiros ciclos de carregamento. A partir do momento em que o modelo começou a sofrer deslocamentos, o efeito do atrito gerado pela protensão começou a perder eficiência.

Comparando os modelos 05 e 11, ambos com chumbadores retos de $25 \mathrm{~mm}$ de diâmetro, foi observado que a força de compressão não possibilitou o aparecimento de folgas no modelo 11, sendo que para o modelo 05 foi verificada uma folga de $2 \mathrm{~mm}$.

Entre os modelos 09 e 13, ambos com chumbadores inclinados a $45^{\circ}$ e diâmetro de $20 \mathrm{~mm}$, a folga verificada no modelo 13, sem força de compressão, foi de 1,5 mm. Já no modelo 09, a força de compressão impediu o aparecimento de folgas.

De um modo geral foi observado no último ciclo de carregamento um pequeno aumento de rigidez causado pela força de compressão aplicada.

Em chumbadores de eixo reto, a contribuição da força de atrito mobilizada foi mais evidente que nos modelos com chumbadores inclinados. 


\section{e) Sobre o modelo numérico}

O modelo numérico conseguiu representar de forma satisfatória o comportamento força x deslocamento dos modelos ensaiados, sendo possível simular e confirmar as influências das variáveis aqui apresentadas.

Foi verificado que os resultados dos modelos numéricos para representar o comportamento a cisalhamento do chumbador, no caso específico dos modelos ensaiados nesta pesquisa, eram muito influenciados pelas características da interface bloco interno - almofada e almofada - bloco externo.

Baseado nos resultados experimentais e nas simulações numéricas, foi verificado que tanto o módulo de rigidez normal quanto o transversal, inerentes à interface, eram influenciados pelo diâmetro do chumbador e pela resistência à tração dos materiais associados à interface. Para o módulo de rigidez transversal, a folga medida após os ciclos de carga e descarga, descritos no Capítulo 03, também exerceu influência.

Face à sensibilidade apresentada nos modelos numéricos aos parâmetros inerentes à interface, foram desenvolvidas expressões para estimar os módulos de rigidez normal e transversal, contemplando as influências observadas. As expressões propostas também representam uma contribuição relevante ao uso de elementos de interface em simulações numéricas semelhantes à realizada neste trabalho, via Método dos Elementos Finitos, pois a definição dos valores para o módulo de rigidez normal e transversal constitui uma das maiores dificuldades da análise.

\section{f) Sobre o modelo analítico}

O modelo analítico também conseguiu representar de forma satisfatória o comportamento força x deslocamento dos modelos ensaiados, sendo possível simular e confirmar as influências das variáveis aqui apresentadas, com exceção da influência da força de compressão, não contemplada na proposta pelo fato de não exercer quase influência na capacidade resistente do chumbador.

A proposta contemplou duas parcelas distintas da capacidade resistente do chumbador, sendo elas a parcela relativa à formação da rótula plástica e a parcela de consideração da força normal.

Com base na equação proposta, para o deslocamento de $0,1 \phi$, foi verificado que a parcela relativa à formação da rótula plástica em chumbadores retilíneos (inclinação de $0^{\circ}$ ) é em média $98 \%$ da capacidade do chumbador. 
Para chumbadores inclinados a $45^{\circ}$, foi observado que a parcela relativa à formação da rótula plástica é em média $45 \%$ da capacidade do chumbador. Já nos chumbadores inclinados a $60^{\circ}$, essa parcela representa em média 35\% da capacidade do chumbador. Assim, verifica-se que a contribuição da força normal em chumbadores inclinados representa uma parcela importante de sua capacidade de carga.

O uso da formulação proposta em chumbadores de eixo reto conduzem a resultados satisfatórios quando a resistência à compressão do concreto utilizado é da ordem dos valores obtidos nesta pesquisa ou superiores.

É importante registrar que a primeira parcela da formulação proposta pode ser substituída por outras equações clássicas, por exemplo a Equação (2.28), inerentes à determinação da capacidade de carga em chumbadores de eixo reto.

Com base nos resultados apresentados, considera-se que os objetivos da pesquisa foram alcançados. Entretanto, como muitas são as variáveis envolvidas no estudo do comportamento dos chumbadores grauteados, são aqui apresentadas algumas sugestões para pesquisas futuras:

a) Estudar a influência de outras inclinações, por exemplo $30^{\circ}$, no mecanismo resistente dos chumbadores grauteados e verificar se o modelo analítico proposto conduz a resultados satisfatórios;

b) Estudar a influência da rugosidade da almofada de apoio no comportamento do mecanismo resistente dos chumbadores, uma vez que a pesquisa aqui realizada só contemplou o uso de almofadas lisas;

c) Desenvolver modelos analíticos para ligações viga-pilar parcialmente resistentes a momento fletor com chumbadores grauteados, implementando o modelo analítico proposto. 



\section{REFERÊNCIAS BIBLIOGRÁFICAS}

AMERICAN INSTITUTE OF STEEL CONSTRUCTION (1986). Manual of steel construction: load and resistance factor design. $1^{\text {st }}$ ed., Chicago, USA.

AMERICAN INSTITUTE OF STEEL CONSTRUCTION (1989). Steel construction manual. $9^{\text {th }}$ ed. Chicago, USA.

AGUIAR, E.A.B; EL DEBS, M.K. (2008). Comportamento de chumbadores grauteados para ligações viga-pilar parcialmente resistentes a momento fletor. In: II CONGRESSO NACIONAL DA PREFABRICAÇÃO EM BETÃO. Lisboa, Portugal. p.1-20.

ASSOCIAÇÃO BRASILEIRA DE NORMAS TÉCNICAS (1984). NBR 8522: Concreto -Determinação do módulo de deformação estática e diagrama - Tensãodeformação - Procedimento.Rio de Janeiro.

ASSOCIAÇÃO BRASILEIRA DE NORMAS TÉCNICAS (1985). NBR 9062: Projeto e Execução de Estruturas de Concreto Pré-Moldado - Procedimento.Rio de Janeiro.

ASSOCIAÇÃO BRASILEIRA DE NORMAS TÉCNICAS (2003).NBR 6118: Projeto de estruturas de concreto - Procedimento.Rio de Janeiro.

ASSOCIAÇÃO BRASILEIRA DE NORMAS TÉCNICAS (2003). Texto base para revisão da NBR 8800: Projeto e execução de estruturas de aço de edifícios. Rio de janeiro. 
BALDISSERA, A. B. (2006). Estudo experimental de uma ligação viga-pilar de concreto pré-moldado parcialmente resistente a momento fletor. 149p. Dissertação (Mestrado) - Escola de engenharia de São Carlos, Universidade de São Paulo, São Carlos. 2006

BALLARIN, A.W. (1993). Desempenho das ligações de elementos estruturais prémoldados de concreto. 255p. Dissertação (Mestrado) - Escola de engenharia de São Carlos, Universidade de São Paulo, São Carlos. 1993.

BARBOZA, A.S.R (2002). Comportamento de juntas de argamassa solicitadas à compressão na ligação entre elementos pré-moldados. 143p. Tese (Doutorado) Escola de engenharia de São Carlos, Universidade de São Paulo, São Carlos. 2001.

CHEFDEBIEN, A. (1998). Precast concrete beam to column head connections. In: CONTROL OF THE SEMI-RIGID BEHAVIOUR OF CIVIL ENGINEERING STRUCTURAL CONNECTIONS, COST C1 INTERNATIONAL CONFERENCE, 1998. Cost C1: Proceedings. Liege, Belgium. p. 35-43.

CHEOK, G.S.; LEW, H.S. (1991). Performance of precast concrete beam-to-column connections subject to cyclic loading. PCI journal precast/prestressed concrete institute, v.36, n. 3, p. 56-67, May-June.

COMITE EURO-INTERNATIONAL DU BETON (1990). CEB-FIP Model Code for Concrete Structures. Paris: CEB, 1991. Bulletin d'Information 203.

CONNECTIONS, COST C1 INTERNATIONAL CONFERENCE, 1994. Cost C1: Proceedings. Prague. p. 31-40.

COST C1 (1996). Composite steel concrete joints in braced frames for building. Brussels, Luxembourg.

CRUZ, J. S., BARROS, J. A. O. e AZEVEDO, A. (2004). Elasto-plastic multi-fixed smeared crack model for concrete. 70 p. Technical Report N. 04-DEC/E-05, Universidade do Minho e Universidade do Porto, Portugal. 
DEI POLI, S.;DI PRISCO,M.; GAMBAROVA,P.G. (1992). Shear response, deformations and subgrade stiffness of dowel bar embedded in concrete. ACI structural journal, v.89, n 6, p 62-74.

DIANA (2005). DIANA Finite Element Analysis. User`s manual release 9. Element Library. TNO DIANA, Delft, Netherland.

DIANA (2005). DIANA Finite Element Analysis. User`s manual release 9. Material Library. TNO DIANA, Delft, Netherland.

DOLAN, C.W.; STANTON, J.F.; ANDERSON, R.G. (1987). Moment resistant connections and simple connections. PCI journal precast/prestressed concrete institute, v.32, n 2, p 62-74, March-April.

EL DEBS, M.K. (2000). Concreto pré-moldado: Fundamentos e aplicações. 1.ed. São Carlos, EESC-USP, 441p.

EL DEBS, M.K.; BALDISSERA, A. (2008). Estudo experimental de uma ligação vigapilar de concreto pré-moldado parcialmente resistente a momento fletor. In: II CONGRESSO NACIONAL DA PREFABRICAÇÃO EM BETÃO. Lisboa, Portugal. p.1-18.

ELLIOT, K.S. (1998). Semi-rigid connections in precast concrete structures and bridges. In: CONTROL OF THE SEMI-RÍGID BEHAVIOUR OF CIVIL ENGINEERING STRUCTURAL CONNECTIONS, COST C1 INTERNATIONAL CONFERENCE, 1998. Cost C1: Proceedings. Liege, Belgium. p. 3-12.

ELLIOT, K.S et alii (1998). Precast concrete semi-rigid beam-to-column connections in skeletal frames. In: CONTROL OF THE SEMI-RÍGID BEHAVIOUR OF CIVIL ENGINEERING STRUCTURAL CONNECTIONS, COST C1 INTERNATIONAL CONFERENCE, 1998. Cost C1: Proceedings. Liege, Belgium. p. 45-54.

ELLIOTT, K.S. et alii. (2003). Can precast concrete structures be designed as semirigid frames. Structural Engineer, v.81, n.16, p. 14-37, August. 
ENGSTROM, B. (1992a). Anchorage of ribbed bars in the post yield stage. In: WORKSHOP ON SEMI-RIGID BEHAVIOUR OF CIVIL ENGINEERING STRUCTURAL CONNECTIONS, 1992. Cost C1: Proceedings. Strasbourg, France.p.65-76.

ENGSTROM, B. (1992b). Combined effects of dowel action and friction in bolted connections. In: WORKSHOP ON SEMI-RIGID BEHAVIOUR OF CIVIL ENGINEERING STRUCTURAL CONNECTIONS, 1992. Cost C1: Proceedings. Strasbourg, France.p.77-98.

EUROCODE 3 (2002). Design of steel structures, part 1.8: design of joints. European committee for standardization, CEN, Brussels.

FERREIRA, M.A. (1993). Estudo de deformabilidade de ligações para análise linear em pórticos planos de elementos pré-moldados de concreto. 166p. Dissertação (Mestrado) -Escola de engenharia de São Carlos, Universidade de São Paulo, São Carlos. 1993.

FERREIRA, M.A. (1999). Deformabilidade de ligações viga pilar de concerto prémoldado. 232p. Tese (Doutorado) - Escola de engenharia de São Carlos, Universidade de São Paulo, São Carlos. 1999.

FÉDÉRATION INTERNATIONALE DU BÉTON - FIB (2007). Structural connections for precast concrete buildings. Lausanne, Suíça.

GOMES, F.C.T. et alii (1998). Recent developments on classification of joint. In: CONTROL OF THE SEMI-RÍGID BEHAVIOUR OF CIVIL ENGINEERING STRUCTURAL CONNECTIONS, COST C1 INTERNATIONAL CONFERENCE, 1998. Cost C1: Proceedings. Liege, Belgium. p. 187-198.

JASPART, J. P.; MAQUOI, R. (1992) Survey of existing types of joint modeling. In: WORKSHOP ON SEMI-RIGID BEHAVIOUR OF CIVIL ENGINEERING STRUCTURAL CONNECTIONS, 1992. Cost C1: Proceedings. Strasbourg, France. p. 370-381. 
KATAOKA, M.N. (2007). Estudo da continuidade em ligações laje-viga-pilar em estruturas pré-moldadas de concreto . 113p. Dissertação (Mestrado) - Universidade Federal de São Carlos, São Carlos. 2007.

KERONEN, A. (1996). Effect of semi-rigid connections in rc portal frame: Load tests. Report of Tampare University of Technology, Finlândia. p 95.

LEON, R.T. (1998) Developments in the use of partial restraint frames in the United States. In: CONTROL OF THE SEMI-RÍGID BEHAVIOUR OF CIVIL ENGINEERING STRUCTURAL CONNECTIONS, COST C1 INTERNATIONAL CONFERENCE, 1998. Cost C1: Proceedings. Liege, Belgium. p. 95-104.

LIMA JUNIOR, H.C. (2003). Avaliação da ductilidade de pilares de concreto armado, submetidos a flexo-compressão reta com e sem adição de fibras metálicas. 221p. Tese (Doutorado) - Escola de engenharia de São Carlos, Universidade de São Paulo, São Carlos. 2003.

LIN, C. (1991). Friction connection of precast concrete construction. G.B. HASSELWANDER (Ed.) “anchorage to concrete”. SP-103 (pp.27-46). Detroit: American Concrete Institute.

MAEKAWA, K.; PIMANMAS, A.;OKAMURA, H. (2004). Nonlinear mechanics of reinforced concrete. Spon press. New York, USA.p.721.

MIOTTO, A.M. (2002). Ligações viga-pilar de estruturas de concreto pré-moldado: Análise com ênfase na deformabilidade ao momento fletor. 234p. Tese (Doutorado) - Escola de engenharia de São Carlos, Universidade de São Paulo, São Carlos. 2002.

MONTEDOR, L.C. (2004). Desenvolvimento de compósito a ser utilizado como almofada de apoio nas ligações entre elementos pré-moldados. 144p. Dissertação (Mestrado) - Escola de engenharia de São Carlos, Universidade de São Paulo, São Carlos. 2004 
MOTA, J.E. (2009). Contribuição ao projeto de estruturas multi-piso reticuladas em concreto pré-moldado. 246p. Tese (Doutorado) - Escola de engenharia de São Carlos, Universidade de São Paulo, São Carlos. 2009.

ORDONEZ, J.A.F. et alii (1974). Prefabricación: teoría y práctica.Barcelona, Editores Técnicos Associados.

PRESTRESSED CONCRETE INSTITUTE (1988). Design and typical detail of connections for precast and prestressed concrete. 2 ed.Chicago, PCI.

SIQUEIRA, G.H. (2007). Almofada de apoio de compósito de cimento para ligações em concreto pré-moldado. 173p. Dissertação (Mestrado) - Escola de engenharia de São Carlos, Universidade de São Paulo, São Carlos. 2007

SOARES, A.M.M. (1998). Análise estrutural de pórticos planos de elementos préfabricados de concreto considerando a deformabilidade das ligações. 178p. Dissertação (Mestrado) - Escola de engenharia de São Carlos, Universidade de São Paulo, São Carlos. 1998.

TSCHEMMERNEGG, F.; HUBER, G. (1998). Classification and assessment of joints. In: CONTROL OF THE SEMI-RÍGID BEHAVIOUR OF CIVIL ENGINEERING STRUCTURAL CONNECTIONS, COST C1, 1998. Innsbruck, april 1998.

VECCIO, F. J. e COLLINS, M. P., The Modified compression-field theory for reinforced concrete elements subjected to shear. ACI Journal, v. 83, n. 2, March-April, 1986, p. 219-231. 
